\title{
PROTECTIVE RELAYING STUDENT LABORATORY
}

\author{
A Thesis \\ presented to \\ the Faculty of California Polytechnic State University, \\ San Luis Obispo
}

\author{
In Partial Fulfillment \\ of the Requirements for the Degree \\ Master of Science in Electrical Engineering
}

by

Kenan W Pretzer

May 2017 
(C) 2017

Kenan W Pretzer

ALL RIGHTS RESERVED 
TITLE: $\quad$ Protective Relaying Student Laboratory

DATE SUBMITTED: May 2017

COMMITTE CHAIR: Ali Shaban, Ph.D.

Professor of Electrical Engineering

COMMITTEE MEMBER: $\quad$ Ahmad Nafisi, Ph.D.

Professor of Electrical Engineering

COMMITTEE MEMBER: Taufik, Ph.D.

Professor of Electrical Engineering 


\section{ABSTRACT \\ Protective Relaying Student Laboratory \\ Kenan W Pretzer}

Facing a rapidly-changing power industry, the electrical engineering department at Cal Poly San Luis Obispo proposed Advanced Power Systems Initiatives to better prepare its students for entering the power industry. These initiatives call for the creation of a new laboratory curriculum that uses microprocessor-based relays to reinforce the fundamental concepts of power system protection. This paper summarizes a laboratory system fit for this task and presents a set of proposed laboratory experiments to establish a new laboratory course at Cal Poly. The experiments expose students to the capabilities of industry-standard microprocessor-based relays through hands-on procedures that demonstrate common power system protection schemes. Relays studied in this project support transformer, transmission line, and induction motor protection.

Keywords: power systems education, protection laboratory 


\section{ACKNOWLEDGMENTS}

Cal Poly electrical engineering students Mr. Ian Hellman-Wylie and Mr. Joey Navarro provided indispensable assistance and support in designing, implementing, and testing the work described in this paper. The breadth and depth of the project scope accomplished in this paper would not have been realized without their help.

Cal Poly professor Dr. Ali Shaban advised this project. I am very grateful to him for encouraging me to take on this project before his retirement. Dr. Shaban's continual encouragement and support made this project a joy to work on.

Cal Poly professors Dr. Taufik and Dr. Ahmad Nafisi gave valuable recommendations on preparing and presenting a conference paper summarizing this project.

Cal Poly electrical engineering students Mr. Eric Osborn, Mr. Allen Scozzari, Ms. Amanda Barley, and Mr. Joshua Chung performed the proposed laboratory experiments in their initial stages. Their instrumental feedback allowed refining and restructuring the procedures included in this paper.

Schweitzer Engineering Laboratories made implementation of this work possible through ongoing equipment donations to the Cal Poly electrical engineering department.

Mr. Roger P Baldevia, Jr., an application engineer with Schweitzer Engineering Laboratories, Inc., assisted with establishing a communication connection between a human-machine interface (computer) and protective relays through an intermediate SEL2032 communications processor.

Mr. Robin Jenkins, a senior application engineer with Schweitzer Engineering Laboratories, Inc., assisted with establishing a communication connection between a human-machine interface (computer) and protective relays through an intermediate SEL3530 real-time automation controller. Mr. Jenkins also assisted with setting up the web interface of the real-time automation controller to display relay trip signals.

Mr. Bill Cook, of San Diego Gas \& Electric's Grid Operations Division, assisted with troubleshooting the phasing of transformer line currents in a differential relay.

The Cal Poly Electrical Engineering Department repeatedly provided tangible support for this project. Network analyst Mr. Rob Randle lent assistance in setting up software for the information processors. Equipment technician Mr. Jaime Carmo provided ring terminals and wire for connecting circuit components. Mr. Carmo also supplied acrylic sheets, project boxes, and banana jacks for construction of additional circuit breaker boxes. The department also subsidized my travel to a technical seminar put on by Schweitzer Engineering Laboratories, Inc.

Cal Poly manufacturing engineering student Mr. Steven Dallezotte fabricated the faceplates for seven additional circuit breaker boxes. 
Liberty University Writing Center coach Ms. Jennifer Pretzer voluntarily edited this document.

It is He who changes the times and the epochs;

He removes kings and establishes kings;

He gives wisdom to wise men

And knowledge to men of understanding.

It is $\mathrm{He}$ who reveals the profound and hidden things;

He knows what is in the darkness,

And the light dwells with Him.

To You, O God of my fathers, I give thanks and praise,

For You have given me wisdom and power;

(Daniel 2:21-23b, NASB)

Soli Deo Gloria! 


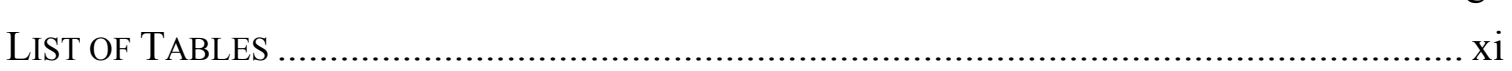

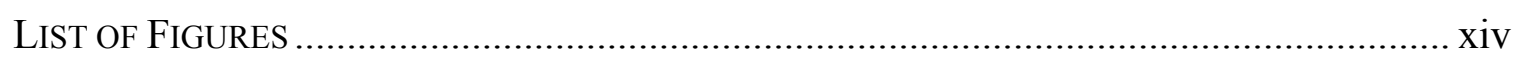

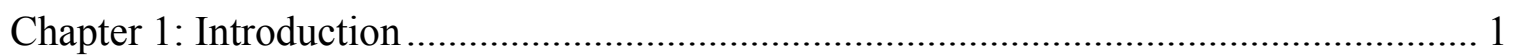

1.1 Traditional Radial Distribution Systems....................................................... 1

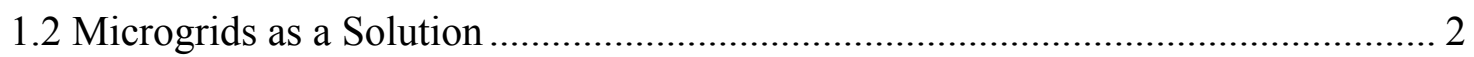

1.3 Microgrid Protection Student Laboratory ………………….......................... 4

Chapter 2: Customer Needs, Requirements, and Specifications......................................... 5

2.1 Customer Needs Assessment ...................................................................... 5

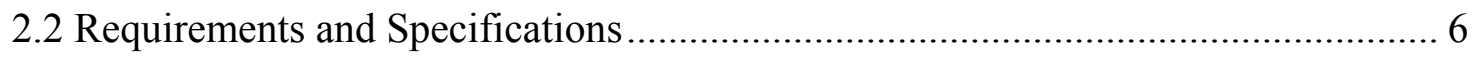

Chapter 3: Protection Equipment Overview ……………….................................... 12

3.1 SEL Protection Equipment Introduction....................................................... 12

3.2 SEL-311L: Transmission Line Protection ....................................................... 12

3.3 SEL-387E: Transformer Protection ............................................................. 12

3.4 SEL-587: Transformer Protection................................................................ 13

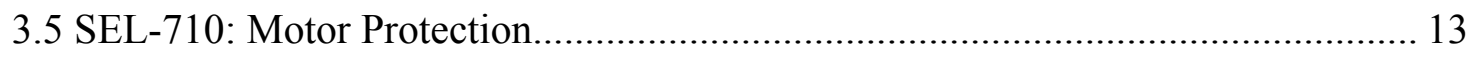

3.6 SEL-2032: Communications Processor .............................................................. 13

3.7 SEL-3530: Real-Time Automation Controller ................................................ 14

3.8 SEL-2407: Satellite-Synchronized Clock .......................................................... 14

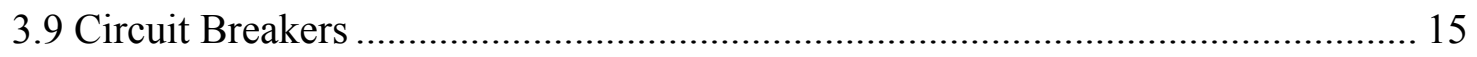

Chapter 4: Functional Decomposition ................................................................. 18

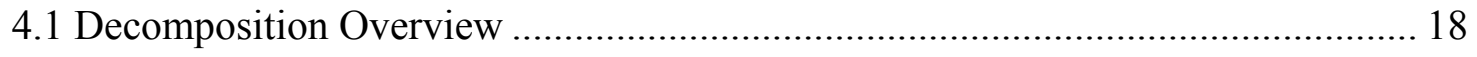

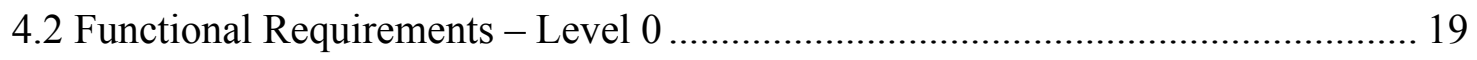

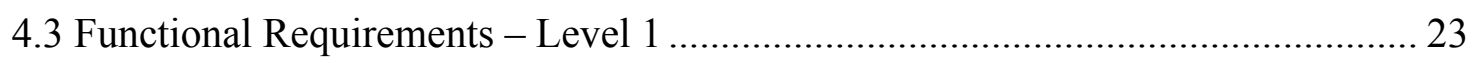

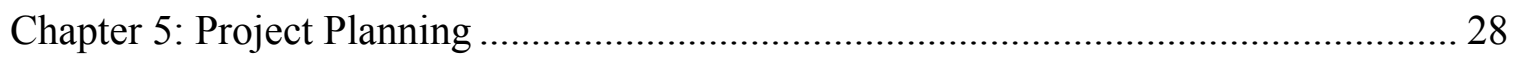

5.1 Gantt Chart - Proposed Project Timelines......................................................... 28

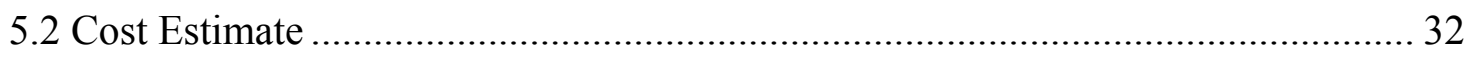

Chapter 6: Introduction to the Radial Systems (Phase I) .................................................. 34

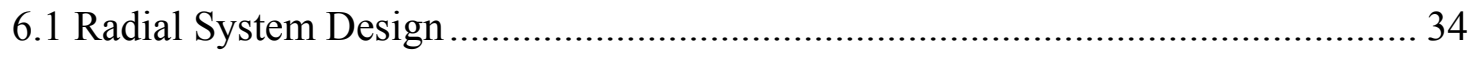

6.2 Radial System Testing ..................................................................................... 38

Chapter 7: SEL-311L Overcurrent Protection ............................................................ 39

7.1 Inverse-Time Overcurrent Protection Overview …………………………........... 39

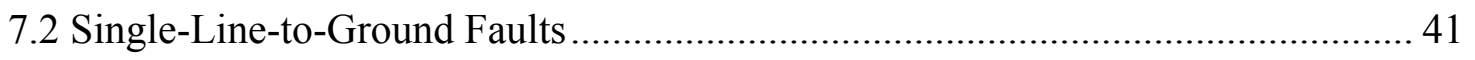

7.3 Double-Line-to-Ground Faults ...................................................................... 44 


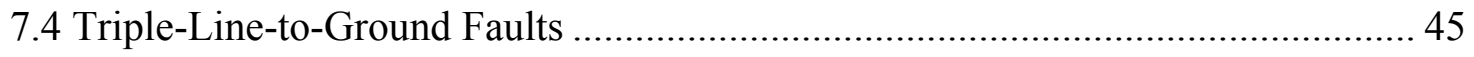

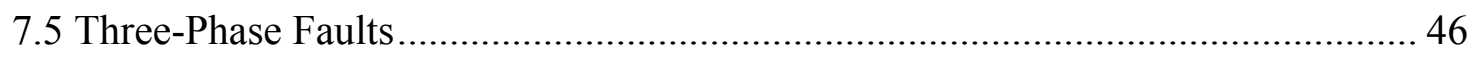

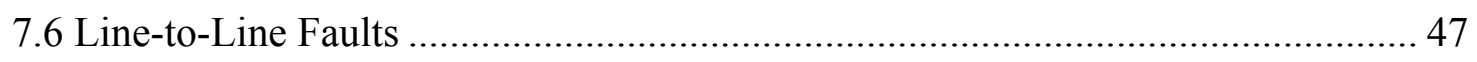

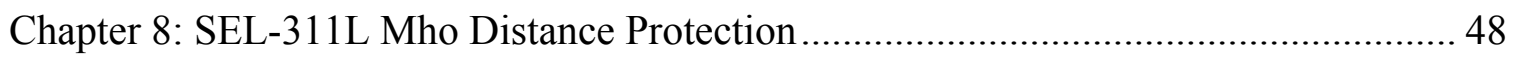

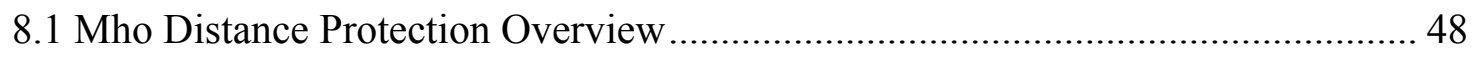

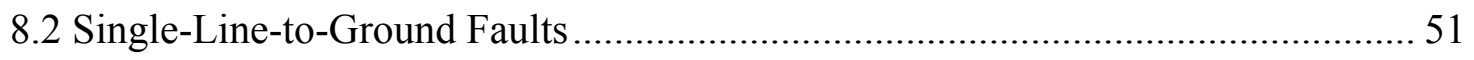

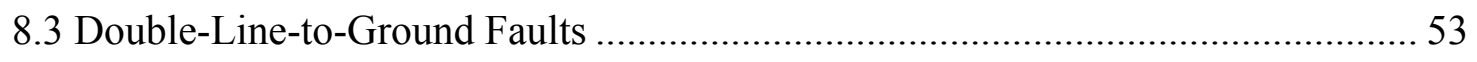

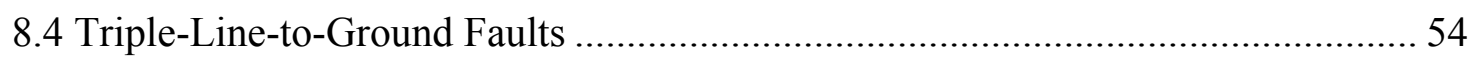

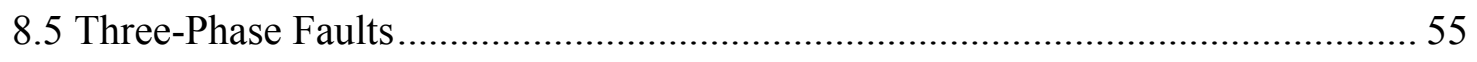

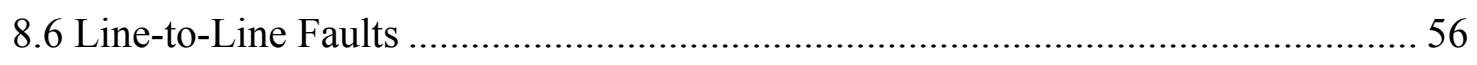

Chapter 9: SEL-387E Overcurrent Protection ............................................................ 57

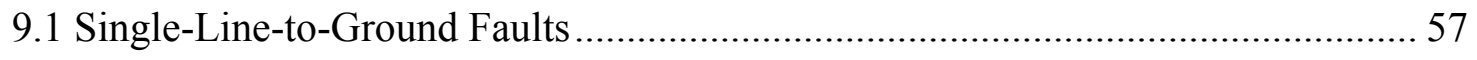

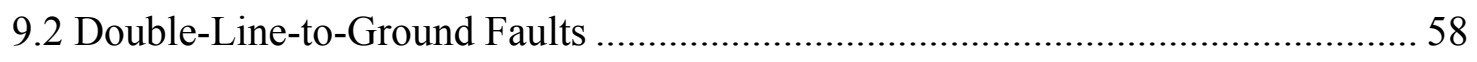

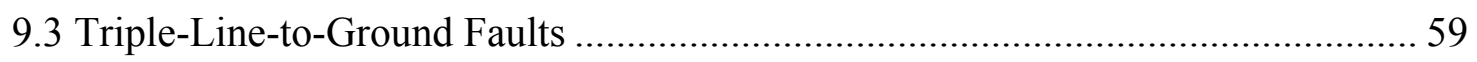

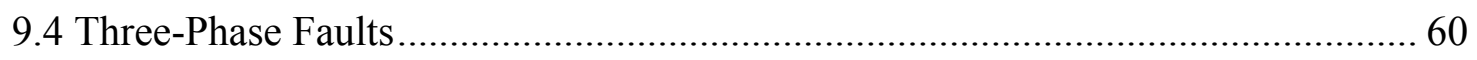

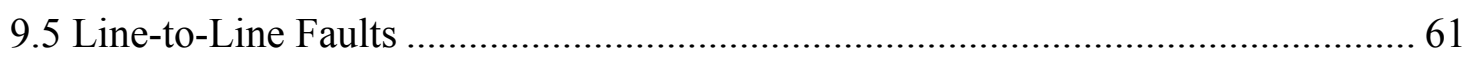

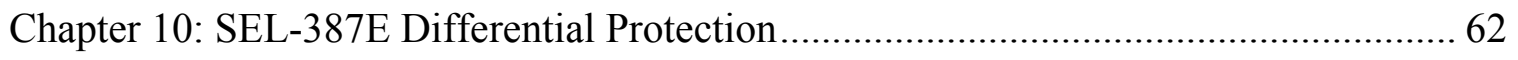

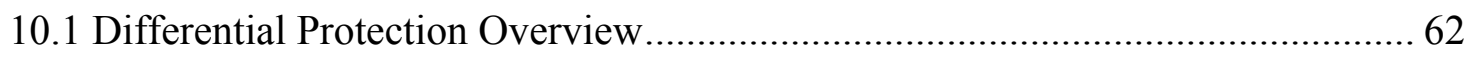

10.2 Differential Protection in a Microprocessor-Based Relay ....................................... 65

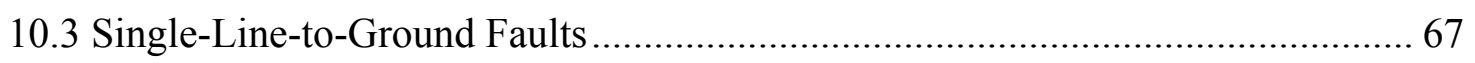

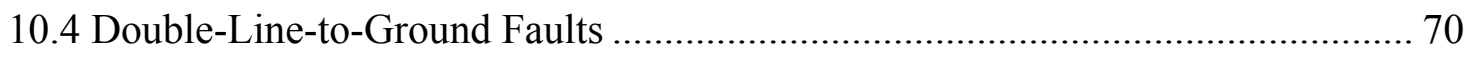

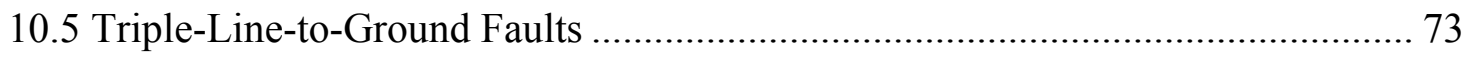

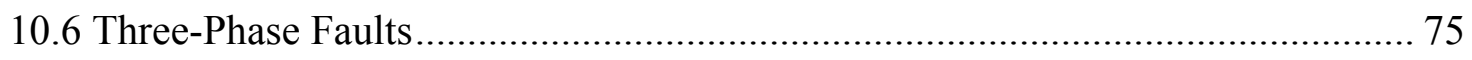

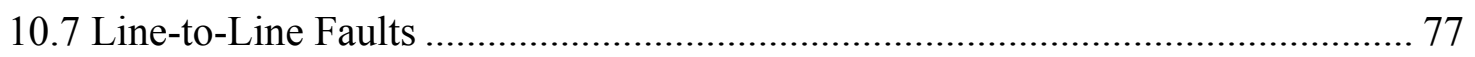

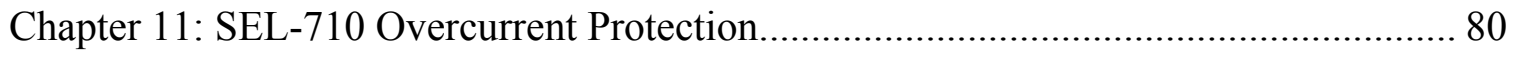

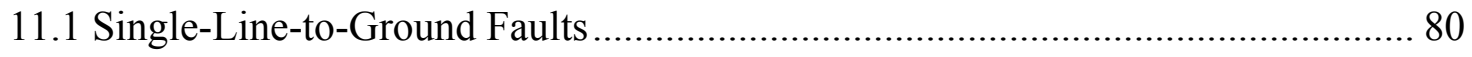

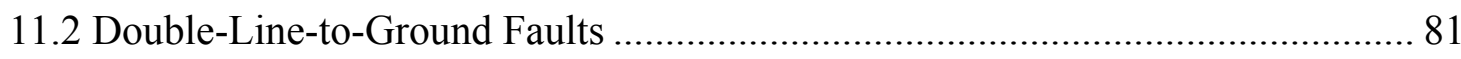

11.3 Triple-Line-to-Ground Faults ………………........................................... 82

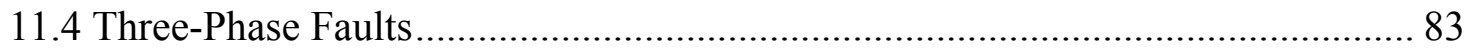

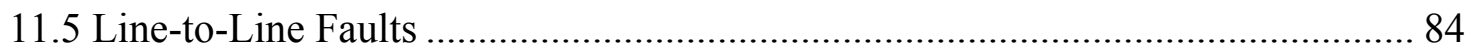

Chapter 12: SEL-710 Undervoltage, Locked-Rotor, and Thermal Overload Protection . 85

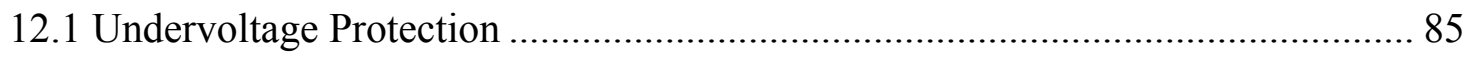

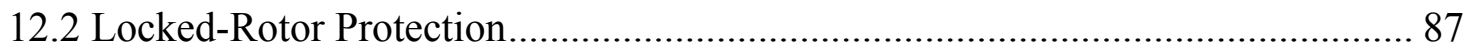

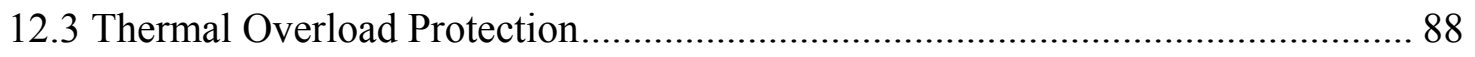


Chapter 13: SEL-587 Overcurrent Protection.............................................................. 89

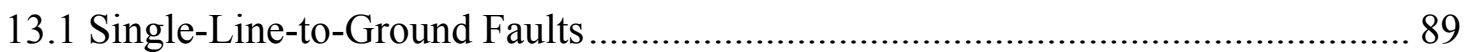

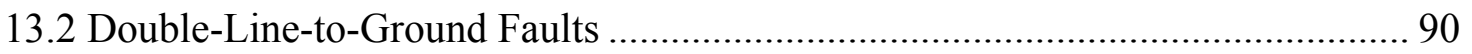

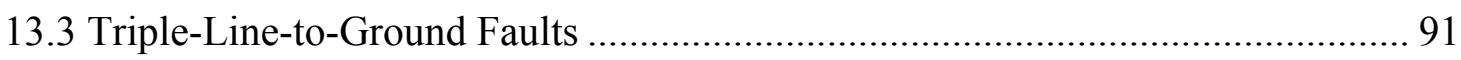

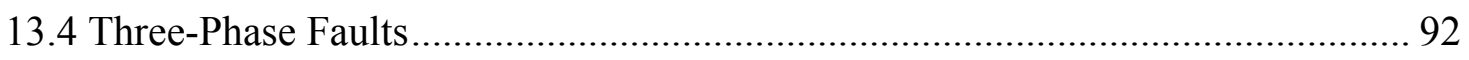

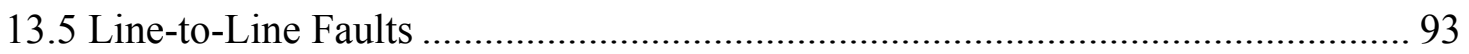

Chapter 14: SEL-587 Differential Protection ……………......................................... 94

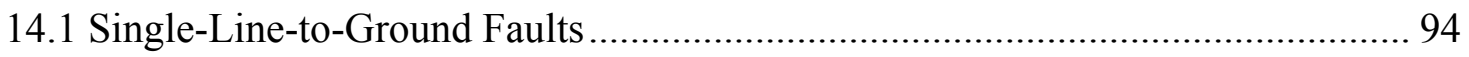

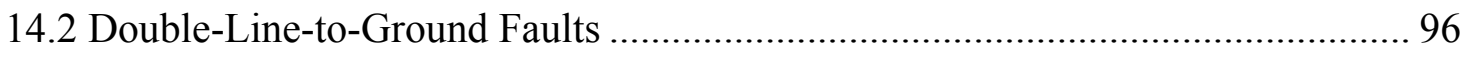

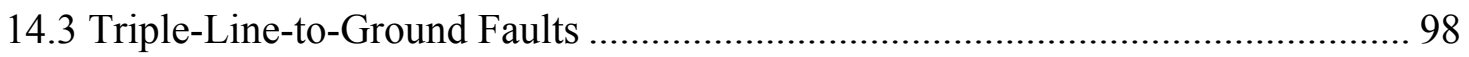

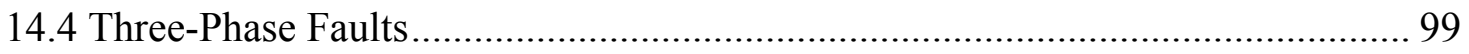

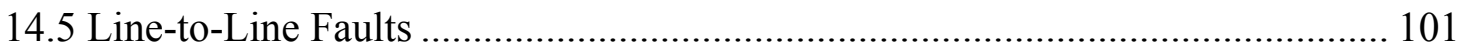

Chapter 15: Radial System Relay Coordination ........................................................ 103

15.1 Demonstrating Coordination in a Radial System............................................... 103

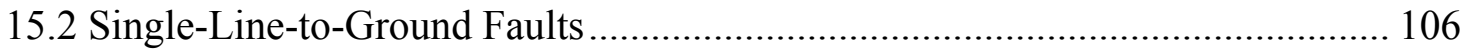

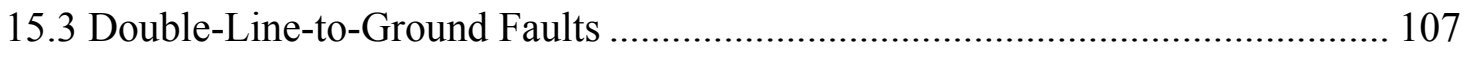

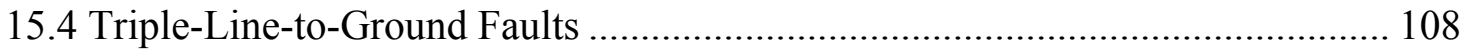

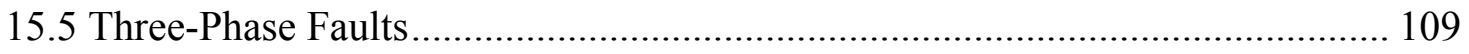

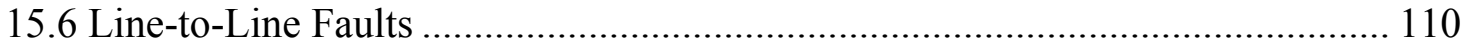

Chapter 16: Introduction to the Bidirectional System (Phase II)................................... 111

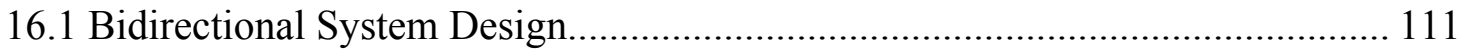

16.2 Bidirectional System Operation ................................................................... 114

Chapter 17: SEL-311L Pilot Protection ................................................................... 115

17.1 Pilot Protection Overview ........................................................................... 115

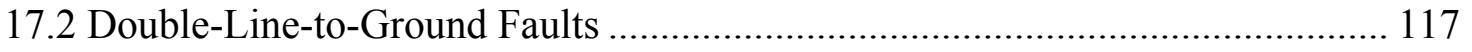

17.3 Triple-Line-to-Ground Faults .................................................................... 118

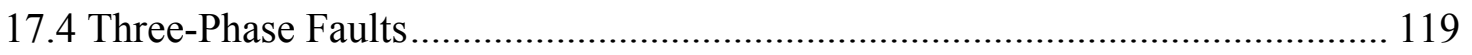

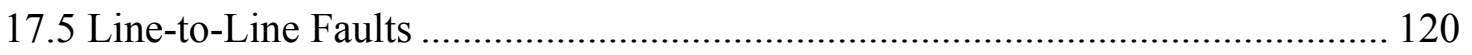

Chapter 18: Bidirectional System Relay Coordination................................................ 121

18.1 Demonstrating Coordination in a Bidirectional System ..................................... 121

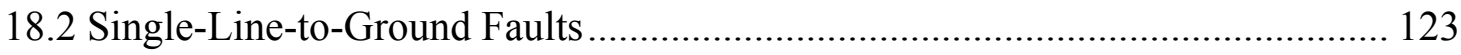

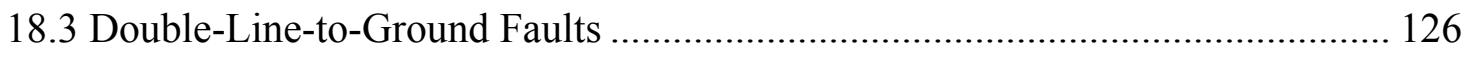

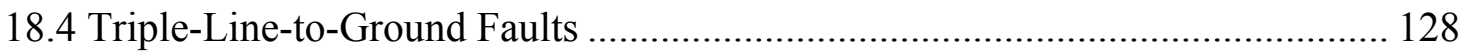

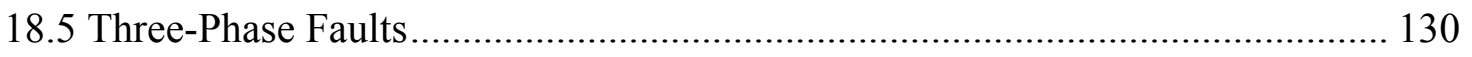




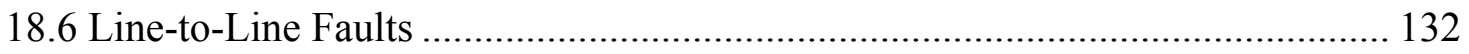

Chapter 19: The Information Processors ................................................................. 134

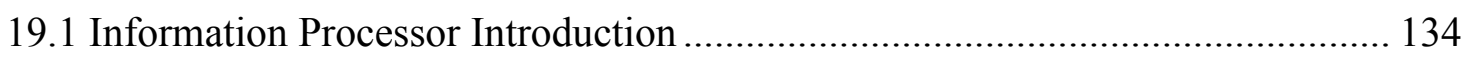

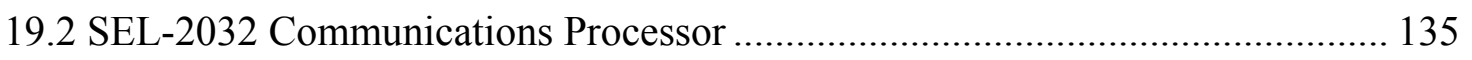

19.3 SEL-3530 Real-Time Automation Controller ………….................................. 137

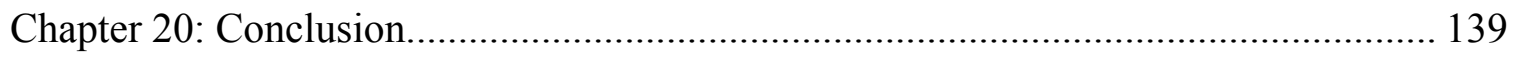

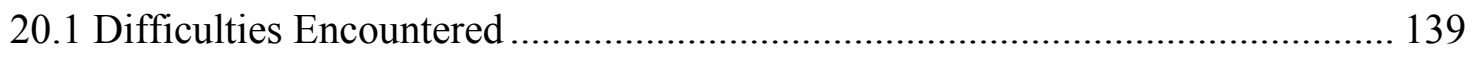

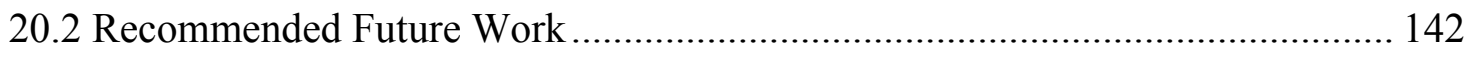

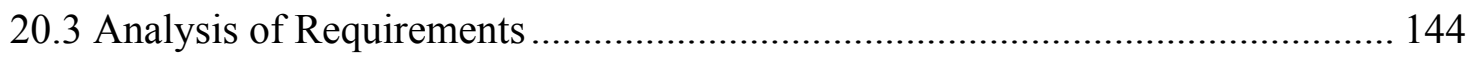

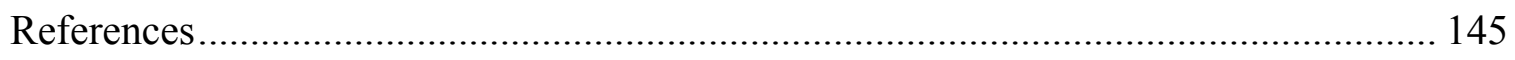

APPENDICES

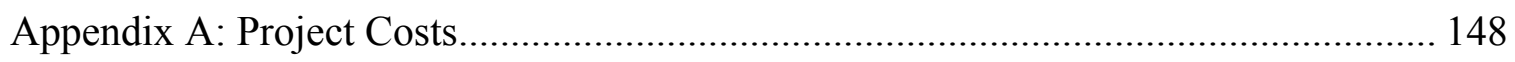

Appendix B: Bidirectional System Three-Line Diagram ............................................. 149

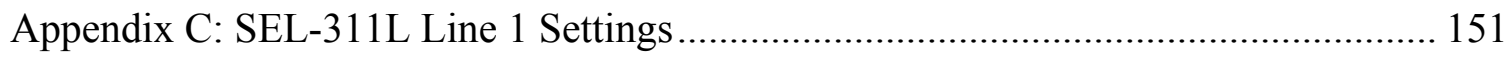

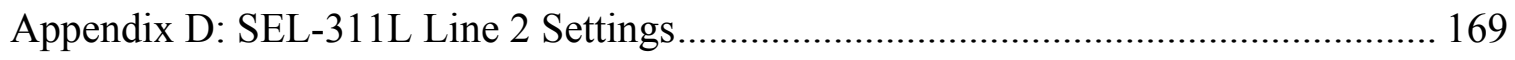

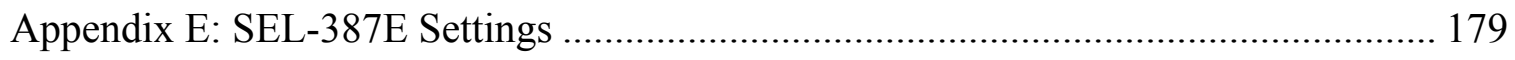

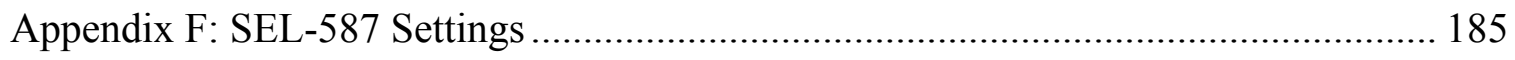

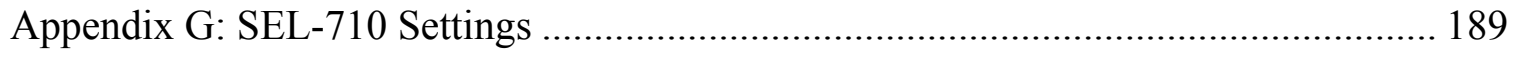

Appendix H: SEL-587 Differential Protection Procedure ……………………….......... 202

Appendix I: SEL-587 Overcurrent Protection Procedure ............................................... 219

Appendix J: SEL-710 Overcurrent and Undervoltage Protection Procedure .................. 233

Appendix K: SEL-311L Overcurrent Protection Procedure ............................................. 252

Appendix L: SEL-387E Differential Protection Procedure .............................................. 271

Appendix M: SEL-387E Overcurrent Protection Procedure ………………………........ 289

Appendix N: Radial System Coordination Procedure ………………………………... 304

Appendix O: ABET Senior Project Analysis.................................................................... 321 


\section{LIST OF TABLES}

Page

Table 1: Fault Protection Requirements and Specifications ........................................ 9

Table 2: Induction Motor Protection Requirements and Specificiations ....................... 10

Table 3: Microgrid Network Deliverables ............................................................... 11

Table 4: Radial System Functional Requirements, Level 0..................................... 20

Table 5: Bidirectional System Functional Requirements, Level 0 ............................... 22

Table 6: SEL-311L Line Protection Relay Functional Requirements ........................... 23

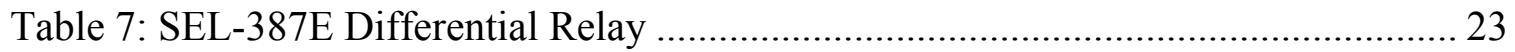

Table 8: SEL-587 Differential Protection Relay Functional Requirements ................... 24

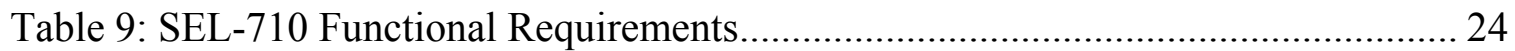

Table 10: SEL-2032 Communications Processor Functional Requirements................... 24

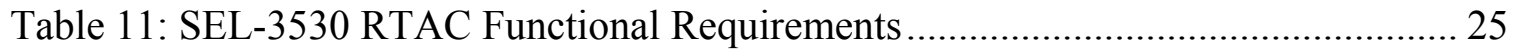

Table 12: SEL-2407 Satellite-Synchronized Clock .................................................. 25

Table 13: Key for Proposed Project Timeline Responsibilities ................................... 28

Table 14: Proposed Timeline for Project Introduction ............................................ 29

Table 15: Proposed Timeline for Project Phase I (Radial System) ............................... 29

Table 16: Proposed Timeline for Project Phase II (Bidirectional System)...................... 30

Table 17: Proposed Timeline for Project Phase III (Microgrid) ................................... 31

Table 18: Proposed Timeline for Project Conclusion ............................................. 31

Table 19: Estimated Project Costs (All Project Phases) ............................................. 33

Table 20: Radial System Primary Protection Zones and Methods ............................... 37

Table 21: Radial System Secondary Protection Zones and Methods ............................ 37 
Table 22: Radial System Detection of a Single-Line-to-Ground Fault at Bus 3 ........... 106

Table 23: Radial System Tripping for a Single-Line-to-Ground Fault at Bus 3 ........... 106

Table 24: Radial System Detection of a Double-Line-to-Ground Fault at Bus 3.......... 107

Table 25: Radial System Tripping for a Double-Line-to-Ground Fault at Bus 3 .......... 107

Table 26: Radial System Detection of a Triple-Line-to-Ground Fault at Bus 3............ 108

Table 27: Radial System Tripping for a Triple-Line-to-Ground Fault at Bus 3 ............ 108

Table 28: Radial System Detection of a Three-Phase Fault at Bus 3 .......................... 109

Table 29: Radial System Tripping for a Three-Phase Fault at Bus 3 .......................... 109

Table 30: Radial System Detection of a Line-to-Line Fault at Bus 3........................ 110

Table 31: Radial System Tripping for a Line-to-Line Fault at Bus 3 .......................... 110

Table 32: SEL-311L POTT Scheme, Double-Line-to-Ground Fault, Bus 3 ................. 117

Table 33: SEL-311L POTT Scheme, Triple-Line-to-Ground Fault, Bus 3 ................... 118

Table 34: SEL-311L POTT Scheme, Three-Phase Fault, Bus 3 ................................. 119

Table 35: SEL-311L POTT Scheme, Line-to-Line Fault, Bus 3 ................................. 120

Table 36: Bidirectional System Detection of a Single-Line-to-Ground Fault................ 123

Table 37: Bidirectional System Tripping for a Single-Line-to-Ground Fault ............... 123

Table 38: Bidirectional System Detection of a Double-Line-to-Ground Fault ............. 126

Table 39: Bidirectional System Tripping for a Double-Line-to-Ground Fault............... 127

Table 40: Bidirectional System Detection of a Triple-Line-to-Ground Fault ............... 128

Table 41: Bidirectional System Tripping for a Triple-Line-to-Ground Fault................ 129

Table 42: Bidirectional System Detection of a Three-Phase Fault ............................ 130

Table 43: Bidirectional System Tripping for a Three-Phase Fault ............................. 131

Table 44: Bidirectional System Detection of a Line-to-Line Fault ............................ 132 
Table 45: Bidirectional System Tripping for a Line-to-Line Fault.

Table 46: Incurred Project Costs............................................................................ 148

Table 47: Per-Phase Sequential Points of Connection................................................ 215

Table 48: Per-Phase Sequential Points of Connection............................................ 229

Table 49: Per-Phase Sequential Points of Connection................................................ 248

Table 50: Per-Phase Sequential Points of Connection............................................... 268

Table 51: Per-Phase Sequential Points of Connection............................................... 285

Table 52: Per-Phase Sequential Points of Connection................................................ 300 


\section{LIST OF FIGURES}

Page

Figure 1: Radial Network Single-Line Diagram (Project Phase I) ................................. 7

Figure 2: Alternate Radial Network Topology .................................................. 7

Figure 3: Bidirectional Network Single-Line Diagram (Project Phases II and III) ........... 8

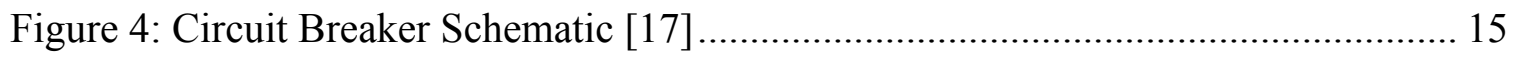

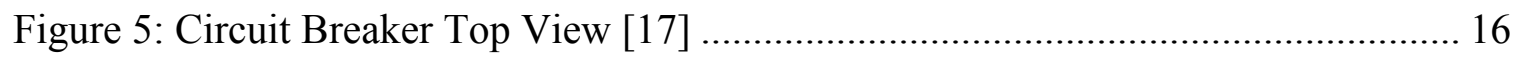

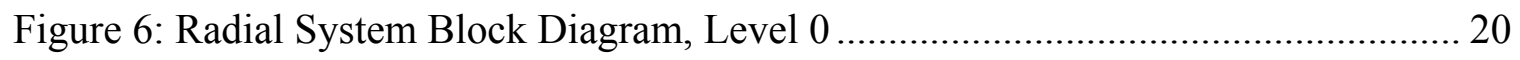

Figure 7: Bidirectional System Block Diagram, Level 0........................................ 21

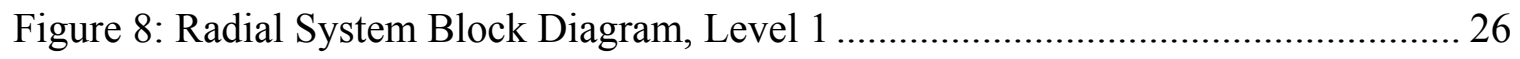

Figure 9: Bidirectional System Block Diagram, Level 1 ........................................... 27

Figure 10: Radial System Single-Line Protection Diagram, Wye-Wye Transformer ...... 35

Figure 11: Radial Single-Line Protection Diagram, Delta-Delta Transformer................ 36

Figure 12: SEL-311L Single-Line-to-Ground Fault, Bus 3, Phase A …....................... 42

Figure 13: SEL-311L Double-Line-to-Ground Fault, Bus 3, Phases A and B ............... 44

Figure 14: SEL-311L Triple-Line-to-Ground Fault, Bus 3, Phases A, B, and C ............ 45

Figure 15: SEL-311L Three-Phase Fault, Bus 3, Phases A, B, and C........................... 46

Figure 16: SEL-311L Line-to-Line Fault, Bus 3, Phases A and B .............................. 47

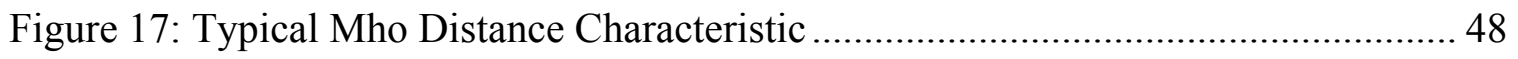

Figure 18: Mho Distance Relay Zones of Protection............................................... 50

Figure 19: Three-Line Diagram of Simulated Transmission Line with Split Phase A..... 52

Figure 20: SEL-311L Double-Line-to-Ground Fault, Bus 3, Phases A and B ................ 53

Figure 21: SEL-311L Triple-Line-to-Ground Fault, Bus 3, Phases A, B, and C ............ 54 
Figure 22: SEL-311L Three-Phase Fault, Bus 3, Phases A, B, and C........................... 55

Figure 23: SEL-311L Line-to-Line Fault, Bus 3, Phases A and B ............................... 56

Figure 24: SEL-387E Single-Line-to-Ground Fault, Bus 3, Phase A ............................ 57

Figure 25: SEL-387E Double-Line-to-Ground Fault, Bus 3, Phases A and B ................ 58

Figure 26: SEL-387E Triple-Line-to-Ground Fault, Bus 3, Phases A, B, and C ............ 59

Figure 27: SEL-387E Three-Phase Fault, Bus 3, Phases A, B, and C........................... 60

Figure 28: SEL-387E Line-to-Line Fault, Bus 3, Phases A and B ................................ 61

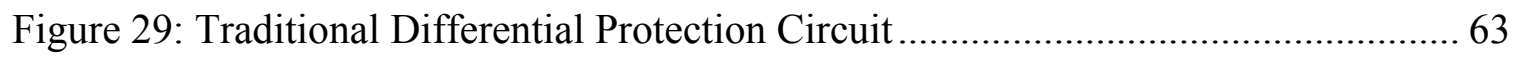

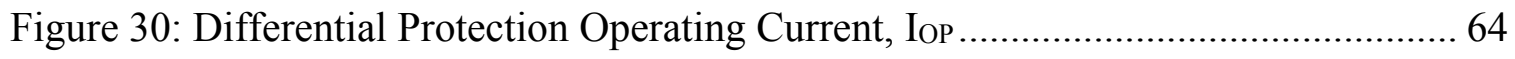

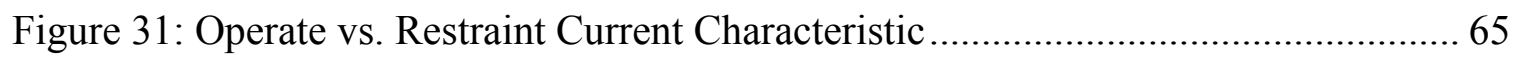

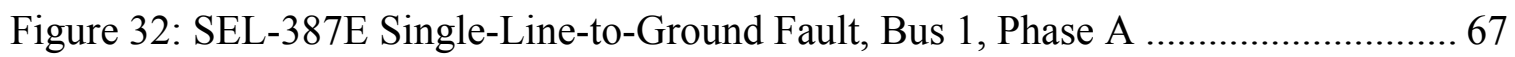

Figure 33: SEL-387E Single-Line-to-Ground Fault, Bus 2, Phase A .............................. 69

Figure 34: SEL-387E Double-Line-to-Ground Fault, Bus 1, Phases A and B ................ 70

Figure 35: SEL-387E Double-Line-to-Ground Fault, Bus 2, Phases A and B …............ 72

Figure 36: SEL-387E Triple-Line-to-Ground Fault, Bus 1, Phases A, B, and C ............ 73

Figure 37: SEL-387E Triple-Line-to-Ground Fault, Bus 2, Phases A, B, and C ............ 74

Figure 38: SEL-387E Three-Phase Fault, Bus 1, Phases A, B, and C.......................... 75

Figure 39: SEL-387E Three-Phase Fault, Bus 2, Phases A, B, and C........................... 76

Figure 40: SEL-387E Line-to-Line Fault, Bus 1, Phases A and B .............................. 77

Figure 41: SEL-387E Line-to-Line Fault, Bus 2, Phases A and B .............................. 79

Figure 42: SEL-710 Single-Line-to-Ground Fault, Bus 3, Phase A …......................... 80

Figure 43: SEL-710 Double-Line-to-Ground Fault, Bus 3, Phases A and B ................. 81

Figure 44: SEL-710 Triple-Line-to-Ground Fault, Bus 3, Phases A, B, and C............... 82 
Figure 45: SEL-710 Three-Phase Fault, Bus 3, Phases A, B, and C ............................ 83

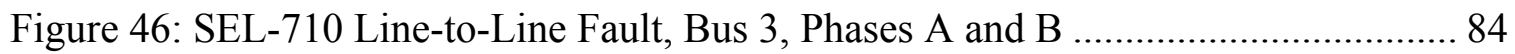

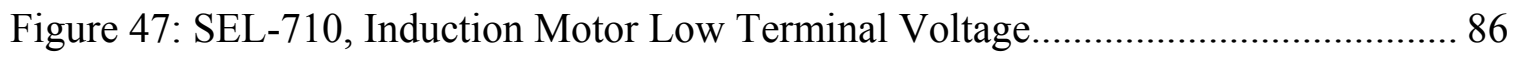

Figure 48: SEL-710, Induction Motor Locked-Rotor Condition ................................. 87

Figure 49: SEL-710, Induction Motor Thermal Overload Condition............................. 88

Figure 50: SEL-587 Single-Line-to-Ground Fault, Bus 3, Phase A .............................. 89

Figure 51: SEL-587 Double-Line-to-Ground Fault, Bus 3, Phases A and B .................. 90

Figure 52: SEL-587 Triple-Line-to-Ground Fault, Bus 3, Phases A, B, and C............... 91

Figure 53: SEL-587 Three-Phase Fault, Bus 3, Phases A, B, and C ............................. 92

Figure 54: SEL-587 Line-to-Line Fault, Bus 3, Phases A and B ................................. 93

Figure 55: SEL-587 Single-Line-to-Ground Fault, Bus 4, Phase A .............................. 95

Figure 56: SEL-587 Double-Line-to-Ground Fault, Bus 4, Phases A and B .................. 97

Figure 57: SEL-587 Triple-Line-to-Ground Fault, Bus 4, Phases A, B, and C............... 98

Figure 58: SEL-587 Three-Phase Fault, Bus 5, Phases A, B, and C ............................. 99

Figure 59: SEL-587 Three-Phase Fault, Bus 4, Phases A, B, and C ........................... 100

Figure 60: SEL-587 Line-to-Line Fault, Bus 5, Phases A and B ............................... 101

Figure 61: SEL-587 Line-to-Line Fault, Bus 4, Phases A and B ............................... 102

Figure 62: Bidirectional System Single-Line Protection Diagram ............................. 112

Figure 63: Wye-Connected Portion of Bidirectional System .................................. 113

Figure 64: Delta-Connected Portion of Bidirectional System .................................. 113

Figure 65: Permissive Overreaching Transfer Trip (POTT) Scheme Example.............. 115

Figure 66: SEL-710 Response to Single-Line-to-Ground Fault in Coordination Study 125

Figure 67: Communications Cable Management in the Bidirectional System.............. 136 
Figure 68: Bidirectional System Three-Line Diagram ................................................ 149

Figure 69: Bidirectional System Three-Line Diagram, Continued................................ 150

Figure 70: SEL-587 Differential Procedure Single-Line Diagram................................... 203

Figure 71: QuickSet Main Window ........................................................................... 204

Figure 72: SEL-587 Communication Parameters Window ............................................ 205

Figure 73: Identifying SEL-587 Relay Family, Model, and Version ............................. 206

Figure 74: Identifying SEL-587 Relay Part Number................................................... 206

Figure 75: Example SEL-587 Label with Relay Part Number ...................................... 206

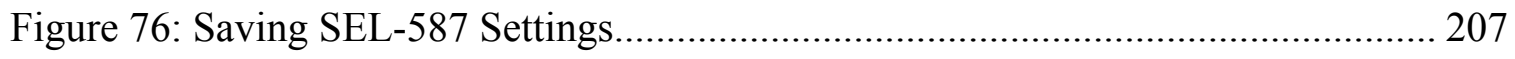

Figure 77: Choosing Location for New SEL-587 Relay Settings Database ................... 207

Figure 78: SEL-587 Settings Editor Main Window ……………………................... 209

Figure 79: SEL-587 General Data Settings ............................................................. 209

Figure 80: SEL-587 Current TAPs Settings …………………………………….... 209

Figure 81: SEL-587 Differential Elements Settings ……............................................... 210

Figure 82: SEL-587 Differential Elements Settings, cont. .......................................... 210

Figure 83: SEL-587 Power System Data Settings ………………………………........ 211

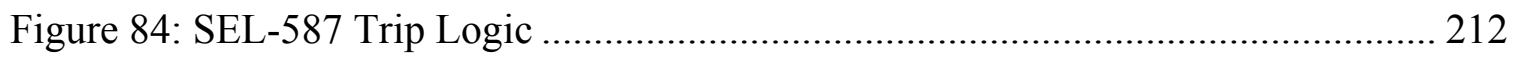

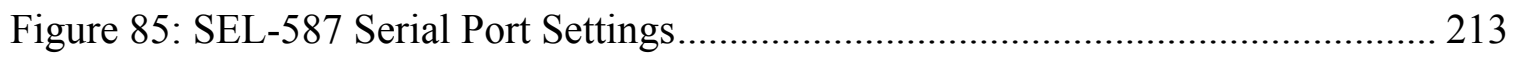

Figure 86: Send Modified Settings to SEL-587 ........................................................ 214

Figure 87: SEL-587 Overcurrent Procedure Single-Line Diagram ................................. 221

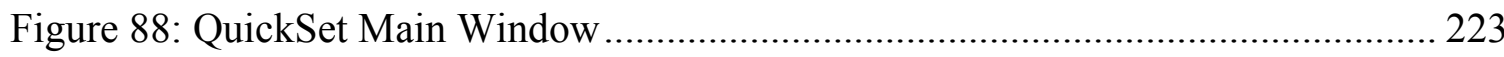

Figure 89: SEL-587 Communication Parameters Window ………………………….... 224

Figure 90: SEL-587 Overcurrent Elements .................................................................. 226 
Figure 91: SEL-587 Overcurrent Elements, cont. .................................................... 226

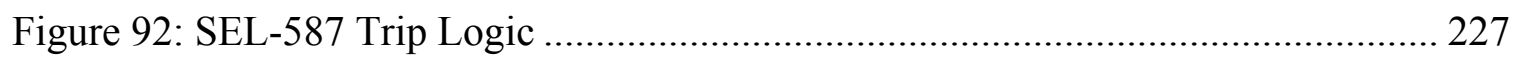

Figure 93: Send Modified Settings to SEL-587 ........................................................ 228

Figure 94: SEL-710 Procedure Single-Line Diagram ............................................... 234

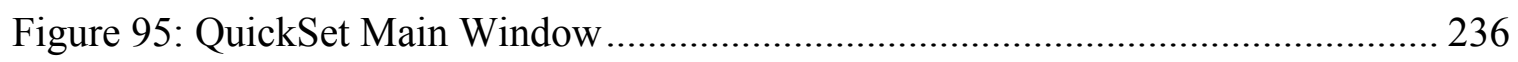

Figure 96: SEL-710 Communication Parameters Window ………………………….. 237

Figure 97: Identifying SEL-710 Relay Family, Model, and Version ............................ 238

Figure 98: Identifying SEL-710 Relay Part Number ................................................ 238

Figure 99: Example SEL-710 Label with Relay Part Number ....................................... 238

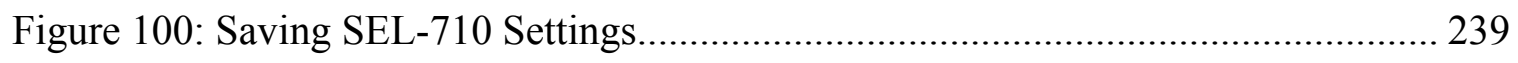

Figure 101: Choosing Location for New SEL-710 Relay Settings Database................. 239

Figure 102: SEL-710 Settings Editor Main Window ……………………………...... 240

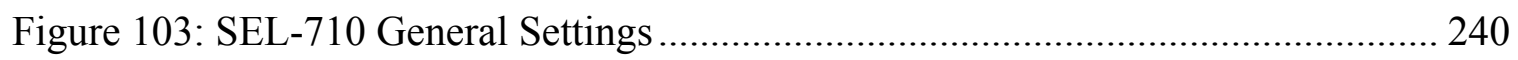

Figure 104: SEL-710 Breaker Monitor Settings .......................................................... 240

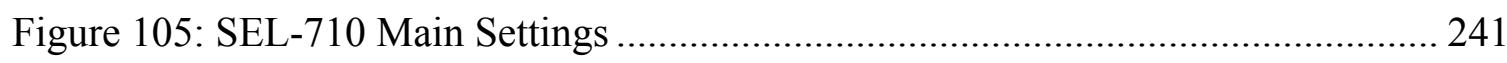

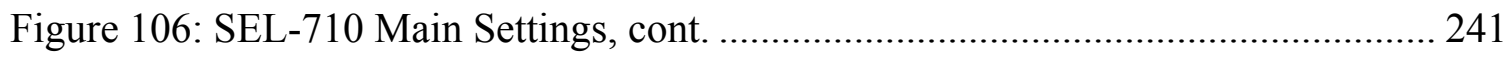

Figure 107: SEL-710 Phase Overcurrent Settings ........................................................ 242

Figure 108: SEL-710 Residual Overcurrent Settings …………………………........ 242

Figure 109: SEL-710 Negative-Sequence Overcurrent Settings ................................... 242

Figure 110: SEL-710 Undervoltage Elements ............................................................ 243

Figure 111: SEL-710 Trip and Close Logic ……………......................................... 243

Figure 112: SEL-710 Logic 1, Slot A Output Logic ……………………………........ 244

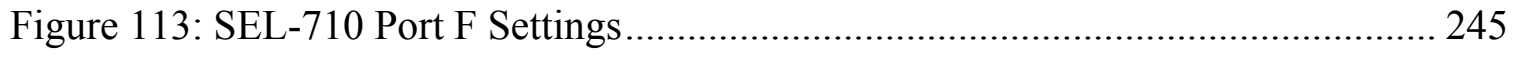


Figure 114: SEL-710 Trigger Lists Settings ............................................................ 246

Figure 115: SEL-710 Event Report Settings ............................................................ 246

Figure 116: Send Modified Settings to the SEL-710 ................................................... 246

Figure 117: SEL-311L Overcurrent Procedure Single-Line Diagram............................ 253

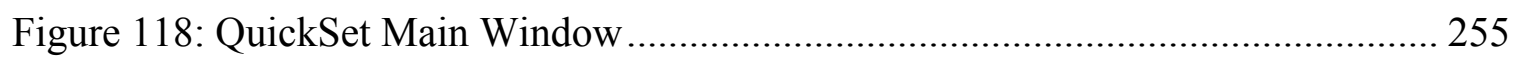

Figure 119: SEL-311L Communication Parameters Window ......................................... 256

Figure 120: Identifying SEL-311L Relay Family, Model, and Version......................... 257

Figure 121: Identifying SEL-311L Relay Part Number …………………………..... 257

Figure 122: Example SEL-311L Label with Relay Part Number.................................... 257

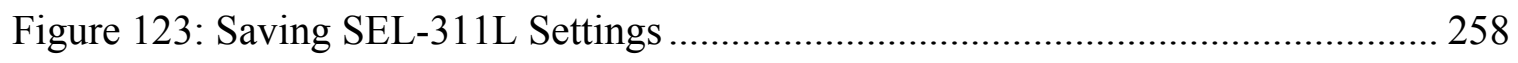

Figure 124: Choosing Location for New SEL-311L Relay Settings Database .............. 258

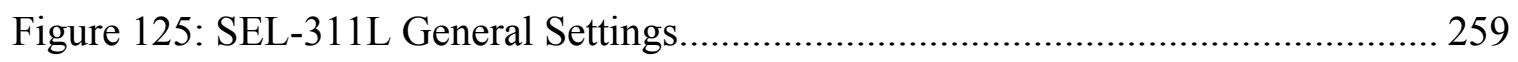

Figure 126: SEL-311L Backup Protection and Line Parameters Settings...................... 260

Figure 127: SEL-311L Inverse-Time Phase Overcurrent Settings .................................. 260

Figure 128: SEL-311L Inverse-Time Residual Overcurrent Settings ............................ 261

Figure 129: SEL-311L Inverse-Time Negative-Sequence Overcurrent Settings ........... 261

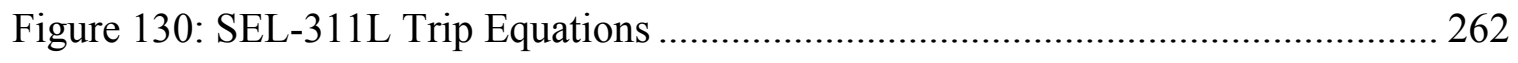

Figure 131: SEL-311L Output Contacts Equation...................................................... 262

Figure 132: SEL-311L Event Report Trigger Conditions ............................................. 263

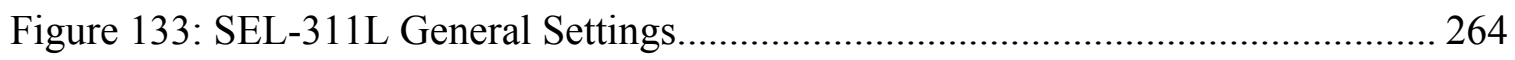

Figure 134: SEL-311L Sequential Events Recorder Equations....................................... 265

Figure 135: SEL-311L Port 2 Serial Communications Settings...................................... 266

Figure 136: Send Modified Settings to SEL-311L ………………….......................... 267 
Figure 137: SEL-387E Differential Procedure Single-Line Diagram 272

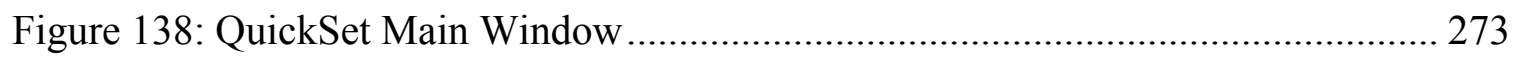

Figure 139: SEL-387E Communication Parameters Window ..................................... 274

Figure 140: Identifying SEL-387E Relay Family, Model, and Version....................... 275

Figure 141: Identifying SEL-387E Relay Part Number ........................................... 275

Figure 142: Example SEL-387E Label with Relay Part Number................................ 275

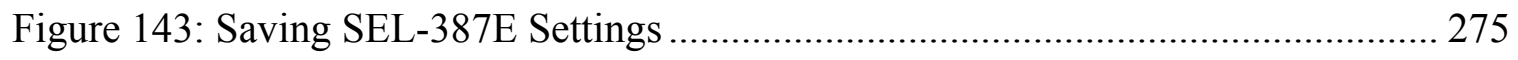

Figure 144: Choosing Location for New SEL-387E Relay Settings Database .............. 276

Figure 145: SEL-387E Settings Editor Window …............................................ 276

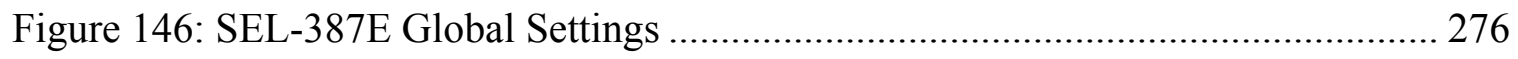

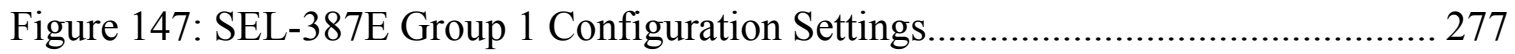

Figure 148: SEL-387E Group 1 Configuration Settings, cont.................................... 278

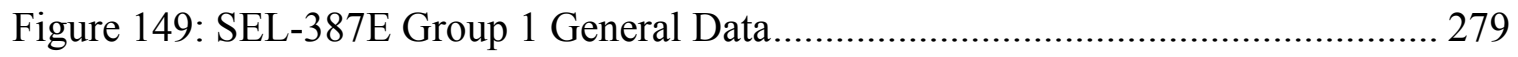

Figure 150: SEL-387E Group 1 General Data, cont.............................................. 279

Figure 151: SEL-387E Group 1 Differential Protection Elements ............................... 280

Figure 152: SEL-387E Group 1 Differential Protection Elements, cont...................... 280

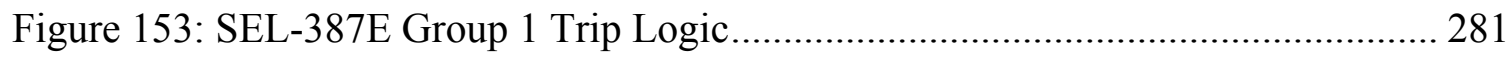

Figure 154: SEL-387E Group 1 Output Contact Logic ............................................. 282

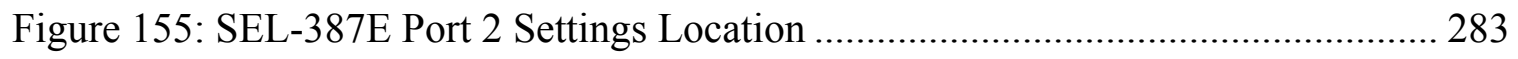

Figure 156: SEL-387E Serial Port 2 Settings ......................................................... 283

Figure 157: Send Modified Settings to SEL-387E .................................................. 284

Figure 158: SEL-387E Overcurrent Procedure Single-Line Diagram.......................... 291

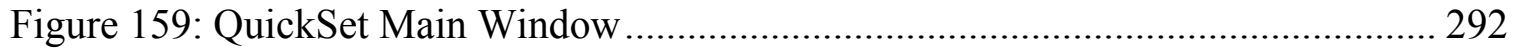


Figure 160: SEL-387E Communication Parameters Window 293

Figure 161: SEL-387E Group 1 Overcurrent Protection Elements ............................... 295

Figure 162: SEL-387E Group 1 Overcurrent Protection Elements, cont. ...................... 295

Figure 163: SEL-387E Group 1 Overcurrent Protection Elements, cont. ..................... 296

Figure 164: SEL-387E Group 1 Overcurrent Protection Elements, cont. ...................... 296

Figure 165: SEL-387E Group 1 Trip Logic............................................................ 297

Figure 166: SEL-387E Group 1 Output Contact Logic ............................................ 298

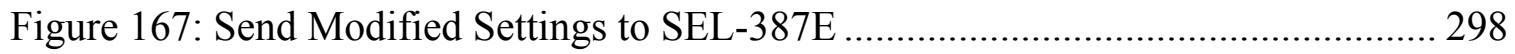

Figure 168: Radial Power Distribution System Model............................................. 305

Figure 169: SEL-5020 Settings Assistant Software Main Screen ................................ 306

Figure 170: Obtaining Level 1 and Level 2 Access to a Communications Processor .... 307

Figure 171: Establish SEL-2020/32 Master Port Using QuickSet Terminal................. 307

Figure 172: SEL-2020/32 Communication Parameters .......................................... 308

Figure 173: Defining SEL-2020/32 Device Options ............................................... 309

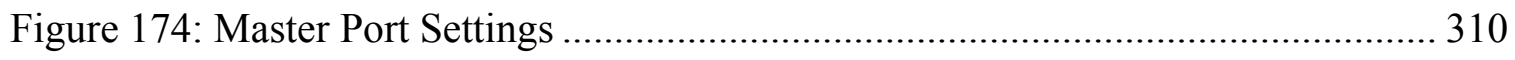

Figure 175: Main Screen before Establishing Connection ....................................... 311

Figure 176: Main Screen after Establishing Connection ........................................ 311

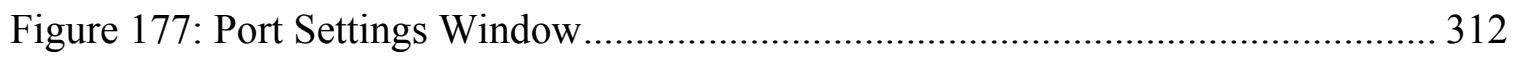

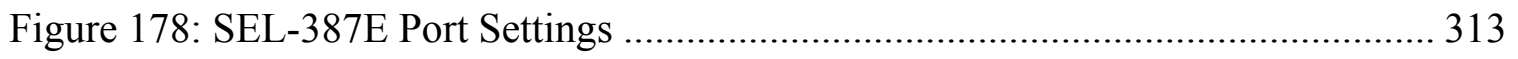

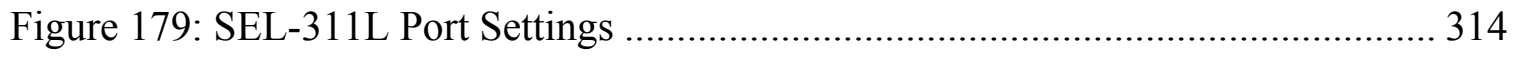

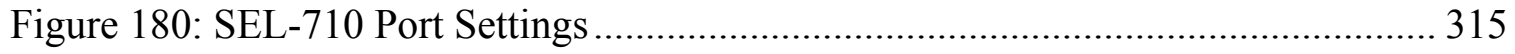

Figure 181: AcSELerator QuickSet Communication Parameters Window................... 316

Figure 182: Establishing Transparent Communications Using the QuickSet Terminal. 317 
Figure 183: Radial Circuit Three-Line Diagram 319

xxii 


\section{Chapter 1: Introduction}

\subsection{Traditional Radial Distribution Systems}

Utilities traditionally deliver electrical power to their customers using radial distribution systems. These systems feed numerous customers from a single, relatively large generating station far from their location. Interconnection of radial distribution circuits enables system operators to shift and balance electrical load between centralized generation locations. High-voltage transmission lines serve as additional, indirect connections between radial distribution circuits at the substation level. Although a radial distribution system allows the flexible allocation of customer load, it can also cause widespread collapse of the electrical grid [1]. The North American Electric Reliability Corporation (NERC) oversees eight regional entities to maintain a regulated system performance and avoid such catastrophes.

Traditional radial systems behave predictably, since power only flows from the generating station to the customer load under normal operating conditions. Protection of radial distribution systems takes advantage of this simplifying assumption when detecting fault conditions by only measuring currents flowing from the point of generation to the point of load. However, the recent addition of distributed energy resources (DERs), which send power upstream from the customer to the electrical grid, invalidates this assumption. Electrical utilities must therefore redesign their traditional approach to power distribution and system protection. 


\subsection{Microgrids as a Solution}

Microgrids stand as a potential solution to several difficulties inherent in modern radial distribution circuits. Reference [2] defines a microgrid as "a cluster of loads and microsources $(<100 \mathrm{~kW})$ operating as a single controllable system that provides both power and heat to its local area." A microgrid improves power system efficiency by generating power near the location of the load it serves. The proximity of generation to load reduces losses associated with long-distance transmission of power from a centralized generating station to a remote customer. Recycling heat energy associated with power generation further increases system efficiency. Furthermore, microgrids also demonstrate the capability to operate both with and without the larger grid network [3]. The ability to operate a microgrid independently of the grid network increases the reliability of uninterrupted power delivery to customers.

Advances in power electronics facilitate effective interaction between microgrids and the grid network. Simulations of back-to-back converters connecting a microgrid and grid network demonstrate the converters' ability to isolate each entity from the other's voltage and frequency fluctuations [4]. This connection supports independent and dynamic sharing of both real and reactive power between the microgrid and the grid network. For example, the grid network may supply excess reactive power to meet reactive load demands on the microgrid, while the microgrid simultaneously supplies excess real power to meet resistive load demands on the grid network. Synchronized communication and control operations unify all areas of a microgrid in order to maintain a stable balance of generation and load. If the grid network cannot supply additional power to meet increased load on the microgrid, the microgrid must initiate load-shedding 
procedures to maintain an equal balance of load and generation. Similarly, if the grid network cannot accept additional power from the microgrid, the microgrid must reduce generation when its load declines. Effective real-time balancing of generation and load requires fast and reliable communication links throughout the system. 


\subsection{Microgrid Protection Student Laboratory}

This project builds on the work of [5] to propose laboratory-scale microprocessorbased relay experiments for students, illustrating the principles of real-time fault protection in radial and bidirectional networks. The experiments apply the fundamental principles of power systems in conjunction with industry-standard protection equipment in a unified network. Early experiments focus on protection of a radial power system fed by the infinite bus, the topology with which students are most familiar. A bidirectional power system replaces the radial system in the final experiments.

Student learning outcomes include: applying the fundamental principles of power system protection to detect faults in transformers, transmission lines, and an induction motor; comparing experimentally-derived results with expected theoretical circuit performance through post-fault data analysis; developing experience in wiring common circuit connections; understanding the relationship between a relay and a circuit breaker in detecting and clearing faults; operating industry-standard relays; and coordinating relay operations in unified radial and bidirectional circuit topologies. This work also lays a foundation for the future development of a microgrid lab in the Cal Poly electrical engineering department. 


\section{Chapter 2: Customer Needs, Requirements, and Specifications}

\subsection{Customer Needs Assessment}

This project directly serves Cal Poly electrical engineering power systems students. It arose from the expressed desire of electrical engineering department faculty to introduce a new laboratory course utilizing protective relaying equipment donated by Schweitzer Engineering Laboratories, Inc. (SEL). Cal Poly currently offers a graduatelevel power systems protection lecture course, EE 518, to which this project adds an accompanying laboratory component. Curriculum resulting from this project should give students hands-on experience applying the fundamentals of power system protection through microprocessor-based relays. The following section describes the high-level functionality of the proposed student laboratory experiments. 


\subsection{Requirements and Specifications}

The nature of the proposed experiments justifies two sets of specifications for this project. The first set details component protection and applies to all topology stages and operating conditions of the circuit. A second set of specifications establishes allowable operating limits for an induction motor. Both sets of specifications aim to limit or stop power delivery during dangerous operating conditions. Single-line diagrams in Figure 1, Figure 2, and Figure 3 illustrate the general circuit topologies. For simplicity, protective devices do not appear.

Power system protection rests at the heart of this project. In general, protection is "the science, skill, and art of applying and setting relays or fuses, or both, to provide maximum sensitivity to faults and undesirable conditions, but to avoid their operation under all permissible or tolerable conditions" [6]. The protection scheme established for this system must recognize and eliminate fault conditions but never interrupt normal circuit operation. This balance in discerning normal load from fault conditions requires considering the impacts to the system caused by single-line-to-ground, double-line-toground, triple-line-to-ground, three-phase, and line-to-line bolted faults. All relays used to detect these faults require coordination so that a relay closer to a fault operates before any of the relays further upstream from the fault location. This first set of requirements and associated specifications appears in Table 1. 


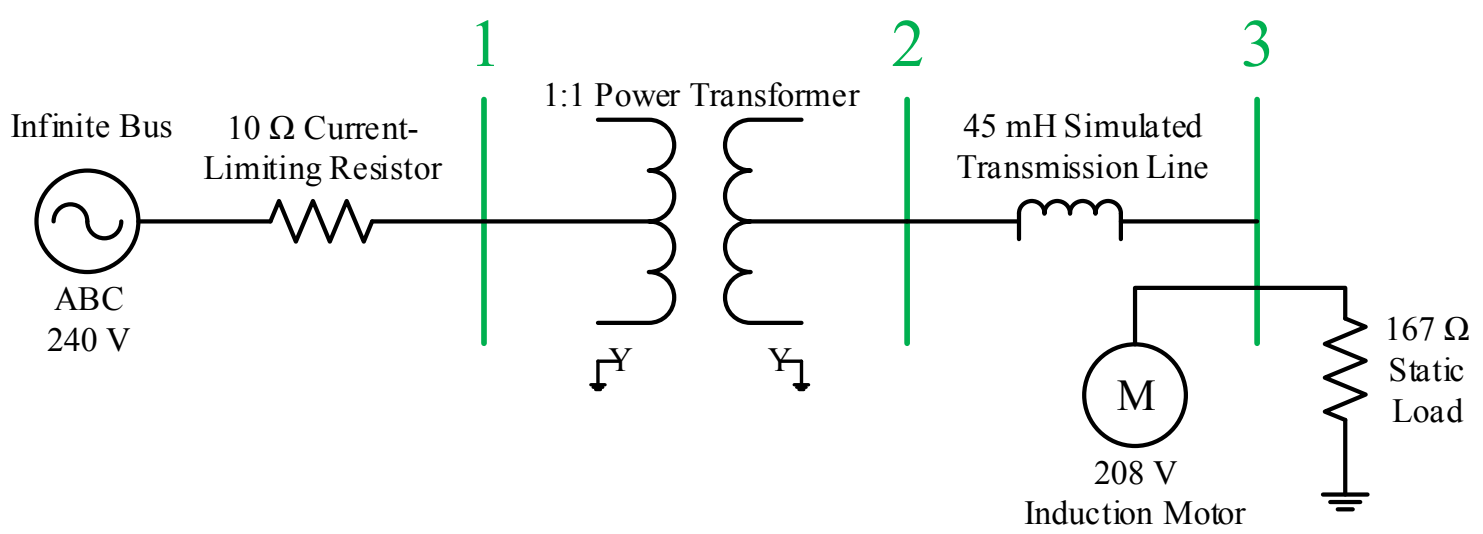

Figure 1: Radial Network Single-Line Diagram (Project Phase I)

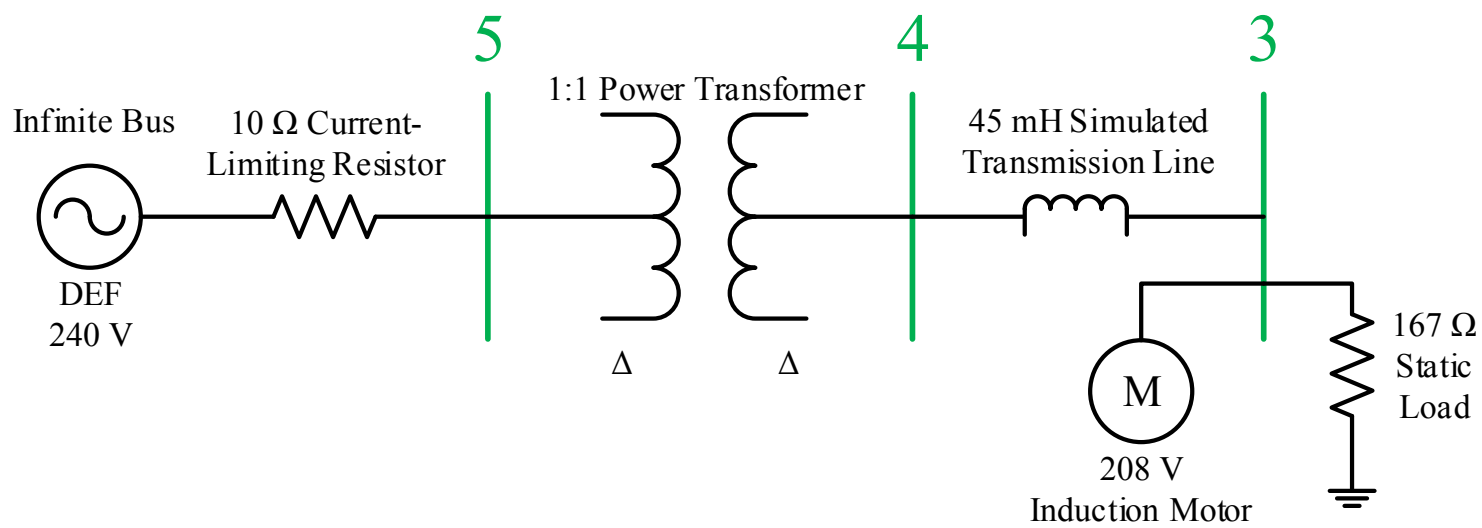

Figure 2: Alternate Radial Network Topology

Safe and reliable operation of an induction motor requires more than protection against fault conditions. For this reason, the following requirements specify additional circumstances in which the motor should halt for the safety of the equipment. Induction motor operation must cease under thermal overload, locked-rotor, and undervoltage conditions, with a time-stamped record of the condition documented. A tabulation of this second set of requirements and their associated specifications appears in Table 2. 


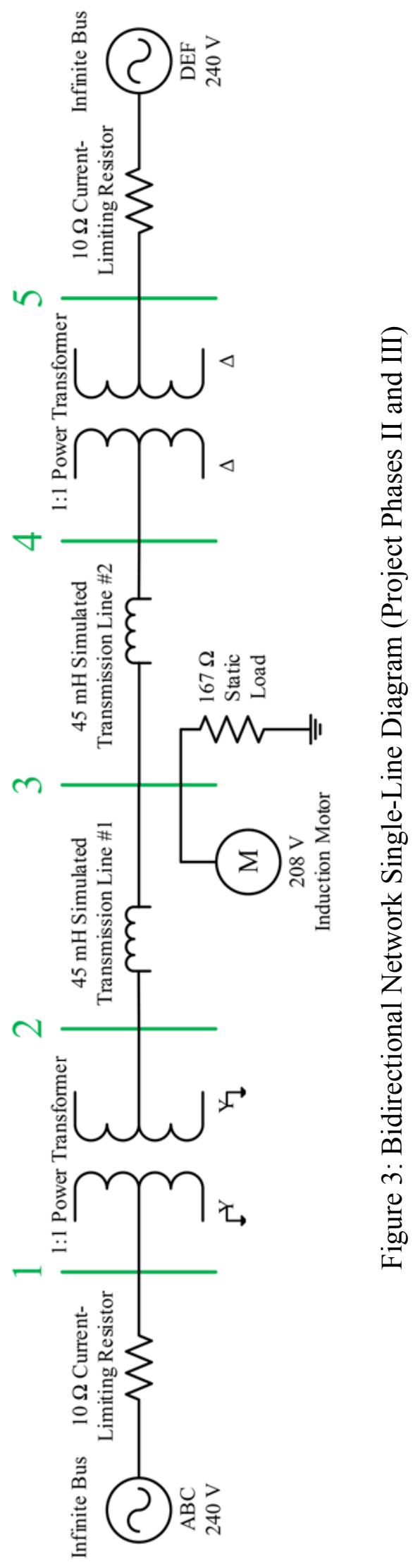


Table 1: Fault Protection Requirements and Specifications

\begin{tabular}{|c|c|c|}
\hline $\begin{array}{c}\text { Marketing } \\
\text { Requirements }\end{array}$ & $\begin{array}{c}\text { Engineering } \\
\text { Specifications }\end{array}$ & Justification \\
\hline $1-5$ & $\begin{array}{l}\text { Isolate faults in a primary zone } \\
\text { of protection within } 1 \mathrm{~s} \text { of fault } \\
\text { inception. }\end{array}$ & $\begin{array}{l}\text { Prompt termination of fault conditions } \\
\text { avoids harming people and equipment. A } \\
\text { protective device should operate quickly } \\
\text { in its primary zone of protection, where it } \\
\text { must respond before more distant } \\
\text { protective devices react. }\end{array}$ \\
\hline 6 & $\begin{array}{l}\text { Coordinate secondary protection } \\
\text { for every point in the circuit } \\
\text { between source buses. }\end{array}$ & $\begin{array}{l}\text { A minimum number of protective devices } \\
\text { should respond to a fault condition. } \\
\text { Backup protection helps ensure fault } \\
\text { termination. }\end{array}$ \\
\hline 7 & $\begin{array}{l}\text { Do not operate fault protection } \\
\text { features in response to nominal } \\
\text { induction motor operation. }\end{array}$ & $\begin{array}{l}\text { Fault protection should never interrupt } \\
\text { nominal circuit operation [6]. Negative- } \\
\text { sequence and residual overcurrent } \\
\text { protection detect faults in both low- and } \\
\text { high-magnitude currents. }\end{array}$ \\
\hline $1-5$ & $\begin{array}{l}\text { Maintain chronological records } \\
\text { of fault trip conditions using a } \\
\text { synchronized IRIG-B timing } \\
\text { signal. }\end{array}$ & $\begin{array}{l}\text { Knowing when abnormal system } \\
\text { conditions occurred provides clues to } \\
\text { their causes and effects within the } \\
\text { system. Distributing a synchronized } \\
\text { IRIG-B timing signal ensures accurate } \\
\text { time stamping of events. }\end{array}$ \\
\hline \multicolumn{3}{|c|}{$\begin{array}{l}\text { Marketing Requirements } \\
\text { 1. Detect, isolate, and record bolted single-line-to-ground faults downstream of source buses. } \\
\text { 2. Detect, isolate, and record bolted double-line-to-ground faults downstream of source buses. } \\
\text { 3. Detect, isolate, and record bolted triple-line-to-ground faults downstream of source buses. } \\
\text { 4. Detect, isolate, and record bolted three-phase faults downstream of source buses. } \\
\text { 5. Detect, isolate, and record bolted line-to-line faults downstream of source buses. } \\
\text { 6. Coordinate primary and secondary zones of protection. } \\
\text { 7. Initiate protection measures only during faults, never nominal load conditions. }\end{array}$} \\
\hline
\end{tabular}

The requirements and specifications table format derives from [7], Chapter 3. 
Table 2: Induction Motor Protection Requirements and Specificiations

\begin{tabular}{|c|c|c|}
\hline $\begin{array}{c}\text { Marketing } \\
\text { Requirements }\end{array}$ & $\begin{array}{c}\text { Engineering } \\
\text { Specifications } \\
\end{array}$ & Justification \\
\hline 8 & $\begin{array}{l}\text { Terminate power delivery to a } \\
\text { three-phase induction motor } \\
\text { when it continuously draws } \\
\text { more than } 2.1 \text { A } \text { Arms in a }_{\text {r }} \\
\text { bidirectional circuit. }\end{array}$ & $\begin{array}{l}\text { Continuously exceeding the } 2.1 \mathrm{~A}_{\text {rms }} \\
\text { current rating of a one-third-horsepower } \\
\text { induction motor endangers the machine } \\
\text { [8]. }\end{array}$ \\
\hline 9 & $\begin{array}{l}\text { Isolate an induction motor when } \\
\text { its load stops the rotor from } \\
\text { turning for } 3 \mathrm{~s} \text {. }\end{array}$ & $\begin{array}{l}\text { Continuously supplying current and } \\
\text { voltage to an induction motor with a } \\
\text { locked-rotor condition endangers the } \\
\text { machine [8]. }\end{array}$ \\
\hline 10 & $\begin{array}{l}\text { Isolate an induction motor when } \\
\text { bus } 3 \text { falls below } 119 \text { VLL }(70 \% \\
\text { of the induction motor no-load } \\
\text { terminal voltage in the radial } \\
\text { system). }\end{array}$ & $\begin{array}{l}\text { Ensure steady motor performance by } \\
\text { limiting operation to a minimum of } 58 \% \\
\text { of its rated } 208 \text { VLL terminal voltage } \\
\text { (reflected in motor relay settings). The } \\
\text { radial system only supports a load already } \\
\text { significantly below the motor's rated } \\
\text { voltage. }\end{array}$ \\
\hline $8-10$ & $\begin{array}{l}\text { Maintain chronological records } \\
\text { of motor trip conditions using a } \\
\text { synchronized IRIG-B timing } \\
\text { signal. }\end{array}$ & $\begin{array}{l}\text { Knowing when abnormal system } \\
\text { conditions occurred provides clues to } \\
\text { their causes and effects within the system. } \\
\text { Distributing a synchronized IRIG-B } \\
\text { timing signal ensures accurate time } \\
\text { stamping of events. }\end{array}$ \\
\hline \multicolumn{3}{|c|}{$\begin{array}{l}\text { Marketing Requirements } \\
\text { 8. Detect, eliminate, and record induction motor thermal overload conditions. } \\
\text { 9. Detect, eliminate, and record induction motor locked-rotor conditions. } \\
\text { 10. Detect, eliminate, and record induction motor undervoltage conditions. }\end{array}$} \\
\hline
\end{tabular}


Table 3 chronologically lists expected project deliverables. Quarterly reports reflect progress achieved on a quarterly basis. Demos highlight system functionality, as defined by specifications listed in Table 1 and Table 2, for approval by the project advisor. The design review apprises a small faculty committee of current progress and future design plans. An ABET Senior Project Analysis, included in Appendix O, addresses Cal Poly electrical engineering department accreditation requirements. Formal project culmination consists of the thesis defense and acceptance as well as the end-ofyear senior project poster session.

Table 3: Microgrid Network Deliverables

\begin{tabular}{|c|l|}
\hline $\begin{array}{c}\text { Delivery } \\
\text { Date }\end{array}$ & \multicolumn{1}{|c|}{ Deliverable Description } \\
\hline $09 / 30 / 16$ & Preliminary Design Review \\
\hline $12 / 07 / 16$ & Fall Quarter Report \\
\hline $01 / 11 / 17$ & Demo: Radial System Coordination \\
\hline $02 / 16 / 17$ & Final Design Review \\
\hline $03 / 17 / 17$ & Winter Quarter Report \\
\hline $04 / 19 / 17$ & ABET Senior Project Analysis \\
\hline $04 / 27 / 17$ & Demo: Bidirectional System Coordination \\
\hline $05 / 20 / 17$ & Thesis Final Draft Submission \\
\hline $05 / 24 / 17$ & Thesis Defense \\
\hline $06 / 02 / 17$ & Senior Project Poster Expo \\
\hline
\end{tabular}




\section{Chapter 3: Protection Equipment Overview}

\subsection{SEL Protection Equipment Introduction}

As mentioned in Chapter 2, this project utilizes SEL equipment donated to Cal Poly in the establishment of new laboratory curriculum. This chapter introduces the various devices that comprise the protection scheme throughout the various project phases. Information on SEL device capabilities and characteristics derives from the company's product literature.

\subsection{SEL-311L: Transmission Line Protection}

The SEL-311L offers impedance and overcurrent fault protection and can provide line current differential protection [9]. The first phase of this project uses an SEL-311L to monitor a simulated transmission line (between buses 2 and 3 in Figure 1) using impedance and instantaneous overcurrent settings. Phases 2 and 3 of this project incorporate a second SEL-311L (between buses 3 and 4 in Figure 3) to establish differential protection for the expanded power transmission system.

\subsection{SEL-387E: Transformer Protection}

Boasting a suite of integrated capabilities including differential, overcurrent, restricted earth fault, overvoltage, undervoltage, overfrequency, underfrequency, and overexcitation protection, the SEL-387E monitors power transformers with up to three windings [10]. All three project phases utilize the differential and inverse-time overcurrent protection features of the SEL-387E on a grounded wye-wye transformer. 


\subsection{SEL-587: Transformer Protection}

Like the SEL-387E, but with fewer capabilities, the SEL-587 supports differential and overcurrent protection of a two-winding power transformer [11]. An SEL-587 protects the delta-delta transformer, shown in Figure 2 and Figure 3. A fixed event recording period of 15 cycles (with only 3 cycles of prefault data) [12] limits the amount of information that this device can store compared to the other SEL relays utilized in this project.

\subsection{SEL-710: Motor Protection}

Replete with a variety of real-time performance analysis metrics, the SEL-710 verifies stable motor operation through thermal overload, locked-rotor, overcurrent, loadloss, current-unbalance, start inhibition, overvoltage, undervoltage, overfrequency, underfrequency, loss-of-potential, and power factor protection [13]. An SEL-710 provides thermal overload, locked rotor, undervoltage, and instantaneous overcurrent protection to an induction motor in each phase of this project.

\subsection{SEL-2032: Communications Processor}

A communications processor unifies a power system by streamlining communications to and from each of the relays connected to it. Rather than making independent connections from each relay to the human-machine interface (HMI), or computer, a single connection between the SEL-2032 communications processor and the HMI enables communication between the HMI and all the relays connected to the communication processor [14]. The SEL-2032 further unifies the system by time- 
stamping data obtained by the relays and distributing a synchronized IRIG-B timing signal to all connected relays. An autoconfiguration feature of the SEL-2032 simplifies and expedites the process of connecting SEL relays to the system. An SEL-2032 provides system integration during the first two phases of this project.

\subsection{SEL-3530: Real-Time Automation Controller}

More powerful than the SEL-2032, the SEL-3530 RTAC builds upon the functionality of a communications processor with cybersecurity, automation, and relay control features [15]. Phase 3 of this project replaces the SEL-2032 communications processor with the SEL-3530 RTAC, increasing remote control of relays and enabling future real-time microgrid operation.

\subsection{SEL-2407: Satellite-Synchronized Clock}

Consistent and accurate relay event reporting depends on the timing source for each relay. The SEL-2407 satellite-synchronized clock generates an IRIG-B timing signal, which it can distribute to all system relays through an information processor [16]. This project utilizes an SEL-2407 to supply a demodulated IRIG-B timing signal to the SEL-2032 communications processor (Phases 1 and 2) and SEL-3530 RTAC (Phase 3). Time-stamping relay events with a synchronized timing signal generates consistent data for post-fault review and analysis. 


\subsection{Circuit Breakers}

Microprocessor-based relays prove difficult to test safely during operation in a laboratory environment. For example, running an induction motor necessitates high nominal load currents, which lead to high fault currents. A former Cal Poly student, Ozro Corulli, recognized this challenge and developed the circuit breaker described in Figure 4 and Figure 5. An input voltage of 125 VDC (across the red and black Breaker Control terminals in Figure 5) supports circuit breaker operation. Trip and Close Breaker Control inputs from a relay carry less than 0.25 A, while Circuit Breaker and Fault Switch connections carry a continuous 3 A and momentary 12 A [17].

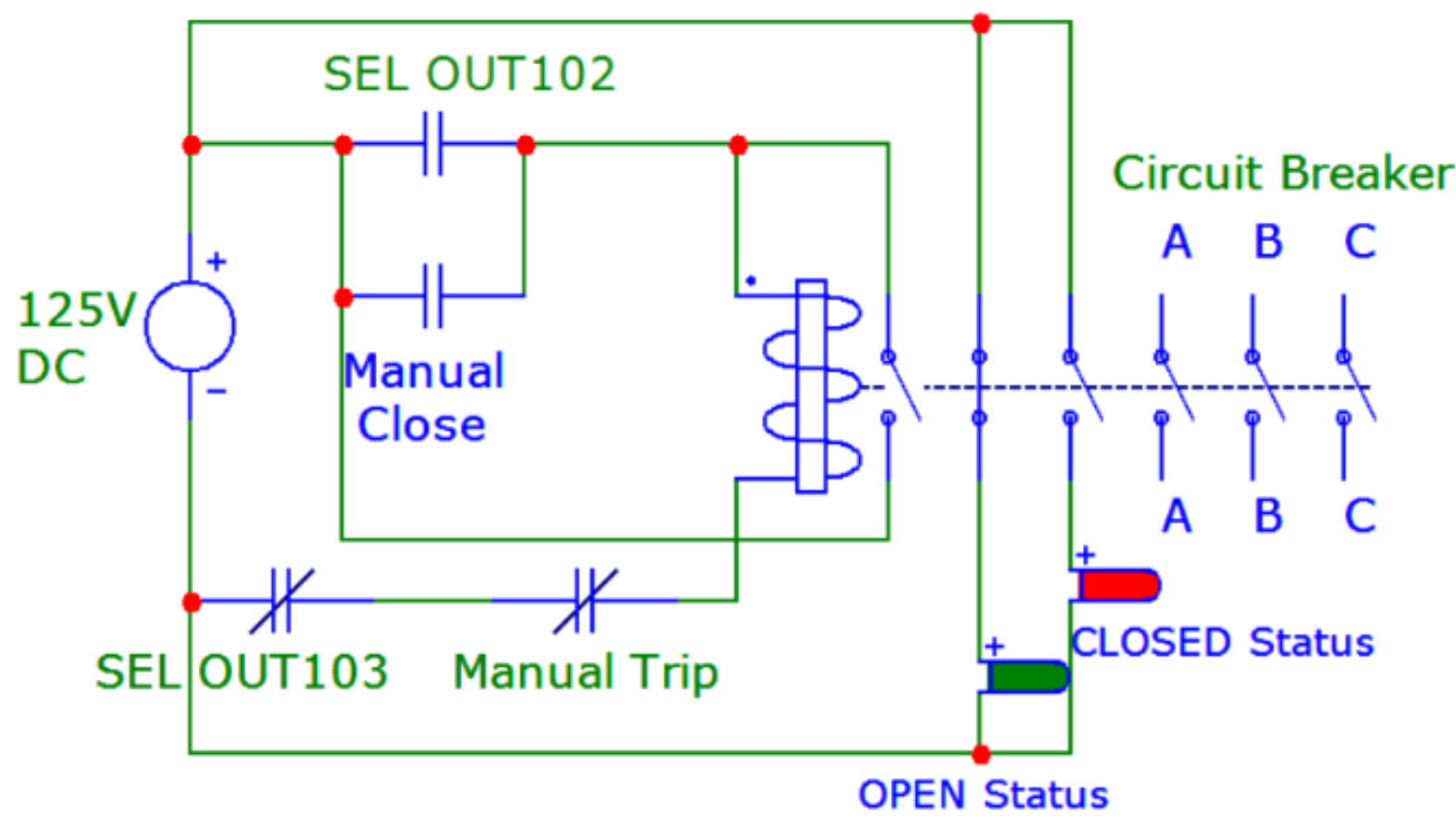

Figure 4: Circuit Breaker Schematic [17]

A green Open lamp in the Breaker Status section of the circuit breaker (right side of Figure 5) signifies that the three-phase Circuit Breaker switch across the phase A, B, 
and C terminals (left side of Figure 5) is open. No current flows between the red and black Circuit Breaker terminals in this condition. Conversely, the red Closed lamp signifies that the breaker is closed. The circuit breaker defaults to the Open status upon initial application of $125 \mathrm{VDC}$ control power.

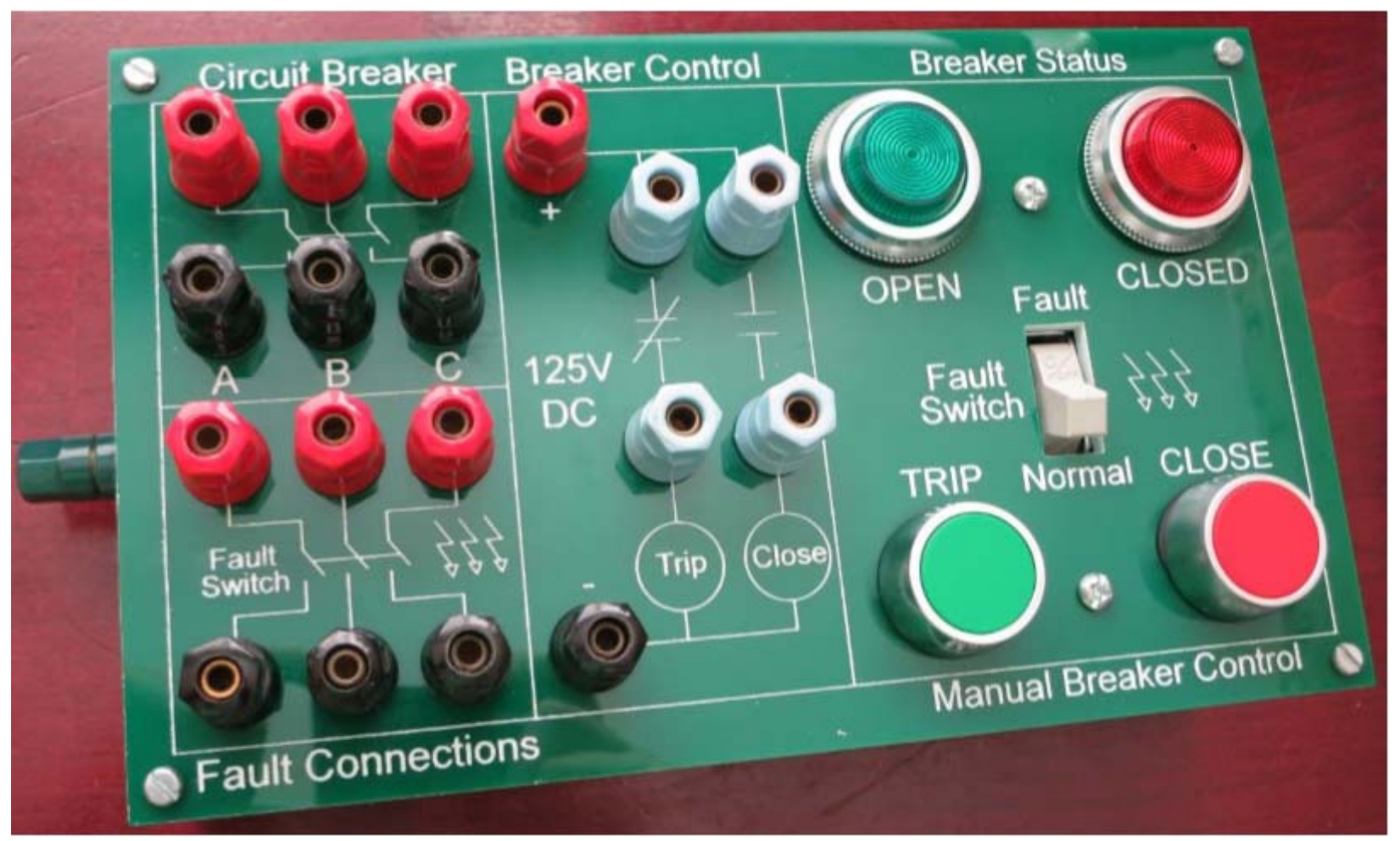

Figure 5: Circuit Breaker Top View [17]

The circuit breaker design supports a variety of operation schemes utilizing both manual and relay input. A fault switch, on the right side of the unit in Figure 5, defines the two main modes of operation. In "Normal" mode, the fault switch connections on the left side of the unit in Figure 5 remain open for each phase. Flipping the Fault Switch (right side of unit) to "Fault" mode closes the fault switch connections between the Fault Connections terminals (left side of unit). This design allows wiring faults into the circuit 
by connecting jumpers between the black Circuit Breaker terminals and red Fault Connections terminals. Doing so diverts power to faults configured at the black Fault Connections terminals when Fault mode is active. Ground fault wiring configurations use direct connections to bench ground. Isolating ground connections for faults precludes energizing equipment chassis and potentially electrocuting system operators.

The switches labeled "SEL OUT102" and "SEL OUT103" in Figure 4 correspond to circuit breaker output ports on an SEL relay. Note that since the user defines these ports in the settings for each relay, the exact output port used on a connected SEL relay device may vary. For example, the trip signal, alternatively, could come from output ports 101 and 104 on a connected SEL relay.

As the schematic in Figure 4 illustrates, manual and relay input signals work together in circuit breaker operation. For simplicity or proof-of-concept operation, inserting a jumper across the Breaker Control Trip terminals replaces required input from a relay. Doing so shorts the normally-open "SEL OUT102" switch in Figure 4, allowing the Manual Breaker Control Close push-button switch to close in the Circuit Breaker switch contacts. To close in the Circuit Breaker contacts, the Breaker Control Trip terminals must remain either appropriately connected to a relay or shorted together. 


\section{Chapter 4: Functional Decomposition}

\subsection{Decomposition Overview}

The previous two chapters identified customer needs and high-level system information. This chapter structures a framework in which the capabilities of the protective devices presented in Chapter 3 fulfill the customer needs and project specifications presented in Chapter 2. The following decomposition characterizes

protection systems for both the radial and bidirectional circuit topologies. A level zero decomposition describes system-level characteristics, while a level one decomposition focuses on device-level characteristics. 


\subsection{Functional Requirements - Level 0}

Level zero functional decomposition describes the entire system as a black box. Block diagrams (Figure 6 and Figure 7) define high-level operation requirements for protection systems in the radial and bidirectional circuit topologies. A tabulation of functional requirements (Table 4 and Table 5) follows each diagram, further describing system inputs, outputs, and necessary capabilities. Since both topologies require comparable protection functionalities, the bidirectional system merely extends the protection functionality of the radial system.

Input requirements in Table 4 reflect bolted fault conditions that the protection system must recognize and interrupt. Ratings for the input values, received by protective devices within the black box, derive from the nominal system operating voltage and measured circuit component impedances. Specifications also appear for input power to the protective devices. The statuses of the relevant output contacts for each protective device (which control the trip/close status for the circuit breakers) comprise most of the system outputs. An additional output for fault data refers to event reports pulled from the system protective devices. The specification for recording time-stamped abnormal system events supports analysis of event files generated by the protective devices. 


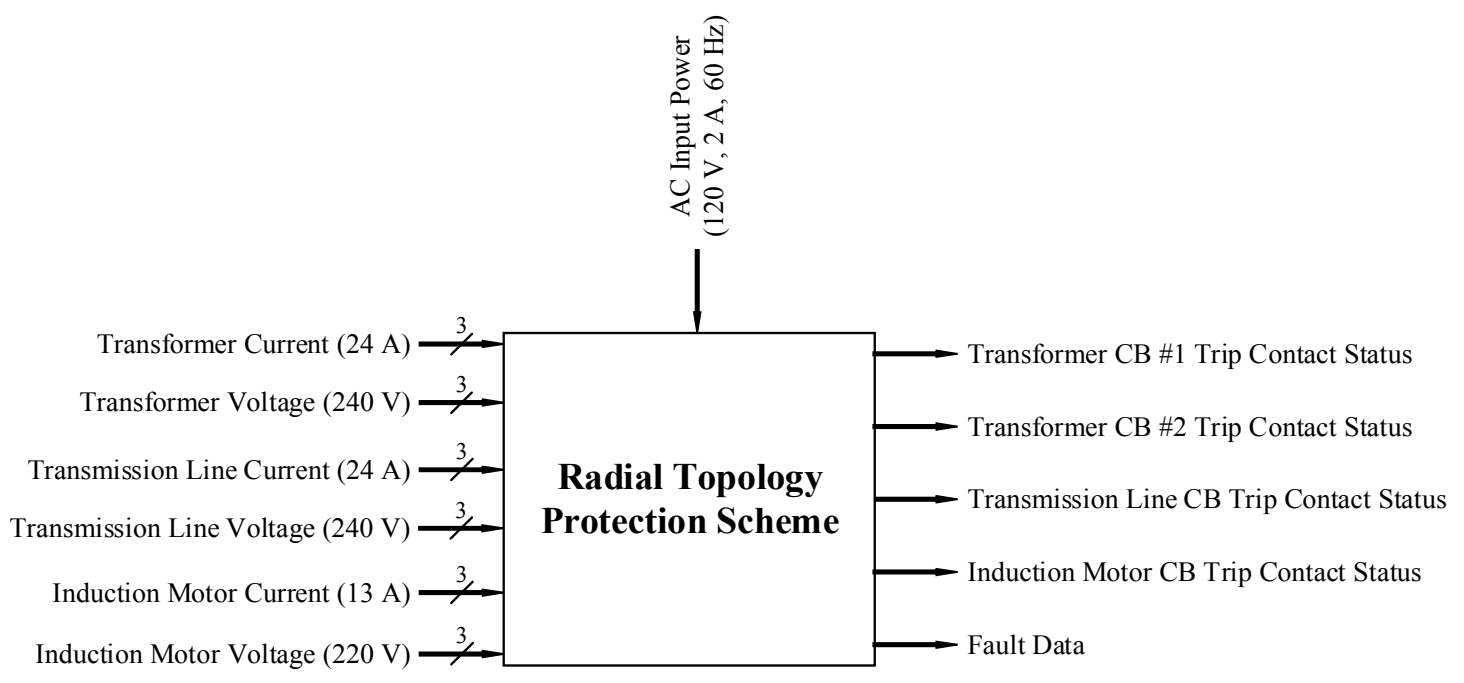

Figure 6: Radial System Block Diagram, Level 0

Table 4: Radial System Functional Requirements, Level 0

\begin{tabular}{|c|c|}
\hline Module & Radial Microgrid Protection Scheme \\
\hline Inputs & $\begin{array}{l}\text { - Three-Phase Transformer Current }\left(24 \mathrm{~A}_{\mathrm{rms}}\right) \\
\text { - Three-Phase Transformer Voltage }\left(240 \mathrm{~V}_{\mathrm{rms}} \text { line-to-line }\right) \\
\text { - Three-Phase Transmission Line Current }\left(24 \mathrm{~A}_{\mathrm{rms}}\right) \\
\text { - Three-Phase Transmission Line Voltage }\left(240 \mathrm{~V}_{\mathrm{rms}} \text { line-to-line }\right) \\
\text { - Three-Phase Induction Motor Current }\left(13 \mathrm{~A}_{\mathrm{rms}}\right) \\
\text { - Three-Phase Induction Motor Voltage }\left(231 \mathrm{~V}_{\mathrm{rms}} \text { line-to-line }\right) \\
\text { - AC Input Power }\left(120 \mathrm{~V}_{\mathrm{rms}}, 2 \mathrm{~A}_{\mathrm{rms}}, 60 \mathrm{~Hz}\right)\end{array}$ \\
\hline Outputs & $\begin{array}{l}\text { - Transformer Circuit Breaker \#1 Trip Contact Status } \\
\text { - Transformer Circuit Breaker \#2 Trip Contact Status } \\
\text { - Transmission Line Circuit Breaker Trip Contact Status } \\
\text { - Induction Motor Circuit Breaker Trip Contact Status } \\
\text { - Time-Stamped Record of Fault Data (EIA-232 Serial) }\end{array}$ \\
\hline Functionality & $\begin{array}{l}\text { - Operate protection scheme using } 120 \mathrm{~V}_{\mathrm{rms}} \text { input power. } \\
\text { - Detect transformer faults using voltage and current inputs from } \\
\text { circuit. } \\
\text { - Detect transmission line faults using current inputs from circuit. } \\
\text { - Detect induction motor faults using voltage and current inputs from } \\
\text { circuit. } \\
\text { - Initiate circuit breaker trip signals in response to fault conditions. } \\
\text { - Collect and report abnormal system events in chronological order. }\end{array}$ \\
\hline
\end{tabular}




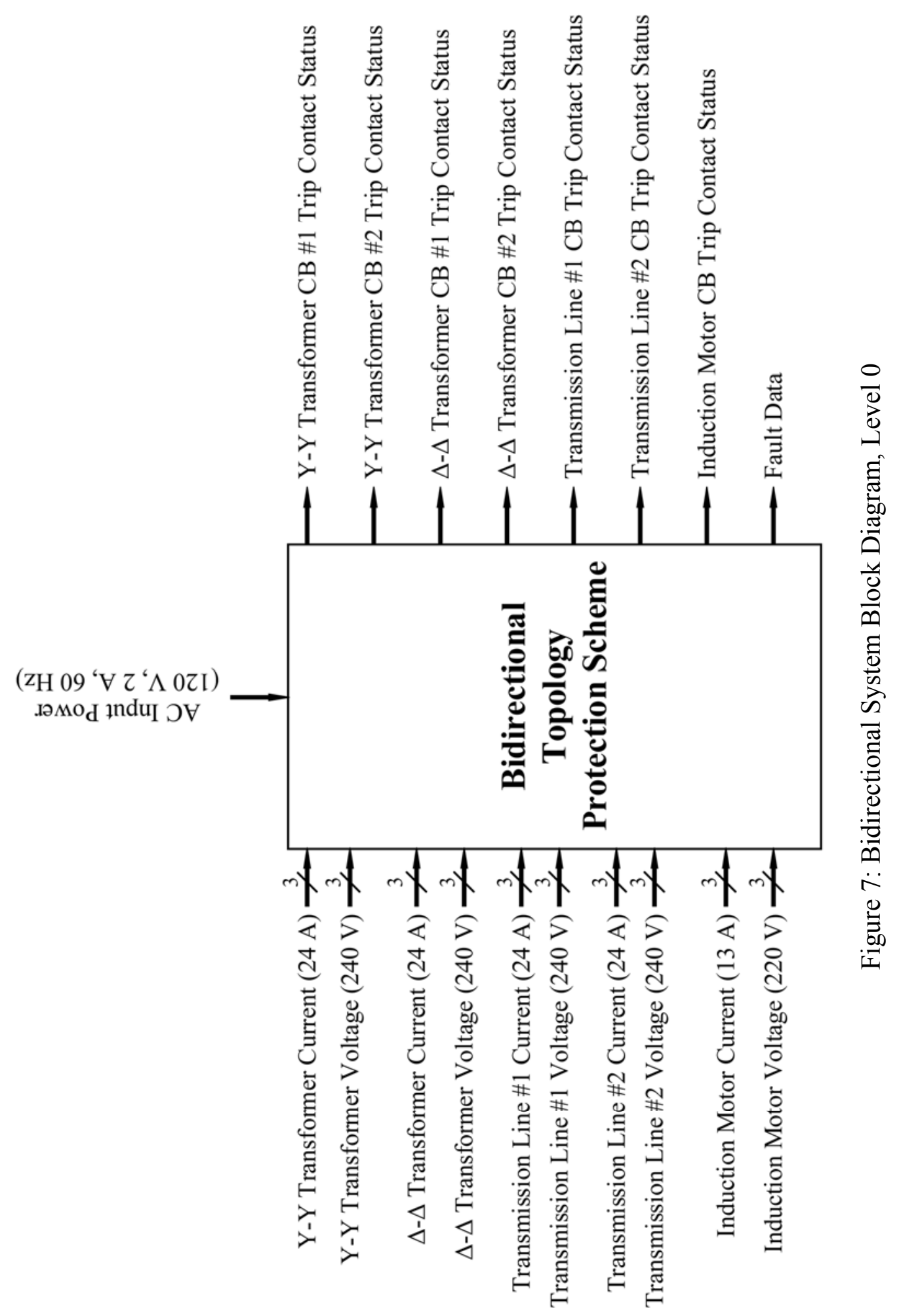


Specifications presented in Table 5 expand the functionality specified in Table 4 to protect additional devices incorporated when converting the radial system into a bidirectional system. Basic system functionality remains unchanged.

Table 5: Bidirectional System Functional Requirements, Level 0

\begin{tabular}{|c|c|}
\hline Module & Bidirectional Microgrid Protection Scheme \\
\hline Inputs & $\begin{array}{l}\text { - Three-Phase Y-Y Transformer Current }\left(24 \mathrm{~A}_{\mathrm{rms}}\right) \\
\text { - Three-Phase Y-Y Transformer Voltage }\left(240 \mathrm{~V}_{\mathrm{rms}} \text { line-to-line }\right) \\
\text { - Three-Phase } \Delta-\Delta \text { Transformer Current }\left(24 \mathrm{~A}_{\mathrm{rms}}\right) \\
\text { - Three-Phase } \Delta-\Delta \text { Transformer Voltage }\left(240 \mathrm{~V}_{\mathrm{rms}} \text { line-to-line }\right) \\
\text { - Three-Phase Transmission Line } \# 1 \text { Current }\left(24 \mathrm{~A}_{\mathrm{rms}}\right) \\
\text { - Three-Phase Transmission Line } \# 1 \text { Voltage }\left(240 \mathrm{~V}_{\mathrm{rms}} \text { line-to-line }\right) \\
\text { - Three-Phase Transmission Line } \# 2 \text { Current }\left(24 \mathrm{~A}_{\mathrm{rms}}\right) \\
\text { - Three-Phase Transmission Line } \# 2 \text { Voltage }\left(240 \mathrm{~V}_{\mathrm{rms}} \text { line-to-line }\right) \\
\text { - Three-Phase Induction Motor Current }\left(13 \mathrm{~A}_{\mathrm{rms}}\right) \\
\text { - Three-Phase Induction Motor Voltage }\left(220 \mathrm{~V}_{\mathrm{rms}} \text { line-to-line }\right) \\
\text { - AC Input Power }\left(120 \mathrm{~V}_{\mathrm{rms}}, 2 \mathrm{~A}_{\mathrm{rms}}, 60 \mathrm{~Hz}\right)\end{array}$ \\
\hline Outputs & $\begin{array}{l}\text { - Y-Y Transformer Circuit Breaker \#1 Trip Contact Status } \\
\text { - Y-Y Transformer Circuit Breaker \#2 Trip Contact Status } \\
\text { - } \Delta-\Delta \text { Transformer Circuit Breaker \#1 Trip Contact Status } \\
\text { - } \Delta-\Delta \text { Transformer Circuit Breaker \#2 Trip Contact Status } \\
\text { - Transmission Line \#1 Circuit Breaker Trip Contact Status } \\
\text { - Transmission Line \#2 Circuit Breaker Trip Contact Status } \\
\text { - Induction Motor Circuit Breaker Trip Contact Status } \\
\text { - Time-Stamped Record of Fault Data (EIA-232 Serial) } \\
\end{array}$ \\
\hline Functionality & $\begin{array}{l}\text { - Operate protection scheme using } 120 \mathrm{~V}_{\mathrm{rms}} \text { input power. } \\
\text { - Detect three-phase transformer faults using voltage and current inputs } \\
\text { from circuit. } \\
\text { - Detect three-phase transmission line faults using current inputs from } \\
\text { circuit. } \\
\text { - Detect three-phase induction motor faults using voltage and current } \\
\text { inputs from circuit. } \\
\text { - Initiate circuit breaker trip signals in response to fault conditions. } \\
\text { - Collect and report abnormal system events in chronological order. }\end{array}$ \\
\hline
\end{tabular}




\subsection{Functional Requirements - Level 1}

The functional requirements given below describe the protection scheme in the radial and bidirectional circuit topologies. Figure 8 illustrates a radial system level 1 block diagram, while Figure 9 illustrates the bidirectional system level 1 block diagram. Table 6 through Table 12 describe functional requirements for the devices in the radial and bidirectional systems.

Table 6: SEL-311L Line Protection Relay Functional Requirements

\begin{tabular}{|c|l|}
\hline Module & SEL-311L Line Protection Relay \\
\hline \multirow{5}{*}{ Inputs } & $\begin{array}{l}\text { - Three-Phase Transmission Line Current (24 Arms) } \\
\text { - Three-Phase Transmission Line Voltage (240 V rms line-to-line) } \\
\text { - AC Input Power (120 Vrms, 25 W, 60 Hz) [9] } \\
\text { - Demodulated IRIG-B Clock-Synchronization Signal (TTL 2.5 mADC, } \\
\text { 2.4 VDC) [15] }\end{array}$ \\
\hline \multirow{3}{*}{ Outputs } & $\begin{array}{l}\text { - Transmission Line Circuit Breaker Trip Contact Status } \\
\text { - Time-Stamped Record of Fault Data (EIA-232 Serial) }\end{array}$ \\
\hline \multirow{3}{*}{ Functionality } & $\begin{array}{l}\text { - Detect three-phase transmission line faults. } \\
\text { - Initiate circuit breaker trip signals in response to fault conditions. } \\
\text { - Collect and report abnormal system events chronologically to SEL- } \\
\text { 2032/3530. }\end{array}$ \\
\hline
\end{tabular}

Table 7: SEL-387E Differential Relay

\begin{tabular}{|c|c|}
\hline Module & SEL-387E Differential Relay \\
\hline Inputs & $\begin{array}{l}\text { - Three-Phase Y-Y Transformer Current (24 Arms) } \\
\text { - Three-Phase Y-Y Transformer Voltage (240 V } \mathrm{V}_{\text {rms }} \text { line-to-line) } \\
\text { - AC Input Power }\left(120 \mathrm{~V}_{\mathrm{rms}}, 25 \mathrm{~W}, 60 \mathrm{~Hz}\right)[10] \\
\text { - Demodulated IRIG-B Clock-Synchronization Signal (TTL } 2.5 \mathrm{mADC} \text {, } \\
2.4 \mathrm{VDC})[15]\end{array}$ \\
\hline Outputs & $\begin{array}{l}\text { - Y-Y Transformer Circuit Breaker \#1 Trip Contact Status } \\
\text { - Y-Y Transformer Circuit Breaker \#2 Trip Contact Status } \\
\text { - Time-Stamped Record of Fault Data (EIA-232 Serial) }\end{array}$ \\
\hline Functionality & $\begin{array}{l}\text { - Detect three-phase transformer faults. } \\
\text { - Initiate circuit breaker trip signals in response to fault conditions. } \\
\text { - Collect and report abnormal system events chronologically to SEL- } \\
\text { 2032/3530. }\end{array}$ \\
\hline
\end{tabular}


Table 8: SEL-587 Differential Protection Relay Functional Requirements

\begin{tabular}{|c|c|}
\hline Module & SEL-587 Differential Protection Relay \\
\hline Inputs & $\begin{array}{l}\text { - Three-Phase } \Delta-\Delta \text { Transformer Current }\left(24 \mathrm{~A}_{\mathrm{rms}}\right) \\
\text { - AC Input Power }\left(120 \mathrm{~V}_{\mathrm{rms}}, 5.5 \mathrm{~W}, 60 \mathrm{~Hz}\right)[11] \\
\text { - Demodulated IRIG-B Clock-Synchronization Signal (TTL } 2.5 \mathrm{mADC} \text {, } \\
2.4 \mathrm{VDC})[15]\end{array}$ \\
\hline Outputs & $\begin{array}{l}\text { - } \Delta-\Delta \text { Transformer Circuit Breaker \#1 Trip Contact Status } \\
\text { - } \Delta-\Delta \text { Transformer Circuit Breaker \#2 Trip Contact Status } \\
\text { - Time-Stamped Record of Fault Data (EIA-232 Serial) }\end{array}$ \\
\hline Functionality & $\begin{array}{l}\text { - Detect three-phase transformer faults. } \\
\text { - Initiate circuit breaker trip signals in response to fault conditions. } \\
\text { - Collect and report abnormal system events chronologically to SEL- } \\
\text { 2032/3530. }\end{array}$ \\
\hline
\end{tabular}

Table 9: SEL-710 Functional Requirements

\begin{tabular}{|c|c|}
\hline Module & SEL-710 Motor Protection Relay \\
\hline Inputs & $\begin{array}{l}\text { - Three-Phase Induction Motor Current }\left(13 \mathrm{~A}_{\mathrm{rms}}\right) \\
\text { - Three-Phase Induction Motor Voltage }\left(220 \mathrm{~V}_{\mathrm{rms}} \text { line-to-line) }\right. \\
\text { - AC Input Power }\left(120 \mathrm{~V}_{\mathrm{rms}}, 40 \mathrm{VA}, 60 \mathrm{~Hz}\right) \text { [13] } \\
\text { - Demodulated IRIG-B Clock-Synchronization Signal (TTL } 2.5 \mathrm{mADC} \text {, } \\
2.4 \mathrm{VDC})[15]\end{array}$ \\
\hline Outputs & $\begin{array}{l}\text { - Induction Motor Circuit Breaker Trip Contact Status } \\
\text { - Time-Stamped Record of Fault Data (EIA-232 Serial) }\end{array}$ \\
\hline Functionality & $\begin{array}{l}\text { - Detect three-phase induction motor faults. } \\
\text { - Initiate circuit breaker trip signals in response to fault conditions. } \\
\text { - Collect and report abnormal system events chronologically to SEL- } \\
\text { 2032/3530. }\end{array}$ \\
\hline
\end{tabular}

Table 10: SEL-2032 Communications Processor Functional Requirements

\begin{tabular}{|c|l|}
\hline Module & SEL-2032 Communications Processor \\
\hline Inputs & $\begin{array}{l}\text { - Time-Stamped Record of Fault Data from Relays } \\
\text { - AC Input Power (120 V Vms, 25 W, 60 Hz) [14] } \\
\text { - Demodulated IRIG-B Clock-Synchronization Signal (TTL 3.5 VDC, } \\
120 \text { mADC) [16] }\end{array}$ \\
\hline Outputs & $\begin{array}{l}\text { - Demodulated IRIG-B Clock-Synchronization Signal } \\
\text { - Time-Stamped Record of Fault Data (EIA-232 Serial) }\end{array}$ \\
\hline Functionality & $\begin{array}{l}\text { - Distribute a demodulated IRIG-B signal to synchronize all relay } \\
\text { clocks. } \\
\text { - Collect abnormal system events from a relay, and report them } \\
\text { chronologically to the human-machine interface. }\end{array}$ \\
\hline
\end{tabular}


Table 11: SEL-3530 RTAC Functional Requirements

\begin{tabular}{|c|c|}
\hline Module & SEL-3530 Real-Time Automation Controller \\
\hline Inputs & $\begin{array}{l}\text { - Time-Stamped Record of Fault Data } \\
\text { - AC Input Power (120 Vrms, } 30 \mathrm{~W}+40 \mathrm{VA}, 60 \mathrm{~Hz})[15] \\
\text { - Demodulated IRIG-B Clock-Synchronization Signal (TTL } 3.5 \mathrm{VDC} \text {, } \\
120 \text { mADC) [16] }\end{array}$ \\
\hline Outputs & $\begin{array}{l}\text { - Demodulated IRIG-B Clock-Synchronization Signal (TTL } 2.5 \text { mADC, } \\
2.4 \text { VDC) [15] } \\
\text { - Time-Stamped Record of Fault Data }\end{array}$ \\
\hline Functionality & $\begin{array}{l}\text { - Distribute a demodulated IRIG-B signal to synchronize all relay } \\
\text { clocks. } \\
\text { - Collect abnormal system events from a relay, and report them } \\
\text { chronologically to the human-machine interface. }\end{array}$ \\
\hline
\end{tabular}

Table 12: SEL-2407 Satellite-Synchronized Clock

\begin{tabular}{|c|l|}
\hline Module & SEL-2407 Satellite-Synchronized Clock \\
\hline Inputs & $\bullet$ AC Input Power (120 V Vms, 15 W + 35 VA, 60 Hz) [16] \\
\hline Outputs & $\begin{array}{l}\bullet \text { Demodulated an IRIG-B Clock-Synchronization Signal (TTL 3.5 } \\
\text { VDC, 120 mADC) [16] }\end{array}$ \\
\hline Functionality & $\bullet$ Send demodulated IRIG-B reference signal to SEL-2032/3530 \\
\hline
\end{tabular}




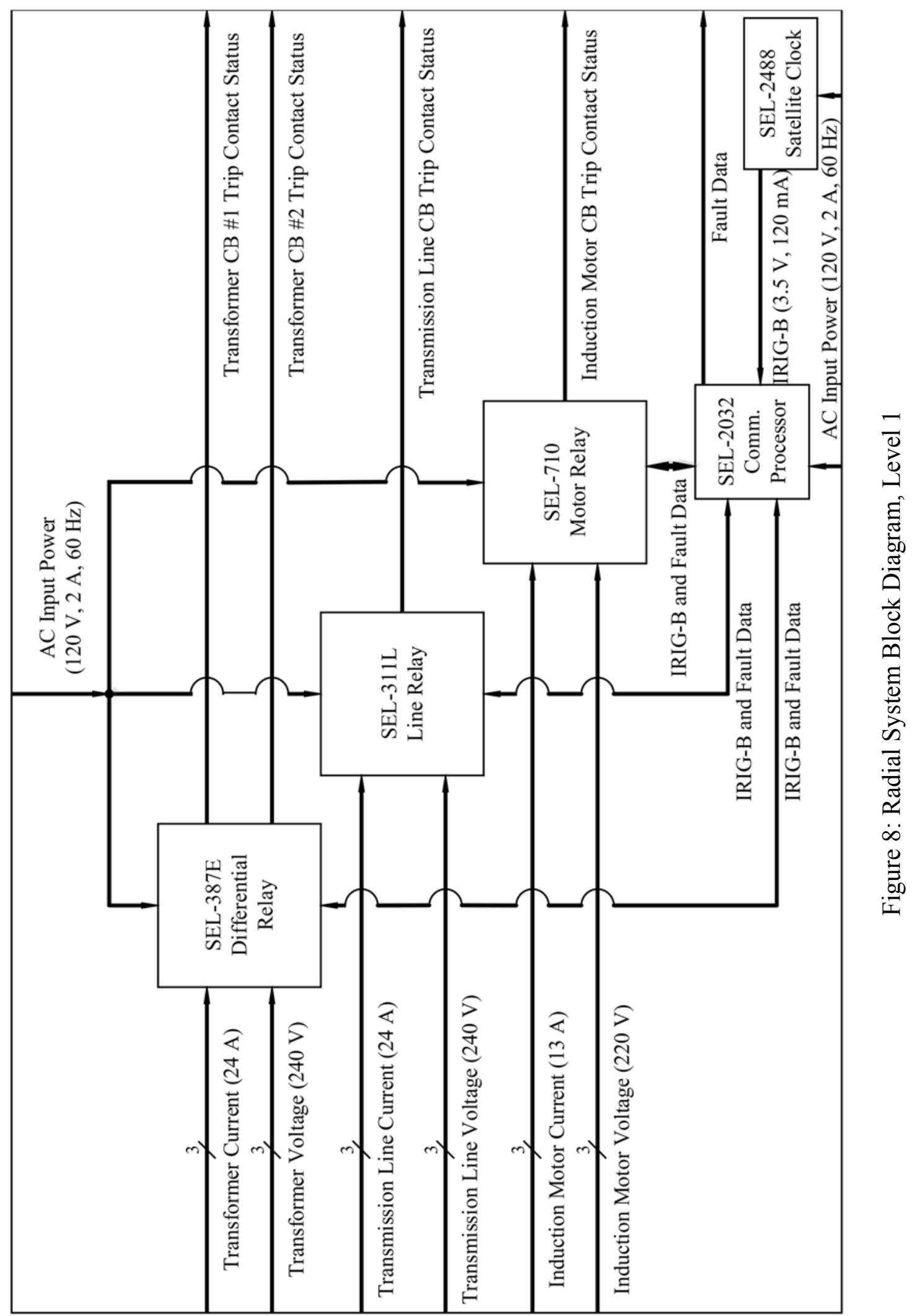




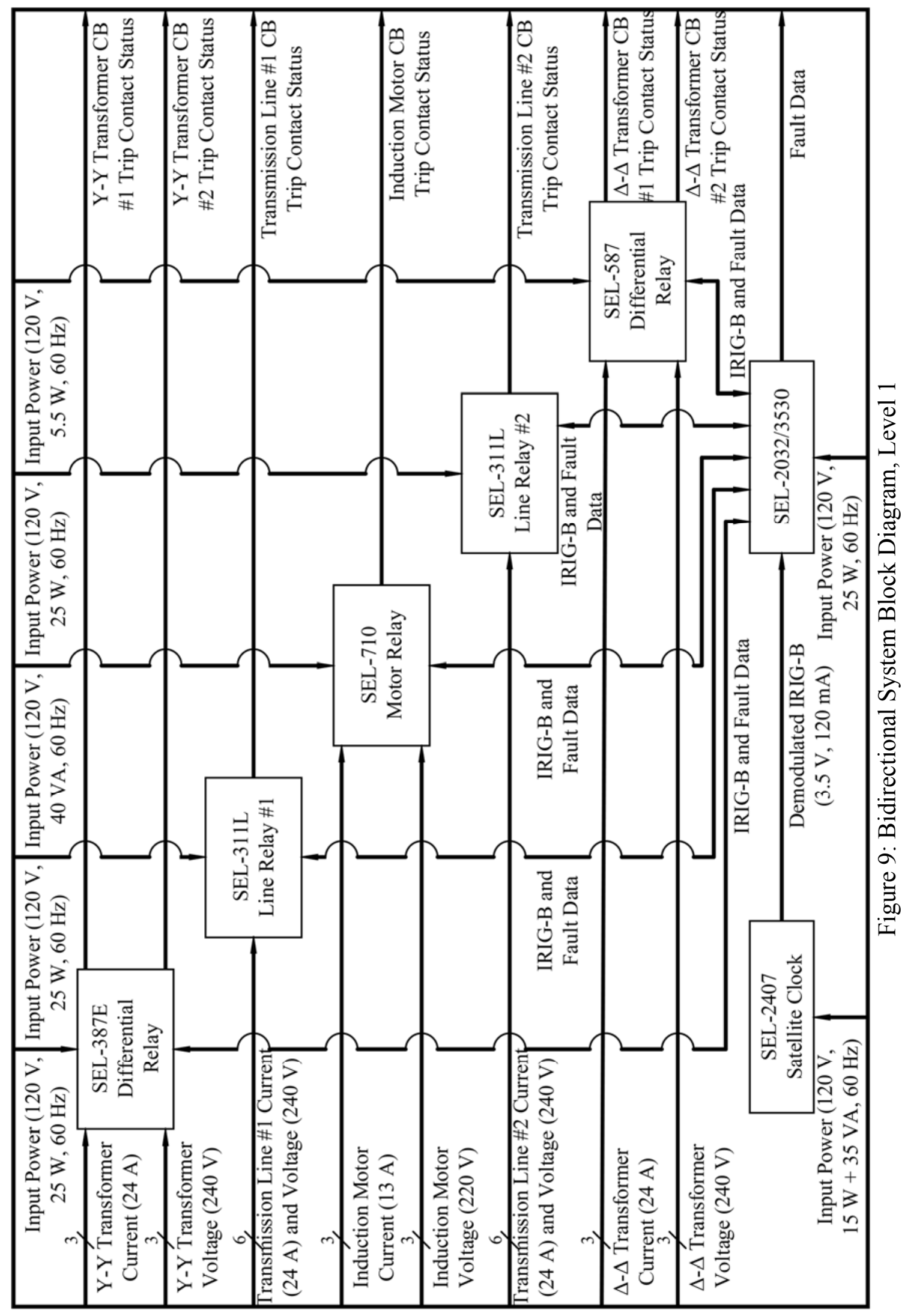




\section{Chapter 5: Project Planning}

\subsection{Gantt Chart - Proposed Project Timelines}

A proposed timeline for the various project phases appears below (Table 14 through Table 18). Table 13 illustrates the allocation of responsibilities among team members. Each team member focuses on specific areas of the project to facilitate efficiency and productivity. As Table 15 and Table 16 show, the selection of relay trip settings lays the foundation for each team member's portion in the project design. Longterm project scheduling depends on the successful selection of settings. Division of this task into two iterations allows for selecting and refining settings of both primary and secondary (back-up) protection. Since the performance of each relay remains relatively constant between the radial and bidirectional topologies, most of the design time takes place during the first project phase (Table 15). The same relay settings, with only minor modifications, see use in the second and third project phases (Table 16 and Table 17). Table 18 presents a culmination of the project through individual project reports and a thesis defense.

Table 13: Key for Proposed Project Timeline Responsibilities

\begin{tabular}{|l|l|}
\hline Symbol & \multicolumn{1}{c|}{ Definition } \\
\hline & Formal Progress Check with Dr. Shaban \\
\hline & Task Overseen by Ian Hellman-Wylie \\
\hline & Task Overseen by Joey Navarro \\
\hline & Task Overseen by Kenan Pretzer \\
\hline & Task Shared by Ian, Joey, and Kenan \\
\hline
\end{tabular}


Table 14: Proposed Timeline for Project Introduction

\begin{tabular}{|l|c|c|c|c|c|c|c|c|c|}
\hline \multicolumn{1}{|c|}{ Week of } & $\mathbf{0 9 / 2 6 / 1 6}$ & $\mathbf{1 0 / 0 3 / 1 6}$ & $\mathbf{1 0 / 1 0 / 1 6}$ & $\mathbf{1 0 / 1 7 / 1 6}$ & $\mathbf{1 0 / 2 4 / 1 6}$ & $\mathbf{1 0 / 3 1 / 1 6}$ & $\mathbf{1 1 / 0 7 / 1 6}$ & $\mathbf{1 1 / 1 4 / 1 6}$ & $\mathbf{1 1 / 2 8 / 1 6}$ \\
\hline $\begin{array}{l}\text { Prepare Proposal for } \\
\text { Power Faculty }\end{array}$ & & & & & & & & & \\
\hline $\begin{array}{l}\text { Present Proposal to } \\
\text { Power Faculty }\end{array}$ & & & & & & & & & \\
\hline $\begin{array}{l}\text { ID and Order Required } \\
\text { SEL Supplies }\end{array}$ & & & & & & & & & \\
\hline $\begin{array}{l}\text { Requirements and } \\
\text { Specifications }\end{array}$ & \multicolumn{2}{|c|}{ Abstract, Marketing Requirements, } \\
Engineering Specifications, Literature Search \\
$\begin{array}{l}\text { Sensitivity Analysis } \\
\text { Bidirectional System) }\end{array}$
\end{tabular}

Table 15: Proposed Timeline for Project Phase I (Radial System)

\begin{tabular}{|l|l|l|l|l|l|l|l|l|l|}
\hline \multicolumn{1}{|c|}{ Week of } & $\mathbf{0 9 / 2 6 / 1 6}$ & $\mathbf{1 0 / 0 3 / 1 6}$ & $\mathbf{1 0 / 1 0 / 1 6}$ & $\mathbf{1 0 / 1 7 / 1 6}$ & $\mathbf{1 0 / 2 4 / 1 6}$ & $\mathbf{1 0 / 3 1 / 1 6}$ & $\mathbf{1 1 / 0 7 / 1 6}$ & $\mathbf{1 1 / 1 4 / 1 6}$ & $\mathbf{1 1 / 2 8 / 1 6}$ \\
\hline $\begin{array}{l}\text { Component } \\
\text { Characterization }\end{array}$ & & & & & & & & & \\
\hline $\begin{array}{l}\text { Choose and Test Trip } \\
\text { Settings for SEL-311L }\end{array}$ & Iteration 1 & $\begin{array}{c}\text { Iteration } \\
2\end{array}$ & & & & & & \\
\hline $\begin{array}{l}\text { Choose and Test Trip } \\
\text { Settings for SEL-387 }\end{array}$ & Iteration 1 & $\begin{array}{c}\text { Iteration } \\
2\end{array}$ & & & & & & \\
\hline $\begin{array}{l}\text { Choose and Test Trip } \\
\text { Settings for SEL-710 }\end{array}$ & Iteration 1 & $\begin{array}{c}\text { Iteration } \\
2\end{array}$ & & & & & & \\
\hline $\begin{array}{l}\text { Implement SEL-311L } \\
\text { in Radial System }\end{array}$ & & & & & & & & & \\
\hline $\begin{array}{l}\text { Implement SEL-387 } \\
\text { in Radial System }\end{array}$ & & & & & & & & & \\
\hline $\begin{array}{l}\text { Implement SEL-710 } \\
\text { in Radial System }\end{array}$ & & & & & & & & & \\
\hline $\begin{array}{l}\text { Confirm Relay Trip } \\
\text { Settings }\end{array}$ & & & & & & & & & \\
\hline $\begin{array}{l}\text { Interface SEL-2032 with } \\
\text { SEL-311L }\end{array}$ & & & & & & & & & \\
\hline $\begin{array}{l}\text { Interface SEL-2032 with } \\
\text { SEL-387 }\end{array}$ & & & & & & & & & \\
\hline $\begin{array}{l}\text { Interface SEL-2032 with } \\
\text { SEL-710 }\end{array}$ & & & & & & & & & \\
\hline $\begin{array}{l}\text { Interface SEL-2032 with } \\
\text { Entire Radial System }\end{array}$ & & & & & & & & & \\
\hline $\begin{array}{l}\text { Showcase Phase I } \\
\text { Completion }\end{array}$ & & & & & & & & & \\
\hline
\end{tabular}


Table 16: Proposed Timeline for Project Phase II (Bidirectional System)

\begin{tabular}{|l|l|l|l|l|l|}
\hline \multicolumn{1}{|c|}{ Week of } & $\mathbf{0 1 / 0 9 / 1 7}$ & $\mathbf{0 1 / 1 6 / 1 7}$ & $\mathbf{0 1 / 2 3 / 1 7}$ & $\mathbf{0 1 / 3 0 / 1 7}$ & $\mathbf{0 2 / 0 6 / 1 7}$ \\
\hline $\begin{array}{l}\text { Component } \\
\text { Characterization }\end{array}$ & & & & & \\
\hline $\begin{array}{l}\text { Revise and Test Trip } \\
\text { Settings for SEL-311L }\end{array}$ & Iteration 1 & Iteration 2 & & & \\
\hline $\begin{array}{l}\text { Revise and Test Trip } \\
\text { Settings for SEL-387 }\end{array}$ & Iteration 1 & Iteration 2 & & & \\
\hline $\begin{array}{l}\text { Revise and Test Trip } \\
\text { Settings for SEL-587 }\end{array}$ & Iteration 1 & Iteration 2 & & & \\
\hline $\begin{array}{l}\text { Revise and Test Trip } \\
\text { Settings for SEL-710 }\end{array}$ & Iteration 1 & Iteration 2 & & & \\
\hline $\begin{array}{l}\text { Implement SEL-311L } \\
\text { in Bidirectional System }\end{array}$ & & & & & \\
\hline $\begin{array}{l}\text { Implement SEL-387 } \\
\text { in Bidirectional System }\end{array}$ & & & & & \\
\hline $\begin{array}{l}\text { Implement SEL-587 } \\
\text { in Bidirectional System }\end{array}$ & & & & & \\
\hline $\begin{array}{l}\text { Implement SEL-710 } \\
\text { in Bidirectional System }\end{array}$ & & & & & \\
\hline $\begin{array}{l}\text { Confirm Relay Trip } \\
\text { Settings }\end{array}$ & & & & & \\
\hline $\begin{array}{l}\text { Interface SEL-2032 with } \\
\text { Entire System }\end{array}$ & & & & & \\
\hline $\begin{array}{l}\text { Showcase Phase II } \\
\text { Completion }\end{array}$ & & & & & \\
\hline
\end{tabular}


Table 17: Proposed Timeline for Project Phase III (Microgrid)

\begin{tabular}{|c|c|c|c|c|c|c|}
\hline \multirow{2}{*}{\multicolumn{7}{|c|}{\begin{tabular}{l}
\multicolumn{1}{c}{ Week of } \\
Identify Master/Slave \\
Communication Protocol
\end{tabular}}} \\
\hline & & & & & & \\
\hline $\begin{array}{l}\text { Choose Slave Data to be } \\
\text { Polled }\end{array}$ & & & & & & \\
\hline $\begin{array}{l}\text { Interface SEL-2032 as } \\
\text { Slave to SEL-3530 }\end{array}$ & & & & & & \\
\hline $\begin{array}{l}\text { Showcase Master/Slave } \\
\text { Interaction in System }\end{array}$ & & & & & & \\
\hline $\begin{array}{l}\text { Interface SEL-311L } \\
\text { Directly to SEL-3530 }\end{array}$ & & & & & & \\
\hline $\begin{array}{l}\text { Interface SEL-387 } \\
\text { Directly to SEL-3530 }\end{array}$ & & & & & & \\
\hline $\begin{array}{l}\text { Interface SEL-587 } \\
\text { Directly to SEL-3530 }\end{array}$ & & & & & & \\
\hline $\begin{array}{l}\text { Interface SEL-710 } \\
\text { Directly to SEL-3530 }\end{array}$ & & & & & & \\
\hline $\begin{array}{l}\text { Interface SEL-3530 with } \\
\text { Entire System }\end{array}$ & & & & & & \\
\hline $\begin{array}{l}\text { Showcase Phase III } \\
\text { Completion }\end{array}$ & & & & & & \\
\hline
\end{tabular}

Table 18: Proposed Timeline for Project Conclusion

\begin{tabular}{|l|l|l|l|l|l|l|l|}
\hline \multicolumn{1}{|c|}{ Week of } & $\mathbf{0 4 / 0 3 / 1 7}$ & $\mathbf{0 4 / 1 0 / 1 7}$ & $\mathbf{0 4 / 1 7 / 1 7}$ & $\mathbf{0 4 / 2 4 / 1 7}$ & $\mathbf{0 5 / 0 1 / 1 7}$ & $\mathbf{0 5 / 0 8 / 1 7}$ & $\mathbf{0 6 / 0 5 / 1 7}$ \\
\hline $\begin{array}{l}\text { Ian Finalize Senior } \\
\text { Project Report }\end{array}$ & & & & & & & \\
\hline $\begin{array}{l}\text { Joey Finalize Senior } \\
\text { Project Report }\end{array}$ & & & & & & & \\
\hline $\begin{array}{l}\text { Kenan Finalize } \\
\text { Thesis Paper }\end{array}$ & & & & & & & \\
\hline $\begin{array}{l}\text { Ian Create Senior } \\
\text { Project Poster }\end{array}$ & & & & & & & \\
\hline $\begin{array}{l}\text { Joey Create Senior } \\
\text { Project Poster }\end{array}$ & & & & & & & \\
\hline $\begin{array}{l}\text { Kenan Submit } \\
\text { Thesis Paper }\end{array}$ & & & & & & & \\
\hline $\begin{array}{l}\text { Kenan Prepare } \\
\text { Thesis Defense }\end{array}$ & & & & & & & \\
\hline $\begin{array}{l}\text { Kenan Deliver } \\
\text { Thesis Defense }\end{array}$ & & & & & & & \\
\hline $\begin{array}{l}\text { Ian Present Senior } \\
\text { Project }\end{array}$ & & & & & & & \\
\hline $\begin{array}{l}\text { Joey Present Senior } \\
\text { Project }\end{array}$ & & & & & & & \\
\hline
\end{tabular}




\subsection{Cost Estimate}

Estimation of labor costs derives from a formula proposed by [18], where costa represents the optimistic estimate, costb represents the most probable estimate, and costc represents the pessimistic estimate:

$$
\operatorname{Cost}=\frac{\operatorname{cost}_{\mathrm{a}}+4 \cdot \operatorname{cost}_{\mathrm{b}}+\operatorname{cost}_{\mathrm{c}}}{6}
$$

This project optimistically requires approximately 15 hours of labor per week. More likely, the project requires approximately 21 hours of labor per week. Pessimistically, the project requires approximately 30 hours of labor per week. Assuming an hourly wage of $\$ 30$, the estimated labor cost over the 27 -week period shown on Table 14 through Table 18 comes to $\$ 17,415$ at 580.5 hours of labor.

Table 19 summarizes the costs associated with all phases of the project. The project costs exclude certain items that are available from the Cal Poly Electrical Engineering department and free for student use. These items include relays, information processors, cables, and software that SEL donated for student projects. The costs for the relay equipment shown in Table 19 derive from the SEL website. 
Table 19: Estimated Project Costs (All Project Phases)

\begin{tabular}{|l|r|r|r|}
\hline \multicolumn{1}{|c|}{ Item } & $\begin{array}{c}\text { Retail } \\
\text { Unit Cost }\end{array}$ & Quantity & $\begin{array}{c}\text { Cost for } \\
\text { Project }\end{array}$ \\
\hline Circuit Breakers & $\$ 350.00$ & 7 & $\$ 2,450.00$ \\
\hline Banana Screw-On Connectors & $\$ 0.25$ & 100 & $\$ 25.00$ \\
\hline Gauge-12 Stranded Wire (Cost per Foot) & $\$ 0.20$ & \multicolumn{1}{c|}{500} & $\$ 100.00$ \\
\hline Gauge-16 Stranded Wire (Cost per Foot) & $\$ 0.20$ & \multicolumn{1}{c}{$50^{\prime}$} & $\$ 10.00$ \\
\hline Labor (Cost per Hour) & $\$ 30.00$ & 580.5 & $\$ 17,415.00$ \\
\hline SEL-311L Line Protection Relay & $\$ 5,000.00$ & 2 & $\$ 0.00$ \\
\hline SEL-387E Differential Protection Relay & $\$ 5,780.00$ & 1 & $\$ 0.00$ \\
\hline SEL-587 Differential Protection Relay & $\$ 2,080.00$ & 1 & $\$ 0.00$ \\
\hline SEL-710 Motor Protection Relay & $\$ 2,500.00$ & 1 & $\$ 0.00$ \\
\hline SEL-2032 Communications Processor & $\$ 2,840.00$ & 1 & $\$ 0.00$ \\
\hline SEL-3530 Real-Time Automation Controller & $\$ 2,850.00$ & 1 & $\$ 0.00$ \\
\hline SEL-5030 AcSELerator QuickSet Software & $\$ 0.00$ & 1 & $\$ 0.00$ \\
\hline SEL-C234A 10' Serial Cable & $\$ 50.00$ & 5 & $\$ 0.00$ \\
\hline SEL-C273A 10' Serial Cable & $\$ 50.00$ & 5 & $\$ 250.00$ \\
\hline Spade Crimp-On Connectors (Large) & $\$ 0.10$ & 50 & $\$ 5.00$ \\
\hline Spade Crimp-On Connectors (Small) & $\$ 0.10$ & 50 & $\$ 5.00$ \\
\hline Wire Ties & $\$ 1.00$ & 30 & $\$ 30.00$ \\
\hline TOTAL & & & $\$ \mathbf{2 0 , 2 9 0 . 0 0}$ \\
\hline
\end{tabular}




\section{Chapter 6: Introduction to the Radial Systems (Phase I)}

\subsection{Radial System Design}

Chapters 7 through 12 illustrate the performance of the SEL-311L, SEL-387E, and SEL-710 relays in response to faults and certain other abnormal system conditions in a radial power system with a wye-connected power transformer. Figure 10 presents the single-line diagram for this radial system, superimposing connections to the protective relays onto the system topology presented in Figure 1. Chapters 13 and 14 illustrate the performance of the SEL-587 in protecting a delta-connected transformer in a similar radial system. Figure 11 presents a single-line protection diagram for this radial system based on the circuit presented in Figure 2. The high- and low-side bushings of the deltadelta transformer connect to line phases A and C. This reflects a "DACDAC" configuration [19], which the SEL-587 TRCON setting in Appendix F reflects. 


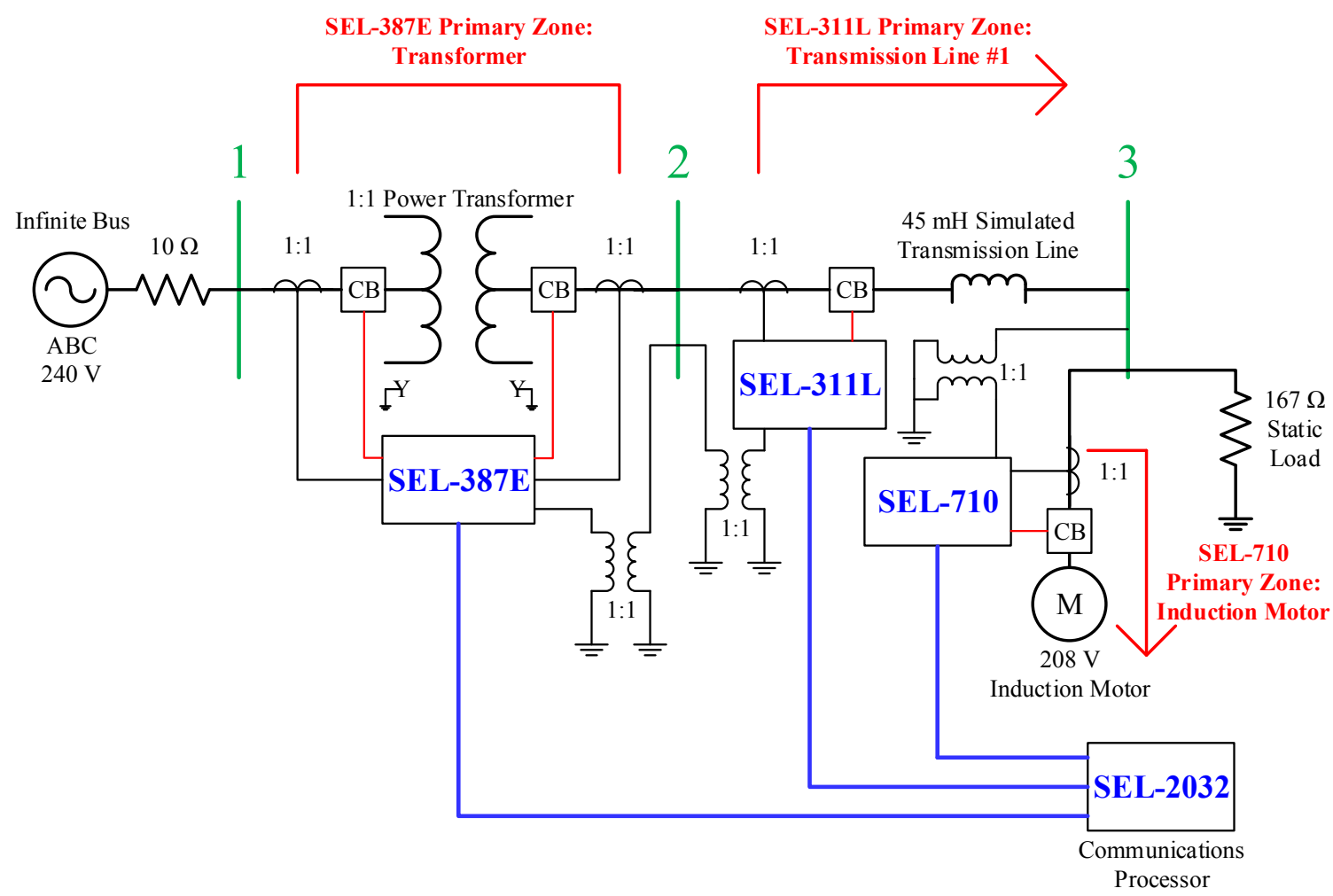

Figure 10: Radial System Single-Line Protection Diagram, Wye-Wye Transformer

An SEL-2032 Communications Processor, shown in Figure 10 and Figure 11, acts as a port switch for the relays in both radial systems. Each relay has its own direct connection (with an SEL-C273A serial cable) to the communications processor. The communications processor, in turn, has one direct connection (with an SEL-C234A serial cable) to the human-machine interface. The human-machine interface in this project is a desktop computer located near the communications processor. This setup allows a system operator to access each of the relays in the system through the AcSELerator QuickSet software on the computer. Using a direct transparent connection between the computer and a relay through the communications processor, the system operator has access to event reports and real-time data from the relay. The communications processor simplifies the device network by limiting the number of physical serial connections to the computer. 


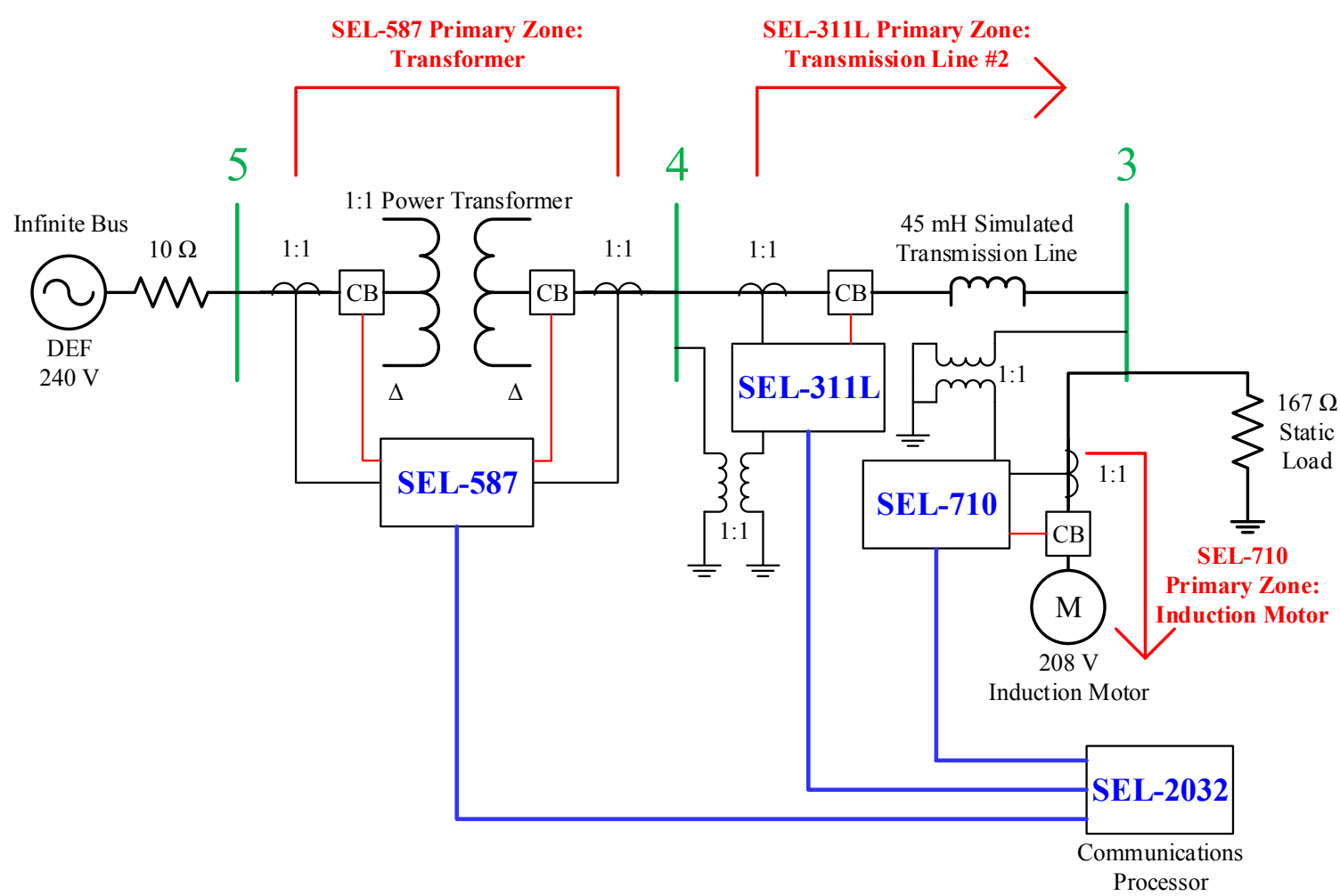

Figure 11: Radial Single-Line Protection Diagram, Delta-Delta Transformer

To increase reliability in the radial systems, certain protection functionalities of the relays overlap. Redundancy in protection increases system reliability in the event that one relay fails to operate as designed. If one relay fails, another relay with overlapping protection functionality can substitute. Table 20 lists the primary protection zone for each relay in the radial topologies, while Table 21 summarizes the secondary (backup) protection zone for applicable relays. Protection functionalities employed by the SEL710, not specifically listed in Table 20, include thermal overload, locked-rotor, current unbalance, undervoltage, and instantaneous overcurrent protection. Note in Figure 10 and Figure 11 that, since the SEL-710 only serves the induction motor, it supports no secondary zone of protection. Chapters 7 through 14 present the independent results of 
each relay's performance, while Chapter 15 exemplifies the coordinated performance of all relays in a radial system.

Table 20: Radial System Primary Protection Zones and Methods

\begin{tabular}{|c|c|c|}
\hline Relay & Primary Protection Zone & Protection Method \\
\hline SEL-311L & Bus 2-Bus 3 & Impedance (Zones 1 and 2) \\
\hline SEL-387E & Bus 1 - Bus 2 & Instantaneous Differential \\
\hline SEL-587 & Bus 4-Bus 5 & Instantaneous Differential \\
\hline SEL-710 & Bus 3 Induction Motor & Various \\
\hline
\end{tabular}

Table 21: Radial System Secondary Protection Zones and Methods

\begin{tabular}{|c|c|c|}
\hline Relay & Secondary Protection Zone & Protection Method \\
\hline SEL-387E & Downstream of Bus 2 & Inverse-Time Overcurrent \\
\hline SEL-587 & Downstream of Bus 4 & Inverse-Time Overcurrent \\
\hline SEL-311L & Downstream of Bus 3 & $\begin{array}{c}\text { Impedance (Zone 2) and Inverse- } \\
\text { Time Overcurrent }\end{array}$ \\
\hline
\end{tabular}




\subsection{Radial System Testing}

To best simulate the performance of the radial topologies under maximum loading conditions, all fault initiation occurred with the induction motor running. Including the induction motor increases the complexity of the necessary protection for the system due to the inrush current drawn by the induction motor as it energizes. Some relays, such as the SEL-387E and SEL-587, require reduced fault current sensitivities so that they do not mistake inrush current as a fault condition. The SEL-311L relay, on the other hand, uses a delay timer to allow inrush current to subside before the relay can trip. SEL-311L group 1 settings, documented in Appendices C and D, establish this delay specifically for the radial system topology.

When operating the system in a laboratory environment, keeping the induction motor's circuit breaker open while energizing the transformer and transmission line helps to reduce the initial inrush current measured by the relays. Attempting to energize the entire system all at once draws a sufficiently high inrush current to trip the SEL-311L relay even with its programmed delay time. This restriction on energizing the system parallels basic industry practice, in which portions of a system or device must come online in a specific order.

The presence of the induction motor also complicates the post-fault event analysis. Although it acts like a load during normal system operation, the induction motor also acts like a generator during fault conditions. As a result, fault current comes from two directions in the radial system: from both the infinite bus and the induction motor. The following chapters explain effects of this situation. 


\section{Chapter 7: SEL-311L Overcurrent Protection}

\subsection{Inverse-Time Overcurrent Protection Overview}

An overcurrent relay monitors the magnitude of current flowing through a circuit. The relay trips if the current that it measures exceeds a specified threshold. An instantaneous overcurrent element trips immediately for faults, while an inverse-time overcurrent element trips after a delay. The delay time required before an inverse-time overcurrent relay trips depends on the amount of fault current detected by the relay. High fault currents require only a short delay, whereas low fault currents require a longer delay. Several common inverse-time overcurrent curves (such as the IEEE inverse, moderately inverse, very inverse, and extremely inverse curves) graphically illustrate this relationship between fault current magnitude and delay time required before a trip. Microprocessor-based relays contain a setting that defines the inverse-time overcurrent curve used by the relay.

Inverse-time overcurrent elements in a microprocessor-based relay fill an essential role in establishing relay coordination across a power system. A time dial setting in an inverse-time overcurrent relay defines a family of curves with similar slopes but different time delays. A low time dial setting (such as 0.50 ) corresponds to a short delay between when the relay detects the fault and when it trips. Conversely, a higher time dial setting corresponds to a longer delay. Assigning lower time dial settings to relays further away from a source and higher time dial settings to relays closer to a source establishes a useful coordination scheme. Consider the following example.

Suppose that a fault occurs in a simple radial circuit at the point furthest from the source. Utility companies desire to isolate this fault using the relay located nearest the 
fault location so that the maximum number of customers remain online after the relay clears the faulted portion of the circuit. Clearing this fault with a relay close to the source (further away from the fault location) increases the number of customers losing power as a result of the fault. To remedy this potential problem, the utility company assigns a low time dial setting to the relay located furthest away from the source (nearest the fault location in this example). The low time dial setting allows the relay to respond to faults after only a short delay. Working backward from this relay toward the source, the utility company progressively increases the time dial settings assigned to the other inverse-time overcurrent relays in the system. As a result, the relay nearest the end of the circuit (the fault location in this example) trips before any of the other overcurrent relays. Should this particular relay fail to operate for any reason, the next-closest relay operates soon afterward to clear the fault. This logic applies to faults at other locations throughout the circuit: the closest relay upstream of the fault trips first. If the closest relay does not clear the fault, the next upstream relay then provides delayed backup protection. 


\subsection{Single-Line-to-Ground Faults}

Figure 12 illustrates the response of the SEL-311L's inverse-time overcurrent element to a bolted single-line-to-ground fault at the induction motor (bus 3 in Figure 10). Current in the faulted phase A immediately increases upon fault inception due to the reduced impedance provided by a short-circuit path to ground. The induction motor, having lost its supply of current from phase A, proceeds to draw additional current from the unfaulted phases B and C. This increased current draw may result from prefault load currents, allowing the induction motor to act as a generator to feed the fault on phase A. Figure 55 illustrates a clearer example of the induction motor feeding a single-line-toground fault at the power transformer. Note also the imbalance present in the prefault current and voltages. Although the origin of the unbalances in the system phases is not understood with certainty, possible causes include an imbalance in the source, imbalance in the circuit components, or ignored mutual inductances between the lines running through the circuit. 


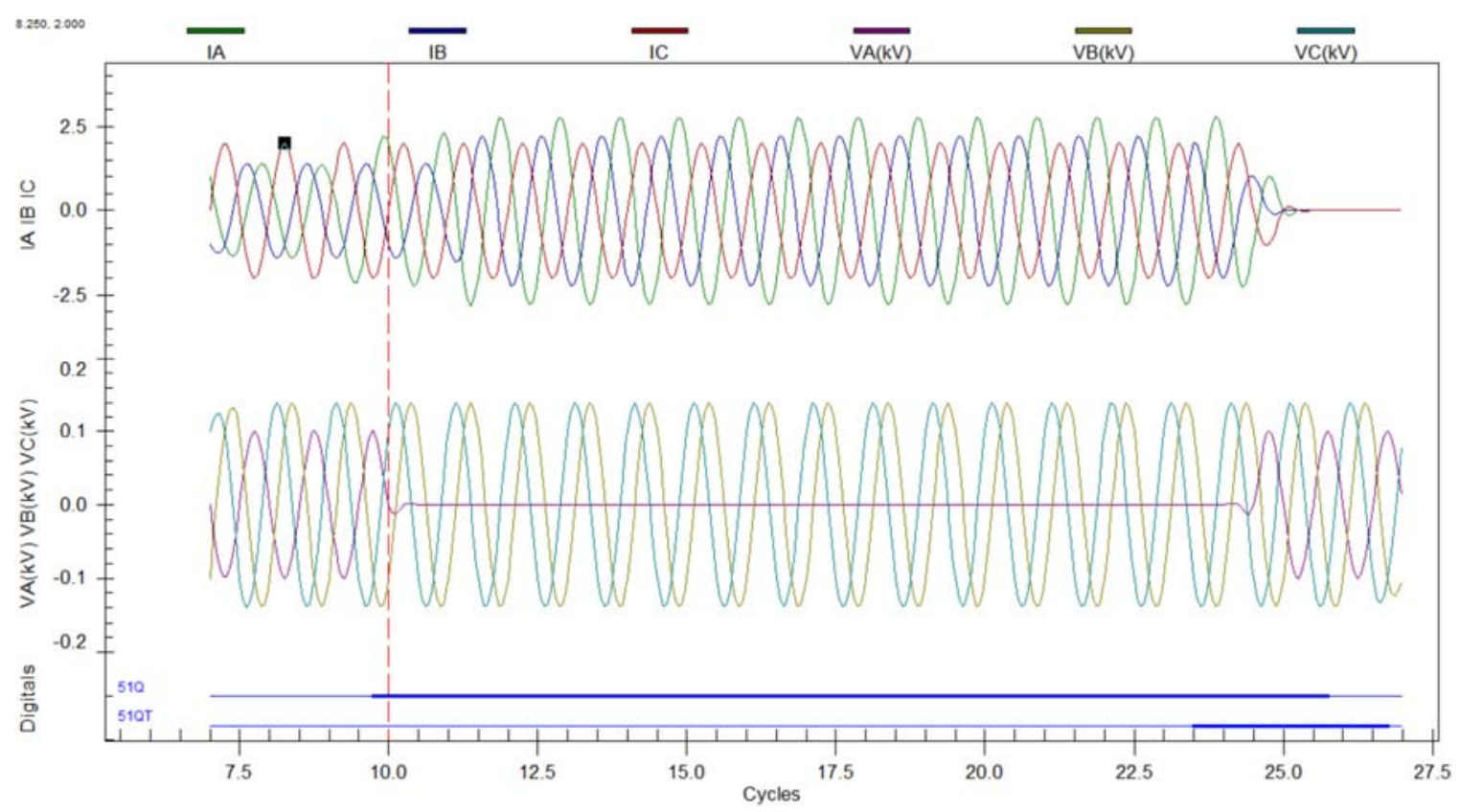

Figure 12: SEL-311L Single-Line-to-Ground Fault, Bus 3, Phase A

Figure 12 (generated from a relay event report using the SEL-5601 AcSELerator Analytic Assistant software) details several important quantities describing a single-lineto-ground fault. The horizontal axis displays time in power system cycles (where one cycle equals approximately $16.7 \mathrm{~ms}$ ), referenced to the point at which the relay began saving data for the fault. The vertical axis displays time-varying voltage and current waveforms, which represent scaled versions of the quantities actually measured by the relays. Notice the digital signals displayed at the bottom of Figure 12. These selected signals indicate when relevant protection elements assert and deassert in the relay. For example, the SEL-311L's inverse-time negative-sequence overcurrent element (51Q) asserts at approximately 10 cycles as the current measured by the relay exceeds the value defined by the inverse-time negative-sequence overcurrent pickup element (51QP). The element 51Q remains asserted until the inverse-time negative-sequence overcurrent 
timeout element (51QT) asserts at approximately 23.5 cycles, whereupon the relay trip element (TRIP) asserts.

As the digital signals of Figure 12 illustrate, the negative-sequence inverse-time overcurrent element (51Q) on the SEL-311L times out approximately 14 cycles after fault inception, whereupon the relay trips its circuit breaker on bus 2 to clear the fault. The negative-sequence element picks up the fault before the phase element due to the increased sensitivity of the negative-sequence overcurrent element (reflected in the useradjustable relay settings shown in the appendices). 


\subsection{Double-Line-to-Ground Faults}

Figure 13 illustrates the response of the SEL-311L's inverse-time overcurrent element to a bolted double-line-to-ground fault at the induction motor (bus 3 in Figure 10). Current in the faulted phases A and B immediately increases upon fault inception due to the reduced impedance provided by a short-circuit path to ground. The induction motor, having lost its supply of current from phases A and B, proceeds to draw additional current from the unfaulted phase C. This increased cu

rrent draw allows the induction motor to act as a generator to feed the fault on phases A and B. The negative-sequence inverse-time overcurrent element (51Q) on the SEL-311L times out approximately 5 cycles after fault inception, whereupon the relay trips its circuit breaker on bus 2 to clear the fault.

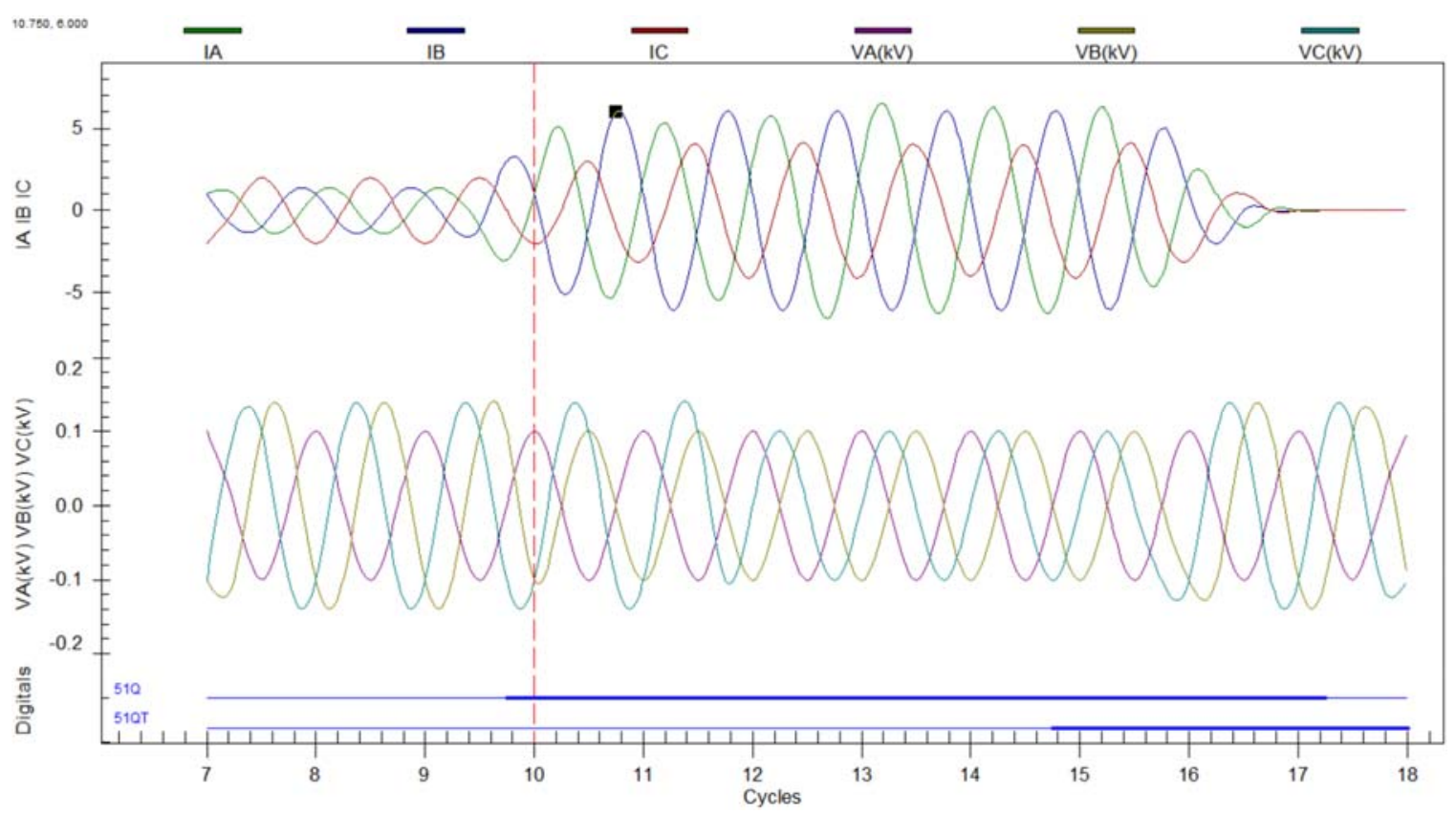

Figure 13: SEL-311L Double-Line-to-Ground Fault, Bus 3, Phases A and B 


\subsection{Triple-Line-to-Ground Faults}

Figure 14 illustrates the response of the SEL-311L's inverse-time overcurrent element to a bolted triple-line-to-ground fault at the induction motor (bus 3 in Figure 10). Current in the faulted phases A, B, and C immediately increases upon fault inception due to the reduced impedance provided by a short-circuit path to ground. The phase inversetime overcurrent element (51P) on the SEL-311L times out approximately 38 cycles after fault inception, whereupon the relay trips its circuit breaker on bus 2 to clear the fault.

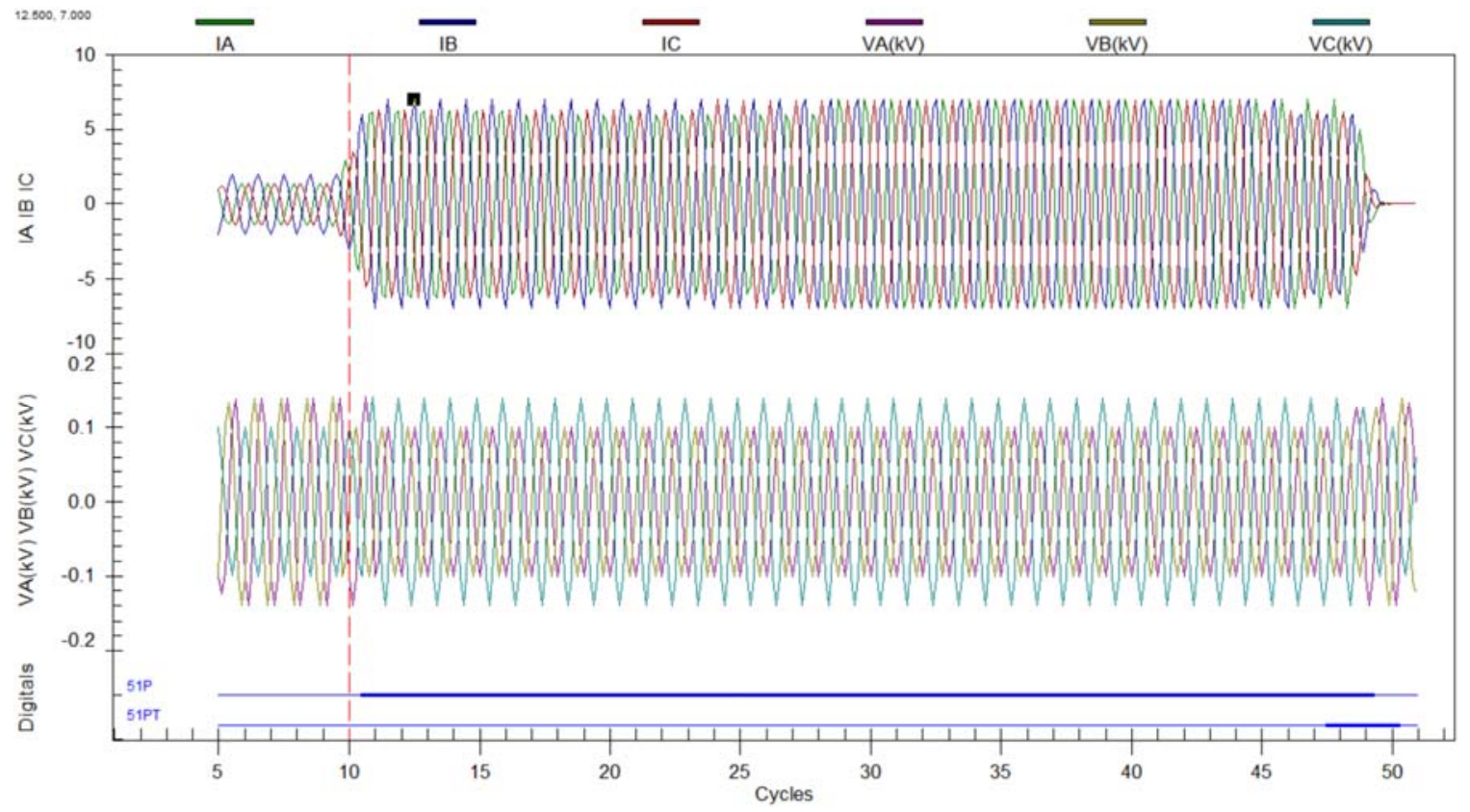

Figure 14: SEL-311L Triple-Line-to-Ground Fault, Bus 3, Phases A, B, and C 


\subsection{Three-Phase Faults}

Figure 15 illustrates the response of the SEL-311L's inverse-time overcurrent element to a bolted three-phase (ungrounded) fault at the induction motor (bus 3 in Figure 10). Current in the faulted phases A, B, and C immediately increases upon fault inception due to the reduced impedance provided by a short-circuit path to ground. The phase inverse-time overcurrent element (51P) on the SEL-311L times out approximately 38 cycles after fault inception, whereupon the relay trips its circuit breaker on bus 2 to clear the fault.

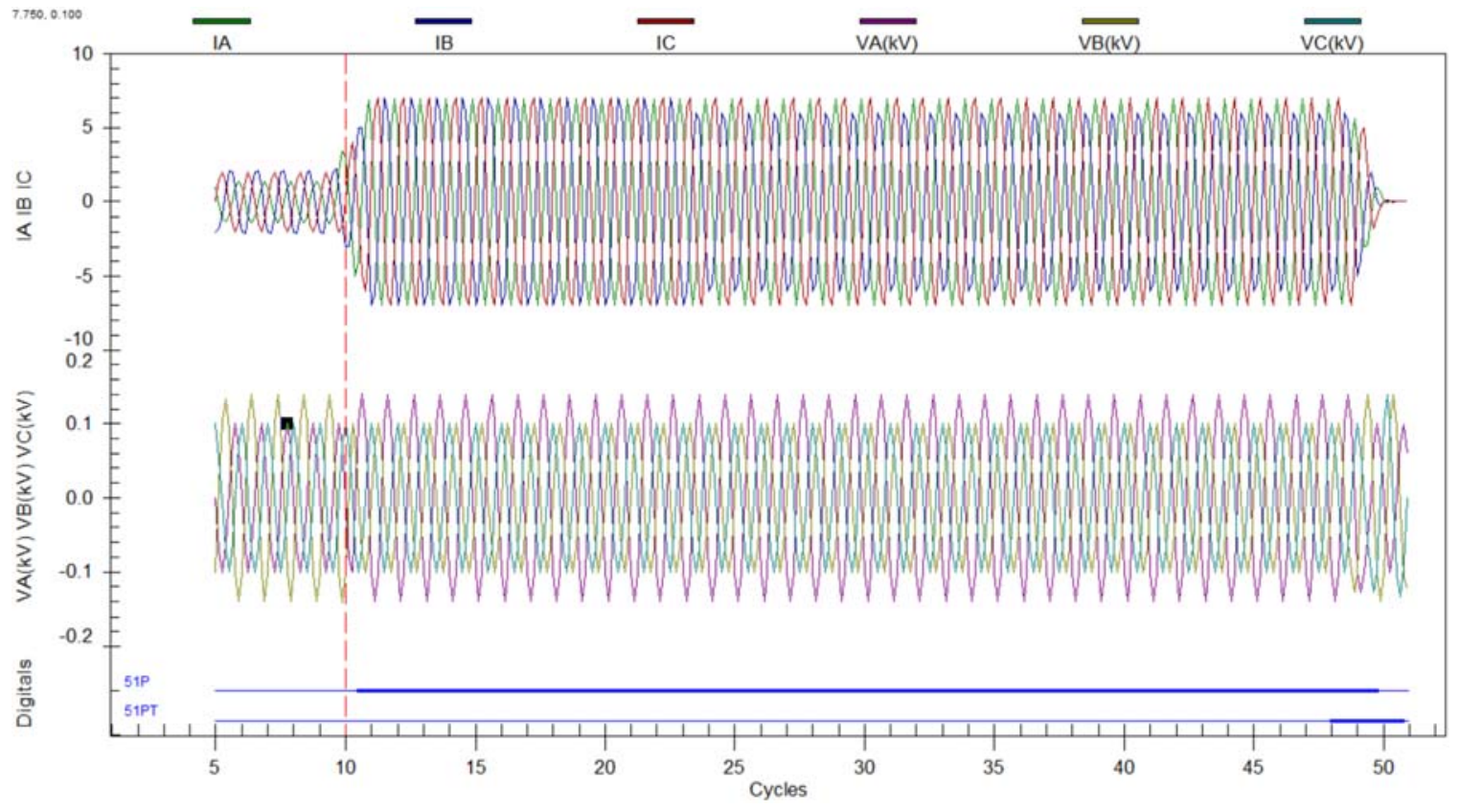

Figure 15: SEL-311L Three-Phase Fault, Bus 3, Phases A, B, and C 


\subsection{Line-to-Line Faults}

Figure 16 illustrates the response of the SEL-311L's inverse-time overcurrent element to a bolted line-to-line fault at the induction motor (bus 3 in Figure 10). Current in the faulted phases A and B immediately increases upon fault inception due to the reduced impedance provided by a short-circuit path to ground. Differences in impedance between the inductive components in each phase account for slight phase differences between the faulted current waveforms. The induction motor, having lost its supply of current from phases $\mathrm{A}$ and $\mathrm{B}$, proceeds to draw additional current from the unfaulted phase $\mathrm{C}$. This increased current draw allows the induction motor to act as a generator to feed the fault on phases A and B. The negative-sequence inverse-time overcurrent element (51Q) on the SEL-311L times out approximately 5 cycles after fault inception, whereupon the relay trips its circuit breaker on bus 2 to clear the fault.

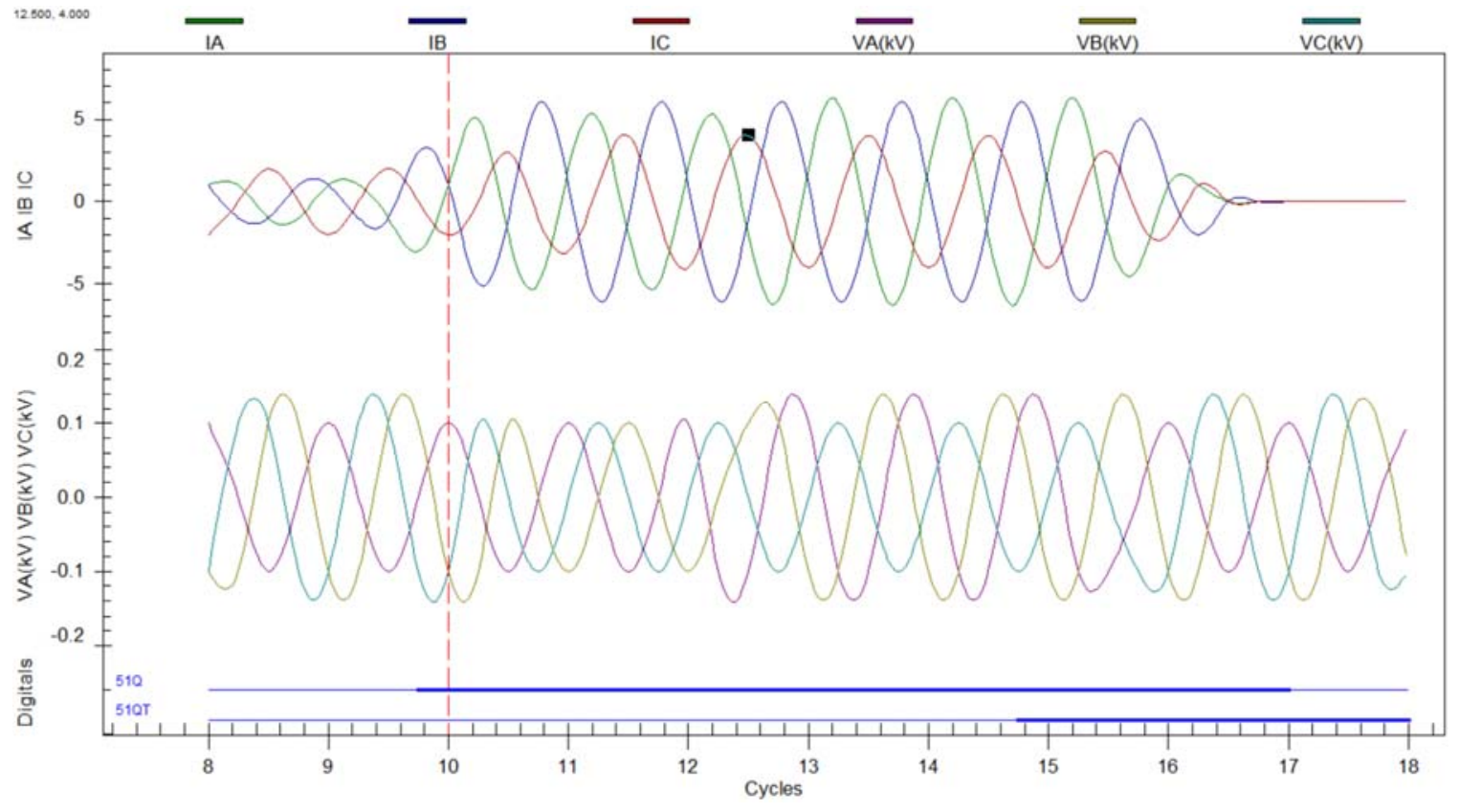

Figure 16: SEL-311L Line-to-Line Fault, Bus 3, Phases A and B 


\section{Chapter 8: SEL-311L Mho Distance Protection}

\subsection{Mho Distance Protection Overview}

Distance relays use voltage and current measurements to detect fault conditions. These relays have fixed zones of protection that generally do not vary much in response to changes in loading conditions, which allows them to employ higher sensitivity than overcurrent relays in detecting faults [20]. Distance relays often protect transmission lines, which have known impedances based on the conductor characteristics.

Typical three-phase mho distance relays operate using the characteristic illustrated in Figure 17. A circle passing through the origin of the R-X plane defines the boundary between the operating and non-operating regions of the relay. This circle defines a baseline impedance, often representative of some percentage of a transmission line's impedance. A reach point on the circumference of the circle, often along a line taken at about $75^{\circ}$ above the positive R-axis, shows this baseline.

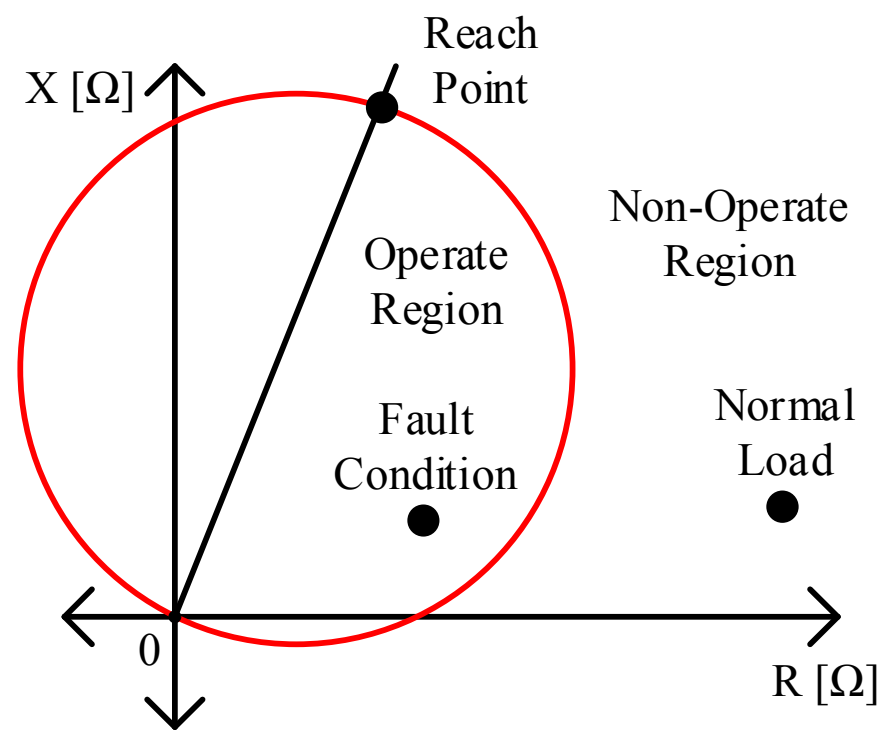

Figure 17: Typical Mho Distance Characteristic 
Local ground faults cause voltage to decrease (closer to ground potential) and current to increase (due to a reduced-impedance path available to ground). This condition decreases the impedance measured by the relay and moves the operating point on the R-X plane closer to the origin, the point of minimum impedance. Faults outside the defined distance covered by the relay cause the impedance measured by the relay (based on the measured voltage and current) to decrease, but not by enough to come inside the circle. Faults inside the defined distance cause a greater drop in impedance, bringing the operating point inside the circle. The larger impedance drop alerts the relay to the fault, leading the relay to trip for the fault condition. Calculating impedance in this way allows a distance relay to distinguish between internal and external faults.

Many distance relays support multiple zones of protection. An example of such a characteristic on the R-X plane appears in Figure 18. Notice that for this three-zone mho distance relay, all of the circles pass through the origin of the R-X plane. This reference point defines the relative location of the relay in the circuit. Quadrant 1 of the R-X plane contains the portion of the circuit protected by the relay. Zone 1 typically covers about 90 $\%$ of the impedance assigned to the relay for protection, while zone 2 typically covers about $150 \%$ [21]. Quadrant 3 of the R-X plane lies behind the distance relay. Zone 3 serves as a blocking signal to keep a pilot protection system from tripping for faults behind the portion of the circuit assigned to a relay's protection (see section 17.1).

In many applications, the portion of the circuit in the zone 1 region receives its primary fault protection from the distance relay, so a fault in zone 1 triggers an instantaneous trip in the relay. However, a second relay located at the edge (100\%) of the zone assigned to the distance relay may provide primary protection for that portion of the 
circuit. Therefore, the distance relay often delays before tripping for faults in its zone 2 region to give the second relay a chance to operate. Chapters 15 and 18 further describe relay coordination.

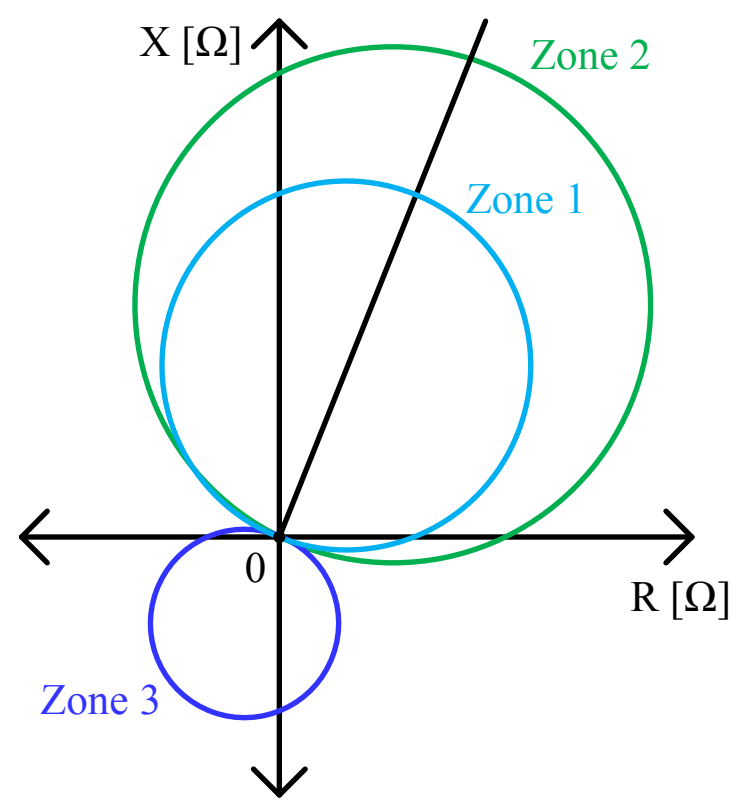

Figure 18: Mho Distance Relay Zones of Protection

Zone 3 traditionally served as a third forward-reaching zone, extending beyond zone 2 and providing remote backup protection for downstream portions of a circuit [22]. However, abnormally high loading conditions occasionally fall within the zone 3 region, causing the distance relay to mistake high circuit loads as fault conditions. Reversing zone 3 to instead prevent linked distance relays from tripping for nearby upstream faults limits the possibility of tripping for unexpectedly high loads and improves pilot protection schemes. A rearward-reaching zone 3 makes sense for this system, since no portions of the circuit downstream of the SEL-311L require backup distance protection. 


\subsection{Single-Line-to-Ground Faults}

Constraints in the radial and bidirectional system topologies inhibit the SEL-311L from reliably detecting single-line-to-ground faults at the induction motor (bus 3 in Figure 10) with its mho phase distance element. A single-line-to-ground fault at this location draws a relatively small amount of fault current because of the limited change in impedance between the source (bus 1 in Figure 10) and ground. With only the induction motor and static load removed from the faulted phase, the impedances of the currentlimiting resistor, power transformer, and transmission line are sufficiently high to keep currents low in the faulted phase. This relationship derives from Ohm's Law where, for a constant voltage (set by the infinite bus), a small decrease in impedance causes a proportionally small increase in current.

In an attempt to overcome this obstacle, fault initiation for the single-line-toground fault moved upstream from bus 3. Initiating faults midway along the transmission line provides an ideal test of mho ground distance protection with the SEL-311L. Figure 19 illustrates a split transmission line phase between buses 2 and 3 (the three-line diagram equivalent of the transmission line shown in Figure 10). Splitting the transmission line in this way explores the response of distance protection to faults in both the zone 1 and zone 2 regions programmed into the SEL-311L, and further decreases the impedance between the source and fault. Adding additional discrete inductors to the circuit accomplishes this partition, enabling fault initiation between equivalent series inductors. For example, adding three more inductors to phase A of the transmission line to create a series combination of two sets of two parallel inductors (illustrated in Figure 19) models a transmission line with a relatively unchanged total inductance in the split 
phase. Placing a circuit breaker between the two segments of the line allows initiating faults halfway along the transmission line.

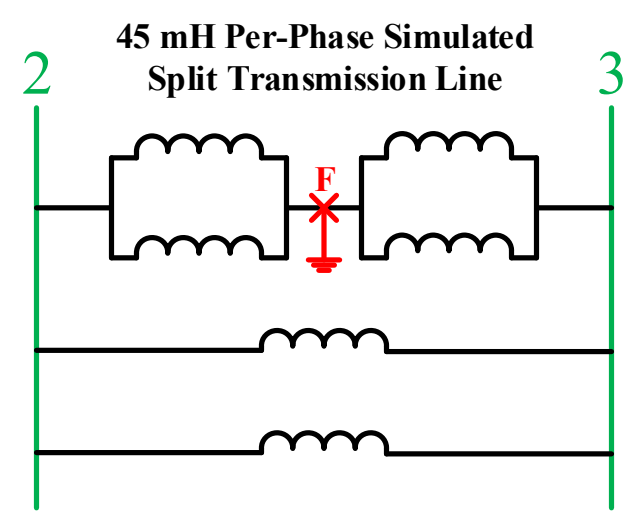

Figure 19: Three-Line Diagram of Simulated Transmission Line with Split Phase A The appropriate addition of more discrete inductors allows splitting the transmission line at various other points. However, the limited number of discrete inductors available for this project made it impractical to split more than a single phase of the transmission line. For this reason, only the initiation of single-line-to-ground faults occurred midway along the transmission line. Unfortunately, the mho ground distance element in the SEL-311L did not reliably detect faults at this location.

The SEL-311L's inability to reliably trip for single-line-to-ground faults using its distance protection does not, however, compromise the security of the system. As demonstrated in Chapter 7, the relay successfully detects and isolates single-line-toground faults with its inverse-time negative-sequence overcurrent element. Therefore, this shortcoming with distance protection in the SEL-311L does not violate the specifications defined in Chapter 2. 


\subsection{Double-Line-to-Ground Faults}

Figure 20 illustrates the response of the SEL-311L's mho distance protection to a bolted double-line-to-ground fault at the induction motor (bus 3 in Figure 10). Current in the faulted phases A and B immediately increases upon fault inception due to the reduced impedance provided by a short-circuit path to ground. The induction motor, having lost its supply of current from phases A and B, proceeds to draw additional current from the unfaulted phase $\mathrm{C}$. This increased current draw allows the induction motor to act as a generator to feed the fault on phases A and B. The zone 2 mho phase distance element (M2P) on the SEL-311L times out approximately 6 cycles after fault inception, whereupon the relay trips its circuit breaker on bus 2 to clear the fault.

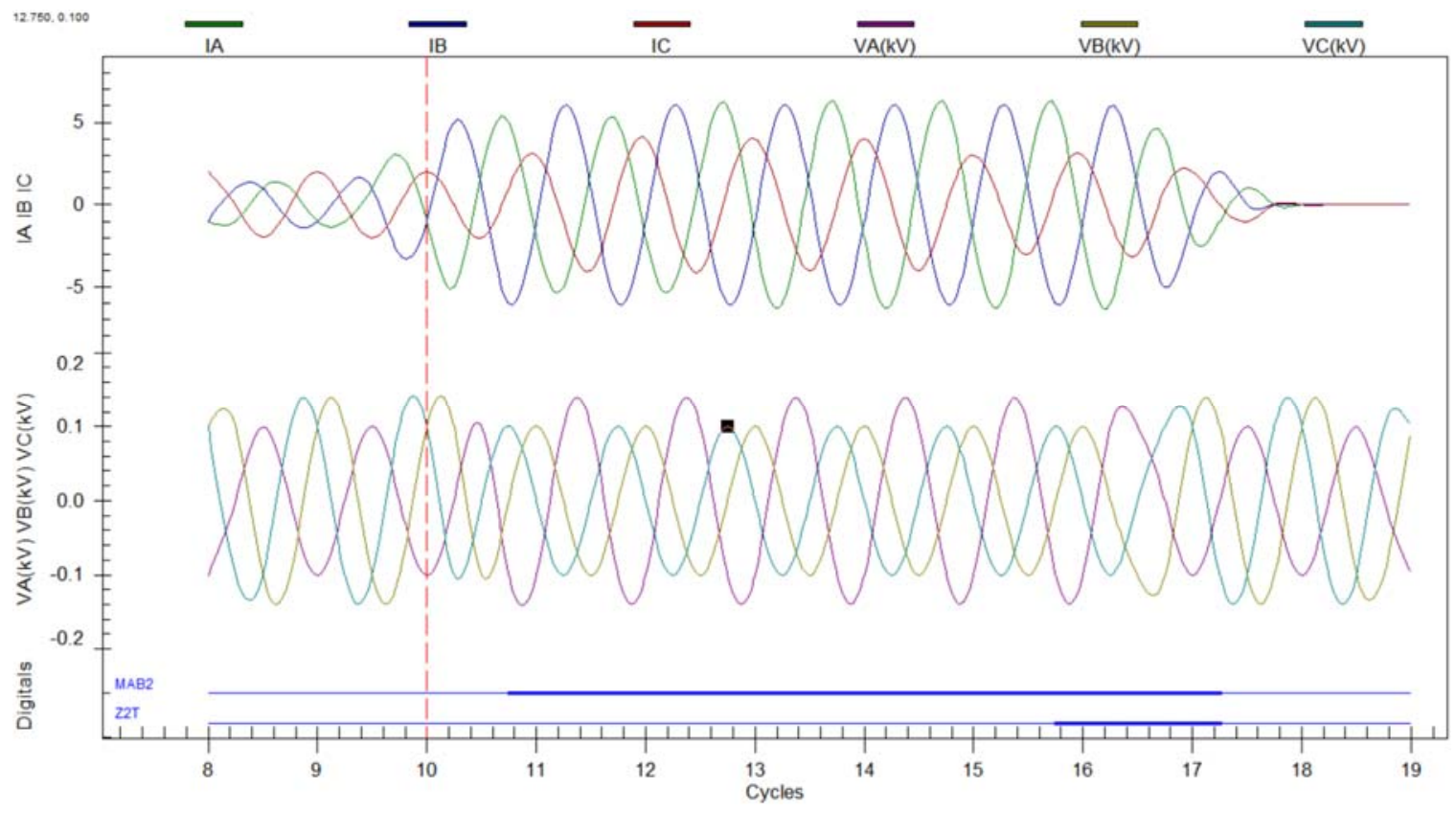

Figure 20: SEL-311L Double-Line-to-Ground Fault, Bus 3, Phases A and B 


\subsection{Triple-Line-to-Ground Faults}

Figure 21 illustrates the response of the SEL-311L's mho distance protection to a bolted triple-line-to-ground fault at the induction motor (bus 3 in Figure 10). Current in the faulted phases A, B, and C immediately increases upon fault inception due to the reduced impedance provided by a short-circuit path to ground. The zone 2 mho phase distance element (M2P) on the SEL-311L times out approximately 6 cycles after fault inception, whereupon the relay trips its circuit breaker on bus 2 to clear the fault.

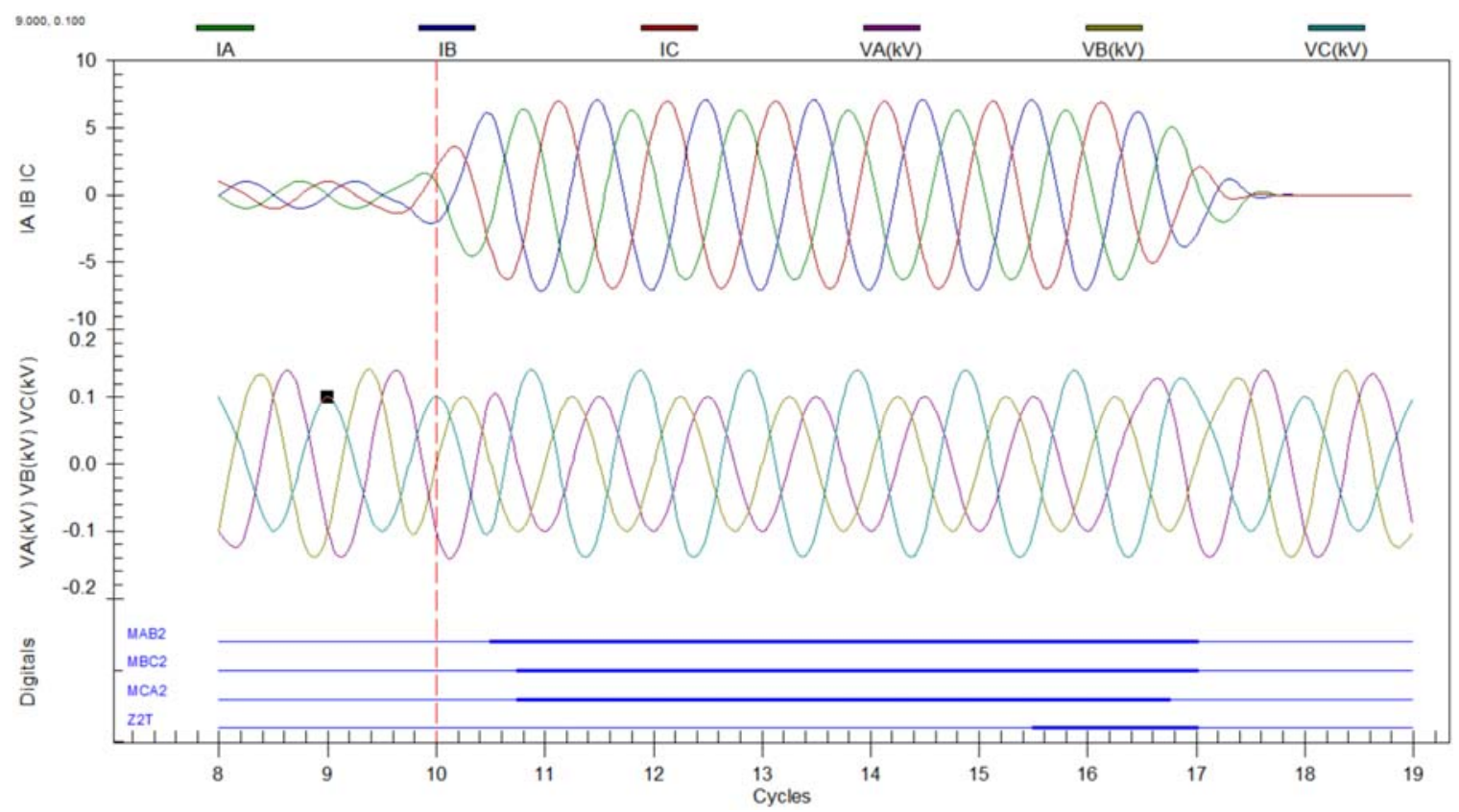

Figure 21: SEL-311L Triple-Line-to-Ground Fault, Bus 3, Phases A, B, and C 


\subsection{Three-Phase Faults}

Figure 22 illustrates the response of the SEL-311L's mho distance protection to a bolted three-phase (ungrounded) fault at the induction motor (bus 3 in Figure 10). Current in the faulted phases A, B, and C immediately increases upon fault inception due to the reduced impedance provided by a short-circuit path to ground. The zone 2 mho phase distance element (M2P) on the SEL-311L times out approximately 6 cycles after fault inception, whereupon the relay trips its circuit breaker on bus 2 to clear the fault.

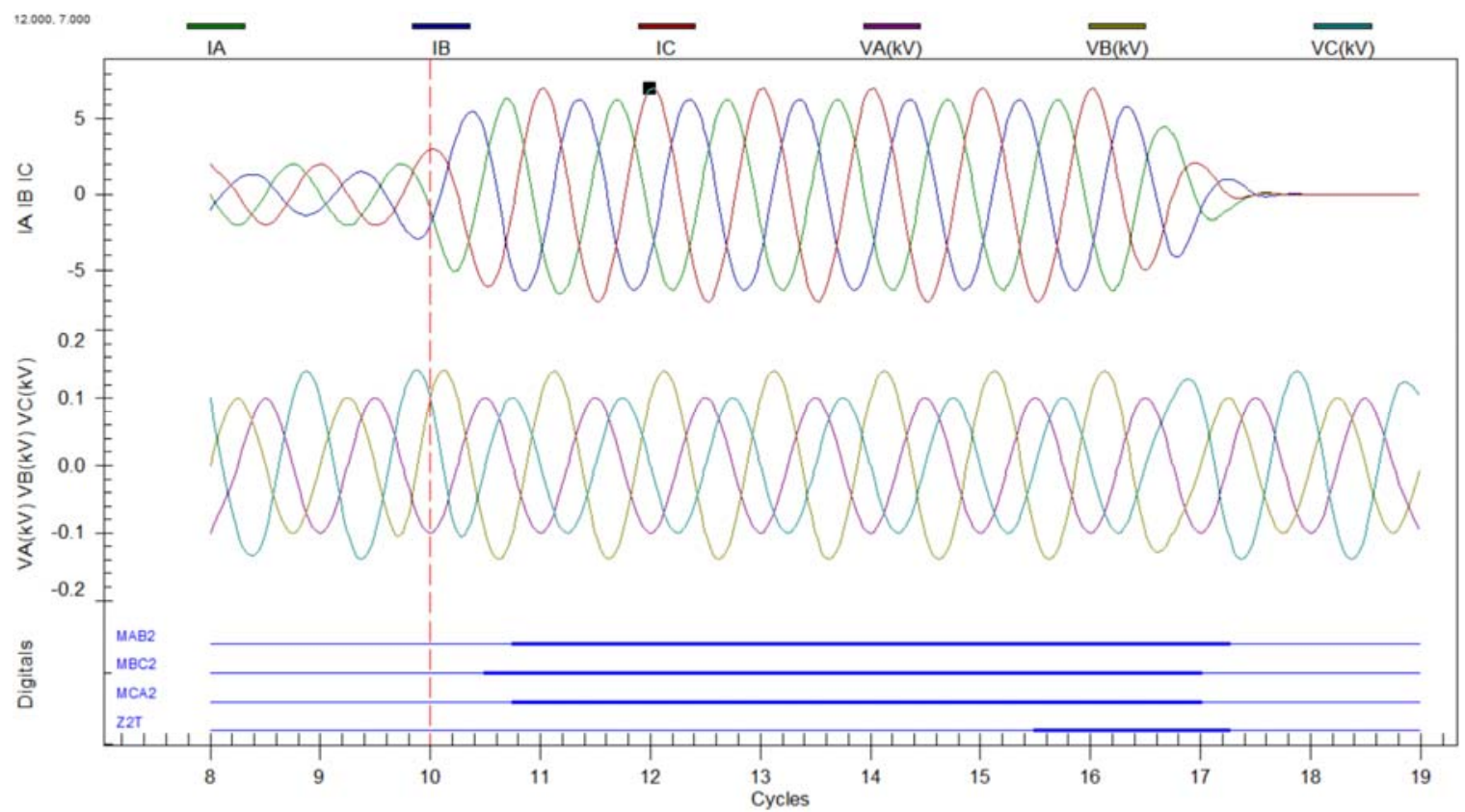

Figure 22: SEL-311L Three-Phase Fault, Bus 3, Phases A, B, and C 


\subsection{Line-to-Line Faults}

Figure 23 illustrates the response of the SEL-311L's mho distance protection to a bolted line-to-line fault at the induction motor (bus 3 in Figure 10). Current in the faulted phases A and B immediately increases upon fault inception due to the reduced impedance provided by a short-circuit path to ground. The induction motor, having lost its supply of current from phases $\mathrm{A}$ and $\mathrm{B}$, proceeds to draw additional current from the unfaulted phase $\mathrm{C}$. This increased current draw allows the induction motor to act as a generator to feed the fault on phases A and B. The zone 2 mho phase distance element (M2P) on the SEL-311L times out approximately 6 cycles after fault inception, whereupon the relay trips its circuit breaker on bus 2 to clear the fault.

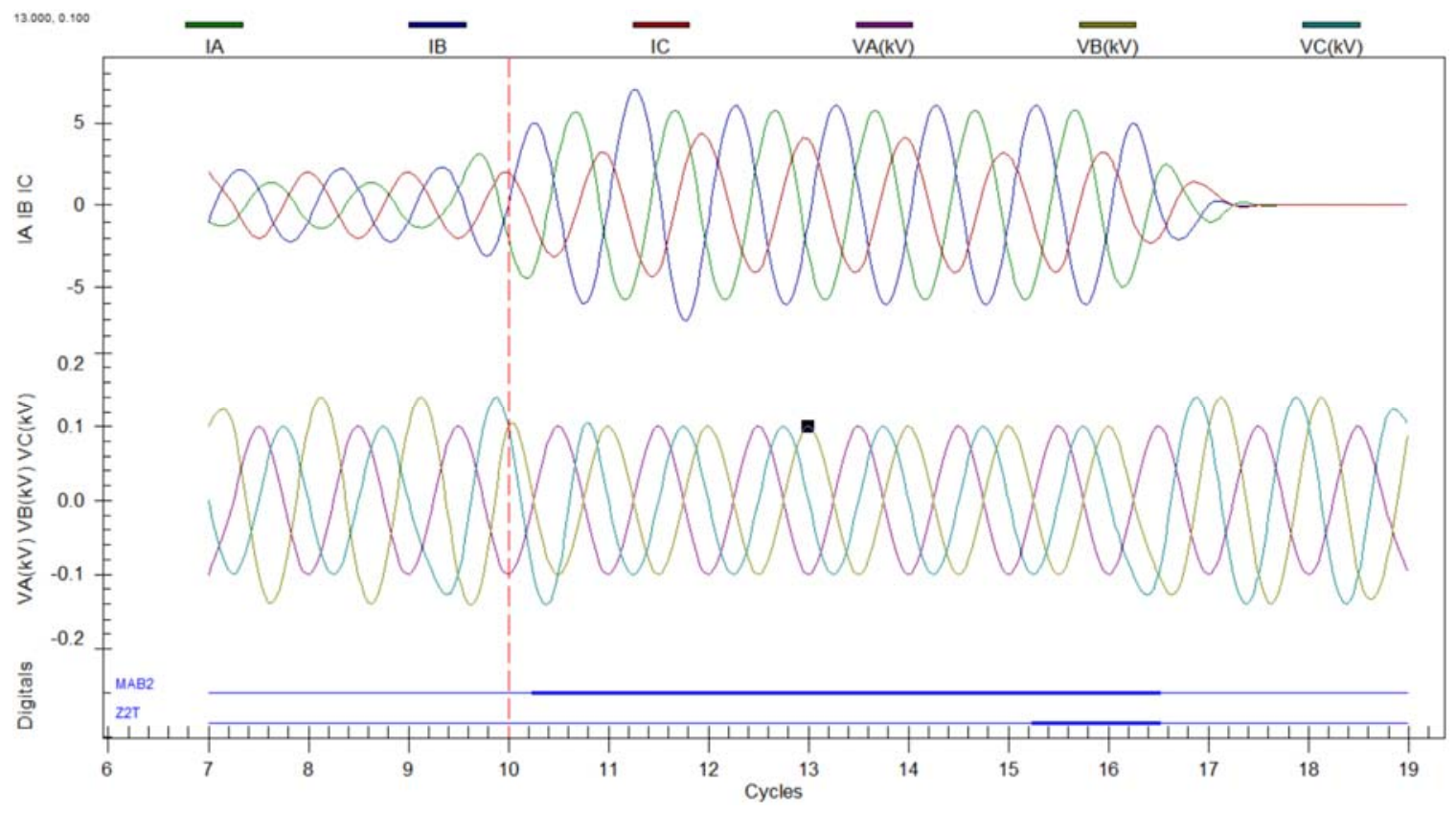

Figure 23: SEL-311L Line-to-Line Fault, Bus 3, Phases A and B 


\section{Chapter 9: SEL-387E Overcurrent Protection}

\subsection{Single-Line-to-Ground Faults}

Figure 24 illustrates the response of the SEL-387E's inverse-time overcurrent element to a bolted single-line-to-ground fault at the induction motor (bus 3 in Figure 10). Current in the faulted phase A immediately increases upon fault inception due to the reduced impedance provided by a short-circuit path to ground. The induction motor, having lost its supply of current from phase A, proceeds to draw additional current from the unfaulted phases B and C. This increased current draw allows the induction motor to act as a generator to feed the fault on phase A. The winding 2 negative-sequence inversetime overcurrent element (51Q2) on the SEL-387E times out approximately 41 cycles after fault inception, whereupon the relay trips its circuit breaker on bus 2 to clear the fault.

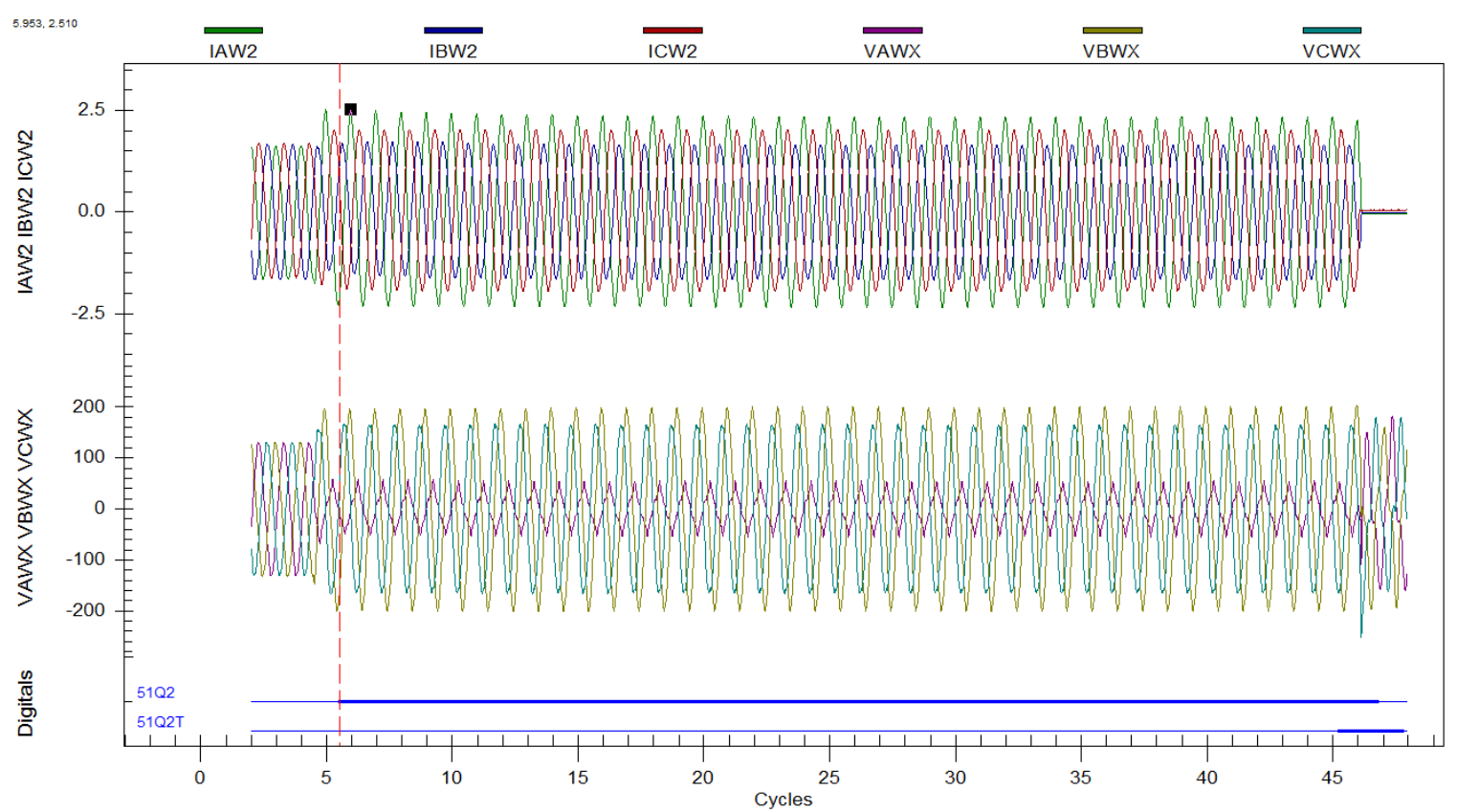

Figure 24: SEL-387E Single-Line-to-Ground Fault, Bus 3, Phase A 


\subsection{Double-Line-to-Ground Faults}

Figure 25 illustrates the response of the SEL-387E's inverse-time overcurrent element to a bolted double-line-to-ground fault at the induction motor (bus 3 in Figure 10). Current in the faulted phases A and B immediately increases upon fault inception due to the reduced impedance provided by a short-circuit path to ground. The induction motor, having lost its supply of current from phases A and B, proceeds to draw additional current from the unfaulted phase $\mathrm{C}$. This increased current draw allows the induction motor to act as a generator to feed the fault on phases A and B. The winding 2 negativesequence inverse-time overcurrent element (51Q2) on the SEL-387E times out approximately 8 cycles after fault inception, whereupon the relay trips its circuit breaker on bus 2 to clear the fault.

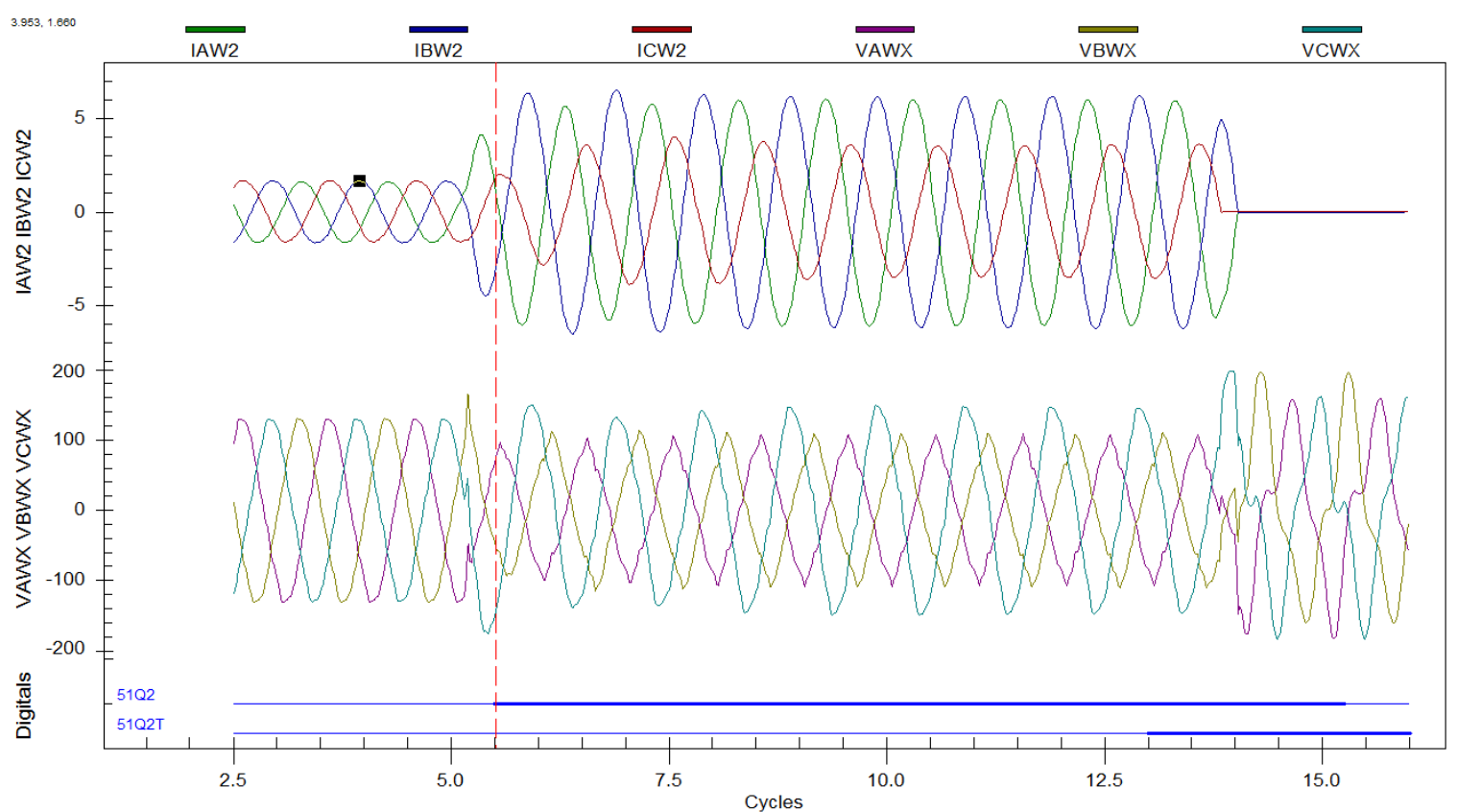

Figure 25: SEL-387E Double-Line-to-Ground Fault, Bus 3, Phases A and B 


\subsection{Triple-Line-to-Ground Faults}

Figure 26 illustrates the response of the SEL-387E's inverse-time overcurrent element to a bolted triple-line-to-ground fault at the induction motor (bus 3 in Figure 10). Current in the faulted phases A, B, and C immediately increases upon fault inception due to the reduced impedance provided by a short-circuit path to ground. The winding 2 phase inverse-time overcurrent element (51P2) on the SEL-387E times out approximately 42 cycles after fault inception, whereupon the relay trips its circuit breaker on bus 2 to clear the fault.

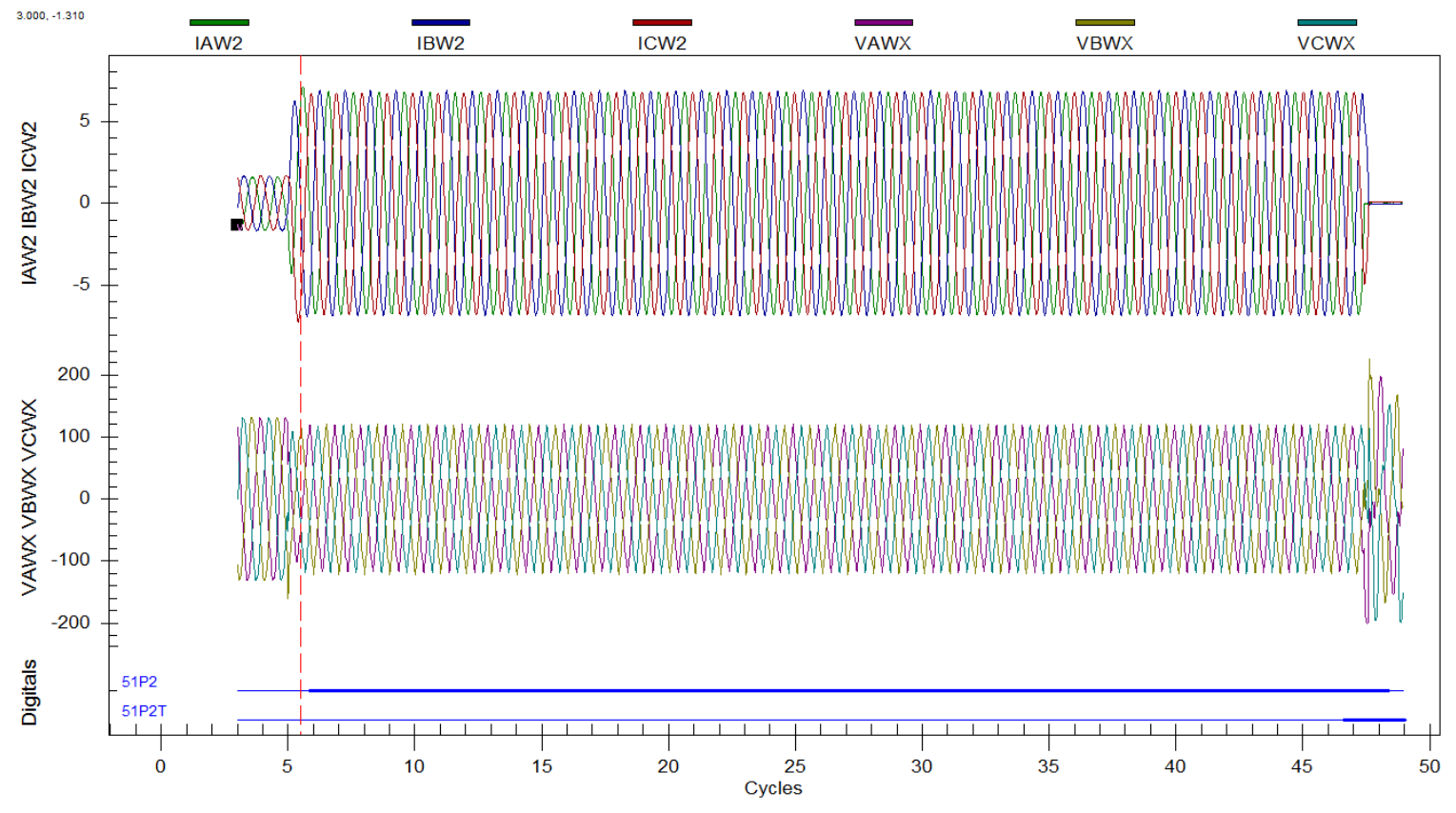

Figure 26: SEL-387E Triple-Line-to-Ground Fault, Bus 3, Phases A, B, and C 


\subsection{Three-Phase Faults}

Figure 27 illustrates the response of the SEL-387E's inverse-time overcurrent element to a bolted three-phase (ungrounded) fault at the induction motor (bus 3 in Figure 10). Current in the faulted phases $\mathrm{A}, \mathrm{B}$, and $\mathrm{C}$ immediately increases upon fault inception due to the reduced impedance provided by a short-circuit path to ground. The secondary winding phase inverse-time overcurrent element (51P2) on the SEL-387E times out approximately 42 cycles after fault inception, whereupon the relay trips its circuit breaker on bus 2 to clear the fault.

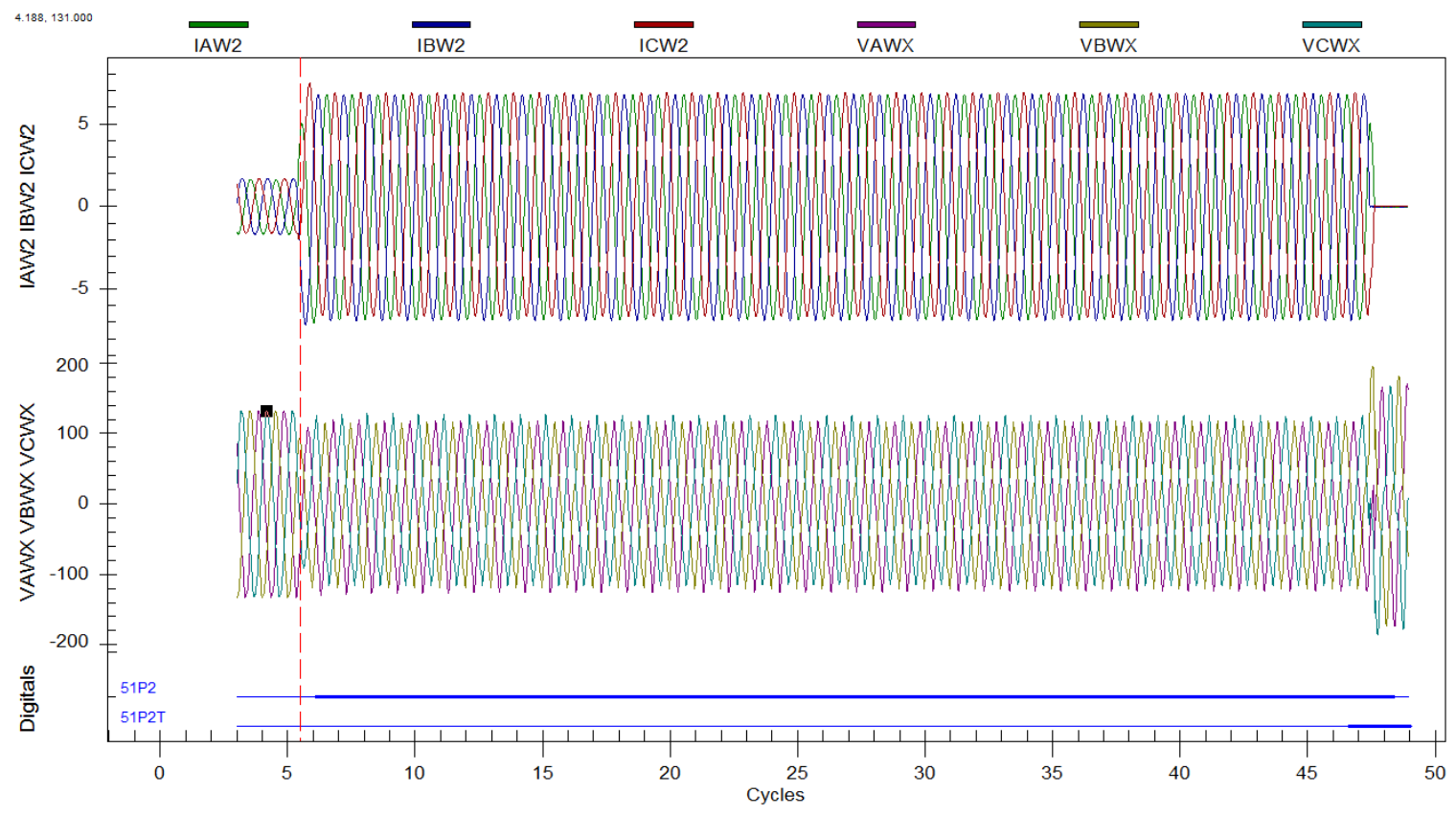

Figure 27: SEL-387E Three-Phase Fault, Bus 3, Phases A, B, and C 


\subsection{Line-to-Line Faults}

Figure 28 illustrates response of the SEL-387E's inverse-time overcurrent element to a bolted line-to-line fault at the induction motor (bus 3 in Figure 10). Current in the faulted phases A and B immediately increases upon fault inception due to the reduced impedance provided by a short-circuit path to ground. The induction motor, having lost its supply of current from phases A and B, proceeds to draw additional current from the unfaulted phase $\mathrm{C}$. This increased current draw allows the induction motor to act as a generator to feed the fault on phases A and B. The secondary winding negative-sequence inverse-time overcurrent element (51Q2) on the SEL-387E times out approximately 8 cycles after fault inception, whereupon the relay trips its circuit breaker on bus 2 to clear the fault.

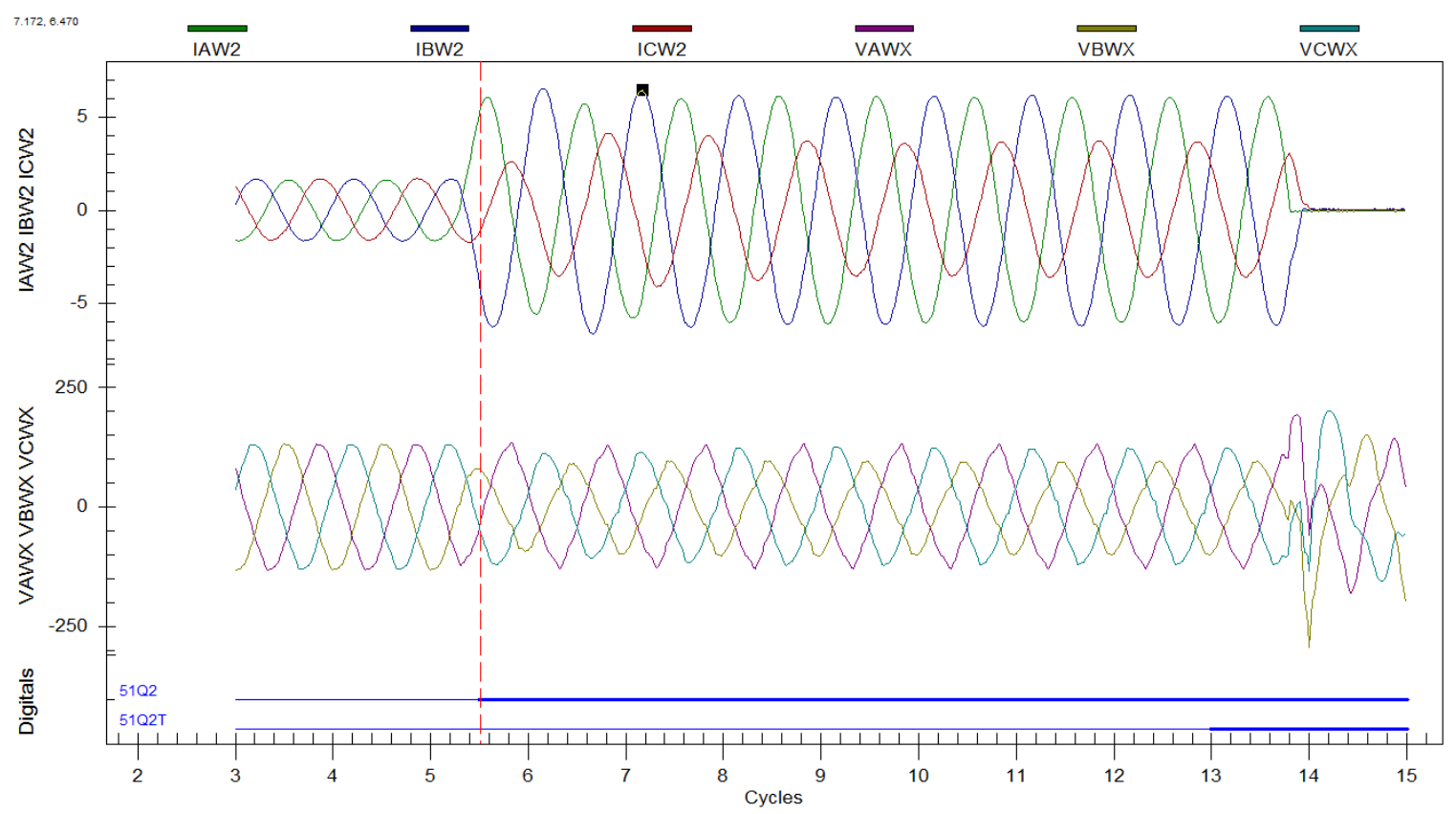

Figure 28: SEL-387E Line-to-Line Fault, Bus 3, Phases A and B 


\section{Chapter 10: SEL-387E Differential Protection}

\subsection{Differential Protection Overview}

Differential protection provides security against faults located between two fixed points, a region known as the differential zone of protection. When the differential zone operates normally (that is, there is no internal fault between the two fixed points) the currents entering and leaving these two points match. During internal fault conditions, in which a fault exists within the differential zone, the current entering the zone significantly exceeds the current leaving the zone.

Consider the example illustrated by the single-line diagram in Figure 29. Buses 1 and 2, shown in green, represent the two fixed points bounding the protected region. In ideal normal operation, the current (shown with black arrows) flows straight through the differential zone. All of the current entering the zone from bus 1 exits the zone at bus 2 . This current induces current to flow in current transformers CT1 and CT2 in counterclockwise loops adjacent to the instantaneous-overcurrent relay. The currents from CT1 and CT2 cancel each other, since they travel through the relay in opposite directions. Under these ideal operating conditions, no net current flows through the relay and Iop $=0$ A.

Now, consider the alternate case illustrated in Figure 29, in which a fault exists within the differential zone of protection. The internal fault causes current (shown with red arrows) to flow into the differential zone from both bus 1 and bus 2 . This change in the direction of current at bus 2 results in a different direction of current flowing in CT2. Currents from CT1 and CT2 now flow through the relay in the same direction, producing a positive net operating current Iop. This operating current causes the relay to trip its 
circuit breakers at both ends of the differential zone to isolate the fault from the rest of the system.

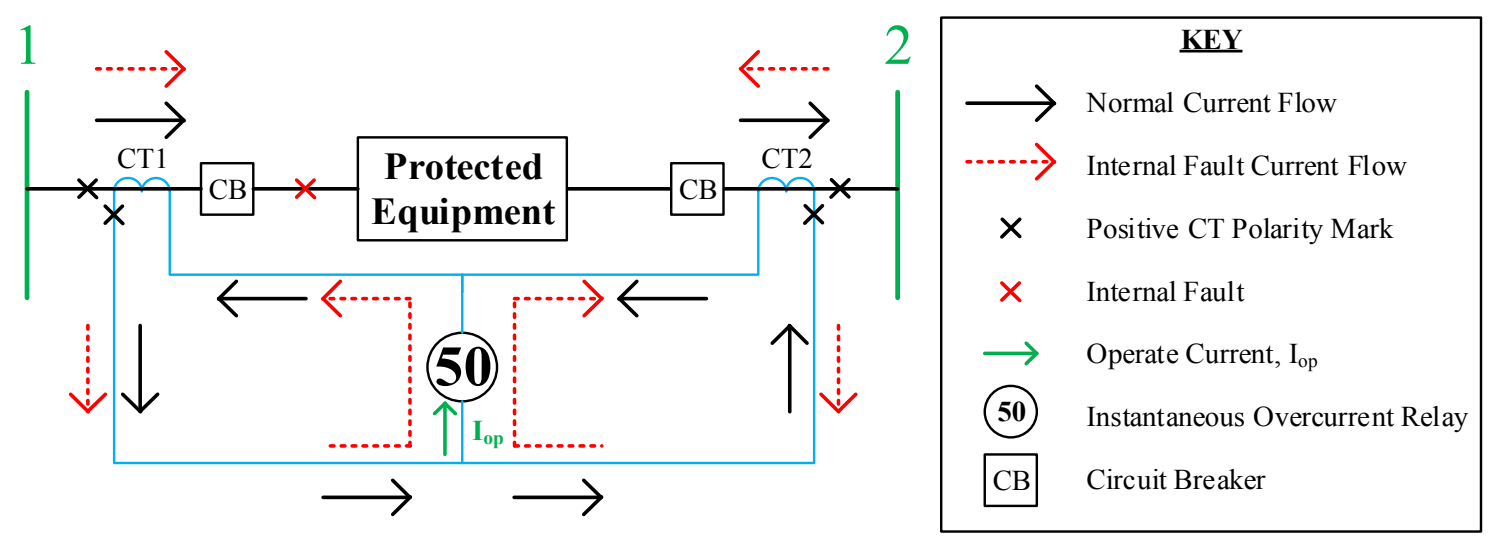

Figure 29: Traditional Differential Protection Circuit

External fault conditions (those outside the differential zone) should not cause the differential relay to operate. Even for high currents flowing through the differential zone to feed an external fault, the operating current ideally remains at zero because the high currents enter and leave the differential zone, cancelling each other at the relay. This gives the differential relay selectivity between internal faults (those within the differential zone) and external faults (those outside the differential zone). In reality, the operating current Iop is never exactly zero. Current losses across the differential zone and variations in the construction and saturation point in the two current transformers (which never perfectly match) result in a nonzero operating current [21]. Furthermore, as [21] explains, external faults lead to significant transient operating currents. As a result, differential relays must operate quickly in order to clear internal faults, but not so quickly that they operate for external faults or minor variations in construction between the two current transformers. 
Figure 30 illustrates various fault and loading conditions in terms of the differential relay pickup current IPU and the relay operating current Iop. The operating current remains near zero for normal loading conditions and for "ideal" faults located outside the differential zone. An "ideal" external fault does not saturate the current transformers of the differential relay. However, high currents passing through the differential zone to feed an external fault can saturate the current transformers. Since saturation occurs at different current levels in any two current transformers, saturated current transformers do not accurately reflect the primary currents in the differential zone. This inaccuracy creates a nonzero operating current flowing through the differential relay, which easily exceeds the defined pickup current. As a result, saturated current transformers cause a differential relay to unnecessarily trip for external faults.
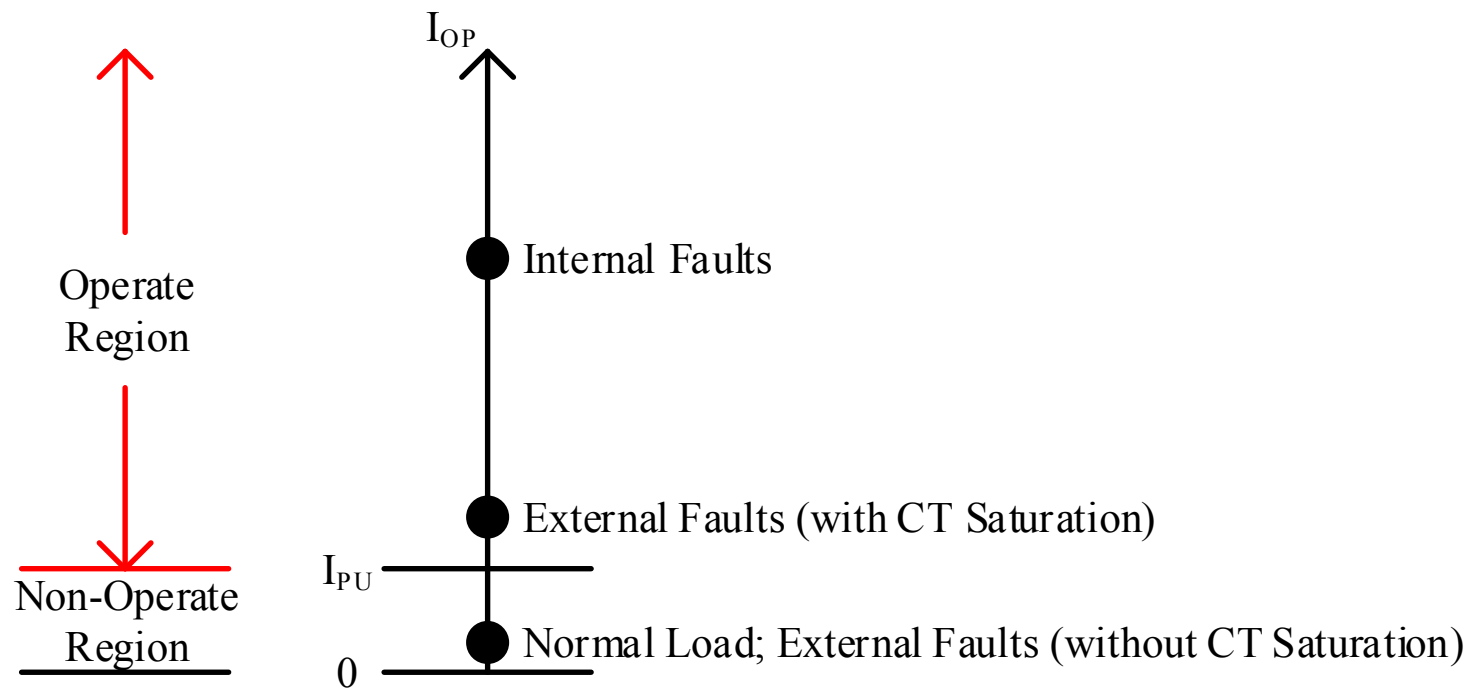

Figure 30: Differential Protection Operating Current, IoP 


\subsection{Differential Protection in a Microprocessor-Based Relay}

Microprocessor-based differential relays build on the theory presented in the previous section by better differentiating between internal and external faults. Figure 31 illustrates a typical two-slope percentage restraint differential characteristic. With this characteristic, the relay trips whenever the operating current Iop lies above the curve that separates the operate and restraint regions of the characteristic. The unrestrained differential pickup current value on the Iop axis corresponds to a sufficiently-high current in the differential zone, which indicates the presence of an internal fault. Adjustable relay settings control the location and rise of the various regions, enabling the creation of customized differential protection schemes.

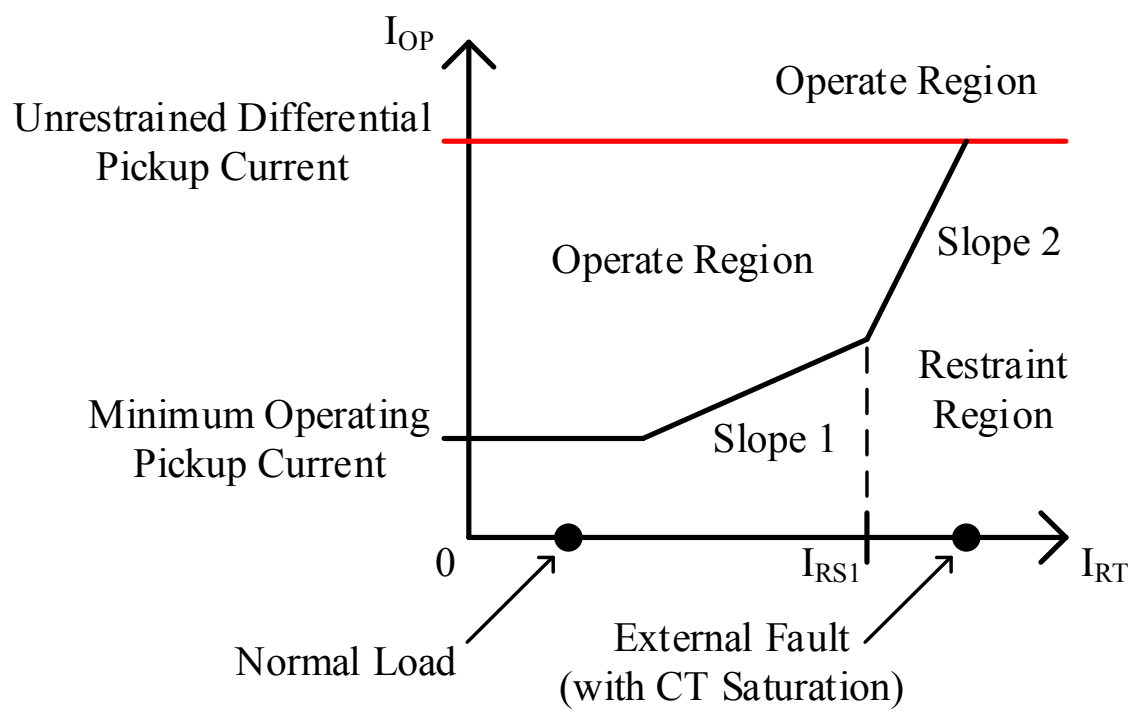

Figure 31: Operate vs. Restraint Current Characteristic

As Figure 31 illustrates, normal load currents lie beneath the curve separating the operate and restraint regions of the differential characteristic. For properly-chosen slope characteristics, external faults also lie beneath the curve [23]. This follows from the high 
levels of the restraint current produced by external faults. If the current transformers in the differential zone do not saturate, the operating current in the relay remains near zero, and the relay faces no danger of inappropriately tripping for the external fault. If the current transformers do saturate, the resulting increase in operating current (a vertical shift up from the external fault point shown in Figure 31) should still remain below the operating point above the curve.

The microprocessor-based differential relays used in this project calculate the operate (IoP) and restraint (IRT) currents based on the currents flowing in the primary and secondary windings of a power transformer. The SEL-387E and SEL-587 both use the following equations described by [12] and [23]:

$$
I_{O P}=\left|\overline{I_{1}}+\overline{I_{2}}\right| \quad I_{R T}=\frac{1}{2} \cdot\left(\left|\overline{I_{1}}\right|+\left|\overline{I_{2}}\right|\right)
$$

The first equation states that the operate current equals the magnitude of the phasor sum of the primary winding current $\left(\mathrm{I}_{1}\right)$ and secondary winding current $\left(\mathrm{I}_{2}\right)$. In other words, the relay adds together the current in the primary and secondary power transformer windings as vectors, and assigns the magnitude of the resulting vector as the operate current. Conversely, the second equation establishes the restraint current as the scaled sum of the magnitudes of the primary winding current $\left(\mathrm{I}_{1}\right)$ and secondary winding current (I $\mathrm{I}_{2}$. In other words, the relay adds together only the magnitudes (treating the currents as scalar quantities) of the primary and secondary winding current, divides the sum by two, and assigns the resulting value to the restraint current. These operate and restraint currents allow the SEL-387E and SEL-587 differential relays to discern between internal faults (a valid trip condition) and other conditions, like current transformer saturation (an invalid trip condition). 


\subsection{Single-Line-to-Ground Faults}

Figure 32 illustrates the response of the SEL-387E's differential protection to a bolted single-line-to-ground fault at the wye-connected power transformer primary winding (bus 1 in Figure 10) from the perspective of the primary transformer winding. Current in the faulted phase A immediately increases upon fault inception due to the reduced impedance provided by a short-circuit path to ground. The induction motor, having lost its supply of current from phase A, proceeds to draw additional current from the unfaulted phases B and C. This increased current draw allows the induction motor to act as a generator to feed the fault on phase A. The restrained differential element (87R) on the SEL-387E asserts approximately 3 cycles after fault inception, whereupon the relay trips its circuit breakers on bus 1 and bus 2 to clear the fault.

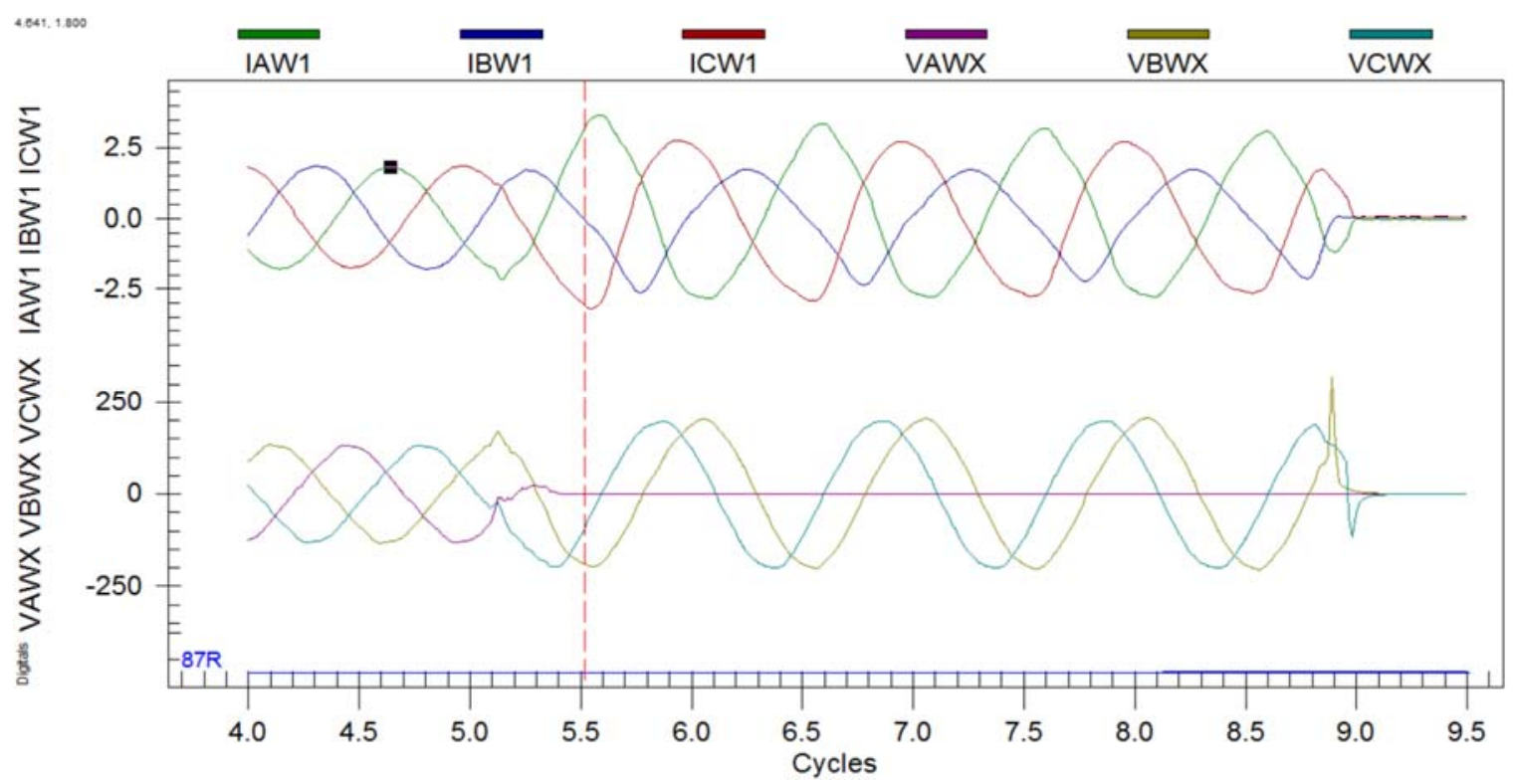

Figure 32: SEL-387E Single-Line-to-Ground Fault, Bus 1, Phase A

Figure 33 illustrates the response of the SEL-387E's differential protection to a bolted single-line-to-ground fault at the wye-connected power transformer secondary 
winding (bus 2 in Figure 10) from the perspective of the secondary transformer winding. Current measured by the relay in the transformer's faulted phase A secondary winding immediately decreases in magnitude upon fault inception. This decrease relates to the fault location, which is upstream of the point where the relay samples currents flowing through the secondary transformer windings. Hence, the phase A current, after fault inception, comes from the motor as it sends current upstream to feed the fault. The induction motor, now acting as a source of current for phase A, proceeds to draw additional current from the unfaulted phase $\mathrm{C}$ in order to source fault current to phase $\mathrm{A}$. The SEL-387E identifies and acknowledges the fault condition by asserting its restrained differential element (87R). This assertion occurs approximately 3 cycles after fault inception, whereupon the relay trips its circuit breakers on bus 1 and bus 2 to clear the fault. The instantaneous restrained differential element asserts before the negativesequence inverse-time overcurrent element (51Q) times out. 


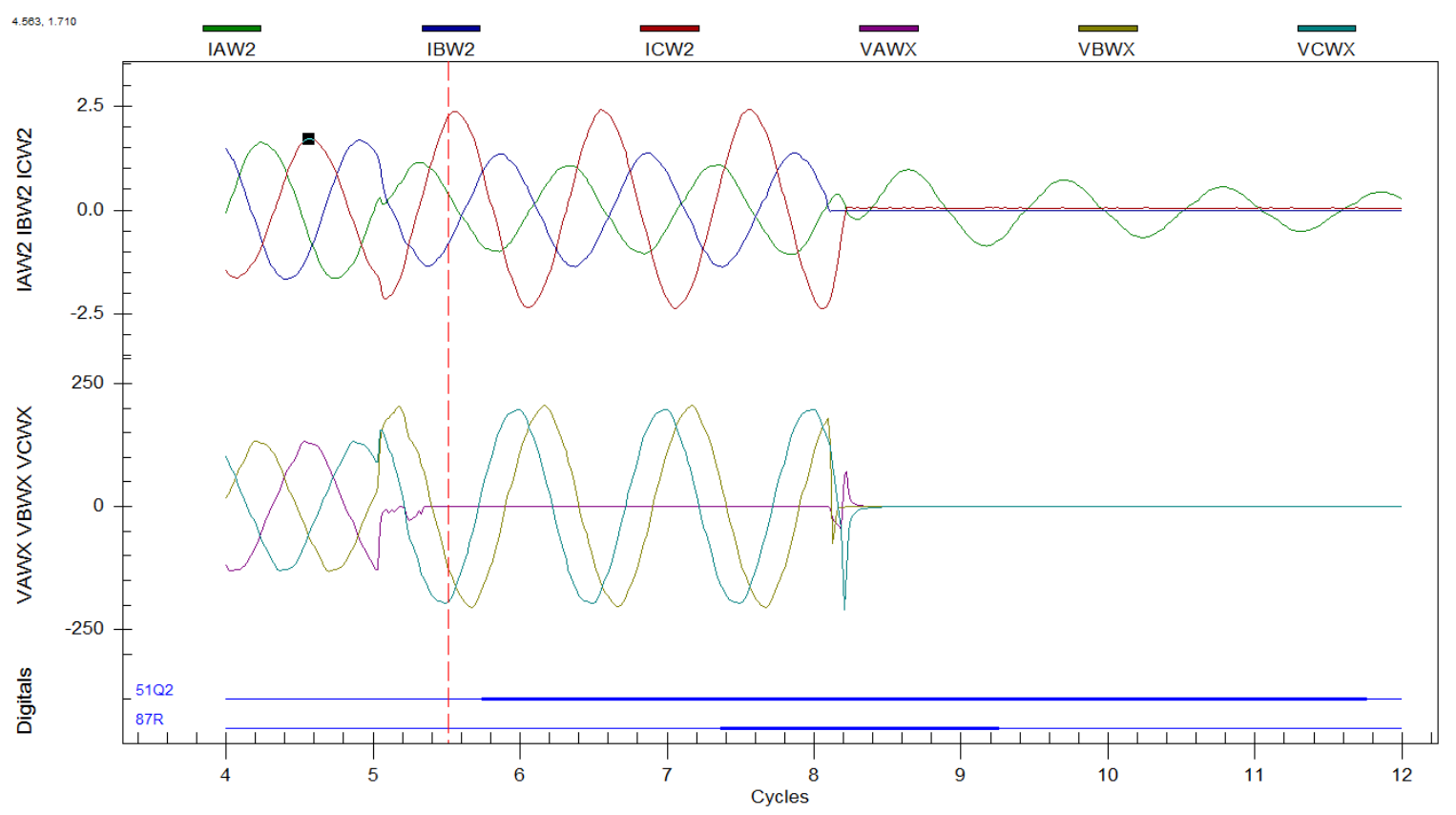

Figure 33: SEL-387E Single-Line-to-Ground Fault, Bus 2, Phase A 


\subsection{Double-Line-to-Ground Faults}

Figure 34 illustrates the response of the SEL-387E's differential protection to a bolted double-line-to-ground fault at the wye-connected power transformer primary winding (bus 1 in Figure 10) from the perspective of the primary transformer winding. Current in the faulted phases A and B immediately increases upon fault inception due to the reduced impedance provided by a short-circuit path to ground. The induction motor, having lost its supply of current from phases A and B, proceeds to draw additional current from the unfaulted phase $\mathrm{C}$. This increased current draw allows the induction motor to act as a generator to feed the fault on phases A and B. The restrained differential element (87R) on the SEL-387E asserts approximately 3 cycles after fault inception, whereupon the relay trips its circuit breakers on bus 1 and bus 2 to clear the fault.

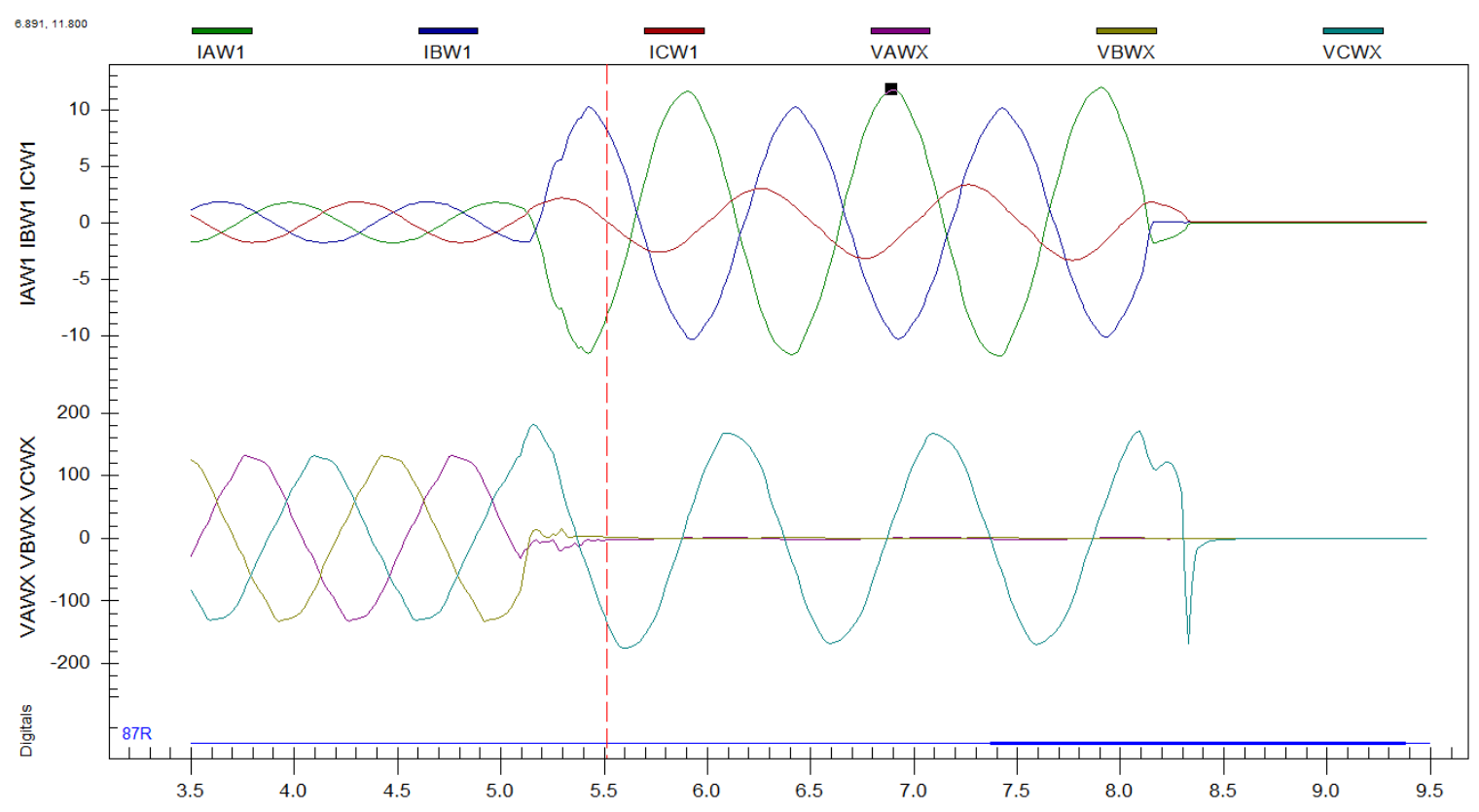

Figure 34: SEL-387E Double-Line-to-Ground Fault, Bus 1, Phases A and B 
Figure 35 illustrates the response of the SEL-387E's differential protection to a bolted double-line-to-ground fault at the wye-connected power transformer secondary winding (bus 2 in Figure 10) from the perspective of the secondary transformer winding. Current magnitudes measured by the relay in the transformer's faulted phase A and phase B secondary windings initially spike upon fault inception, followed by a decrease in magnitude throughout the duration of the fault. Measured current in the unfaulted phase $\mathrm{C}$ increases as the induction motor draws additional current to source fault current to phases A and B. The phase A and phase B currents, after fault inception, come from the motor as it sends current upstream to feed the fault. The SEL-387E identifies and acknowledges the fault condition by asserting its restrained differential element (87R). This assertion occurs approximately 3 cycles after fault inception, whereupon the relay trips its circuit breakers on bus 1 and bus 2 to clear the fault. The instantaneous restrained differential element asserts before the negative-sequence inverse-time overcurrent element (51Q) times out. Once the circuit breaker opens, current provided by the induction motor to the faulted phases decays as the energy stored in the motor diminishes. 


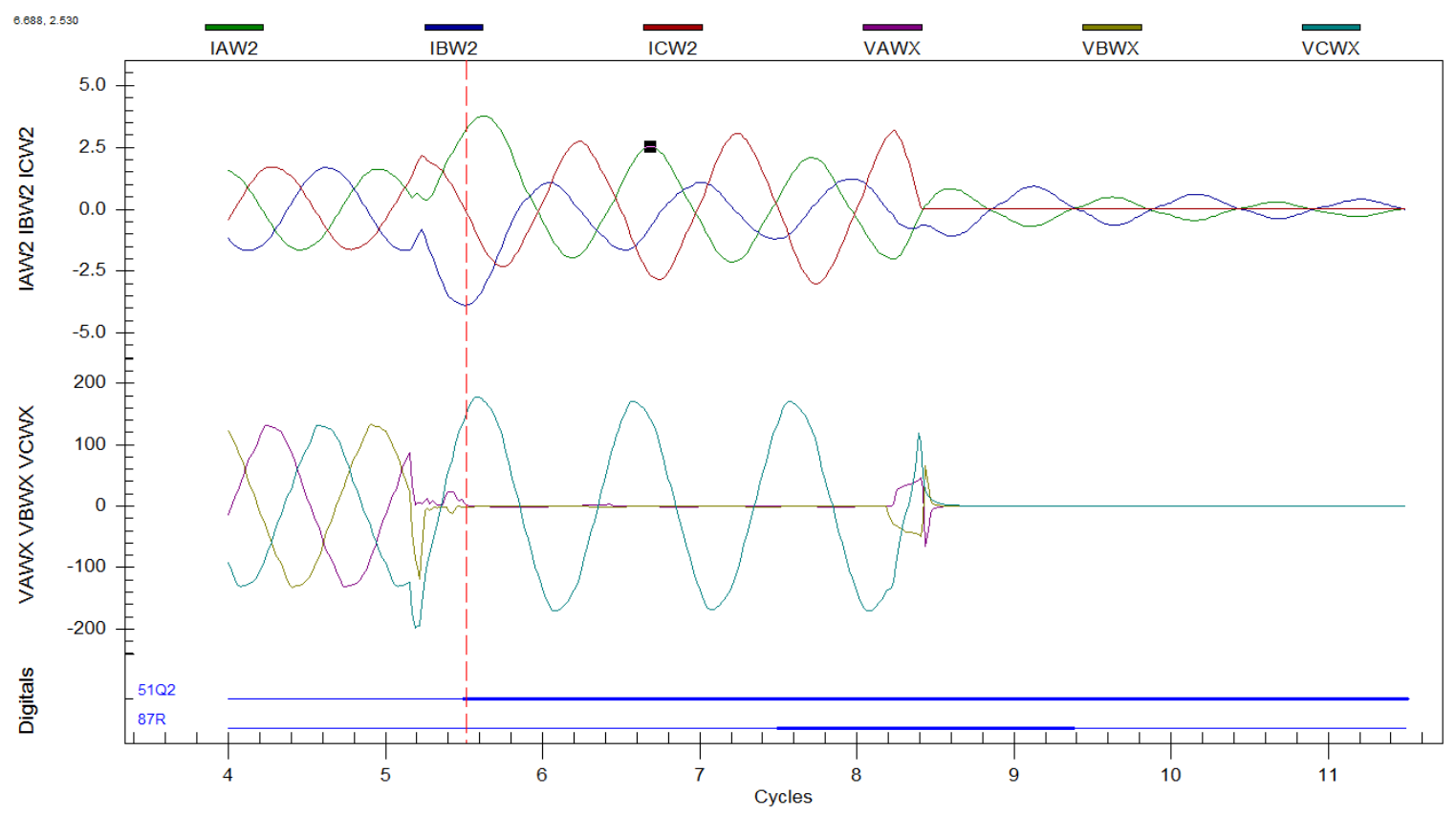

Figure 35: SEL-387E Double-Line-to-Ground Fault, Bus 2, Phases A and B 


\subsection{Triple-Line-to-Ground Faults}

Figure 36 illustrates the response of the SEL-387E's differential protection to a bolted triple-line-to-ground fault at the wye-connected power transformer primary winding (bus 1 in Figure 10) from the perspective of the primary transformer winding. Current in the faulted phases A, B, and C immediately increases upon fault inception due to the reduced impedance provided by a short-circuit path to ground. The restrained differential element (87R) on the SEL-387E asserts approximately 3 cycles after fault inception, whereupon the relay trips its circuit breakers on bus 1 and bus 2 to clear the fault.

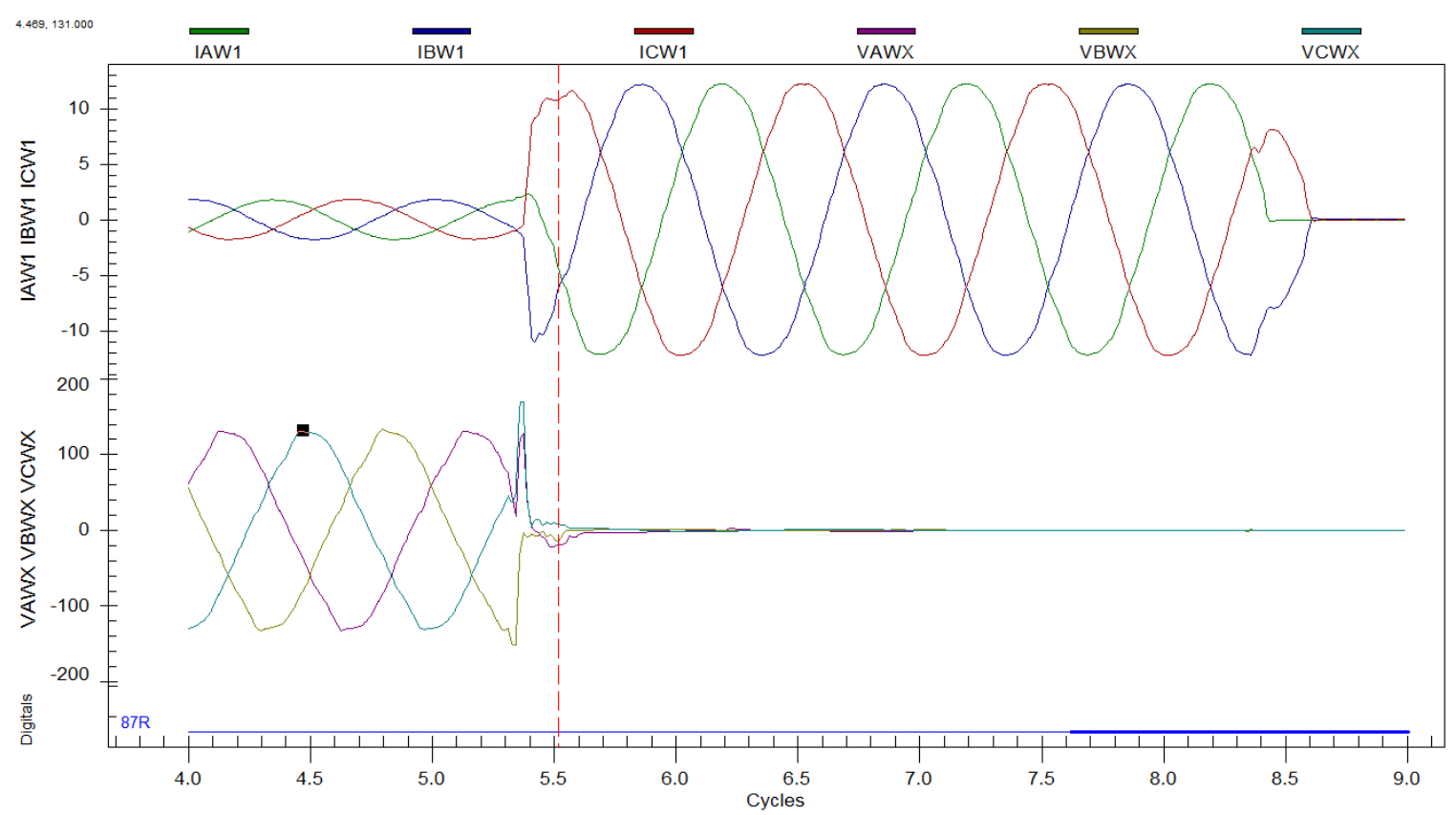

Figure 36: SEL-387E Triple-Line-to-Ground Fault, Bus 1, Phases A, B, and C

Figure 37 illustrates the response of the SEL-387E's differential protection to a bolted triple-line-to-ground fault at the wye-connected power transformer secondary winding (bus 2 in Figure 10) from the perspective of the secondary transformer winding. 
Current magnitudes measured by the relay in the transformer's faulted phase A, B, and C secondary windings initially spike upon fault inception, followed by a decrease in magnitude throughout the duration of the fault as the energy stored in the motor diminishes. After fault inception, all current comes from the motor as it sends current upstream to feed the fault. The SEL-387E identifies and acknowledges the fault condition by asserting its restrained differential element (87R). This assertion occurs approximately 3 cycles after fault inception, whereupon the relay trips its circuit breakers on bus 1 and bus 2 to clear the fault.

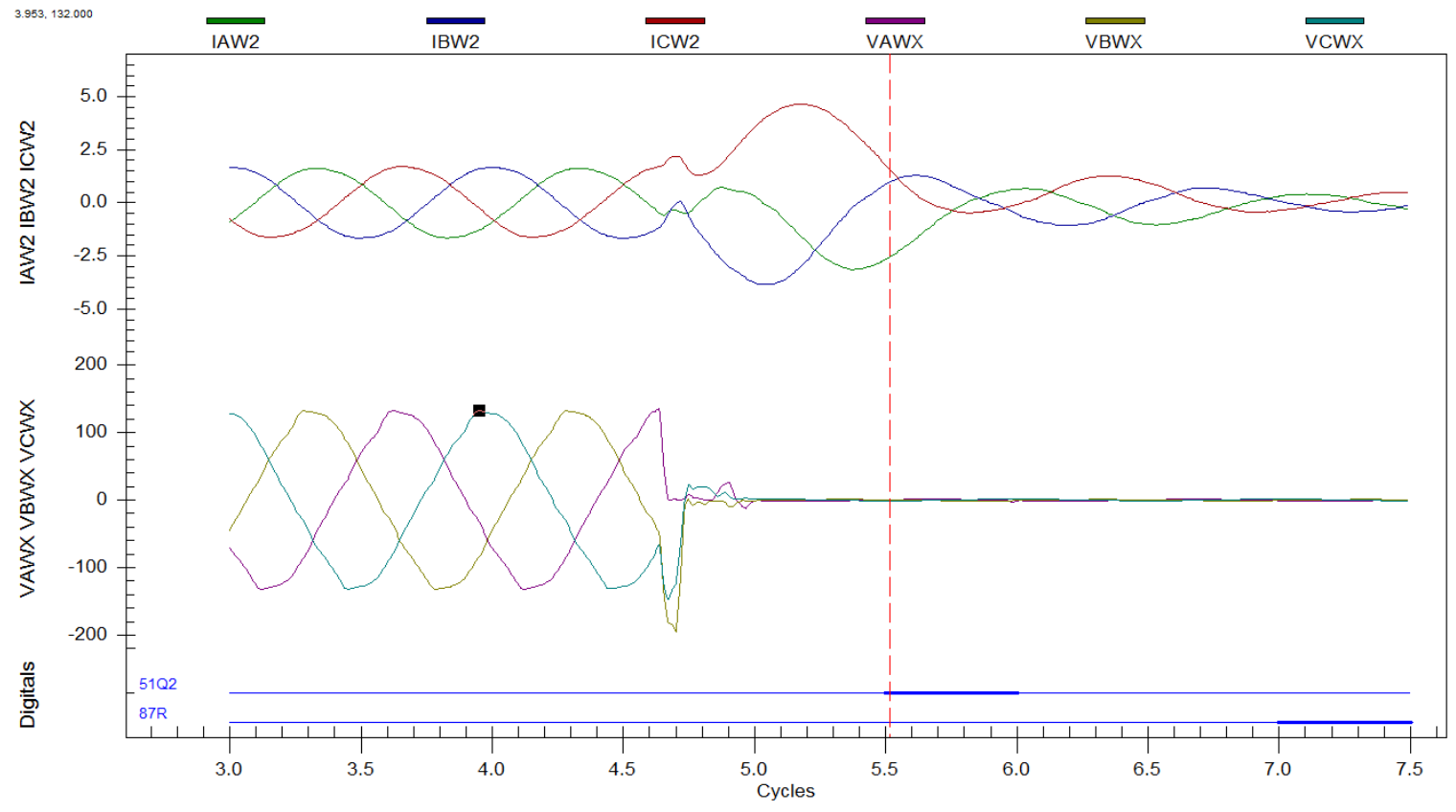

Figure 37: SEL-387E Triple-Line-to-Ground Fault, Bus 2, Phases A, B, and C 


\subsection{Three-Phase Faults}

Figure 38 illustrates the response of the SEL-387E's differential protection to a bolted three-phase fault at the wye-connected power transformer primary winding (bus 1 in Figure 10) from the perspective of the primary transformer winding. Current in the faulted phases A, B, and C immediately increases upon fault inception due to the reduced impedance provided by a short-circuit path to ground. The restrained differential element (87R) on the SEL-387E asserts approximately 2 cycles after fault inception, whereupon the relay trips its circuit breakers on bus 1 and bus 2 to clear the fault.

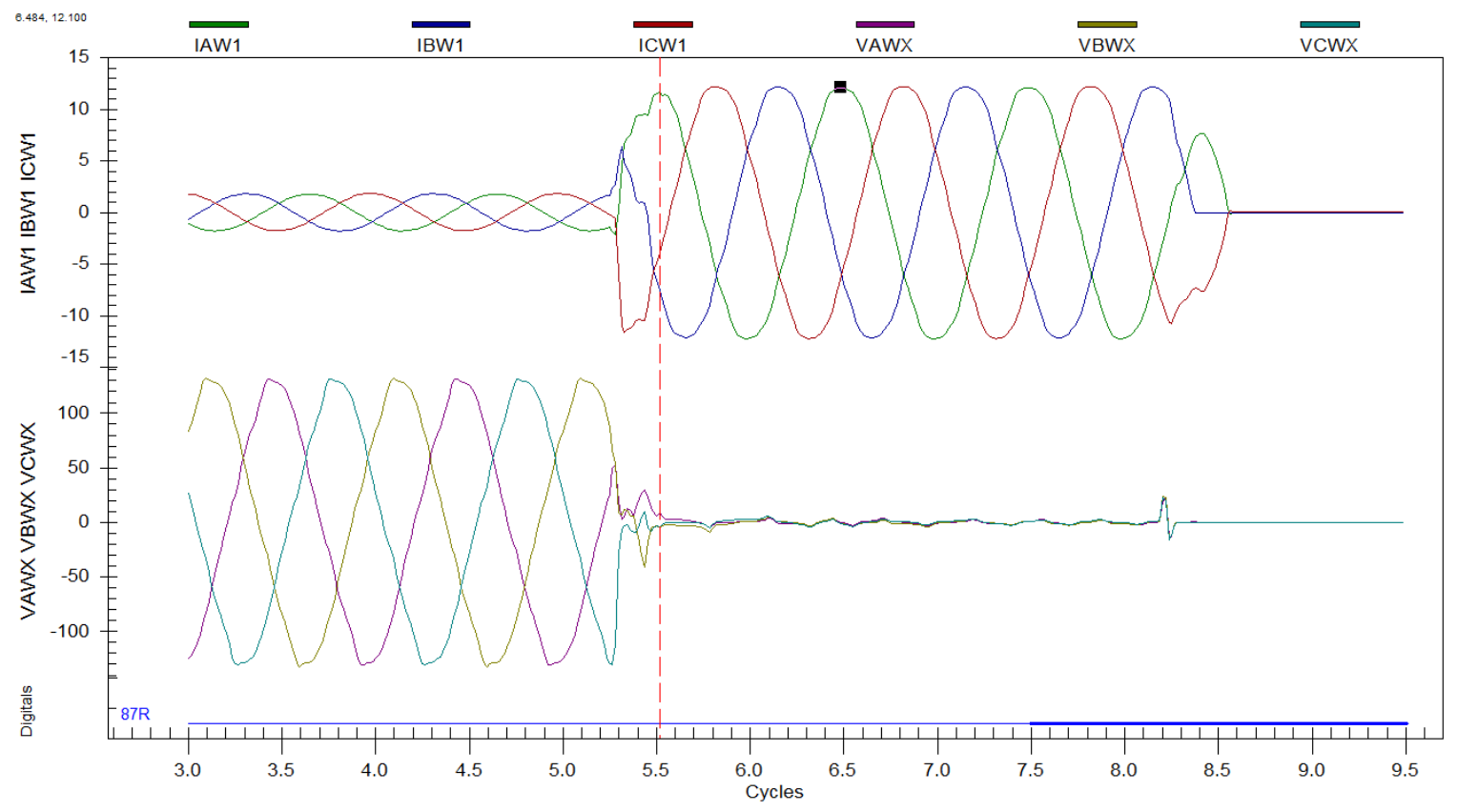

Figure 38: SEL-387E Three-Phase Fault, Bus 1, Phases A, B, and C

Figure 39 illustrates the response of the SEL-387E's differential protection to a bolted three-phase fault at the wye-connected power transformer secondary winding (bus 2 in Figure 10) from the perspective of the secondary transformer winding. Current magnitudes measured by the relay in the transformer's faulted phase A, B, and C 
secondary windings initially spike upon fault inception, followed by a decrease in magnitude throughout the duration of the fault as the energy stored in the motor diminishes. After fault inception, all current comes from the motor as it sends current upstream to feed the fault. The SEL-387E identifies and acknowledges the fault condition by asserting its restrained differential element (87R). This assertion occurs approximately 2 cycles after fault inception, whereupon the relay trips its circuit breakers on bus 1 and bus 2 to clear the fault.

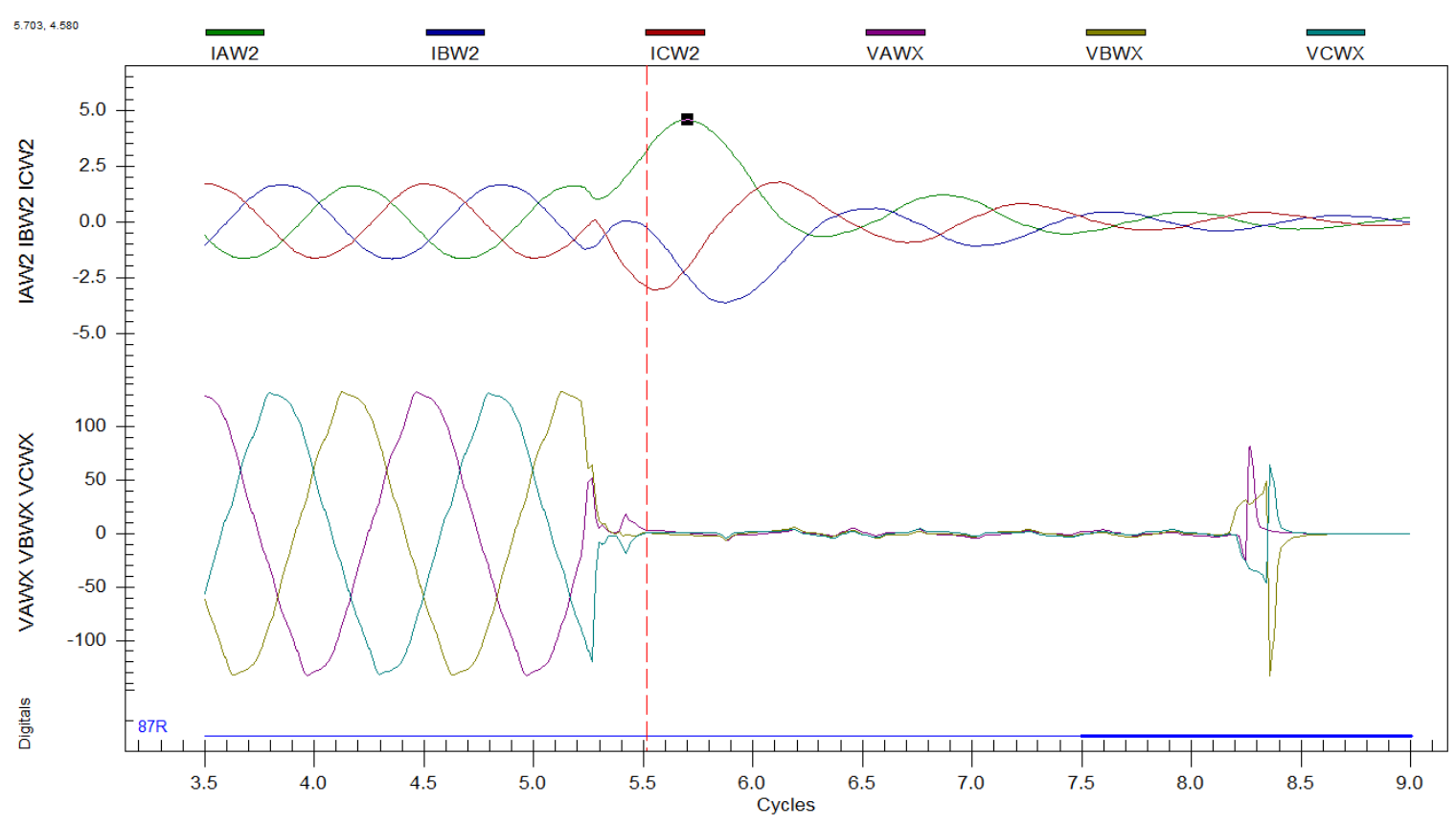

Figure 39: SEL-387E Three-Phase Fault, Bus 2, Phases A, B, and C 


\subsection{Line-to-Line Faults}

Figure 40 illustrates the response of the SEL-387E's differential protection to a bolted line-to-line fault at the wye-connected power transformer primary winding (bus 1 in Figure 10) from the perspective of the primary transformer winding. Current in the faulted phases A and B immediately increases upon fault inception due to the reduced impedance provided by a short-circuit path to ground. The induction motor, having lost its supply of current from phases A and B, proceeds to draw additional current from the unfaulted phase C. This increased current draw allows the induction motor to act as a generator to feed the fault on phases A and B. The restrained differential element $(87 \mathrm{R})$ on the SEL-387E asserts approximately 3 cycles after fault inception, whereupon the relay trips its circuit breakers on bus 1 and bus 2 to clear the fault.

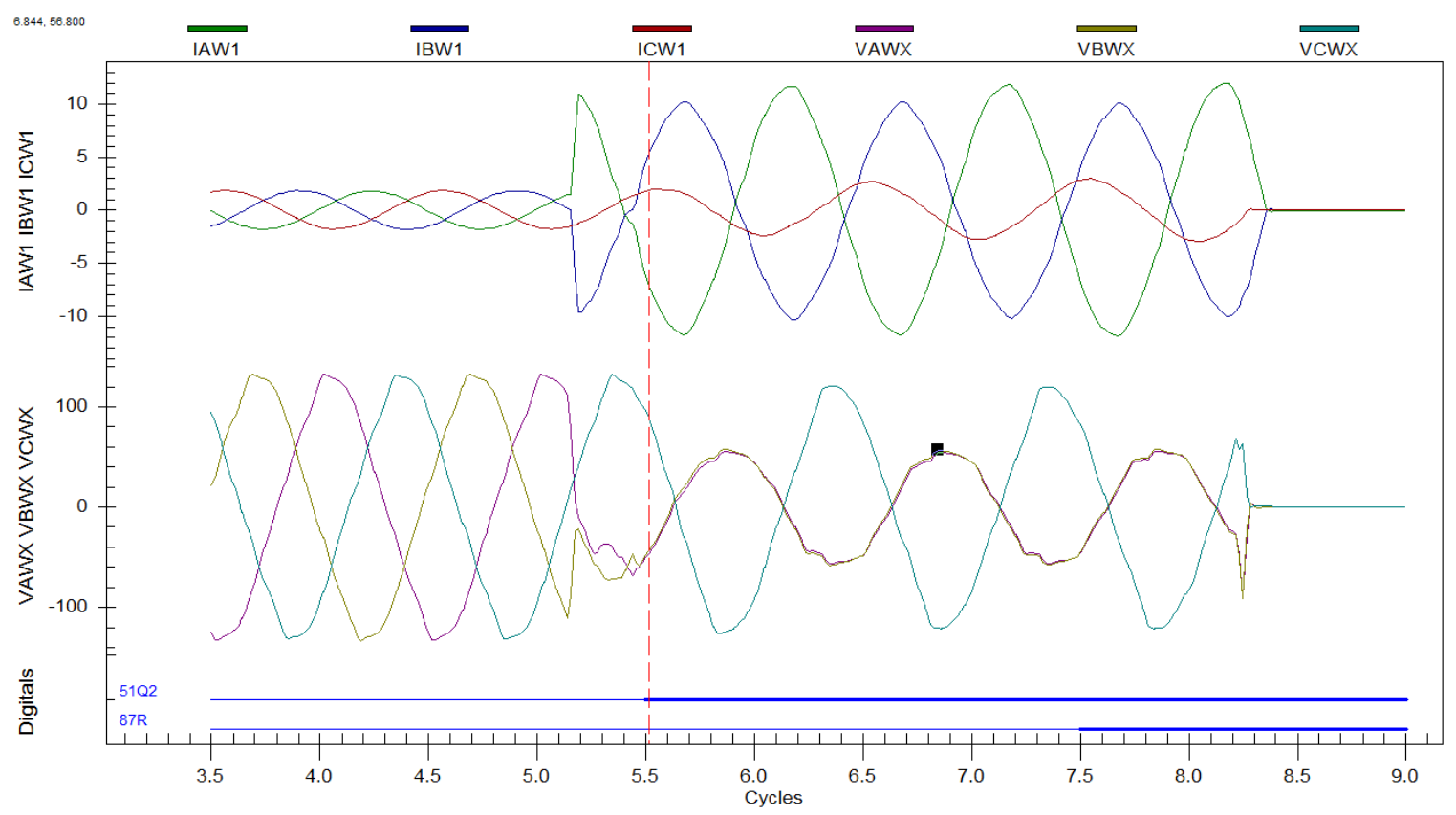

Figure 40: SEL-387E Line-to-Line Fault, Bus 1, Phases A and B 
Figure 41 illustrates the response of the SEL-387E's differential protection to a bolted line-to-line fault at the wye-connected power transformer secondary winding (bus 2 in Figure 10) from the perspective of the secondary transformer winding. Current magnitudes measured by the relay in the transformer's faulted phase A and phase B secondary windings initially spike upon fault inception, followed by a decrease in magnitude throughout the duration of the fault. Measured current in the unfaulted phase $\mathrm{C}$ increases as the induction motor draws additional current to source fault current to phases $\mathrm{A}$ and $\mathrm{B}$. The phase $\mathrm{A}$ and phase $\mathrm{B}$ currents, after fault inception, come from the motor as it sends current upstream to feed the fault. The SEL-387E identifies and acknowledges the fault condition by asserting its restrained differential element (87R). This assertion occurs approximately 2 cycles after fault inception, whereupon the relay trips its circuit breakers on bus 1 and bus 2 to clear the fault. The instantaneous restrained differential element asserts before the negative-sequence inverse-time overcurrent element (51Q) times out. Once the circuit breaker opens, current provided by the induction motor to the faulted phases decays as the energy stored in the motor diminishes. 


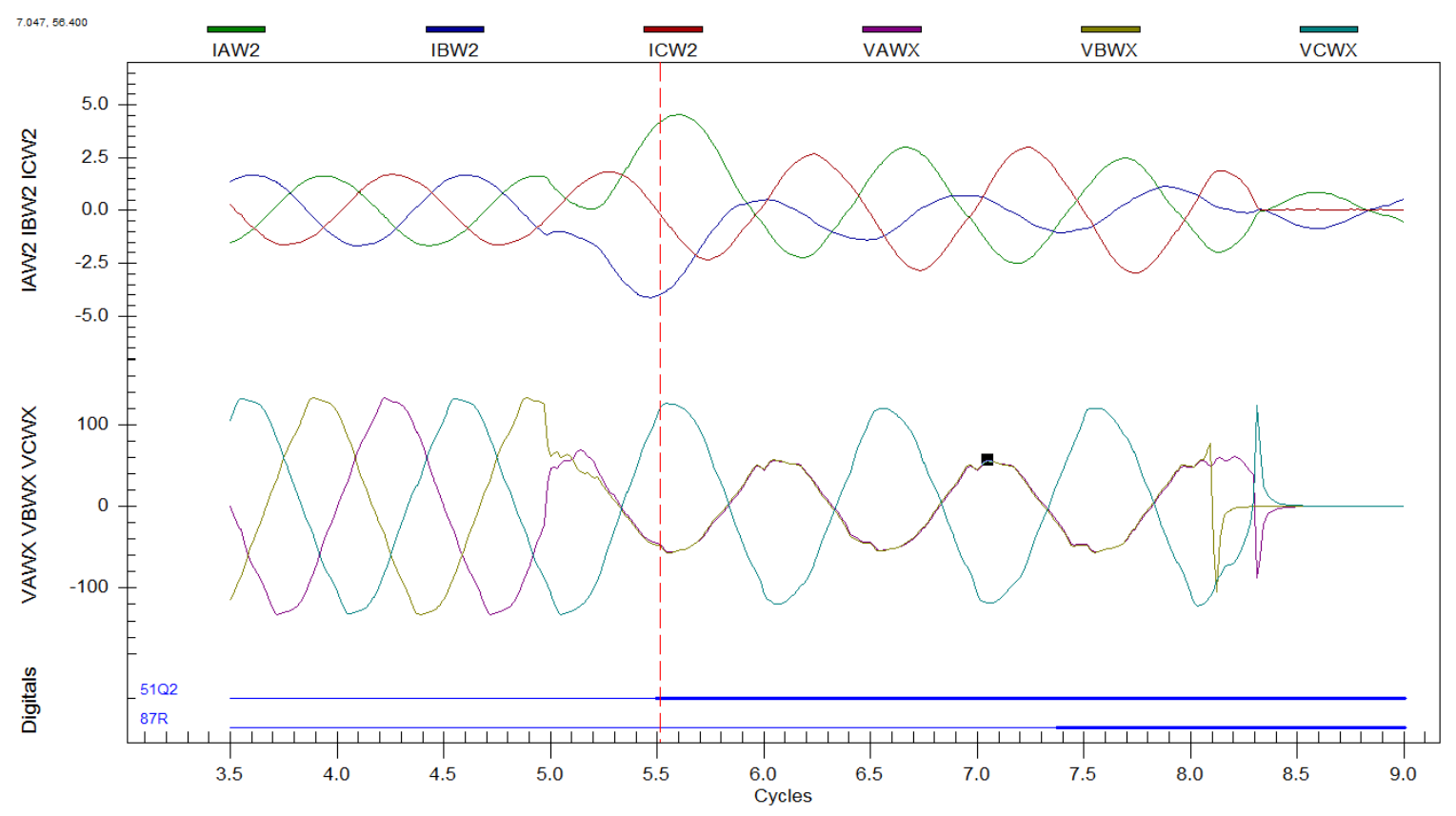

Figure 41: SEL-387E Line-to-Line Fault, Bus 2, Phases A and B 


\section{Chapter 11: SEL-710 Overcurrent Protection}

\subsection{Single-Line-to-Ground Faults}

Figure 42 illustrates the response of the SEL-710 to a bolted single-line-to-ground fault at the induction motor (bus 3 in Figure 10). Current in the faulted phase A immediately increases upon fault inception due to the reduced impedance provided by a short-circuit path to ground. The level 1 residual instantaneous overcurrent element (50G1) on the SEL-710 times out approximately 7 cycles after fault inception, whereupon the relay trips its circuit breaker on bus 3 to clear the fault. Voltage measured by the SEL-710 decays after the circuit breaker clears the fault. Although initially sustained by the rotation of the induction motor rotor, the voltage dies away as the motor slows to a halt.

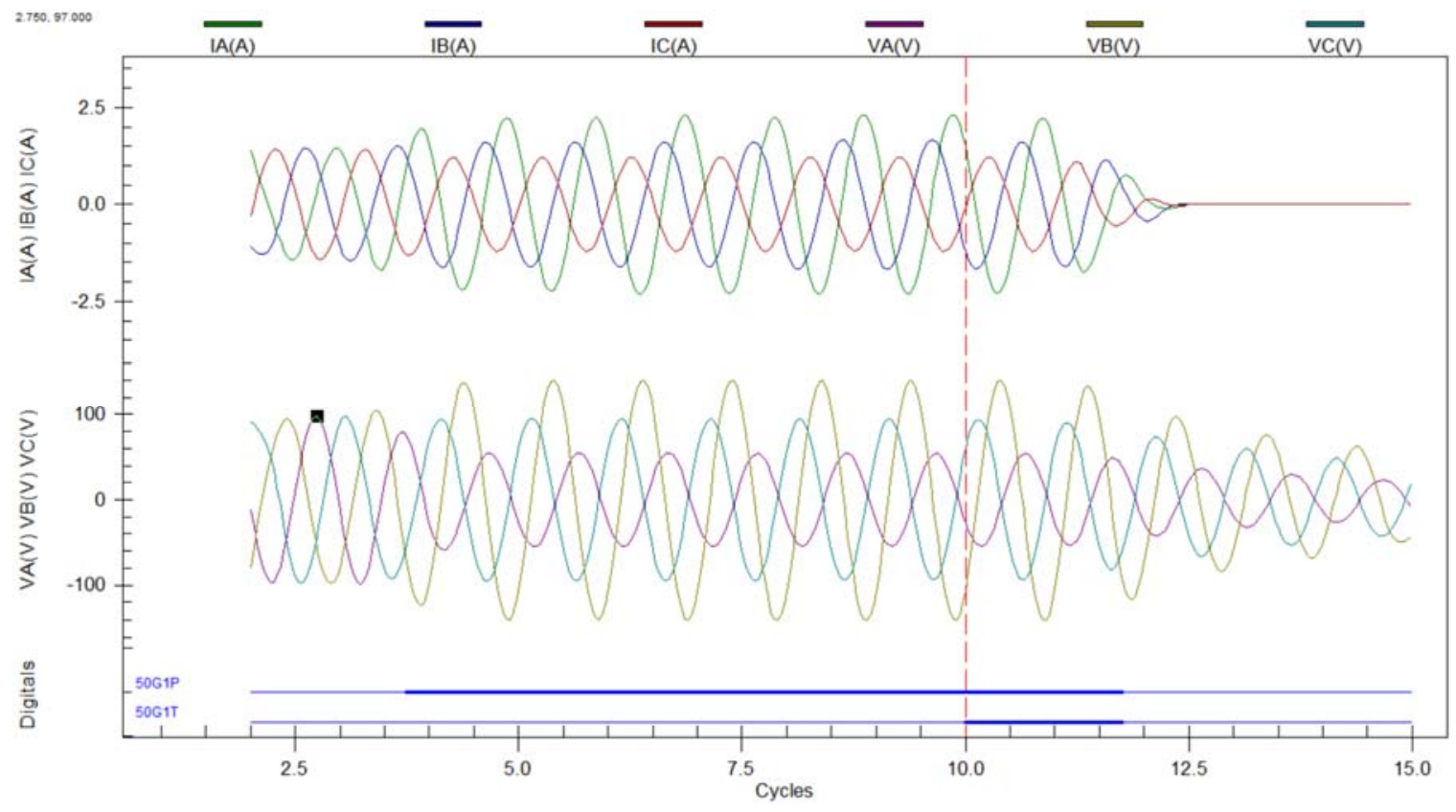

Figure 42: SEL-710 Single-Line-to-Ground Fault, Bus 3, Phase A 


\subsection{Double-Line-to-Ground Faults}

Figure 43 illustrates the response of the SEL-710 to a bolted double-line-toground fault at the induction motor (bus 3 in Figure 10). Current in the faulted phases A and B immediately increases upon fault inception due to the reduced impedance provided by a short-circuit path to ground. The induction motor, having lost its supply of current from phases $\mathrm{A}$ and $\mathrm{B}$, proceeds to draw additional current from the unfaulted phase $\mathrm{C}$. This increased current draw allows the induction motor to act as a generator to feed the fault on phases A and B. The level 1 phase instantaneous overcurrent element (50P1) on the SEL-710 asserts approximately 1 cycle after fault inception, whereupon the relay trips its circuit breaker on bus 3 to clear the fault. Voltage measured by the SEL-710 decays after the circuit breaker clears the fault. Although initially sustained by the rotation of the induction motor rotor, the voltage dies away as the motor slows to a halt.

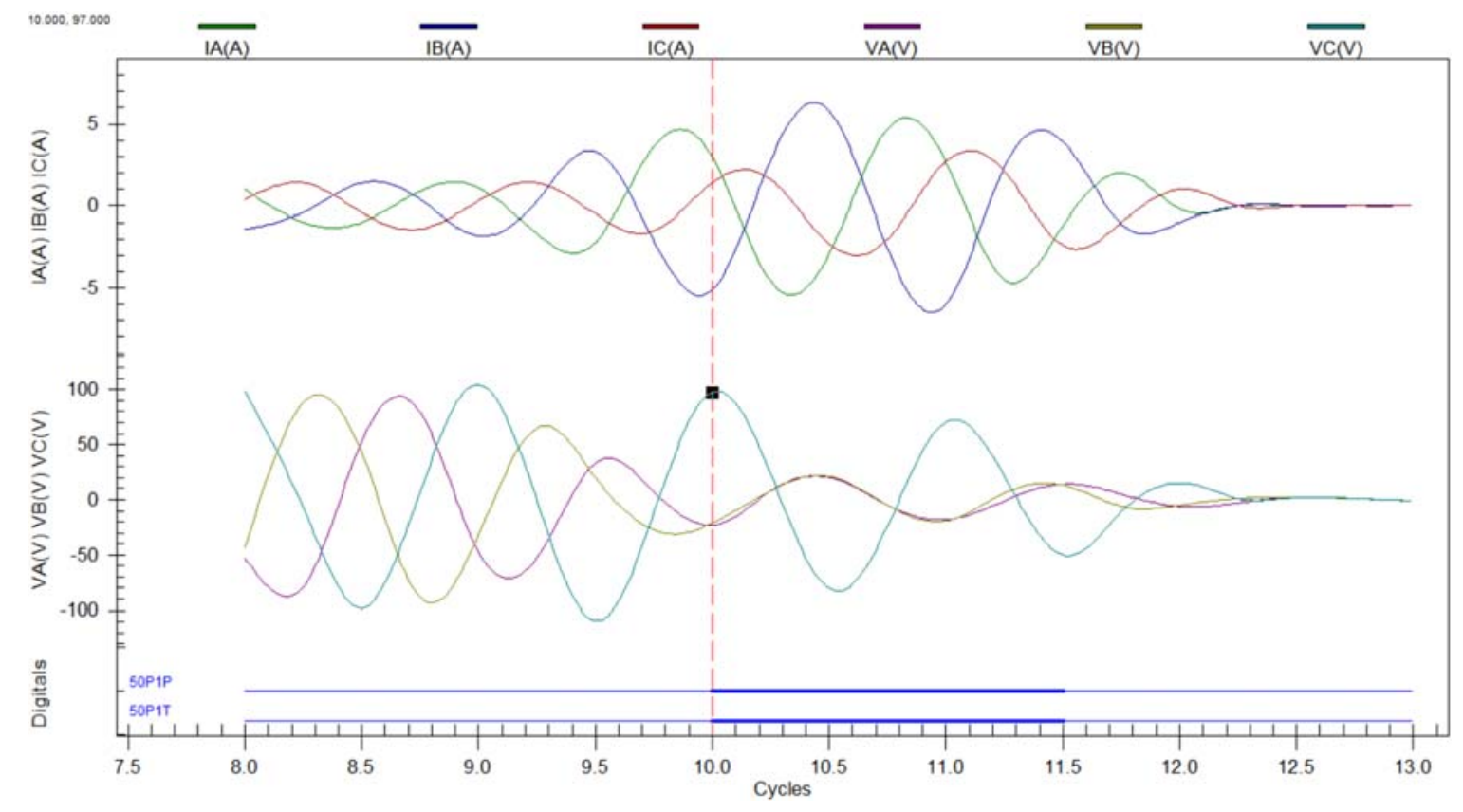

Figure 43: SEL-710 Double-Line-to-Ground Fault, Bus 3, Phases A and B 


\subsection{Triple-Line-to-Ground Faults}

Figure 44 illustrates the response of the SEL-710 to a bolted triple-line-to-ground fault at the induction motor (bus 3 in Figure 10). Current in the faulted phases A, B, and C immediately increases upon fault inception due to the reduced impedance provided by a short-circuit path to ground. The level 1 phase instantaneous overcurrent element (50P1) on the SEL-710 times out approximately 1 cycle after fault inception, whereupon the relay trips its circuit breaker on bus 3 to clear the fault. Voltage measured by the SEL710 decays after the circuit breaker clears the fault. Although initially sustained by the rotation of the induction motor rotor, the voltage dies away as the motor slows to a halt.

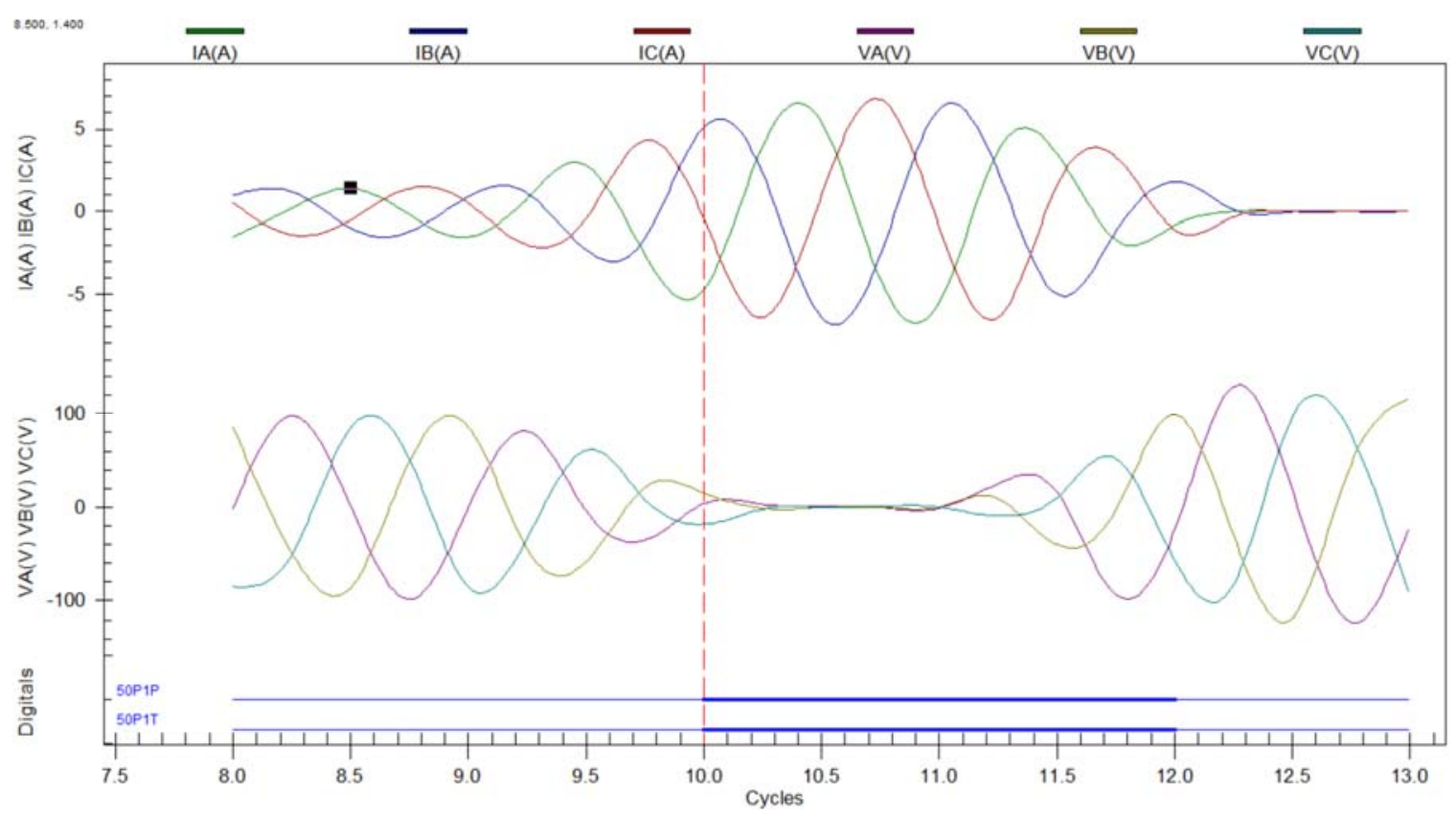

Figure 44: SEL-710 Triple-Line-to-Ground Fault, Bus 3, Phases A, B, and C 


\subsection{Three-Phase Faults}

Figure 45 illustrates the response of the SEL-710 to a bolted three-phase (ungrounded) fault at the induction motor (bus 3 in Figure 10). Current in the faulted phases $\mathrm{A}, \mathrm{B}$, and $\mathrm{C}$ immediately increases upon fault inception due to the reduced impedance provided by a short-circuit path to ground. The level 1 phase instantaneous overcurrent element (50P1) on the SEL-710 times out approximately 1 cycle after fault inception, whereupon the relay trips its circuit breaker on bus 3 to clear the fault. Voltage measured by the SEL-710 decays after the circuit breaker clears the fault. Although initially sustained by the rotation of the induction motor rotor, the voltage dies away as the motor slows to a halt.

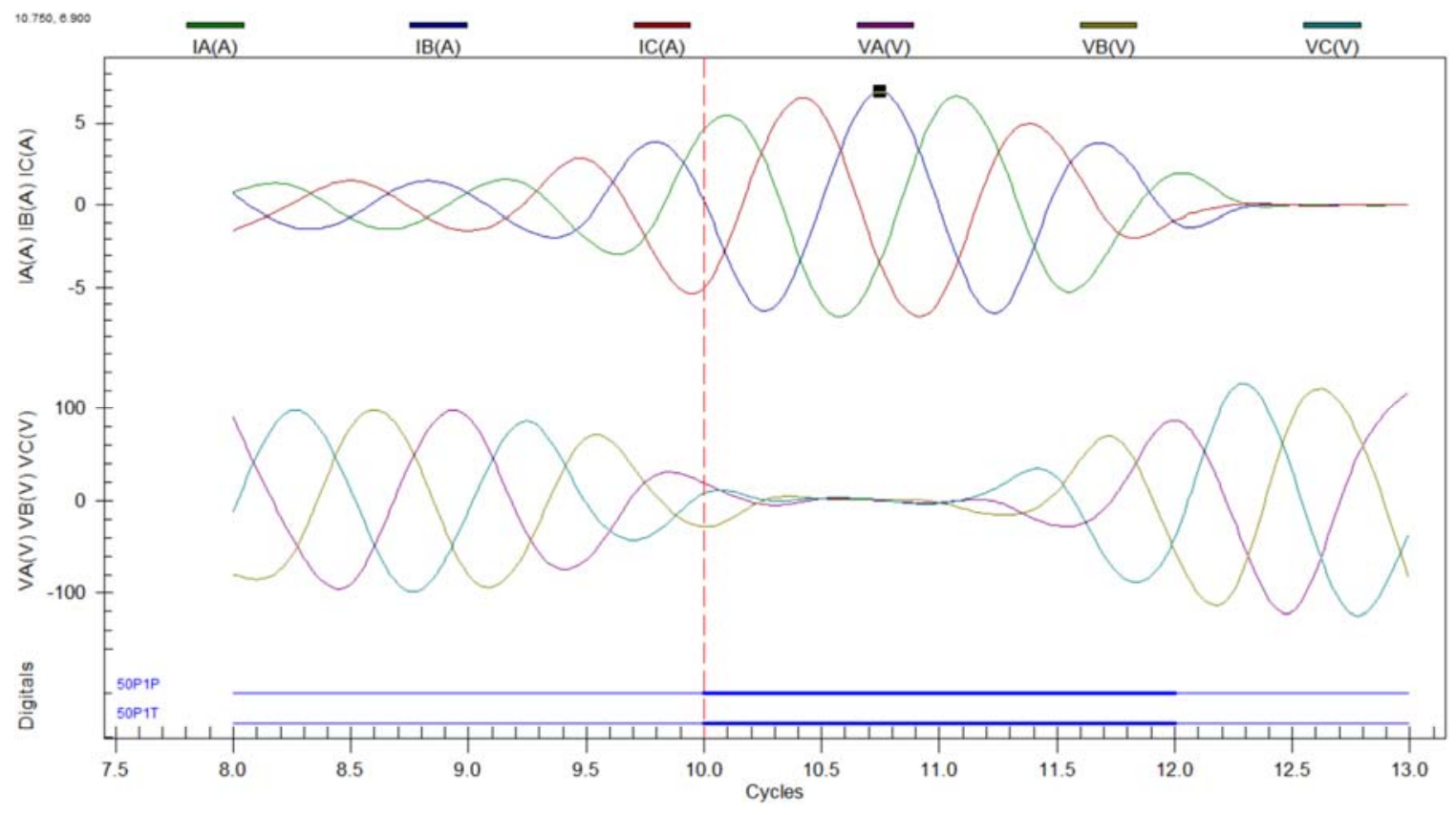

Figure 45: SEL-710 Three-Phase Fault, Bus 3, Phases A, B, and C 


\subsection{Line-to-Line Faults}

Figure 46 illustrates the response of the SEL-710 to a bolted line-to-line fault at the induction motor (bus 3 in Figure 10). Current in the faulted phases A and B immediately increases upon fault inception due to the reduced impedance provided by a short-circuit path to ground. The induction motor, having lost its supply of current from phases $\mathrm{A}$ and $\mathrm{B}$, proceeds to draw additional current from the unfaulted phase $\mathrm{C}$. This increased current draw allows the induction motor to act as a generator to feed the fault on phases A and B. The level 1 phase instantaneous overcurrent element (50P1) on the SEL-710 times out approximately 1 cycle after fault inception, whereupon the relay trips its circuit breaker on bus 3 to clear the fault. Voltage measured by the SEL-710 decays after the circuit breaker clears the fault. Although initially sustained by the rotation of the induction motor rotor, the voltage dies away as the motor slows to a halt.

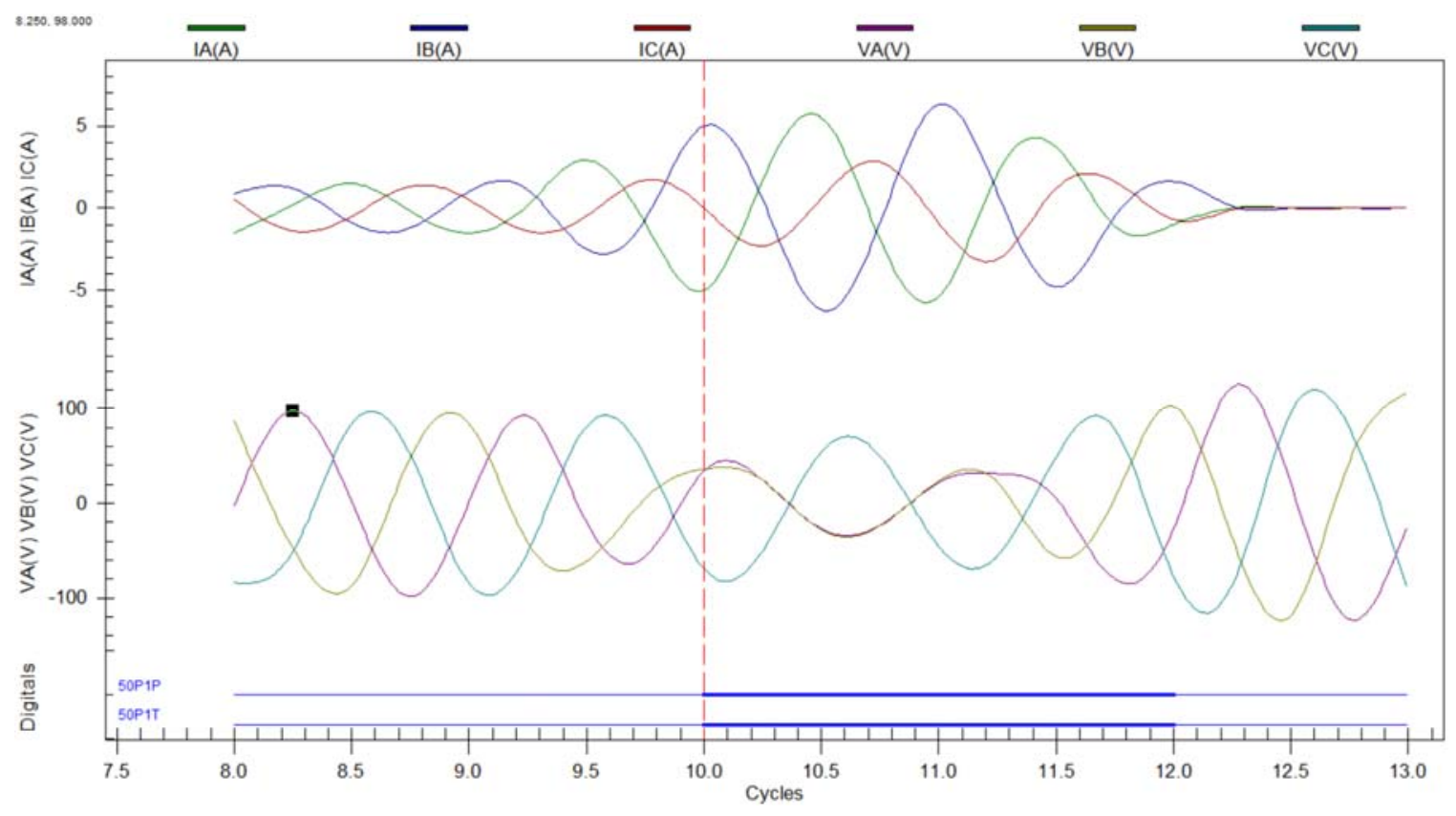

Figure 46: SEL-710 Line-to-Line Fault, Bus 3, Phases A and B 


\section{Chapter 12: SEL-710 Undervoltage, Locked-Rotor, and Thermal Overload Protection}

\subsection{Undervoltage Protection}

Figure 47 illustrates the response of the SEL-710's undervoltage element to an undervoltage condition at the induction motor terminals (bus 3 in Figure 10). Voltage at the motor bus varies with the external torque load applied on the motor. An increased torque load causes the induction motor to draw additional current to support this mechanical load. An increase in current through the current-limiting resistors, transformer, and transmission line results in an increased voltage drop between the source and the induction motor. A sufficiently high torque load on the motor causes the induction motor terminal voltage to drop below the undervoltage trip limit programmed into the SEL-710. The level 1 undervoltage element (27P1) on the SEL-710 times out, whereupon the relay trips its circuit breaker on bus 3 to clear the fault. 


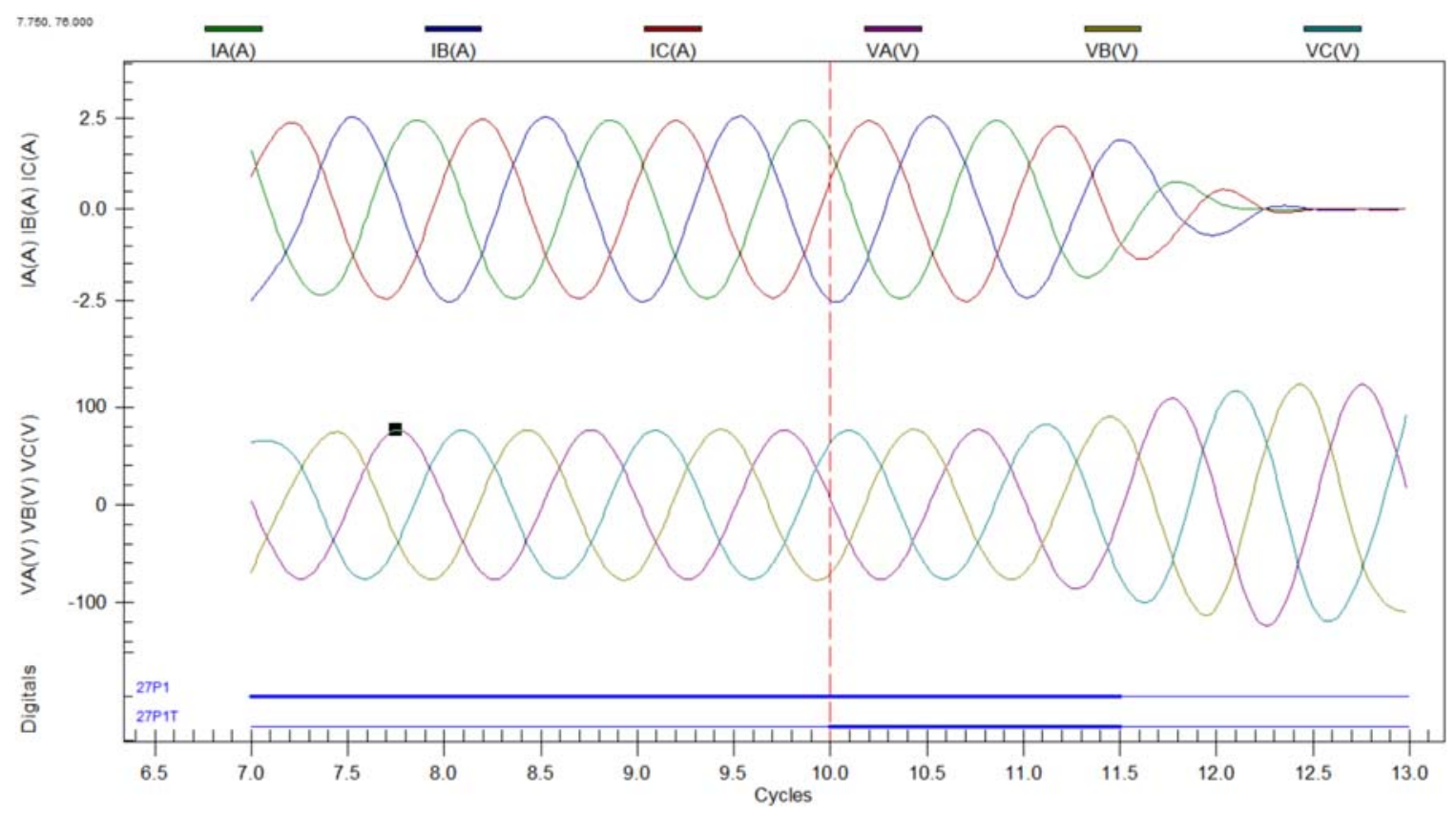

Figure 47: SEL-710, Induction Motor Low Terminal Voltage 


\subsection{Locked-Rotor Protection}

The amount of current drawn by an induction motor increases with its mechanical load. At a certain point, the power supplied to the motor fails to keep up with the motor's mechanical load demands. When this happens, the rotor stops turning and locks. An induction motor draws high levels of current during a locked rotor condition, which can damage the machine. The SEL-710 offers a setting for detecting locked-rotor protection. This setting, in amps, defines a current limit over which the induction motor's rotor locks. Figure 48 illustrates the response of the SEL-710 to a locked-rotor condition. The locked-rotor element (49) on the SEL-710 times out approximately 33 cycles after its assertion, whereupon the relay trips its circuit breaker on bus 3 to clear the fault.

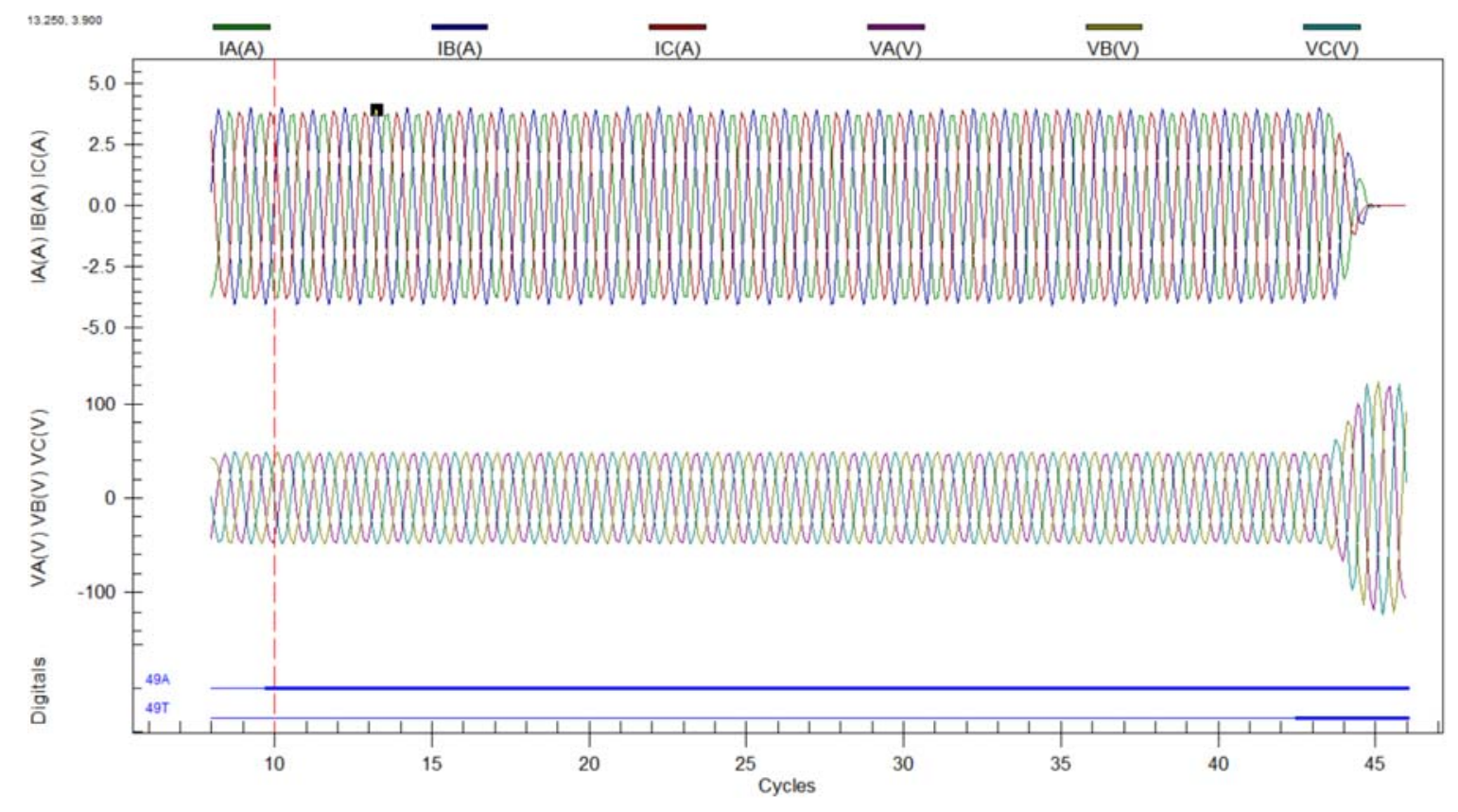

Figure 48: SEL-710, Induction Motor Locked-Rotor Condition 


\subsection{Thermal Overload Protection}

A more general form of the locked-rotor protection, the SEL-710 relay contains a setting for thermal overload protection (49). This setting specifies a minimum level of current that can cause damage to an induction motor when drawn by the machine for an extended period of time. Varying the torque load applied to the induction motor tests the thermal overload protection functionality. Figure 49 illustrates the response of the SEL710 to such a test of the thermal overload protection. The relay detects the high current levels drawn by the motor and asserts an alarm for the thermal overload element. After a short delay, the element times out, whereupon the relay trips its circuit breaker on bus 3 to clear the fault.

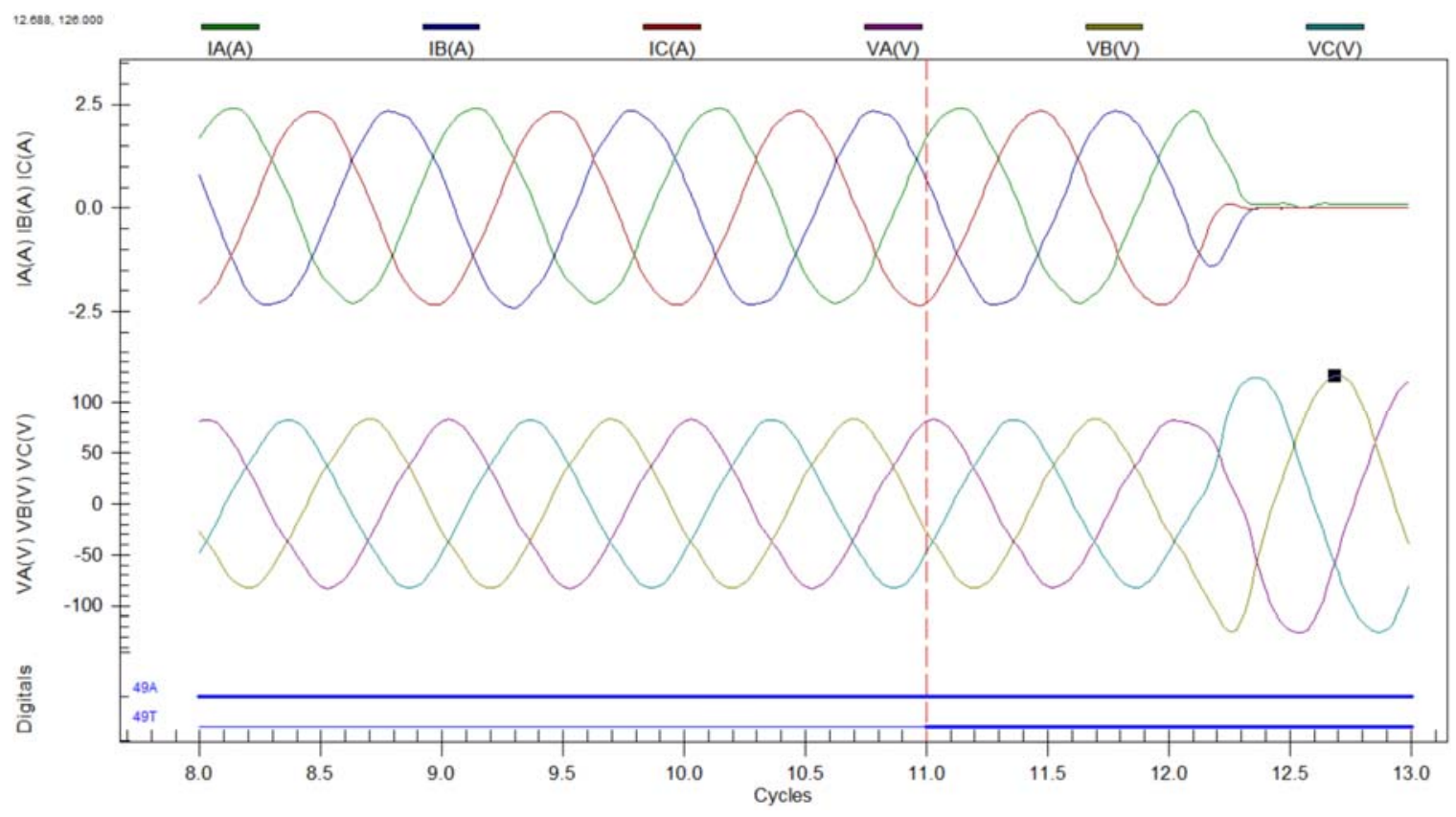

Figure 49: SEL-710, Induction Motor Thermal Overload Condition 


\section{Chapter 13: SEL-587 Overcurrent Protection}

\subsection{Single-Line-to-Ground Faults}

Figure 50 illustrates the response of the SEL-587 to a bolted single-line-to-ground fault at the induction motor (bus 3 in Figure 11). A negative-sequence current component measured in the power transformer secondary winding (described in Figure 50 by the turquoise analog quantity 3IW22) indicates the fault condition. As a result, the winding 2 negative-sequence inverse-time overcurrent element (51Q2) on the SEL-587 asserts and then times out, whereupon the relay trips its circuit breaker on bus 2 to clear the fault.

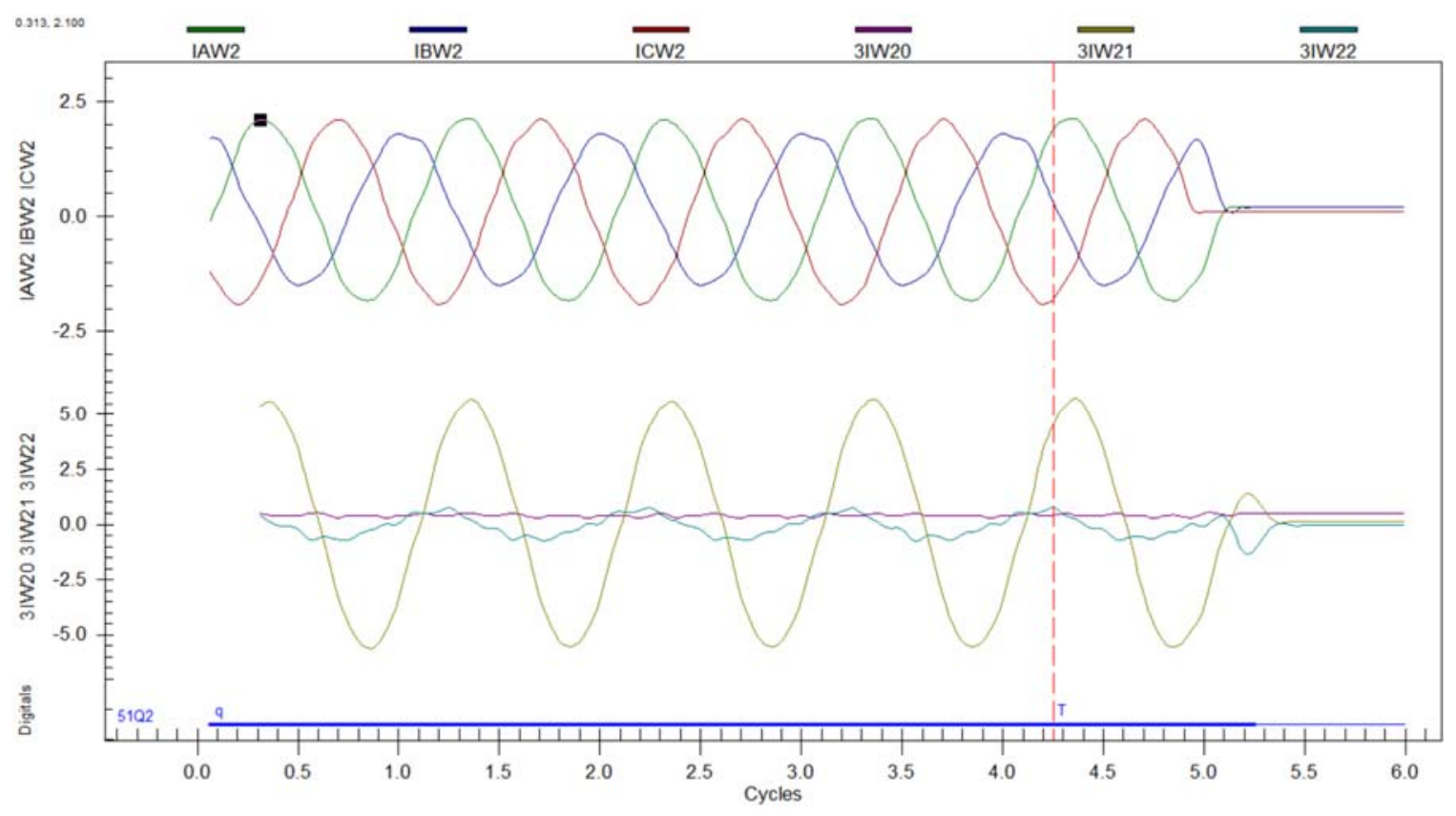

Figure 50: SEL-587 Single-Line-to-Ground Fault, Bus 3, Phase A 


\subsection{Double-Line-to-Ground Faults}

Figure 51 illustrates the response of the SEL-587 to a bolted double-line-toground fault at the induction motor (bus 3 in Figure 11). A negative-sequence current component measured in the power transformer secondary winding (described in Figure 51 by the turquoise analog quantity 3IW22) indicates the fault condition. As a result, the winding 2 negative-sequence inverse-time overcurrent element (51Q2) on the SEL-587 asserts and then times out, whereupon the relay trips its circuit breaker on bus 2 to clear the fault.

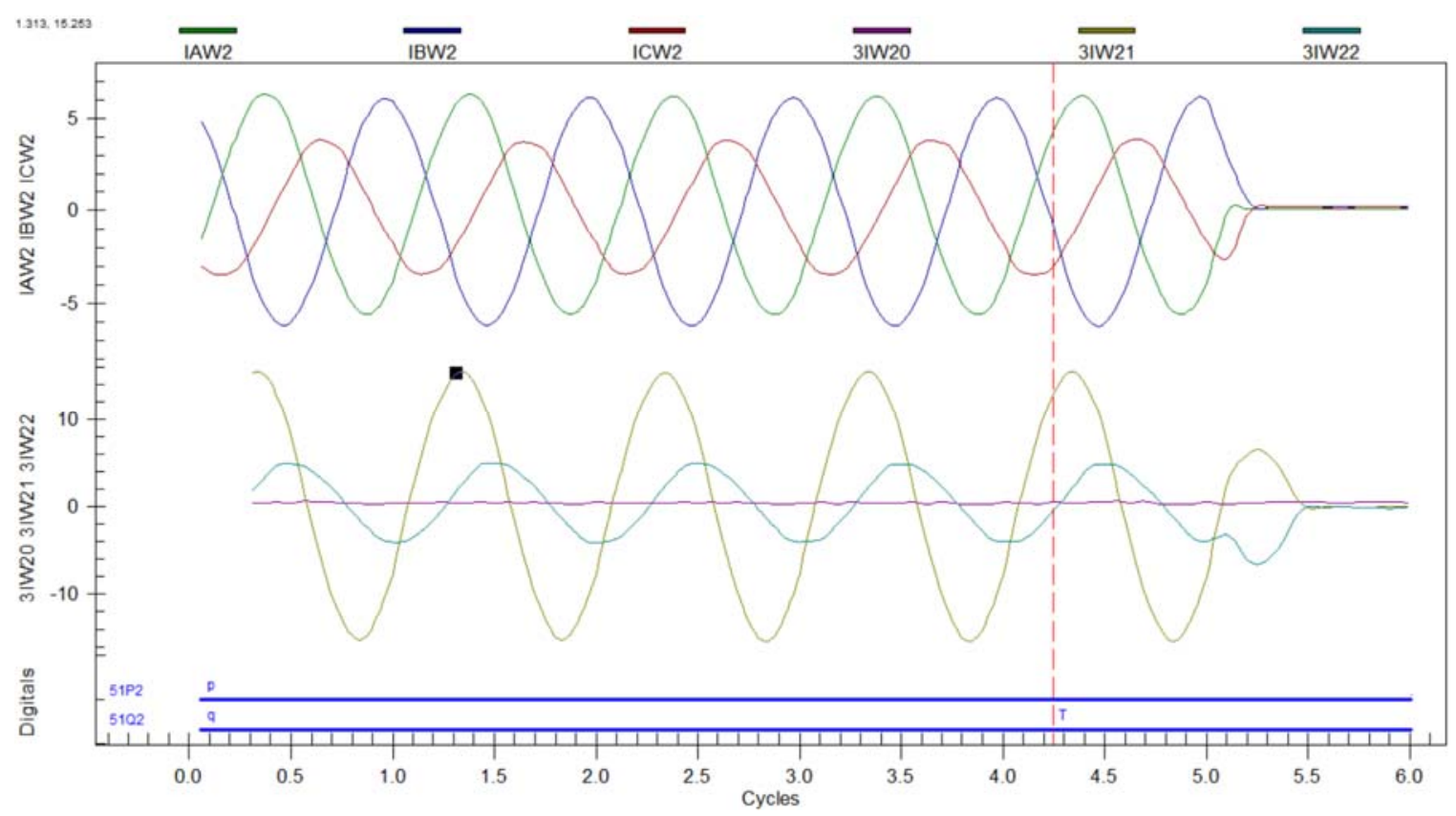

Figure 51: SEL-587 Double-Line-to-Ground Fault, Bus 3, Phases A and B 


\subsection{Triple-Line-to-Ground Faults}

Figure 52 illustrates the response of the SEL-587 to a bolted triple-line-to-ground fault at the induction motor (bus 3 in Figure 11). Note in Figure 52 that the analog signal 3IW21 describes the positive-sequence current component in the power transformer secondary winding. The large positive-sequence current components measured in the power transformer indicate a fault condition. As a result, the winding 2 inverse-time phase overcurrent element (51P2) on the SEL-587 asserts and then times out, whereupon the relay trips its circuit breaker on bus 2 to clear the fault.

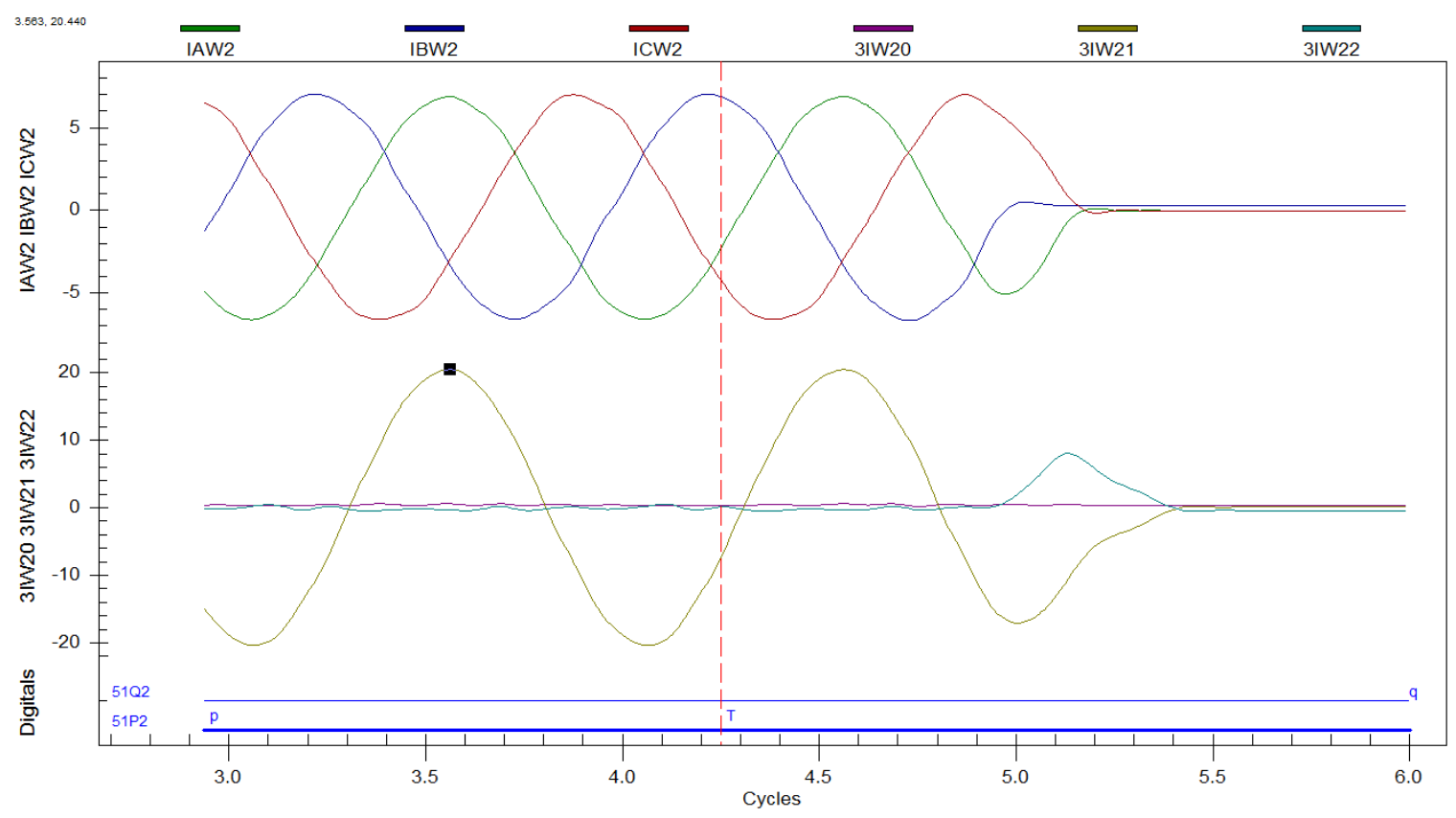

Figure 52: SEL-587 Triple-Line-to-Ground Fault, Bus 3, Phases A, B, and C 


\subsection{Three-Phase Faults}

Figure 53 illustrates the response of the SEL-587 to a bolted three-phase (ungrounded) fault at the induction motor (bus 3 in Figure 11). High currents in phases A, $\mathrm{B}$, and $\mathrm{C}$ indicate the fault condition. As a result, the winding 2 phase inverse-time overcurrent element (51P2) on the SEL-587 asserts and then times out, whereupon the relay trips its circuit breaker on bus 2 to clear the fault.

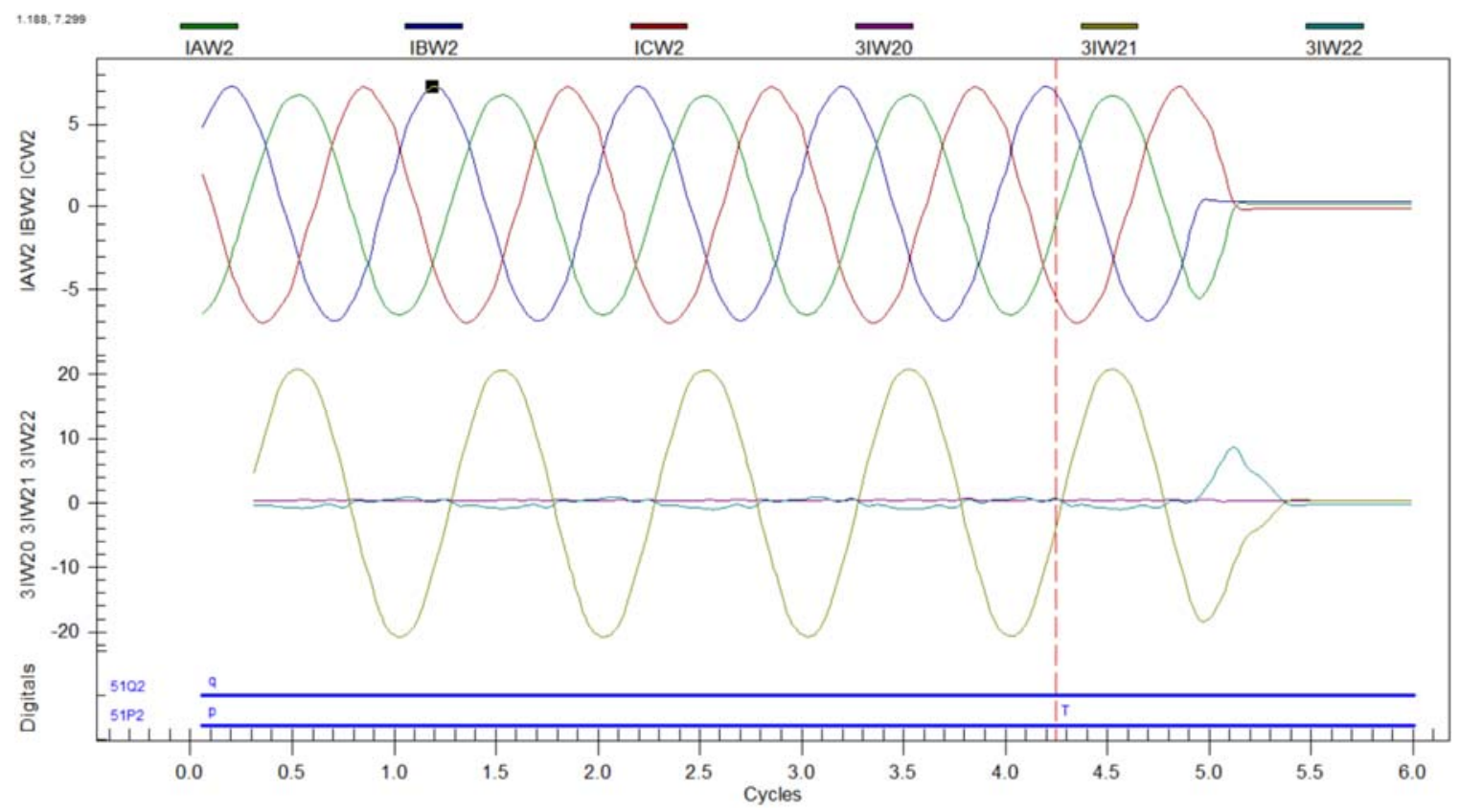

Figure 53: SEL-587 Three-Phase Fault, Bus 3, Phases A, B, and C 


\subsection{Line-to-Line Faults}

Figure 54 illustrates the response of the SEL-587 to a bolted line-to-line fault at the induction motor (bus 3 in Figure 11). A negative-sequence current component measured in the power transformer secondary winding (described in Figure 54 by the turquoise analog quantity 3IW22) indicates the fault condition. As a result, the winding 2 negative-sequence inverse-time overcurrent element (51Q2) on the SEL-587 asserts and then times out, whereupon the relay trips its circuit breaker on bus 2 to clear the fault.

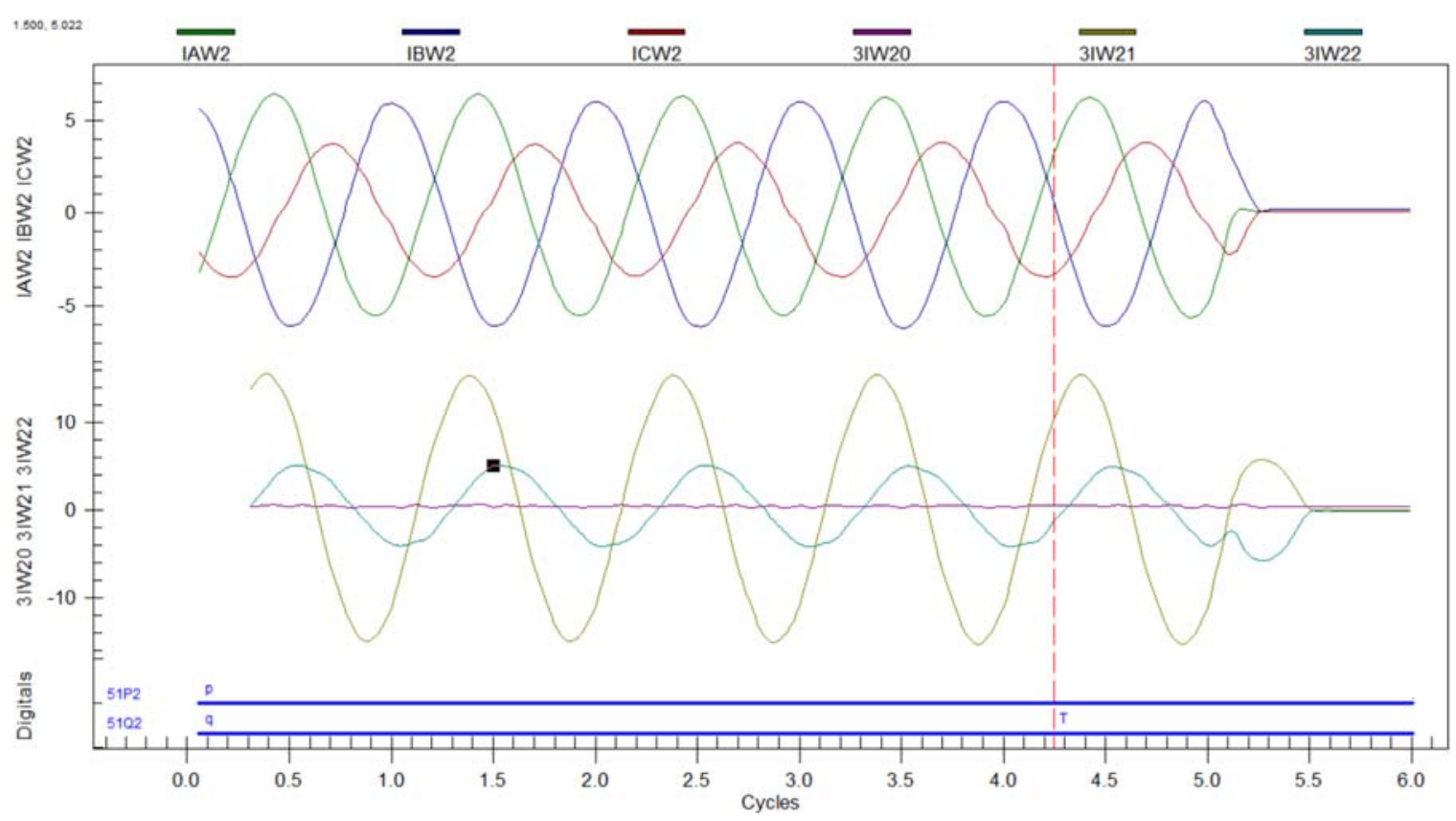

Figure 54: SEL-587 Line-to-Line Fault, Bus 3, Phases A and B 


\section{Chapter 14: SEL-587 Differential Protection}

\subsection{Single-Line-to-Ground Faults}

Figure 55 illustrates the response of the SEL-587's differential protection to a bolted single-line-to-ground fault at the delta-connected power transformer secondary winding (bus 4 in Figure 11) from the perspective of the secondary transformer winding. Current in the faulted phase A immediately increases upon fault inception due to the reduced impedance provided by a short-circuit path to ground. The restrained differential element (87R) on the SEL-587 asserts approximately 3 cycles after fault inception, whereupon the relay trips its circuit breakers on bus 4 and bus 5 to clear the fault. The induction motor continues to feed the faulted phase for several cycles after the circuit breaker clears the fault. The presence of a zero-sequence current (represented by the analog signal 3IW20) flowing through the power transformer secondary winding confirms that current flows from the motor to the fault, since zero-sequence current cannot flow through a delta-connected transformer. 


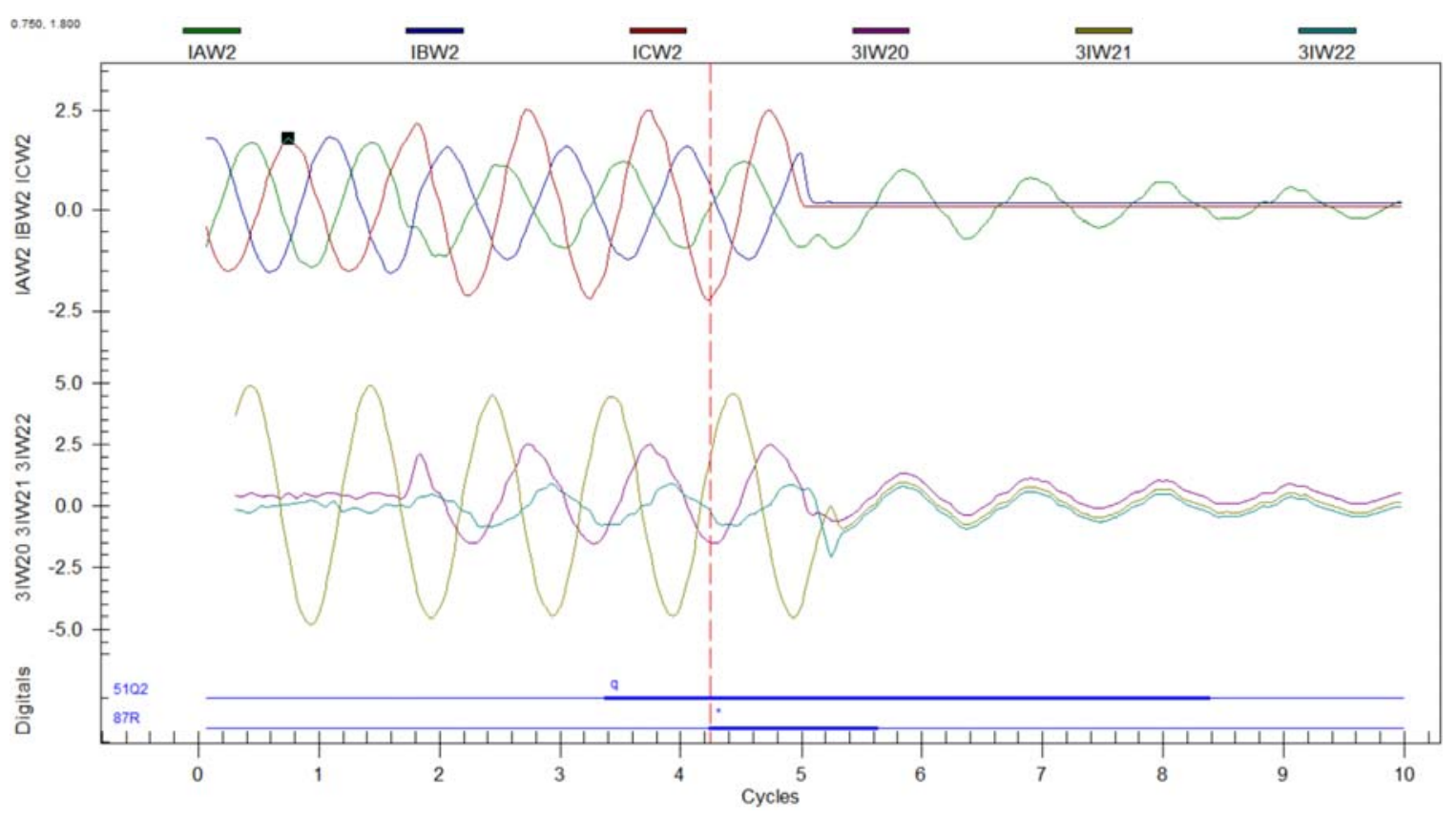

Figure 55: SEL-587 Single-Line-to-Ground Fault, Bus 4, Phase A 


\subsection{Double-Line-to-Ground Faults}

Figure 56 illustrates the response of the SEL-587's differential protection to a bolted double-line-to-ground fault at the delta-connected power transformer secondary winding (bus 4 in Figure 11) from the perspective of the secondary transformer winding. Current in the faulted phase A immediately increases upon fault inception due to the reduced impedance provided by a short-circuit path to ground. The restrained differential element (87R) on the SEL-587 asserts approximately 3 cycles after fault inception, whereupon the relay trips its circuit breakers on bus 4 and bus 5 to clear the fault. The induction motor continues to feed the faulted phases for several cycles after the circuit breaker clears the fault. The presence of a zero-sequence current (represented by the analog signal 3IW20) flowing through the power transformer secondary winding confirms that current flows from the motor to the fault, since zero-sequence current cannot flow through a delta-connected transformer. 


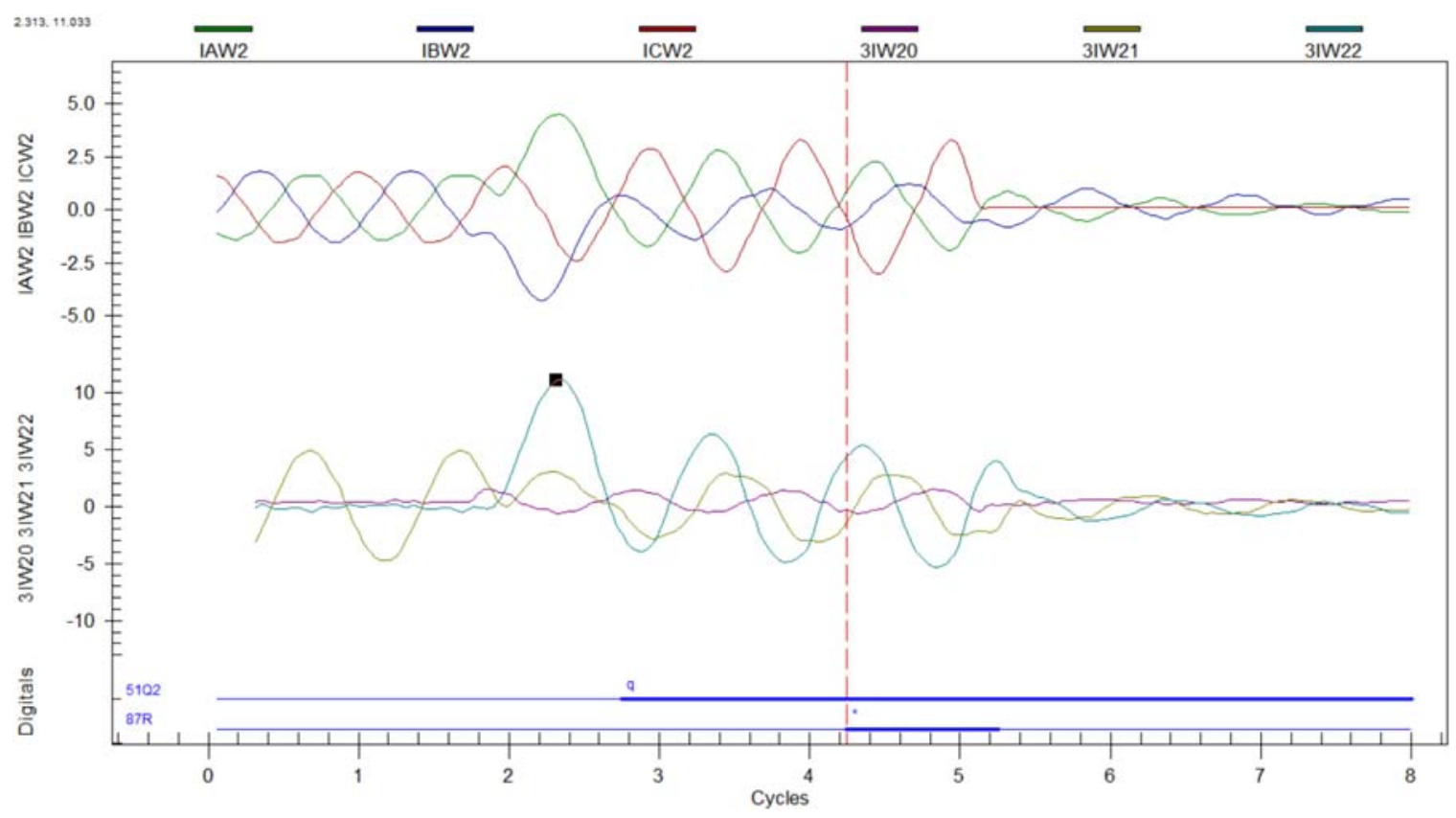

Figure 56: SEL-587 Double-Line-to-Ground Fault, Bus 4, Phases A and B 


\subsection{Triple-Line-to-Ground Faults}

Figure 57 illustrates the response of the SEL-587's differential protection to a bolted triple-line-to-ground fault at the delta-connected power transformer secondary winding (bus 4 in Figure 11) from the perspective of the secondary transformer winding. Current in the faulted phases A, B, and C immediately increases upon fault inception due to the reduced impedance provided by a short-circuit path to ground. The restrained differential element (87R) on the SEL-587 asserts approximately 3 cycles after fault inception, whereupon the relay trips its circuit breakers on bus 4 and bus 5 to clear the fault. The induction motor continues to feed the faulted phases for several cycles after the circuit breaker clears the fault.

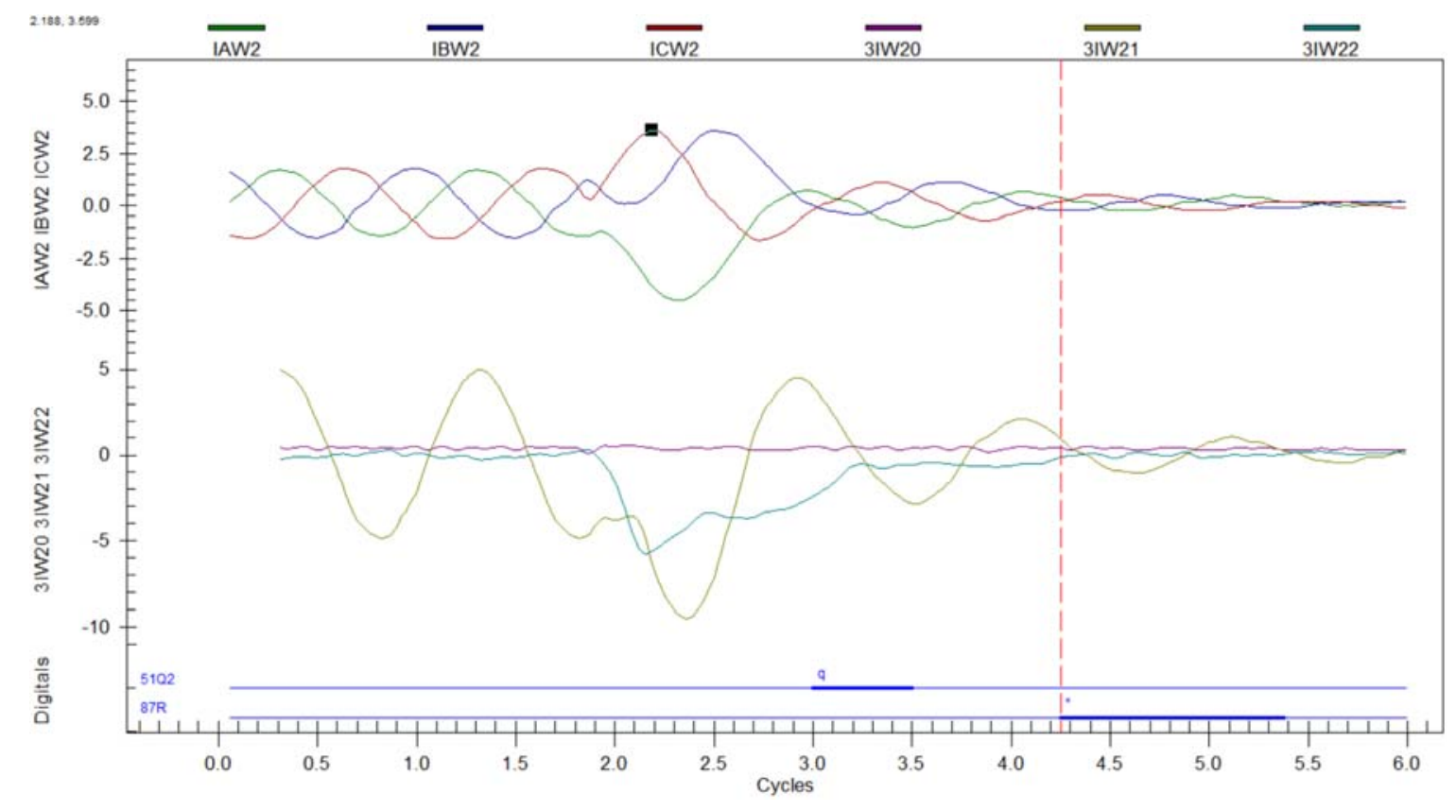

Figure 57: SEL-587 Triple-Line-to-Ground Fault, Bus 4, Phases A, B, and C 


\subsection{Three-Phase Faults}

Figure 58 illustrates the response of the SEL-587's differential protection to a bolted three-phase fault at the delta-connected power transformer primary winding (bus 5 in Figure 11) from the perspective of the primary transformer winding. Current in the faulted phases A, B, and C immediately increases upon fault inception due to the reduced impedance provided by a short-circuit path to ground. The restrained differential element (87R) on the SEL-587 asserts approximately 3 cycles after fault inception, whereupon the relay trips its circuit breakers on bus 4 and bus 5 to clear the fault. The induction motor continues to feed the faulted phases for several cycles after the circuit breaker clears the fault.

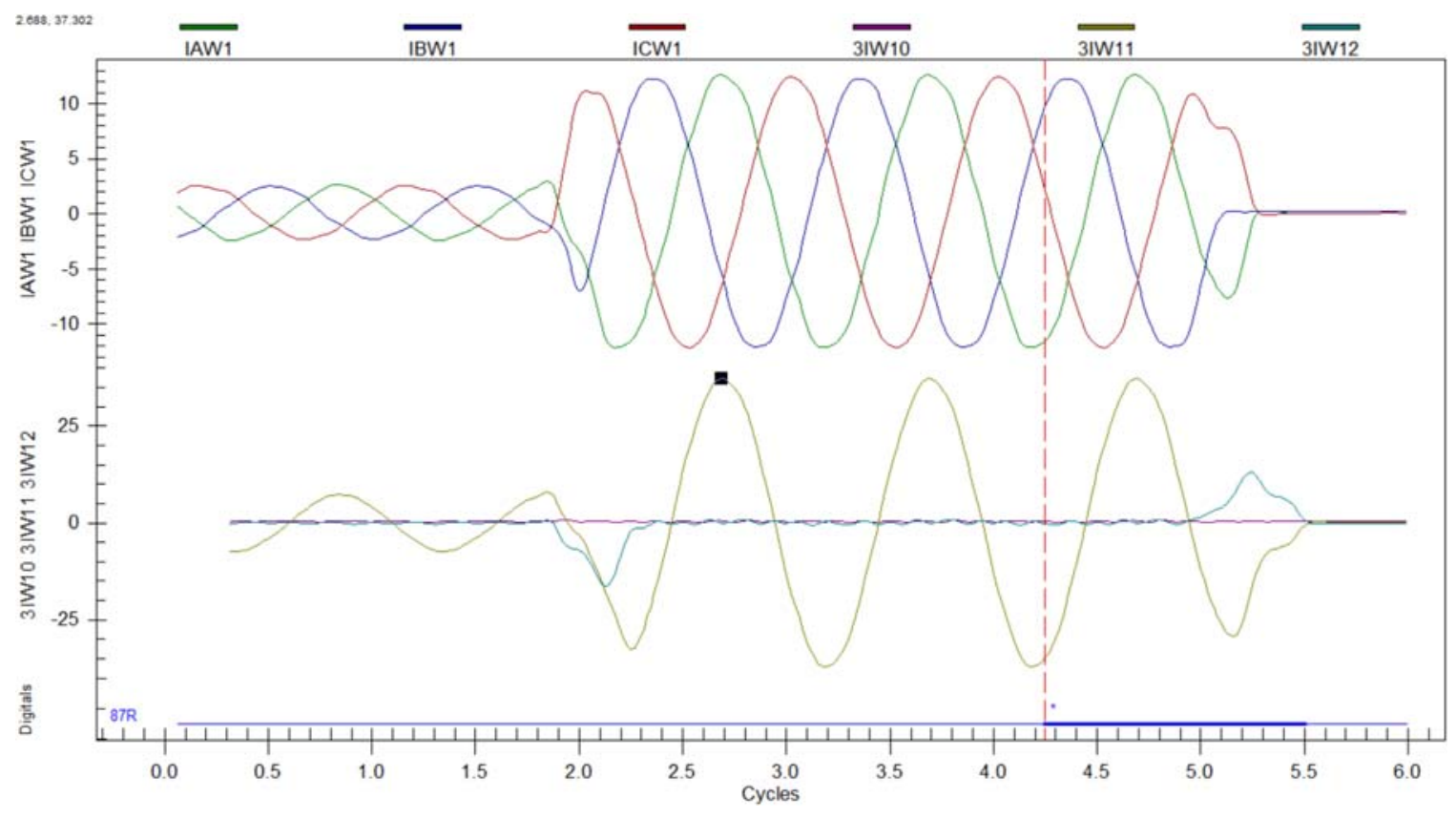

Figure 58: SEL-587 Three-Phase Fault, Bus 5, Phases A, B, and C 
Figure 59 illustrates the response of the SEL-587's differential protection to a bolted three-phase fault at the delta-connected power transformer secondary winding (bus 4 in Figure 11) from the perspective of the secondary transformer winding. Current in the faulted phases A, B, and C immediately increases upon fault inception due to the reduced impedance provided by a short-circuit path to ground. The restrained differential element (87R) on the SEL-587 asserts approximately 3 cycles after fault inception, whereupon the relay trips its circuit breakers on bus 4 and bus 5 to clear the fault. The induction motor continues to feed the faulted phases for several cycles after the circuit breaker clears the fault.

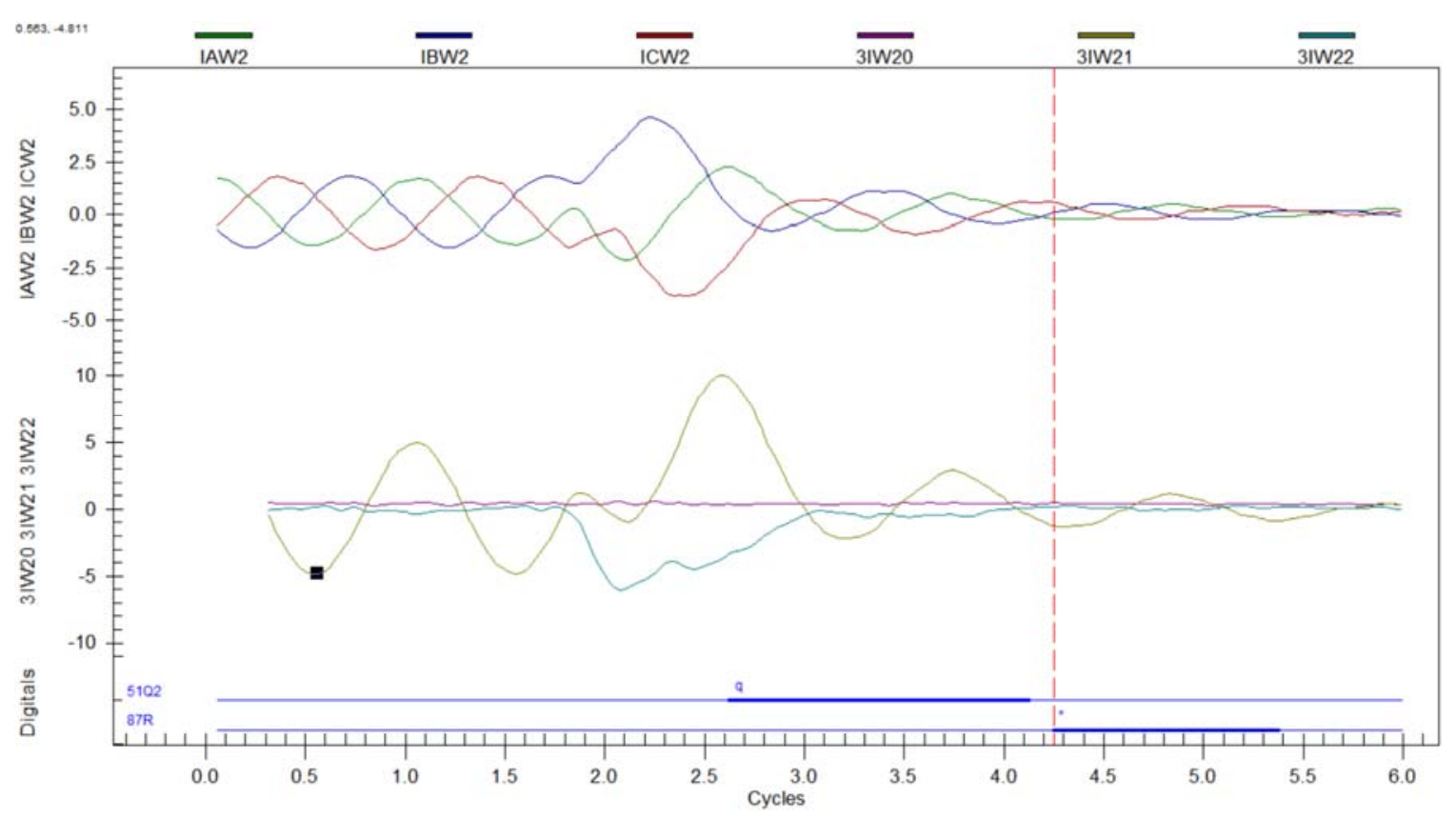

Figure 59: SEL-587 Three-Phase Fault, Bus 4, Phases A, B, and C 


\subsection{Line-to-Line Faults}

Figure 60 illustrates the response of the SEL-587's differential protection to a bolted line-to-line fault at the delta-connected power transformer primary winding (bus 5 in Figure 11) from the perspective of the primary transformer winding. Current in the faulted phases A and B immediately increases upon fault inception due to the reduced impedance provided by a short-circuit path to ground. The restrained differential element (87R) on the SEL-587 asserts approximately 3 cycles after fault inception, whereupon the relay trips its circuit breakers on bus 4 and bus 5 to clear the fault. The induction motor continues to feed the faulted phases for several cycles after the circuit breaker clears the fault.

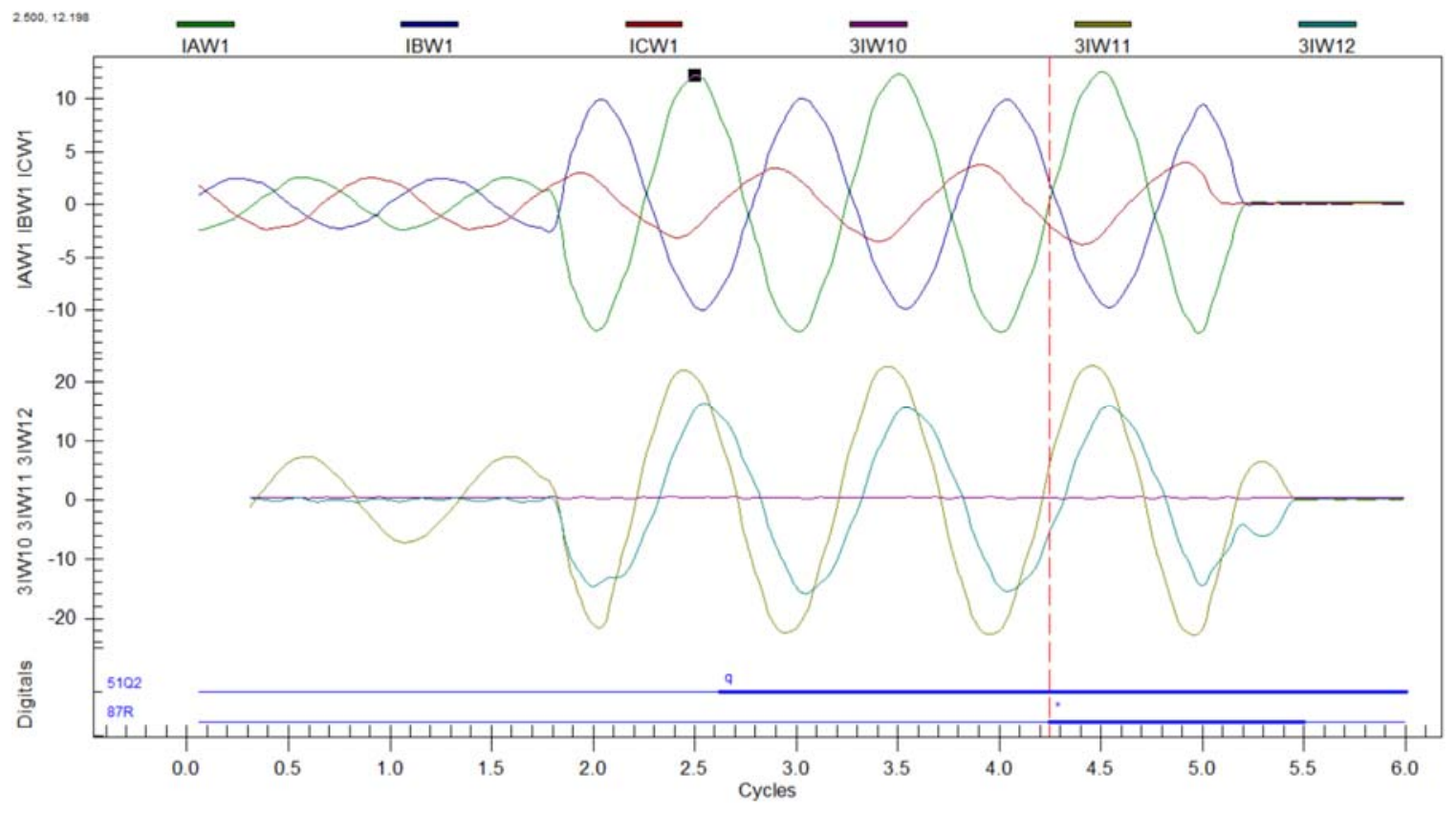

Figure 60: SEL-587 Line-to-Line Fault, Bus 5, Phases A and B 
Figure 61 illustrates the response of the SEL-587's differential protection to a bolted line-to-line fault at the delta-connected power transformer secondary winding (bus 4 in Figure 11) from the perspective of the secondary transformer winding. Current in the faulted phases A and B immediately increases upon fault inception due to the reduced impedance provided by a short-circuit path to ground. The restrained differential element (87R) on the SEL-587 asserts approximately 3 cycles after fault inception, whereupon the relay trips its circuit breakers on bus 4 and bus 5 to clear the fault. The induction motor continues to feed the faulted phases for several cycles after the circuit breaker clears the fault.

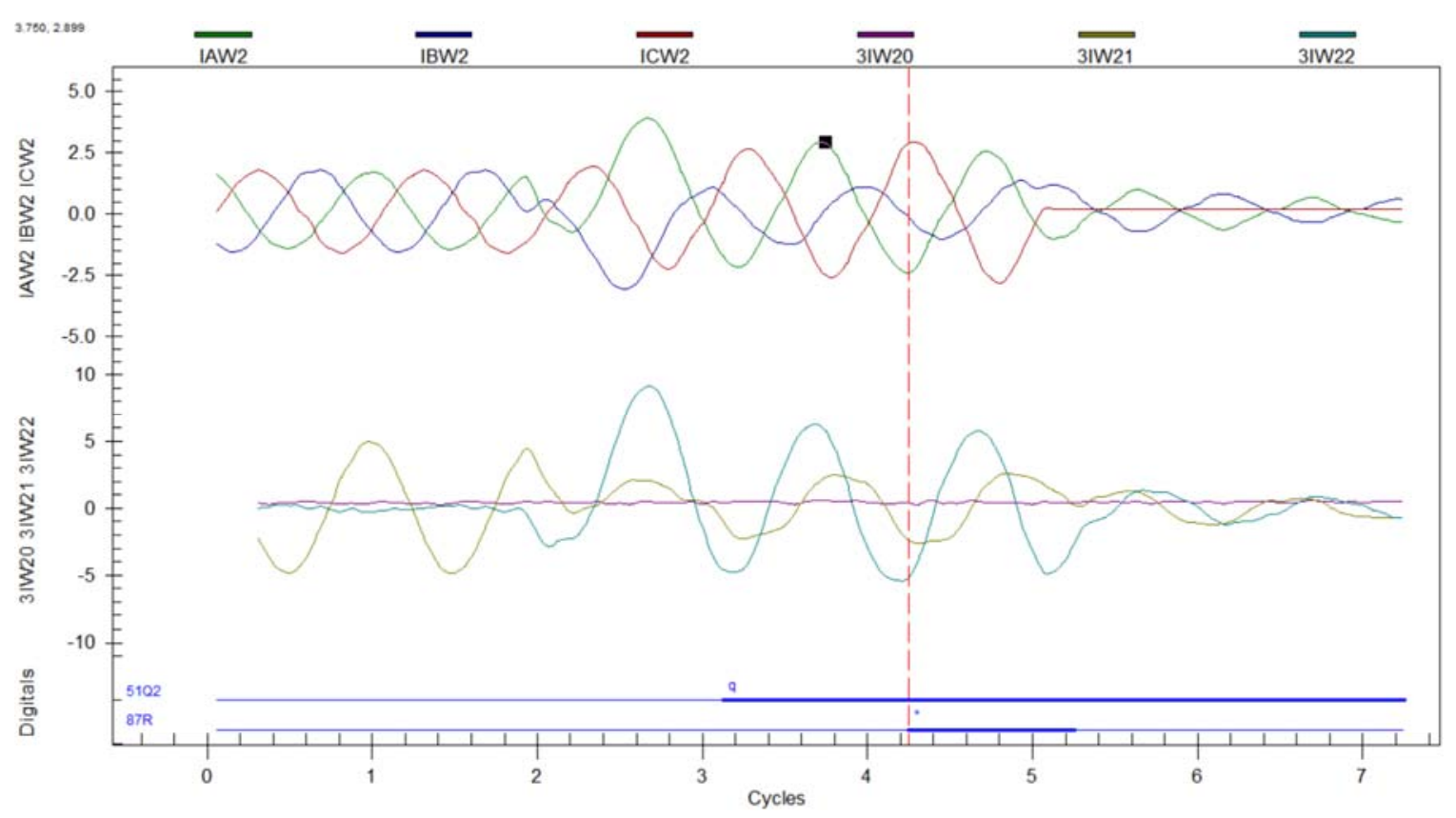

Figure 61: SEL-587 Line-to-Line Fault, Bus 4, Phases A and B 


\section{Chapter 15: Radial System Relay Coordination}

\subsection{Demonstrating Coordination in a Radial System}

The following sections demonstrate relay coordination in the radial system shown in Figure 10. Fault initiation occurred at the bus 3 circuit breaker with the induction motor running. This placement for the fault location simulates a fault at the motor terminals. At this fault location, the relays should trip in the following order, if properly coordinated: SEL-710, SEL-311L, and SEL-387E. The SEL-710 provides immediate protection to the induction motor, since the fault occurs within that relay's primary zone of protection (see Table 20). However, suppose that the SEL-710 fails to properly clear the fault. As the next closest relay to the fault location, the SEL-311L then provides delayed protection to isolate the fault. The delay in the SEL-311L's response to the fault gives the SEL-710 a chance to isolate the fault first. If neither the SEL-710 nor the SEL311L operates to clear the fault, the SEL-387E then acts to isolate the fault after an additional delay. Coordinating the relays in this way, from closest to the fault location to furthest from the fault location, ensures that only a minimum portion of the circuit goes offline when a relay operates. This concept translates directly to the work of electrical utility companies, who desire to minimize the number of customers who lose electricity as a result of a fault.

Several options exist for demonstrating coordination. In a practical, hands-on approach, appropriately shorting out relay trip coils shows how the relays sequentially operate. To implement this approach, go through the following sequence of steps. Begin by initiating a fault at bus 3 with no modifications to the circuit's protection scheme. If it responds as expected, the SEL-710 quickly detects the fault and trips its circuit breaker at 
bus 3 to isolate the induction motor (and thus the fault) from the system. None of the other relays operate. To continue the demonstration, jumper the bus 3 circuit breaker Breaker Control Trip terminals (see Figure 5) to prevent the SEL-710 from tripping its circuit breaker. Initiating a fault at bus 3 now allows the SEL-311L to operate for the fault by giving it sufficient time for its time-overcurrent or mho distance protection element to time out. The SEL-387E does not yet trip because it has a higher time dial (delay) setting programmed into its time-overcurrent characteristics than the SEL-311L does. To demonstrate the additional protection provided by the SEL-387E, simply jumper the Breaker Control Trip terminals on the circuit breaker connected downstream of bus 2 to prevent the SEL-311L from tripping its circuit breaker. Reinitiating a fault at bus 3 now allows the SEL-387E to operate for the fault, by giving it sufficient time for its timeovercurrent protection element to time out.

Although the practical approach described above provides an excellent visual verification of relay coordination in the radial circuit, it fails to provide numerical data associated with how long each relay delayed before proceeding to trip its circuit breaker. An alternate approach, used for this project, provides data detailing when each of the relays tripped. The SEL-2407 satellite-synchronized clock provides an IRIG-B timing signal directly to the communications processor, which in turn distributes the timing signal to all of the connected relays. As a result, all of the relays use a common reference when time-stamping events. Sequential event reports, generated by the relays, list the time at which each of their protection elements asserts.

To demonstrate relay coordination using the sequential event reports, use the SEL-387E to operate for a fault at bus 3 (by shorting the Breaker Control Trip terminals 
on the circuit breakers controlled by the SEL-311L and SEL-710). Doing so ensures that each of the relays has an opportunity to assert its protection element during the fault. Access this data on the computer from the sequential event reports generated for the fault by each of the relays. The combined data from all of the relays demonstrates a properlycoordinated radial system. The following sections contain the data for this demonstration, showing the time each relevant element (the first from each relay to clear a fault) asserts relative to the first element that recognized the fault. 


\subsection{Single-Line-to-Ground Faults}

Table 22 and Table 23 show the response of the radial system protection scheme to a single-line-to-ground fault at the terminals of the induction motor (bus 3 in Figure 10). The SEL-311L and SEL-387E detect the fault with their negative-sequence inversetime overcurrent elements. The SEL-710 then detects the fault through its definite-time residual overcurrent element. After a delay, the SEL-710 trips as its overcurrent element times out. This programmed delay allows the instantaneous phase overcurrent element (50P) to operate first. However, the relatively-high phase overcurrent pickup setting does not catch single-line-to-ground faults due to the small amounts of current that they draw. Following the delay required for the SEL-710 to react to the fault, the overcurrent element on the SEL-311L times out and trips the relay. Lastly, the overcurrent element on the SEL-387E times out and trips the relay. The relays thus trip in the proper order to demonstrate coordination for a single-line-to-ground fault at the induction motor.

Table 22: Radial System Detection of a Single-Line-to-Ground Fault at Bus 3

\begin{tabular}{|c|c|c|c|}
\hline $\begin{array}{c}\text { TIME } \\
\text { DELTA } \\
\text { (mSEC) }\end{array}$ & $\begin{array}{c}\text { SEL RELAY } \\
\text { DEVICE }\end{array}$ & $\begin{array}{c}\text { ASSERTED } \\
\text { ELEMENTS }\end{array}$ & COMMENT \\
\hline 0 & $311 \mathrm{~L}$ & $51 \mathrm{Q}$ & Fault Detected \\
\hline 10 & $387 \mathrm{E}$ & $51 \mathrm{Q} 2$ & Fault Detected \\
\hline 11 & 710 & $50 \mathrm{G} 1 \mathrm{P}$ & Fault Detected \\
\hline
\end{tabular}

Table 23: Radial System Tripping for a Single-Line-to-Ground Fault at Bus 3

\begin{tabular}{|c|c|c|c|}
\hline $\begin{array}{c}\text { TIME } \\
\text { DELTA } \\
\text { (mSEC) }\end{array}$ & $\begin{array}{c}\text { SEL RELAY } \\
\text { DEVICE }\end{array}$ & $\begin{array}{c}\text { ASSERTED } \\
\text { ELEMENTS }\end{array}$ & COMMENT \\
\hline 115 & 710 & 50 G1T, TRIP & Timeout and Trip \\
\hline 230 & $311 \mathrm{~L}$ & $51 \mathrm{Q}$, TRIP & Timeout and Trip \\
\hline 622 & $387 \mathrm{E}$ & $51 \mathrm{Q} 2 \mathrm{~T}$, TRIP & Timeout and Trip \\
\hline
\end{tabular}




\subsection{Double-Line-to-Ground Faults}

Table 24 and Table 25 show the response of the radial system protection scheme to a double-line-to-ground fault at the terminals of the induction motor (bus 3 in Figure 10). The SEL-311L and SEL-387E detect the fault with their negative-sequence inversetime overcurrent elements. The SEL-710 detects the fault with its instantaneous phase overcurrent element and immediately trips. Next, the overcurrent element on the SEL311L times out and trips the relay. Lastly, the overcurrent element on the SEL-387E times out and trips the relay. The relays thus trip in the proper order to demonstrate coordination for a double-line-to-ground fault at the induction motor.

Table 24: Radial System Detection of a Double-Line-to-Ground Fault at Bus 3

\begin{tabular}{|c|c|c|c|}
\hline $\begin{array}{c}\text { TIME } \\
\text { DELTA } \\
\text { (mSEC) }\end{array}$ & $\begin{array}{c}\text { SEL RELAY } \\
\text { DEVICE }\end{array}$ & $\begin{array}{c}\text { ASSERTED } \\
\text { ELEMENTS }\end{array}$ & COMMENT \\
\hline 0 & $311 \mathrm{~L}$ & $51 \mathrm{Q}$ & Fault Detected \\
\hline 6 & $387 \mathrm{E}$ & $51 \mathrm{Q} 2$ & Fault Detected \\
\hline 22 & 710 & $50 \mathrm{P} 1 \mathrm{P}$ & Fault Detected \\
\hline
\end{tabular}

Table 25: Radial System Tripping for a Double-Line-to-Ground Fault at Bus 3

\begin{tabular}{|c|c|c|c|}
\hline $\begin{array}{c}\text { TIME } \\
\text { DELTA } \\
\text { (mSEC) }\end{array}$ & $\begin{array}{c}\text { SEL RELAY } \\
\text { DEVICE }\end{array}$ & $\begin{array}{c}\text { ASSERTED } \\
\text { ELEMENTS }\end{array}$ & COMMENT \\
\hline 22 & 710 & TRIP & Instantaneous Trip \\
\hline 87 & $311 \mathrm{~L}$ & 51QT, TRIP & Timeout and Trip \\
\hline 139 & $387 \mathrm{E}$ & 51Q2T, TRIP & Timeout and Trip \\
\hline
\end{tabular}




\subsection{Triple-Line-to-Ground Faults}

Table 26 and Table 27 show the response of the radial system protection scheme to a triple-line-to-ground fault at the terminals of the induction motor (bus 3 in Figure 10). The SEL-311L detects the fault with its mho distance element but delays before tripping. The SEL-710 detects the fault with its instantaneous phase overcurrent element and immediately trips. Soon after, the SEL-387E detects the fault with its inverse-time phase overcurrent element. Next, the distance element on the SEL-311L times out and trips the relay. Lastly, the overcurrent element on the SEL-387E times out and trips the relay. The relays thus trip in the proper order to demonstrate coordination for a tripleline-to-ground fault at the induction motor.

Table 26: Radial System Detection of a Triple-Line-to-Ground Fault at Bus 3

\begin{tabular}{|c|c|c|c|}
\hline $\begin{array}{c}\text { TIME } \\
\text { DELTA } \\
\text { (mSEC) }\end{array}$ & $\begin{array}{c}\text { SEL RELAY } \\
\text { DEVICE }\end{array}$ & $\begin{array}{c}\text { ASSERTED } \\
\text { ELEMENTS }\end{array}$ & COMMENT \\
\hline 0 & $311 \mathrm{~L}$ & M2P & Fault Detected \\
\hline 6 & 710 & $50 \mathrm{P} 1 \mathrm{P}$ & Fault Detected \\
\hline 11 & $387 \mathrm{E}$ & $51 \mathrm{P} 2$ & Fault Detected \\
\hline
\end{tabular}

Table 27: Radial System Tripping for a Triple-Line-to-Ground Fault at Bus 3

\begin{tabular}{|c|c|c|c|}
\hline $\begin{array}{c}\text { TIME } \\
\text { DELTA } \\
\text { (mSEC) }\end{array}$ & $\begin{array}{c}\text { SEL RELAY } \\
\text { DEVICE }\end{array}$ & $\begin{array}{c}\text { ASSERTED } \\
\text { ELEMENTS }\end{array}$ & COMMENT \\
\hline 6 & 710 & TRIP & Instantaneous Trip \\
\hline 417 & $311 \mathrm{~L}$ & M2PT, TRIP & Timeout and Trip \\
\hline 707 & $387 \mathrm{E}$ & 51P2T, TRIP & Timeout and Trip \\
\hline
\end{tabular}




\subsection{Three-Phase Faults}

Table 28 and Table 29 show the response of the radial system protection scheme to a three-phase fault at the terminals of the induction motor (bus 3 in Figure 10). The SEL-311L detects the fault with its mho phase distance element but delays before tripping. The SEL-710 detects the fault with its instantaneous phase overcurrent element and immediately trips. Soon after, the SEL-387E detects the fault with its inverse-time phase overcurrent element. Next, the mho phase distance element on the SEL-311L times out and trips the relay. Lastly, the overcurrent element on the SEL-387E times out and trips the relay. The relays thus trip in the proper order to demonstrate coordination for a three-phase fault at the induction motor.

Table 28: Radial System Detection of a Three-Phase Fault at Bus 3

\begin{tabular}{|c|c|c|c|}
\hline $\begin{array}{c}\text { TIME } \\
\text { DELTA } \\
\text { (mSEC) }\end{array}$ & $\begin{array}{c}\text { SEL RELAY } \\
\text { DEVICE }\end{array}$ & $\begin{array}{c}\text { ASSERTED } \\
\text { ELEMENTS }\end{array}$ & COMMENT \\
\hline 0 & SEL 311L & M2P & Fault Detected \\
\hline 6 & SEL 710 & $50 \mathrm{P} 1 \mathrm{P}$ & Fault Detected \\
\hline 11 & SEL 387E & $51 \mathrm{P} 2$ & Fault Detected \\
\hline
\end{tabular}

Table 29: Radial System Tripping for a Three-Phase Fault at Bus 3

\begin{tabular}{|c|c|c|c|}
\hline $\begin{array}{c}\text { TIME } \\
\text { DELTA } \\
\text { (mSEC) }\end{array}$ & $\begin{array}{c}\text { SEL RELAY } \\
\text { DEVICE }\end{array}$ & $\begin{array}{c}\text { ASSERTED } \\
\text { ELEMENTS }\end{array}$ & COMMENT \\
\hline 6 & SEL 710 & TRIP & Instantaneous Trip \\
\hline 416 & SEL 311L & M2PT, TRIP & Timeout and Trip \\
\hline 706 & SEL 387E & 51P2T, TRIP & Timeout and Trip \\
\hline
\end{tabular}




\subsection{Line-to-Line Faults}

Table 30 and Table 31 show the response of the radial system protection scheme to a line-to-line fault at the terminals of the induction motor (bus 3 in Figure 10). The SEL-311L detects the fault with its negative-sequence inverse-time overcurrent element but delays before tripping. The SEL-710 detects the fault with its instantaneous phase overcurrent element and immediately trips. At the same time, the SEL-387E detects the fault with its negative-sequence inverse-time overcurrent element but delays before tripping. Next, the overcurrent element on the SEL-311L times out and trips the relay. Lastly, the overcurrent element on the SEL-387E times out and trips the relay. The relays thus trip in the proper order to demonstrate coordination for a line-to-line fault at the induction motor.

Table 30: Radial System Detection of a Line-to-Line Fault at Bus 3

\begin{tabular}{|c|c|c|c|}
\hline $\begin{array}{c}\text { TIME } \\
\text { DELTA } \\
\text { (mSEC) }\end{array}$ & $\begin{array}{c}\text { SEL RELAY } \\
\text { DEVICE }\end{array}$ & $\begin{array}{c}\text { ASSERTED } \\
\text { ELEMENTS }\end{array}$ & COMMENT \\
\hline 0 & SEL 311L & $51 \mathrm{Q}$ & Fault Detected \\
\hline 32 & SEL 710 & $50 \mathrm{P} 1 \mathrm{P}$ & Fault Detected \\
\hline 32 & SEL 387E & $51 \mathrm{Q} 2$ & Fault Detected \\
\hline
\end{tabular}

Table 31: Radial System Tripping for a Line-to-Line Fault at Bus 3

\begin{tabular}{|c|c|c|c|}
\hline $\begin{array}{c}\text { TIME } \\
\text { DELTA } \\
\text { (mSEC) }\end{array}$ & $\begin{array}{c}\text { SEL RELAY } \\
\text { DEVICE }\end{array}$ & $\begin{array}{c}\text { ASSERTED } \\
\text { ELEMENTS }\end{array}$ & COMMENT \\
\hline 32 & SEL 710 & TRIP & Instantaneous Trip \\
\hline 87 & SEL 311L & 51QT, TRIP & Timeout and Trip \\
\hline 157 & SEL 387E & 51Q2T, TRIP & Timeout and Trip \\
\hline
\end{tabular}




\section{Chapter 16: Introduction to the Bidirectional System (Phase II)}

\subsection{Bidirectional System Design}

Chapters 17 and 18 illustrate coordinated relay performance in a bidirectional power system. Figure 62 presents the single-line diagram for this bidirectional system, superimposing connections to the protective relays onto the system topology presented in Figure 3. Notice that the bidirectional system is a combination of the two radial topologies, where the original radial topologies overlap at bus 3. Figure 63 and Figure 64 show the realization of the bidirectional system in a laboratory environment. Figure 63 contains all of the elements of a complete radial system, while Figure 64 contains all of the elements except for the induction motor and static load. The two sub-systems exist on opposite sides of a lab bench and connect at the shared load bus (bus 3 in Figure 3 and Figure 62).

The relays from the radial systems described in Chapters 7 through 14 work together in this bidirectional system to isolate faults. Chapter 17 describes the transmission line protection provided by two SEL-311L units that share a special fiber optic communication link. Chapter 18 describes the coordination of all of the relays in the bidirectional system, such that a minimum portion of the circuit loses power when the relays isolate a fault. 


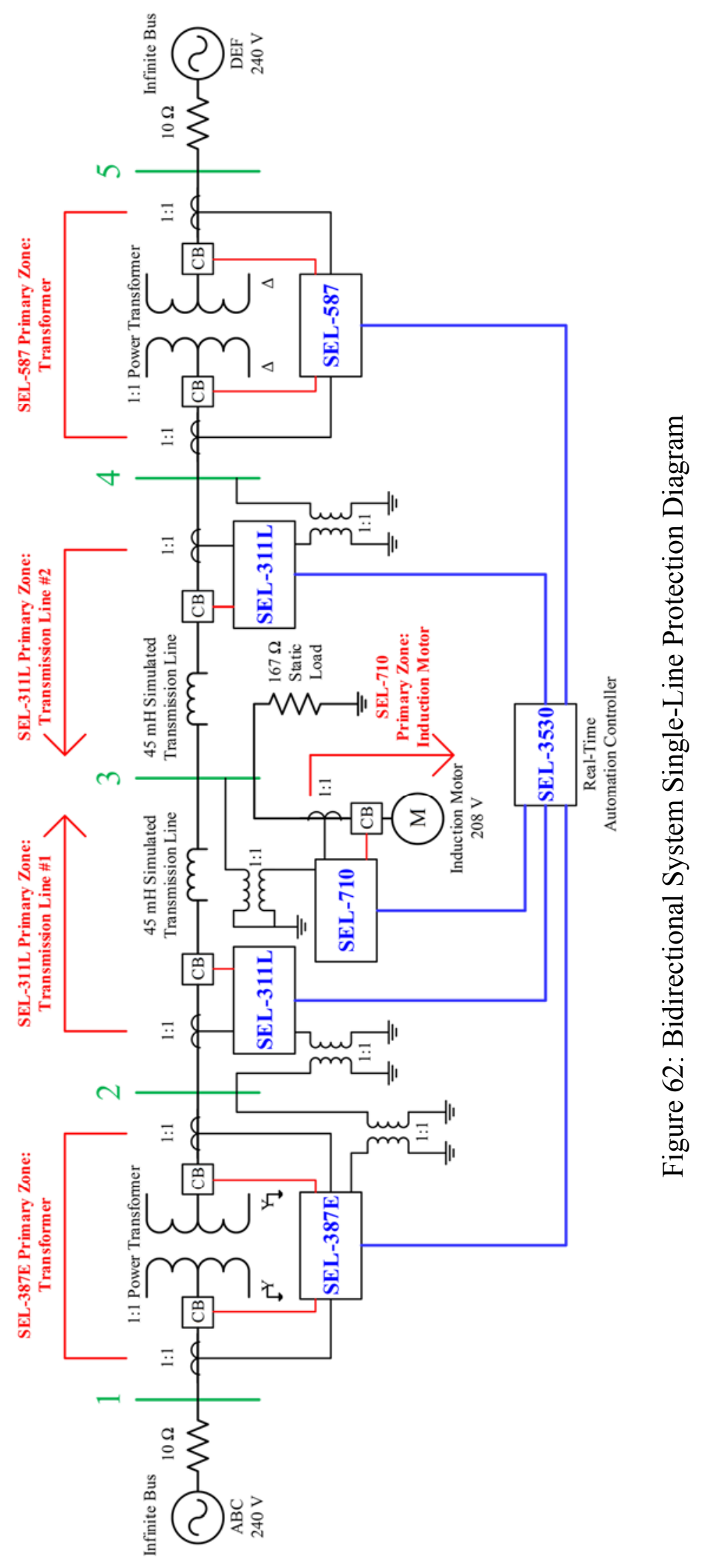




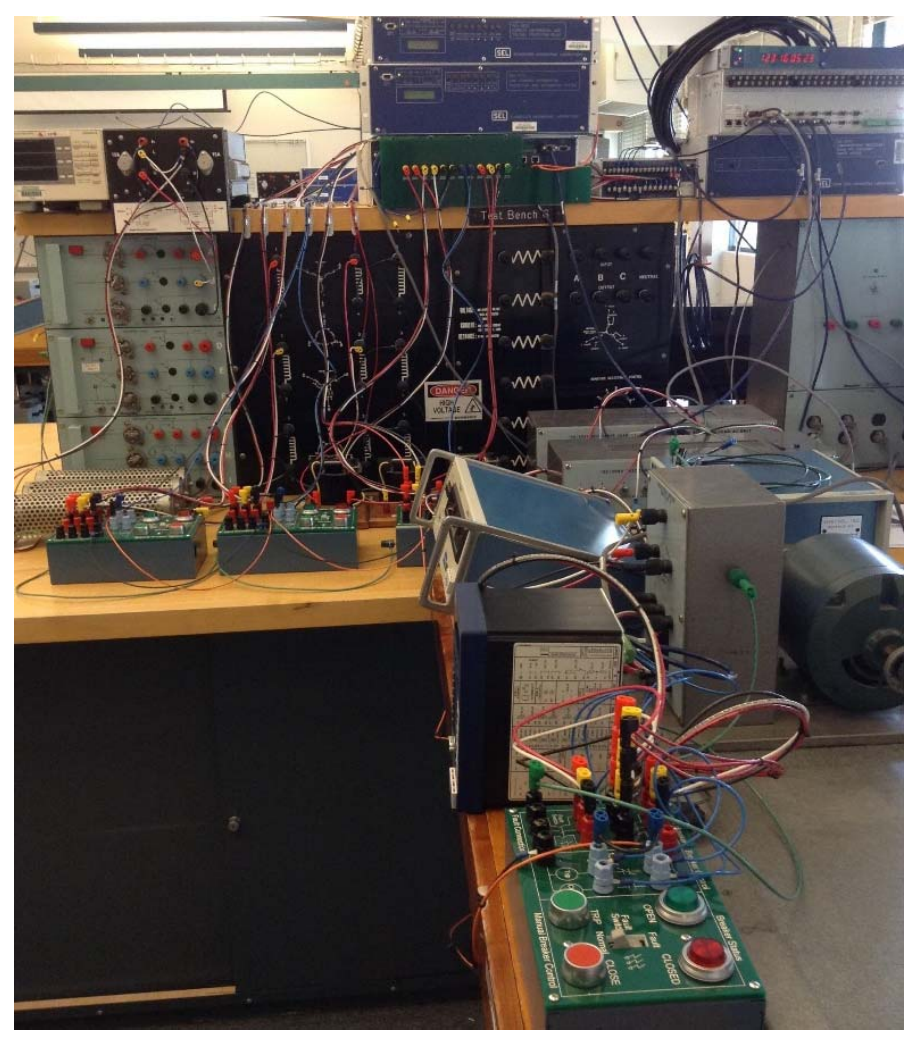

Figure 63: Wye-Connected Portion of Bidirectional System

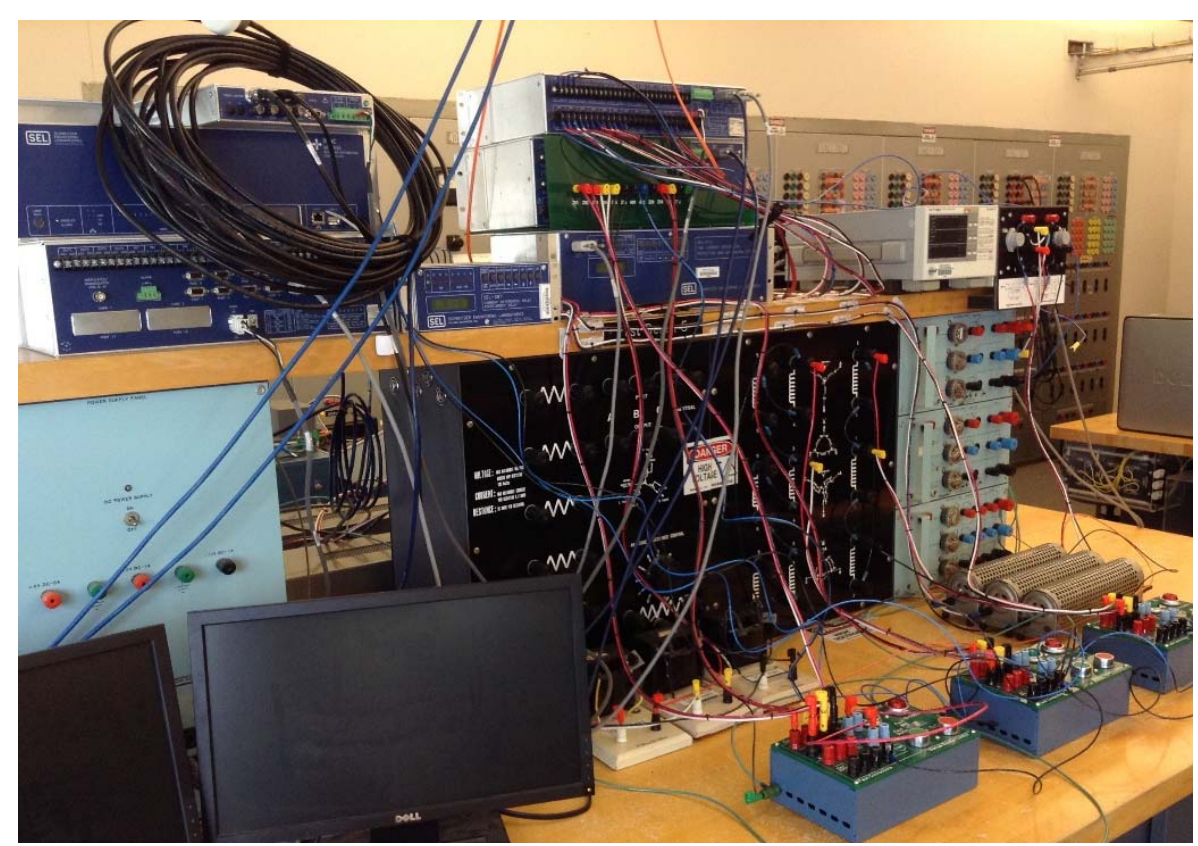

Figure 64: Delta-Connected Portion of Bidirectional System 


\subsection{Bidirectional System Operation}

As with the radial systems, inrush current remains an issue of key concern when energizing the bidirectional system. To maximize the speed with which the system clears faults, the SEL-311L settings documented in Appendices C and D list delay times that only marginally avoid tripping for inrush current. Minimizing the time that the SEL-311L relays delay before tripping improves fault clearing times, but makes the system more susceptible to tripping for inrush current.

Opening the circuit breaker to the induction motor before applying power to the system reduces the initial inrush current drawn through the transformer and transmission line inductors. To minimize the likelihood of tripping the SEL-311L relays on inrush current during system energization, apply power to both ends of the bidirectional system before closing the induction motor's circuit breaker to start the machine. If the SEL-311L units still trip for inrush current, jumpering the trip coils on those relays' circuit breakers allows the induction motor to start without tripping the circuit offline. The jumper wires effectively disable the relays' control of their circuit breakers. Despite the inability to trip their circuit breakers, jumpering the trip coils on the SEL-311L units for system energization does not significantly reduce the protection against faults during startup because the overcurrent elements on the SEL-387E and SEL-587 provide backup protection for the SEL-311L relays (see Table 21 in Chapter 6). 


\section{Chapter 17: SEL-311L Pilot Protection}

\subsection{Pilot Protection Overview}

The SEL-311L relays used in the bidirectional system offer permissive overreaching transfer trip (POTT) elements to expedite isolating faults in a transmission line. Figure 65 presents an example POTT scheme employed by two SEL-311L relays on a single, continuous transmission line. Two distance relays (ANSI designation 21) represent the SEL-311L units. See section 8.1 for a review of mho phase distance relays. The first relay, shown in blue and located at bus 1 in this example, looks for faults along the transmission line towards bus 2 . In contrast, the second relay, shown in green and located at bus 2, looks for faults along the transmission line towards bus 1. Zones 1, 2 and 3 for each relay represent the various regions associated with each relay's distance protection elements.

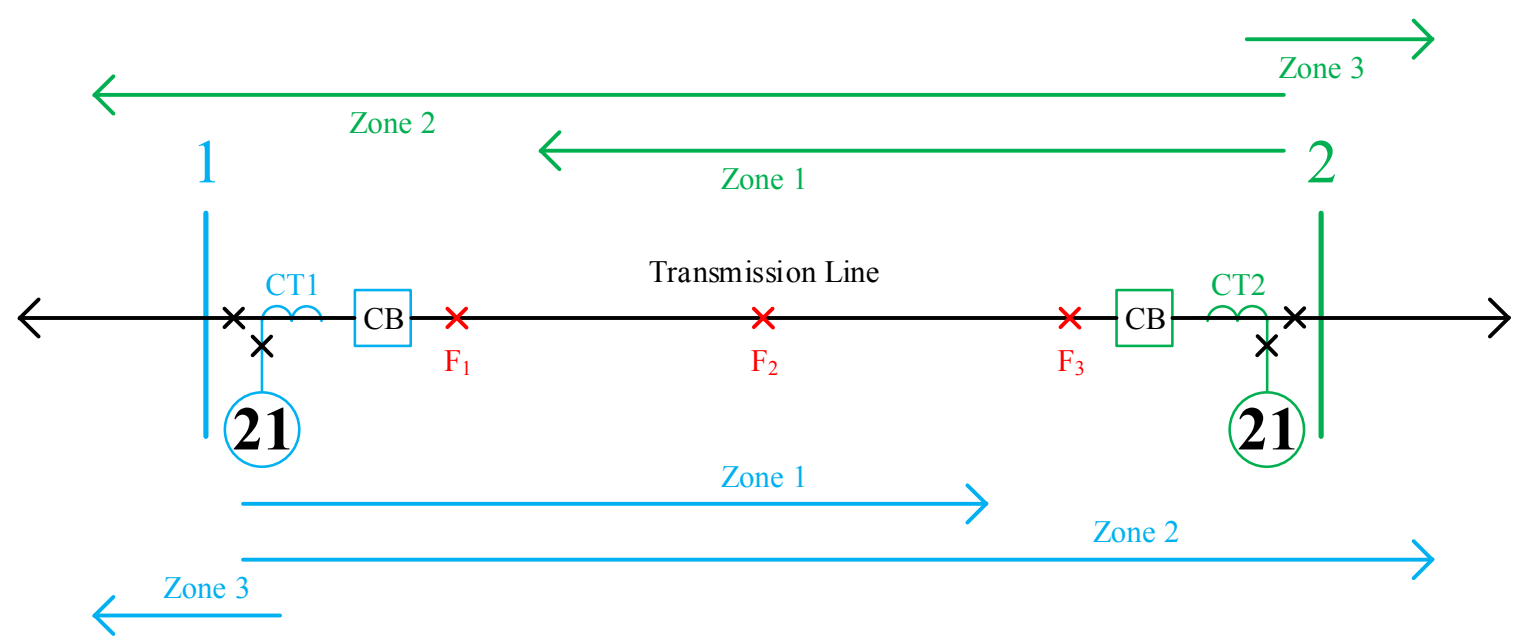

Figure 65: Permissive Overreaching Transfer Trip (POTT) Scheme Example

Suppose that each distance relay shown in Figure 65 operates instantaneously for faults in its zone 1 region, but delays before operating for faults in its zone 2 region. The 
first relay (shown in blue) trips instantaneously for faults located at F1 and F2 but delays before tripping for a fault at F3. Conversely, the second relay (shown in green) trips instantaneously for faults F2 and F3 but delays before tripping for a fault at F1. If the two relays have a communications link, a POTT scheme allows both relays to trip for faults with a reduced delay time.

Now suppose that a fault occurs at F1 in Figure 65. Although the first (blue) relay operates immediately for this fault, the second (green) relay delays. In a POTT scheme, one relay sends another a permissive trip signal if it sees a fault in one of its forward zones of protection. Since F1 lies in the forward direction for both relays in Figure 65, both relays send each other a permissive trip signal. Taken together, these signals indicate that the fault lies between the two relays. The permissive trip signal overrides the zone 2 delay of the second (green) relay, allowing it to trip as soon as it receives the permissive signal from the first (blue) relay. In this way, a POTT scheme allows distance relays to trip faster for faults outside of their zone 1 region. 


\subsection{Double-Line-to-Ground Faults}

Table 32 describes the POTT response of the line 1 (between bus 2 and bus 3 in Figure 62) and line 2 (between bus 3 and bus 4 in Figure 62) SEL-311L relays to a bolted double-line-to-ground fault at the induction motor (bus 3 in Figure 62). The relays detect the fault, exchange signals acknowledging the fault, and trip to isolate the fault from the system. Utilizing the SEL-311Ls' POTT elements isolates the double-line-to-ground fault before the relay's distance protection element times out.

Table 32: SEL-311L POTT Scheme, Double-Line-to-Ground Fault, Bus 3

\begin{tabular}{|c|c|c|l|}
\hline $\begin{array}{c}\text { TIME } \\
\text { DELTA } \\
\text { (mSEC) }\end{array}$ & $\begin{array}{c}\text { SEL-311L } \\
\text { DEVICE }\end{array}$ & $\begin{array}{c}\text { ASSERTED } \\
\text { ELEMENT(S) }\end{array}$ & \multicolumn{1}{|c|}{ COMMENTS } \\
\hline 0 & Line 2 & $\begin{array}{c}\text { M2P, KEY, } \\
\text { SV1 }\end{array}$ & $\begin{array}{l}\text { Line 2 picks up fault in zone 2 (M2P), } \\
\text { generates KEY based on M2P, starts SV1 } \\
\text { timer from KEY generation }\end{array}$ \\
\hline 3 & Line 1 & $\begin{array}{c}\text { M2P, KEY, } \\
\text { SV1 }\end{array}$ & $\begin{array}{l}\text { Line 1 picks up fault in zone 2 (M2P), } \\
\text { generates KEY based on M2P, starts SV1 } \\
\text { timer from KEY generation }\end{array}$ \\
\hline 200 & Line 2 & SV1T & $\begin{array}{l}\text { Line 2 SV1 timer times out sending } \\
\text { permissive trip bit to line 1 }\end{array}$ \\
\hline 212 & Line 1 & R1X & $\begin{array}{l}\text { Line 1 receives bit used for permissive } \\
\text { tripping }\end{array}$ \\
\hline 215 & Line 1 & PTRX, TRIP & $\begin{array}{l}\text { Line 1 permissive bit (PTRX=RX1) } \\
\text { registered and allows M2P to TRIP } \\
\text { immediately prior to zone 2 timeout }\end{array}$ \\
\hline 236 & Line 1 & SV1T & $\begin{array}{l}\text { Line 1 SV1 timer times out sending } \\
\text { permissive trip bit to line 2 }\end{array}$ \\
\hline 250 & Line 2 & PTRX, TRIP & $\begin{array}{l}\text { Line 2 permissive bit (PTRX=RX1) } \\
\text { registered and allows M2P to TRIP } \\
\text { immediately prior to zone 2 timeout }\end{array}$ \\
\hline
\end{tabular}




\subsection{Triple-Line-to-Ground Faults}

Table 33 describes the POTT response of the line 1 (between bus 2 and bus 3 in Figure 62) and line 2 (between bus 3 and bus 4 in Figure 62) SEL-311L relays to a bolted triple-line-to-ground fault at the induction motor (bus 3 in Figure 62). The relays detect the fault, exchange signals acknowledging the fault, and trip to isolate the fault from the system. Utilizing the SEL-311Ls' POTT elements isolates the triple-line-to-ground fault before the relay's distance protection element times out.

Table 33: SEL-311L POTT Scheme, Triple-Line-to-Ground Fault, Bus 3

\begin{tabular}{|c|c|c|l|}
\hline $\begin{array}{c}\text { TIME } \\
\text { DELTA } \\
\text { (mSEC) }\end{array}$ & $\begin{array}{c}\text { SEL-311L } \\
\text { DEVICE }\end{array}$ & $\begin{array}{c}\text { ASSERTED } \\
\text { ELEMENT(S) }\end{array}$ & \multicolumn{1}{c|}{ COMMENTS } \\
\hline 0 & Line 1 & $\begin{array}{c}\text { M2P, KEY, } \\
\text { SV1 }\end{array}$ & $\begin{array}{l}\text { Line 1 picks up fault in zone 2 (M2P), } \\
\text { generates KEY based on M2P, starts SV1 } \\
\text { timer from KEY generation }\end{array}$ \\
\hline 0 & Line 2 & M2P, KEY, & $\begin{array}{l}\text { Line 2 picks up fault in zone 2 (M2P), } \\
\text { generates KEY based on M2P, starts SV1 } \\
\text { timer from KEY generation }\end{array}$ \\
\hline 200 & Line 2 & SV1T & $\begin{array}{l}\text { Line 2 SV1 timer times out sending } \\
\text { permissive trip bit to line 1 }\end{array}$ \\
\hline 202 & Line 1 & R1X & $\begin{array}{l}\text { Line 1 receives bit used for permissive } \\
\text { tripping }\end{array}$ \\
\hline 243 & Line 1 & PTRX, TRIP & $\begin{array}{l}\text { Line 1 permissive bit (PTRX=RX1) } \\
\text { registered and allows M2P to TRIP } \\
\text { immediately prior to zone 2 timeout }\end{array}$ \\
\hline 242 & Line 2 & R1X & $\begin{array}{l}\text { Line 1 SV1 timer times out sending } \\
\text { permissive trip bit to line 2 }\end{array}$ \\
\hline tripping
\end{tabular}




\subsection{Three-Phase Faults}

Table 34 describes the POTT response of the line 1 (between bus 2 and bus 3 in Figure 62) and line 2 (between bus 3 and bus 4 in Figure 62) SEL-311L relays to a bolted three-phase fault at the induction motor (bus 3 in Figure 62). The relays detect the fault, exchange signals acknowledging the fault, and trip to isolate the fault from the system. Utilizing the SEL-311Ls' POTT elements isolates the three-phase fault before the relay's distance protection element times out.

Table 34: SEL-311L POTT Scheme, Three-Phase Fault, Bus 3

\begin{tabular}{|c|c|c|l|}
\hline $\begin{array}{c}\text { TIME } \\
\text { DELTA } \\
\text { (mSEC) }\end{array}$ & $\begin{array}{c}\text { SEL-311L } \\
\text { DEVICE }\end{array}$ & $\begin{array}{c}\text { ASSERTED } \\
\text { ELEMENT(S) }\end{array}$ & \multicolumn{1}{|c|}{ COMMENTS } \\
\hline 0 & Line 1 & $\begin{array}{c}\text { M2P, KEY, } \\
\text { SV1 }\end{array}$ & $\begin{array}{l}\text { Line 1 picks up fault in zone 2 (M2P), } \\
\text { generates KEY based on M2P, starts SV1 } \\
\text { timer from KEY generation }\end{array}$ \\
\hline 3 & Line 2 & $\begin{array}{c}\text { M2P, KEY, } \\
\text { SV1 }\end{array}$ & $\begin{array}{l}\text { Line 2 picks up fault in zone 2 (M2P), } \\
\text { generates KEY based on M2P, starts SV1 } \\
\text { timer from KEY generation }\end{array}$ \\
\hline 203 & Line 2 & SV1T & $\begin{array}{l}\text { Line 2 SV1 timer times out sending } \\
\text { permissive trip bit to line 1 }\end{array}$ \\
\hline 213 & Line 1 & R1X & $\begin{array}{l}\text { Line 1 receives bit used for permissive } \\
\text { tripping }\end{array}$ \\
\hline 217 & Line 1 & PTRX, TRIP & $\begin{array}{l}\text { Line 1 permissive bit (PTRX=RX1) } \\
\text { registered and allows M2P to TRIP } \\
\text { immediately prior to zone 2 timeout }\end{array}$ \\
\hline 234 & Line 1 & SV1T & $\begin{array}{l}\text { Line 1 SV1 timer times out sending } \\
\text { permissive trip bit to line 2 }\end{array}$ \\
\hline 243 & Line 2 & R1X & $\begin{array}{l}\text { Line 2 receives bit used for permissive } \\
\text { tripping }\end{array}$ \\
\hline 249 & Line 2 & PTRX, TRIP & $\begin{array}{l}\text { Line 2 permissive bit (PTRX=RX1) } \\
\text { registered and allows M2P to TRIP } \\
\text { immediately prior to zone 2 timeout }\end{array}$ \\
\hline
\end{tabular}




\subsection{Line-to-Line Faults}

Table 35 describes the POTT response of the line 1 (between bus 2 and bus 3 in Figure 62) and line 2 (between bus 3 and bus 4 in Figure 62) SEL-311L relays to a bolted line-to-line fault at the induction motor (bus 3 in Figure 62). The relays detect the fault, exchange signals acknowledging the fault, and trip to isolate the fault from the system. Utilizing the SEL-311Ls' POTT elements isolates the line-to-line fault before the relay's distance protection element times out.

Table 35: SEL-311L POTT Scheme, Line-to-Line Fault, Bus 3

\begin{tabular}{|c|c|c|l|}
\hline $\begin{array}{c}\text { TIME } \\
\text { DELTA } \\
\text { (mSEC) }\end{array}$ & $\begin{array}{c}\text { SEL-311L } \\
\text { DEVICE }\end{array}$ & $\begin{array}{c}\text { ASSERTED } \\
\text { ELEMENT(S) }\end{array}$ & \multicolumn{1}{c|}{ COMMENTS } \\
\hline 0 & Line 1 & $\begin{array}{c}\text { M2P, KEY, } \\
\text { SV1 }\end{array}$ & $\begin{array}{l}\text { Line 1 picks up fault in zone 2 (M2P), } \\
\text { generates KEY based on M2P, starts SV1 } \\
\text { timer from KEY generation }\end{array}$ \\
\hline 0 & Line 2 & M2P, KEY, & $\begin{array}{l}\text { Line 2 picks up fault in zone 2 (M2P), } \\
\text { generates KEY based on M2P, starts SV1 } \\
\text { timer from KEY generation }\end{array}$ \\
\hline 200 & Line 2 & SV1T & $\begin{array}{l}\text { Line 2 SV1 timer times out sending } \\
\text { permissive trip bit to line 1 }\end{array}$ \\
\hline 207 & Line 1 & R1X & $\begin{array}{l}\text { Line 1 receives bit used for permissive } \\
\text { tripping }\end{array}$ \\
\hline 233 & Line 1 & PTRX, TRIP & $\begin{array}{l}\text { Line 1 permissive bit (PTRX=RX1) } \\
\text { registered and allows M2P to TRIP } \\
\text { immediately prior to zone 2 timeout }\end{array}$ \\
\hline 237 & Line 2 & R1X & $\begin{array}{l}\text { Line 1 SV1 timer times out sending } \\
\text { permissive trip bit to line 2 }\end{array}$ \\
\hline tripping
\end{tabular}




\section{Chapter 18: Bidirectional System Relay Coordination}

\subsection{Demonstrating Coordination in a Bidirectional System}

Demonstrating relay coordination in the bidirectional system follows the same principles and procedures as mentioned in Chapter 15 for the radial system. In a properlycoordinated system, a relay located closer to a fault operates before a relay further away from the fault. The relay further away from the fault only operates in the event that a problem keeps the closer relay from isolating the fault.

As with the radial system, sequential event reports obtained from all of the relays for a specific fault event provide data to demonstrate proper coordination. The following tables show only the relevant elements (those which assert first) to clear each fault. Time values given in the tables, with respect to the first recorded event, derive from a common timing source. An SEL-2407 satellite-synchronized clock generates this IRIG-B timing signal and sends it to the communications processor (project phase 2) or the RTAC (project phase 3) for distribution to the individual relays. Section 18.2 illustrates the proximity between a fault inception and its initial detection by a relay.

The following sections distinguish between the two SEL-311L units by referring to the transmission line that each protects. "Line 1" refers to the SEL-311L unit guarding the transmission line between buses 2 and 3 in Figure 62. "Line 2" refers to the SEL311L unit guarding the transmission line between buses 3 and 4 .

Since sources $\mathrm{ABC}$ and $\mathrm{DEF}$ both remain active during the coordination demonstrations, bus 3 remains the point in the circuit furthest downstream from the infinite bus. The relays in this bidirectional system should therefore trip in the following 
order, if properly coordinated: SEL-710 first, both SEL-311L units second and third, and the SEL-387E and SEL-587 fourth and fifth.

The following results build on the data in Chapter 15 to confirm that the overcurrent elements of all relays in the system coordinate for a variety of faults. This relationship follows from the time dial settings chosen for each relay and is reflected in the overcurrent relay settings located in the appendices. Time dial settings increase across the circuit from the load to the source. The SEL-710, located at the load, uses instantaneous overcurrent protection and has no time dial setting. Just upstream of the SEL-710, the SEL-311L relays use small time dial settings to coordinate with the SEL710's instantaneous overcurrent protection. Likewise, the SEL-387E and SEL-587 use slightly higher time dial settings that coordinate with both the SEL-311L and SEL-710 relays. From an overcurrent protection perspective, all of the relays used in this project provide comparable performance in protecting the system from faults. 


\subsection{Single-Line-to-Ground Faults}

Table 36 and Table 37 show the response of the bidirectional system protection scheme to a single-line-to-ground fault at the terminals of the induction motor (bus 3 in Figure 62). Both SEL-311L units detect the fault with their inverse-time negativesequence overcurrent elements but delay before tripping. Meanwhile, the SEL-710 detects the fault through its definite-time residual overcurrent element. After a delay, the SEL-710 trips as its overcurrent element times out. This programmed delay allows the instantaneous phase overcurrent element (50P) to operate first. However, the relativelyhigh phase overcurrent pickup setting does not catch single-line-to-ground faults due to the small amounts of current that they draw.

Table 36: Bidirectional System Detection of a Single-Line-to-Ground Fault

\begin{tabular}{|c|c|c|l|}
\hline $\begin{array}{c}\text { TIME } \\
\text { DELTA } \\
\text { (mSEC) }\end{array}$ & $\begin{array}{c}\text { SEL RELAY } \\
\text { DEVICE }\end{array}$ & $\begin{array}{c}\text { ASSERTED } \\
\text { ELEMENTS }\end{array}$ & COMMENT \\
\hline 0 & $311 \mathrm{~L}-$ LINE 1 & $51 \mathrm{Q}$ & Fault Detected \\
\hline 1 & 710 & $50 \mathrm{G} 1 \mathrm{P}$ & Fault Detected \\
\hline 6 & $311 \mathrm{~L}-$ LINE 2 & $51 \mathrm{Q}$ & Fault Detected \\
\hline 9 & $387 \mathrm{E}$ & $51 \mathrm{Q} 2$ & Fault Detected \\
\hline 1360 & 587 & $51 \mathrm{Q} 2$ & Fault Detected \\
\hline
\end{tabular}

Table 37: Bidirectional System Tripping for a Single-Line-to-Ground Fault

\begin{tabular}{|c|c|c|c|}
\hline $\begin{array}{c}\text { TIME } \\
\text { DELTA } \\
\text { (mSEC) }\end{array}$ & $\begin{array}{c}\text { SEL RELAY } \\
\text { DEVICE }\end{array}$ & $\begin{array}{c}\text { ASSERTED } \\
\text { ELEMENTS }\end{array}$ & COMMENT \\
\hline 105 & 710 & $50 \mathrm{G} 1 \mathrm{~T}$, TRIP & Timeout and Trip \\
\hline 321 & $311 \mathrm{~L}-$ LINE 1 & $51 \mathrm{~T}$, TRIP & Timeout and Trip \\
\hline 401 & $311 \mathrm{~L}-$ LINE 2 & $51 \mathrm{Q}$, TRIP & Timeout and Trip \\
\hline 1735 & $387 \mathrm{E}$ & $51 \mathrm{Q} 2 \mathrm{~T}$, TRIP & Timeout and Trip \\
\hline 2593 & 587 & $51 \mathrm{Q} 2 \mathrm{~T}$, TRIP & Timeout and Trip \\
\hline
\end{tabular}


Between the SEL-710's pickup and timeout, the inverse-time negative-sequence overcurrent element on the SEL-387E detects the fault but delays before tripping. Following the delay required for the SEL-710 to react to the fault, the overcurrent element on the SEL-311L times out and trips its relay. After a significant delay, the inverse-time negative-sequence overcurrent element on the SEL-587 detects the fault but delays before tripping. The overcurrent element on the SEL-387E next times out, followed by the overcurrent element on the SEL-587. The relays thus trip in the proper order to demonstrate coordination for a single-line-to-ground fault at the induction motor.

Single-line-to-ground faults prove to be the limiting case in the bidirectional system coordination. Due to their low current draw, the inverse-time overcurrent elements delay the relays from tripping for a long time before timing out. However, since the SEL-387E and SEL-587 use overcurrent protection only as a backup for other downstream zones of protection, this delay does not violate the fault-clearing criteria for primary zones of protection specified in Table 1 .

The time range in Table 36 over which the relays initially detect the fault prompts the question of how closely the zero-indexed time value corresponds to the actual fault inception. In other words, how long does it take the first relay to detect a fault? Figure 66 answers this question. This figure displays the response of the SEL-710 to the same single-line-to-ground fault documented in Table 36. The cursor in Figure 66 shows the approximate fault inception at a time-stamped value of 10 hours, 45 minutes, 4 seconds, 910 milliseconds (local time). The SEL-710's residual overcurrent element (50G1) detects the fault at $921 \mathrm{~ms}$, less than one cycle after fault inception. This value serves as the reference for all times shown in Table 36. Although not listed in Table 36, the SEL- 
710's negative-sequence element (50Q1) detects the fault at $933 \mathrm{~ms}$. Both overcurrent elements thus detect the fault within two cycles of fault inception. This analysis shows that the relays detect faults quickly, though not instantaneously.

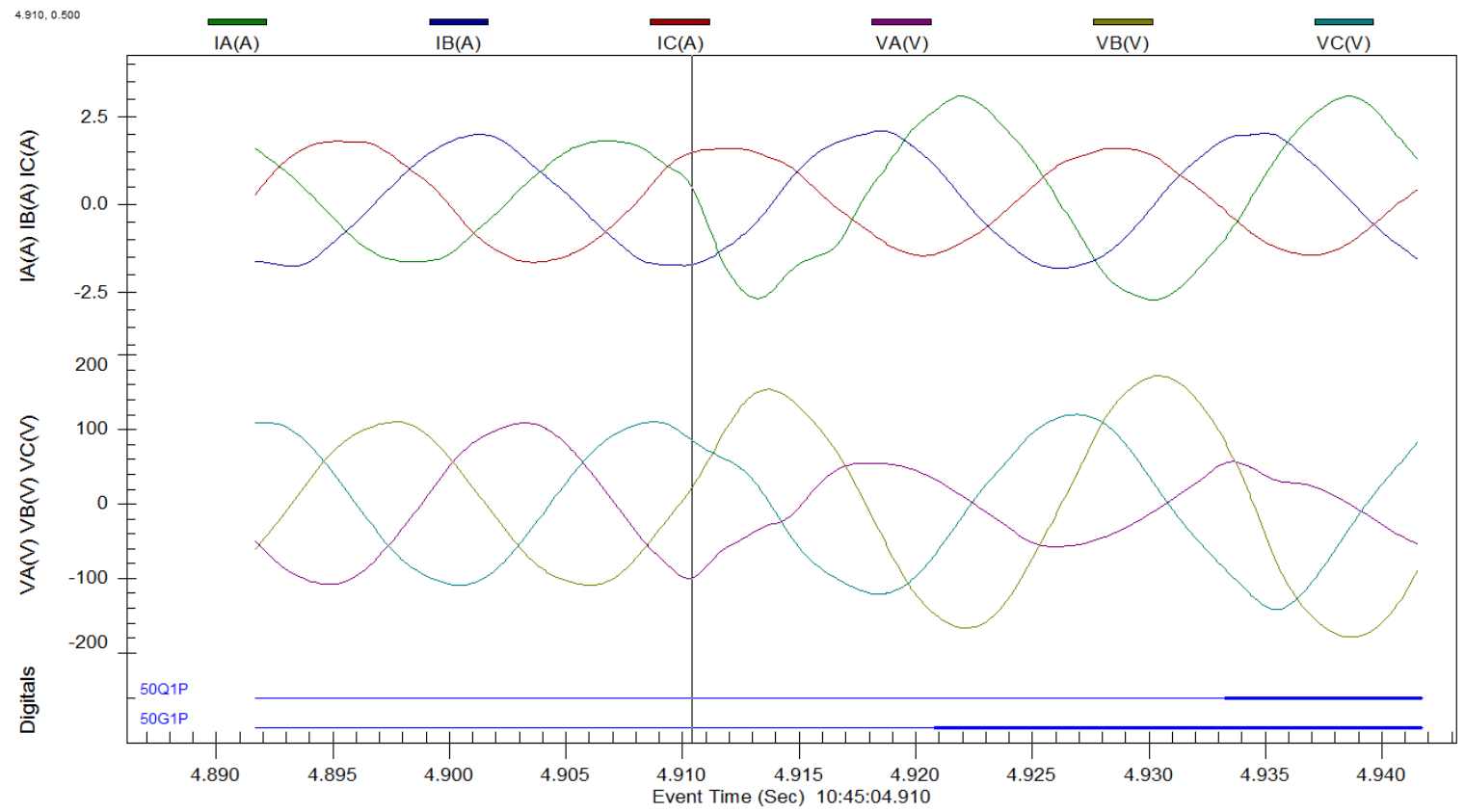

Figure 66: SEL-710 Response to Single-Line-to-Ground Fault in Coordination Study 


\subsection{Double-Line-to-Ground Faults}

Table 38 and Table 39 show the response of the bidirectional system protection scheme to a double-line-to-ground fault at the terminals of the induction motor (bus 3 in Figure 62). Both SEL-311L units and the SEL-387E detect the fault with their inversetime negative-sequence overcurrent elements but delay before tripping. The SEL-710 then detects the fault through its instantaneous phase overcurrent element and immediately trips. Shortly thereafter, the SEL-587 detects the fault with its inverse-time negative-sequence overcurrent element but delays before tripping. After a delay, the overcurrent elements on the SEL-311L units time out and trip the two relays. Following an additional delay, the overcurrent elements on the SEL-387E and SEL-587 also time out and trip the last two relays. All of the relays thus trip in the proper order to demonstrate coordination for a double-line-to-ground fault at the induction motor.

Table 38: Bidirectional System Detection of a Double-Line-to-Ground Fault

\begin{tabular}{|c|c|c|c|}
\hline $\begin{array}{c}\text { TIME } \\
\text { DELTA } \\
\text { (mSEC) }\end{array}$ & $\begin{array}{c}\text { SEL RELAY } \\
\text { DEVICE }\end{array}$ & $\begin{array}{c}\text { ASSERTED } \\
\text { ELEMENTS }\end{array}$ & COMMENT \\
\hline 0 & $311 \mathrm{~L}-$ LINE 1 & $51 \mathrm{Q}$ & Fault Detected \\
\hline 1 & $311 \mathrm{~L}-$ LINE 2 & $51 \mathrm{Q}$ & Fault Detected \\
\hline 2 & $387 \mathrm{E}$ & $51 \mathrm{Q} 2$ & Fault Detected \\
\hline 7 & 710 & $50 \mathrm{P} 1 \mathrm{P}$ & Fault Detected \\
\hline 9 & 587 & $51 \mathrm{Q} 2$ & Fault Detected \\
\hline
\end{tabular}


Table 39: Bidirectional System Tripping for a Double-Line-to-Ground Fault

\begin{tabular}{|c|c|c|c|}
\hline $\begin{array}{c}\text { TIME } \\
\text { DELTA } \\
\text { (mSEC) }\end{array}$ & $\begin{array}{c}\text { SEL RELAY } \\
\text { DEVICE }\end{array}$ & $\begin{array}{c}\text { ASSERTED } \\
\text { ELEMENTS }\end{array}$ & COMMENT \\
\hline 7 & 710 & TRIP & Instantaneous Trip \\
\hline 80 & 311L - LINE 2 & 51QT, TRIP & Timeout and Trip \\
\hline 84 & 311L - LINE 1 & 51QT, TRIP & Timeout and Trip \\
\hline 109 & 587 & 51Q2T, TRIP & Timeout and Trip \\
\hline 114 & 387E & 51Q2T, TRIP & Timeout and Trip \\
\hline
\end{tabular}




\subsection{Triple-Line-to-Ground Faults}

Table 40 and Table 41 show the response of the bidirectional system protection scheme to a triple-line-to-ground fault at the terminals of the induction motor (bus 3 in Figure 62). Both SEL-311L units detect the fault with their mho phase distance elements but delay before tripping. The SEL-710 then detects the fault through its instantaneous phase overcurrent element and immediately trips. Shortly thereafter, the SEL-387E and SEL-587 detect the fault with their inverse-time phase overcurrent elements but delay before tripping. Next, both SEL-311L units send each other a permissive trip signal, allowing the two relays to bypass the remaining distance protection delay time and trip. Following an additional delay, the overcurrent elements on the SEL-387E and SEL-587 time out and trip the last two relays. All of the relays thus trip in the proper order to demonstrate coordination for a triple-line-to-ground fault at the induction motor.

Table 40: Bidirectional System Detection of a Triple-Line-to-Ground Fault

\begin{tabular}{|c|c|c|c|}
\hline $\begin{array}{c}\text { TIME } \\
\text { DELTA } \\
\text { (mSEC) }\end{array}$ & $\begin{array}{c}\text { SEL RELAY } \\
\text { DEVICE }\end{array}$ & $\begin{array}{c}\text { ASSERTED } \\
\text { ELEMENTS }\end{array}$ & COMMENT \\
\hline 0 & $311 \mathrm{~L}-$ LINE 1 & M2P & Fault Detected \\
\hline 2 & $311 \mathrm{~L}-$ LINE 2 & M2P & Fault Detected \\
\hline 6 & 710 & $50 \mathrm{P} 1 \mathrm{P}$ & Fault Detected \\
\hline 7 & 587 & $51 \mathrm{P} 2$ & Fault Detected \\
\hline 8 & $387 \mathrm{E}$ & $51 \mathrm{P} 2$ & Fault Detected \\
\hline
\end{tabular}


Table 41: Bidirectional System Tripping for a Triple-Line-to-Ground Fault

\begin{tabular}{|c|c|c|c|}
\hline $\begin{array}{c}\text { TIME } \\
\text { DELTA } \\
\text { (mSEC) }\end{array}$ & $\begin{array}{c}\text { SEL RELAY } \\
\text { DEVICE }\end{array}$ & $\begin{array}{c}\text { ASSERTED } \\
\text { ELEMENTS }\end{array}$ & COMMENT \\
\hline 6 & 710 & TRIP & Instantaneous Trip \\
\hline 217 & 311 L - LINE 1 & PTRX, TRIP & Permissive Signal Received and Trip \\
\hline 248 & 311 L - LINE 2 & PTRX, TRIP & Permissive Signal Received and Trip \\
\hline 699 & 587 & 51 P2T, TRIP & Timeout and Trip \\
\hline 701 & $387 \mathrm{E}$ & 51P2T, TRIP & Timeout and Trip \\
\hline
\end{tabular}




\subsection{Three-Phase Faults}

Table 42 and Table 43 show the response of the bidirectional system protection scheme to a three-phase fault at the terminals of the induction motor (bus 3 in Figure 62). The SEL-710 detects the fault through its instantaneous phase overcurrent element and immediately trips. Both SEL-311L units then detect the fault with their mho phase distance elements but delay before tripping. Shortly thereafter, the SEL-387E and SEL587 detect the fault with their inverse-time phase overcurrent elements, but delay before tripping. Next, both SEL-311L units send each other a permissive trip signal, allowing the two relays to bypass the remaining distance protection delay time and trip. Following an additional delay, the overcurrent elements on the SEL-387E and SEL-587 time out and trip the last two relays. All of the relays thus trip in the proper order to demonstrate coordination for a three-phase fault at the induction motor.

Table 42: Bidirectional System Detection of a Three-Phase Fault

\begin{tabular}{|c|c|c|c|}
\hline $\begin{array}{c}\text { TIME } \\
\text { DELTA } \\
\text { (mSEC) }\end{array}$ & $\begin{array}{c}\text { SEL RELAY } \\
\text { DEVICE }\end{array}$ & $\begin{array}{c}\text { ASSERTED } \\
\text { ELEMENTS }\end{array}$ & COMMENT \\
\hline 0 & 710 & $50 \mathrm{P} 1 \mathrm{P}$ & Fault Detected \\
\hline 0 & $311 \mathrm{~L}-$ LINE 2 & M2P & Fault Detected \\
\hline 1 & $311 \mathrm{~L}-$ LINE 1 & M2P & Fault Detected \\
\hline 10 & 587 & $51 \mathrm{P} 2$ & Fault Detected \\
\hline 35 & $387 \mathrm{E}$ & $51 \mathrm{P} 2$ & Fault Detected \\
\hline
\end{tabular}


Table 43: Bidirectional System Tripping for a Three-Phase Fault

\begin{tabular}{|c|c|c|c|}
\hline $\begin{array}{c}\text { TIME } \\
\text { DELTA } \\
\text { (mSEC) }\end{array}$ & $\begin{array}{c}\text { SEL RELAY } \\
\text { DEVICE }\end{array}$ & $\begin{array}{c}\text { ASSERTED } \\
\text { ELEMENTS }\end{array}$ & COMMENT \\
\hline 0 & 710 & TRIP & Instantaneous Trip \\
\hline 213 & 311 L - LINE 1 & PTRX, TRIP & Permissive Signal Received and Trip \\
\hline 245 & $311 \mathrm{~L}-$ LINE 2 & PTRX, TRIP & Permissive Signal Received and Trip \\
\hline 701 & 587 & 51 P2T, TRIP & Timeout and Trip \\
\hline 751 & $387 \mathrm{E}$ & 51P2T, TRIP & Timeout and Trip \\
\hline
\end{tabular}




\subsection{Line-to-Line Faults}

Table 44 and Table 45 show the response of the bidirectional system protection scheme to a line-to-line fault at the terminals of the induction motor (bus 3 in Figure 62). Both SEL-311L units and the SEL-587 detect the fault with their inverse-time negativesequence overcurrent elements but delay before tripping. The SEL-710 then detects the fault through its instantaneous phase overcurrent element and immediately trips. Shortly thereafter, the SEL-387E detects the fault with its inverse-time negative-sequence overcurrent element but delays before tripping. After a delay, the overcurrent elements on the SEL-311L units time out and trip the two relays. Following an additional delay, the overcurrent elements on the SEL-387E and SEL-587 also time out and trip the last two relays. All of the relays thus trip in the proper order to demonstrate coordination for a line-to-line fault at the induction motor.

Table 44: Bidirectional System Detection of a Line-to-Line Fault

\begin{tabular}{|c|c|c|c|}
\hline $\begin{array}{c}\text { TIME } \\
\text { DELTA } \\
\text { (mSEC) }\end{array}$ & $\begin{array}{c}\text { SEL RELAY } \\
\text { DEVICE }\end{array}$ & $\begin{array}{c}\text { ASSERTED } \\
\text { ELEMENTS }\end{array}$ & COMMENT \\
\hline 0 & $311 \mathrm{~L}-$ LINE 1 & $51 \mathrm{Q}$ & Fault Detected \\
\hline 1 & $311 \mathrm{~L}-$ LINE 2 & $51 \mathrm{Q}$ & Fault Detected \\
\hline 11 & 587 & $51 \mathrm{Q} 2$ & Fault Detected \\
\hline 13 & 710 & $50 \mathrm{P} 1 \mathrm{P}$ & Fault Detected \\
\hline 28 & $387 \mathrm{E}$ & $51 \mathrm{Q} 2$ & Fault Detected \\
\hline
\end{tabular}


Table 45: Bidirectional System Tripping for a Line-to-Line Fault

\begin{tabular}{|c|c|c|c|}
\hline $\begin{array}{c}\text { TIME } \\
\text { DELTA } \\
\text { (mSEC) }\end{array}$ & $\begin{array}{c}\text { SEL RELAY } \\
\text { DEVICE }\end{array}$ & $\begin{array}{c}\text { ASSERTED } \\
\text { ELEMENTS }\end{array}$ & COMMENT \\
\hline 13 & 710 & TRIP & Instantaneous Trip \\
\hline 85 & 311L - LINE 2 & 51QT, TRIP & Timeout and Trip \\
\hline 88 & 311L - LINE 1 & 51QT, TRIP & Timeout and Trip \\
\hline 111 & 587 & 51Q2T, TRIP & Timeout and Trip \\
\hline 140 & $387 \mathrm{E}$ & 51Q2T, TRIP & Timeout and Trip \\
\hline
\end{tabular}




\section{Chapter 19: The Information Processors}

\subsection{Information Processor Introduction}

The SEL-2032 Communications Processor and SEL-3530 Real-Time Automation Controller (RTAC) operated behind the scenes in this project to streamline and simplify communication and data acquisition. This chapter highlights the benefits derived from utilizing these information processors as they relate to their roles in this project. 


\subsection{SEL-2032 Communications Processor}

The SEL-2032 Communications Processor simplifies cable management in a multi-relay system. Rather than running separate serial cables from each relay to the computer (or switching back and forth between cables in the back of the computer), the communications processor allows the computer to access each of the relays in the system with a single serial connection. One SEL-C234A serial cable connects the computer to the communications processor, eliminating the need to alternate between various cables on the back of the computer.

Each relay connects to an assigned serial port on the communications processor with its own SEL-C273A serial cable, establishing a connection path from the computer to all relays in the system. By creating a direct transparent connection (using the SEL5030 AcSELerator QuickSet software) between the computer and one of the system relays, a system operator can access any of the system relays without changing the arrangement of the serial cables. A direct transparent connection maintains all of the normal functionalities (such as sending and reading settings, monitoring real-time data, and downloading event files) available if the relay were directly connected to the back of the computer. Figure 67 illustrates the communications hierarchy in the bidirectional system.

Additionally, the communications processor provides a service that greatly enhances analysis of relay coordination. It contains an IRIG-B timing signal input port that connects to the output of an SEL-2407 Satellite-Synchronized Clock. The communications processor distributes the demodulated IRIG-B timing signal that it receives from the satellite clock to all of the relays in the system. Each relay uses this 
common time when time-stamping its fault events. A consistent timing reference for all events shows when the various relays throughout the system operate with respect to each other following a fault. This timing data supports the coordination analysis presented in Chapters 15 and 18.

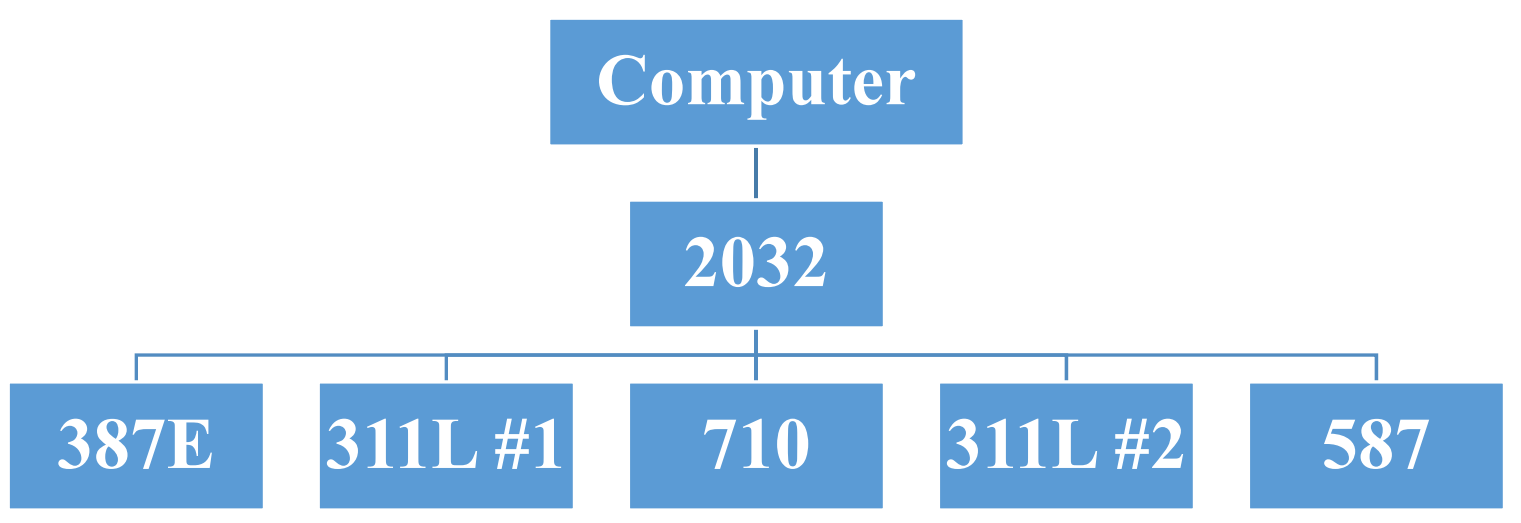

Figure 67: Communications Cable Management in the Bidirectional System 


\subsection{SEL-3530 Real-Time Automation Controller}

The SEL-3530 RTAC utilized in this project provides all of the functionality obtained from the SEL-2032 Communications Processor. However, this project also capitalizes on a few of the many advantages offered by this unit. First, the RTAC initiates an autoconfiguration routine when first connected to an expected relay. The communications processor also supports an autoconfiguration feature through its SEL5020 Settings Assistant software, but only runs it when specifically prompted by the user through the software program. Second, the RTAC automatically posts the event records and reports that it receives from the relays into a web server. This provides an alternate means for accessing fault data, rather than connecting to each relay (through the RTAC) with the AcSELerator QuickSet software.

Replication of the functionality obtained from the communications processor with the RTAC resulted from settings assigned using the SEL-5033 AcSELerator RTAC software. In these settings, the RTAC stands as the centerpiece in the multi-relay bidirectional system. Adding a device tag specifically for the SEL-3530 establishes the unit as a server device between the computer and the relays. In this project, the SEL-3530 device tag tells the RTAC to operate as a virtual communications processor for the system.

A device tag for each relay contains pertinent information needed by the RTAC for carrying out the autoconfiguration routine when first connecting to the relay. Additionally, the device tag specifies which word bits (such as the inverse-time overcurrent timeout signal 51P2T) the RTAC watches for. If each relay has appropriate settings chosen to alert the RTAC to changes in its word bits [by putting the desired word 
bits in that relay's Sequential Event Recorder (SER) equation and turning on the AUTO port setting to send this information through the serial port connected to the RTAC], then the RTAC obtains access to all fault data picked up by the system relays. Appropriately copying and setting the relay word bits from the relay device tag into the RTAC information processor tab causes the RTAC to post the data obtained from the relays on its web server. Although this project merely scratches the surface of the automation capabilities available with the SEL-3530 RTAC, it establishes a foundation for future projects to build on. 


\section{Chapter 20: Conclusion}

\subsection{Difficulties Encountered}

Certain challenges that occurred during this project correspond to relatively simple misunderstandings in operating the equipment. For example, during a short period after the SEL-587 trips for an overcurrent fault, pushing the Target Reset button on the relay's front panel is necessary before manually reclosing the tripped circuit breaker. This section notes several such lessons learned, in support of future student endeavors.

Project testing began with basic operation of the circuit breakers described in Chapter 3. In an effort to test elementary functionality, the circuit breaker relay control signal terminals were left unconnected. It seemed logical that manual input operates the circuit breakers without the need for a control signal from the relay. This assumption proved incorrect. An analysis of the circuit breaker schematic revealed that the breaker control trip terminals (labeled "SEL OUT103" in Figure 4) was in series with the circuit breaker trip coil. Leaving the breaker control trip terminals unconnected thus opened the circuit and prohibited the breaker contacts from manually closing. Shorting the Breaker Control Trip terminals (see Figure 5) overcame this obstacle.

Demonstrating relay coordination through post-fault event reports relies on accurate timekeeping across the circuit. The IRIG-B timing signal generated by an SEL2407 Satellite-Synchronized Clock and distributed by an information processor allows all relays on the circuit to use a common reference when timestamping events. Upon initial power-up, however, the SEL-2407 did not generate an IRIG-B output signal. Keeping the clock antenna inside the laboratory room enabled successful connection to GPS satellites, as evidenced by the updated time on the front-panel display (holdover mode). However, 
it inhibited the clock from creating the satellite lock necessary to obtain a Coordinated Universal Time (UTC) offset signal for initializing the clock's IRIG-B output [16]. Running the antenna out through the laboratory window facilitated a successful satellitelock connection, at which point the clock began generating an IRIG-B output signal. Signal output continued after the antenna returned into the laboratory.

Additional timing difficulties arose when setting up the RTAC. The RTAC defaults to UTC, which is several hours off from the local time at Cal Poly. Since the RTAC sends a coordinated timing signal to the relays, correcting this timing discrepancy affects the experimental data taken. Entering a Set_System_Time_UTC_Offset input pin value of -480 , the number of minutes between local time at Cal Poly and UTC, in the Program Organizational Unit (POU) Pin Settings tab of the System_Time_Control options corrected this discrepancy.

This project limits abstraction of fundamental power systems concepts by directly wiring system line currents to relays without using intermediate current transformers. Eliminating current transformers presented a problem when setting up differential protection with the SEL-387E relay. Initially, differential protection on the relay tripped for nominal load currents. Increasing the default Restrained Element Operating Current Pickup (O87P) sensitivity setting from 0.30 to 0.65 caused differential protection to operate for transformer faults, but not for currents associated with the transmission line and static load. However, differential protection on the relay continued to trip for downstream faults and nominal loads associated with running the induction motor. Rolling the phases of the transformer secondary windings [reversing the connections between SEL-387E back-panel terminals Z07 and Z08 (phase A), Z09 and Z10 (phase 
B), and Z11 and Z12 (phase C)] solved this problem, permitting both simultaneous differential and downstream inverse-time overcurrent protection at the nominal O87P setting. Rolling the line current phases accomplished successful phasing of the currents on the SEL-387E and SEL-587 relays.

The operating characteristics of the laboratory bench power transformers presented certain difficulties in this project. Due to their construction, the transformers consistently operate in saturation. This initially presented a setback when protecting the delta-connected power transformer. The high magnetization currents (of approximately 1 A) during system energization caused the SEL-587 to issue a differential fault trip signal. The first solution, decreasing the relay's sensitivity (by incrementing the O87P setting from 0.3 to 0.4 ), successfully prevented the relay from tripping under normal operating conditions. An alternative solution utilized the signature fifth harmonic present in overexcited transformers [12]. The harmonic blocking settings of the SEL-587 prevent the relay from initiating a differential fault trip signal when the input current harmonics exceed a certain percentage of the fundamental component of the input current. Lowering the fifth-harmonic blocking (PTC5) setting to $5 \%$ of the fundamental component allowed the relay to retain its original sensitivity level, yielding fewer trips in response to the overexcitation that resulted from the saturated power transformer. However, even with fifth-harmonic blocking, the relay occasionally still identified a differential fault under nominal circuit operating conditions. Since protective relays should never operate under nominal loading conditions, reduced differential sensitivity provides a more secure protection scheme. 


\subsection{Recommended Future Work}

The electrical engineering department at Cal Poly, San Luis Obispo hopes to use the bidirectional circuit (Figure 62) presented in this project as the basis for a microgrid. Expanding the RTAC-controlled bidirectional system into a microgrid requires the addition of local energy generation sources to allow the system to run independent of the electric utility. Examples of local energy generation sources include solar panels and synchronous generators. Adding energy storage elements such as batteries supplements the energy generation units, increasing the available fault current that the system can supply. Creating a human-machine interface for the RTAC-controlled system with available SEL software also serves as an important step in establishing and monitoring a functional microgrid. Each of these additions involves adding new relays or automation to the existing system and creates opportunities for future senior projects and master's theses.

In addition to the work necessary for establishing a microgrid, several other possibilities exist for building on the existing bidirectional system. Power system analysis software such as PSCAD and ETAP presents opportunities for future groups to analyze transient and steady-state imbalances in the system. Placing a three-phase capacitor bank at the load bus (bus 3) compensates for the voltage drop across the transformer and transmission line, providing voltage support for the induction motor. Adding a feeder terminated with an induction motor to the existing circuit allows students to simulate power delivery to industrial and agricultural customers. Feeder protection also utilizes the capabilities of the SEL-351, incorporating this popular relay into the system. Finally, programming the relays in the bidirectional system to automatically reclose and test for 
faults gives students hands-on experience in this valuable technique for responding to fault conditions. 


\subsection{Analysis of Requirements}

The project requirements stated in Chapter 2 describe the necessary performance for the radial and bidirectional system protection schemes. Industry-standard SEL microprocessor-based relays provide overcurrent, mho distance, and differential protection to detect faults in each circuit. The chosen relay settings cause the relays to detect and trip for faults located in their primary zones of protection within $1 \mathrm{~s}$ of fault inception. An SEL-710 provides additional protection to supervise the operation of an induction motor. Each relay uses a common timing reference that unifies all event reports generated throughout the system and confirms relay coordination. 


\section{REFERENCES}

[1] G. Andersson et al., "Causes of the 2003 major grid blackouts in North America and Europe, and recommended means to improve system dynamic performance," IEEE Trans. Power Syst., vol. 20, no. 4, pp. 1922-1928, Nov. 2005.

[2] R. H. Lasseter, "Microgrids," in Power Engineering Society Winter Meeting, Madison, WI, 2002.

[3] H. Nikkhajoei and R. H. Lasseter, "Microgrid protection," in Power Engineering Society General Meeting, 2007 C IEEE. doi: 10.1109/PES.2007.385805

[4] R. Majumder et al., "Power management and power flow control with back-to-back converters in a utility connected microgrid," IEEE Trans. Power Syst., vol. 25, no. 2, pp. 821-834, May 2010.

[5] C. Ewing and B. Keefer, "Integration of SEL relays to provide motor, transmission line and transformer protection," Senior project report, Dept. Elect. Eng., California Polytechnic State Univ., San Luis Obispo, 2016.

[6] J. L. Blackburn and T. J. Domin, "Introduction and general philosophies," in Protective Relaying: Principles and Applications, 3rd ed., H. L. Willis and M. H. Rashid, Eds., Boca Raton, Florida: CRC Press, 2007, p. 4.

[7] R. Ford and C. Coulston, "The requirements specification," in Design for Electrical and Computer Engineers. New York, NY: McGraw-Hill, 2008, p. 37.

[8] (2012). Equipment damage motor curves [Online], SKM Systems Analysis Inc. Available: http://www.skm.com/applicationguides6.html

[9] SEL-311L line current differential protection and automation system, Schweitzer Engineering Laboratories, Inc., Pullman, WA, Datasheet, Jul. 15, 2016, pp. 2, 23 24. Available: https://selinc.com/products/3111/\#tab-literature

[10] SEL-387E current differential and voltage protection relay, Schweitzer Engineering Laboratories, Inc., Pullman, WA, Datasheet, Jan. 22, 2016, pp. 2-4, 19-20.

Available: https://selinc.com/products/387e/\#tab-literature

[11] SEL-587 current differential relay, Schweitzer Engineering Laboratories, Inc., Pullman, WA, Datasheet, Nov. 5, 2015, pp. 1, 14-16. Available: https://selinc.com/products/587/\#tab-literature

[12] SEL-587-0, -1 relay: current differential relay, overcurrent relay, Schweitzer Engineering Laboratories, Inc., Pullman, WA, Instruction Manual, Nov. 5, 2015, pp. 39-40, 46, 111. 
[13] SEL-710 motor protection relay, Schweitzer Engineering Laboratories, Inc., Pullman, WA, Datasheet, Jan. 30, 2015, pp. 4-6, 22-26. Available:

https://selinc.com/products/710/\#tab-literature

[14] SEL-2032 communications processor, Schweitzer Engineering Laboratories, Inc., Pullman, WA, Datasheet, Sep. 3, 2015, pp. 1-2, 14-15. Available:

https://selinc.com/products/2032/\#tab-literature

[15] RTAC: SEL-3530 real-time automation controller, Schweitzer Engineering Laboratories, Inc., Pullman, WA, Datasheet, Jun. 24, 2016, pp. 1-2, 10-12. Available: https://selinc.com/products/3530/\#tab-literature

[16] SEL-2407 satellite-synchronized clock instruction manual, Schweitzer Engineering Laboratories, Inc., Pullman, WA, Datasheet, May. 25, 2016, pp. 1, 7, 29-30. Available: https://selinc.com/products/2407/\#tab-literature

[17] O. Corulli, "Motor protection lab experiment using SEL-710," Senior project report, Dept. Elect. Eng., California Polytechnic State Univ., San Luis Obispo, Jun. 2013, pp. 13-14. Available:

http://digitalcommons.calpoly.edu/cgi/viewcontent.cgi?article $=1236 \&$ context $=$ eesp

[18] R. Ford and C. Coulston, "Project management," in Design for Electrical and Computer Engineers. New York, NY: McGraw-Hill, 2008, p. 205.

[19] C. Werstiuk, "Chapter 2: Percent Differential (87) Element Testing," in The Relay Testing Handbook: Testing Differential Protection (87), 1st ed. Arvada: Valence Electrical Training Services, 2012, ch. 2, sec. C, pp. 51-52.

[20] H. J. Li and F. Calero, "Line and circuit protection," in Protective relaying theory and applications, W. A. Elmore, Ed. 1st ed. New York, NY: Marcel Dekker, 1994, ch. 12 , sec. 4 , pp. 227-231.

[21] J. L. Blackburn and T. J. Domin, "Protection Fundamentals and Basic Design Principles," in Protective Relaying: Principles and Applications, 3rd ed., H. L. Willis and M. H. Rashid, Eds., Boca Raton, Florida: CRC Press, 2007, pp. 164, 180.

[22] S. H. Horowitz and A. G. Phadke, "Third zone revisited," IEEE Trans. Power Del., vol. 21, no. 1, pp. 23-29, Jan. 2006.

[23] SEL-387E relay: current differential and voltage protection relay, Schweitzer Engineering Laboratories, Inc., Pullman, WA, Instruction Manual, Aug. 12, 2016, pp. $55,57$.

[24] J. A. Wafer, "The evolution of arc fault circuit interrupters," in Proc. Fifty-First IEEE Holm Conf. Electrical Contacts, 2005, Chicago, IL, 2005, pp. 156-161. 
[25] IEEE Policies, June 2016 ed., Institute of Electrical and Electronics Engineers, Inc., New York, NY, 2016, p. 7.3.

[26] Ten-year product warranty, Schweitzer Engineering Laboratories, Inc., Pullman, WA, Warranty, Jan. 20, 2016. Available: https://cdn.selinc.com/assets/Literature/Miscellaneous/SEL-Warranty20160120.pdf? v=20160120-100207 


\section{APPENDICES}

\section{Appendix A: Project Costs}

Table 46 details the costs incurred throughout the duration of the project. See Chapter 5 for a comparison to the estimated project costs.

Table 46: Incurred Project Costs

\begin{tabular}{|c|c|c|c|}
\hline Item & Quantity & Unit Cost & Cost \\
\hline \#10 Spade Terminal, 100 pcs. & 1 & $\$ 6.19$ & $\$ 6.19$ \\
\hline \#10 Spade Terminal, 75 pcs. & 1 & $\$ 6.97$ & $\$ 6.97$ \\
\hline Banana Plug, Colored 25 pcs. & 6 & $\$ 10.99$ & $\$ 65.94$ \\
\hline Cable Zip Ties, 1000 pcs. & 1 & $\$ 5.79$ & $\$ 5.79$ \\
\hline Command Clips & 3 & $\$ 9.98$ & $\$ 29.94$ \\
\hline Crimp Tool & 1 & $\$ 5.95$ & $\$ 5.95$ \\
\hline M10 Ring Crimp Terminal, 50 pcs. & 1 & $\$ 10.99$ & $\$ 10.99$ \\
\hline Velcro Straps (50 per pack) & 1 & $\$ 7.99$ & $\$ 7.99$ \\
\hline Wire-12 AWG, $100 \mathrm{ft}$ & 1 & $\$ 20.37$ & $\$ 20.37$ \\
\hline Wire-12 AWG, $50 \mathrm{ft}$ & 8 & $\$ 12.97$ & $\$ 103.76$ \\
\hline Wire-12 AWG, $50 \mathrm{ft}$ & 2 & $\$ 11.37$ & $\$ 22.74$ \\
\hline Total & & & $\$ 286.63$ \\
\hline
\end{tabular}




\section{Appendix B: Bidirectional System Three-Line Diagram}

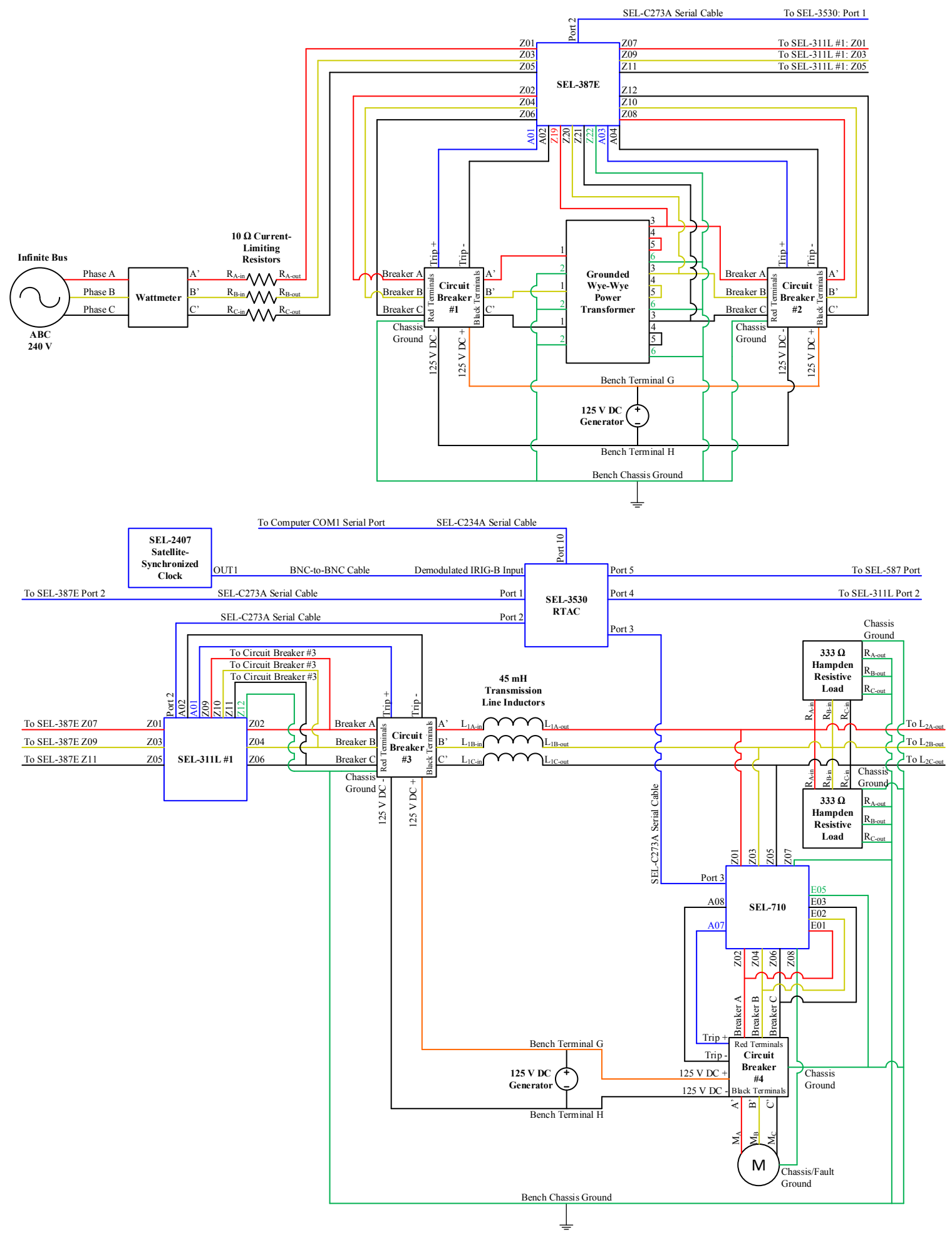

Figure 68: Bidirectional System Three-Line Diagram 


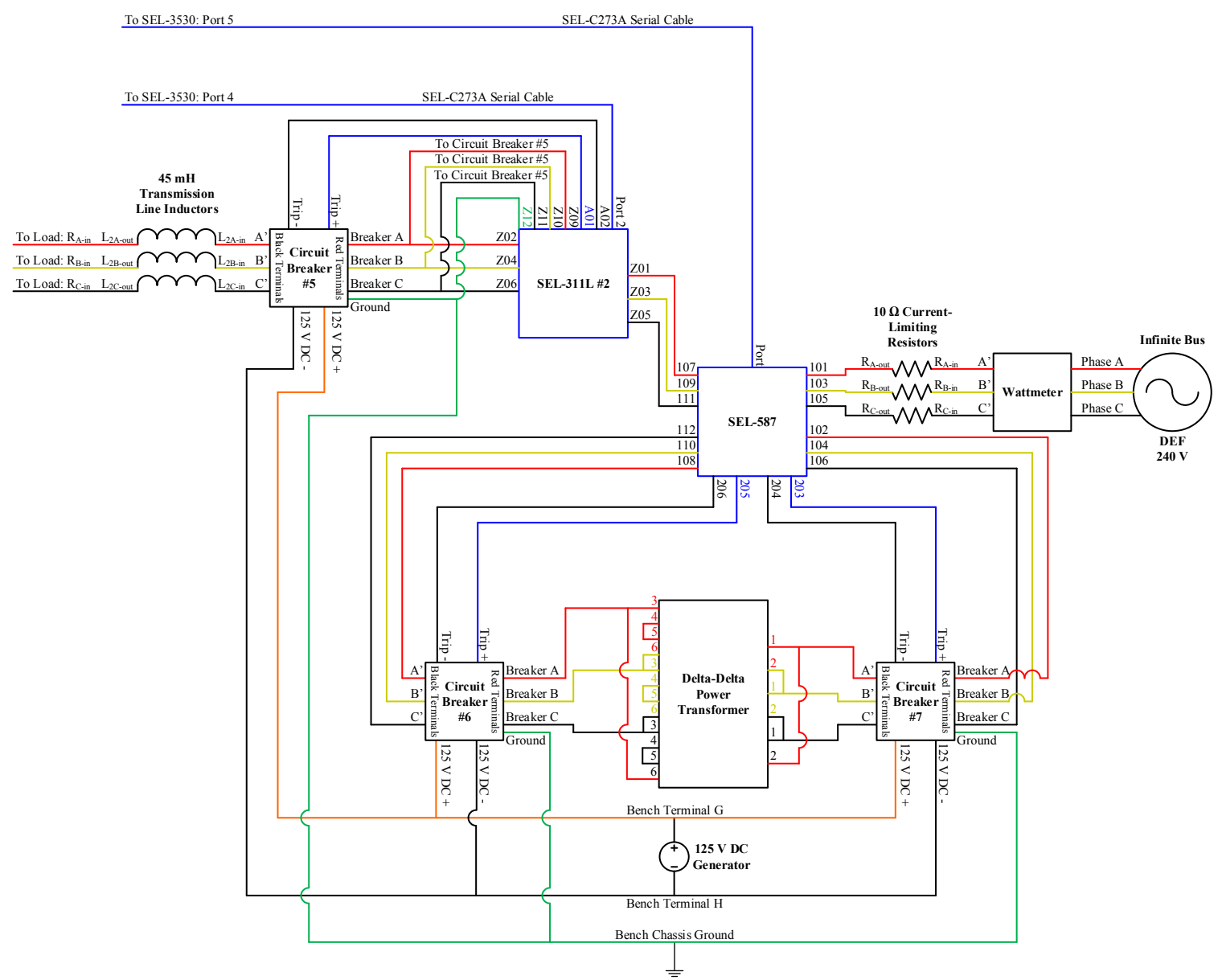

Figure 69: Bidirectional System Three-Line Diagram, Continued 


\section{Appendix C: SEL-311L Line 1 Settings}

\begin{tabular}{|c|c|c|c|}
\hline \multicolumn{4}{|c|}{ Group 1} \\
\hline Setting & Description & Range & Value \\
\hline RID & Relay Identifier (30 chars) & $\begin{array}{l}\text { Range }=\text { ASCII } \\
\text { string with a } \\
\text { maximum } \\
\text { length of } 30 .\end{array}$ & SEL-311L \\
\hline TID & |Terminal Identifier (30 chars) & $\begin{array}{l}\text { Range }=\text { ASCII } \\
\text { string with a } \\
\text { maximum } \\
\text { length of } 30 .\end{array}$ & LINE 1 (RADIAL) \\
\hline CTR & $\begin{array}{l}\text { Local Phase (IA,IB,IC) CT } \\
\text { Ratio, CTR:1 }\end{array}$ & $\begin{array}{l}\text { Range }=1 \text { to } \\
6000\end{array}$ & 1 \\
\hline APP & Application & \begin{tabular}{|l} 
Select: 87L, \\
87L21, 87L21P, \\
87LSP, 311L
\end{tabular} & $311 \mathrm{~L}$ \\
\hline EADVS & Advanced Settings Enable & Select: Y, N & $\mathrm{Y}$ \\
\hline E87L & Number of 87L Terminals & $\begin{array}{l}\text { Select: 2, 3, 3R, } \\
\mathrm{N}\end{array}$ & $\mathrm{N}$ \\
\hline CTRP & \begin{tabular}{|l} 
Polarizing (IPOL) CT Ratio, \\
CTRP:1
\end{tabular} & $\begin{array}{l}\text { Range }=1 \text { to } \\
6000\end{array}$ & 200 \\
\hline PTR & $\begin{array}{l}\text { Phase (VA,VB,VC) PT Ratio, } \\
\text { PTR:1 }\end{array}$ & $\begin{array}{l}\text { Range }=1.00 \text { to } \\
10000.00\end{array}$ & 1.00 \\
\hline PTRS & $\begin{array}{l}\text { Synch. Voltage (VS) PT Ratio, } \\
\text { PTRS:1 }\end{array}$ & $\begin{array}{l}\text { Range }=1.00 \text { to } \\
10000.00\end{array}$ & 2000.00 \\
\hline Z1MAG & \begin{tabular}{|l} 
Pos-Seq Line Impedance \\
Magnitude (Ohms secondary)
\end{tabular} & $\begin{array}{l}\text { Range }=0.05 \text { to } \\
255.00\end{array}$ & 17.33 \\
\hline Z1ANG & $\begin{array}{l}\begin{array}{l}\text { Pos-Seq Line Impedance Angle } \\
\text { (degrees) }\end{array} \\
\end{array}$ & $\begin{array}{l}\text { Range }=5.00 \text { to } \\
90.00\end{array}$ & 88.68 \\
\hline Z0MAG & \begin{tabular}{|l|} 
Zero-Seq Line Impedance \\
Magnitude (Ohms secondary) \\
\end{tabular} & $\begin{array}{l}\text { Range }=0.05 \text { to } \\
255.00\end{array}$ & 17.33 \\
\hline ZOANG & \begin{tabular}{|l|}
$\begin{array}{l}\text { Zero-Seq Line Impedance Angle } \\
\text { (degrees) }\end{array}$ \\
\end{tabular} & $\begin{array}{l}\text { Range }=5.00 \text { to } \\
90.00\end{array}$ & 88.68 \\
\hline LL & Line Length (unitless) & $\begin{array}{l}\text { Range }=0.10 \text { to } \\
999.00\end{array}$ & 100.00 \\
\hline EFLOC & Fault Location Enable & Select: Y, N & $\mathrm{N}$ \\
\hline E21P & $\begin{array}{l}\text { Enable Mho Phase Distance } \\
\text { Elements }\end{array}$ & $\begin{array}{l}\text { Select: N, 1-4, } \\
\text { 1C-4C }\end{array}$ & 3 \\
\hline ECCVT & $\begin{array}{l}\text { CCVT Transient Detection } \\
\text { Enable }\end{array}$ & Select: Y, N & $\mathrm{N}$ \\
\hline Z1P & Reach Zone 1 (Ohms secondary) & $\begin{array}{l}\text { Range }=0.05 \text { to } \\
64.00, \text { OFF }\end{array}$ & 14.73 \\
\hline $\mathrm{Z} 2 \mathrm{P}$ & Reach Zone 2 (Ohms secondary) & $\begin{array}{l}\text { Range }=0.05 \text { to } \\
64.00, \text { OFF }\end{array}$ & 20.70 \\
\hline $\mathrm{Z3P}$ & Reach Zone 3 (Ohms secondary) & $\begin{array}{l}\text { Range }=0.05 \text { to } \\
64.00, \text { OFF }\end{array}$ & 5.00 \\
\hline
\end{tabular}




\begin{tabular}{|c|c|c|c|}
\hline \multicolumn{4}{|c|}{ Group 1} \\
\hline Setting & Description & Range & Value \\
\hline $50 \mathrm{PP} 1$ & $\begin{array}{l}\text { Phase-Phase Overcurrent Fault } \\
\text { Detector Zone } 1 \text { (Amps } \\
\text { secondary) }\end{array}$ & $\begin{array}{l}\text { Range }=0.50 \text { to } \\
170.00\end{array}$ & 0.50 \\
\hline $50 \mathrm{PP} 2$ & $\begin{array}{l}\text { Phase-Phase Overcurrent Fault } \\
\text { Detector Zone } 2 \text { (Amps } \\
\text { secondary) }\end{array}$ & $\begin{array}{l}\text { Range }=0.50 \text { to } \\
170.00\end{array}$ & $\mid 0.50$ \\
\hline $50 \mathrm{PP} 3$ & $\begin{array}{l}\text { Phase-Phase Overcurrent Fault } \\
\text { Detector Zone } 3 \text { (Amps } \\
\text { secondary) }\end{array}$ & $\begin{array}{l}\text { Range }=0.50 \text { to } \\
170.00\end{array}$ & $\mid 0.50$ \\
\hline E21MG & $\begin{array}{l}\text { Enable Mho Ground Distance } \\
\text { Elements }\end{array}$ & Select: N, 1-4 & 3 \\
\hline Z1MG & Zone 1 (Ohms secondary) & \begin{tabular}{|l|} 
Range $=0.05$ to \\
64.00, OFF
\end{tabular} & 14.73 \\
\hline Z2MG & Zone 2 (Ohms secondary) & $\begin{array}{l}\text { Range }=0.05 \text { to } \\
64.00, \text { OFF }\end{array}$ & 20.70 \\
\hline Z3MG & Zone 3 (Ohms secondary) & $\begin{array}{l}\text { Range }=0.05 \text { to } \\
64.00, \text { OFF }\end{array}$ & 5.00 \\
\hline E21XG & $\begin{array}{l}\text { Enable Quad Ground Distance } \\
\text { Elements }\end{array}$ & Select: N, 1-4 & N \\
\hline $50 \mathrm{~L} 1$ & $\begin{array}{l}\text { Zone 1 Phase Current FD (Amps } \\
\text { secondary) }\end{array}$ & \begin{tabular}{|l|} 
Range $=0.50$ to \\
100.00
\end{tabular} & 0.50 \\
\hline $50 \mathrm{~L} 2$ & $\begin{array}{l}\text { Zone 2 Phase Current FD (Amps } \\
\text { secondary) }\end{array}$ & \begin{tabular}{l|} 
Range $=0.50$ to \\
100.00
\end{tabular} & 0.50 \\
\hline $50 \mathrm{~L} 3$ & $\begin{array}{l}\text { Zone 3 Phase Current FD (Amps } \\
\text { secondary) }\end{array}$ & $\begin{array}{l}\text { Range }=0.50 \text { to } \\
100.00\end{array}$ & 0.50 \\
\hline $50 \mathrm{GZ1}$ & $\begin{array}{l}\begin{array}{l}\text { Zone 1 Residual Current FD } \\
\text { (Amps secondary) }\end{array} \\
\end{array}$ & $\begin{array}{l}\text { Range }=0.50 \text { to } \\
100.00\end{array}$ & 0.50 \\
\hline $50 \mathrm{GZ2}$ & \begin{tabular}{|l}
$\begin{array}{l}\text { Zone } 2 \text { Residual Current FD } \\
\text { (Amps secondary) }\end{array}$ \\
\end{tabular} & \begin{tabular}{|l|} 
Range $=0.50$ to \\
100.00
\end{tabular} & 0.50 \\
\hline $50 \mathrm{GZ3}$ & $\begin{array}{l}\text { Zone } 3 \text { Residual Current FD } \\
\text { (Amps secondary) }\end{array}$ & \begin{tabular}{|l|} 
Range $=0.50$ to \\
100.00
\end{tabular} & 0.50 \\
\hline k0M1 & $\begin{array}{l}\begin{array}{l}\text { Zone 1 ZSC Factor Mag } \\
\text { (unitless) }\end{array} \\
\text { (n) }\end{array}$ & $\begin{array}{l}\text { Range }=0.000 \\
\text { to } 6.000\end{array}$ & 0.726 \\
\hline k0A1 & $\begin{array}{l}\text { Zone } 1 \text { ZSC Factor Ang } \\
\text { (degrees) }\end{array}$ & $\begin{array}{l}\text { Range }=- \\
180.00 \text { to } \\
180.00\end{array}$ & -3.69 \\
\hline $\mathrm{k} 0 \mathrm{M}$ & $\begin{array}{l}\text { Zone 2,3,\&4 ZSC Factor Mag } \\
\text { (unitless) }\end{array}$ & $\begin{array}{l}\text { Range }=0.000 \\
\text { to } 6.000\end{array}$ & 0.726 \\
\hline $\mathrm{k} 0 \mathrm{~A}$ & $\begin{array}{l}\text { Zone 2,3,\&4 ZSC Factor Ang } \\
\text { (degrees) }\end{array}$ & \begin{tabular}{|l|} 
Range $=-$ \\
180.00 to \\
180.00 \\
\end{tabular} & -3.69 \\
\hline Z1PD & $\begin{array}{l}\text { Zone } 1 \text { Time Delay (cycles in } \\
0.25 \text { increments) }\end{array}$ & $\begin{array}{l}\text { Range }=0.00 \text { to } \\
16000.00, \text { OFF }\end{array}$ & 22.00 \\
\hline Z2PD & $\begin{array}{l}\text { Zone } 2 \text { Time Delay (cycles in } \\
0.25 \text { increments) }\end{array}$ & $\begin{array}{l}\text { Range }=0.00 \text { to } \\
16000.00, \text { OFF }\end{array}$ & 25.00 \\
\hline
\end{tabular}




\begin{tabular}{|c|c|c|c|}
\hline \multicolumn{4}{|l|}{ Group 1} \\
\hline Setting & Description & Range & Value \\
\hline Z3PD & $\begin{array}{l}\text { Zone } 3 \text { Time Delay (cycles in } \\
0.25 \text { increments) }\end{array}$ & $\begin{array}{l}\text { Range }=0.00 \text { to } \\
16000.00, \text { OFF } \\
\end{array}$ & 25.00 \\
\hline Z1GD & $\begin{array}{l}\text { Zone } 1 \text { Time Delay (cycles in } \\
0.25 \text { increments) }\end{array}$ & \begin{tabular}{|l|} 
Range $=0.00$ to \\
16000.00, OFF \\
\end{tabular} & 2.00 \\
\hline Z2GD & $\begin{array}{l}\text { Zone } 2 \text { Time Delay (cycles in } \\
0.25 \text { increments) }\end{array}$ & $\begin{array}{l}\text { Range }=0.00 \text { to } \\
16000.00, \text { OFF } \\
\end{array}$ & 5.00 \\
\hline Z3GD & $\begin{array}{l}\text { Zone } 3 \text { Time Delay (cycles in } \\
0.25 \text { increments) }\end{array}$ & $\begin{array}{l}\text { Range }=0.00 \text { to } \\
16000.00, \text { OFF } \\
\end{array}$ & 5.00 \\
\hline Z1D & \begin{tabular}{|l} 
Zone 1 Time Delay (cycles in \\
0.25 increments)
\end{tabular} & $\begin{array}{l}\text { Range }=0.00 \text { to } \\
16000.00, \text { OFF } \\
\end{array}$ & 5.00 \\
\hline Z2D & $\begin{array}{l}\text { Zone } 2 \text { Time Delay (cycles in } \\
0.25 \text { increments) }\end{array}$ & $\begin{array}{l}\text { Range }=0.00 \text { to } \\
16000.00, \text { OFF } \\
\end{array}$ & 5.00 \\
\hline Z3D & $\begin{array}{l}\text { Zone } 3 \text { Time Delay (cycles in } \\
0.25 \text { increments) } \\
\end{array}$ & $\begin{array}{l}\text { Range }=0.00 \text { to } \\
16000.00, \text { OFF } \\
\end{array}$ & 5.00 \\
\hline E50P & $\begin{array}{l}\text { Enable Phase Overcurrent } \\
\text { Elements }\end{array}$ & Select: N, 1-3 & $\| \mathrm{N}$ \\
\hline E50G & \begin{tabular}{|l|} 
Enable Residual Ground \\
Overcurrent Elements
\end{tabular} & Select: N, 1-4 & N \\
\hline E50Q & \begin{tabular}{|l|} 
Enable Negative-Sequence \\
Overcurrent Elements \\
\end{tabular} & Select: N, 1-4 & $\| \mathrm{N}$ \\
\hline E51P & $\begin{array}{l}\text { Enable Phase Time-Overcurrent } \\
\text { Elements }\end{array}$ & Select: Y, N & Y \\
\hline $51 \mathrm{PP}$ & Pickup (Amps secondary) & \begin{tabular}{|l|} 
Range $=0.25$ to \\
16.00, OFF
\end{tabular} & 4.50 \\
\hline $51 \mathrm{PC}$ & Curve & \begin{tabular}{|l|} 
Select: U1-U5, \\
C1-C5
\end{tabular} & U1 \\
\hline 51PTD & Time Dial & $\begin{array}{l}\text { Range }=0.50 \text { to } \\
15.00\end{array}$ & 0.50 \\
\hline 51PRS & Electromechanical Reset Delay & Select: Y, N & $\mathrm{N}$ \\
\hline E51G & $\begin{array}{l}\text { Enable Residual Ground Time- } \\
\text { Overcurrent Elements }\end{array}$ & Select: Y, N & Y \\
\hline $51 \mathrm{GP}$ & Pickup (Amps secondary) & $\begin{array}{l}\text { Range }=0.25 \text { to } \\
16.00, \text { OFF }\end{array}$ & 0.25 \\
\hline $51 \mathrm{GC}$ & Curve & \begin{tabular}{|l|} 
Select: U1-U5, \\
C1-C5 \\
\end{tabular} & U1 \\
\hline $51 \mathrm{GTD}$ & Time Dial & $\begin{array}{l}\text { Range }=0.50 \text { to } \\
15.00\end{array}$ & 0.50 \\
\hline $51 \mathrm{GRS}$ & Electromechanical Reset Delay & Select: Y, N & $\mathrm{N}$ \\
\hline E51Q & \begin{tabular}{|l} 
Enable Negative-Sequence \\
Time-Overcurrent Elements
\end{tabular} & Select: Y, N & $\mathrm{Y}$ \\
\hline $51 \mathrm{QP}$ & Pickup (Amps secondary) & \begin{tabular}{|l|} 
Range $=0.25$ to \\
16.00, OFF \\
\end{tabular} & 0.25 \\
\hline $51 \mathrm{QC}$ & Curve & $\begin{array}{l}\text { Select: U1-U5, } \\
\text { C1-C5 }\end{array}$ & U1 \\
\hline
\end{tabular}




\begin{tabular}{|c|c|c|c|}
\hline \multicolumn{4}{|l|}{ Group 1} \\
\hline Setting & Description & Range & Value \\
\hline 51QTD & Time Dial & \begin{tabular}{|l|} 
Range $=0.50$ to \\
15.00
\end{tabular} & 0.50 \\
\hline $51 \mathrm{QRS}$ & Electromechanical Reset Delay & Select: Y, N & $\mathrm{N}$ \\
\hline EOOS & Enable Out-of-Step Elements & Select: Y, N & $\mathrm{N}$ \\
\hline ELOAD & $\begin{array}{l}\text { Enable Load Encroachment } \\
\text { Elements }\end{array}$ & Select: Y, N & $\mathrm{N}$ \\
\hline E32 & $\begin{array}{l}\text { Enable Directional Control } \\
\text { Elements }\end{array}$ & $\begin{array}{l}\text { Select: Y, } \\
\text { AUTO }\end{array}$ & AUTO \\
\hline ELOP & Loss-Of-Potential Enable & \begin{tabular}{|l} 
Select: Y, Y1, \\
$\mathrm{N}$
\end{tabular} & $\mathrm{N}$ \\
\hline DIR3 & Level 3 Direction & Select: F, R & $\mathrm{R}$ \\
\hline DIR4 & Level 4 Direction & Select: F, R & $\mathrm{F}$ \\
\hline ORDER & \begin{tabular}{|l} 
Ground Directional Element \\
Priority
\end{tabular} & $\begin{array}{l}\text { Select: I, Q, V, } \\
\text { OFF }\end{array}$ & |QVI \\
\hline EVOLT & Enable Voltage Element Enables & Select: Y, N & $\mathrm{N}$ \\
\hline E25 & Synchronism Check Enable & Select: Y, N & $\mathrm{N}$ \\
\hline E81 & Frequency Elements Enables & Select: N, 1-6 & $\mathrm{N}$ \\
\hline E79 & Reclosures Enables & Select: N, 1-4 & $\mathrm{N}$ \\
\hline ESOTF & Enable Switch-Onto-Fault & Select: Y, N & $\mathrm{N}$ \\
\hline ECOMM & \begin{tabular}{||l} 
Comm.-Assisted Trip Scheme \\
Enables
\end{tabular} & \begin{tabular}{|l|} 
Select: N, \\
POTT, DCUB1, \\
DCUB2, DCB \\
\end{tabular} & $\mathrm{N}$ \\
\hline EZ1EXT & Zone 1 Extension & Select: Y, N & $\mathrm{N}$ \\
\hline EDEM & Demand Metering Type & $\begin{array}{l}\text { Select: THM, } \\
\text { ROL }\end{array}$ & THM \\
\hline DMTC & |Time Constant (minutes) & \begin{tabular}{|l} 
Select: 5,10 \\
$15,30,60$
\end{tabular} & 60 \\
\hline PDEMP & Phase Pickup (Amps secondary) & $\begin{array}{l}\text { Range }=0.50 \text { to } \\
16.00, \text { OFF }\end{array}$ & OFF \\
\hline GDEMP & $\begin{array}{l}\text { Residual Ground Pickup (Amps } \\
\text { secondary) }\end{array}$ & \begin{tabular}{|l|} 
Range $=0.50$ to \\
16.00, OFF \\
\end{tabular} & $\mathrm{OFF}$ \\
\hline QDEMP & $\begin{array}{l}\text { Negative-Sequence Pickup } \\
\text { (Amps secondary) }\end{array}$ & \begin{tabular}{|l|} 
Range $=0.50$ to \\
16.00, OFF \\
\end{tabular} & OFF \\
\hline TDURD & $\begin{array}{l}\text { Minimum Trip Duration Time } \\
\text { (cycles in } 0.25 \text { increments) }\end{array}$ & \begin{tabular}{|l|} 
Range $=2.00$ to \\
16000.00 \\
\end{tabular} & 2.00 \\
\hline TOPD & $\begin{array}{l}\text { Trip Open Pole Dropout Delay } \\
\text { (cycles in } 0.25 \text { increments) }\end{array}$ & \begin{tabular}{l|} 
Range $=2.00$ to \\
8000.00
\end{tabular} & 2.00 \\
\hline CFD & \begin{tabular}{|l}
$\begin{array}{l}\text { Close Failure Time Delay } \\
\text { (cycles in } 0.25 \text { increments) }\end{array}$ \\
\end{tabular} & $\begin{array}{l}\text { Range }=0.00 \text { to } \\
16000.00, \text { OFF }\end{array}$ & 60.00 \\
\hline 3POD & \begin{tabular}{|l} 
Three-Pole Open Time Delay \\
(cycles in 0.25 increments)
\end{tabular} & $\begin{array}{l}\text { Range }=0.00 \text { to } \\
60.00\end{array}$ & 0.50 \\
\hline $\mathrm{OPO}$ & Open Pole Option & Select: 27,52 & 52 \\
\hline
\end{tabular}




\begin{tabular}{|c|c|c|c|}
\hline \multicolumn{4}{|c|}{ Group 1} \\
\hline Setting & Description & Range & Value \\
\hline $50 \mathrm{LP}$ & $\begin{array}{l}\text { Load Detection Phase Pickup } \\
\text { (Amps secondary) }\end{array}$ & $\begin{array}{l}\text { Range }=0.25 \text { to } \\
100.00, \text { OFF }\end{array}$ & 0.25 \\
\hline ELAT & SELogic Latch Bit Enables & Select: N, 1-16 & 16 \\
\hline EDP & SELogic Display Point Enables & Select: N, 1-16 & 16 \\
\hline ESV & $\begin{array}{l}\text { SELogic Variable Timers } \\
\text { Enables }\end{array}$ & Select: N, 1-16 & N \\
\hline \multicolumn{4}{|c|}{ Group 1} \\
\hline
\end{tabular}

\begin{tabular}{|c|c|c|c|}
\hline \multicolumn{4}{|c|}{ SELogic 1} \\
\hline Setting & Description & Range & Value \\
\hline TR & Direct Trip Conditions & $\begin{array}{l}\text { Valid range = } \\
\text { Boolean } \\
\text { equation using } \\
\text { word bit } \\
\text { elements and } \\
\text { the legal } \\
\text { operators: ! / ( } \\
*+ \\
\end{array}$ & $\begin{array}{l}\mathrm{M} 1 \mathrm{P}+\mathrm{M} 2 \mathrm{PT}+\mathrm{M} 3 \mathrm{PT}+51 \mathrm{PT}+51 \mathrm{GT}+ \\
51 \mathrm{QT}\end{array}$ \\
\hline DTT & $\begin{array}{l}\text { Direct Transfer Trip } \\
\text { Conditions }\end{array}$ & $\begin{array}{l}\text { Valid range = } \\
\text { Boolean } \\
\text { equation using } \\
\text { word bit } \\
\text { elements and } \\
\text { the legal } \\
\text { operators: ! / } \\
*+ \\
\end{array}$ & 0 \\
\hline ULTR & Unlatch Trip Conditions & $\begin{array}{l}\text { Valid range = } \\
\text { Boolean } \\
\text { equation using } \\
\text { word bit } \\
\text { elements and } \\
\text { the legal } \\
\text { operators: ! / ( } \\
)_{+}^{*}\end{array}$ & $!(50 \mathrm{~L}+51 \mathrm{G})$ \\
\hline $52 \mathrm{~A}$ & Circuit breaker status & $\begin{array}{l}\text { Valid range = } \\
\text { Boolean } \\
\text { equation using } \\
\text { word bit } \\
\text { elements and } \\
\text { the legal } \\
\text { operators: ! / } \\
)^{*}+ \\
\end{array}$ & IN101 \\
\hline $\mathrm{CL}$ & $\begin{array}{l}\text { Close conditions (other than } \\
\text { automatic reclosing or CLOSE } \\
\text { command) }\end{array}$ & \begin{tabular}{|l} 
Valid range $=$ \\
Boolean \\
equation using \\
word bit
\end{tabular} & $\mathrm{CC}$ \\
\hline
\end{tabular}




\begin{tabular}{|c|c|c|c|}
\hline \multicolumn{4}{|c|}{ SELogic 1} \\
\hline Setting & Description & Range & Value \\
\hline & & \begin{tabular}{|l} 
elements and \\
the legal \\
operators: ! / ( \\
$*+$ \\
\end{tabular} & \\
\hline ULCL & Unlatch close conditions & \begin{tabular}{|l} 
Valid range $=$ \\
Boolean \\
equation using \\
word bit \\
elements and \\
the legal \\
operators: ! / \\
*+
\end{tabular} & TRIP + TRIP87 \\
\hline 51PTC & Phase & \begin{tabular}{|l} 
Valid range $=$ \\
Boolean \\
equation using \\
word bit \\
elements and \\
the legal \\
operators: ! \\
*+
\end{tabular} & 1 \\
\hline $51 \mathrm{GTC}$ & Residual Ground & \begin{tabular}{|l} 
Valid range $=$ \\
Boolean \\
equation using \\
word bit \\
elements and \\
the legal \\
operators: ! $\backslash($ \\
$*+$ \\
$*$
\end{tabular} & 1 \\
\hline 51QTC & Negative-Sequence & $\begin{array}{l}\text { Valid range }= \\
\text { Boolean } \\
\text { equation using } \\
\text { word bit } \\
\text { elements and } \\
\text { the legal } \\
\text { operators: ! } \\
*+ \\
*+\end{array}$ & 1 \\
\hline OUT101 & Output Contact 101 & $\begin{array}{l}\text { Valid range }= \\
\text { Boolean } \\
\text { equation using } \\
\text { word bit } \\
\text { elements and } \\
\text { the legal } \\
\text { operators: ! / } \\
*+ \\
*\end{array}$ & !TRIP \\
\hline DP1 & Display Point 1 & $\begin{array}{l}\text { Valid range = } \\
\text { Boolean } \\
\text { equation using } \\
\text { word bit } \\
\text { elements and } \\
\text { the legal } \\
\end{array}$ & $52 \mathrm{~A}$ \\
\hline
\end{tabular}




\begin{tabular}{|c|c|c|c|}
\hline \multicolumn{4}{|c|}{ SELogic 1} \\
\hline Setting & Description & Range & Value \\
\hline & & $\begin{array}{l}\text { operators: } ! / \backslash( \\
*+\end{array}$ & \\
\hline DP2 & Display Point 2 & \begin{tabular}{|l} 
Valid range $=$ \\
Boolean \\
equation using \\
word bit \\
elements and \\
the legal \\
operators: ! / \\
*+
\end{tabular} & CHXAL \\
\hline DP3 & Display Point 3 & $\begin{array}{l}\text { Valid range }= \\
\text { Boolean } \\
\text { equation using } \\
\text { word bit } \\
\text { elements and } \\
\text { the legal } \\
\text { operators: ! / ( } \\
*+\end{array}$ & CHYAL \\
\hline ER & $\begin{array}{l}\text { Event Report Trigger } \\
\text { Conditions }\end{array}$ & $\begin{array}{l}\text { Valid range }= \\
\text { Boolean } \\
\text { equation using } \\
\text { word bit } \\
\text { elements and } \\
\text { the legal } \\
\text { operators: ! / ( } \\
*+ \\
*\end{array}$ & $\begin{array}{l}/ \mathrm{M} 2 \mathrm{P}+/ \mathrm{Z} 2 \mathrm{G}+/ 51 \mathrm{G}+/ 51 \mathrm{Q}+/ 51 \mathrm{P}+ \\
/ \mathrm{LOP}+/ \mathrm{M} 1 \mathrm{P}+/ \mathrm{Z} 1 \mathrm{G}+/ \mathrm{M} 3 \mathrm{P}+/ \mathrm{Z} 3 \mathrm{G}\end{array}$ \\
\hline FAULT & Fault Indication & $\begin{array}{l}\text { Valid range }= \\
\text { Boolean } \\
\text { equation using } \\
\text { word bit } \\
\text { elements and } \\
\text { the legal } \\
\text { operators: ! / } \\
*+ \\
\end{array}$ & $\begin{array}{l}51 G+51 Q+M 2 P+Z 2 G+51 P+M 1 P+ \\
Z 1 G+M 3 P+Z 3 G\end{array}$ \\
\hline E32IV & $\begin{array}{l}\text { Enable for V0 Polarized and } \\
\text { IN Polarized Elements }\end{array}$ & \begin{tabular}{|l} 
Valid range $=$ \\
Boolean \\
equation using \\
word bit \\
elements and \\
the legal \\
operators: ! / ( \\
$*+$ \\
\end{tabular} & 1 \\
\hline ESTUB & Stub Bus Logic Enable & $\begin{array}{l}\text { Valid range }= \\
\text { Boolean } \\
\text { equation using } \\
\text { word bit } \\
\text { elements and } \\
\text { the legal } \\
\text { operators: ! / } \\
*+\end{array}$ & 0 \\
\hline
\end{tabular}




\begin{tabular}{|c|c|c|c|}
\hline SELogic & & & \\
\hline Setting & Description & Range & Value \\
\hline $\mathrm{T} 1 \mathrm{X}$ & 87L Channel X, Transmit Bit 1 & \begin{tabular}{|l} 
Valid range $=$ \\
Boolean \\
equation using \\
word bit \\
elements and \\
the legal \\
operators: ! \\
$*+$ \\
$*+$
\end{tabular} & KEY \\
\hline $\mathrm{T} 2 \mathrm{X}$ & 87L Channel X, Transmit Bit 2 & $\begin{array}{l}\text { Valid range }= \\
\text { Boolean } \\
\text { equation using } \\
\text { word bit } \\
\text { elements and } \\
\text { the legal } \\
\text { operators: ! } \( \\
*+\end{array}$ & 0 \\
\hline $\mathrm{T} 3 \mathrm{X}$ & 87L Channel X, Transmit Bit 3 & $\begin{array}{l}\text { Valid range }= \\
\text { Boolean } \\
\text { equation using } \\
\text { word bit } \\
\text { elements and } \\
\text { the legal } \\
\text { operators: ! } \\
\text { *+ }\end{array}$ & 0 \\
\hline T4X & 87L Channel X, Transmit Bit 4 & \begin{tabular}{|l} 
Valid range $=$ \\
Boolean \\
equation using \\
word bit \\
elements and \\
the legal \\
operators: ! / ( \\
$* *+$
\end{tabular} & 0 \\
\hline $\mathrm{T} 1 \mathrm{Y}$ & 87L Channel Y, Transmit Bit 1 & \begin{tabular}{|l} 
Valid range $=$ \\
Boolean \\
equation using \\
word bit \\
elements and \\
the legal \\
operators: ! / \\
$*+$
\end{tabular} & 0 \\
\hline $\mathrm{T} 2 \mathrm{Y}$ & 87L Channel Y, Transmit Bit 2 & \begin{tabular}{|l} 
Valid range $=$ \\
Boolean \\
equation using \\
word bit \\
elements and \\
the legal \\
operators: ! / ( \\
$*+$
\end{tabular} & 0 \\
\hline $\mathrm{T} 3 \mathrm{Y}$ & 87L Channel Y, Transmit Bit 3 & $\begin{array}{l}\text { Valid range }= \\
\text { Boolean }\end{array}$ & 0 \\
\hline
\end{tabular}




\begin{tabular}{|c|c|c|c|}
\hline \\
\hline \multicolumn{4}{|c|}{\begin{tabular}{|l|l|} 
SELogic 1 \\
Setting & Description
\end{tabular}} \\
\hline & & \begin{tabular}{|l} 
equation using \\
word bit \\
elements and \\
the legal \\
operators: ! / ( \\
)*+
\end{tabular} & \\
\hline T4Y & 87L Channel Y, Transmit Bit 4 & $\begin{array}{l}\text { Valid range = } \\
\text { Boolean } \\
\text { equation using } \\
\text { word bit } \\
\text { elements and } \\
\text { the legal } \\
\text { operators: ! 八 ( } \\
\text { )*++ }\end{array}$ & 0 \\
\hline
\end{tabular}

\begin{tabular}{|c|c|c|c|}
\hline \\
\hline Group 2 & Description & Range & Value \\
\hline RID & Relay Identifier (30 chars) & \begin{tabular}{|l|} 
Range $=$ ASCII \\
string with a \\
maximum \\
length of 30. \\
\end{tabular} & SEL-311L \\
\hline TID & Terminal Identifier (30 chars) & \begin{tabular}{|l|} 
Range $=$ ASCII \\
string with a \\
maximum \\
length of 30. \\
\end{tabular} & LINE 1 (BIDIRECTIONAL) \\
\hline CTR & $\begin{array}{l}\text { Local Phase (IA,IB,IC) CT } \\
\text { Ratio, CTR:1 }\end{array}$ & $\begin{array}{l}\text { Range }=1 \text { to } \\
6000\end{array}$ & 1 \\
\hline APP & Application & \begin{tabular}{|l} 
Select: 87L, \\
87L21, \\
87L21P, \\
87LSP, 311L
\end{tabular} & $87 \mathrm{LSP}$ \\
\hline EADVS & Advanced Settings Enable & Select: Y, N & $\mathrm{Y}$ \\
\hline EHST & High Speed Tripping & \begin{tabular}{|l} 
Select: SP1, \\
SP2, N
\end{tabular} & $\mathrm{N}$ \\
\hline EHSDTT & $\begin{array}{l}\text { Enable High Speed Direct } \\
\text { Transfer Trip } \\
\end{array}$ & Select: $\mathrm{Y}, \mathrm{N}$ & $\mathrm{N}$ \\
\hline EDD & Enable Disturbance Detect & Select: Y, N & $\mathrm{N}$ \\
\hline ETAP & Tapped Load Coordination & Select: $\mathrm{Y}, \mathrm{N}$ & $\mathrm{N}$ \\
\hline EOCTL & Enable Open CT Logic & Select: Y, N & $\mathrm{N}$ \\
\hline PCHAN & Primary 87L Channel & Select: X, Y & $\mathrm{X}$ \\
\hline EHSC & Hot-Standby Channel Feature & Select: Y, N & $\mathrm{N}$ \\
\hline CTR_X & $\begin{array}{l}\text { CTR at Terminal Connected } \\
\text { to Channel X }\end{array}$ & $\begin{array}{l}\text { Range }=1 \text { to } \\
6000\end{array}$ & 1 \\
\hline
\end{tabular}




\begin{tabular}{|c|c|c|c|}
\hline \multicolumn{4}{|l|}{ Group 2} \\
\hline Setting & Description & Range & Value \\
\hline 87LPP & Phase 87L (Amps secondary) & $\begin{array}{l}\text { Range }=1.00 \\
\text { to } 10.00, \text { OFF }\end{array}$ & OFF \\
\hline 87L2P & $\begin{array}{l}\text { 3I2 Negative-Sequence 87L } \\
\text { (Amps secondary) }\end{array}$ & $\begin{array}{l}\text { Range }=0.50 \\
\text { to } 5.00, \text { OFF }\end{array}$ & OFF \\
\hline 87LGP & $\begin{array}{l}\text { Ground 87L (Amps } \\
\text { secondary) }\end{array}$ & $\begin{array}{l}\text { Range }=0.50 \\
\text { to } 5.00, \text { OFF }\end{array}$ & OFF \\
\hline CTALRM & \begin{tabular}{|l} 
Ph. Diff. Current Alarm \\
Pickup (Amps secondary)
\end{tabular} & $\begin{array}{l}\text { Range }=0.50 \\
\text { to } 10.00\end{array}$ & $\| 0.50$ \\
\hline $87 \mathrm{LR}$ & Outer Radius & $\begin{array}{l}\text { Range }=2.0 \text { to } \\
8.0\end{array}$ & 6.0 \\
\hline 87LANG & Angle (degrees) & $\begin{array}{l}\text { Range }=90 \text { to } \\
270\end{array}$ & 195 \\
\hline CTRP & $\begin{array}{l}\text { Polarizing (IPOL) CT Ratio, } \\
\text { CTRP:1 }\end{array}$ & $\begin{array}{l}\text { Range }=1 \text { to } \\
6000\end{array}$ & 200 \\
\hline PTR & $\begin{array}{l}\text { Phase (VA,VB,VC) PT Ratio, } \\
\text { PTR:1 }\end{array}$ & $\begin{array}{l}\text { Range }=1.00 \\
\text { to } 10000.00\end{array}$ & $\mid 1.00$ \\
\hline PTRS & \begin{tabular}{|l} 
Synch. Voltage (VS) PT \\
Ratio, PTRS:1
\end{tabular} & $\begin{array}{l}\text { Range }=1.00 \\
\text { to } 10000.00\end{array}$ & 2000.00 \\
\hline Z1MAG & \begin{tabular}{|l} 
Pos-Seq Line Impedance \\
Magnitude (Ohms secondary)
\end{tabular} & $\begin{array}{l}\text { Range }=0.05 \\
\text { to } 255.00\end{array}$ & 41.69 \\
\hline Z1ANG & $\begin{array}{l}\text { Pos-Seq Line Impedance } \\
\text { Angle (degrees) }\end{array}$ & $\begin{array}{l}\text { Range }=5.00 \\
\text { to } 90.00\end{array}$ & 88.00 \\
\hline Z0MAG & \begin{tabular}{|l} 
Zero-Seq Line Impedance \\
Magnitude (Ohms secondary)
\end{tabular} & $\begin{array}{l}\text { Range }=0.05 \\
\text { to } 255.00\end{array}$ & 41.69 \\
\hline ZOANG & \begin{tabular}{|l} 
Zero-Seq Line Impedance \\
Angle (degrees)
\end{tabular} & $\begin{array}{l}\text { Range }=5.00 \\
\text { to } 90.00\end{array}$ & 88.00 \\
\hline LL & Line Length (unitless) & $\begin{array}{l}\text { Range }=0.10 \\
\text { to } 999.00\end{array}$ & $\mid 100.00$ \\
\hline EFLOC & Fault Location Enable & Select: Y, N & $\mathrm{N}$ \\
\hline E21P & $\begin{array}{l}\text { Enable Mho Phase Distance } \\
\text { Elements }\end{array}$ & Select: N, 1-4 & || 3 \\
\hline ECCVT & $\begin{array}{l}\text { CCVT Transient Detection } \\
\text { Enable }\end{array}$ & Select: Y, N & N \\
\hline Z1P & $\begin{array}{l}\text { Reach Zone 1 (Ohms } \\
\text { secondary) }\end{array}$ & $\begin{array}{l}\text { Range }=0.05 \\
\text { to } 64.00, \text { OFF }\end{array}$ & 14.73 \\
\hline $\mathrm{Z} 2 \mathrm{P}$ & $\begin{array}{l}\text { Reach Zone 2 (Ohms } \\
\text { secondary) }\end{array}$ & $\begin{array}{l}\text { Range }=0.05 \\
\text { to } 64.00, \text { OFF }\end{array}$ & 43.00 \\
\hline $\mathrm{Z3P}$ & $\begin{array}{l}\text { Reach Zone 3 (Ohms } \\
\text { secondary) }\end{array}$ & $\begin{array}{l}\text { Range }=0.05 \\
\text { to } 64.00, \text { OFF }\end{array}$ & $\mid 5.00$ \\
\hline $50 \mathrm{PP} 1$ & $\begin{array}{l}\text { Phase-Phase Overcurrent } \\
\text { Fault Detector Zone } 1 \text { (Amps } \\
\text { secondary) }\end{array}$ & $\begin{array}{l}\text { Range }=0.50 \\
\text { to } 170.00\end{array}$ & 0.50 \\
\hline $50 \mathrm{PP} 2$ & $\begin{array}{l}\text { Phase-Phase Overcurrent } \\
\text { Fault Detector Zone } 2 \text { (Amps } \\
\text { secondary) }\end{array}$ & $\begin{array}{l}\text { Range }=0.50 \\
\text { to } 170.00\end{array}$ & $\mid 0.50$ \\
\hline
\end{tabular}




\begin{tabular}{|c|c|c|c|}
\hline \multicolumn{4}{|l|}{ Group 2} \\
\hline Setting & Description & Range & Value \\
\hline $50 \mathrm{PP} 3$ & $\begin{array}{l}\text { Phase-Phase Overcurrent } \\
\text { Fault Detector Zone } 3 \text { (Amps } \\
\text { secondary) }\end{array}$ & $\begin{array}{l}\text { Range }=0.50 \\
\text { to } 170.00\end{array}$ & $\mid 0.50$ \\
\hline E21MG & $\begin{array}{l}\text { Enable Mho Ground Distance } \\
\text { Elements }\end{array}$ & || Select: N, 1-4 & 3 \\
\hline Z1MG & Zone 1 (Ohms secondary) & $\begin{array}{l}\text { Range }=0.05 \\
\text { to } 64.00, \text { OFF }\end{array}$ & 14.73 \\
\hline Z2MG & Zone 2 (Ohms secondary) & $\begin{array}{l}\text { Range }=0.05 \\
\text { to } 64.00, \text { OFF }\end{array}$ & 43.00 \\
\hline $\mathrm{Z} 3 \mathrm{MG}$ & Zone 3 (Ohms secondary) & $\begin{array}{l}\text { Range }=0.05 \\
\text { to } 64.00, \text { OFF }\end{array}$ & 5.00 \\
\hline E21XG & $\begin{array}{l}\text { Enable Quad Ground Distance } \\
\text { Elements }\end{array}$ & Select: N, 1-4 & 3 \\
\hline $\mathrm{XG1}$ & $\begin{array}{l}\text { Zone 1 Reactance (Ohms } \\
\text { secondary) }\end{array}$ & $\begin{array}{l}\text { Range }=0.05 \\
\text { to } 64.00, \text { OFF }\end{array}$ & 6.24 \\
\hline $\mathrm{XG} 2$ & $\begin{array}{l}\text { Zone 2 Reactance (Ohms } \\
\text { secondary) }\end{array}$ & $\begin{array}{l}\text { Range }=0.05 \\
\text { to } 64.00, \text { OFF }\end{array}$ & 9.36 \\
\hline $\mathrm{XG} 3$ & $\begin{array}{l}\text { Zone } 3 \text { Reactance (Ohms } \\
\text { secondary) }\end{array}$ & $\begin{array}{l}\text { Range }=0.05 \\
\text { to } 64.00, \text { OFF }\end{array}$ & 1.87 \\
\hline RG1 & $\begin{array}{l}\text { Zone } 1 \text { Resistance (Ohms } \\
\text { secondary) }\end{array}$ & $\begin{array}{l}\text { Range }=0.05 \\
\text { to } 50.00\end{array}$ & $\mid 2.50$ \\
\hline RG2 & $\begin{array}{l}\text { Zone } 2 \text { Resistance (Ohms } \\
\text { secondary) }\end{array}$ & $\begin{array}{l}\text { Range }=0.05 \\
\text { to } 50.00\end{array}$ & 5.00 \\
\hline RG3 & $\begin{array}{l}\text { Zone 3 Resistance (Ohms } \\
\text { secondary) }\end{array}$ & $\begin{array}{l}\text { Range }=0.05 \\
\text { to } 50.00\end{array}$ & | 6.00 \\
\hline XGPOL & $\begin{array}{l}\text { Quad Ground Polarizing } \\
\text { Quantity }\end{array}$ & Select: I2, IG & || 12 \\
\hline TANG & $\begin{array}{l}\text { Non-Homogenous Correction } \\
\text { Angle (degrees) }\end{array}$ & $\begin{array}{l}\text { Range }=-45.0 \\
\text { to } 45.0\end{array}$ & -3.0 \\
\hline $50 \mathrm{~L} 1$ & \begin{tabular}{|l|} 
Zone 1 Phase Current FD \\
(Amps secondary)
\end{tabular} & $\begin{array}{l}\text { Range }=0.50 \\
\text { to } 100.00\end{array}$ & 0.50 \\
\hline $50 \mathrm{~L} 2$ & \begin{tabular}{|l} 
Zone 2 Phase Current FD \\
(Amps secondary)
\end{tabular} & $\begin{array}{l}\text { Range }=0.50 \\
\text { to } 100.00\end{array}$ & 0.50 \\
\hline $50 \mathrm{~L} 3$ & $\begin{array}{l}\text { Zone 3 Phase Current FD } \\
\text { (Amps secondary) }\end{array}$ & $\begin{array}{l}\text { Range }=0.50 \\
\text { to } 100.00\end{array}$ & $\mid 0.50$ \\
\hline $50 \mathrm{GZ1}$ & \begin{tabular}{|l|}
$\begin{array}{l}\text { Zone } 1 \text { Residual Current FD } \\
\text { (Amps secondary) }\end{array}$ \\
\end{tabular} & $\begin{array}{l}\text { Range }=0.50 \\
\text { to } 100.00\end{array}$ & $\mid 0.50$ \\
\hline $50 \mathrm{GZ2}$ & \begin{tabular}{|l}
$\begin{array}{l}\text { Zone } 2 \text { Residual Current FD } \\
\text { (Amps secondary) }\end{array}$ \\
\end{tabular} & $\begin{array}{l}\text { Range }=0.50 \\
\text { to } 100.00\end{array}$ & 0.50 \\
\hline $50 \mathrm{GZ3}$ & \begin{tabular}{|l}
$\begin{array}{l}\text { Zone } 3 \text { Residual Current FD } \\
\text { (Amps secondary) }\end{array}$ \\
\end{tabular} & $\begin{array}{l}\text { Range }=0.50 \\
\text { to } 100.00\end{array}$ & 0.50 \\
\hline k0M1 & \begin{tabular}{|l}
$\begin{array}{l}\text { Zone 1 ZSC Factor Mag } \\
\text { (unitless) }\end{array}$ \\
\end{tabular} & $\begin{array}{l}\text { Range }=0.000 \\
\text { to } 6.000\end{array}$ & 0.726 \\
\hline
\end{tabular}




\begin{tabular}{|c|c|c|c|}
\hline \multicolumn{4}{|c|}{ Group 2} \\
\hline Setting & Description & Range & Value \\
\hline k0A1 & $\begin{array}{l}\text { Zone } 1 \text { ZSC Factor Ang } \\
\text { (degrees) }\end{array}$ & $\begin{array}{l}\text { Range }=- \\
180.00 \text { to } \\
180.00\end{array}$ & $\mid-3.69$ \\
\hline $\mathrm{k} 0 \mathrm{M}$ & \begin{tabular}{|l}
$\begin{array}{l}\text { Zone } 2,3, \& 4 \text { ZSC Factor Mag } \\
\text { (unitless) }\end{array}$ \\
\end{tabular} & $\begin{array}{l}\text { Range }=0.000 \\
\text { to } 6.000\end{array}$ & 0.726 \\
\hline $\mathrm{k} 0 \mathrm{~A}$ & $\begin{array}{l}\text { Zone } 2,3, \& 4 \text { ZSC Factor Ang } \\
\text { (degrees) }\end{array}$ & $\begin{array}{l}\text { Range }=- \\
180.00 \text { to } \\
180.00\end{array}$ & $\mid-3.69$ \\
\hline Z1PD & $\begin{array}{l}\text { Zone } 1 \text { Time Delay (cycles in } \\
0.25 \text { increments) }\end{array}$ & $\begin{array}{l}\text { Range }=0.00 \\
\text { to } 16000.00, \\
\text { OFF }\end{array}$ & OFF \\
\hline Z2PD & $\begin{array}{l}\text { Zone } 2 \text { Time Delay (cycles in } \\
0.25 \text { increments) }\end{array}$ & $\begin{array}{l}\text { Range }=0.00 \\
\text { to } 16000.00, \\
\text { OFF }\end{array}$ & 22.00 \\
\hline Z3PD & $\begin{array}{l}\text { Zone } 3 \text { Time Delay (cycles in } \\
0.25 \text { increments) }\end{array}$ & $\begin{array}{l}\text { Range }=0.00 \\
\text { to } 16000.00, \\
\text { OFF }\end{array}$ & OFF \\
\hline Z1GD & $\begin{array}{l}\text { Zone } 1 \text { Time Delay (cycles in } \\
0.25 \text { increments) }\end{array}$ & $\begin{array}{l}\text { Range }=0.00 \\
\text { to } 16000.00, \\
\text { OFF }\end{array}$ & $\mid 5.00$ \\
\hline Z2GD & $\begin{array}{l}\text { Zone } 2 \text { Time Delay (cycles in } \\
0.25 \text { increments) }\end{array}$ & $\begin{array}{l}\text { Range }=0.00 \\
\text { to } 16000.00, \\
\text { OFF }\end{array}$ & $\mid 5.00$ \\
\hline Z3GD & $\begin{array}{l}\text { Zone } 3 \text { Time Delay (cycles in } \\
0.25 \text { increments) }\end{array}$ & $\begin{array}{l}\text { Range }=0.00 \\
\text { to } 16000.00, \\
\text { OFF }\end{array}$ & $\mid 5.00$ \\
\hline Z1D & $\begin{array}{l}\text { Zone } 1 \text { Time Delay (cycles in } \\
0.25 \text { increments) }\end{array}$ & $\begin{array}{l}\text { Range }=0.00 \\
\text { to } 16000.00, \\
\text { OFF }\end{array}$ & $\mid 5.00$ \\
\hline $\mathrm{Z} 2 \mathrm{D}$ & $\begin{array}{l}\text { Zone } 2 \text { Time Delay (cycles in } \\
0.25 \text { increments) }\end{array}$ & $\begin{array}{l}\text { Range }=0.00 \\
\text { to } 16000.00, \\
\text { OFF }\end{array}$ & $\mid 5.00$ \\
\hline Z3D & $\begin{array}{l}\text { Zone } 3 \text { Time Delay (cycles in } \\
0.25 \text { increments) }\end{array}$ & $\begin{array}{l}\text { Range }=0.00 \\
\text { to } 16000.00, \\
\text { OFF }\end{array}$ & $\mid 5.00$ \\
\hline E50P & $\begin{array}{l}\text { Enable Phase Overcurrent } \\
\text { Elements }\end{array}$ & Select: N, 1-3 & $\mathrm{N}$ \\
\hline E50G & $\begin{array}{l}\text { Enable Residual Ground } \\
\text { Overcurrent Elements }\end{array}$ & Select: N, 1-4 & N \\
\hline E50Q & $\begin{array}{l}\text { Enable Negative-Sequence } \\
\text { Overcurrent Elements }\end{array}$ & Select: N, 1-4 & N \\
\hline E51P & \begin{tabular}{|l} 
Enable Phase Time- \\
Overcurrent Elements \\
\end{tabular} & Select: Y, N & |Y \\
\hline $51 \mathrm{PP}$ & Pickup (Amps secondary) & $\begin{array}{l}\text { Range }=0.25 \\
\text { to } 16.00, \text { OFF }\end{array}$ & 4.50 \\
\hline
\end{tabular}




\begin{tabular}{|c|c|c|c|}
\hline \multicolumn{4}{|c|}{ Group 2} \\
\hline Setting & Description & Range & Value \\
\hline $51 \mathrm{PC}$ & Curve & $\begin{array}{l}\text { Select: U1-U5, } \\
\text { C1-C5 }\end{array}$ & U1 \\
\hline 51PTD & Time Dial & $\begin{array}{l}\text { Range }=0.50 \\
\text { to } 15.00\end{array}$ & $\mid 0.50$ \\
\hline 51PRS & $\begin{array}{l}\text { Electromechanical Reset } \\
\text { Delay }\end{array}$ & Select: Y, N & $\mathrm{N}$ \\
\hline E51G & $\begin{array}{l}\text { Enable Residual Ground } \\
\text { Time-Overcurrent Elements }\end{array}$ & Select: Y, N & |Y \\
\hline $51 \mathrm{GP}$ & Pickup (Amps secondary) & $\begin{array}{l}\text { Range }=0.25 \\
\text { to } 16.00, \text { OFF }\end{array}$ & 0.25 \\
\hline $51 \mathrm{GC}$ & Curve & \begin{tabular}{|l|} 
Select: U1-U5, \\
C1-C5
\end{tabular} & U1 \\
\hline 51GTD & Time Dial & $\begin{array}{l}\text { Range }=0.50 \\
\text { to } 15.00\end{array}$ & $\| 0.50$ \\
\hline $51 \mathrm{GRS}$ & $\begin{array}{l}\text { Electromechanical Reset } \\
\text { Delay }\end{array}$ & Select: Y, N & $\| \mathrm{N}$ \\
\hline E51Q & $\begin{array}{l}\text { Enable Negative-Sequence } \\
\text { Time-Overcurrent Elements }\end{array}$ & Select: Y, N & $\mid$ Y \\
\hline $51 \mathrm{QP}$ & Pickup (Amps secondary) & \begin{tabular}{|l} 
Range $=0.25$ \\
to 16.00, OFF
\end{tabular} & 0.25 \\
\hline $51 \mathrm{QC}$ & Curve & \begin{tabular}{|l|} 
Select: U1-U5, \\
C1-C5
\end{tabular} & U1 \\
\hline $51 \mathrm{QTD}$ & Time Dial & \begin{tabular}{|l|} 
Range $=0.50$ \\
to 15.00
\end{tabular} & 0.53 \\
\hline $51 \mathrm{QRS}$ & $\begin{array}{l}\text { Electromechanical Reset } \\
\text { Delay }\end{array}$ & Select: Y, N & $\| \mathrm{N}$ \\
\hline EOOS & Enable Out-of-Step Elements & Select: Y, N & $\mathrm{N}$ \\
\hline ELOAD & \begin{tabular}{|l} 
Enable Load Encroachment \\
Elements
\end{tabular} & Select: Y, N & $\| \mathrm{N}$ \\
\hline E32 & $\begin{array}{l}\text { Enable Directional Control } \\
\text { Elements }\end{array}$ & \begin{tabular}{|l} 
Select: Y, \\
AUTO
\end{tabular} & AUTO \\
\hline ELOP & Loss-Of-Potential Enable & $\begin{array}{l}\text { Select: Y, Y1, } \\
\mathrm{N}\end{array}$ & |Y1 \\
\hline EBBPT & Busbar PT LOP Logic Enable & Select: Y, N & $\mathrm{N}$ \\
\hline DIR3 & Level 3 Direction & Select: F, R & $\mathrm{R}$ \\
\hline DIR4 & Level 4 Direction & Select: F, R & $\mathrm{F}$ \\
\hline ORDER & $\begin{array}{l}\text { Ground Directional Element } \\
\text { Priority }\end{array}$ & \begin{tabular}{|l|} 
Select: I, Q, V, \\
OFF
\end{tabular} & QVI \\
\hline EVOLT & \begin{tabular}{|l} 
Enable Voltage Element \\
Enables
\end{tabular} & Select: Y, N & $\| \mathrm{N}$ \\
\hline E25 & Synchronism Check Enable & Select: Y, N & $\mathrm{N}$ \\
\hline E81 & Frequency Elements Enables & Select: N, 1-6 & $\mathrm{N}$ \\
\hline E79 & Reclosures Enables & Select: N, 1-4 & $\mathrm{N}$ \\
\hline ESOTF & Enable Switch-Onto-Fault & Select: Y, N & $\mathrm{N}$ \\
\hline
\end{tabular}




\begin{tabular}{|c|c|c|c|}
\hline \multicolumn{4}{|l|}{ Group 2} \\
\hline Setting & Description & Range & Value \\
\hline ECOMM & $\begin{array}{l}\text { Comm.-Assisted Trip Scheme } \\
\text { Enables }\end{array}$ & \begin{tabular}{|l} 
Select: N, \\
POTT, \\
DCUB1, \\
DCUB2, DCB \\
\end{tabular} & POTT \\
\hline Z3RBD & $\begin{array}{l}\text { Zone } 3 \text { Reverse Block Time } \\
\text { Delay (cycles in } 0.25 \\
\text { increments) }\end{array}$ & $\begin{array}{l}\text { Range }=0.00 \\
\text { to } 16000.00\end{array}$ & 5.00 \\
\hline EBLKD & \begin{tabular}{|l} 
Echo Block Time Delay \\
(cycles in 0.25 increments)
\end{tabular} & \begin{tabular}{|l} 
Range $=0.00$ \\
to 16000.00 \\
OFF
\end{tabular} & 10.00 \\
\hline ETDPU & \begin{tabular}{|l} 
Echo Time Delay Pickup \\
(cycles in 0.25 increments)
\end{tabular} & $\begin{array}{l}\text { Range }=0.00 \\
\text { to } 16000.00, \\
\text { OFF }\end{array}$ & 2.00 \\
\hline EDURD & $\begin{array}{l}\text { Echo Duration Time Delay } \\
\text { (cycles in } 0.25 \text { increments) }\end{array}$ & $\begin{array}{l}\text { Range }=0.00 \\
\text { to } 16000.00 \\
\end{array}$ & 4.00 \\
\hline EWFC & Weak-Infeed Enable & Select: Y, N & $\mathrm{N}$ \\
\hline EZ1EXT & Zone 1 Extension & Select: Y, N & $\mathrm{N}$ \\
\hline EDEM & Demand Metering Type & \begin{tabular}{|l} 
Select: THM, \\
ROL
\end{tabular} & THM \\
\hline DMTC & Time Constant (minutes) & \begin{tabular}{|l} 
Select: 5,10 \\
$15,30,60$
\end{tabular} & 60 \\
\hline PDEMP & \begin{tabular}{|l} 
Phase Pickup (Amps \\
secondary)
\end{tabular} & $\begin{array}{l}\text { Range }=0.50 \\
\text { to } 16.00, \text { OFF }\end{array}$ & OFF \\
\hline GDEMP & $\begin{array}{l}\text { Residual Ground Pickup } \\
\text { (Amps secondary) }\end{array}$ & $\begin{array}{l}\text { Range }=0.50 \\
\text { to } 16.00, \text { OFF }\end{array}$ & OFF \\
\hline QDEMP & $\begin{array}{l}\text { Negative-Sequence Pickup } \\
\text { (Amps secondary) }\end{array}$ & $\begin{array}{l}\text { Range }=0.50 \\
\text { to } 16.00, \text { OFF }\end{array}$ & OFF \\
\hline TDURD & \begin{tabular}{|l|} 
Minimum Trip Duration Time \\
(cycles in 0.25 increments)
\end{tabular} & $\begin{array}{l}\text { Range }=2.00 \\
\text { to } 16000.00\end{array}$ & 9.00 \\
\hline TOPD & $\begin{array}{l}\text { Trip Open Pole Dropout } \\
\text { Delay (cycles in } 0.25 \\
\text { increments) }\end{array}$ & $\mid \begin{array}{l}\text { Range }=2.00 \\
\text { to } 8000.00\end{array}$ & 2.00 \\
\hline CFD & \begin{tabular}{|l} 
Close Failure Time Delay \\
(cycles in 0.25 increments)
\end{tabular} & $\begin{array}{l}\text { Range }=0.00 \\
\text { to } 16000.00, \\
\text { OFF }\end{array}$ & 60.00 \\
\hline $3 \mathrm{POD}$ & $\begin{array}{l}\text { Three-Pole Open Time Delay } \\
\text { (cycles in } 0.25 \text { increments) }\end{array}$ & \begin{tabular}{|l} 
Range $=0.00$ \\
to 60.00
\end{tabular} & 0.50 \\
\hline $\mathrm{OPO}$ & Open Pole Option & Select: 27,52 & 52 \\
\hline $50 \mathrm{LP}$ & $\begin{array}{l}\text { Load Detection Phase Pickup } \\
\text { (Amps secondary) }\end{array}$ & $\begin{array}{l}\text { Range }=0.25 \\
\text { to } 100.00, \text { OFF } \\
\end{array}$ & 0.25 \\
\hline ELAT & SELogic Latch Bit Enables & Select: N, 1-16 & 16 \\
\hline EDP & \begin{tabular}{|l} 
SELogic Display Point \\
Enables
\end{tabular} & Select: N, 1-16 & $\mid 16$ \\
\hline ESV & $\begin{array}{l}\text { SELogic Variable Timers } \\
\text { Enables }\end{array}$ & Select: N, 1-16 & ||1 \\
\hline
\end{tabular}




\begin{tabular}{|c|c|c|c|}
\hline \multicolumn{4}{|c|}{ Group 2} \\
\hline Setting & Description & Range & Value \\
\hline SV1PU & $\begin{array}{l}\text { SV1 Timer Pickup (cycles in } \\
0.25 \text { increments) }\end{array}$ & $\begin{array}{l}\text { Range }=0.00 \\
\text { to } 999999.00\end{array}$ & $\mid 14.00$ \\
\hline SV1DO & $\begin{array}{l}\text { SV1 Timer Dropout (cycles in } \\
0.25 \text { increments) }\end{array}$ & $\begin{array}{l}\text { Range }=0.00 \\
\text { to } 999999.00\end{array}$ & $\mid 0.00$ \\
\hline \multicolumn{4}{|c|}{ Group 2} \\
\hline
\end{tabular}

\begin{tabular}{|c|c|c|c|}
\hline \multicolumn{4}{|c|}{ SELogic 2} \\
\hline Setting & Description & Range & Value \\
\hline TR & Direct Trip Conditions & & $\begin{array}{l}\mathrm{M} 1 \mathrm{P}+\mathrm{M} 2 \mathrm{PT}+\mathrm{M} 3 \mathrm{PT}+51 \mathrm{PT}+51 \mathrm{GT}+ \\
\text { 51QT }\end{array}$ \\
\hline TRCOMM & $\begin{array}{l}\text { Communications-Assisted Trip } \\
\text { Conditions }\end{array}$ & & M2P \\
\hline DTT & Direct Transfer Trip Conditions & & 0 \\
\hline E3PT & Three-Pole Trip Enable & & 0 \\
\hline ULTR & Unlatch Trip Conditions & & $\mathrm{SPO}+3 \mathrm{PO}$ \\
\hline PT1 & $\begin{array}{l}\text { Permissive Trip 1 (used for } \\
\text { ECOMM = POTT, DCUB1, or } \\
\text { DCUB2) }\end{array}$ & & $\mathrm{R} 1 \mathrm{X}$ \\
\hline $52 \mathrm{AA}$ & Circuit breaker status A-Phase & & IN101 \\
\hline $52 \mathrm{AB}$ & Circuit breaker status B-Phase & & IN102 \\
\hline $52 \mathrm{AC}$ & Circuit breaker status C-Phase & & IN103 \\
\hline $\mathrm{CL}$ & $\begin{array}{l}\text { Close conditions (other than } \\
\text { automatic reclosing or CLOSE } \\
\text { command) }\end{array}$ & & $\mathrm{CC}$ \\
\hline ULCL & Unlatch close conditions & & TRIP + TRIP87 \\
\hline 51PTC & Phase & & 1 \\
\hline $51 \mathrm{GTC}$ & Residual Ground & & 1 \\
\hline $51 \mathrm{QTC}$ & Negative-Sequence & & 1 \\
\hline $87 \mathrm{LTC}$ & 87L Torque Control Equation & & 1 \\
\hline SV1 & \begin{tabular}{|l} 
SELogic Control Equation \\
Variable 1
\end{tabular} & & KEY \\
\hline OUT101 & Output Contact 101 & & !TRIP \\
\hline DP1 & Display Point 1 & & $52 \mathrm{~A}$ \\
\hline DP2 & Display Point 2 & & CHXAL \\
\hline DP3 & Display Point 3 & & CHYAL \\
\hline ER & $\begin{array}{l}\text { Event Report Trigger } \\
\text { Conditions }\end{array}$ & & \begin{tabular}{|l}
$/ \mathrm{M} 2 \mathrm{P}+/ \mathrm{Z} 2 \mathrm{G}+/ 51 \mathrm{G}+/ 51 \mathrm{Q}+/ 51 \mathrm{P}+$ \\
$/ \mathrm{LOP}+/ \mathrm{M} 1 \mathrm{P}+/ \mathrm{Z} 1 \mathrm{G}+/ \mathrm{M} 3 \mathrm{P}+/ \mathrm{Z} 3 \mathrm{G}$ \\
\end{tabular} \\
\hline FAULT & Fault Indication & & \begin{tabular}{|l}
$51 \mathrm{G}+51 \mathrm{Q}+\mathrm{M} 2 \mathrm{P}+\mathrm{Z} 2 \mathrm{G}+51 \mathrm{P}+\mathrm{M} 1 \mathrm{P}+$ \\
$\mathrm{Z} 1 \mathrm{G}+\mathrm{M} 3 \mathrm{P}+\mathrm{Z} 3 \mathrm{G}$
\end{tabular} \\
\hline BSYNCH & $\begin{array}{l}\text { Block Synchronism Check } \\
\text { Elements }\end{array}$ & & 0 \\
\hline
\end{tabular}




\begin{tabular}{|c|c|c|c|}
\hline SELogic & & & \\
\hline Setting & Description & Range & Value \\
\hline CLMON & Close Bus Monitor & & 0 \\
\hline E32IV & $\begin{array}{l}\text { Enable for V0 Polarized and IN } \\
\text { Polarized Elements }\end{array}$ & & 1 \\
\hline ESTUB & Stub Bus Logic Enable & & 0 \\
\hline T1X & 87L Channel X, Transmit Bit 1 & & SV1T \\
\hline $\mathrm{T} 2 \mathrm{X}$ & 87L Channel X, Transmit Bit 2 & & 0 \\
\hline $\mathrm{T} 3 \mathrm{X}$ & 87L Channel X, Transmit Bit 3 & & 0 \\
\hline $\mathrm{T} 4 \mathrm{X}$ & 87L Channel X, Transmit Bit 4 & & 0 \\
\hline $\mathrm{T} 1 \mathrm{Y}$ & 87L Channel Y, Transmit Bit 1 & & 0 \\
\hline $\mathrm{T} 2 \mathrm{Y}$ & 87L Channel Y, Transmit Bit 2 & & 0 \\
\hline T3Y & 87L Channel Y, Transmit Bit 3 & & 0 \\
\hline $\mathrm{T} 4 \mathrm{Y}$ & 87L Channel Y, Transmit Bit 4 & & 0 \\
\hline
\end{tabular}

\begin{tabular}{|c|c|c|c|}
\hline \multicolumn{4}{|l|}{ Global } \\
\hline Setting & Description & Range & Value \\
\hline TGR & $\begin{array}{l}\text { Group Change Delay (cycles in } \\
0.25 \text { increments) } \\
\end{array}$ & \begin{tabular}{|l|} 
Range $=0.00$ to \\
16000.00
\end{tabular} & 1800.00 \\
\hline NFREQ & Nominal Frequency $(\mathrm{Hz})$ & Select: 50,60 & 60 \\
\hline PHROT & Phase Rotation & $\begin{array}{l}\text { Select: ABC, } \\
\text { ACB }\end{array}$ & $\mathrm{ACB}$ \\
\hline DATE_F & Date Format & \begin{tabular}{|l|} 
Select: MDY, \\
YMD \\
\end{tabular} & MDY \\
\hline FP_TO & Front Panel Timeout (minutes) & $\begin{array}{l}\text { Range }=0.00 \text { to } \\
30.00\end{array}$ & 15.00 \\
\hline SCROLD & Display Update Rate (seconds) & Range $=1$ to 60 & 5 \\
\hline LER & \begin{tabular}{|l||}
$\begin{array}{l}\text { Length of Event Report } \\
\text { (cycles) }\end{array}$ \\
\end{tabular} & \begin{tabular}{|l|} 
Select: 15,30 \\
60
\end{tabular} & 60 \\
\hline PRE & \begin{tabular}{|l|} 
Cycle Length of Prefault in \\
Event Report (cycles in \\
increments of 1)
\end{tabular} & Range $=1$ to 59 & $\mid 10$ \\
\hline DCLOP & $\begin{array}{l}\text { DC Battery LO Voltage Pickup } \\
(\mathrm{Vdc})\end{array}$ & $\begin{array}{l}\text { Range }=20.00 \\
\text { to } 300.00, \text { OFF }\end{array}$ & OFF \\
\hline DCHIP & \begin{tabular}{|l|} 
DC Battery HI Voltage Pickup \\
$(\mathrm{Vdc})$
\end{tabular} & $\begin{array}{l}\text { Range }=20.00 \\
\text { to } 300.00, \text { OFF }\end{array}$ & OFF \\
\hline IN101D & $\begin{array}{l}\text { Input } 101 \text { Debounce Time } \\
\text { (cycles in } 0.25 \text { increments) }\end{array}$ & \begin{tabular}{l|} 
Range $=0.00$ to \\
2.00
\end{tabular} & 0.00 \\
\hline IN102D & \begin{tabular}{|l}
$\begin{array}{l}\text { Input } 102 \text { Debounce Time } \\
\text { (cycles in } 0.25 \text { increments) }\end{array}$ \\
\end{tabular} & \begin{tabular}{|l|} 
Range $=0.00$ to \\
2.00
\end{tabular} & 0.00 \\
\hline IN103D & $\begin{array}{l}\text { Input } 103 \text { Debounce Time } \\
\text { (cycles in } 0.25 \text { increments) }\end{array}$ & \begin{tabular}{|l|} 
Range $=0.00$ to \\
2.00
\end{tabular} & 0.00 \\
\hline
\end{tabular}




\begin{tabular}{|c|c|c|c|}
\hline \multicolumn{4}{|l|}{ Global } \\
\hline Setting & Description & Range & Value \\
\hline IN104D & $\begin{array}{l}\text { Input } 104 \text { Debounce Time } \\
\text { (cycles in } 0.25 \text { increments) }\end{array}$ & \begin{tabular}{|l|} 
Range $=0.00$ to \\
2.00
\end{tabular} & 0.00 \\
\hline IN105D & $\begin{array}{l}\text { Input } 105 \text { Debounce Time } \\
\text { (cycles in } 0.25 \text { increments) }\end{array}$ & $\begin{array}{l}\text { Range }=0.00 \text { to } \\
2.00\end{array}$ & 0.00 \\
\hline IN106D & \begin{tabular}{|l} 
Input 106 Debounce Time \\
(cycles in 0.25 increments)
\end{tabular} & \begin{tabular}{|l|} 
Range $=0.00$ to \\
2.00
\end{tabular} & 0.00 \\
\hline EPMU & $\begin{array}{l}\text { Synchronized Phasor } \\
\text { Measurement }\end{array}$ & Select: Y, N & N \\
\hline \multicolumn{4}{|l|}{ Global } \\
\hline
\end{tabular}

\begin{tabular}{|c|c|c|c|}
\hline \multicolumn{4}{|l|}{ SER } \\
\hline Setting & Description & Range & Value \\
\hline SER1 & $\begin{array}{l}\text { Sequential Events Recorder 1, } \\
24 \text { elements max. (enter NA to } \\
\text { null) }\end{array}$ & \begin{tabular}{|l|} 
Valid range $=0$, \\
NA or a list of \\
relay elements.
\end{tabular} & TRIP, 51P, 51G, 51Q, 51PT, 51GT, 51QT \\
\hline SER2 & $\begin{array}{l}\text { Sequential Events Recorder 2, } \\
24 \text { elements max. (enter NA to } \\
\text { null) }\end{array}$ & $\begin{array}{l}\text { Valid range }=0, \\
\text { NA or a list of } \\
\text { relay elements. }\end{array}$ & TRIP, M1P, M2P, M2PT \\
\hline SER3 & $\begin{array}{l}\text { Sequential Events Recorder 3, } \\
24 \text { elements max. (enter NA to } \\
\text { null) }\end{array}$ & \begin{tabular}{|l|} 
Valid range $=0$, \\
NA or a list of \\
relay elements.
\end{tabular} & TRIP, PTRX \\
\hline \multicolumn{4}{|l|}{ SER } \\
\hline
\end{tabular}

\begin{tabular}{|l|l||l||l||}
\hline \multicolumn{2}{|l||}{ Channel X } \\
\hline Setting & Description & Range & Value \\
\hline \hline EADDCX & Channel X Address Check & Select: Y, G, N & N \\
\hline \hline RBADXP & $\begin{array}{l}\text { Continuous Dropout Alarm } \\
\text { (Seconds) }\end{array}$ & $\begin{array}{l}\text { Range }=1 \text { to } \\
1000\end{array}$ & 1 \\
\hline \hline AVAXP & $\begin{array}{l}\text { Packets Lost in Last 10,000 } \\
\text { Alarm }\end{array}$ & $\begin{array}{l}\text { Range }=1 \text { to } \\
5000\end{array}$ & 10 \\
\hline \hline DBADXP & $\begin{array}{l}\text { One Way Channel Delay } \\
\text { Alarm (msec.) }\end{array}$ & $\begin{array}{l}\text { Range }=1 \text { to } \\
24\end{array}$ & 10 \\
\hline \hline TIMRX & $\begin{array}{l}\text { Timing Source (I=Internal, } \\
\text { E=External) }\end{array}$ & Select: I, E & E \\
\hline \hline Channel X
\end{tabular}




\begin{tabular}{|l|l||l||l||}
\hline \hline Channel Y \\
\hline Setting & Description & Range & Value \\
\hline EADDCY & Channel Y Address Check & Select: Y, G, N & N \\
\hline \hline RBADYP & $\begin{array}{l}\text { Continuous Dropout Alarm } \\
\text { Seconds) }\end{array}$ & $\begin{array}{l}\text { Range }=1 \text { to } \\
1000\end{array}$ & 1 \\
\hline \hline AVAYP & $\begin{array}{l}\text { Packets Lost in Last 10,000 } \\
\text { Alarm }\end{array}$ & $\begin{array}{l}\text { Range }=1 \text { to } \\
5000\end{array}$ & 10 \\
\hline \hline DBADYP & $\begin{array}{l}\text { One Way Channel Delay } \\
\text { Alarm (msec.) }\end{array}$ & $\begin{array}{l}\text { Range }=1 \text { to } \\
24\end{array}$ & 10 \\
\hline \hline TIMRY & $\begin{array}{l}\text { Timing Source (I=Internal, } \\
\text { E=External) }\end{array}$ & Select: I, E & E \\
\hline Channel Y
\end{tabular}

\begin{tabular}{|c|c|c|c|}
\hline Port 2 & & & \\
\hline Setting & Description & Range & Value \\
\hline PROTO & Protocol & $\begin{array}{l}\text { Select: SEL, } \\
\text { LMD, DNP, } \\
\text { MBA, MB8A, } \\
\text { MBGA, MBB, } \\
\text { MB8B, MBGB } \\
\end{array}$ & SEL \\
\hline T_OUT & Minutes to Port Time-out & $\begin{array}{l}\text { Range }=0 \text { to } \\
30\end{array}$ & 15 \\
\hline DTA & Meter Format & Select: Y, N & $\mathrm{N}$ \\
\hline SPEED & Baud Rate & \begin{tabular}{|l} 
Select: 300, \\
1200,2400, \\
4800,9600, \\
19200,38400 \\
\end{tabular} & 19200 \\
\hline AUTO & Send Auto Messages to Port & Select: Y, N & $\mathrm{Y}$ \\
\hline BITS & Data Bits & Select: 6-8 & 8 \\
\hline RTSCTS & Enable Hardware Handshaking & Select: Y, N & $\mathrm{N}$ \\
\hline PARITY & (Odd, Even, None) & Select: O, E, N & $\mathrm{N}$ \\
\hline FASTOP & Fast Operate Enable & Select: Y, N & $\mathrm{N}$ \\
\hline STOP & Stop Bits & Select: 1,2 & 1 \\
\hline Port 2 & & & \\
\hline
\end{tabular}




\section{Appendix D: SEL-311L Line 2 Settings}

\begin{tabular}{|c|c|c|c|}
\hline \multicolumn{4}{|c|}{ Group 1} \\
\hline Setting & Description & Range & Value \\
\hline RID & Relay Identifier (30 chars) & $\begin{array}{l}\text { Range }=\text { ASCII } \\
\text { string with a } \\
\text { maximum } \\
\text { length of } 30 .\end{array}$ & SEL-311L \\
\hline TID & |Terminal Identifier (30 chars) & $\begin{array}{l}\text { Range }=\text { ASCII } \\
\text { string with a } \\
\text { maximum } \\
\text { length of } 30 .\end{array}$ & LINE 2 (RADIAL) \\
\hline CTR & $\begin{array}{l}\text { Local Phase (IA,IB,IC) CT } \\
\text { Ratio, CTR:1 }\end{array}$ & $\begin{array}{l}\text { Range }=1 \text { to } \\
6000\end{array}$ & 1 \\
\hline APP & Application & \begin{tabular}{|l} 
Select: 87L, \\
87L21, 87L21P, \\
87LSP, 311L
\end{tabular} & $311 \mathrm{~L}$ \\
\hline EADVS & Advanced Settings Enable & Select: Y, N & $\mathrm{Y}$ \\
\hline E87L & Number of 87L Terminals & $\begin{array}{l}\text { Select: 2, 3, 3R, } \\
\mathrm{N}\end{array}$ & $\mathrm{N}$ \\
\hline CTRP & \begin{tabular}{|l} 
Polarizing (IPOL) CT Ratio, \\
CTRP:1
\end{tabular} & $\begin{array}{l}\text { Range }=1 \text { to } \\
6000\end{array}$ & 200 \\
\hline PTR & $\begin{array}{l}\text { Phase (VA,VB,VC) PT Ratio, } \\
\text { PTR:1 }\end{array}$ & $\begin{array}{l}\text { Range }=1.00 \text { to } \\
10000.00\end{array}$ & 1.00 \\
\hline PTRS & $\begin{array}{l}\text { Synch. Voltage (VS) PT Ratio, } \\
\text { PTRS:1 }\end{array}$ & $\begin{array}{l}\text { Range }=1.00 \text { to } \\
10000.00\end{array}$ & 2000.00 \\
\hline Z1MAG & \begin{tabular}{|l} 
Pos-Seq Line Impedance \\
Magnitude (Ohms secondary)
\end{tabular} & $\begin{array}{l}\text { Range }=0.05 \text { to } \\
255.00\end{array}$ & 24.37 \\
\hline Z1ANG & $\begin{array}{l}\begin{array}{l}\text { Pos-Seq Line Impedance Angle } \\
\text { (degrees) }\end{array} \\
\end{array}$ & $\begin{array}{l}\text { Range }=5.00 \text { to } \\
90.00\end{array}$ & 89.00 \\
\hline Z0MAG & \begin{tabular}{|l|} 
Zero-Seq Line Impedance \\
Magnitude (Ohms secondary) \\
\end{tabular} & $\begin{array}{l}\text { Range }=0.05 \text { to } \\
255.00\end{array}$ & 24.37 \\
\hline ZOANG & \begin{tabular}{|l|}
$\begin{array}{l}\text { Zero-Seq Line Impedance Angle } \\
\text { (degrees) }\end{array}$ \\
\end{tabular} & $\begin{array}{l}\text { Range }=5.00 \text { to } \\
90.00\end{array}$ & 89.00 \\
\hline LL & Line Length (unitless) & $\begin{array}{l}\text { Range }=0.10 \text { to } \\
999.00\end{array}$ & 100.00 \\
\hline EFLOC & Fault Location Enable & Select: Y, N & $\mathrm{N}$ \\
\hline E21P & $\begin{array}{l}\text { Enable Mho Phase Distance } \\
\text { Elements }\end{array}$ & $\begin{array}{l}\text { Select: N, 1-4, } \\
\text { 1C-4C }\end{array}$ & 3 \\
\hline ECCVT & $\begin{array}{l}\text { CCVT Transient Detection } \\
\text { Enable }\end{array}$ & Select: Y, N & $\mathrm{N}$ \\
\hline Z1P & Reach Zone 1 (Ohms secondary) & $\begin{array}{l}\text { Range }=0.05 \text { to } \\
64.00, \text { OFF }\end{array}$ & 13.35 \\
\hline $\mathrm{Z} 2 \mathrm{P}$ & Reach Zone 2 (Ohms secondary) & $\begin{array}{l}\text { Range }=0.05 \text { to } \\
64.00, \text { OFF }\end{array}$ & 22.90 \\
\hline $\mathrm{Z3P}$ & Reach Zone 3 (Ohms secondary) & $\begin{array}{l}\text { Range }=0.05 \text { to } \\
64.00, \text { OFF }\end{array}$ & 5.00 \\
\hline
\end{tabular}




\begin{tabular}{|c|c|c|c|}
\hline \multicolumn{4}{|c|}{ Group 1} \\
\hline Setting & Description & Range & Value \\
\hline $50 \mathrm{PP} 1$ & $\begin{array}{l}\text { Phase-Phase Overcurrent Fault } \\
\text { Detector Zone } 1 \text { (Amps } \\
\text { secondary) }\end{array}$ & $\begin{array}{l}\text { Range }=0.50 \text { to } \\
170.00\end{array}$ & 0.50 \\
\hline $50 \mathrm{PP} 2$ & $\begin{array}{l}\text { Phase-Phase Overcurrent Fault } \\
\text { Detector Zone } 2 \text { (Amps } \\
\text { secondary) }\end{array}$ & $\begin{array}{l}\text { Range }=0.50 \text { to } \\
170.00\end{array}$ & $\mid 0.50$ \\
\hline $50 \mathrm{PP} 3$ & $\begin{array}{l}\text { Phase-Phase Overcurrent Fault } \\
\text { Detector Zone } 3 \text { (Amps } \\
\text { secondary) }\end{array}$ & $\begin{array}{l}\text { Range }=0.50 \text { to } \\
170.00\end{array}$ & $\mid 0.50$ \\
\hline E21MG & $\begin{array}{l}\text { Enable Mho Ground Distance } \\
\text { Elements }\end{array}$ & Select: N, 1-4 & 3 \\
\hline Z1MG & Zone 1 (Ohms secondary) & \begin{tabular}{|l|} 
Range $=0.05$ to \\
64.00, OFF
\end{tabular} & 13.35 \\
\hline Z2MG & Zone 2 (Ohms secondary) & $\begin{array}{l}\text { Range }=0.05 \text { to } \\
64.00, \text { OFF }\end{array}$ & 22.90 \\
\hline Z3MG & Zone 3 (Ohms secondary) & $\begin{array}{l}\text { Range }=0.05 \text { to } \\
64.00, \text { OFF }\end{array}$ & 5.00 \\
\hline E21XG & $\begin{array}{l}\text { Enable Quad Ground Distance } \\
\text { Elements }\end{array}$ & Select: N, 1-4 & N \\
\hline $50 \mathrm{~L} 1$ & $\begin{array}{l}\text { Zone 1 Phase Current FD (Amps } \\
\text { secondary) }\end{array}$ & \begin{tabular}{|l|} 
Range $=0.50$ to \\
100.00
\end{tabular} & 0.50 \\
\hline $50 \mathrm{~L} 2$ & $\begin{array}{l}\text { Zone 2 Phase Current FD (Amps } \\
\text { secondary) }\end{array}$ & \begin{tabular}{l|} 
Range $=0.50$ to \\
100.00
\end{tabular} & 0.50 \\
\hline $50 \mathrm{~L} 3$ & $\begin{array}{l}\text { Zone 3 Phase Current FD (Amps } \\
\text { secondary) }\end{array}$ & $\begin{array}{l}\text { Range }=0.50 \text { to } \\
100.00\end{array}$ & 0.50 \\
\hline $50 \mathrm{GZ1}$ & $\begin{array}{l}\begin{array}{l}\text { Zone 1 Residual Current FD } \\
\text { (Amps secondary) }\end{array} \\
\end{array}$ & $\begin{array}{l}\text { Range }=0.50 \text { to } \\
100.00\end{array}$ & 0.50 \\
\hline $50 \mathrm{GZ2}$ & \begin{tabular}{|l}
$\begin{array}{l}\text { Zone } 2 \text { Residual Current FD } \\
\text { (Amps secondary) }\end{array}$ \\
\end{tabular} & \begin{tabular}{|l|} 
Range $=0.50$ to \\
100.00
\end{tabular} & 0.50 \\
\hline $50 \mathrm{GZ3}$ & $\begin{array}{l}\text { Zone } 3 \text { Residual Current FD } \\
\text { (Amps secondary) }\end{array}$ & \begin{tabular}{|l|} 
Range $=0.50$ to \\
100.00
\end{tabular} & 0.50 \\
\hline k0M1 & $\begin{array}{l}\begin{array}{l}\text { Zone 1 ZSC Factor Mag } \\
\text { (unitless) }\end{array} \\
\text { (n) }\end{array}$ & $\begin{array}{l}\text { Range }=0.000 \\
\text { to } 6.000\end{array}$ & 0.726 \\
\hline k0A1 & $\begin{array}{l}\text { Zone } 1 \text { ZSC Factor Ang } \\
\text { (degrees) }\end{array}$ & $\begin{array}{l}\text { Range }=- \\
180.00 \text { to } \\
180.00\end{array}$ & -3.69 \\
\hline $\mathrm{k} 0 \mathrm{M}$ & $\begin{array}{l}\text { Zone 2,3,\&4 ZSC Factor Mag } \\
\text { (unitless) }\end{array}$ & $\begin{array}{l}\text { Range }=0.000 \\
\text { to } 6.000\end{array}$ & 0.726 \\
\hline $\mathrm{k} 0 \mathrm{~A}$ & $\begin{array}{l}\text { Zone 2,3,\&4 ZSC Factor Ang } \\
\text { (degrees) }\end{array}$ & \begin{tabular}{|l|} 
Range $=-$ \\
180.00 to \\
180.00 \\
\end{tabular} & -3.69 \\
\hline Z1PD & $\begin{array}{l}\text { Zone } 1 \text { Time Delay (cycles in } \\
0.25 \text { increments) }\end{array}$ & $\begin{array}{l}\text { Range }=0.00 \text { to } \\
16000.00, \text { OFF }\end{array}$ & 5.00 \\
\hline Z2PD & $\begin{array}{l}\text { Zone } 2 \text { Time Delay (cycles in } \\
0.25 \text { increments) }\end{array}$ & $\begin{array}{l}\text { Range }=0.00 \text { to } \\
16000.00, \text { OFF }\end{array}$ & 5.00 \\
\hline
\end{tabular}




\begin{tabular}{|c|c|c|c|}
\hline \multicolumn{4}{|l|}{ Group 1} \\
\hline Setting & Description & Range & Value \\
\hline Z3PD & $\begin{array}{l}\text { Zone } 3 \text { Time Delay (cycles in } \\
0.25 \text { increments) }\end{array}$ & $\begin{array}{l}\text { Range }=0.00 \text { to } \\
16000.00, \text { OFF } \\
\end{array}$ & 5.00 \\
\hline Z1GD & $\begin{array}{l}\text { Zone } 1 \text { Time Delay (cycles in } \\
0.25 \text { increments) }\end{array}$ & \begin{tabular}{|l|} 
Range $=0.00$ to \\
16000.00, OFF \\
\end{tabular} & 5.00 \\
\hline Z2GD & $\begin{array}{l}\text { Zone } 2 \text { Time Delay (cycles in } \\
0.25 \text { increments) }\end{array}$ & $\begin{array}{l}\text { Range }=0.00 \text { to } \\
16000.00, \text { OFF } \\
\end{array}$ & 5.00 \\
\hline Z3GD & $\begin{array}{l}\text { Zone } 3 \text { Time Delay (cycles in } \\
0.25 \text { increments) }\end{array}$ & $\begin{array}{l}\text { Range }=0.00 \text { to } \\
16000.00, \text { OFF } \\
\end{array}$ & 5.00 \\
\hline Z1D & \begin{tabular}{|l} 
Zone 1 Time Delay (cycles in \\
0.25 increments)
\end{tabular} & $\begin{array}{l}\text { Range }=0.00 \text { to } \\
16000.00, \text { OFF } \\
\end{array}$ & 5.00 \\
\hline Z2D & $\begin{array}{l}\text { Zone } 2 \text { Time Delay (cycles in } \\
0.25 \text { increments) }\end{array}$ & $\begin{array}{l}\text { Range }=0.00 \text { to } \\
16000.00, \text { OFF } \\
\end{array}$ & 5.00 \\
\hline Z3D & $\begin{array}{l}\text { Zone } 3 \text { Time Delay (cycles in } \\
0.25 \text { increments) } \\
\end{array}$ & $\begin{array}{l}\text { Range }=0.00 \text { to } \\
16000.00, \text { OFF } \\
\end{array}$ & 5.00 \\
\hline E50P & $\begin{array}{l}\text { Enable Phase Overcurrent } \\
\text { Elements }\end{array}$ & Select: N, 1-3 & $\| \mathrm{N}$ \\
\hline E50G & \begin{tabular}{|l|} 
Enable Residual Ground \\
Overcurrent Elements
\end{tabular} & Select: N, 1-4 & N \\
\hline E50Q & \begin{tabular}{|l|} 
Enable Negative-Sequence \\
Overcurrent Elements \\
\end{tabular} & Select: N, 1-4 & $\| \mathrm{N}$ \\
\hline E51P & $\begin{array}{l}\text { Enable Phase Time-Overcurrent } \\
\text { Elements }\end{array}$ & Select: Y, N & Y \\
\hline $51 \mathrm{PP}$ & Pickup (Amps secondary) & \begin{tabular}{|l|} 
Range $=0.25$ to \\
16.00, OFF
\end{tabular} & 4.50 \\
\hline $51 \mathrm{PC}$ & Curve & \begin{tabular}{|l|} 
Select: U1-U5, \\
C1-C5
\end{tabular} & U1 \\
\hline 51PTD & Time Dial & $\begin{array}{l}\text { Range }=0.50 \text { to } \\
15.00\end{array}$ & 0.50 \\
\hline 51PRS & Electromechanical Reset Delay & Select: Y, N & $\mathrm{N}$ \\
\hline E51G & $\begin{array}{l}\text { Enable Residual Ground Time- } \\
\text { Overcurrent Elements }\end{array}$ & Select: Y, N & Y \\
\hline $51 \mathrm{GP}$ & Pickup (Amps secondary) & $\begin{array}{l}\text { Range }=0.25 \text { to } \\
16.00, \text { OFF }\end{array}$ & 0.25 \\
\hline $51 \mathrm{GC}$ & Curve & \begin{tabular}{|l|} 
Select: U1-U5, \\
C1-C5 \\
\end{tabular} & U1 \\
\hline $51 \mathrm{GTD}$ & Time Dial & $\begin{array}{l}\text { Range }=0.50 \text { to } \\
15.00\end{array}$ & 0.50 \\
\hline $51 \mathrm{GRS}$ & Electromechanical Reset Delay & Select: Y, N & $\mathrm{N}$ \\
\hline E51Q & \begin{tabular}{|l} 
Enable Negative-Sequence \\
Time-Overcurrent Elements
\end{tabular} & Select: Y, N & $\mathrm{Y}$ \\
\hline $51 \mathrm{QP}$ & Pickup (Amps secondary) & \begin{tabular}{|l|} 
Range $=0.25$ to \\
16.00, OFF \\
\end{tabular} & 0.25 \\
\hline $51 \mathrm{QC}$ & Curve & $\begin{array}{l}\text { Select: U1-U5, } \\
\text { C1-C5 }\end{array}$ & U1 \\
\hline
\end{tabular}




\begin{tabular}{|c|c|c|c|}
\hline \multicolumn{4}{|l|}{ Group 1} \\
\hline Setting & Description & Range & Value \\
\hline 51QTD & Time Dial & \begin{tabular}{|l|} 
Range $=0.50$ to \\
15.00
\end{tabular} & 0.50 \\
\hline $51 \mathrm{QRS}$ & Electromechanical Reset Delay & Select: Y, N & $\mathrm{N}$ \\
\hline EOOS & Enable Out-of-Step Elements & Select: Y, N & $\mathrm{N}$ \\
\hline ELOAD & $\begin{array}{l}\text { Enable Load Encroachment } \\
\text { Elements }\end{array}$ & Select: Y, N & $\mathrm{N}$ \\
\hline E32 & $\begin{array}{l}\text { Enable Directional Control } \\
\text { Elements }\end{array}$ & $\begin{array}{l}\text { Select: Y, } \\
\text { AUTO }\end{array}$ & AUTO \\
\hline ELOP & Loss-Of-Potential Enable & \begin{tabular}{|l} 
Select: Y, Y1, \\
$\mathrm{N}$
\end{tabular} & $\mathrm{N}$ \\
\hline DIR3 & Level 3 Direction & Select: F, R & $\mathrm{R}$ \\
\hline DIR4 & Level 4 Direction & Select: F, R & $\mathrm{F}$ \\
\hline ORDER & \begin{tabular}{|l} 
Ground Directional Element \\
Priority
\end{tabular} & $\begin{array}{l}\text { Select: I, Q, V, } \\
\text { OFF }\end{array}$ & |QVI \\
\hline EVOLT & Enable Voltage Element Enables & Select: Y, N & $\mathrm{N}$ \\
\hline E25 & Synchronism Check Enable & Select: Y, N & $\mathrm{N}$ \\
\hline E81 & Frequency Elements Enables & Select: N, 1-6 & $\mathrm{N}$ \\
\hline E79 & Reclosures Enables & Select: N, 1-4 & $\mathrm{N}$ \\
\hline ESOTF & Enable Switch-Onto-Fault & Select: Y, N & $\mathrm{N}$ \\
\hline ECOMM & \begin{tabular}{||l} 
Comm.-Assisted Trip Scheme \\
Enables
\end{tabular} & \begin{tabular}{|l|} 
Select: N, \\
POTT, DCUB1, \\
DCUB2, DCB \\
\end{tabular} & $\mathrm{N}$ \\
\hline EZ1EXT & Zone 1 Extension & Select: Y, N & $\mathrm{N}$ \\
\hline EDEM & Demand Metering Type & $\begin{array}{l}\text { Select: THM, } \\
\text { ROL }\end{array}$ & THM \\
\hline DMTC & |Time Constant (minutes) & \begin{tabular}{|l} 
Select: 5,10 \\
$15,30,60$
\end{tabular} & 60 \\
\hline PDEMP & Phase Pickup (Amps secondary) & $\begin{array}{l}\text { Range }=0.50 \text { to } \\
16.00, \text { OFF }\end{array}$ & OFF \\
\hline GDEMP & $\begin{array}{l}\text { Residual Ground Pickup (Amps } \\
\text { secondary) }\end{array}$ & \begin{tabular}{|l|} 
Range $=0.50$ to \\
16.00, OFF \\
\end{tabular} & $\mathrm{OFF}$ \\
\hline QDEMP & $\begin{array}{l}\text { Negative-Sequence Pickup } \\
\text { (Amps secondary) }\end{array}$ & \begin{tabular}{|l|} 
Range $=0.50$ to \\
16.00, OFF \\
\end{tabular} & OFF \\
\hline TDURD & $\begin{array}{l}\text { Minimum Trip Duration Time } \\
\text { (cycles in } 0.25 \text { increments) }\end{array}$ & \begin{tabular}{|l|} 
Range $=2.00$ to \\
16000.00 \\
\end{tabular} & 2.00 \\
\hline TOPD & $\begin{array}{l}\text { Trip Open Pole Dropout Delay } \\
\text { (cycles in } 0.25 \text { increments) }\end{array}$ & \begin{tabular}{l|} 
Range $=2.00$ to \\
8000.00
\end{tabular} & 2.00 \\
\hline CFD & \begin{tabular}{|l}
$\begin{array}{l}\text { Close Failure Time Delay } \\
\text { (cycles in } 0.25 \text { increments) }\end{array}$ \\
\end{tabular} & $\begin{array}{l}\text { Range }=0.00 \text { to } \\
16000.00, \text { OFF }\end{array}$ & 60.00 \\
\hline 3POD & \begin{tabular}{|l} 
Three-Pole Open Time Delay \\
(cycles in 0.25 increments)
\end{tabular} & $\begin{array}{l}\text { Range }=0.00 \text { to } \\
60.00\end{array}$ & 0.50 \\
\hline $\mathrm{OPO}$ & Open Pole Option & Select: 27,52 & 52 \\
\hline
\end{tabular}




\begin{tabular}{|c|c|c|c|}
\hline \multicolumn{4}{|c|}{ Group 1} \\
\hline Setting & Description & Range & Value \\
\hline $50 \mathrm{LP}$ & \begin{tabular}{|l} 
Load Detection Phase Pickup \\
(Amps secondary)
\end{tabular} & $\begin{array}{l}\text { Range }=0.25 \text { to } \\
100.00, \text { OFF }\end{array}$ & 0.25 \\
\hline ELAT & SELogic Latch Bit Enables & Select: N, 1-16 & 16 \\
\hline EDP & SELogic Display Point Enables & Select: N, 1-16 & 16 \\
\hline ESV & $\begin{array}{l}\text { SELogic Variable Timers } \\
\text { Enables }\end{array}$ & Select: N, 1-16 & $\mathrm{N}$ \\
\hline \multicolumn{4}{|c|}{ Group 1} \\
\hline
\end{tabular}

\begin{tabular}{|c|c|c|c|}
\hline \multicolumn{4}{|l|}{ Group 2} \\
\hline Setting & Description & Range & Value \\
\hline RID & Relay Identifier (30 chars) & \begin{tabular}{|l|} 
Range $=$ ASCII \\
string with a \\
maximum \\
length of 30.
\end{tabular} & SEL-311L \\
\hline TID & Terminal Identifier (30 chars) & \begin{tabular}{|l||} 
Range $=$ ASCII \\
string with a \\
maximum \\
length of 30.
\end{tabular} & LINE 2 (BIDIRECTIONAL) \\
\hline CTR & $\begin{array}{l}\text { Local Phase (IA,IB,IC) CT } \\
\text { Ratio, CTR:1 }\end{array}$ & $\begin{array}{l}\text { Range }=1 \text { to } \\
6000\end{array}$ & 1 \\
\hline APP & Application & $\begin{array}{l}\text { Select: 87L, } \\
\text { 87L21, } \\
\text { 87L21P, } \\
\text { 87LSP, 311L } \\
\end{array}$ & $311 \mathrm{~L}$ \\
\hline EADVS & Advanced Settings Enable & Select: Y, N & $\mathrm{N}$ \\
\hline E87L & Number of 87L Terminals & $\begin{array}{l}\text { Select: } 2,3 \\
3 \mathrm{R}, \mathrm{N}\end{array}$ & 2 \\
\hline EHST & High Speed Tripping & Select: $1-6, \mathrm{~N}$ & $\mathrm{~N}$ \\
\hline EHSDTT & $\begin{array}{l}\text { Enable High Speed Direct } \\
\text { Transfer Trip } \\
\end{array}$ & Select: Y, N & $\mathrm{N}$ \\
\hline EDD & Enable Disturbance Detect & Select: Y, N & $\mathrm{N}$ \\
\hline ETAP & Tapped Load Coordination & Select: Y, N & $\mathrm{N}$ \\
\hline EOCTL & Enable Open CT Logic & Select: Y, N & $\mathrm{N}$ \\
\hline PCHAN & Primary 87L Channel & Select: X, Y & $\mathrm{X}$ \\
\hline EHSC & Hot-Standby Channel Feature & Select: Y, N & $\mathrm{N}$ \\
\hline CTR_X & $\begin{array}{l}\text { CTR at Terminal Connected } \\
\text { to Channel X }\end{array}$ & $\begin{array}{l}\text { Range }=1 \text { to } \\
6000\end{array}$ & 1 \\
\hline 87LPP & Phase 87L (Amps secondary) & $\begin{array}{l}\text { Range }=1.00 \\
\text { to } 10.00, \text { OFF }\end{array}$ & OFF \\
\hline 87L2P & $\begin{array}{l}\text { 3I2 Negative-Sequence 87L } \\
\text { (Amps secondary) }\end{array}$ & $\begin{array}{l}\text { Range }=0.50 \\
\text { to } 5.00, \text { OFF }\end{array}$ & OFF \\
\hline
\end{tabular}




\begin{tabular}{|c|c|c|c|}
\hline \multicolumn{4}{|l|}{ Group 2} \\
\hline Setting & Description & Range & Value \\
\hline $87 \mathrm{LGP}$ & $\begin{array}{l}\text { Ground 87L (Amps } \\
\text { secondary) }\end{array}$ & $\begin{array}{l}\text { Range }=0.50 \\
\text { to 5.00, OFF }\end{array}$ & OFF \\
\hline CTALRM & $\begin{array}{l}\text { Ph. Diff. Current Alarm } \\
\text { Pickup (Amps secondary) }\end{array}$ & $\begin{array}{l}\text { Range }=0.50 \\
\text { to } 10.00\end{array}$ & 0.50 \\
\hline $87 \mathrm{LR}$ & Outer Radius & $\begin{array}{l}\text { Range }=2.0 \text { to } \\
8.0\end{array}$ & |6.0 6.0 \\
\hline 87LANG & Angle (degrees) & $\begin{array}{l}\text { Range }=90 \text { to } \\
270\end{array}$ & 195 \\
\hline CTRP & $\begin{array}{l}\text { Polarizing (IPOL) CT Ratio, } \\
\text { CTRP:1 }\end{array}$ & $\begin{array}{l}\text { Range }=1 \text { to } \\
6000\end{array}$ & 200 \\
\hline PTR & $\begin{array}{l}\text { Phase (VA,VB,VC) PT Ratio, } \\
\text { PTR:1 }\end{array}$ & $\begin{array}{l}\text { Range }=1.00 \\
\text { to } 10000.00\end{array}$ & 1.00 \\
\hline PTRS & \begin{tabular}{|l} 
Synch. Voltage (VS) PT \\
Ratio, PTRS:1
\end{tabular} & $\begin{array}{l}\text { Range }=1.00 \\
\text { to } 10000.00\end{array}$ & 2000.00 \\
\hline Z1MAG & \begin{tabular}{|l} 
Pos-Seq Line Impedance \\
Magnitude (Ohms secondary)
\end{tabular} & $\begin{array}{l}\text { Range }=0.05 \\
\text { to } 255.00\end{array}$ & 41.69 \\
\hline Z1ANG & $\begin{array}{l}\text { Pos-Seq Line Impedance } \\
\text { Angle (degrees) }\end{array}$ & $\begin{array}{l}\text { Range }=5.00 \\
\text { to } 90.00\end{array}$ & 88.00 \\
\hline Z0MAG & \begin{tabular}{|l} 
Zero-Seq Line Impedance \\
Magnitude (Ohms secondary)
\end{tabular} & $\begin{array}{l}\text { Range }=0.05 \\
\text { to } 255.00\end{array}$ & 41.69 \\
\hline ZOANG & \begin{tabular}{|l} 
Zero-Seq Line Impedance \\
Angle (degrees)
\end{tabular} & $\begin{array}{l}\text { Range }=5.00 \\
\text { to } 90.00\end{array}$ & 88.00 \\
\hline LL & Line Length (unitless) & \begin{tabular}{|l} 
Range $=0.10$ \\
to 999.00
\end{tabular} & 100.00 \\
\hline EFLOC & Fault Location Enable & Select: Y, N & $\mathrm{N}$ \\
\hline E21P & $\begin{array}{l}\text { Enable Mho Phase Distance } \\
\text { Elements }\end{array}$ & $\begin{array}{l}\text { Select: N, 1-4, } \\
\text { 1C-4C }\end{array}$ & 3 \\
\hline ECCVT & $\begin{array}{l}\text { CCVT Transient Detection } \\
\text { Enable }\end{array}$ & Select: Y, N & N \\
\hline Z1P & \begin{tabular}{|l} 
Reach Zone 1 (Ohms \\
secondary)
\end{tabular} & $\begin{array}{l}\text { Range }=0.05 \\
\text { to } 64.00, \text { OFF }\end{array}$ & 14.50 \\
\hline $\mathrm{Z} 2 \mathrm{P}$ & \begin{tabular}{|l} 
Reach Zone 2 (Ohms \\
secondary)
\end{tabular} & $\begin{array}{l}\text { Range }=0.05 \\
\text { to } 64.00, \text { OFF }\end{array}$ & 43.00 \\
\hline Z3P & \begin{tabular}{|l} 
Reach Zone 3 (Ohms \\
secondary)
\end{tabular} & $\begin{array}{l}\text { Range }=0.05 \\
\text { to } 64.00, \text { OFF }\end{array}$ & 5.00 \\
\hline $50 \mathrm{PP} 1$ & $\begin{array}{l}\text { Phase-Phase Overcurrent } \\
\text { Fault Detector Zone } 1 \text { (Amps } \\
\text { secondary) }\end{array}$ & $\begin{array}{l}\text { Range }=0.50 \\
\text { to } 170.00\end{array}$ & 0.50 \\
\hline E21MG & $\begin{array}{l}\text { Enable Mho Ground Distance } \\
\text { Elements }\end{array}$ & Select: N, 1-4 & 3 \\
\hline $\mathrm{Z} 1 \mathrm{MG}$ & Zone 1 (Ohms secondary) & $\begin{array}{l}\text { Range }=0.05 \\
\text { to } 64.00, \text { OFF }\end{array}$ & 14.50 \\
\hline Z2MG & Zone 2 (Ohms secondary) & $\begin{array}{l}\text { Range }=0.05 \\
\text { to } 64.00, \text { OFF }\end{array}$ & 43.00 \\
\hline
\end{tabular}




\begin{tabular}{|c|c|c|c|}
\hline \multicolumn{4}{|c|}{ Group 2} \\
\hline Setting & Description & Range & Value \\
\hline Z3MG & Zone 3 (Ohms secondary) & $\begin{array}{l}\text { Range }=0.05 \\
\text { to } 64.00, \text { OFF }\end{array}$ & $\mid 5.00$ \\
\hline E21XG & $\begin{array}{l}\text { Enable Quad Ground Distance } \\
\text { Elements }\end{array}$ & Select: N, 1-4 & || 3 \\
\hline $\mathrm{XG1}$ & \begin{tabular}{|l|} 
Zone 1 Reactance (Ohms \\
secondary)
\end{tabular} & $\begin{array}{l}\text { Range }=0.05 \\
\text { to } 64.00, \text { OFF }\end{array}$ & |6.24 \\
\hline $\mathrm{XG} 2$ & $\begin{array}{l}\text { Zone } 2 \text { Reactance (Ohms } \\
\text { secondary) }\end{array}$ & $\begin{array}{l}\text { Range }=0.05 \\
\text { to } 64.00, \text { OFF }\end{array}$ & $\mid 9.36$ \\
\hline $\mathrm{XG} 3$ & $\begin{array}{l}\text { Zone 3 Reactance (Ohms } \\
\text { secondary) }\end{array}$ & $\begin{array}{l}\text { Range }=0.05 \\
\text { to } 64.00, \text { OFF }\end{array}$ & $\mid 1.87$ \\
\hline RG1 & $\begin{array}{l}\text { Zone 1 Resistance (Ohms } \\
\text { secondary) }\end{array}$ & $\begin{array}{l}\text { Range }=0.05 \\
\text { to } 50.00\end{array}$ & $\mid 2.50$ \\
\hline RG2 & $\begin{array}{l}\text { Zone } 2 \text { Resistance (Ohms } \\
\text { secondary) }\end{array}$ & $\begin{array}{l}\text { Range }=0.05 \\
\text { to } 50.00\end{array}$ & $\mid 5.00$ \\
\hline RG3 & $\begin{array}{l}\text { Zone } 3 \text { Resistance (Ohms } \\
\text { secondary) }\end{array}$ & $\begin{array}{l}\text { Range }=0.05 \\
\text { to } 50.00\end{array}$ & 6.00 \\
\hline $50 \mathrm{~L} 1$ & $\begin{array}{l}\text { Zone 1 Phase Current FD } \\
\text { (Amps secondary) }\end{array}$ & $\begin{array}{l}\text { Range }=0.50 \\
\text { to } 100.00\end{array}$ & $\mid 0.50$ \\
\hline $50 \mathrm{GZ1}$ & \begin{tabular}{|l}
$\begin{array}{l}\text { Zone } 1 \text { Residual Current FD } \\
\text { (Amps secondary) }\end{array}$ \\
\end{tabular} & $\begin{array}{l}\text { Range }=0.50 \\
\text { to } 100.00\end{array}$ & $\mid 0.50$ \\
\hline k0M1 & \begin{tabular}{|l}
$\begin{array}{l}\text { Zone 1 ZSC Factor Mag } \\
\text { (unitless) }\end{array}$ \\
\end{tabular} & $\begin{array}{l}\text { Range }=0.000 \\
\text { to } 6.000\end{array}$ & 0.726 \\
\hline k0A1 & $\begin{array}{l}\text { Zone } 1 \text { ZSC Factor Ang } \\
\text { (degrees) }\end{array}$ & $\begin{array}{l}\text { Range }=- \\
180.00 \text { to } \\
180.00\end{array}$ & $\mid-3.69$ \\
\hline Z1PD & $\begin{array}{l}\text { Zone } 1 \text { Time Delay (cycles in } \\
0.25 \text { increments) }\end{array}$ & $\begin{array}{l}\text { Range }=0.00 \\
\text { to } 16000.00, \\
\text { OFF }\end{array}$ & OFF \\
\hline Z2PD & $\begin{array}{l}\text { Zone } 2 \text { Time Delay (cycles in } \\
0.25 \text { increments) }\end{array}$ & $\begin{array}{l}\text { Range }=0.00 \\
\text { to } 16000.00, \\
\text { OFF }\end{array}$ & 22.00 \\
\hline Z3PD & $\begin{array}{l}\text { Zone } 3 \text { Time Delay (cycles in } \\
0.25 \text { increments) }\end{array}$ & $\begin{array}{l}\text { Range }=0.00 \\
\text { to } 16000.00, \\
\text { OFF }\end{array}$ & OFF \\
\hline Z1GD & $\begin{array}{l}\text { Zone } 1 \text { Time Delay (cycles in } \\
0.25 \text { increments) }\end{array}$ & $\begin{array}{l}\text { Range }=0.00 \\
\text { to } 16000.00, \\
\text { OFF }\end{array}$ & || 5.00 \\
\hline Z2GD & $\begin{array}{l}\text { Zone } 2 \text { Time Delay (cycles in } \\
0.25 \text { increments) }\end{array}$ & $\begin{array}{l}\text { Range }=0.00 \\
\text { to } 16000.00, \\
\text { OFF }\end{array}$ & $\mid 5.00$ \\
\hline Z3GD & $\begin{array}{l}\text { Zone } 3 \text { Time Delay (cycles in } \\
0.25 \text { increments) }\end{array}$ & $\begin{array}{l}\text { Range }=0.00 \\
\text { to } 16000.00, \\
\text { OFF }\end{array}$ & $\mid 5.00$ \\
\hline Z1D & $\begin{array}{l}\text { Zone } 1 \text { Time Delay (cycles in } \\
0.25 \text { increments) }\end{array}$ & $\begin{array}{l}\text { Range }=0.00 \\
\text { to } 16000.00, \\
\text { OFF }\end{array}$ & $\mid 5.00$ \\
\hline
\end{tabular}




\begin{tabular}{|c|c|c|c|}
\hline \multicolumn{4}{|c|}{ Group 2} \\
\hline Setting & Description & Range & Value \\
\hline Z2D & $\begin{array}{l}\text { Zone } 2 \text { Time Delay (cycles in } \\
0.25 \text { increments) }\end{array}$ & $\begin{array}{l}\text { Range }=0.00 \\
\text { to } 16000.00, \\
\text { OFF }\end{array}$ & $\mid 5.00$ \\
\hline $\mathrm{Z} 3 \mathrm{D}$ & $\begin{array}{l}\text { Zone } 3 \text { Time Delay (cycles in } \\
0.25 \text { increments) }\end{array}$ & $\begin{array}{l}\text { Range }=0.00 \\
\text { to } 16000.00, \\
\text { OFF }\end{array}$ & $\mid 5.00$ \\
\hline E50P & $\begin{array}{l}\text { Enable Phase Overcurrent } \\
\text { Elements }\end{array}$ & Select: N, 1-3 & $\| \mathrm{N}$ \\
\hline E50G & $\begin{array}{l}\text { Enable Residual Ground } \\
\text { Overcurrent Elements }\end{array}$ & Select: N, 1-4 & N \\
\hline E50Q & $\begin{array}{l}\text { Enable Negative-Sequence } \\
\text { Overcurrent Elements }\end{array}$ & Select: N, 1-4 & $\mathrm{N}$ \\
\hline E51P & \begin{tabular}{|l} 
Enable Phase Time- \\
Overcurrent Elements \\
\end{tabular} & Select: Y, N & |Y \\
\hline $51 \mathrm{PP}$ & Pickup (Amps secondary) & $\begin{array}{l}\text { Range }=0.25 \\
\text { to } 16.00, \text { OFF }\end{array}$ & 4.50 \\
\hline $51 \mathrm{PC}$ & Curve & \begin{tabular}{|l} 
Select: U1-U5, \\
C1-C5
\end{tabular} & U1 \\
\hline 51PTD & Time Dial & $\begin{array}{l}\text { Range }=0.50 \\
\text { to } 15.00\end{array}$ & $\mid 0.50$ \\
\hline 51PRS & $\begin{array}{l}\text { Electromechanical Reset } \\
\text { Delay }\end{array}$ & Select: Y, N & N \\
\hline E51G & $\begin{array}{l}\text { Enable Residual Ground } \\
\text { Time-Overcurrent Elements }\end{array}$ & Select: Y, N & |Y \\
\hline $51 \mathrm{GP}$ & Pickup (Amps secondary) & $\begin{array}{l}\text { Range }=0.25 \\
\text { to } 16.00, \text { OFF }\end{array}$ & 0.25 \\
\hline $51 \mathrm{GC}$ & Curve & \begin{tabular}{|l} 
Select: U1-U5, \\
C1-C5
\end{tabular} & U1 \\
\hline $51 \mathrm{GTD}$ & Time Dial & $\begin{array}{l}\text { Range }=0.50 \\
\text { to } 15.00\end{array}$ & $\mid 0.50$ \\
\hline $51 \mathrm{GRS}$ & $\begin{array}{l}\text { Electromechanical Reset } \\
\text { Delay }\end{array}$ & Select: Y, N & $\| \mathrm{N}$ \\
\hline E51Q & $\begin{array}{l}\text { Enable Negative-Sequence } \\
\text { Time-Overcurrent Elements }\end{array}$ & Select: Y, N & |Y \\
\hline $51 \mathrm{QP}$ & Pickup (Amps secondary) & $\begin{array}{l}\text { Range }=0.25 \\
\text { to } 16.00, \text { OFF }\end{array}$ & 0.25 \\
\hline $51 \mathrm{QC}$ & Curve & \begin{tabular}{|l} 
Select: U1-U5, \\
C1-C5
\end{tabular} & U1 \\
\hline 51QTD & Time Dial & $\begin{array}{l}\text { Range }=0.50 \\
\text { to } 15.00\end{array}$ & 0.53 \\
\hline $51 \mathrm{QRS}$ & $\begin{array}{l}\text { Electromechanical Reset } \\
\text { Delay }\end{array}$ & Select: Y, N & N \\
\hline EOOS & Enable Out-of-Step Elements & Select: Y, N & $\mathrm{N}$ \\
\hline ELOAD & $\begin{array}{l}\text { Enable Load Encroachment } \\
\text { Elements }\end{array}$ & Select: Y, N & N \\
\hline
\end{tabular}




\begin{tabular}{|c|c|c|c|}
\hline Group 2 & & & \\
\hline Setting & Description & Range & Value \\
\hline E32 & \begin{tabular}{|l|} 
Enable Directional Control \\
Elements
\end{tabular} & $\begin{array}{l}\text { Select: Y, } \\
\text { AUTO }\end{array}$ & AUTO \\
\hline ELOP & Loss-Of-Potential Enable & $\begin{array}{l}\text { Select: Y, Y1, } \\
\mathrm{N}\end{array}$ & Y \\
\hline EBBPT & Busbar PT LOP Logic Enable & Select: Y, N & $\mathrm{N}$ \\
\hline DIR3 & Level 3 Direction & Select: F, R & $\mathrm{R}$ \\
\hline DIR4 & Level 4 Direction & Select: F, R & $\mathrm{F}$ \\
\hline ORDER & \begin{tabular}{|l|} 
Ground Directional Element \\
Priority
\end{tabular} & $\begin{array}{l}\text { Select: I, Q, V, } \\
\text { OFF }\end{array}$ & QVI \\
\hline EVOLT & \begin{tabular}{|l} 
Enable Voltage Element \\
Enables
\end{tabular} & Select: Y, N & $\| \mathrm{N}$ \\
\hline E25 & Synchronism Check Enable & Select: Y, N & $\mathrm{N}$ \\
\hline E81 & Frequency Elements Enables & Select: N, 1-6 & $\mathrm{N}$ \\
\hline E79 & Reclosures Enables & Select: N, 1-4 & $\mathrm{N}$ \\
\hline ESOTF & Enable Switch-Onto-Fault & Select: Y, N & $\mathrm{N}$ \\
\hline ECOMM & $\begin{array}{l}\text { Comm.-Assisted Trip Scheme } \\
\text { Enables }\end{array}$ & \begin{tabular}{|l} 
Select: N, \\
POTT, \\
DCUB1, \\
DCUB2, DCB \\
\end{tabular} & POTT \\
\hline Z3RBD & $\begin{array}{l}\text { Zone } 3 \text { Reverse Block Time } \\
\text { Delay (cycles in } 0.25 \\
\text { increments) }\end{array}$ & $\begin{array}{l}\text { Range }=0.00 \\
\text { to } 16000.00\end{array}$ & 5.00 \\
\hline EBLKD & $\begin{array}{l}\text { Echo Block Time Delay } \\
\text { (cycles in } 0.25 \text { increments) }\end{array}$ & \begin{tabular}{|l} 
Range $=0.00$ \\
to 16000.00 \\
OFF
\end{tabular} & 10.00 \\
\hline ETDPU & $\begin{array}{l}\text { Echo Time Delay Pickup } \\
\text { (cycles in } 0.25 \text { increments) }\end{array}$ & $\begin{array}{l}\text { Range }=0.00 \\
\text { to } 16000.00, \\
\text { OFF }\end{array}$ & 2.00 \\
\hline EDURD & $\begin{array}{l}\text { Echo Duration Time Delay } \\
\text { (cycles in } 0.25 \text { increments) }\end{array}$ & $\begin{array}{l}\text { Range }=0.00 \\
\text { to } 16000.00\end{array}$ & 4.00 \\
\hline EWFC & Weak-Infeed Enable & Select: Y, N & $\mathrm{N}$ \\
\hline EZ1EXT & Zone 1 Extension & Select: Y, N & $\mathrm{N}$ \\
\hline EDEM & Demand Metering Type & $\begin{array}{l}\text { Select: THM, } \\
\text { ROL }\end{array}$ & THM \\
\hline DMTC & Time Constant (minutes) & \begin{tabular}{|l} 
Select: 5,10 \\
$15,30,60$ \\
\end{tabular} & 60 \\
\hline PDEMP & $\begin{array}{l}\text { Phase Pickup (Amps } \\
\text { secondary) }\end{array}$ & $\begin{array}{l}\text { Range }=0.50 \\
\text { to } 16.00, \text { OFF }\end{array}$ & OFF \\
\hline GDEMP & $\begin{array}{l}\begin{array}{l}\text { Residual Ground Pickup } \\
\text { (Amps secondary) }\end{array} \\
\end{array}$ & $\begin{array}{l}\text { Range }=0.50 \\
\text { to } 16.00, \text { OFF }\end{array}$ & OFF \\
\hline QDEMP & $\begin{array}{l}\begin{array}{l}\text { Negative-Sequence Pickup } \\
\text { (Amps secondary) }\end{array} \\
\end{array}$ & $\begin{array}{l}\text { Range }=0.50 \\
\text { to } 16.00, \text { OFF }\end{array}$ & OFF \\
\hline TDURD & $\begin{array}{l}\text { Minimum Trip Duration Time } \\
\text { (cycles in } 0.25 \text { increments) }\end{array}$ & $\begin{array}{l}\text { Range }=2.00 \\
\text { to } 16000.00\end{array}$ & 9.00 \\
\hline
\end{tabular}




\begin{tabular}{|c|c|c|c|}
\hline \multicolumn{4}{|l|}{ Group 2} \\
\hline Setting & Description & Range & Value \\
\hline TOPD & $\begin{array}{l}\text { Trip Open Pole Dropout } \\
\text { Delay (cycles in } 0.25 \\
\text { increments) }\end{array}$ & $\begin{array}{l}\text { Range }=2.00 \\
\text { to } 8000.00\end{array}$ & $\mid 2.00$ \\
\hline CFD & $\begin{array}{l}\text { Close Failure Time Delay } \\
\text { (cycles in } 0.25 \text { increments) }\end{array}$ & $\begin{array}{l}\text { Range }=0.00 \\
\text { to } 16000.00, \\
\text { OFF }\end{array}$ & 60.00 \\
\hline 3POD & $\begin{array}{l}\text { Three-Pole Open Time Delay } \\
\text { (cycles in } 0.25 \text { increments) }\end{array}$ & $\begin{array}{l}\text { Range }=0.00 \\
\text { to } 60.00\end{array}$ & 0.50 \\
\hline $\mathrm{OPO}$ & Open Pole Option & Select: 27,52 & 52 \\
\hline $50 \mathrm{LP}$ & $\begin{array}{l}\text { Load Detection Phase Pickup } \\
\text { (Amps secondary) }\end{array}$ & $\begin{array}{l}\text { Range }=0.25 \\
\text { to } 100.00, \text { OFF }\end{array}$ & 0.25 \\
\hline ELAT & SELogic Latch Bit Enables & Select: N, 1-16 & 16 \\
\hline EDP & $\begin{array}{l}\text { SELogic Display Point } \\
\text { Enables }\end{array}$ & Select: N, 1-16 & $\mid 16$ \\
\hline ESV & $\begin{array}{l}\text { SELogic Variable Timers } \\
\text { Enables }\end{array}$ & Select: N, 1-16 & $\mid 1$ \\
\hline SV1PU & $\begin{array}{l}\text { SV1 Timer Pickup (cycles in } \\
0.25 \text { increments) }\end{array}$ & $\begin{array}{l}\text { Range }=0.00 \\
\text { to } 999999.00\end{array}$ & 12.00 \\
\hline SV1DO & $\begin{array}{l}\text { SV1 Timer Dropout (cycles in } \\
0.25 \text { increments) }\end{array}$ & $\begin{array}{l}\text { Range }=0.00 \\
\text { to } 999999.00\end{array}$ & 0.00 \\
\hline \multicolumn{4}{|c|}{ Group 2} \\
\hline
\end{tabular}




\section{Appendix E: SEL-387E Settings}

\begin{tabular}{|c|c|c|c|}
\hline \multicolumn{4}{|l|}{ Global } \\
\hline Setting & Description & Range & Value \\
\hline LER & Length of Event Report & \begin{tabular}{|l|} 
Select: 15,29, \\
60
\end{tabular} & 60 \\
\hline PRE & $\begin{array}{l}\text { Length of Prefault in Event } \\
\text { Report }\end{array}$ & $1-59$ cyc & 4 \\
\hline NFREQ & Nominal Frequency & Select: 50,60 & 60 \\
\hline PHROT & Phase Rotation & $\begin{array}{l}\text { Select: ABC, } \\
\text { ACB }\end{array}$ & $\mathrm{ACB}$ \\
\hline DELTA_Y & Phase Potential Connection & Select: Y, D & $\mathrm{Y}$ \\
\hline DATE_F & Date Format & $\begin{array}{l}\text { Select: MDY, } \\
\text { YMD }\end{array}$ & MDY \\
\hline SCROLD & Display Update Rate & $1-60 \mathrm{~S}$ & 2 \\
\hline FP_TO & Front Panel Timeout & OFF, 0-30 min & 16 \\
\hline TGR & Group Change Delay & $0-900 \mathrm{~S}$ & 3 \\
\hline BKMON1 & $\begin{array}{l}\text { Bkr 1 Monitor Input(SELogic } \\
\text { Equation) }\end{array}$ & & TRIP1 \\
\hline $\mathrm{B} 1 \mathrm{COP} 1$ & $\begin{array}{l}\text { Close/Open Operations Set } \\
\text { Point } 1 \text { max }\end{array}$ & $1-65000$ & 10000 \\
\hline B1KAP1 & kA Interrupted Set Point $1 \mathrm{~min}$ & $0.1-999 \mathrm{kA}$ & 1.2 \\
\hline $\mathrm{B} 1 \mathrm{COP} 2$ & \begin{tabular}{|l|} 
Close/Open Operations Set \\
Point 2 max
\end{tabular} & $1-65000$ & 160 \\
\hline B1KAP2 & kA Interrupted Set Point $2 \mathrm{~min}$ & $0.1-999 \mathrm{kA}$ & 8.0 \\
\hline $\mathrm{B} 1 \mathrm{COP} 3$ & \begin{tabular}{|l|} 
Close/Open Operations Set \\
Point 3 max
\end{tabular} & $1-65000$ & 12 \\
\hline B1KAP3 & kA Interrupted Set Point $3 \mathrm{~min}$ & $0.1-999 \mathrm{kA}$ & 20.0 \\
\hline BKMON2 & \begin{tabular}{|l|} 
Bkr 2 Monitor Input(SELogic \\
Equation)
\end{tabular} & & (TRIP2 + TRIP3 + TRIP4) \\
\hline $\mathrm{B} 2 \mathrm{COP} 1$ & \begin{tabular}{|l} 
Close/Open Operations Set \\
Point 1 max \\
\end{tabular} & $1-65000$ & 10000 \\
\hline B2KAP1 & kA Interrupted Set Point $1 \mathrm{~min}$ & $0.1-999 \mathrm{kA}$ & 1.2 \\
\hline B2COP2 & \begin{tabular}{|l|} 
Close/Open Operations Set \\
Point 2 max
\end{tabular} & $1-65000$ & 160 \\
\hline B2KAP2 & kA Interrupted Set Point $2 \mathrm{~min}$ & $0.1-999 \mathrm{kA}$ & 8.0 \\
\hline $\mathrm{B} 2 \mathrm{COP} 3$ & \begin{tabular}{|l|} 
Close/Open Operations Set \\
Point 3 max
\end{tabular} & $1-65000$ & 12 \\
\hline B2KAP3 & kA Interrupted Set Point $3 \mathrm{~min}$ & $0.1-999 \mathrm{kA}$ & 20.0 \\
\hline BKMON3 & \begin{tabular}{|l|} 
Bkr 3 Monitor Input(SELogic \\
Equation)
\end{tabular} & & TRIP3 + TRIP4 \\
\hline B3COP1 & \begin{tabular}{|l} 
Close/Open Operations Set \\
Point 1 max
\end{tabular} & $1-65000$ & 10000 \\
\hline B3KAP1 & kA Interrupted Set Point $1 \mathrm{~min}$ & $0.1-999 \mathrm{kA}$ & 1.2 \\
\hline
\end{tabular}




\begin{tabular}{|l|l|l||l||}
\hline \multicolumn{2}{|l|}{ Global } \\
\hline \hline Setting & Description & Range & Value \\
\hline \hline B3COP2 & $\begin{array}{l}\text { Close/Open Operations Set } \\
\text { Point 2 max }\end{array}$ & $1-65000$ & 160 \\
\hline \hline B3KAP2 & kA Interrupted Set Point 2 min & $0.1-999 \mathrm{kA}$ & 8.0 \\
\hline \hline B3COP3 & $\begin{array}{l}\text { Close/Open Operations Set } \\
\text { Point 3 max }\end{array}$ & $1-65000$ & 12 \\
\hline \hline B3KAP3 & kA Interrupted Set Point 3 min & $0.1-999 \mathrm{kA}$ & 20.0 \\
\hline \hline ETHRU & $\begin{array}{l}\text { Enable Through Fault Event } \\
\text { Winding }\end{array}$ & Select: N, 1-3 & $\mathrm{N}$ \\
\hline Global & & \\
\hline
\end{tabular}

\begin{tabular}{|c|c|c|c|}
\hline \multicolumn{4}{|c|}{ Group 1} \\
\hline Setting & Description & Range & Value \\
\hline RID & \begin{tabular}{|l|} 
Relay Identifier (39 \\
Characters) \\
\end{tabular} & & 387E_Y-Y \\
\hline TID & $\begin{array}{l}\text { Terminal Identifier (59 } \\
\text { Characters) }\end{array}$ & & BENCH5 \\
\hline E87W1 & $\begin{array}{l}\text { Enable Wdg1 in Differential } \\
\text { Element }\end{array}$ & Select: N, Y, Y1 & Y1 \\
\hline E87W2 & $\begin{array}{l}\text { Enable Wdg2 in Differential } \\
\text { Element }\end{array}$ & Select: N, Y, Y1 & Y1 \\
\hline E87W3 & $\begin{array}{l}\text { Enable Wdg3 in Differential } \\
\text { Element }\end{array}$ & Select: N, Y, Y1 & N \\
\hline EOC1 & $\begin{array}{l}\text { Enable Wdg1 O/C Elements } \\
\text { and Dmd. Thresholds }\end{array}$ & Select: N, Y & $\mathrm{N}$ \\
\hline EOC2 & $\begin{array}{l}\text { Enable Wdg2 O/C Elements } \\
\text { and Dmd. Thresholds }\end{array}$ & Select: N, Y & Y \\
\hline EOC3 & $\begin{array}{l}\text { Enable Wdg3 O/C Elements } \\
\text { and Dmd. Thresholds }\end{array}$ & Select: N, Y & $\mathrm{N}$ \\
\hline EOCC & \begin{tabular}{|l} 
Enable Combined O/C \\
Elements
\end{tabular} & Select: N, Y & $\mathrm{N}$ \\
\hline E24 & Enable Volts/Hertz Protection & Select: N, Y & $\mathrm{N}$ \\
\hline E27 & \begin{tabular}{|l|} 
Enable Undervoltage \\
Protection \\
\end{tabular} & Select: N, Y & $\mathrm{N}$ \\
\hline E59 & $\begin{array}{l}\text { Enable Overvoltage } \\
\text { Protection } \\
\end{array}$ & Select: N, Y & N \\
\hline E81 & Enable Frequency Protection & Select: N, 1-6 & $\mathrm{N}$ \\
\hline ESLS1 & Enable SELogic Set 1 & Select: N, Y & $\mathrm{N}$ \\
\hline ESLS2 & Enable SELogic Set 2 & Select: N, Y & $\mathrm{N}$ \\
\hline ESLS3 & Enable SELogic Set 3 & Select: N, Y & $\mathrm{N}$ \\
\hline W1CT & Wdg 1 CT Connection & Select: D, Y & $\mathrm{Y}$ \\
\hline W2CT & Wdg 2 CT Connection & Select: D, Y & $\mathrm{Y}$ \\
\hline
\end{tabular}




\begin{tabular}{|c|c|c|c|}
\hline \multicolumn{4}{|l|}{ Group 1} \\
\hline Setting & Description & Range & Value \\
\hline W3CT & Wdg 3 CT Connection & Select: D, Y & $\mathrm{Y}$ \\
\hline CTR1 & Wdg 1 CT Ratio & $1-50000$ & 1 \\
\hline CTR2 & Wdg 2 CT Ratio & $1-50000$ & 1 \\
\hline CTR3 & Wdg 3 CT Ratio & $1-50000$ & 1 \\
\hline MVA & $\begin{array}{l}\text { Maximum Power Xfmr } \\
\text { Capacity }\end{array}$ & $\begin{array}{l}\text { OFF, } 0.2-5000.0 \\
\text { MVA }\end{array}$ & OFF \\
\hline ICOM & \begin{tabular}{|l|} 
Define Internal CT \\
Connection Compensation \\
\end{tabular} & Select: N, Y & $\mathrm{N}$ \\
\hline PTR & PT Ratio & $1-6500$ & 1 \\
\hline COMPANG & Compensation Angle & 0-360deg & 0 \\
\hline VIWDG & Voltage-Current Winding & Select: $1-3,12$ & 1 \\
\hline TPVI & Three Phase Voltage Input & Select: N, Y & $\mathrm{Y}$ \\
\hline TAP1 & Wdg 1 Current Tap & $0.50-155.00$ & 3.00 \\
\hline TAP2 & Wdg 2 Current Tap & $0.50-155.00$ & 3.00 \\
\hline O87P & $\begin{array}{l}\text { Restrained Element Current } \\
\mathrm{PU}\end{array}$ & $0.10-1.00$ TAP & 0.30 \\
\hline SLP1 & Restraint Slope 1 Percentage & $5-100 \%$ & 25 \\
\hline SLP2 & Restraint Slope 2 Percentage & OFF, $25-200 \%$ & 50 \\
\hline IRS1 & \begin{tabular}{|l|} 
Restraint Current Slope 1 \\
Limit
\end{tabular} & $1.0-20.0$ TAP & 3.0 \\
\hline U87P & $\begin{array}{l}\text { Unrestrained Element Current } \\
\mathrm{PU}\end{array}$ & $1-20$ TAP & 3.0 \\
\hline РCТ2 & $\begin{array}{l}\text { 2nd Harmonic Blocking } \\
\text { Percentage }\end{array}$ & OFF,5-100\% & 15 \\
\hline PCT4 & $\begin{array}{l}\text { 4th Harmonic Blocking } \\
\text { Percentage }\end{array}$ & OFF,5-100\% & 15 \\
\hline PCT5 & $\begin{array}{l}\text { 5th Harmonic Blocking } \\
\text { Percentage }\end{array}$ & OFF,5-100\% & 35 \\
\hline TH5P & $\begin{array}{l}\text { 5th Harmonic Alarm } \\
\text { Threshold }\end{array}$ & $\begin{array}{l}\text { OFF, } 0.02-3.2 \\
\text { TAP }\end{array}$ & OFF \\
\hline DCRB & DC Ratio Blocking & Select: N, Y & $\mathrm{Y}$ \\
\hline HRSTR & Harmonic Restraint & Select: N, Y & $\mathrm{Y}$ \\
\hline E32I & \begin{tabular}{|l|} 
Enable 32I(SELogic \\
Equation)
\end{tabular} & & 0 \\
\hline $50 \mathrm{P} 21 \mathrm{P}$ & $\begin{array}{l}\text { Phase Def-Time O/C Lvl } 1 \\
\text { PU }\end{array}$ & \begin{tabular}{|l|} 
OFF, $0.25-$ \\
$100 \mathrm{~A}, \mathrm{sec}$ \\
\end{tabular} & OFF \\
\hline $50 \mathrm{P} 22 \mathrm{P}$ & Phase Inst O/C Lvl 2 PU & \begin{tabular}{|l|} 
OFF, $0.25-$ \\
$100.00 \mathrm{~A}, \mathrm{sec}$ \\
\end{tabular} & OFF \\
\hline $50 \mathrm{P} 23 \mathrm{P}$ & Phase Inst O/C Lvl 3 PU & \begin{tabular}{|l|} 
OFF, $0.25-$ \\
$100.00 \mathrm{~A}, \mathrm{sec}$ \\
\end{tabular} & OFF \\
\hline 50P24P & Phase Inst O/C Lvl 4 PU & $\begin{array}{l}\text { OFF, } 0.25- \\
100.00 \mathrm{~A}, \mathrm{sec}\end{array}$ & OFF \\
\hline
\end{tabular}




\begin{tabular}{|c|c|c|c|}
\hline \multicolumn{4}{|l|}{ Group 1} \\
\hline Setting & Description & Range & Value \\
\hline $51 \mathrm{P} 2 \mathrm{P}$ & Phase Inv-Time O/C PU & $\begin{array}{l}\text { OFF,0.50- } \\
16.00 A, s e c\end{array}$ & 4.50 \\
\hline $51 \mathrm{P} 2 \mathrm{C}$ & Phase Inv-Time O/C Curve & $\begin{array}{l}\text { Select: U1, U2, } \\
\text { U3, U4, U5, C1, } \\
\text { C2, C3, C4, C5 } \\
\end{array}$ & $\mathrm{U} 1$ \\
\hline $51 \mathrm{P} 2 \mathrm{TD}$ & $\begin{array}{l}\text { Phase Inv-Time O/C Time- } \\
\text { Dial }\end{array}$ & $0.50-15.00$ & 0.55 \\
\hline 51P2RS & $\begin{array}{l}\begin{array}{l}\text { Phase Inv-Time O/C EM } \\
\text { Reset }\end{array} \\
\end{array}$ & Select: N, Y & $\mathrm{N}$ \\
\hline $51 \mathrm{P} 2 \mathrm{TC}$ & \begin{tabular}{|l} 
51P2 Torque Control \\
(SELogic Equation)
\end{tabular} & & 1 \\
\hline $50 \mathrm{Q} 21 \mathrm{P}$ & $\begin{array}{l}\text { Neg-Seq Def-Time O/C Lvl } 1 \\
\text { PU }\end{array}$ & $\begin{array}{l}\text { OFF, } 0.25- \\
100 \mathrm{~A}, \mathrm{sec}\end{array}$ & OFF \\
\hline $50 \mathrm{Q} 22 \mathrm{P}$ & Neg-Seq Inst O/C Lvl 2 PU & $\begin{array}{l}\text { OFF, } 0.25- \\
100.00 \mathrm{~A}, \mathrm{sec}\end{array}$ & OFF \\
\hline $51 \mathrm{Q} 2 \mathrm{P}$ & Neg-Seq Inv-Time O/C PU & $\begin{array}{l}\text { OFF, } 0.50- \\
16.00 \mathrm{~A}, \mathrm{sec}\end{array}$ & 0.50 \\
\hline $51 \mathrm{Q} 2 \mathrm{C}$ & Neg-Seq Inv-Time O/C Curve & \begin{tabular}{|l} 
Select: U1, U2, \\
U3, U4, U5, C1, \\
C2, C3, C4, C5 \\
\end{tabular} & $\mathrm{U} 1$ \\
\hline 51Q2TD & $\begin{array}{l}\text { Neg-Seq Inv-Time O/C Time- } \\
\text { Dial }\end{array}$ & $0.50-15.00$ & 0.55 \\
\hline 51Q2RS & $\begin{array}{l}\text { Neg-Seq Inv-Time O/C EM } \\
\text { Reset }\end{array}$ & Select: N, Y & $\mathrm{N}$ \\
\hline 51Q2TC & \begin{tabular}{|l} 
51Q2 Torque Control \\
(SELogic Equation)
\end{tabular} & & 1 \\
\hline $50 \mathrm{~N} 21 \mathrm{P}$ & Res. Def-Time O/C Lvl 1 PU & \begin{tabular}{|l} 
OFF, $0.25-$ \\
$100.00 \mathrm{~A}, \mathrm{sec}$
\end{tabular} & OFF \\
\hline $50 \mathrm{~N} 22 \mathrm{P}$ & Res. Inst O/C Lvl 2 PU & \begin{tabular}{|l} 
OFF, $0.25-$ \\
$100.00 \mathrm{~A}, \mathrm{sec}$
\end{tabular} & OFF \\
\hline $51 \mathrm{~N} 2 \mathrm{P}$ & Res. Inv-Time O/C PU & $\begin{array}{l}\text { OFF,0.50- } \\
16.00 \mathrm{~A}, \mathrm{sec}\end{array}$ & 0.50 \\
\hline $51 \mathrm{~N} 2 \mathrm{C}$ & Res. Inv-Time O/C Curve & $\begin{array}{l}\text { Select: U1, U2, } \\
\text { U3, U4, U5, C1, } \\
\text { C2, C3, C4, C5 }\end{array}$ & U1 \\
\hline $51 \mathrm{~N} 2 \mathrm{TD}$ & Res. Inv-Time O/C Time-Dial & $0.50-15.00$ & 0.55 \\
\hline 51N2RS & Res. Inv-Time O/C EM Reset & Select: N, Y & $\mathrm{N}$ \\
\hline $51 \mathrm{~N} 2 \mathrm{TC}$ & \begin{tabular}{|l|} 
51N2 Torque Control \\
(SELogic Equation)
\end{tabular} & & 1 \\
\hline DATC2 & $\begin{array}{l}\text { Demand Ammeter Time } \\
\text { Constant }\end{array}$ & OFF,5-255min & 15 \\
\hline PDEM2P & $\begin{array}{l}\text { Phase Demand Ammeter } \\
\text { Thresh } \\
\end{array}$ & $0.50-16.00 \mathrm{~A}, \mathrm{sec}$ & 7.00 \\
\hline QDEM2P & $\begin{array}{l}\text { Neg-Seq Demand Ammeter } \\
\text { Thresh }\end{array}$ & $0.50-16.00 \mathrm{~A}, \mathrm{sec}$ & 1.00 \\
\hline
\end{tabular}




\begin{tabular}{|c|c|c|c|}
\hline \multicolumn{4}{|l|}{ Group 1} \\
\hline Setting & Description & Range & Value \\
\hline NDEM2P & $\begin{array}{l}\text { Res. Demand Ammeter } \\
\text { Thresh }\end{array}$ & $0.50-16.00 \mathrm{~A}, \mathrm{sec}$ & 1.00 \\
\hline TDURD & Trip Duration Delay & $\begin{array}{l}4.000-8000.000 \\
\text { cyc }\end{array}$ & 9.000 \\
\hline CFD & Close Failure Delay & $\begin{array}{l}\text { OFF, } 0.000- \\
8000.000 \text { cyc }\end{array}$ & OFF \\
\hline TR1 & & & $87 \mathrm{R}+\mathrm{OC} 1$ \\
\hline TR2 & & & $87 \mathrm{R}+51 \mathrm{P} 2 \mathrm{~T}+\mathrm{OC} 2$ \\
\hline TR3 & & & 51Q2T \\
\hline TR4 & & & $51 \mathrm{~N} 2 \mathrm{~T}$ \\
\hline ULTR1 & & & $! 50 \mathrm{P} 13$ \\
\hline ULTR2 & & & $! 50 \mathrm{P} 23$ \\
\hline ULTR3 & & & !50P33 \\
\hline ULTR4 & & & $!(50 \mathrm{P} 13+50 \mathrm{P} 23+50 \mathrm{P} 33)$ \\
\hline $52 \mathrm{~A} 1$ & & & IN101 \\
\hline $52 \mathrm{~A} 2$ & & & IN102 \\
\hline $52 \mathrm{~A} 3$ & & & IN103 \\
\hline CL1 & & & $\mathrm{CC} 1+\mathrm{LB} 4+/ \mathrm{IN} 104$ \\
\hline CL2 & & & $\mathrm{CC} 2+/ \mathrm{IN} 105$ \\
\hline CL3 & & & $\mathrm{CC} 3+/ \mathrm{IN} 106$ \\
\hline ULCL1 & & & TRIP1 + TRIP4 \\
\hline ULCL2 & & & TRIP2 + TRIP4 \\
\hline ULCL3 & & & TRIP3 + TRIP4 \\
\hline ER & & & $\begin{array}{l}\text { /50P11+/51P1+/51Q1 + /51P2 + /51Q2 } \\
+/ 51 \mathrm{~N} 2+/ 51 \mathrm{P} 3\end{array}$ \\
\hline OUT101 & & & !TRIP1 \\
\hline OUT102 & & & !(TRIP2 + TRIP3 + TRIP4) \\
\hline
\end{tabular}

\begin{tabular}{|l||l|l|l||}
\hline \multicolumn{2}{|l|}{ Report } & Range & Value \\
\hline Setting & Description & & IN101, IN102, IN103, IN104, IN105, IN106 \\
\hline \hline SER1 & & & $\begin{array}{l}\text { OUT101, OUT102, OUT103, OUT104, } \\
\text { OUT105, OUT106, OUT107 }\end{array}$ \\
\hline SER2 & & & $\begin{array}{l}\text { 51Q2T, 51Q2, 87R, 51P2T, 51P2, 51N2T, } \\
\text { 51N2, TRIP1, TRIP2, TRIP3, TRIP4 }\end{array}$ \\
\hline \hline SER3 & & & 0 \\
\hline SER4 & & & \\
\hline Report & & \\
\hline
\end{tabular}




\begin{tabular}{|c|c|c|c|}
\hline \multicolumn{4}{|l|}{ Port 2} \\
\hline Setting & Description & Range & Value \\
\hline PROTO & Protocol & $\begin{array}{l}\text { Select: SEL, } \\
\text { LMD, DNP }\end{array}$ & SEL \\
\hline SPEED & Baud rate & \begin{tabular}{|l} 
Select: 300, \\
1200,2400, \\
4800,9600, \\
$19200,19.2$
\end{tabular} & $\mid 19200$ \\
\hline BITS & Data bits & Select: 7,8 & 8 \\
\hline PARITY & Parity & Select: N, E, O & $\mathrm{N}$ \\
\hline STOP & Stop bits & Select: 1,2 & 1 \\
\hline T_OUT & Timeout & $0-30$ min & 30 \\
\hline AUTO & Send auto messages to port & Select: N, Y & $\mathrm{Y}$ \\
\hline RTSCTS & Enable hardware handshaking & Select: N, Y & $\mathrm{N}$ \\
\hline FASTOP & Fast operate enable & Select: N, Y & $\mathrm{N}$ \\
\hline Port 2 & & & \\
\hline
\end{tabular}

\begin{tabular}{|c|c|c|c|}
\hline Port 3 & & & \\
\hline Setting & Description & Range & Value \\
\hline PROTO & Protocol & $\begin{array}{l}\text { Select: SEL, } \\
\text { LMD, DNP }\end{array}$ & SEL \\
\hline SPEED & Baud rate & $\begin{array}{l}\text { Select: } 300, \\
1200,2400, \\
4800,9600, \\
19200,19.2\end{array}$ & $\mid 19200$ \\
\hline BITS & Data bits & Select: 7, 8 & 8 \\
\hline PARITY & Parity & Select: N, E, O & $\mathrm{N}$ \\
\hline STOP & Stop bits & Select: 1,2 & 1 \\
\hline T_OUT & Timeout & $0-30 \mathrm{~min}$ & 30 \\
\hline AUTO & Send auto messages to port & Select: N, Y & $\mathrm{Y}$ \\
\hline RTSCTS & Enable hardware handshaking & Select: N, Y & $\mathrm{N}$ \\
\hline FASTOP & Fast operate enable & Select: N, Y & $\mathrm{N}$ \\
\hline Port 3 & & & \\
\hline
\end{tabular}




\section{Appendix F: SEL-587 Settings}

\begin{tabular}{|c|c|c|c|}
\hline \multicolumn{4}{|l|}{ Device } \\
\hline Setting & Description & Range & Value \\
\hline RID & $\begin{array}{l}\text { Relay Identifier (12 } \\
\text { characters) }\end{array}$ & $\begin{array}{l}\text { Range }=\text { ASCII } \\
\text { string with a } \\
\text { maximum length } \\
\text { of } 12 .\end{array}$ & 587_D-D \\
\hline TID & $\begin{array}{l}\text { Terminal Identifier }(12 \\
\text { characters) }\end{array}$ & $\begin{array}{l}\text { Range }=\text { ASCII } \\
\text { string with a } \\
\text { maximum length } \\
\text { of } 12 .\end{array}$ & BENCH5 \\
\hline MVA & \begin{tabular}{|l|} 
Maximum Power Transformer \\
Capacity (MVA)
\end{tabular} & $\begin{array}{l}\text { Range }=0.2 \text { to } \\
5000.0, \text { OFF }\end{array}$ & OFF \\
\hline TRCON & Xfmr & $\begin{array}{l}\text { Select: YY, } \\
\text { YDAC, YDAB, } \\
\text { DACDAC, } \\
\text { DABDAB, } \\
\text { DABY, DACY, } \\
\text { OTHER } \\
\end{array}$ & DACDAC \\
\hline CTCON & CT Connection & Select: YY & $\mathrm{YY}$ \\
\hline RZS & $\begin{array}{l}\text { Remove I0 from Y Connection } \\
\text { Compensation }\end{array}$ & Select: Y, N & $\mathrm{N}$ \\
\hline CTR1 & Winding 1 CT Ratio & $\begin{array}{l}\text { Range }=1 \text { to } \\
50000\end{array}$ & 1 \\
\hline CTR2 & Winding 2 CT Ratio & $\begin{array}{l}\text { Range }=1 \text { to } \\
50000\end{array}$ & 1 \\
\hline DATC & \begin{tabular}{|l} 
Demand Ammeter Time \\
Constant (minutes)
\end{tabular} & $\begin{array}{l}\text { Range }=5 \text { to } \\
255, \text { OFF }\end{array}$ & 15 \\
\hline PDEM & $\begin{array}{l}\text { Phase Demand Ammeter } \\
\text { Threshold (A) }\end{array}$ & $\begin{array}{l}\text { Range }=0.5 \text { to } \\
16.0\end{array}$ & 5.3 \\
\hline QDEM & $\begin{array}{l}\text { Neg.-Seq. Demand Ammeter } \\
\text { Threshold (A) }\end{array}$ & $\begin{array}{l}\text { Range }=0.5 \text { to } \\
16.0\end{array}$ & 1.0 \\
\hline NDEM & $\begin{array}{l}\text { Residual Demand Ammeter } \\
\text { Threshold (A) }\end{array}$ & $\begin{array}{l}\text { Range }=0.5 \text { to } \\
16.0\end{array}$ & 1.0 \\
\hline TAP1 & Winding 1 Current Tap & $\begin{array}{l}\text { Range }=0.50 \text { to } \\
160.00\end{array}$ & 3.00 \\
\hline TAP2 & Winding 2 Current Tap & $\begin{array}{l}\text { Range }=0.50 \text { to } \\
160.00\end{array}$ & 3.00 \\
\hline IN1 & |Input 1 & $\begin{array}{l}\text { Select: NA, } \\
\text { 52A1, !52A1, } \\
\text { TCEN, TCBL }\end{array}$ & NA \\
\hline IN2 & Input 2 & $\begin{array}{l}\text { Select: NA, } \\
\text { 52A2, !52A2, } \\
\text { TCEN, TCBL }\end{array}$ & NA \\
\hline $\mathrm{O} 87 \mathrm{P}$ & Operating Current PU (TAP) & $\begin{array}{l}\text { Range }=0.2 \text { to } \\
1.0\end{array}$ & 0.4 \\
\hline SLP1 & Restraint Slope $1(\%)$ & Range $=5$ to 100 & 40 \\
\hline
\end{tabular}




\begin{tabular}{|c|c|c|c|}
\hline \multicolumn{4}{|l|}{ Device } \\
\hline Setting & Description & Range & Value \\
\hline SLP2 & Restraint Slope $2(\%)$ & $\begin{array}{l}\text { Range }=25 \text { to } \\
200, \text { OFF }\end{array}$ & 50 \\
\hline IRS1 & $\begin{array}{l}\text { Restraint Current Slope } 1 \\
\text { Limit (TAP) }\end{array}$ & $\begin{array}{l}\text { Range }=1.0 \text { to } \\
16.0\end{array}$ & 3.0 \\
\hline U87P & $\begin{array}{l}\text { Inst Unrestrained Current PU } \\
\text { (TAP) }\end{array}$ & $\begin{array}{l}\text { Range }=1.0 \text { to } \\
16.0\end{array}$ & 10.0 \\
\hline PCT2 & \begin{tabular}{|l} 
2nd Harmonic Blocking \\
Percentage $(\%)$
\end{tabular} & $\begin{array}{l}\text { Range }=5 \text { to } \\
100, \text { OFF }\end{array}$ & 15 \\
\hline PCT4 & $\begin{array}{l}\text { 4th Harmonic Blocking } \\
\text { Percentage }(\%)\end{array}$ & $\begin{array}{l}\text { Range }=5 \text { to } \\
100, \text { OFF }\end{array}$ & 15 \\
\hline PCT5 & $\begin{array}{l}\text { 5th Harmonic Blocking } \\
\text { Percentage (\%) }\end{array}$ & $\begin{array}{l}\text { Range }=5 \text { to } \\
100, \text { OFF }\end{array}$ & 35 \\
\hline TH5 & \begin{tabular}{|l} 
th Harmonic Threshold \\
(TAP) \\
\end{tabular} & $\begin{array}{l}\text { Range }=0.2 \text { to } \\
3.2\end{array}$ & 0.3 \\
\hline TH5D & $\begin{array}{l}\text { 5th Harmonic Alarm TDPU } \\
\text { (cyc) }\end{array}$ & $\begin{array}{l}\text { Range }=0.000 \text { to } \\
8000.000\end{array}$ & 30.000 \\
\hline DCRB & DC Ratio Blocking & Select: Y, N & $Y$ \\
\hline HRSTR & Harmonic Restraint & Select: Y, N & $\mathrm{Y}$ \\
\hline $50 \mathrm{P} 1 \mathrm{P}$ & Phase Def.-Time O/C PU & $\begin{array}{l}\text { Range }=0.5 \text { to } \\
80.0, \text { OFF }\end{array}$ & OFF \\
\hline $50 \mathrm{P} 1 \mathrm{H}$ & Phase Inst O/C PU (A) & $\begin{array}{l}\text { Range }=0.5 \text { to } \\
80.0, \text { OFF }\end{array}$ & OFF \\
\hline 51P1P & ||Phase Inv.-Time O/C PU (A) & $\begin{array}{l}\text { Range }=0.5 \text { to } \\
16.0, \text { OFF }\end{array}$ & OFF \\
\hline $50 \mathrm{Q} 1 \mathrm{P}$ & $\begin{array}{l}\text { Neg.-Seq. Def.-Time O/C PU } \\
\text { (A) }\end{array}$ & $\begin{array}{l}\text { Range }=0.5 \text { to } \\
80.0, \text { OFF }\end{array}$ & OFF \\
\hline $51 \mathrm{Q} 1 \mathrm{P}$ & $\begin{array}{l}\text { Neg.-Seq. Inv.-Time O/C PU } \\
\text { (A) }\end{array}$ & $\begin{array}{l}\text { Range }=0.5 \text { to } \\
16.0, \text { OFF }\end{array}$ & OFF \\
\hline $50 \mathrm{~N} 1 \mathrm{P}$ & $\begin{array}{l}\text { Residual Def.-Time O/C PU } \\
\text { (A) }\end{array}$ & $\begin{array}{l}\text { Range }=0.5 \text { to } \\
80.0, \text { OFF }\end{array}$ & OFF \\
\hline $50 \mathrm{~N} 1 \mathrm{H}$ & Residual Inst O/C PU (A) & $\begin{array}{l}\text { Range }=0.5 \text { to } \\
80.0, \text { OFF }\end{array}$ & OFF \\
\hline $51 \mathrm{~N} 1 \mathrm{P}$ & $\begin{array}{l}\text { Residual Inv.-Time O/C PU } \\
\text { (A) }\end{array}$ & $\begin{array}{l}\text { Range }=0.5 \text { to } \\
16.0, \text { OFF }\end{array}$ & OFF \\
\hline $50 \mathrm{P} 2 \mathrm{P}$ & Phase Def.-Time O/C PU & $\begin{array}{l}\text { Range }=0.5 \text { to } \\
80.0, \text { OFF }\end{array}$ & OFF \\
\hline $50 \mathrm{P} 2 \mathrm{H}$ & Phase Inst O/C PU (A) & $\begin{array}{l}\text { Range }=0.5 \text { to } \\
80.0, \text { OFF }\end{array}$ & OFF \\
\hline $51 \mathrm{P} 2 \mathrm{P}$ & Phase Inv.-Time O/C PU (A) & $\begin{array}{l}\text { Range }=0.5 \text { to } \\
16.0, \text { OFF }\end{array}$ & 4.5 \\
\hline $51 \mathrm{P} 2 \mathrm{C}$ & Phase Inv.-Time O/C Curve & $\begin{array}{l}\text { Select: U1, U2, } \\
\text { U3, U4, C1, C2, } \\
\text { C3, C4 }\end{array}$ & U1 \\
\hline $51 \mathrm{P} 2 \mathrm{TD}$ & $\begin{array}{l}\text { Phase Inv.-Time O/C Time- } \\
\text { Dial }\end{array}$ & $\begin{array}{l}\text { Range }=0.50 \text { to } \\
15.00\end{array}$ & 0.55 \\
\hline
\end{tabular}




\begin{tabular}{|c|c|c|c|}
\hline Device & & & \\
\hline Setting & Description & Range & Value \\
\hline 51P2RS & $\begin{array}{l}\text { Phase Inv.-Time O/C EM } \\
\text { Reset }\end{array}$ & Select: Y, N & $\mathrm{N}$ \\
\hline $50 \mathrm{Q} 2 \mathrm{P}$ & $\begin{array}{l}\text { Neg.-Seq. Def.-Time O/C PU } \\
\text { (A) }\end{array}$ & $\begin{array}{l}\text { Range }=0.5 \text { to } \\
80.0, \text { OFF }\end{array}$ & OFF \\
\hline 51Q2P & $\begin{array}{l}\text { Neg.-Seq. Inv.-Time O/C PU } \\
\text { (A) }\end{array}$ & $\begin{array}{l}\text { Range }=0.5 \text { to } \\
16.0, \text { OFF }\end{array}$ & 0.5 \\
\hline $51 \mathrm{Q} 2 \mathrm{C}$ & $\begin{array}{l}\text { Neg.-Seq. Inv.-Time O/C } \\
\text { Curve }\end{array}$ & $\begin{array}{l}\text { Select: U1, U2, } \\
\text { U3, U4, C1, C2, } \\
\text { C3, C4 }\end{array}$ & U1 \\
\hline 51Q2TD & $\begin{array}{l}\text { Neg.-Seq. Inv.-Time O/C } \\
\text { Time-Dial }\end{array}$ & $\begin{array}{l}\text { Range }=0.50 \text { to } \\
15.00\end{array}$ & 0.55 \\
\hline 51Q2RS & $\begin{array}{l}\text { Neg.-Seq. Inv.-Time O/C EM } \\
\text { Reset }\end{array}$ & Select: Y, N & $\mathrm{N}$ \\
\hline $50 \mathrm{~N} 2 \mathrm{P}$ & $\begin{array}{l}\text { Residual Def.-Time O/C PU } \\
\text { (A) }\end{array}$ & $\begin{array}{l}\text { Range }=0.5 \text { to } \\
80.0, \text { OFF }\end{array}$ & OFF \\
\hline $50 \mathrm{~N} 2 \mathrm{H}$ & Residual Inst O/C PU (A) & $\begin{array}{l}\text { Range }=0.5 \text { to } \\
80.0, \text { OFF }\end{array}$ & OFF \\
\hline $51 \mathrm{~N} 2 \mathrm{P}$ & $\begin{array}{l}\text { Residual Inv.-Time O/C PU } \\
\text { (A) }\end{array}$ & $\begin{array}{l}\text { Range }=0.5 \text { to } \\
16.0, \text { OFF }\end{array}$ & OFF \\
\hline LTRP & Latch Trips & $\begin{array}{l}\text { Select: Y, N, } \\
\text { NL, 1-3 }\end{array}$ & $\mathrm{N}$ \\
\hline TDURD & $\begin{array}{l}\text { Minimum Trip Duration Time } \\
\text { Delay (cyc) }\end{array}$ & $\begin{array}{l}\text { Range }=0.000 \text { to } \\
2000.000\end{array}$ & 9.000 \\
\hline TXPU & ||Timer X Pickup Delay (cyc) & $\begin{array}{l}\text { Range }=0.000 \text { to } \\
8000.000\end{array}$ & 0.000 \\
\hline TXDO & Timer X Dropout Delay (cyc) & \begin{tabular}{|l|} 
Range $=0.000$ to \\
8000.000
\end{tabular} & 0.000 \\
\hline TYPU & Timer Y Pickup Delay (cyc) & \begin{tabular}{|l|} 
Range $=0.000$ to \\
8000.000
\end{tabular} & 0.000 \\
\hline TYDO & Timer Y Dropout Delay (cyc) & $\begin{array}{l}\text { Range }=0.000 \text { to } \\
8000.000\end{array}$ & 0.000 \\
\hline NFREQ & Nominal Frequency (Hz) & Select: 50,60 & 60 \\
\hline PHROT & Phase Rotation & $\begin{array}{l}\text { Select: ABC, } \\
\text { ACB }\end{array}$ & $\mathrm{ACB}$ \\
\hline Device & & & \\
\hline
\end{tabular}

\begin{tabular}{|l|l|l|l||}
\hline Logic & \multicolumn{2}{|l|}{} \\
\hline Setting & Description & Range & Value \\
\hline $\mathrm{X}$ & (SELogic Equation) & & NA \\
\hline $\mathrm{Y}$ & (SELogic Equation) & & NA \\
\hline MTU1 & (SELogic Equation) & & $87 \mathrm{R}+$ OC1 \\
\hline MTU2 & (SELogic Equation) & & $87 \mathrm{R}+51 \mathrm{P} 2 \mathrm{~T}+51 \mathrm{Q} 2 \mathrm{~T}+\mathrm{OC} 2$ \\
\hline
\end{tabular}




\begin{tabular}{|l|l|l||l||}
\hline \multicolumn{2}{|l|}{ Logic } \\
\hline Setting & Description & Range & Value \\
\hline MTU3 & (SELogic Equation) & & $51 \mathrm{~N} 2 \mathrm{~T}$ \\
\hline \hline MER & (SELogic Equation) & & $\begin{array}{l}87 \mathrm{R}+51 \mathrm{P} 2 \mathrm{~T}+51 \mathrm{Q} 2 \mathrm{~T}+51 \mathrm{~N} 2 \mathrm{~T}+51 \mathrm{P} 1 \mathrm{P}+1 \\
51 \mathrm{Q} 2 \mathrm{P}+51 \mathrm{~N} 2 \mathrm{P}\end{array}$ \\
\hline \hline OUT1 & (SELogic Equation) & & !TRP1 \\
\hline \hline OUT2 & (SELogic Equation) & & !TRP2 * !TRP3 \\
\hline \hline OUT3 & (SELogic Equation) & & NA \\
\hline \hline OUT4 & (SELogic Equation) & & NA \\
\hline Logic & & \\
\hline
\end{tabular}

\begin{tabular}{|c|c|c|c|}
\hline Port & & & \\
\hline Setting & Description & Range & Value \\
\hline PROTOCOL & Port Protocol & $\begin{array}{l}\text { Select: SEL, } \\
\text { LMD }\end{array}$ & SEL \\
\hline SPEED & Baud Rate (bps) & \begin{tabular}{|l} 
Select: 300, \\
1200,2400, \\
4800,9600, \\
19200,38400 \\
\end{tabular} & 19200 \\
\hline DATA_BITS & Number Data Bits & Select: 7,8 & 8 \\
\hline PARITY & Parity & Select: O, E, N & $\mathrm{N}$ \\
\hline STOP & Stop Bits (bits) & Select: 1,2 & 1 \\
\hline TIMEOUT & Timeout (min) & $\begin{array}{l}\text { Range }=0 \text { to } \\
30\end{array}$ & 10 \\
\hline AUTO & Auto Message Output & Select: Y, N & $\mathrm{Y}$ \\
\hline RTS_CTS & Enable RTS/CTS Handshaking & Select: Y, N & $\mathrm{N}$ \\
\hline FAST_OP & Enable Fast Operate & Select: Y, N & $\mathrm{N}$ \\
\hline Port & & & \\
\hline
\end{tabular}




\section{Appendix G: SEL-710 Settings}

\begin{tabular}{|c|c|c|c|c|}
\hline \multicolumn{5}{|l|}{ Global } \\
\hline Setting & Description & Range & Value & Comment \\
\hline APP & $\begin{array}{l}\text { Application WARNING: } \\
\text { Nameplate sets most } \\
\text { settings to Defaults, See } \\
\text { on-line help. }\end{array}$ & $\begin{array}{l}\text { Select: FULL, } \\
\text { NAMEPLATE }\end{array}$ & FULL & \\
\hline PHROT & Phase Rotation & $\begin{array}{l}\text { Select: ABC, } \\
\text { ACB }\end{array}$ & $\mathrm{ACB}$ & \\
\hline FNOM & Rated Frequency (Hz) & Select: 50,60 & 60 & \\
\hline DATE_F & Date Format & \begin{tabular}{|l} 
Select: MDY, \\
YMD, DMY
\end{tabular} & MDY & \\
\hline FAULT & $\begin{array}{l}\text { Fault Condition } \\
\text { (SELogic) }\end{array}$ & & TRIP & \\
\hline TGR & $\begin{array}{l}\text { Group Change Delay } \\
\text { (seconds) }\end{array}$ & Range $=0-400$ & 1 & \\
\hline SS1 & $\begin{array}{l}\begin{array}{l}\text { Select Settings Group1 } \\
\text { (SELogic) }\end{array} \\
\end{array}$ & & 0 & \begin{tabular}{|l} 
(Set to '1' for Radial System \\
Settings)
\end{tabular} \\
\hline $\mathrm{SS} 2$ & $\begin{array}{l}\text { Select Settings Group2 } \\
\text { (SELogic) }\end{array}$ & & 1 & \begin{tabular}{|l} 
(Set to '1' for Bidirectional \\
System Settings)
\end{tabular} \\
\hline SS3 & $\begin{array}{l}\begin{array}{l}\text { Select Settings Group3 } \\
\text { (SELogic) }\end{array} \\
\end{array}$ & & 0 & \\
\hline IRIGC & \begin{tabular}{|l|} 
IRIG-B Control Bits \\
Definition
\end{tabular} & \begin{tabular}{|l|} 
Select: NONE, \\
C37.118 \\
\end{tabular} & NONE & \\
\hline UTC_OFF & \begin{tabular}{|l|} 
Offset from UTC (hours, \\
in 0.25 hour increments)
\end{tabular} & $\begin{array}{l}\text { Range }=-24.00 \text { to } \\
24.00\end{array}$ & 0.00 & \\
\hline DST_BEGM & Month To Begin DST & $\begin{array}{l}\text { Range }=\text { OFF, } 1- \\
12\end{array}$ & OFF & \\
\hline $52 \mathrm{ABF}$ & $\begin{array}{l}\text { 52A Interlock in } \mathrm{BF} \\
\text { Logic }\end{array}$ & Select: Y, N & $\mathrm{N}$ & \\
\hline BFD & \begin{tabular}{|l|}
$\begin{array}{l}\text { Breaker Failure Delay } \\
\text { (seconds) }\end{array}$ \\
\end{tabular} & $\begin{array}{l}\text { Range }=0.00- \\
2.00\end{array}$ & 0.50 & \\
\hline BFI & $\begin{array}{l}\text { Breaker Failure Initiate } \\
\text { (SELogic) }\end{array}$ & & \begin{tabular}{|l} 
R_TRIG \\
TRIP \\
\end{tabular} & \\
\hline AI301NAM & \begin{tabular}{|l} 
AI301 Instrument Tag \\
Name ( 8 characters)
\end{tabular} & & AI301 & \\
\hline AI301TYP & AI301 Input Type & Select: I, V & $\mathrm{I}$ & \\
\hline AI301L & AI301 Low Input Value & $\begin{array}{l}\text { Range }=-20.480 \\
\text { to } 20.480 \\
\end{array}$ & 4.000 & \\
\hline AI301H & AI301 High Input Value & $\begin{array}{l}\text { Range }=-20.480 \\
\text { to } 20.480\end{array}$ & 20.000 & \\
\hline AI301EU & \begin{tabular}{|l|} 
AI301 Engineering Units \\
$(16$ characters $)$
\end{tabular} & & $\mathrm{mA}$ & \\
\hline AI301EL & \begin{tabular}{||l} 
AI301 Low Input \\
Engineering Units
\end{tabular} & \begin{tabular}{|l} 
Range $=-$ \\
99999.000 to \\
99999.000
\end{tabular} & 4.000 & \\
\hline
\end{tabular}




\begin{tabular}{|c|c|c|c|c|}
\hline \multicolumn{5}{|l|}{ Global } \\
\hline Setting & Description & Range & Value & Comment \\
\hline AI301EH & $\begin{array}{l}\text { AI301 High Input } \\
\text { Engineering Units }\end{array}$ & $\begin{array}{l}\text { Range }=- \\
99999.000 \text { to } \\
99999.000\end{array}$ & 20.000 & \\
\hline AI302NAM & $\begin{array}{l}\text { AI302 Instrument Tag } \\
\text { Name ( } 8 \text { characters) } \\
\end{array}$ & & AI302 & \\
\hline AI302TYP & AI302 Input Type & Select: I, V & $\mathrm{I}$ & \\
\hline AI302L & AI302 Low Input Value & $\begin{array}{l}\text { Range }=-20.480 \\
\text { to } 20.480\end{array}$ & 4.000 & \\
\hline $\mathrm{AI} 302 \mathrm{H}$ & AI302 High Input Value & $\begin{array}{l}\text { Range }=-20.480 \\
\text { to } 20.480\end{array}$ & 20.000 & \\
\hline AI302EU & \begin{tabular}{|l|} 
AI302 Engineering Units \\
(16 characters)
\end{tabular} & & $\mathrm{mA}$ & \\
\hline AI302EL & \begin{tabular}{|l} 
AI302 Low Input \\
Engineering Units
\end{tabular} & $\begin{array}{l}\text { Range }=- \\
99999.000 \text { to } \\
99999.000\end{array}$ & 4.000 & \\
\hline AI302EH & $\begin{array}{l}\text { AI302 High Input } \\
\text { Engineering Units }\end{array}$ & $\begin{array}{l}\text { Range }=- \\
99999.000 \text { to } \\
99999.000\end{array}$ & 20.000 & \\
\hline AI303NAM & $\begin{array}{l}\text { AI303 Instrument Tag } \\
\text { Name ( } 8 \text { characters) } \\
\end{array}$ & & AI303 & \\
\hline AI303TYP & AI303 Input Type & Select: I, V & $\mathrm{I}$ & \\
\hline AI303L & AI303 Low Input Value & $\begin{array}{l}\text { Range }=-20.480 \\
\text { to } 20.480\end{array}$ & 4.000 & \\
\hline $\mathrm{AI} 303 \mathrm{H}$ & AI303 High Input Value & $\begin{array}{l}\text { Range }=-20.480 \\
\text { to } 20.480\end{array}$ & 20.000 & \\
\hline AI303EU & \begin{tabular}{|l|} 
AI303 Engineering Units \\
$(16$ characters $)$
\end{tabular} & & $\mathrm{mA}$ & \\
\hline AI303EL & $\begin{array}{l}\text { AI303 Low Input } \\
\text { Engineering Units }\end{array}$ & $\begin{array}{l}\text { Range }=- \\
99999.000 \text { to } \\
99999.000\end{array}$ & 4.000 & \\
\hline AI303EH & $\begin{array}{l}\text { AI303 High Input } \\
\text { Engineering Units }\end{array}$ & $\begin{array}{l}\text { Range }=- \\
99999.000 \text { to } \\
99999.000\end{array}$ & 20.000 & \\
\hline AI304NAM & \begin{tabular}{|l|} 
AI304 Instrument Tag \\
Name ( 8 characters) \\
\end{tabular} & & AI304 & \\
\hline AI304TYP & AI304 Input Type & Select: I, V & $\mathrm{I}$ & \\
\hline AI304L & AI304 Low Input Value & $\begin{array}{l}\text { Range }=-20.480 \\
\text { to } 20.480\end{array}$ & 4.000 & \\
\hline AI304H & AI304 High Input Value & $\begin{array}{l}\text { Range }=-20.480 \\
\text { to } 20.480\end{array}$ & 20.000 & \\
\hline AI304EU & \begin{tabular}{|l|} 
AI304 Engineering Units \\
$(16$ characters $)$
\end{tabular} & & $\mathrm{mA}$ & \\
\hline AI304EL & \begin{tabular}{|l} 
AI304 Low Input \\
Engineering Units
\end{tabular} & $\begin{array}{l}\text { Range }=- \\
99999.000 \text { to } \\
99999.000\end{array}$ & 4.000 & \\
\hline
\end{tabular}




\begin{tabular}{|c|c|c|c|c|}
\hline \multicolumn{5}{|l|}{ Global } \\
\hline Setting & Description & Range & Value & Comment \\
\hline AI304EH & \begin{tabular}{|l} 
AI304 High Input \\
Engineering Units
\end{tabular} & $\begin{array}{l}\text { Range }=- \\
99999.000 \text { to } \\
99999.000\end{array}$ & 20.000 & \\
\hline AO304AQ & $\begin{array}{l}\text { AO304 Analog Quantity } \\
\text { (Off, } 1 \text { analog quantity) }\end{array}$ & & OFF & \\
\hline BLKMBSET & $\begin{array}{l}\text { Block Modbus Settings } \\
\text { Edit }\end{array}$ & $\begin{array}{l}\text { Select: NONE, } \\
\text { R_S, ALL } \\
\end{array}$ & NONE & \\
\hline TIME_SRC & IRIG Time Source & $\begin{array}{l}\text { Select: IRIG1, } \\
\text { IRIG2 }\end{array}$ & IRIG1 & \\
\hline EBMON & Enable Breaker Monitor & Select: Y, N & $\mathrm{N}$ & \\
\hline Global & & & & \\
\hline
\end{tabular}

\begin{tabular}{|c|c|c|c|c|}
\hline \multicolumn{5}{|l|}{ Group 1} \\
\hline Setting & Description & Range & Value & Comment \\
\hline RID & $\begin{array}{l}\text { Relay Identifier (16 } \\
\text { characters) }\end{array}$ & & SEL-710 & \\
\hline TID & $\begin{array}{l}\text { Terminal Identifier (16 } \\
\text { characters) }\end{array}$ & & $\begin{array}{l}\text { MOTOR } \\
\text { RELAY }\end{array}$ & \\
\hline CTR1 & Phase (IA,IB,IC) CT Ratio & Range $=1-5000$ & 1 & \\
\hline FLA1 & $\begin{array}{l}\text { Motor FLA [Full Load } \\
\text { Amps] (amps) }\end{array}$ & $\begin{array}{l}\text { Range }=0.2- \\
5000.0\end{array}$ & 1.6 & Radial System \\
\hline E2SPEED & Two-Speed Protection & Select: Y, N & $\mathrm{N}$ & \\
\hline CTRN & Neutral (IN) CT Ratio & Range $=1-2000$ & 1 & \\
\hline PTR & PT Ratio & $\begin{array}{l}\text { Range }=1.00- \\
250.00\end{array}$ & 1.00 & \\
\hline VNOM & $\begin{array}{l}\text { Line Voltage, Nominal } \\
\text { Line-to-Line (volts) } \\
\end{array}$ & $\begin{array}{l}\text { Range }=100- \\
30000\end{array}$ & 170 & \\
\hline DELTA_Y & Transformer Connection & $\begin{array}{l}\text { Select: WYE, } \\
\text { DELTA }\end{array}$ & WYE & \\
\hline SINGLEV & Single Voltage Input & Select: Y, N & $\mathrm{N}$ & \\
\hline E49MOTOR & $\begin{array}{l}\text { Thermal Overload } \\
\text { Protection }\end{array}$ & Select: Y, N & $\mathrm{Y}$ & \\
\hline FLS & $\begin{array}{l}\text { Full Load Slip (per unit } \\
\text { Synchronous Speed) }\end{array}$ & $\begin{array}{l}\text { Range }= \\
\text { OFF, } 0.0010- \\
0.1000\end{array}$ & OFF & \\
\hline SETMETH & Thermal Overload Method & $\begin{array}{l}\text { Select: } \\
\text { RATING, } \\
\text { RATING_1, } \\
\text { CURVE } \\
\end{array}$ & RATING & \\
\hline 49RSTP & $\begin{array}{l}\text { Thermal Overload Reset } \\
\text { Level (\%TCU) }\end{array}$ & Range $=10-99$ & 75 & \\
\hline SF & Service Factor & $\begin{array}{l}\text { Range }=1.01- \\
1.50\end{array}$ & 1.35 & \\
\hline
\end{tabular}




\begin{tabular}{|c|c|c|c|c|}
\hline \multicolumn{5}{|l|}{ Group 1} \\
\hline Setting & Description & Range & Value & Comment \\
\hline LRA1 & \begin{tabular}{|l} 
Motor LRA (Locked Rotor \\
Amps) (xFLA)
\end{tabular} & $\begin{array}{l}\text { Range }=2.5- \\
12.0\end{array}$ & 2.5 & \\
\hline LRTHOT1 & \begin{tabular}{|l|}
$\begin{array}{l}\text { Locked Rotor Time } \\
\text { (seconds) }\end{array}$ \\
\end{tabular} & $\begin{array}{l}\text { Range }=1.0- \\
600.0\end{array}$ & 3.0 & \\
\hline TD1 & ACCEL FACTOR & $\begin{array}{l}\text { Range }=0.10- \\
1.50\end{array}$ & 1.00 & \\
\hline RTC1 & $\begin{array}{l}\text { Stator Time Constant } \\
\text { (minutes) }\end{array}$ & $\begin{array}{l}\text { Range }= \\
\text { AUTO,1-2000 }\end{array}$ & AUTO & \\
\hline TCAPU & $\begin{array}{l}\text { Thermal Overload Alarm } \\
\text { Pickup (\%TCU) }\end{array}$ & \begin{tabular}{|l} 
Range $=$ \\
OFF,50-99
\end{tabular} & 85 & \\
\hline TCSTART & Start Inhibit Level (\%TCU) & $\begin{array}{l}\text { Range = OFF,1- } \\
99\end{array}$ & OFF & \\
\hline COOLTIME & $\begin{array}{l}\text { Stopped Cool Time } \\
\text { (minutes) }\end{array}$ & Range $=1-6000$ & 3 & \\
\hline $50 \mathrm{P} 1 \mathrm{P}$ & $\begin{array}{l}\text { Phase Overcurrent Trip } \\
\text { Pickup (xFLA) }\end{array}$ & \begin{tabular}{|l|} 
Range $=$ \\
OFF, $0.10-20.00$
\end{tabular} & 3.00 & \\
\hline $50 \mathrm{P} 2 \mathrm{P}$ & $\begin{array}{l}\text { Phase Overcurrent Alarm } \\
\text { Pickup (xFLA) }\end{array}$ & \begin{tabular}{|l|} 
Range $=$ \\
OFF, $0.10-20.00$
\end{tabular} & OFF & \\
\hline $50 \mathrm{P} 1 \mathrm{D}$ & $\begin{array}{l}\text { Phase Overcurrent Trip } \\
\text { Delay (seconds) }\end{array}$ & $\begin{array}{l}\text { Range }=0.00- \\
5.00\end{array}$ & 0.00 & \\
\hline $50 \mathrm{~N} 1 \mathrm{P}$ & $\begin{array}{l}\text { Neutral Overcurrent Trip } \\
\text { Pickup (amps pri) } \\
\end{array}$ & \begin{tabular}{|l|} 
Range $=$ \\
OFF, $0.01-25.00$
\end{tabular} & OFF & \\
\hline $50 \mathrm{~N} 2 \mathrm{P}$ & \begin{tabular}{|l|} 
Neutral Overcurrent Alarm \\
Pickup (amps pri) \\
\end{tabular} & \begin{tabular}{|l|} 
Range $=$ \\
OFF, $0.01-25.00$
\end{tabular} & OFF & \\
\hline $50 \mathrm{G} 1 \mathrm{P}$ & $\begin{array}{l}\text { Residual Overcurrent Trip } \\
\text { Pickup (xFLA) }\end{array}$ & $\begin{array}{l}\text { Range }= \\
\text { OFF, } 0.10-20.00\end{array}$ & 0.50 & \\
\hline $50 \mathrm{G} 2 \mathrm{P}$ & \begin{tabular}{|l} 
Residual Overcurrent \\
Alarm Pickup (xFLA) \\
\end{tabular} & $\begin{array}{l}\text { Range }= \\
\text { OFF, } 0.10-20.00\end{array}$ & OFF & \\
\hline $50 \mathrm{G} 1 \mathrm{D}$ & \begin{tabular}{|l|} 
Residual Overcurrent Trip \\
Delay (seconds) \\
\end{tabular} & $\begin{array}{l}\text { Range }=0.00- \\
5.00\end{array}$ & 0.10 & \\
\hline $50 \mathrm{Q} 1 \mathrm{P}$ & $\begin{array}{l}\text { Negative Sequence } \\
\text { Overcurrent Trip Pickup } \\
\text { (xFLA) }\end{array}$ & $\begin{array}{l}\text { Range }= \\
\text { OFF, } 0.10-20.00\end{array}$ & 0.50 & \\
\hline $50 \mathrm{Q} 2 \mathrm{P}$ & \begin{tabular}{|l|} 
Negative Sequence \\
Overcurrent Alarm Pickup \\
(xFLA)
\end{tabular} & $\begin{array}{l}\text { Range }= \\
\text { OFF,0.10-20.00 }\end{array}$ & OFF & \\
\hline $50 \mathrm{Q} 1 \mathrm{D}$ & $\begin{array}{l}\text { Negative Sequence } \\
\text { Overcurrent Trip Delay } \\
\text { (seconds) }\end{array}$ & $\begin{array}{l}\text { Range }=0.10- \\
120.00\end{array}$ & 0.15 & \\
\hline ESTAR_D & Star-Delta & Select: Y, N & $\mathrm{N}$ & \\
\hline E47T & Phase Reversal Detection & Select: Y, N & $\mathrm{Y}$ & \\
\hline SPDSDLYT & $\begin{array}{l}\text { Speed Switch Trip Delay } \\
\text { (seconds) }\end{array}$ & $\begin{array}{l}\text { Range }=\text { OFF,1- } \\
240\end{array}$ & OFF & \\
\hline SPDSDLYA & $\begin{array}{l}\text { Speed Switch Alarm Delay } \\
\text { (seconds) }\end{array}$ & $\begin{array}{l}\text { Range }=\text { OFF,1- } \\
240\end{array}$ & OFF & \\
\hline
\end{tabular}




\begin{tabular}{|c|c|c|c|c|}
\hline \multicolumn{5}{|c|}{ Group 1} \\
\hline Setting & Description & Range & Value & Comment \\
\hline E49RTD & RTD Enable & $\begin{array}{l}\text { Select: INT, } \\
\text { EXT, NONE }\end{array}$ & NONE & \\
\hline 27P1P & $\begin{array}{l}\text { UV TRIP LEVEL (Off, } \\
0.02-1.00 ; \mathrm{xVnm})\end{array}$ & $\begin{array}{l}\text { Range }= \\
\text { OFF,0.02-1.00 } \\
\mathrm{xVnm}\end{array}$ & OFF & \\
\hline 27P2P & $\begin{array}{l}\text { UV WARN LEVEL (Off, } \\
0.02-1.00 ; \mathrm{xVnm})\end{array}$ & $\begin{array}{l}\text { Range }= \\
\text { OFF,0.02-1.00 } \\
x \text { Vnm }\end{array}$ & OFF & \\
\hline 59P1P & $\begin{array}{l}\text { OV TRIP LEVEL (Off, } \\
0.02-1.20 ; \mathrm{xVnm})\end{array}$ & $\begin{array}{l}\text { Range }= \\
\text { OFF,0.02-1.20 } \\
\mathrm{xVnm}\end{array}$ & OFF & \\
\hline $59 \mathrm{P} 2 \mathrm{P}$ & $\begin{array}{l}\text { OV WARN LEVEL (Off, } \\
0.02-1.20 ; \mathrm{xVnm})\end{array}$ & $\begin{array}{l}\text { Range }= \\
\text { OFF,0.02-1.20 } \\
\mathrm{xVnm}\end{array}$ & OFF & \\
\hline TDURD & \begin{tabular}{|l} 
Minimum Trip Time \\
(seconds)
\end{tabular} & $\begin{array}{l}\text { Range }=0.0- \\
400.0\end{array}$ & 0.5 & \\
\hline TR & Trip (SELogic) & & \begin{tabular}{|l|}
$49 \mathrm{~T}$ OR \\
$50 \mathrm{P} 1 \mathrm{~T}$ OR \\
$50 \mathrm{G} 1 \mathrm{~T}$ OR \\
$50 \mathrm{Q} 1 \mathrm{~T}$ OR \\
(27P1T \\
AND NOT \\
LOP ) OR \\
STOP \\
\end{tabular} & \\
\hline STREQ & Start (SELogic) & & PB03 & \\
\hline Group & & & & \\
\hline
\end{tabular}

\begin{tabular}{|c|c|c|c|c|}
\hline \multicolumn{5}{|l|}{ Logic 1} \\
\hline Setting & Description & Range & Value & Comment \\
\hline ELAT & SELogic Latches & $\begin{array}{l}\text { Range }= \\
\mathrm{N}, 1-32\end{array}$ & $\mathrm{~N}$ & \\
\hline ESV & SELogic Variables/Timers & $\begin{array}{l}\text { Range = } \\
\mathrm{N}, 1-32\end{array}$ & 1 & \\
\hline ESC & SELogic Counters & $\begin{array}{l}\text { Range = } \\
\mathrm{N}, 1-32\end{array}$ & $\mathrm{~N}$ & \\
\hline EMV & SELogic Math Variables & $\begin{array}{l}\text { Range = } \\
\mathrm{N}, 1-32\end{array}$ & $\mathrm{~N}$ & \\
\hline SV01 & SV_Input (SELogic) & & \begin{tabular}{|l} 
WDGTRIP \\
OR \\
BRGTRIP \\
OR \\
OTHTRIP \\
OR \\
AMBTRIP \\
OR \\
\end{tabular} & \\
\hline
\end{tabular}




\begin{tabular}{|c|c|c|c|c|}
\hline \multicolumn{5}{|l|}{ Logic 1} \\
\hline Setting & Description & Range & Value & Comment \\
\hline & & & \begin{tabular}{|l} 
REMTRIP \\
OR 37PT \\
OR VART \\
OR \\
PTCTRIP \\
OR 81D1T \\
OR 81D2T \\
OR 81D3T \\
OR 81D4T \\
OR 50Q1T \\
OR 87M1T \\
OR 87M2T \\
\end{tabular} & \\
\hline OUT101FS & OUT101 Fail-Safe & Select: Y, N & $\mathrm{N}$ & \\
\hline OUT102FS & OUT102 Fail-Safe & Select: Y, N & $\mathrm{Y}$ & \\
\hline OUT103FS & OUT103 Fail-Safe & Select: Y, N & $\mathrm{Y}$ & \\
\hline OUT101 & (SELogic) & & $\begin{array}{l}\text { HALARM } \\
\text { OR } \\
\text { SALARM }\end{array}$ & \\
\hline OUT102 & (SELogic) & & $\begin{array}{l}\text { NOT } \\
\text { START }\end{array}$ & \\
\hline OUT103 & (SELogic) & & $\begin{array}{l}\text { TRIP OR } \\
\text { PB04 }\end{array}$ & \\
\hline \multicolumn{5}{|l|}{ Logic 1} \\
\hline
\end{tabular}

\begin{tabular}{|c|c|c|c|c|}
\hline \multicolumn{5}{|l|}{ Group 2} \\
\hline Setting & Description & Range & Value & Comment \\
\hline RID & $\begin{array}{l}\text { Relay Identifier (16 } \\
\text { characters) }\end{array}$ & & SEL-710 & \\
\hline TID & $\begin{array}{l}\text { Terminal Identifier (16 } \\
\text { characters) }\end{array}$ & & \begin{tabular}{|l|} 
MOTOR \\
RELAY \\
\end{tabular} & \\
\hline CTR1 & Phase (IA,IB,IC) CT Ratio & Range $=1-5000$ & 1 & \\
\hline FLA1 & $\begin{array}{l}\text { Motor FLA [Full Load } \\
\text { Amps] (amps) }\end{array}$ & \begin{tabular}{|l|} 
Range $=0.2-$ \\
5000.0
\end{tabular} & 2.1 & | Bidirectional System \\
\hline E2SPEED & Two-Speed Protection & Select: Y, N & $\mathrm{N}$ & \\
\hline CTRN & Neutral (IN) CT Ratio & Range $=1-2000$ & 1 & \\
\hline PTR & PT Ratio & \begin{tabular}{|l|} 
Range $=1.00-$ \\
250.00
\end{tabular} & 1.00 & \\
\hline VNOM & \begin{tabular}{|l} 
Line Voltage, Nominal \\
Line-to-Line (volts) \\
\end{tabular} & $\begin{array}{l}\text { Range }=100- \\
30000\end{array}$ & 190 & \\
\hline DELTA_Y & Transformer Connection & $\begin{array}{l}\text { Select: WYE, } \\
\text { DELTA }\end{array}$ & WYE & \\
\hline SINGLEV & Single Voltage Input & Select: Y, N & $\mathrm{N}$ & \\
\hline
\end{tabular}




\begin{tabular}{|c|c|c|c|c|}
\hline \multicolumn{5}{|l|}{ Group 2} \\
\hline Setting & Description & Range & Value & Comment \\
\hline E49MOTOR & \begin{tabular}{|l} 
Thermal Overload \\
Protection
\end{tabular} & Select: Y, N & Y & \\
\hline FLS & $\begin{array}{l}\text { Full Load Slip (per unit } \\
\text { Synchronous Speed) }\end{array}$ & $\begin{array}{l}\text { Range }= \\
\text { OFF,0.0010- } \\
0.1000 \\
\end{array}$ & OFF & \\
\hline SETMETH & Thermal Overload Method & $\begin{array}{l}\text { Select: } \\
\text { RATING, } \\
\text { RATING_1, } \\
\text { CURVE }\end{array}$ & RATING & \\
\hline 49RSTP & \begin{tabular}{|l} 
Thermal Overload Reset \\
Level (\%TCU)
\end{tabular} & Range $=10-99$ & 75 & \\
\hline SF & Service Factor & $\begin{array}{l}\text { Range }=1.01- \\
1.50\end{array}$ & $\mid 1.35$ & \\
\hline LRA1 & \begin{tabular}{|l} 
Motor LRA (Locked Rotor \\
Amps) (xFLA)
\end{tabular} & $\begin{array}{l}\text { Range }=2.5- \\
12.0\end{array}$ & 2.5 & \\
\hline LRTHOT1 & \begin{tabular}{|l} 
Locked Rotor Time \\
(seconds)
\end{tabular} & $\begin{array}{l}\text { Range }=1.0- \\
600.0\end{array}$ & 1.0 & \\
\hline TD1 & ACCEL FACTOR & $\begin{array}{l}\text { Range }=0.10- \\
1.50\end{array}$ & 1.00 & \\
\hline RTC1 & \begin{tabular}{|l}
$\begin{array}{l}\text { Stator Time Constant } \\
\text { (minutes) }\end{array}$ \\
\end{tabular} & $\begin{array}{l}\text { Range }= \\
\text { AUTO,1-2000 }\end{array}$ & AUTO & \\
\hline TCAPU & $\begin{array}{l}\text { Thermal Overload Alarm } \\
\text { Pickup (\%TCU) }\end{array}$ & $\begin{array}{l}\text { Range }= \\
\text { OFF,50-99 }\end{array}$ & 85 & \\
\hline TCSTART & 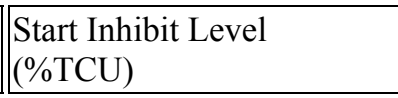 & $\begin{array}{l}\text { Range }=\text { OFF,1- } \\
99\end{array}$ & OFF & \\
\hline COOLTIME & 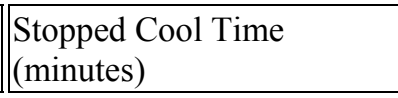 & Range $=1-6000$ & 3 & \\
\hline 50P1P & $\begin{array}{l}\text { Phase Overcurrent Trip } \\
\text { Pickup (xFLA) }\end{array}$ & $\begin{array}{l}\text { Range }= \\
\text { OFF, } 0.10-20.00\end{array}$ & 3.00 & \\
\hline $50 \mathrm{P} 2 \mathrm{P}$ & $\begin{array}{l}\text { Phase Overcurrent Alarm } \\
\text { Pickup (xFLA) }\end{array}$ & \begin{tabular}{|l|} 
Range $=$ \\
OFF, $0.10-20.00$
\end{tabular} & OFF & \\
\hline 50P1D & $\begin{array}{l}\text { Phase Overcurrent Trip } \\
\text { Delay (seconds) }\end{array}$ & $\begin{array}{l}\text { Range }=0.00- \\
5.00\end{array}$ & 0.00 & \\
\hline $50 \mathrm{~N} 1 \mathrm{P}$ & \begin{tabular}{|l} 
Neutral Overcurrent Trip \\
Pickup (amps pri)
\end{tabular} & \begin{tabular}{|l|} 
Range $=$ \\
OFF, $0.01-25.00$
\end{tabular} & OFF & \\
\hline $50 \mathrm{~N} 2 \mathrm{P}$ & \begin{tabular}{|l} 
Neutral Overcurrent Alarm \\
Pickup (amps pri)
\end{tabular} & \begin{tabular}{|l|} 
Range $=$ \\
OFF, $0.01-25.00$
\end{tabular} & OFF & \\
\hline $50 \mathrm{G} 1 \mathrm{P}$ & $\begin{array}{l}\text { Residual Overcurrent Trip } \\
\text { Pickup (xFLA) }\end{array}$ & $\begin{array}{l}\text { Range }= \\
\text { OFF, } 0.10-20.00\end{array}$ & 0.50 & \\
\hline $50 \mathrm{G} 2 \mathrm{P}$ & $\begin{array}{l}\text { Residual Overcurrent } \\
\text { Alarm Pickup (xFLA) }\end{array}$ & \begin{tabular}{|l|} 
Range $=$ \\
OFF, $0.10-20.00$
\end{tabular} & OFF & \\
\hline $50 \mathrm{G} 1 \mathrm{D}$ & $\begin{array}{l}\text { Residual Overcurrent Trip } \\
\text { Delay (seconds) }\end{array}$ & $\begin{array}{l}\text { Range }=0.00- \\
5.00\end{array}$ & 0.10 & \\
\hline
\end{tabular}




\begin{tabular}{|c|c|c|c|c|}
\hline \multicolumn{5}{|l|}{ Group 2} \\
\hline Setting & Description & Range & Value & Comment \\
\hline 50Q1P & $\begin{array}{l}\text { Negative Sequence } \\
\text { Overcurrent Trip Pickup } \\
\text { (xFLA) }\end{array}$ & $\begin{array}{l}\text { Range }= \\
\text { OFF, } 0.10-20.00\end{array}$ & 0.50 & \\
\hline $50 \mathrm{Q} 2 \mathrm{P}$ & $\begin{array}{l}\text { Negative Sequence } \\
\text { Overcurrent Alarm Pickup } \\
\text { (xFLA) }\end{array}$ & $\begin{array}{l}\text { Range }= \\
\text { OFF,0.10-20.00 }\end{array}$ & OFF & \\
\hline 50Q1D & $\begin{array}{l}\text { Negative Sequence } \\
\text { Overcurrent Trip Delay } \\
\text { (seconds) }\end{array}$ & $\begin{array}{l}\text { Range }=0.10- \\
120.00\end{array}$ & 0.15 & \\
\hline E47T & Phase Reversal Detection & Select: Y, N & $\mathrm{Y}$ & \\
\hline TDURD & $\begin{array}{l}\text { Minimum Trip Time } \\
\text { (seconds) }\end{array}$ & $\begin{array}{l}\text { Range }=0.0- \\
400.0\end{array}$ & 0.5 & \\
\hline TR & Trip (SELogic) & & \begin{tabular}{|l|}
$49 \mathrm{~T}$ OR \\
$50 \mathrm{P} 1 \mathrm{~T}$ OR \\
$50 \mathrm{G} 1 \mathrm{~T}$ OR \\
$50 \mathrm{Q} 1 \mathrm{~T}$ OR \\
(27P1T \\
AND NOT \\
LOP ) OR \\
STOP \\
\end{tabular} & \\
\hline STREQ & Start (SELogic) & & PB03 & \\
\hline \multicolumn{5}{|l|}{ Group 2} \\
\hline
\end{tabular}

\begin{tabular}{|c|c|c|c|c|}
\hline \multicolumn{5}{|l|}{ Logic 2} \\
\hline Setting & Description & Range & Value & Comment \\
\hline ELAT & SELogic Latches & $\begin{array}{l}\text { Range }= \\
\mathrm{N}, 1-32\end{array}$ & $\| \mathrm{N}$ & \\
\hline ESV & SELogic Variables/Timers & $\begin{array}{l}\text { Range }= \\
\text { N,1-32 }\end{array}$ & $\mid 1$ & \\
\hline ESC & SELogic Counters & \begin{tabular}{|l} 
Range $=$ \\
$\mathrm{N}, 1-32$
\end{tabular} & N & \\
\hline EMV & SELogic Math Variables & $\begin{array}{l}\text { Range }= \\
\mathrm{N}, 1-32\end{array}$ & $\mathrm{~N}$ & \\
\hline SV01 & SV_Input (SELogic) & & \begin{tabular}{|l} 
WDGTRIP \\
OR \\
BRGTRIP \\
OR \\
OTHTRIP \\
OR \\
AMBTRIP \\
OR \\
REMTRIP \\
OR 37PT \\
OR VART \\
OR
\end{tabular} & \\
\hline
\end{tabular}




\begin{tabular}{|c|c|c|c|c|}
\hline \multicolumn{5}{|l|}{ Logic 2} \\
\hline Setting & Description & Range & Value & Comment \\
\hline & & & \begin{tabular}{|l} 
PTCTRIP \\
OR 81D1T \\
OR 81D2T \\
OR 81D3T \\
OR 81D4T \\
OR 50Q1T \\
OR 87M1T \\
OR 87M2T
\end{tabular} & \\
\hline OUT101FS & OUT101 Fail-Safe & Select: Y, N & $\mathrm{N}$ & \\
\hline OUT102FS & OUT102 Fail-Safe & Select: Y, N & $\mathrm{Y}$ & \\
\hline OUT103FS & OUT103 Fail-Safe & Select: Y, N & $\mathrm{Y}$ & \\
\hline OUT101 & $\mid($ SELogic) & & $\begin{array}{l}\text { HALARM } \\
\text { OR } \\
\text { SALARM } \\
\end{array}$ & \\
\hline OUT102 & (SELogic) & & \begin{tabular}{|l} 
NOT \\
START
\end{tabular} & \\
\hline OUT103 & (SELogic) & & \begin{tabular}{|l} 
TRIP OR \\
PB04 \\
\end{tabular} & \\
\hline Logic 2 & & & & \\
\hline
\end{tabular}

\begin{tabular}{|c|c|c|c|c|}
\hline Port 3 & & & & \\
\hline Setting & Description & Range & Value & Comment \\
\hline PROTO & Protocol & \begin{tabular}{|l|} 
Select: SEL, \\
MOD, MBA, \\
MBB, \\
MB8A, \\
MB8B, \\
MBTA, \\
MBTB \\
\end{tabular} & SEL & \\
\hline SPEED & Data Speed (bps) & \begin{tabular}{|l|} 
Select: 300, \\
1200,2400, \\
4800,9600, \\
19200,38400 \\
\end{tabular} & 19200 & \\
\hline BITS & Data Bits (bits) & Select: 7,8 & 8 & \\
\hline PARITY & Parity & $\begin{array}{l}\text { Select: O, E, } \\
\text { N }\end{array}$ & $\mathrm{N}$ & \\
\hline STOP & Stop Bits (bits) & Select: 1,2 & 1 & \\
\hline RTSCTS & Hardware Handshaking & Select: Y, N & $\mathrm{N}$ & \\
\hline T_OUT & Port Time-Out (minutes) & Range $=0-30$ & 5 & \\
\hline AUTO & $\begin{array}{l}\text { Send Auto Messages to } \\
\text { Port }\end{array}$ & Select: Y, N & $\mathrm{Y}$ & \\
\hline FASTOP & Fast Operate & Select: Y, N & $\mathrm{N}$ & \\
\hline Port 3 & & & & \\
\hline
\end{tabular}




\begin{tabular}{|c|c|c|c|c|}
\hline \multicolumn{5}{|c|}{ Front Panel } \\
\hline Setting & Description & Range & Value & Comment \\
\hline EDP & Display Points Enable & Range $=\mathrm{N}, 1-32$ & 4 & \\
\hline ELB & Local Bits Enable & Range $=\mathrm{N}, 1-32$ & $\mathrm{~N}$ & \\
\hline $\mathrm{FP} \_\mathrm{TO}$ & Front-Panel Timeout & $\begin{array}{l}\text { Range }=\text { OFF, } 1- \\
30\end{array}$ & 15 & \\
\hline FP_CONT & Front-Panel Contrast & Range $=1-8$ & 4 & \\
\hline FP_AUTO & $\begin{array}{l}\text { Front-Panel } \\
\text { Automessages }\end{array}$ & $\begin{array}{l}\text { Select: } \\
\text { OVERRIDE, } \\
\text { ROTATING } \\
\end{array}$ & OVERRIDE & \\
\hline RSTLED & $\begin{array}{l}\text { Reset Trip-Latched } \\
\text { LEDs On Close }\end{array}$ & Select: Y, N & Y & \\
\hline T01LEDL & Trip Latch T_LED & Select: Y, N & $\mathrm{Y}$ & \\
\hline T01_LED & (SELogic) & & \begin{tabular}{|l} 
49T OR \\
AMBTRIP \\
OR \\
BRGTRIP \\
OR \\
OTHTRIP \\
OR \\
WDGTRIP \\
\end{tabular} & \\
\hline T02LEDL & Trip Latch T_LED & Select: Y, N & Y & \\
\hline T02_LED & (SELogic) & & \begin{tabular}{|l}
$50 \mathrm{P} 1 \mathrm{~T}$ OR \\
$50 \mathrm{~N} 1 \mathrm{~T}$ OR \\
$50 \mathrm{G} 1 \mathrm{~T}$ \\
\end{tabular} & \\
\hline T03LEDL & Trip Latch T_LED & Select: Y, N & $\mathrm{Y}$ & \\
\hline T03_LED & (SELogic) & & $\begin{array}{l}46 \mathrm{UBT} \text { OR } \\
47 \mathrm{~T}\end{array}$ & \\
\hline T04LEDL & Trip Latch T_LED & Select: Y, N & Y & \\
\hline T04_LED & (SELogic) & & \begin{tabular}{|l} 
LOSSTRIP \\
OR 37PT \\
\end{tabular} & \\
\hline T05LEDL & Trip Latch T_LED & Select: Y, N & $\mathrm{Y}$ & \\
\hline T05_LED & (SELogic) & & \begin{tabular}{|l|} 
NOT \\
STOPPED \\
AND 27P1T $)$ \\
OR 59P1T \\
\end{tabular} & \\
\hline T06LEDL & Trip Latch T_LED & Select: Y, N & $\mathrm{Y}$ & \\
\hline T06_LED & (SELogic) & & $\begin{array}{l}87 \mathrm{M} 1 \mathrm{~T} \text { OR } \\
87 \mathrm{M} 2 \mathrm{~T}\end{array}$ & \\
\hline PB1A_LED & (SELogic) & & PB01 & \\
\hline PB2A_LED & (SELogic) & & PB02 & \\
\hline PB3A_LED & (SELogic) & & PB03 & \\
\hline PB4A_LED & (SELogic) & & PB04 & \\
\hline PB1B_LED & (SELogic) & & 0 & \\
\hline
\end{tabular}




\begin{tabular}{|c|c|c|c|c|}
\hline \multicolumn{5}{|c|}{ Front Panel } \\
\hline Setting & Description & Range & Value & Comment \\
\hline PB2B_LED & (SELogic) & & 0 & \\
\hline PB3B_LED & (SELogic) & & $\begin{array}{l}\text { STARTING } \\
\text { OR } \\
\text { RUNNING } \\
\end{array}$ & \\
\hline PB4B_LED & (SELogic) & & STOPPED & \\
\hline DP01 & $\begin{array}{l}\begin{array}{l}\text { Display Point (60 } \\
\text { characters) }\end{array} \\
\end{array}$ & & RID, " $\{16\} "$ & \\
\hline DP02 & $\begin{array}{l}\text { Display Point (60 } \\
\text { characters) }\end{array}$ & & TID, " $\{16\} "$ & \\
\hline DP03 & $\begin{array}{l}\text { Display Point (60 } \\
\text { characters) }\end{array}$ & & $\begin{array}{l}\text { IAV, "I } \\
\text { MOTOR }\{6\} \\
\text { A" }\end{array}$ & \\
\hline DP04 & $\begin{array}{l}\text { Display Point (60 } \\
\text { characters) }\end{array}$ & & \begin{tabular}{|l|} 
TCUSTR, \\
"Stator TCU \\
$\{3\} \% "$ \\
\end{tabular} & \\
\hline \multicolumn{5}{|c|}{ Front Panel } \\
\hline
\end{tabular}

\begin{tabular}{|c|c|c|c|c|}
\hline \multicolumn{5}{|l|}{ Report } \\
\hline Setting & Description & Range & Value & Comment \\
\hline SER1 & (24 Relay Word bits) & & $\begin{array}{l}\text { IN101 IN102 PB01 } \\
\text { PB02 PB03 PB04 } \\
\text { ABSLO TBSLO } \\
\text { NOSLO THERMLO } \\
\text { TRIP PB04 50P1P } \\
\text { 50G1P 50Q1P }\end{array}$ & \\
\hline SER2 & (24 Relay Word bits) & & \begin{tabular}{|l||} 
49T 49T_STR \\
49T_RTR LOSSTRIP \\
JAMTRIP 46UBT \\
50P1T RTDT PTCTRIP \\
50G1T VART 37PT \\
27P1T 59P1T 47T 55T \\
SPDSTR 50N1T \\
SMTRIP 81D1T 81D2T \\
OTHTRIP 87M1T \\
87M2T \\
\end{tabular} & \\
\hline SER3 & (24 Relay Word bits) & & \begin{tabular}{|l|} 
AMBTRIP PTCFLT \\
RTDFLT COMMIDLE \\
COMMLOSS \\
REMTRIP RSTTRGT \\
49A LOSSALRM \\
JAMALRM 46UBA \\
RTDA 55A 50N2T \\
50G2T VARA 37PA \\
27P2T 59P2T 50P2T \\
50Q1T 50Q2T \\
\end{tabular} & \\
\hline
\end{tabular}




\begin{tabular}{|c|c|c|c|c|}
\hline \multicolumn{5}{|l|}{ Report } \\
\hline Setting & Description & Range & Value & Comment \\
\hline SER4 & (24 Relay Word bits) & & \begin{tabular}{|l|} 
SPDSAL 81D3T \\
81D4T OTHALRM \\
AMBALRM SALARM \\
WARNING LOADUP \\
LOADLOW 50P2T \\
STOPPED RUNNING \\
STARTING STAR \\
DELTA START \\
SPEED2 \\
\end{tabular} & \\
\hline EALIAS & Enable ALIAS Settings & $\begin{array}{l}\text { Range }= \\
\mathrm{N}, 1-20\end{array}$ & 15 & \\
\hline ALIAS1 & (59 characters) & & $\begin{array}{l}\text { STARTING } \\
\text { MOTOR_STARTING } \\
\text { BEGINS_ENDS } \\
\end{array}$ & \\
\hline ALIAS2 & (59 characters) & & $\begin{array}{l}\text { RUNNING } \\
\text { MOTOR_RUNNING } \\
\text { BEGINS_ENDS } \\
\end{array}$ & \\
\hline ALIAS3 & (59 characters) & & $\begin{array}{l}\text { STOPPED } \\
\text { MOTOR_STOPPED } \\
\text { BEGINS ENDS } \\
\end{array}$ & \\
\hline ALIAS4 & (59 characters) & & $\begin{array}{l}\text { JAMTRIP } \\
\text { LOAD_JAM_TRIP } \\
\text { PICKUP DROPOUT }\end{array}$ & \\
\hline ALIAS5 & (59 characters) & & \begin{tabular}{|l|} 
LOSSTRIP \\
LOAD_LOSS_TRIP \\
PICKUP DROPOUT \\
\end{tabular} & \\
\hline ALIAS6 & (59 characters) & & \begin{tabular}{|l|} 
LOSSALRM \\
LOAD_LOSS_ALARM \\
PICKUP DROPOUT \\
\end{tabular} & \\
\hline ALIAS7 & (59 characters) & & \begin{tabular}{|l|} 
46UBA \\
UNBALNC_I_ALARM \\
PICKUP DROPOUT \\
\end{tabular} & \\
\hline ALIAS8 & (59 characters) & & \begin{tabular}{|l|} 
46UBT \\
UNBALNC_I_TRIP \\
PICKUP DROPOUT \\
\end{tabular} & \\
\hline ALIAS9 & (59 characters) & & $\begin{array}{l}\text { 49A } \\
\text { THERMAL_ALARM } \\
\text { PICKUP DROPOUT } \\
\end{array}$ & \\
\hline ALIAS10 & |(59 characters) & & $\begin{array}{l}\text { 49T THERMAL_TRIP } \\
\text { PICKUP DROPOUT } \\
\end{array}$ & \\
\hline ALIAS11 & |(59 characters) & & $\begin{array}{l}47 \mathrm{~T} \\
\text { PHS_REVRSL_TRIP } \\
\text { PICKUP DROPOUT } \\
\end{array}$ & \\
\hline ALIAS12 & |(59 characters) & & $\begin{array}{l}\text { PB01 FP_AUX1 } \\
\text { PICKUP DROPOUT } \\
\end{array}$ & \\
\hline ALIAS13 & |(59 characters) & & $\begin{array}{l}\text { PB02 FP_AUX2 } \\
\text { PICKUP DROPOUT }\end{array}$ & \\
\hline
\end{tabular}




\begin{tabular}{|c|c|c|c|c|}
\hline \multicolumn{5}{|l|}{ Report } \\
\hline Setting & Description & Range & Value & Comment \\
\hline ALIAS14 & (59 characters) & & $\begin{array}{l}\text { PB03 FP_START } \\
\text { PICKUP DROPOUT }\end{array}$ & \\
\hline ALIAS15 & (59 characters) & & \begin{tabular}{|l|} 
PB04 FP_STOP \\
PICKUP DROPOUT
\end{tabular} & \\
\hline ER & $\begin{array}{l}\text { Event Report Trigger } \\
\text { (SELogic) }\end{array}$ & & $\begin{array}{l}\text { R_TRIG LOSSALRM } \\
\text { OR R_TRIG 46UBA } \\
\text { OR R_TRIG 49A OR } \\
\text { R_TRIG 37PA OR } \\
\text { R_TRIG 55A OR } \\
\text { R_TRIG VARA }\end{array}$ & \\
\hline LER & $\begin{array}{l}\text { Length of Event Report } \\
\text { (cycles) }\end{array}$ & $\begin{array}{l}\text { Select: } 15 \\
64\end{array}$ & 64 & \\
\hline PRE & \begin{tabular}{|l|}
$\begin{array}{l}\text { Prefault Length } \\
\text { (cycles) }\end{array}$ \\
\end{tabular} & $\begin{array}{l}\text { Range }= \\
\text { OFF,1-59 }\end{array}$ & 10 & \\
\hline MSRR & \begin{tabular}{|l} 
MSR Resolution \\
(cycles)
\end{tabular} & $\begin{array}{l}\text { Select: } \\
0.25,0.5,1 \\
2,5,20\end{array}$ & 5 & \\
\hline MSRTRG & $\begin{array}{l}\text { MSR Report Trigger } \\
\text { (SELogic) }\end{array}$ & & 0 & \\
\hline LDLIST & $\begin{array}{l}\text { Load Profile List (17 } \\
\text { Analog Quantities) }\end{array}$ & & NA & \\
\hline LDAR & $\begin{array}{l}\text { Load Profile } \\
\text { Acquisition Rate } \\
\text { (minutes) }\end{array}$ & $\begin{array}{l}\text { Select: } 5 \\
10,15,30 \\
60\end{array}$ & 15 & \\
\hline Report & & & & \\
\hline
\end{tabular}




\section{Appendix H: SEL-587 Differential Protection Procedure}

\section{ELECTRICAL ENGINEERING DEPARTMENT \\ California Polytechnic State University \\ San Luis Obispo}

EE 518

Power Transformer Differential Protection Using the SEL-587

\section{Learning Outcomes}

- Understand the effect of phasing currents in a differential relay

- Identify, record, and eliminate bolted faults in a two-winding power transformer using differential protection

- Analyze fault conditions from relay-generated event reports

\section{Background}

This experiment presents differential protection as a means of protecting power transformers against internal faults on their primary or secondary windings. A differential relay, such as the SEL-587 used in this experiment, compares the currents entering and leaving a "differential zone of protection." The zone of protection in this experiment is a power transformer, and the SEL-587 monitors the differential (net) current flowing through this zone. For reference, the ANSI code "87" in the name SEL-587 indicates that the device is a differential relay.

In a typical power transformer, current enters the primary winding and exits the secondary winding. These currents balance each other under normal operating conditions; all of the current entering the primary winding (except for the magnetizing current) exits the secondary winding. An imbalance in the currents entering and exiting the relay indicates that a fault exists somewhere in the transformer.

\section{Equipment}

- $25-\Omega$ Single-Phase Power Resistor (3x)

- Bag of Banana-Banana Short Leads (3x)*

- Banana-Banana or Banana-Spade Leads (27x)

- Circuit Breakers (2x)

- Computer with AcSELerator QuickSet Software

- Hampden Resistive Load (1x)

- SEL-587 Differential and Overcurrent Relay

- SEL-C234A Serial Cable

* Beware of extra flexible "small gauge" short leads, which can melt under fault conditions. 


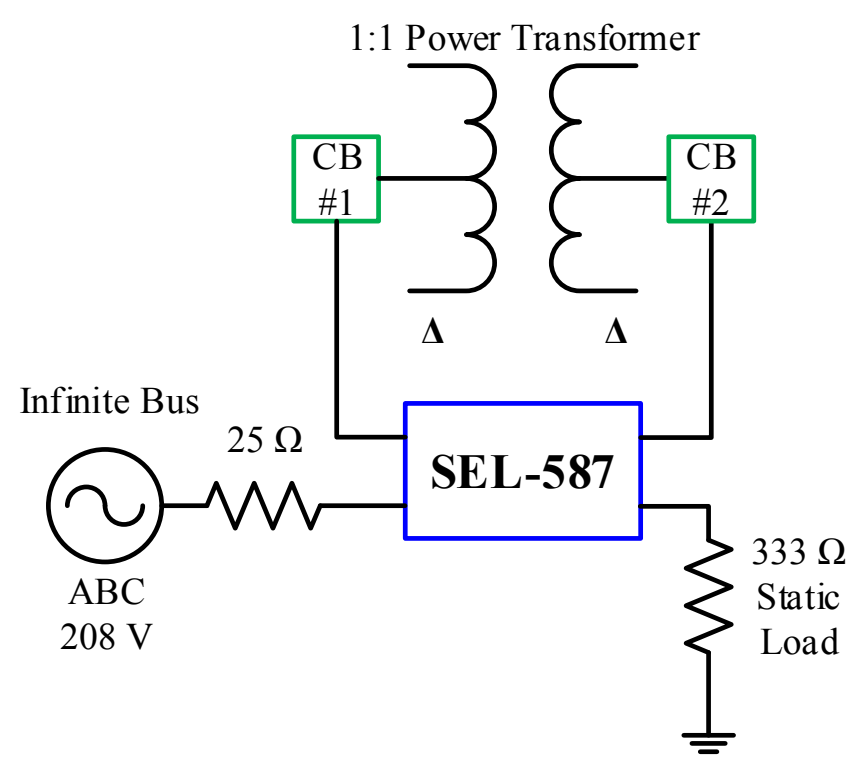

Figure 70: SEL-587 Differential Procedure Single-Line Diagram

\section{Procedure}

1. Plug in the power cord connected to the SEL-587 relay.

2. Connect an SEL-C234A serial cable between the Serial Port on the back of the 587 and the main serial port on the back of the computer (surrounded by a light turquoise color).

3. On the computer, open the AcSELerator QuickSet software.

4. Determine the current baud rate for the rear-panel Serial Port on the 587.

a. On the front panel of the relay, press the button labeled Set.

b. Use the right-arrow button to navigate to Port on the front panel display. Press the button for Select.

c. Navigate to Show and press the button for Select.

d. Use the down-arrow button to navigate through the current Serial Port settings. The baud rate (SPEED) is near the top of the list. If the baud rate is already set to 19200 , press the Exit button to restore the screen to its normal display, and continue to the next step.

e. If the current relay baud rate is not set to 19200, use the following steps to change the baud rate.

f. From the relay's main front-panel screen, press Set and select Port and Set.

g. Use the up-arrow and right-arrow buttons to enter the relay's level 2 password (default is 587). Press Select.

h. Use the down-arrow button to navigate to the SPEED setting and press Select.

i. Press the up/down-arrow buttons until 19200 (not 19.2) appears. Press Select.

j. Press Exit and select Yes to save the new port setting. 
5. On the QuickSet main window (Figure 71), open the Communication Parameters window (Communications, Parameters) (Figure 72) to define and create a communication link with the 587. Enter the following information for a Serial Active Connection Type:

a. Device: COM1: Communications Port

b. SEL Bluetooth Device: Unchecked

c. Data Speed: $\underline{19200}$

d. Data Bits: 8

e. Stop Bits: 1

f. Parity: None

g. RTS/CTS: Off

h. DTR: On

i. XON/XOFF: On

j. RTS: N/A (On)

k. Level 1 Password (Default 587)

1. Level 2 Password (Default 587) Note that the SEL-587 default passwords differ from nearly all other SEL relays. The usual level 1 default password is OTTER, and the usual level 2 default password is TAIL.

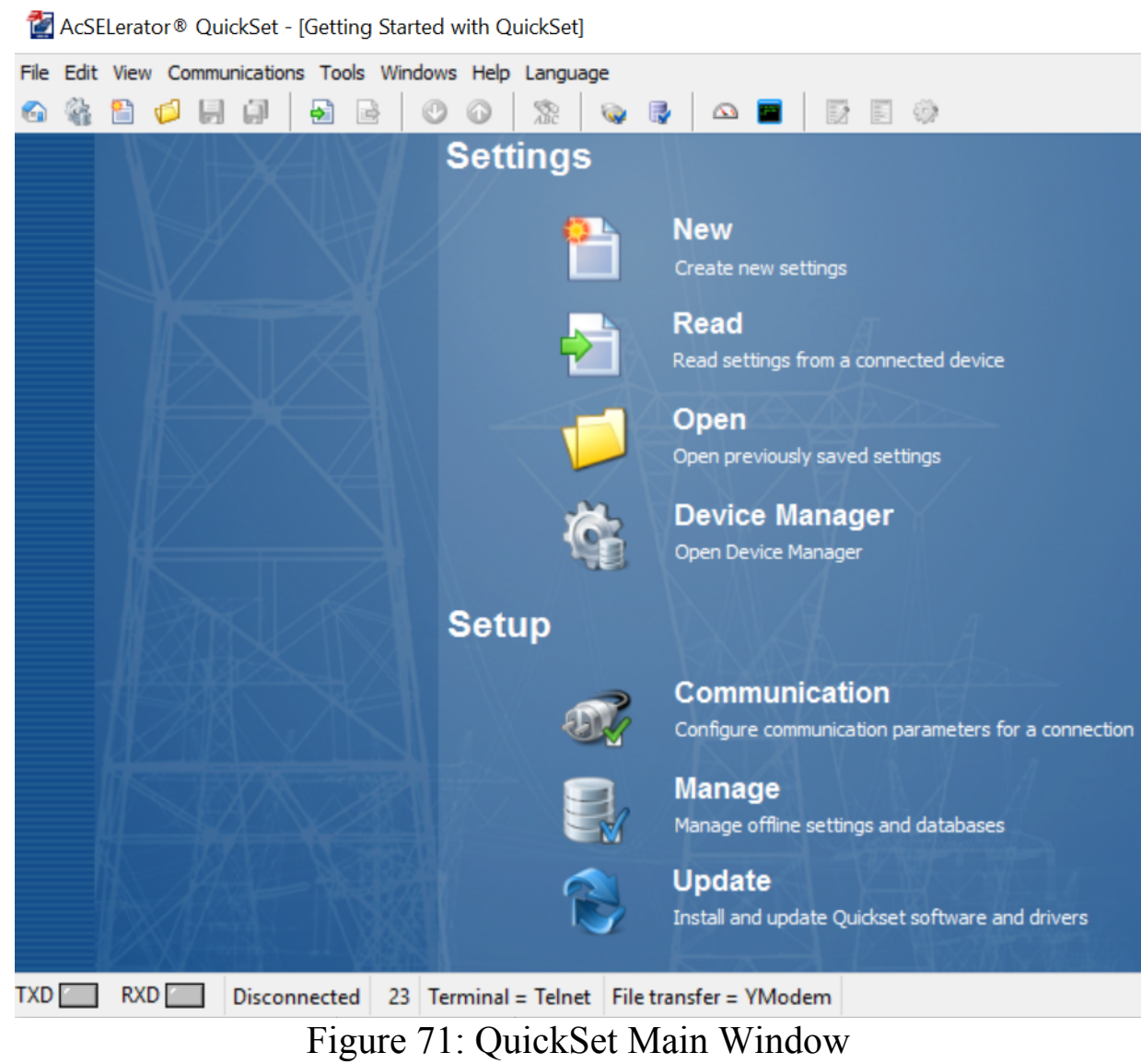




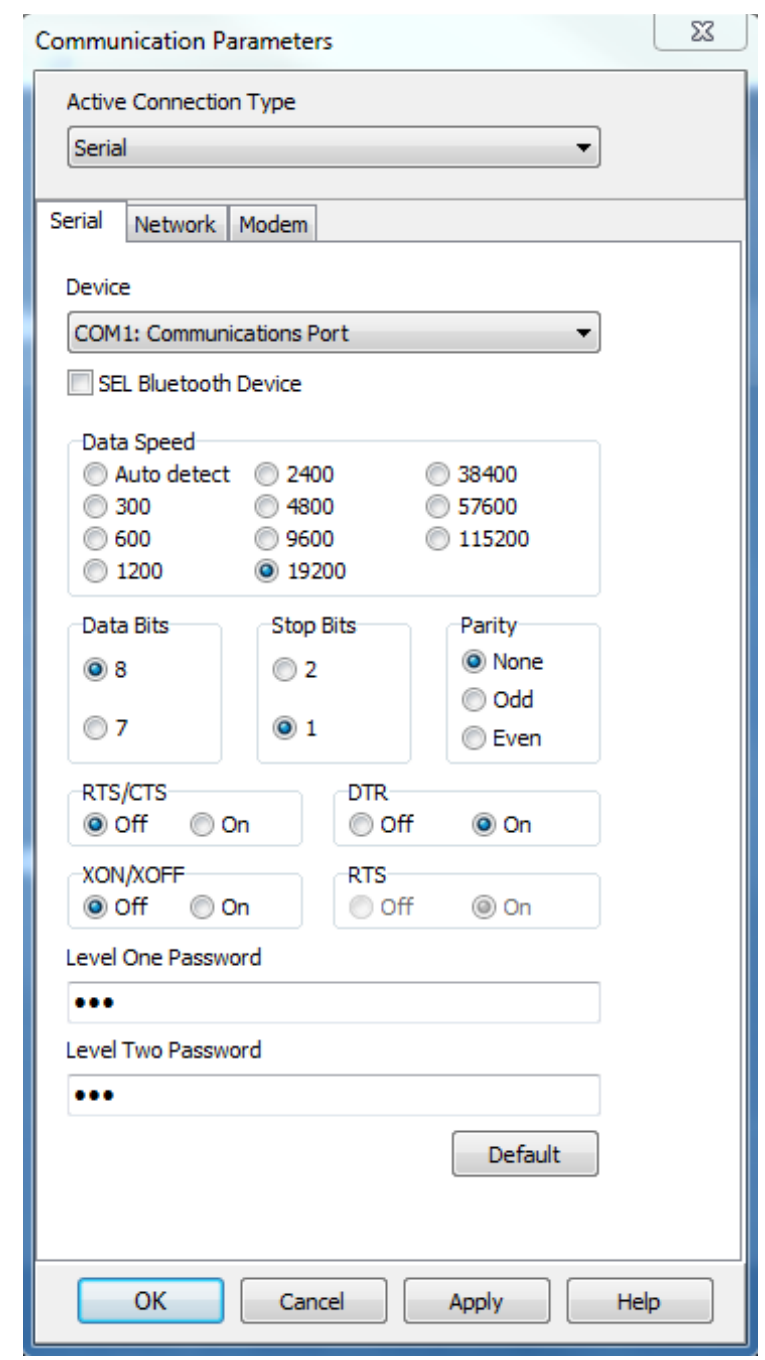

Figure 72: SEL-587 Communication Parameters Window

6. Click Apply at the bottom of the Communication Parameters window. Then click Ok. If the computer successfully connects to the relay, the connection status in the lower-left corner of the QuickSet main window should say "Connected."

7. Create a new settings file for the SEL-587 relay.

a. In the QuickSet main window, create a new settings file for the SEL-587 relay (File, New).

b. Choose the Device Family (SEL-587), Model (SEL-587-1), and Version for this specific relay unit from the available menus, then click Ok (Figure 73). Look up the relay's version number using the front-panel menu on the relay. Press the Status button and use the right-arrow button to navigate across the relay's FID string until you come to the "Z Z-number." The first three digits following the ' $Z$ ' comprise the relay version number. Press the Exit button to restore the front-panel screen to its normal display. Note: if no devices are listed in the QuickSet drop-down menus, then the device drivers need to be installed using the SEL Compass software. Ask for assistance. 


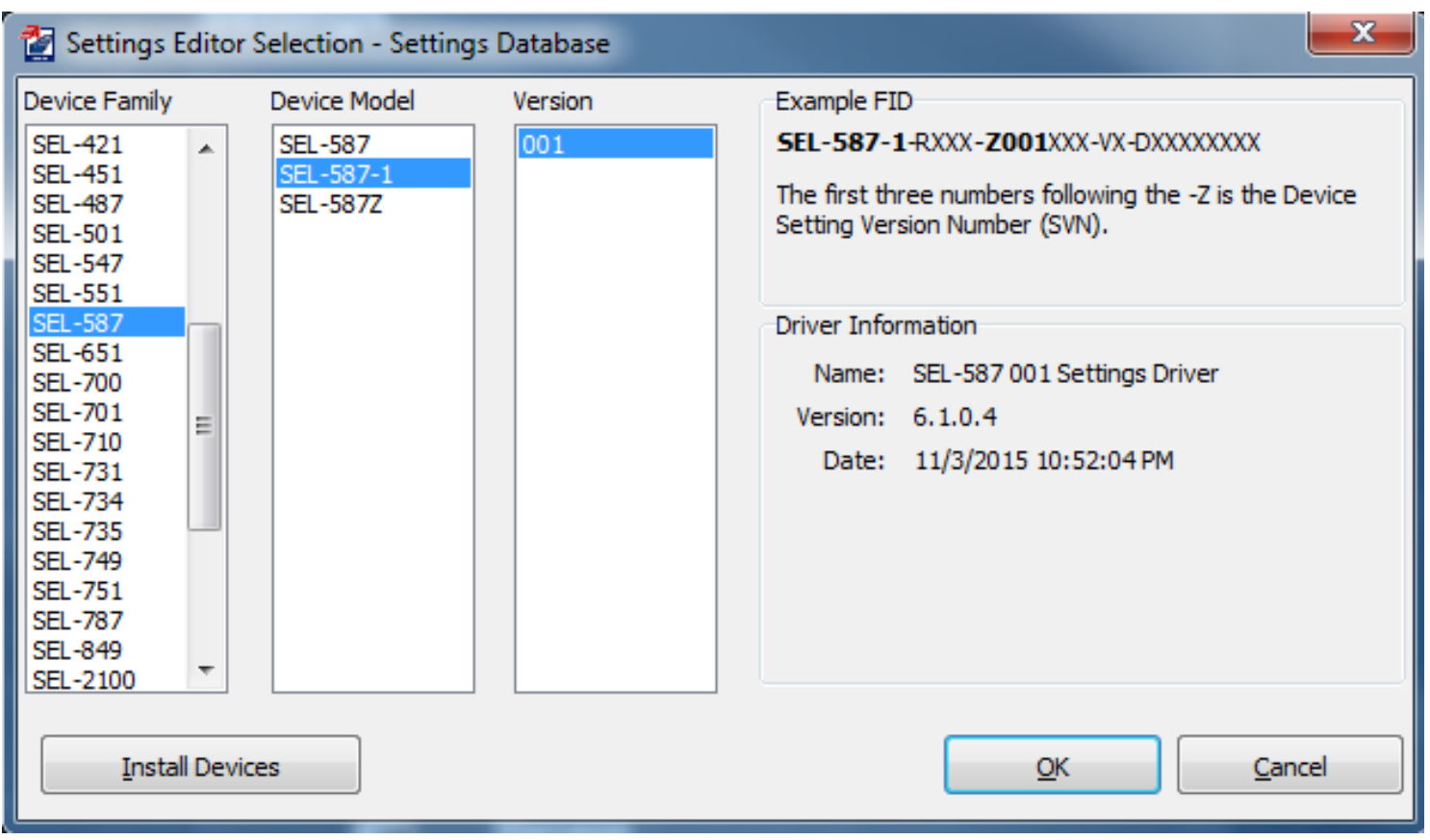

Figure 73: Identifying SEL-587 Relay Family, Model, and Version

c. Enter the relay Part Number (Figure 74) printed on the serial number label $(\mathrm{P} / \mathrm{N}$, Figure 75) attached somewhere on the relay chassis. Note that the 5 A Secondary Input Current reflects the American convention for current transformers.

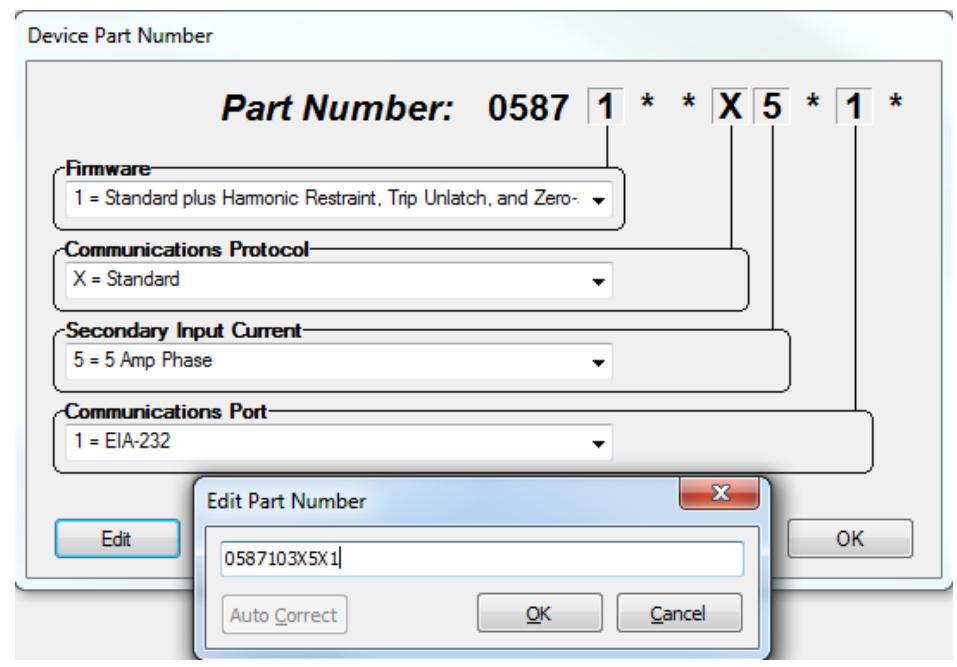

Figure 74: Identifying SEL-587 Relay Part Number

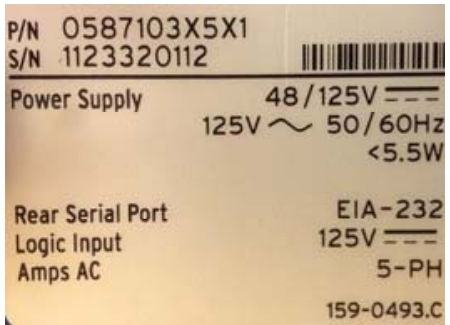

Figure 75: Example SEL587 Label with Relay Part Number

8. Save this new relay settings database file (File, Save As and New) in a location where it may be reused in future experiments. See Figure 76 and Figure 77. Then create a Settings Name for this settings file. 


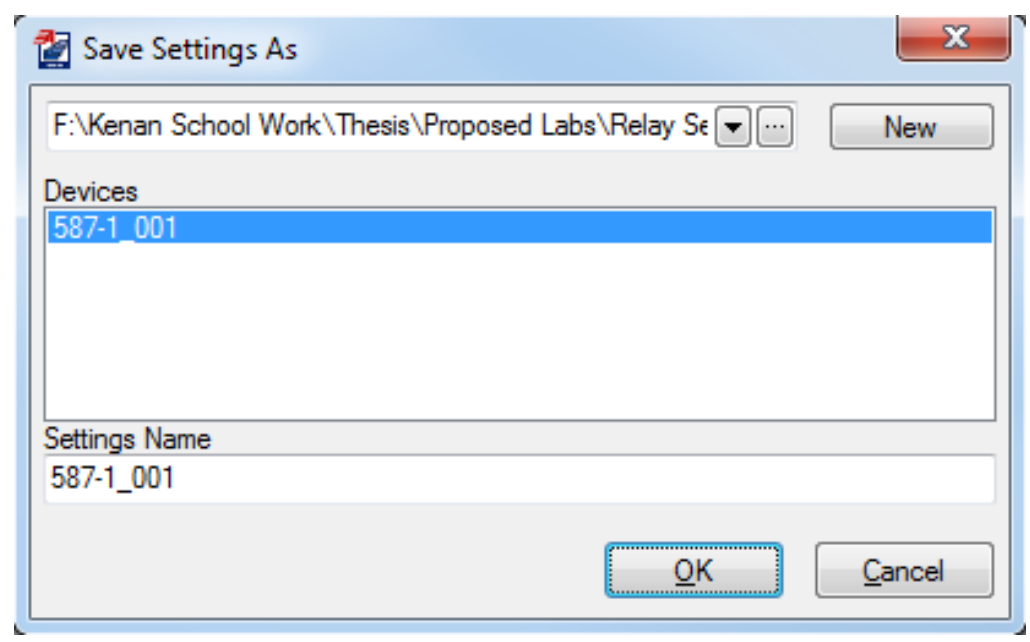

Figure 76: Saving SEL-587 Settings

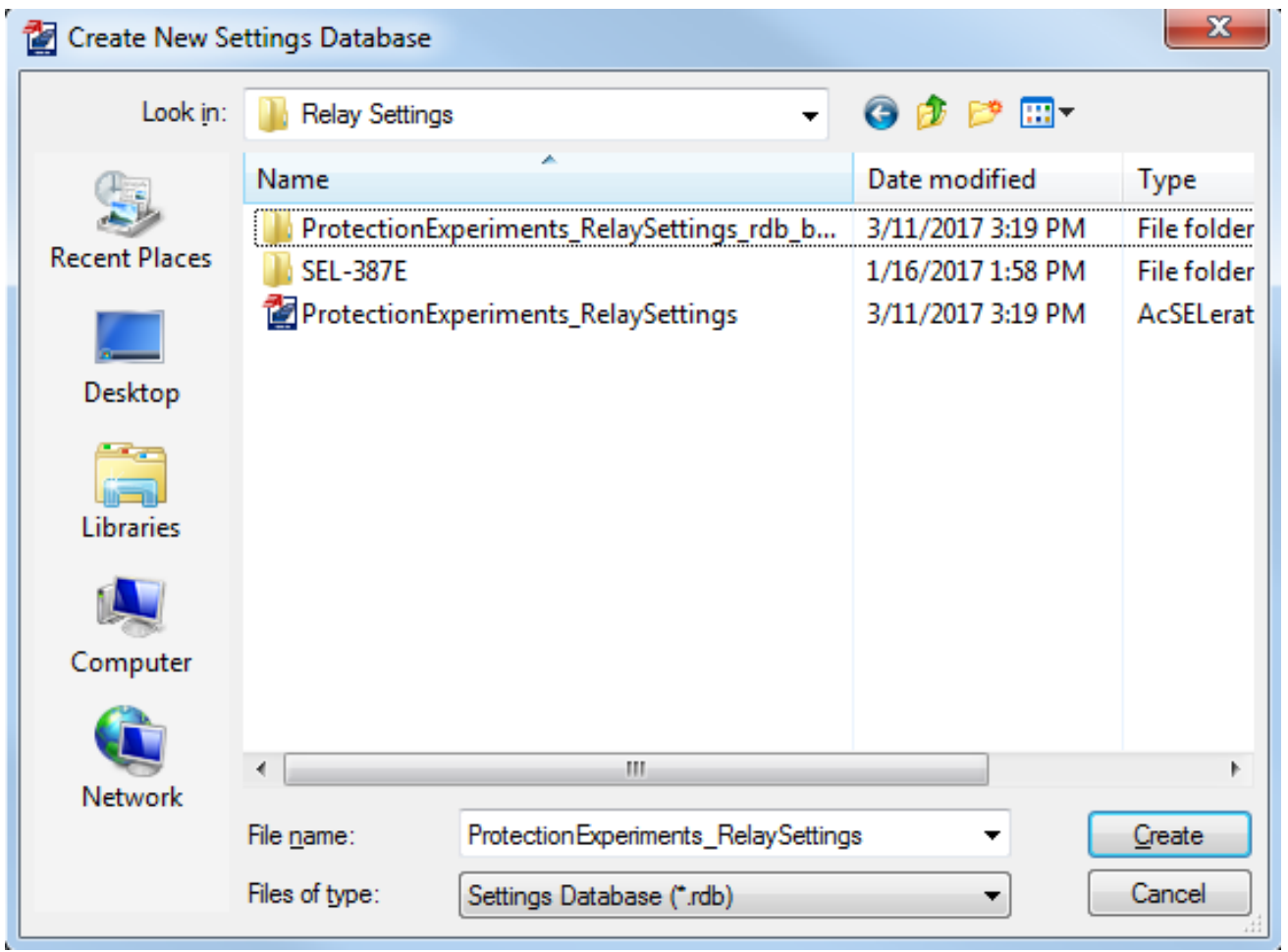

Figure 77: Choosing Location for New SEL-587 Relay Settings Database

9. Open Device settings in the drop-down menu on the left side of the Settings Editor main window (Figure 78).

a. Under General Data (Figure 79), enter RID and TID strings of your choosing to name the relay and workstation.

b. Turn OFF the Maximum Power Transformer Capacity (MVA). This choice allows current tap settings to be entered manually by the relay programmer for the differential elements, rather than relying on calculations made by the relay. 
c. Select the transformer connection (TRCON) to be DACDAC. This notation indicates that the transformer is in a delta-delta configuration and that the $\mathrm{H} 1$ (high side) and X1 (low side) transformer bushings are between phases A and C. Put another way, this notation means that the positive terminal of the phase A winding is connected to the negative terminal of the phase $\mathrm{C}$ winding.

d. Select $\underline{Y Y}$ for the Current Transformer Connection (CTCON). Due to the relatively low levels of current associated with this experiment, actual current transformers are not necessary to step down the line currents in the system. They are therefore not used in the circuit. However, to account for the phase shift that would normally occur due to the current transformers, the line currents must be rolled on either the primary or secondary (but not both) power transformer windings. This phase shift is the basis for switching the input and output connections on winding 2 of the power transformer when wiring up the circuit (see below). Failure to properly phase the currents causes the relay to evaluate normal load conditions as potential faults.

e. Enter 1 for the Winding 1 and Winding 2 Current Transformer Turns Ratios (CTR1 and CTR2). Due to the relatively low currents associated with this experiment, actual current transformers are not necessary to step down the line currents in the system. They are therefore not used in the circuit and are modeled here in the settings with 1:1 CTs.

f. Leave all other General Data settings as their default values. 
AcSELerator® QuickSet - [Settings Editor - 587-1_001 (SE

File Edit View Communications Tools Windows Help

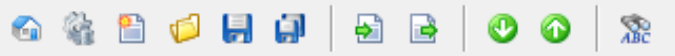

$\triangle$ Device

- General Data

- $\odot$ Current TAPs

-.. Input Assignment

.... Differential Elemer

... Winding 1 Overcur

.... Winding 2 Overcur

.... Misc. Timers

.... PWR System Data

$\odot$ Logic

- Graphical Logic

.... Port

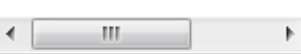

SEL 587 Settin!

Current Differential Rela

Part\#: 0587103X5X1 Device: Device

TXD $\square$ RXD $\square$ Open: Connected COM1: Communic

Figure 78: SEL-587 Settings Editor M Window

\section{General Data}

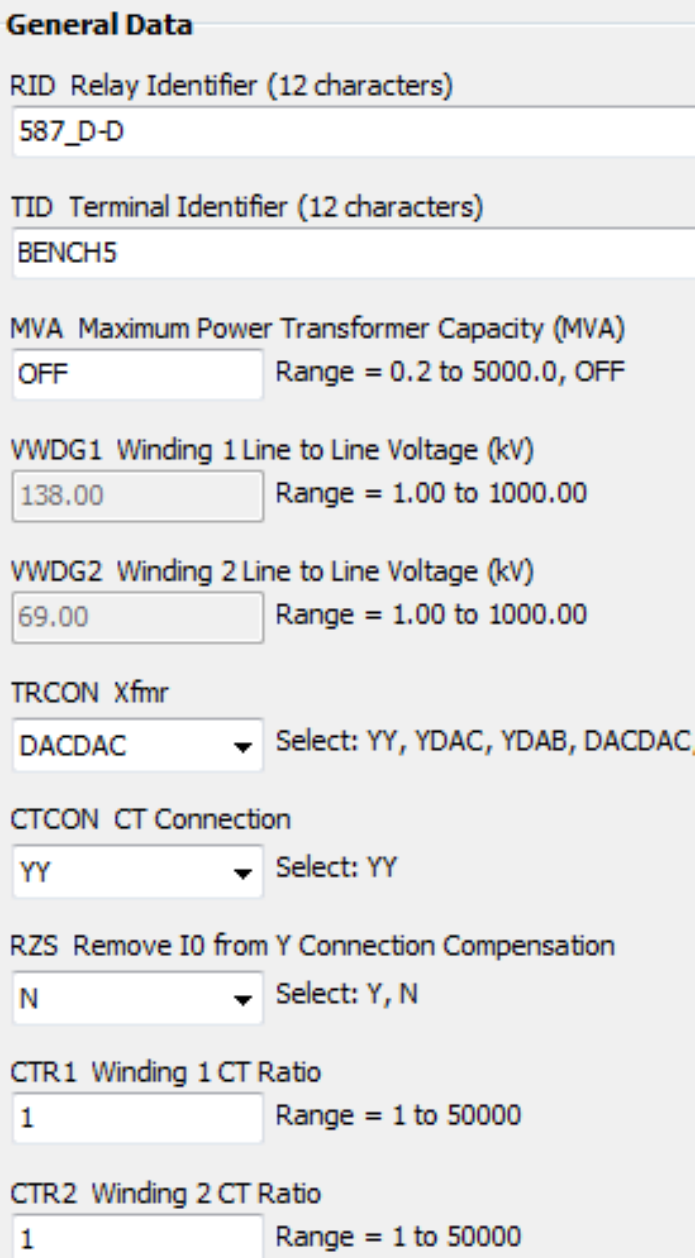

Figure 79: SEL-587 General Data Settings

10. Open the Current TAPs section (Figure 80). Enter Winding 1 and Winding 2 Current Tap (TAP1 and TAP2) values of $\underline{3.00}$. These values define the standard full-load current on the current transformers' secondary windings. The relay autocalculates these values unless the MVA setting is set to OFF.

\title{
Current TAPs
}

\author{
Current TAPs \\ TAP1 Winding 1 Current Tap \\ 3.00 Range $=0.50$ to 160.00 \\ TAP2 Winding 2 Current Tap \\ 3.00 Range $=0.50$ to 160.00
}

Figure 80: SEL-587 Current TAPs Settings 
11. Enter the following information in the Differential Elements section (Figure 81 and Figure 82).

a. Enter a Restraint Slope 2 (SLP2) value of $\underline{50}$.

b. Enter a Fifth-Harmonic Blocking Percentage (PCT5) value of $\underline{5}$. This setting keeps the SEL-587 from initiating a differential trip when the fifth harmonic of the input current is more than $5 \%$ of the fundamental component of the input current. Power transformers have an increased fifth-harmonic component in their input current when operating in saturation (overexcitation). The SEL-587 identifies this characteristic signature and refrains from initiating a differential trip signal if the fifthharmonic current component exceeds a percentage of the fundamental component defined by the PCT5 setting.

c. Leave all other Differential Elements settings as their default values.

\section{Differential Elements}

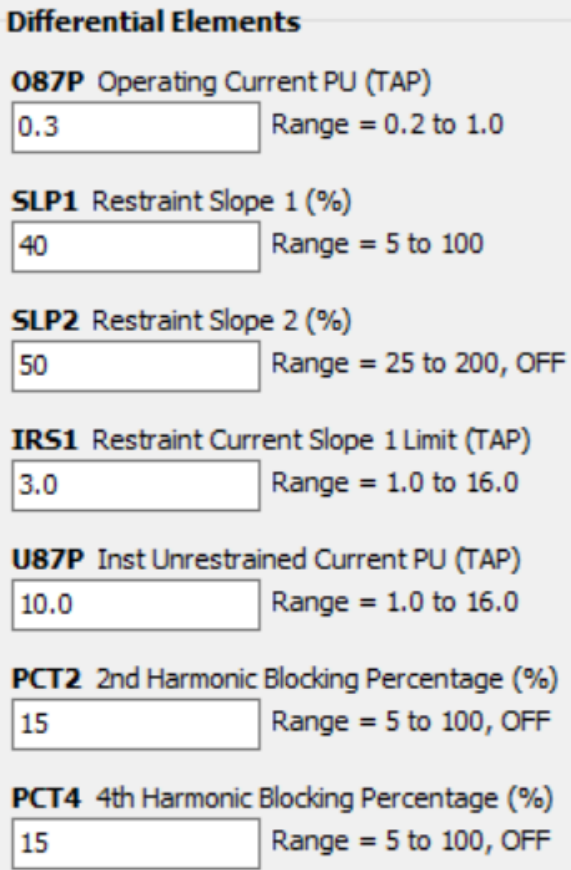

Figure 81: SEL-587 Differential Elements Settings
PCT5 5th Harmonic Blocking Percentage (\%)

TH5 5th Harmonic Threshold (TAP)

0.3 Range $=0.2$ to 3.2

TH5D 5th Harmonic Alarm TDPU (cyc)

30.000

Range $=0.000$ to 8000.

DCRB DC Ratio Blocking

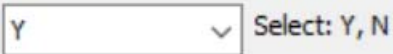

HRSTR Harmonic Restraint

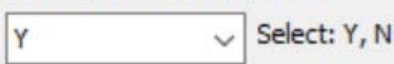

IHBL Independent Harmonic Blocking

Y

Select: $Y, N$

Figure 82: SEL-587 Differential Elements Settings, cont.

12. In the Power System Data section (Figure 83), select a Phase Rotation (PHROT) of $\mathrm{ACB}$. The Phase Rotation and Nominal Frequency (NFREQ) settings define the properties of the electrical grid that the relay is connected to. 


\title{
PWR System Data
}

\author{
PWR System Data \\ NFREQ Nominal Frequency $(\mathrm{Hz})$ \\ 60 Select: 50,60 \\ PHROT Phase Rotation \\ ACB - Select: $A B C, A C B$
}

Figure 83: SEL-587 Power System Data Settings

13. Enter the following information in the Logic section (Figure 84).

a. Modify the first Trip Logic (MTU1) setting. Replace the default contents with $\underline{87 R}$. The SEL-587 will trip under MTU1 conditions when the restrained differential protection $(87 \mathrm{R})$ is asserted.

b. Replace the default contents of MTU2 and MTU3 with NA since these variables are not needed in this experiment.

c. Replace the default contents of the Event Report Trigger Condition Logic (MER) setting with $\underline{87 R}$. The SEL-587 will create an event report when the restrained differential protection $(87 \mathrm{R})$ is asserted.

d. Replace the default contents of OUT1 and OUT2 with!TRP1 to assign the state of the MTU1 setting to digital output ports OUT1 and OUT2 on the back of the relay. Logical inversion is necessary for interfacing the normally-open switch on the SEL-587 with the circuit breaker trip coil. This logic causes both of the circuit breakers connected to the relay to trip for $87 \mathrm{R}$ fault conditions.

e. Replace the contents of OUT3 and OUT4 with NA. These relay output ports are not used in this experiment. 


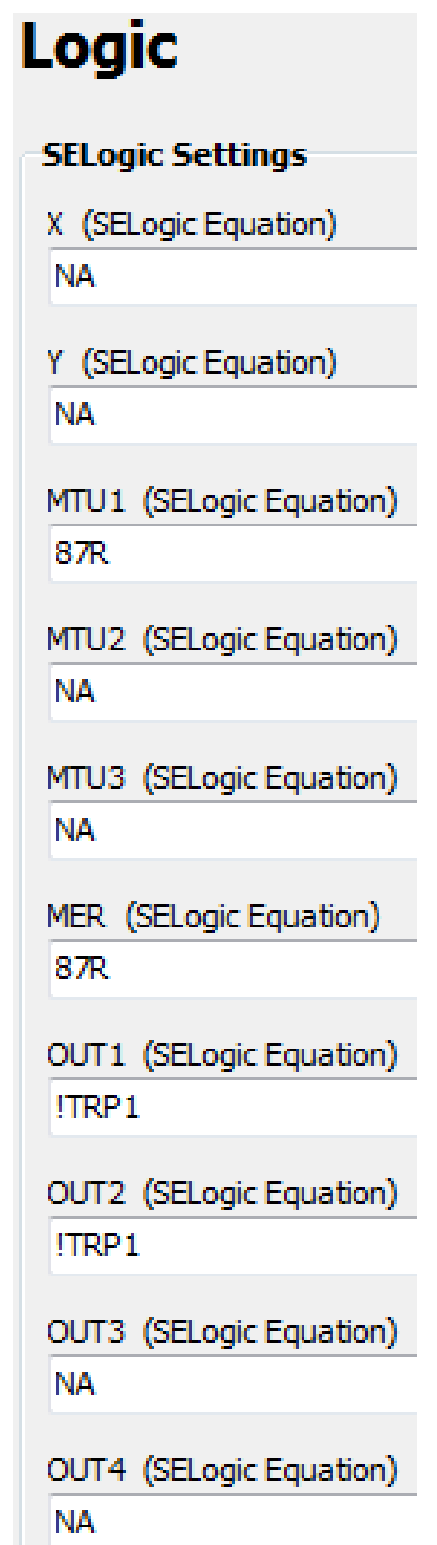

Figure 84: SEL-587 Trip Logic 
14. Open the Port section (Figure 85).

a. Set the Baud Rate (SPEED) to 19,200. This choice significantly speeds up communication between the SEL-587 and a device connected to its serial port. Note that the default baud rate can lead to timeout errors.

b. Increase the Serial Port Time Out (TIMEOUT) setting to $\underline{15}$ minutes.

c. Leave all other Port settings as their default values.

\section{Port}

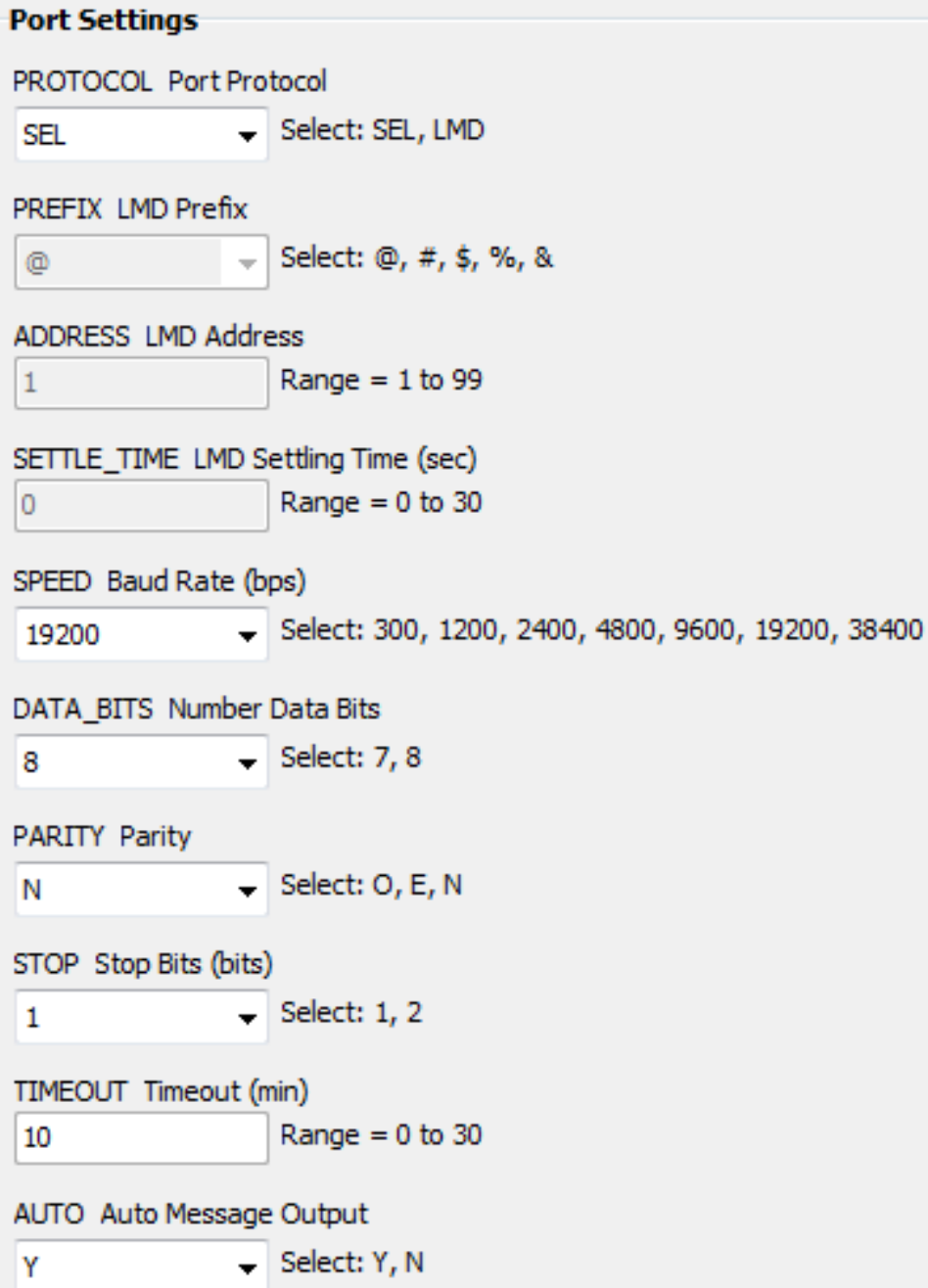

Figure 85: SEL-587 Serial Port Settings

15. Save your settings (File, Save).

16. Send your settings (File, Send...) to the SEL-587. In the window that appears, check the boxes for the Device and Logic settings (Figure 86). Sending only the modified settings shortens the file transfer time. Ignore any error messages associated with changing the baud rate. Since it can take several minutes to transfer the relay settings, now is a good time to start constructing the circuit. 


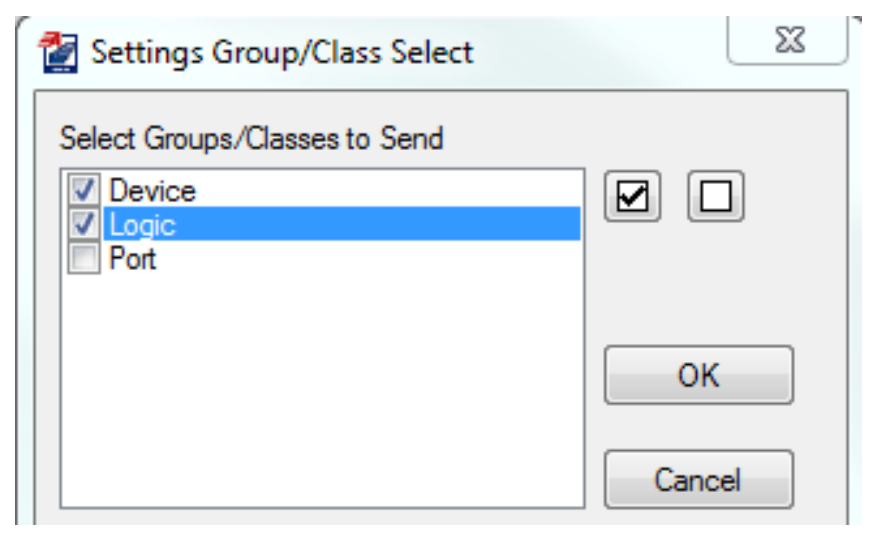

Figure 86: Send Modified Settings to SEL-587

17. Connect the three-phase circuit illustrated in Figure 70. Try to lay out the elements in the order illustrated in the schematic so that power flows across the bench from one end to the other. This linear arrangement limits the number of wires crossing each other and makes the path of current flow easier to review (and troubleshoot). Start with the sequential connection points in Table 47, using the diagrams posted on the wattmeter and transformer at the lab bench for assistance. Then add the following connections:

a. Jumper transformer terminal 1 of phase $A$ and terminal 2 of phase $\mathrm{C}$ together (delta-connected primary). Likewise, connect terminal 1 of phase $\mathrm{B}$ to terminal 2 of phase $\mathrm{A}$, and connect terminal 1 of phase $\mathrm{C}$ to terminal 2 of phase B. This primary winding setup is known as a DAC configuration: D indicates Delta, while AC indicates that the polarity (positive reference terminal) of phase A is connected to the nonpolarity (negative reference terminal) of phase $\mathrm{C}$.

b. Jumper transformer terminals 4 and 5 for each phase of the power transformer secondary windings. This connection creates the 1:1 transformer turns ratio.

c. Jumper transformer terminal 3 of phase A and terminal 6 of phase $C$ together (delta-connected secondary). Likewise, connect terminal 3 of phase $B$ to terminal 6 of phase A, and connect terminal 3 of phase $C$ to terminal 6 of phase $\mathrm{B}$. This secondary winding setup is known as a DAC configuration. Hence, this delta-delta power transformer has a DACDAC configuration.

d. Connect back-panel port $\mathbf{2 0 3}$ of the SEL-587 to the top Breaker Control Trip terminal on circuit breaker \#1 (transformer primary winding). Connect back-panel port 204 to the bottom Breaker Control Trip terminal on circuit breaker $\# 1$.

e. Connect back-panel port $\mathbf{2 0 5}$ of the SEL-587 to the top Breaker Control Trip terminal on circuit breaker \#2 (transformer secondary winding). Connect back-panel port 206 to the bottom Breaker Control Trip terminal on circuit breaker $\# 2$.

f. Connect the positive (upper) Breaker Control $125 V_{D C}$ terminal on both circuit breakers to input terminal $\mathrm{G}$ on the lab bench. Connect the negative 
(lower) Breaker Control 125 VDC terminal on both circuit breakers to terminal $\mathrm{H}$.

g. Connect the green chassis ground terminals on each circuit breaker to the green bench ground terminal.

Table 47: Per-Phase Sequential Points of Connection

\begin{tabular}{|c|c|c|}
\hline Phase A & Phase B & Phase C \\
\hline Input Voltage & Input Voltage & Input Voltage \\
\hline Wattmeter & Wattmeter & Wattmeter \\
\hline $25 \Omega$ Resistor Input & $25 \Omega$ Resistor Input & $25 \Omega$ Resistor Input \\
\hline $25 \Omega$ Resistor Output & $25 \Omega$ Resistor Output & $25 \Omega$ Resistor Output \\
\hline $\begin{array}{l}\text { Relay Port } 101 \\
\text { (Relay Input) }\end{array}$ & $\begin{array}{l}\text { Relay Port } \mathbf{1 0 3} \\
\text { (Relay Input) }\end{array}$ & $\begin{array}{l}\text { Relay Port } 105 \\
\text { (Relay Input) }\end{array}$ \\
\hline $\begin{array}{l}\text { Relay Port } \mathbf{1 0 2} \\
\text { (Relay Output) }\end{array}$ & $\begin{array}{l}\text { Relay Port } 104 \\
\text { (Relay Output) }\end{array}$ & $\begin{array}{l}\text { Relay Port } 106 \\
\text { (Relay Output) }\end{array}$ \\
\hline $\begin{array}{c}\text { CB \#1 (XFMR Primary } \\
\text { Side) Circuit Breaker Red } \\
\text { Terminal }\end{array}$ & $\begin{array}{c}\text { CB \#1 (XFMR Primary } \\
\text { Side) Circuit Breaker Red } \\
\text { Terminal }\end{array}$ & $\begin{array}{c}\text { CB \#1 (XFMR Primary } \\
\text { Side) Circuit Breaker Red } \\
\text { Terminal }\end{array}$ \\
\hline $\begin{array}{l}\text { CB \#1, Circuit Breaker } \\
\text { Black Terminal }\end{array}$ & $\begin{array}{l}\text { CB \#1, Circuit Breaker } \\
\text { Black Terminal }\end{array}$ & $\begin{array}{c}\text { CB \#1, Circuit Breaker } \\
\text { Black Terminal }\end{array}$ \\
\hline $\begin{array}{l}\text { Transformer Primary } \\
\text { Winding, Terminal } 1\end{array}$ & $\begin{array}{l}\text { Transformer Primary } \\
\text { Winding, Terminal } 1\end{array}$ & $\begin{array}{l}\text { Transformer Primary } \\
\text { Winding, Terminal } 1\end{array}$ \\
\hline $\begin{array}{l}\text { Transformer Secondary } \\
\text { Winding, Terminal } 3\end{array}$ & $\begin{array}{l}\text { Transformer Secondary } \\
\text { Winding, Terminal } 3\end{array}$ & $\begin{array}{l}\text { Transformer Secondary } \\
\text { Winding, Terminal } 3\end{array}$ \\
\hline $\begin{array}{l}\text { CB \#2, Circuit Breaker } \\
\text { Red Terminal }\end{array}$ & $\begin{array}{l}\text { CB \#2, Circuit Breaker } \\
\text { Red Terminal }\end{array}$ & $\begin{array}{l}\text { CB \#2, Circuit Breaker } \\
\text { Red Terminal }\end{array}$ \\
\hline $\begin{array}{l}\text { CB \#2, Circuit Breaker } \\
\text { Black Terminal }\end{array}$ & $\begin{array}{l}\text { CB \#2, Circuit Breaker } \\
\text { Black Terminal }\end{array}$ & $\begin{array}{l}\text { CB \#2, Circuit Breaker } \\
\text { Black Terminal }\end{array}$ \\
\hline $\begin{array}{l}\text { Relay Port 108* } \\
\text { (Relay Input) }\end{array}$ & $\begin{array}{l}\text { Relay Port 110* } \\
\text { (Relay Input) }\end{array}$ & $\begin{array}{c}\text { Relay Port 112 * } \\
\text { (Relay Input) }\end{array}$ \\
\hline $\begin{array}{l}\text { Relay Port 107* } \\
\text { (Relay Output) }\end{array}$ & $\begin{array}{c}\text { Relay Port 109* } \\
\text { (Relay Output) }\end{array}$ & $\begin{array}{c}\text { Relay Port 111* } \\
\text { (Relay Output) }\end{array}$ \\
\hline $\begin{array}{l}333 \Omega \text { Hampden Resistive } \\
\text { Load }\end{array}$ & $\begin{array}{l}333 \Omega \text { Hampden Resistive } \\
\text { Load }\end{array}$ & $\begin{array}{l}333 \Omega \text { Hampden Resistive } \\
\text { Load }\end{array}$ \\
\hline Bench Ground & Bench Ground & Bench Ground \\
\hline
\end{tabular}

* Rolling transformer secondary winding current phases.

18. Verify the circuit connections and obtain instructor approval to apply power to the circuit. 
19. Apply both $208 \mathrm{~V}_{\mathrm{AC}}$ and $125 \mathrm{~V}_{\mathrm{DC}}$ power from the bench and close all circuit breakers (with the Manual Breaker Control Close button). Confirm that the threephase power displayed on the wattmeter is approximately $1.5 \mathrm{~A}$. If the displayed current exceeds $2 \mathrm{~A}$, turn off the bench power and check the circuit wiring for errors.

20. Create a line-to-line fault on the primary side of the power transformer.

a. Turn off $\mathrm{AC}$ and DC power from the bench.

b. Jumper the black Circuit Breaker terminals to the red Fault Connections terminals (if present) on circuit breaker \#1. Jumper two of the black Fault Connections terminals together (line-to-line fault configuration).

c. Set the circuit breaker Fault Switches to the Normal position.

d. Turn on AC and DC bench power. Manually close all circuit breakers.

e. Flip the circuit breaker \#1 Fault Switch to the Fault position.

f. Watch the wattmeter to confirm that the SEL-587 trips the circuit breaker to clear the fault. If it does not, turn off AC bench power before sustained fault current damages circuit components.

g. Once the relay clears the fault, turn off $\mathrm{AC}$ and $\mathrm{DC}$ bench power and flip the Fault Switch to the Normal position. Press the Target Reset button on the SEL-587 to clear the relay's front-panel LED display.

h. Retrieve the event file(s) from the SEL-587 (Step 21).

i. Add the $87 \mathrm{R}$ digital signal to the oscillogram plot.

21. Retrieve the SEL-587 event file for the fault trip.

a. In QuickSet, select Tools, Event Files, Get Event Files.

b. In the window that comes up, select Refresh Event History.

c. Choose an Event Type of 16 Samples / Cycle - Raw.

d. Check the boxes of the event file(s) corresponding to the fault. Event files are indexed, with ' 1 ' being the most recent event file saved by the relay.

e. Click Get Selected Events. Save the events in a convenient location using either a default or custom naming convention.

f. Double-click on the event report file in its file path location. The AcSELerator Analytic Assistant software automatically opens an oscillogram plot of the event.

g. Click the Pref button in the lower-right corner of the oscillogram to add digital fault-trip signals to the plot. Left-click on the signal you wish to display (from the available list in the lower-left corner of the screen), then right-click-drag the signal to the Digital Axis list of signals to be displayed.

h. After saving the desired event files, enter the HIS C command in the QuickSet Terminal window (select Communications, Terminal) to clear previous event files from the relay's memory. If an error message appears about an invalid access level, type in ACC, the Enter key, the level relay 1 password (default for SEL-587 is 587), and the Enter key. Proceed to clear the event files. 
22. Create a single-line-to-ground fault on the secondary side of the power transformer.

a. Turn off AC and DC power from the bench.

b. Jumper the black Circuit Breaker terminals to the red Fault Connections terminals (if present) on circuit breaker \#2. Jumper two of the black Fault Connections terminals together and connect these terminals directly to bench ground.

c. Set the circuit breaker Fault Switches to the Normal position.

d. Turn on AC and DC bench power. Manually close all circuit breakers.

e. Flip the circuit breaker \#2 Fault Switch to the Fault position.

f. Watch the wattmeter to confirm that the SEL-587 trips the circuit breaker to clear the fault. If it does not, turn off $\mathrm{AC}$ bench power before sustained fault current damages circuit components.

g. Once the relay clears the fault, turn off AC and DC bench power and flip the Fault Switch to the Normal position. Press the Target Reset button on the SEL-587 to clear the relay's front-panel display.

h. Retrieve the event file(s) from the SEL-587 (Step 21).

i. Add the $87 \mathrm{R}$ digital signal to the oscillogram plot.

23. Create a three-phase fault (not grounded) on the secondary side of the power transformer.

a. Turn off AC and DC power from the bench.

b. Jumper the black Circuit Breaker terminals to the red Fault Connections terminals (if present) on circuit breaker \#2. Jumper all three of the black Fault Connections terminals together.

c. Set the circuit breaker Fault Switches to the Normal position.

d. Turn on AC and DC bench power. Manually close all circuit breakers.

e. Flip the circuit breaker \#2 Fault Switch to the Fault position.

f. Watch the wattmeter to confirm that the SEL-587 trips the circuit breaker to clear the fault. If it does not, turn off AC bench power before sustained fault current damages circuit components.

g. Once the relay clears the fault, turn off AC and DC bench power and flip the Fault Switch to the Normal position. Press the Target Reset button on the SEL-587 to clear the relay's front-panel display.

h. Retrieve the event file(s) from the SEL-587 (Step 21).

i. Add the $87 \mathrm{R}$ digital signal to the oscillogram plot.

\section{Postlab Questions}

- Explain why both circuit breakers \#1 and \#2 tripped for transformer faults (within the differential zone of protection). Base your explanation on the Trip Logic relay settings.

- Explain why the SEL-587 would not have tripped for a single-line-to-ground fault on the primary side of the power transformer if the $208 \mathrm{~V}$ was an ungrounded source. Hint: Consider the relationship between ground currents and the primaryside transformer configuration. 
- Why does the SEL-587 trip for single-line-to-ground faults on the secondary side of the power transformer?

\section{$\underline{\text { Deliverables }}$}

Answer the postlab questions. Turn in oscillograms for the fault events described in the procedure. The bottom of each oscillogram should show the digital signal associated with the type of protection triggered by the fault. Give each plot a caption specifying the relay, fault type and location, and type of protection triggered.

Save the relay settings for use in future experiments. 


\title{
Appendix I: SEL-587 Overcurrent Protection Procedure
}

EE 518

\author{
ELECTRICAL ENGINEERING DEPARTMENT \\ California Polytechnic State University \\ San Luis Obispo
}

Power Transformer Overcurrent Protection Using the SEL-587

\section{Learning Outcomes}

- Identify, record, and eliminate bolted faults downstream of a two-winding power transformer using inverse-time overcurrent protection

- Analyze fault conditions from relay-generated event reports

\section{Background}

Relay coordination is a key component of power system protection because it ensures that vulnerable devices have more than one source of protection. That way, if the primary relay fails to operate during fault conditions, a backup relay can still protect the circuit. Backup relays are typically located further upstream in a circuit, away from the primary relay. This increase in distance away from the fault location means that larger sections of the circuit will be taken off-line when the backup relay trips. Backup relays are designed with delay mechanisms in their protection schemes, allowing the primary relay a chance to operate first. This delay is desirable because operating a relay in its primary zone of protection minimizes the area affected by a fault.

Several options exist for delaying a relay from tripping. In definite-time overcurrent (ANSI prefix "50"), the relay waits a constant amount of time between when it detects a fault and trips a circuit breaker. The relay resets if the fault conditions disappear before the time delay elapses. For example, a definite-time overcurrent relay element of 50Q will trip after measuring continuous negative-sequence currents (symbolized by the letter 'Q') for a specified amount of time.

Inverse-time overcurrent (ANSI prefix "51") offers a more dynamic response to fault conditions. The amount of delay before the relay operates in response to a fault depends on the fault current magnitude. High currents receive a shorter delay, while lower fault currents are assigned a longer delay. This inverse relationship allows an overcurrent relay to respond faster to more dangerous fault conditions. As with definite-time overcurrent, the relay refrains from tripping if the fault disappears before the delay time elapses. As an example, an inverse-time overcurrent relay element of 51P will trip after the relay measures continuous phase currents (symbolized by the letter ' $\mathrm{P}$,' corresponding to the amplitude of the current in the circuit) for an amount of time determined by the magnitude of the fault current. Inverse-time overcurrent curves illustrate the relationship between the relay response delay and fault current magnitude (in terms of multiples of a specified baseline amount called the "pickup current"). 


\section{Prelab}

For calculations, ignore connections to the relay (i.e. circuit breakers, current transformers, and potential transformers). Assume a transformer reactance of $1.8 \Omega$ for all symmetrical component sequences.

a) Calculate the negative-sequence currents (in Amps) produced by bolted line-toline and single-line-to-ground faults at circuit breaker CB \#3 in Figure 87.

b) Assuming a negative-sequence pickup current of $0.5 \mathrm{~A}$ and a time-dial setting of 0.55 , use the following equation to calculate the expected relay operate time in response to these line-to-line and single-line-to-ground faults:

$$
t_{p}=T D \cdot\left[0.0226+\frac{0.0104}{M^{0.02}-1}\right]
$$

In this equation, $t_{p}$ represents the relay operate time, $T D$ represents the relay timedial setting, and $M$ represents the multiples of negative-sequence pickup current detected by the relay. This equation represents the family of curves in a U. S. moderately inverse coordination plot and appears in the SEL-587 instruction manual.

c) Estimate the per-phase current (in Amps) of a triple-line-to-ground fault at the same location. Neglect the relatively small reactance of the transformer. Hint: Apply Ohm's law.

d) Assuming a phase pickup current of $4.50 \mathrm{~A}$ and a time-dial setting of 0.55 , use the above equation to calculate the expected relay operate time in response to this triple-line-to-ground fault. Note that $M$ now represents the multiples of phase pickup current detected by the relay.

\section{Equipment}

- $25-\Omega$ Single-Phase Power Resistor (3x)

- Bag of Banana-Banana Short Leads (3x) *

- Banana-Banana or Banana-Spade Leads (30x)

- Circuit Breakers (3x)

- Computer with AcSELerator QuickSet Software

- Hampden Resistive Load (1x)

- SEL-587 Differential and Overcurrent Relay

- SEL-C234A Serial Cable

* Beware of extra flexible "small gauge" short leads, which can melt under fault current conditions. 


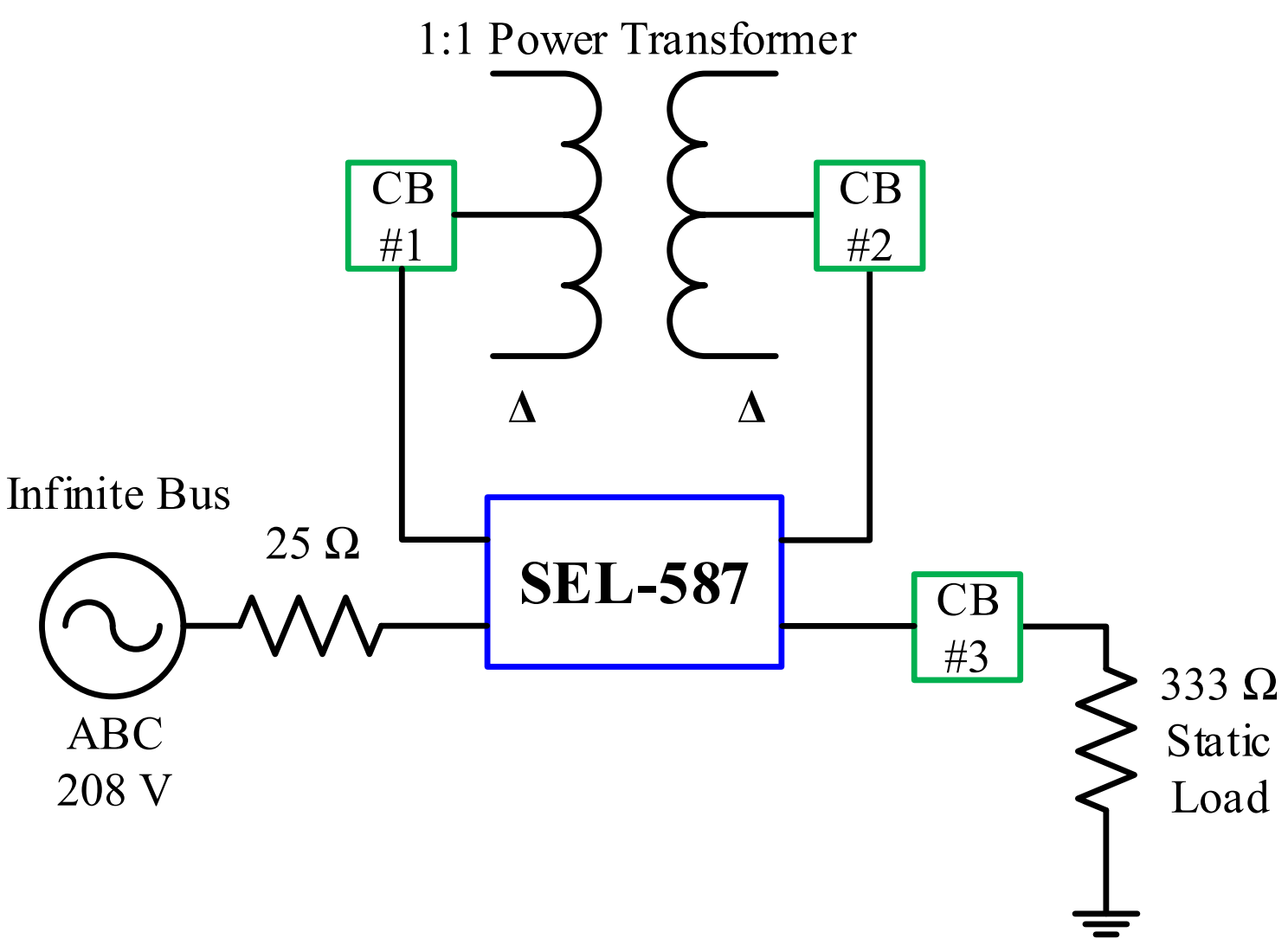

Figure 87: SEL-587 Overcurrent Procedure Single-Line Diagram

\section{Procedure}

1. Plug in the power cord connected to the SEL-587 relay.

2. Connect an SEL-C234A serial cable between Port 3 on the back of the 587 and the main serial port on the back of the computer (surrounded by a light turquoise color).

3. On the computer, open the AcSELerator QuickSet software.

4. Determine the current baud rate for the rear-panel Serial Port on the 587.

a. On the front panel of the relay, press the button labeled Set.

b. Use the right-arrow button to navigate to Port on the front panel display. Press the button for Select.

c. Navigate to Show and press the button for Select.

d. Use the down-arrow button to navigate through the current Serial Port settings. The baud rate (SPEED) is near the top of the list. If the baud rate is already set to 19200 , press the Exit button to restore the screen to its normal display, and continue to the next step.

e. If the current relay baud rate is not set to 19200, use the following steps to change the baud rate.

f. Return to the relay's main front-panel screen by pressing Exit. Then press the Set button and select Port. Now select Set. 
g. Use the up-arrow and right-arrow buttons to enter the relay's level 2 password (default is 587). Press Select.

h. Use the down-arrow button to navigate to the SPEED setting and press Select.

i. Press the up/down-arrow buttons until 19200 (not 19.2) appears. Press Select.

j. Press Exit and select Yes to save the new port setting.

5. On the QuickSet main window (Figure 88), open the Communication Parameters window (Communications, Parameters) (Figure 89) to define and create a communication link with the 587. Enter the following information for a Serial Active Connection Type:

a. Device: COM1: Communications Port

b. SEL Bluetooth Device: Unchecked

c. Data Speed: 19200

d. Data Bits: 8

e. Stop Bits: 1

f. Parity: None

g. RTS/CTS: Off

h. DTR: On

i. XON/XOFF: On

j. RTS: N/A (On)

k. Level 1 Password (Default $\underline{\mathbf{5 8 7}}$ )

1. Level 2 Password (Default $\underline{\mathbf{5 8 7}}$ ) Note that the SEL-587 default passwords differ from nearly all other SEL relays. The usual level 1 default password is OTTER, and the usual level 2 default password is TAIL. 
AcSELerator ${ }^{\circledR}$ QuickSet - [Getting Started with QuickSet]

File Edit View Communications Tools Windows Help Language

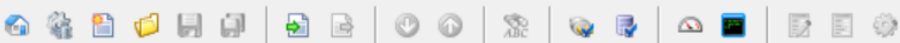

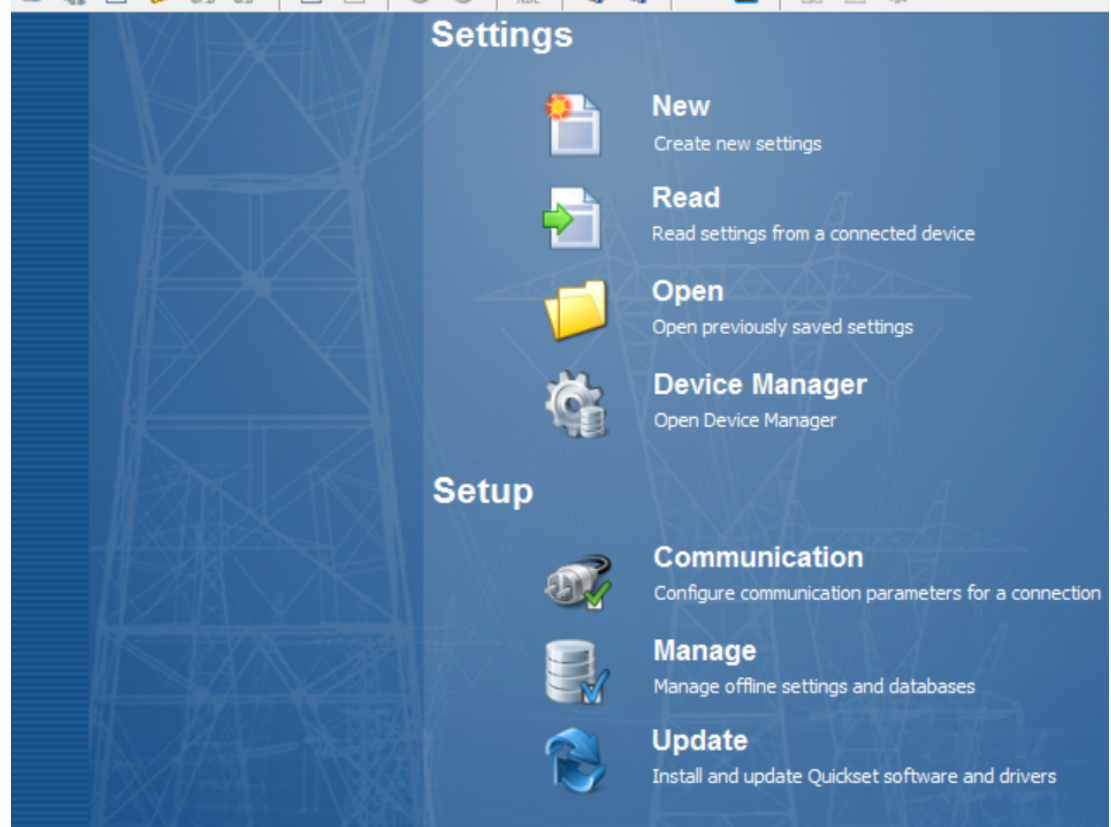

TXD $\square$ RXD $\square$ Disconnected 23 Terminal = Telnet File transfer $=$ YModem

Figure 88: QuickSet Main Window 


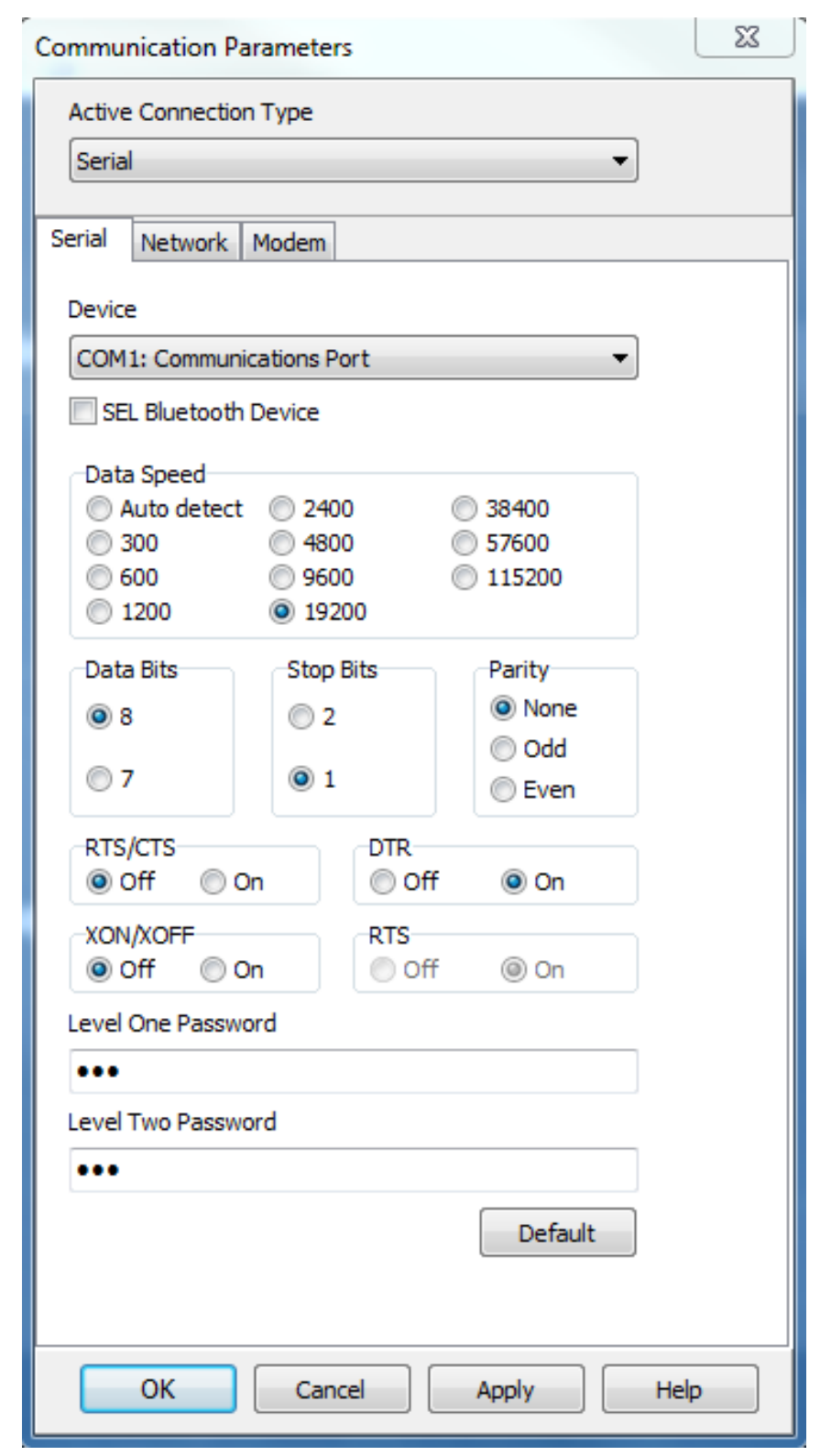

Figure 89: SEL-587 Communication Parameters Window

6. Click Apply at the bottom of the Communication Parameters window. Then click Ok. If the computer successfully connects to the relay, the connection status in the lower-left corner of the QuickSet main window should say "Connected."

7. Open your existing settings file for the SEL-587 relay (from the differential protection experiment).

a. Select File, Open in the QuickSet main window and navigate to the file path where you saved the relay database.

b. Open the database and select the SEL-587 settings file. 
8. Enter the following information in the Winding 2 Overcurrent Elements section (see Figure 90 and Figure 91). These elements provide secondary (backup) protection for faults downstream of the power transformer.

a. Set the winding 2 Phase Definite-Time and Instantaneous Overcurrent elements (50P2P and 50P2H) to OFF.

b. Enter a Phase Inverse-Time Overcurrent Pickup (51P2P) value of $4.50 \mathrm{~A}$. This setting causes the relay to trip (after a delay) for high fault currents flowing through winding 2 of the power transformer. In this experiment, this setting only trips for three-phase faults, triple-line-to-ground faults, or overload conditions. Negative-sequence overcurrent protection will trip first for line-to-line, single-line-to-ground, and double-line-to-ground faults. As an aside, note that the different parts of this protection element describe its function: "51P" denotes inverse-time phase overcurrent, ' 2 ' denotes winding two of the power transformer, and the second ' $\mathrm{P}$ ' denotes the pickup element.

c. Select a Phase Inverse-Time Overcurrent Curve (51P2C) of U1 to allow coordination with other downstream protective devices in future experiments. Curve U1 corresponds to the American moderately-inverse coordination curve.

d. Enter a Phase Inverse-Time Overcurrent Time-Dial (51P2TD) setting of 0.55 . This delay allows time for downstream protective devices to trip first for faults within their primary zone of protection before the SEL-587 trips more of the system off-line.

e. Turn off the Phase Inverse-Time Overcurrent Electromechanical Reset (51P2RS) by selecting $\underline{\mathrm{N}}$. This choice causes the relay to reset after just one cycle of current below the pick-up value, as opposed to the slow reset of a traditional electromechanical relay disk.

f. Enter a Negative-Sequence Inverse-Time Overcurrent Pickup (51Q2P) value of $\underline{0.50} \mathrm{~A}$. This setting causes the relay to trip (after a delay) for line-to-line, single-line-to-ground, and double-line-to-ground faults downstream of the power transformer.

g. Select a Negative-Sequence Inverse-Time Overcurrent Curve (51Q2C) of U1.

h. Enter a Negative-Sequence Inverse-Time Overcurrent Time-Dial (51Q2TD) setting of $\underline{0.55}$.

i. Turn off the Negative-Sequence Inverse-Time Overcurrent Electromechanical Reset (51Q2RS).

j. Set all winding 2 Residual Overcurrent Elements (50N2P, 50N2H, AND 51N2P) to OFF. 


\section{Winding 2 Overcurrent Elements}

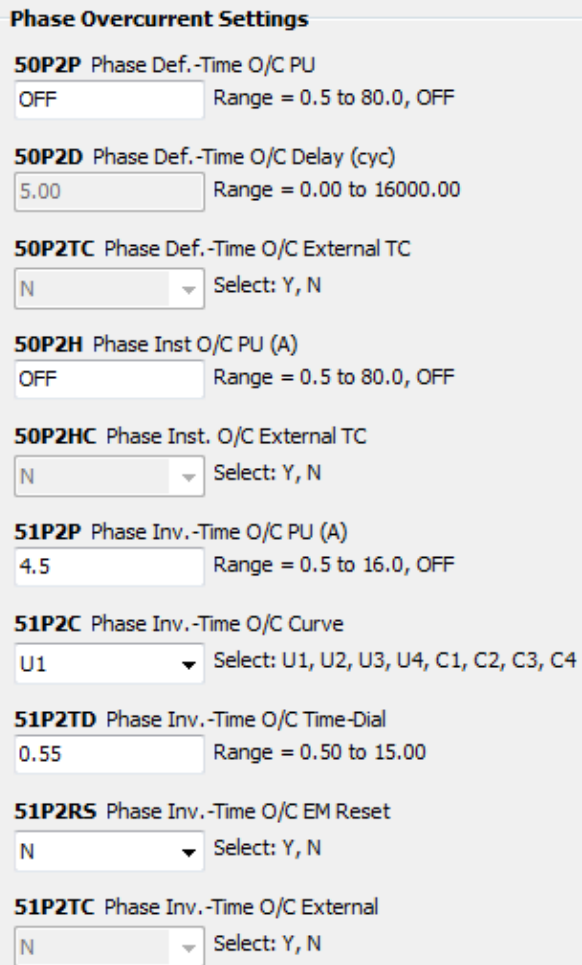

Figure 90: SEL-587 Overcurrent Elements

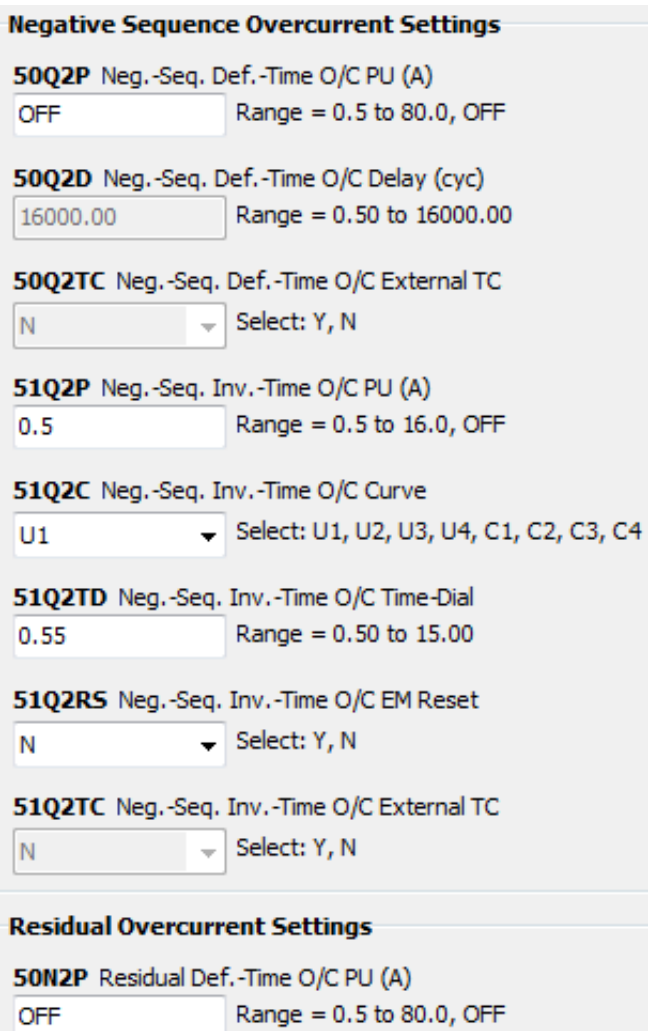

Figure 91: SEL-587 Overcurrent Elements, cont.

9. Enter the following information in the Logic section (Figure 92).

a. Modify the second Trip Logic (MTU2) setting. Replace the current contents with $87 \mathrm{R}+51 \mathrm{P} 2 \mathrm{~T}+51 \mathrm{Q} 2 \mathrm{~T}$. The SEL-587 will trip under MTU1 conditions when the restrained differential (87R), inverse-time phase overcurrent (51P2T), or inverse-time negative-sequence overcurrent (51Q2T) protection elements assert.

b. Replace the current contents of the Event Report Trigger Condition Logic (MER) setting with $\underline{87 \mathrm{R}+51 \mathrm{P} 2 \mathrm{P}+51 \mathrm{P} 2 \mathrm{~T}+51 \mathrm{Q} 2 \mathrm{P}+51 \mathrm{Q} 2 \mathrm{~T}}$. The SEL-587 will create an event report when any of the following elements assert: restrained differential (87R), inverse-time phase overcurrent pickup (51P2P), inverse-time phase overcurrent timeout (51P2T), inverse-time negative-sequence overcurrent pickup (51Q2P), or inverse-time negativesequence overcurrent timeout (51Q2T).

c. Replace the current contents for OUT2 with !TRP2 to assign the state of the MTU2 setting to digital output port OUT2 on the back of the relay. Logical inversion is necessary for interfacing the normally-open switch on the SEL-587 with the circuit breaker trip coil. This logic causes both of the circuit breakers connected to the relay to trip for $87 \mathrm{R}$ assertion, but only the secondary-side breaker to trip for 51P2T and 51Q2T assertion. 


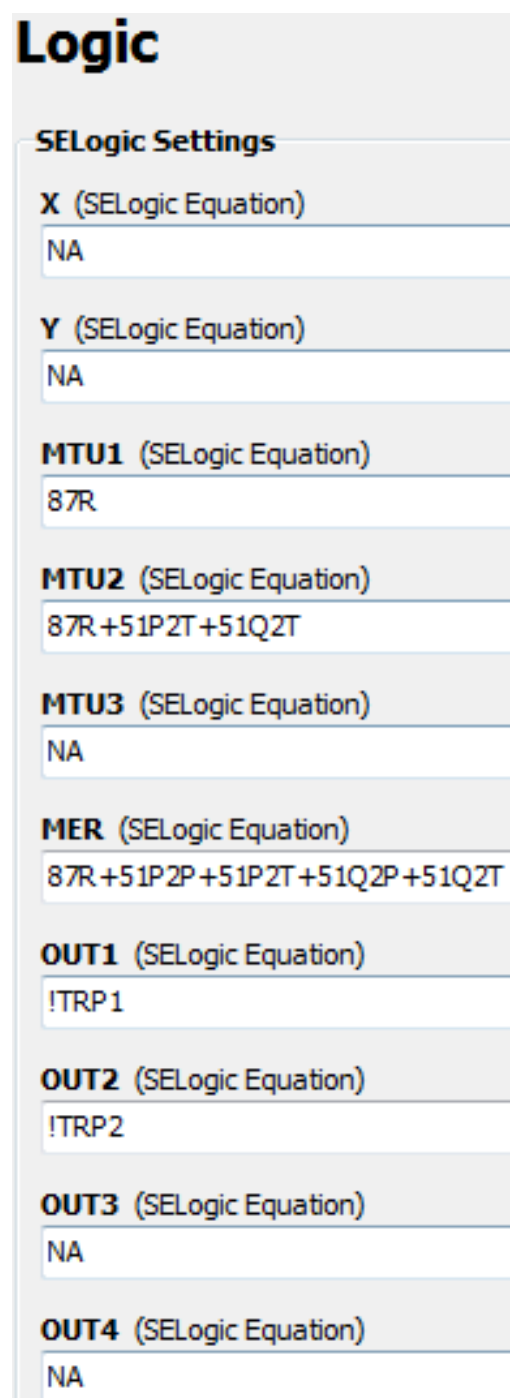

Figure 92: SEL-587 Trip Logic

10. Save your settings (File, Save).

11. Send your settings (File, Send...) to the SEL-587. In the window that appears, check the boxes for the Device and Logic settings (Figure 93). Sending only the modified settings shortens the file transfer time. Since it can take several minutes to transfer the relay settings, now is a good time to start constructing the circuit. 


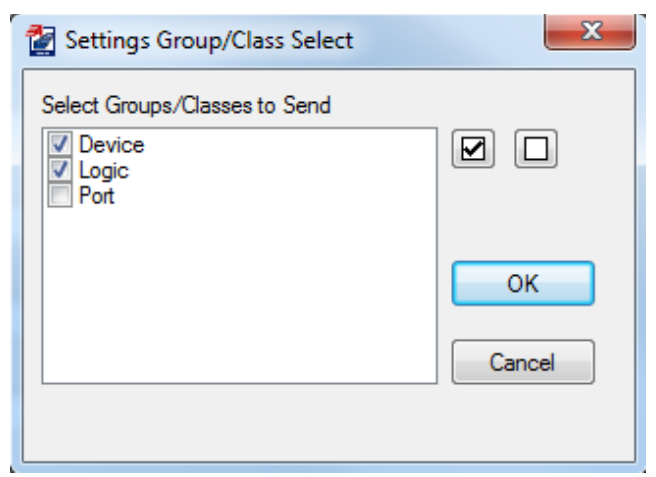

Figure 93: Send Modified Settings to SEL-587

12. Connect the three-phase circuit illustrated in Figure 87. Try to lay out the elements in the order illustrated in the schematic so that power flows across the bench from one end to the other. This linear arrangement limits the number of wires crossing each other and makes the path of current flow easier to review (and troubleshoot). Start with the sequential connection points in Table 48, using the diagrams posted on the wattmeter and transformer at the lab bench for assistance. Then add the following connections:

a. Jumper transformer terminal 1 of phase $A$ and terminal 2 of phase $C$ together (delta-connected primary). Likewise, connect terminal 1 of phase $\mathrm{B}$ to terminal 2 of phase $\mathrm{A}$, and connect terminal 1 of phase $\mathrm{C}$ to terminal 2 of phase B. This primary winding setup is known as a DAC configuration: D indicates Delta, while AC indicates that the polarity (positive reference terminal) of phase $\mathrm{A}$ is connected to the nonpolarity (negative reference terminal) of phase $\mathrm{C}$.

b. Jumper transformer terminals 4 and 5 for each phase of the power transformer secondary windings. This connection creates the 1:1 transformer turns ratio.

c. Jumper transformer terminal 3 of phase A and terminal 6 of phase $\mathrm{C}$ together (delta-connected secondary). Likewise, connect terminal 3 of phase $\mathrm{B}$ to terminal 6 of phase $\mathrm{A}$, and connect terminal 3 of phase $\mathrm{C}$ to terminal 6 of phase B. This secondary winding setup is known as a DAC configuration. Hence, this delta-delta power transformer has a DACDAC configuration.

d. Connect back-panel port 203 of the SEL-587 to the top Breaker Control Trip terminal on circuit breaker \#1 (transformer primary winding). Connect back-panel port 204 to the bottom Breaker Control Trip terminal on circuit breaker \#1.

e. Connect back-panel port $\mathbf{2 0 5}$ of the SEL-587 to the top Breaker Control Trip terminal on circuit breaker \#2 (transformer secondary winding). Connect back-panel port $\mathbf{2 0 6}$ to the bottom Breaker Control Trip terminal on circuit breaker \#2.

f. Connect the positive (upper) Breaker Control $125 \mathrm{~V}_{\mathrm{DC}}$ terminal on both circuit breakers to input terminal $\mathrm{G}$ on the lab bench. Connect the negative (lower) Breaker Control 125 VDC terminal on both circuit breakers to terminal $\mathrm{H}$. 
g. Connect the green chassis ground terminals on each circuit breaker to the green bench ground terminal.

h. Jumper together the positive and negative Breaker Control Trip terminals on circuit breaker \#3. This connection replaces input from a relay and enables manual closing of the circuit breaker.

Table 48: Per-Phase Sequential Points of Connection

\begin{tabular}{|c|c|c|}
\hline Phase A & Phase B & Phase C \\
\hline Input Voltage & Input Voltage & Input Voltage \\
\hline Wattmeter & Wattmeter & Wattmeter \\
\hline $25 \Omega$ Resistor Input & $25 \Omega$ Resistor Input & $25 \Omega$ Resistor Input \\
\hline $25 \Omega$ Resistor Output & $25 \Omega$ Resistor Output & $25 \Omega$ Resistor Output \\
\hline $\begin{array}{l}\text { Relay Port } 101 \\
\text { (Relay Input) }\end{array}$ & $\begin{array}{l}\text { Relay Port } \mathbf{1 0 3} \\
\text { (Relay Input) }\end{array}$ & $\begin{array}{l}\text { Relay Port } 105 \\
\text { (Relay Input) }\end{array}$ \\
\hline $\begin{array}{l}\text { Relay Port } 102 \\
\text { (Relay Output) }\end{array}$ & $\begin{array}{l}\text { Relay Port } 104 \\
\text { (Relay Output) }\end{array}$ & $\begin{array}{l}\text { Relay Port } 106 \\
\text { (Relay Output) }\end{array}$ \\
\hline CB \#1 (XFMR Primary & CB \#1 (XFMR Primary & CB \#1 (XFMR Primary \\
\hline $\begin{array}{l}\text { Side) Circuit Breaker Red } \\
\text { Terminal }\end{array}$ & $\begin{array}{c}\text { Side) Circuit Breaker Red } \\
\text { Terminal }\end{array}$ & $\begin{array}{l}\text { Side) Circuit Breaker Red } \\
\text { Terminal }\end{array}$ \\
\hline $\begin{array}{c}\text { CB \#1, Circuit Breaker } \\
\text { Black Terminal }\end{array}$ & $\begin{array}{c}\text { CB \#1, Circuit Breaker } \\
\text { Black Terminal }\end{array}$ & $\begin{array}{c}\text { CB \#1, Circuit Breaker } \\
\text { Black Terminal }\end{array}$ \\
\hline $\begin{array}{l}\text { Transformer Primary } \\
\text { Winding, Terminal } 1\end{array}$ & $\begin{array}{l}\text { Transformer Primary } \\
\text { Winding, Terminal } 1\end{array}$ & $\begin{array}{l}\text { Transformer Primary } \\
\text { Winding, Terminal } 1\end{array}$ \\
\hline $\begin{array}{c}\text { Transformer Secondary } \\
\text { Winding, Terminal } 3\end{array}$ & $\begin{array}{c}\text { Transformer Secondary } \\
\text { Winding, Terminal } 3\end{array}$ & $\begin{array}{c}\text { Transformer Secondary } \\
\text { Winding, Terminal } 3\end{array}$ \\
\hline $\begin{array}{l}\text { CB \#2, Circuit Breaker } \\
\text { Red Terminal }\end{array}$ & $\begin{array}{l}\text { CB \#2, Circuit Breaker } \\
\text { Red Terminal }\end{array}$ & $\begin{array}{l}\text { CB \#2, Circuit Breaker } \\
\text { Red Terminal }\end{array}$ \\
\hline $\begin{array}{c}\text { CB \#2, Circuit Breaker } \\
\text { Black Terminal }\end{array}$ & $\begin{array}{c}\text { CB \#2, Circuit Breaker } \\
\text { Black Terminal }\end{array}$ & $\begin{array}{c}\text { CB \#2, Circuit Breaker } \\
\text { Black Terminal }\end{array}$ \\
\hline $\begin{array}{l}\text { Relay Port } 108 * \\
\text { (Relay Input) }\end{array}$ & $\begin{array}{l}\text { Relay Port 110* } \\
\quad \text { (Relay Input) }\end{array}$ & $\begin{array}{l}\text { Relay Port } 112 * \\
\text { (Relay Input) }\end{array}$ \\
\hline $\begin{array}{c}\text { Relay Port 107* } \\
\text { (Relay Output) }\end{array}$ & $\begin{array}{c}\text { Relay Port 109* } \\
\text { (Relay Output) }\end{array}$ & $\begin{array}{c}\text { Relay Port } 111 * \\
\text { (Relay Output) }\end{array}$ \\
\hline $\begin{array}{c}\text { CB \#3, Circuit Breaker } \\
\text { Red Terminal }\end{array}$ & $\begin{array}{c}\text { CB \#3, Circuit Breaker } \\
\text { Red Terminal }\end{array}$ & $\begin{array}{c}\text { CB \#3, Circuit Breaker } \\
\text { Red Terminal }\end{array}$ \\
\hline $\begin{array}{c}\text { CB \#3, Circuit Breaker } \\
\text { Black Terminal }\end{array}$ & $\begin{array}{c}\text { CB \#3, Circuit Breaker } \\
\text { Black Terminal }\end{array}$ & $\begin{array}{c}\text { CB \#3, Circuit Breaker } \\
\text { Black Terminal }\end{array}$ \\
\hline $\begin{array}{c}333 \Omega \text { Hampden Resistive } \\
\text { Load }\end{array}$ & $\begin{array}{c}333 \Omega \text { Hampden Resistive } \\
\text { Load }\end{array}$ & $\begin{array}{c}333 \Omega \text { Hampden Resistive } \\
\text { Load }\end{array}$ \\
\hline Bench Ground & Bench Ground & Bench Ground \\
\hline
\end{tabular}


* Rolling transformer secondary winding current phases.

13. Verify the circuit connections and obtain instructor approval to apply power to the circuit.

14. Apply both $208 \mathrm{~V}_{\mathrm{AC}}$ and $125 \mathrm{VDC}$ power from the bench and close all circuit breakers (with the Manual Breaker Control Close button). Confirm that the threephase current displayed on the wattmeter is approximately $0.7 \mathrm{~A}$. If the displayed current exceeds $1 \mathrm{~A}$, turn off the bench power and check the circuit wiring for errors.

15. Create a line-to-line fault downstream of the power transformer.

a. Turn off $\mathrm{AC}$ and DC power from the bench.

b. Jumper the black Circuit Breaker terminals to the red Fault Connections terminals (if present) on circuit breaker \#3. Jumper two of the black Fault Connections terminals together.

c. Set the circuit breaker Fault Switches to the Normal position.

d. Turn on AC and DC bench power. Manually close all circuit breakers.

e. Flip the circuit breaker \#3 Fault Switch to the Fault position.

f. Watch the wattmeter to confirm that the SEL-587 trips the circuit breaker to clear the fault. If it does not, turn off $\mathrm{AC}$ bench power immediately.

g. Once the relay clears the fault, turn off AC and DC bench power and flip the Fault Switch to the Normal position. Press the Target Reset button on the SEL-587 to clear the relay's front-panel LED display.

h. Retrieve the event file(s) from the SEL-587 (Step 16).

i. Add the TRIP2, 51Q2T, and 51Q2 digital signals to the oscillogram plot.

16. Retrieve the SEL-587 event file for the fault trip.

a. In QuickSet, select Tools, Event Files, Get Event Files.

b. In the window that comes up, select Refresh Event History.

c. Choose an Event Type of 16 Samples / Cycle - Raw.

d. Check the boxes of the event file(s) corresponding to the fault. Event files are indexed, with ' 1 ' being the most recent event file saved by the relay.

e. Click Get Selected Events. Save the events in a convenient location using either a default or custom naming convention.

f. Double-click on the event report file in its file path location. The AcSELerator Analytic Assistant software automatically opens an oscillogram plot of the event.

g. Click the Pref button in the lower-right corner of the oscillogram to open the Preferences menu and modify the information displayed on the oscillogram plot.

h. Under the Preferences menu, add digital fault-trip signals to the plot. Leftclick on the signal you wish to display (from the Digitals list in the lowerleft corner of the screen), then right-click-drag the signal to the Digital Axis list of signals to be displayed. 
i. Under the Preferences menu, verify that the following Analog signals are displayed on Axis 1: IAW1, IBW1, and ICW1. Remove an undesired signal by clicking on it and pressing the Delete key on the keyboard. Click $\mathrm{OK}$ to see these changes reflected on the oscillogram.

j. After saving the desired event files, enter the HIS C command in the QuickSet Terminal window (select Communications, Terminal) to clear previous event files from the relay's memory. If an error message appears about an invalid access level, type in ACC, the Enter key, the level relay 1 password (default for SEL-587 is 587), and the Enter key. Proceed to clear the event files.

17. Create a single-line-to-ground fault downstream of the power transformer.

a. Turn off $\mathrm{AC}$ and $\mathrm{DC}$ power from the bench.

b. Jumper the black Circuit Breaker terminals to the red Fault Connections terminals (if present) on circuit breaker \#3. Connect one of the black Fault Connections terminals directly to bench ground.

c. Set the circuit breaker Fault Switches to the Normal position.

d. Turn on AC and DC bench power. Manually close all circuit breakers.

e. Flip the circuit breaker \#3 Fault Switch to the Fault position.

f. Watch the wattmeter to confirm that the SEL-587 trips the circuit breaker to clear the fault. If it does not, turn off $\mathrm{AC}$ bench power immediately.

g. Once the relay clears the fault, turn off AC and DC bench power and flip the Fault Switch to the Normal position. Press the Target Reset button on the SEL-587 to clear the relay's front-panel display.

h. Retrieve the event file(s) from the SEL-587 (Step 16).

i. Add the TRIP2, 51Q2T, and 51Q2 digital signals to the oscillogram plot.

18. Create a triple-line-to-ground fault downstream of the power transformer.

a. Turn off $\mathrm{AC}$ and $\mathrm{DC}$ power from the bench.

b. Jumper the black Circuit Breaker terminals to the red Fault Connections terminals (if present) on circuit breaker \#3. Jumper all three of the black Fault Connections terminals together and connect these terminals directly to bench ground.

c. Set the circuit breaker Fault Switches to the Normal position.

d. Turn on AC and DC bench power. Manually close all circuit breakers.

e. Flip the circuit breaker \#3 Fault Switch to the Fault position.

f. Watch the wattmeter to confirm that the SEL-587 trips the circuit breaker to clear the fault. If it does not, turn off $\mathrm{AC}$ bench power immediately. Note, however, that the relay waits much longer before tripping under this fault condition.

g. Once the relay clears the fault, turn off AC and DC bench power and flip the Fault Switch to the Normal position. Press the Target Reset button on the SEL-587 to clear the relay's front-panel display.

h. Retrieve the event file(s) from the SEL-587 (Step 16).

i. Add the TRIP2, 51P2T, and 51P2 digital signals to the oscillogram plot. 


\section{Postlab Questions}

- Explain why both circuit breakers \#1 and \#2 tripped for transformer faults (within the differential zone of protection described in the previous SEL-587 experiment), whereas only circuit breaker \#2 tripped for faults downstream of the transformer (outside the differential zone of protection). Base your explanation on the Trip Logic relay settings.

- For faults downstream of the transformer, why did negative-sequence overcurrent protection only trip the relay for line-to-line, single-line-to-ground, and (if you tried it) double-line-to-ground faults? Why not three-phase or triple-line-toground faults?

- Compare the relay response time shown on the oscillograms with the expected values calculated in the prelab. Explain possible causes for these differences. Hint: the power transformers in the lab benches operate in saturation (recall the B$\mathrm{H}$ curve), which affects the expected impedance obtained from open-circuit and short-circuit tests.

\section{$\underline{\text { Deliverables }}$}

Answer the postlab questions. Turn in oscillograms for the fault events described in the procedure. The bottom of each oscillogram should show the digital signal associated with the type of protection triggered by the fault. Give each plot a caption specifying the relay, fault type and location, and type of protection triggered.

Keep the relay settings for use in future experiments. 


\title{
Appendix J: SEL-710 Overcurrent and Undervoltage Protection Procedure
}

\author{
ELECTRICAL ENGINEERING DEPARTMENT \\ California Polytechnic State University \\ San Luis Obispo
}

EE 518

Experiment \#3

Induction Motor Overcurrent and Undervoltage Protection Using the SEL-710

\section{Learning Outcomes}

- Identify, record, and eliminate bolted faults at the terminals of a $208 \mathrm{~V}$ induction motor using definite-time overcurrent protection

- Identify, record, and eliminate undervoltage operating conditions in an induction motor

- Analyze fault conditions from relay-generated event reports

\section{Background}

The American National Standards Institute (ANSI) uses the designation '50' to denote instantaneous overcurrent relays. As a general rule, these relays trip immediately when a fault condition is detected. Traditional electromechanical relays illustrate this concept well: the presence of a sufficiently high pickup current activates a coil, which immediately switches a contact in the relay and trips the circuit breaker. Modern microprocessor-based relays (such as the SEL-710) replicate this functionality, but may also give the option to specify a finite amount of time between when the relay senses a sustained fault current and when the relay switches its contact to trip the circuit breaker. Relays with this delay option are known as definite-time overcurrent relays. Since definite-time overcurrent relays use constant delay times and immediately trip when that time expires, they fall under the ANSI category of instantaneous overcurrent relays.

Individual overcurrent elements in many modern microprocessor-based relays, such as the SEL-710, are configured to detect overcurrent conditions in phase (50P) and neutral $(50 \mathrm{~N})$ conductor currents, as well as calculated residual $(50 \mathrm{G})$ and negativesequence (50Q) currents. As an aside, note that $50 \mathrm{~N}$ denotes residual overcurrent in some other SEL relays. These particular designations are explained in the reference material (such as the instruction manual) for each relay.

\section{$\underline{\text { Prelab }}$}

For calculations, ignore connections to the relay (i.e. circuit breakers, current transformers, and potential transformers). Assume that the motor is off when the faults occur.

a) Calculate the negative-sequence currents (in Amps) produced by bolted line-toline and single-line-to-ground faults at Bus 1 in Figure 94.

b) Calculate the per-phase current (in Amps) of a triple-line-to-ground fault at the same location. Hint: use Ohm's law. 
c) Calculate the phase current (in Amps) for the faulted phase in a single-line-toground fault at Bus 1 in Figure 94.

\section{Equipment}

- $25-\Omega$ Single-Phase Power Resistor (3x)

- Bag of Banana-Banana Short Leads (3x)*

- Banana-Banana or Banana-Spade Leads (18x)

- Circuit Breaker (1x)

- Computer with AcSELerator QuickSet Software and a Serial Port

- Induction Motor: 208 V, 1/3 horsepower (1x), with Magtrol Torque-Adjust Unit (1x)

- SEL-710 Differential and Overcurrent Relay (1x)

- SEL-C234A Serial Cable (1x)

- Wattmeter $(1 \mathrm{x})$

* Beware of extra flexible "small gauge" short leads, which can melt under fault conditions.

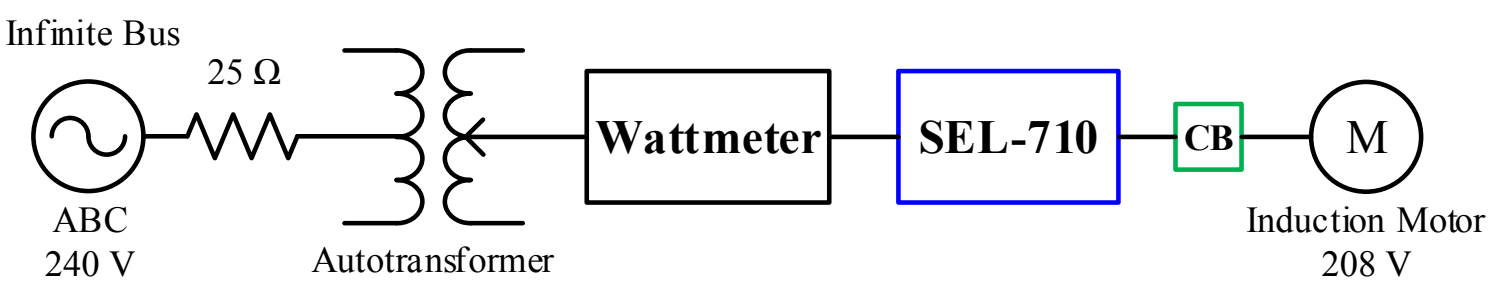

Figure 94: SEL-710 Procedure Single-Line Diagram

\section{Procedure}

1. Plug in the power cord connected to the SEL-710 relay.

2. Connect an SEL-C234A serial cable between Port 3 on the back of the 710 and the main serial port on the back of the computer (surrounded by a light turquoise color).

3. On the computer, open the AcSELerator QuickSet software.

4. Determine the current baud rate for Port 3 on the 710 .

a. On the front panel of the relay, press the enter button, labeled $\underline{\mathbf{E N T}}$.

b. Use the down-arrow button to navigate to Set/Show on the front panel display. Press the enter button.

c. Use the down-arrow button to navigate to Port on the front panel display. Press the enter button.

d. Navigate to Port $\underline{\mathbf{3}}$ and press the enter button.

e. Navigate to Comm Settings and press the enter button.

f. Use the down-arrow button to navigate through the current Port 3 settings. The baud rate (SPEED) is near the top of the list. If the baud rate is 
already set to 19200, press the ESC button several times to restore the screen to its normal display, and continue to the next step.

g. If the current relay baud rate is not set to 19200 , use the following steps to change the baud rate:

h. With the relay's baud rate setting highlighted, press the enter key.

i. Use the up, down, left, and right buttons to enter the relay's level 2 password (default is "TAIL" and is case-sensitive). Press the enter key to select each letter. Navigate to and select Accept after entering the password.

j. Press the up/down-arrow buttons until $\underline{19200}$ (not 19.2) appears. Press the enter key.

k. Press $\underline{\mathbf{E S C}}$ twice, and select $\underline{\text { Yes }}$ to save the new port setting.

5. On the QuickSet main window (Figure 95), open the Communication Parameters window (Communications, Parameters) (Figure 96) to define and create a communication link with the 710. Enter the following information for a Serial Active Connection Type:

a. Device: COM1: Communications Port

b. SEL Bluetooth Device: Unchecked

c. Data Speed: $\underline{19200}$

d. Data Bits: 8

e. Stop Bits: 1

f. Parity: None

g. RTS/CTS: Off

h. DTR: On

i. XON/XOFF: On

j. RTS: N/A (On)

k. Level 1 Password (Default $\underline{\text { OTTER})}$

1. Level 2 Password (Default $\underline{\text { TAIL) }}$ 
AcSELerator ${ }^{\circledR}$ QuickSet - [Getting Started with QuickSet]

File Edit View Communications Tools Windows Help Language

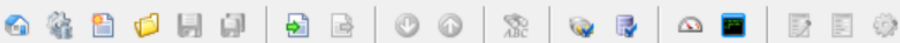

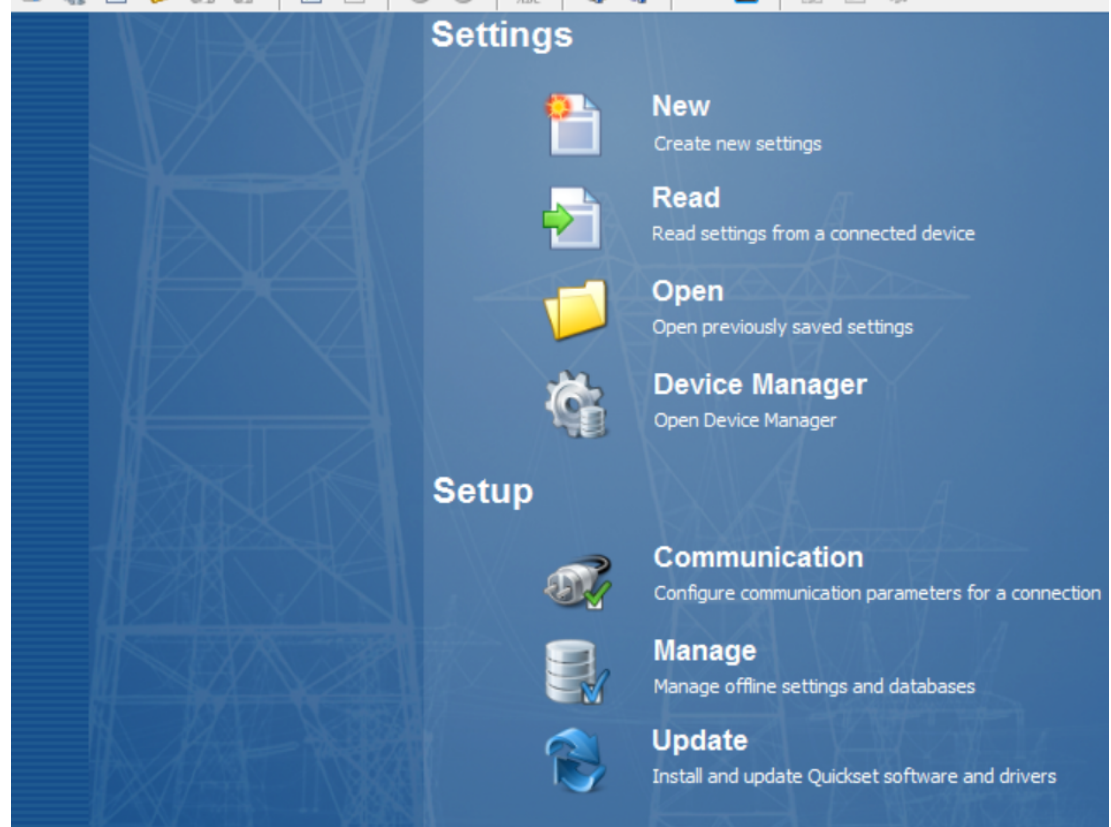

TXD $\square$ RXD $\square$ Disconnected 23 Terminal = Telnet File transfer $=$ YModem

Figure 95: QuickSet Main Window 


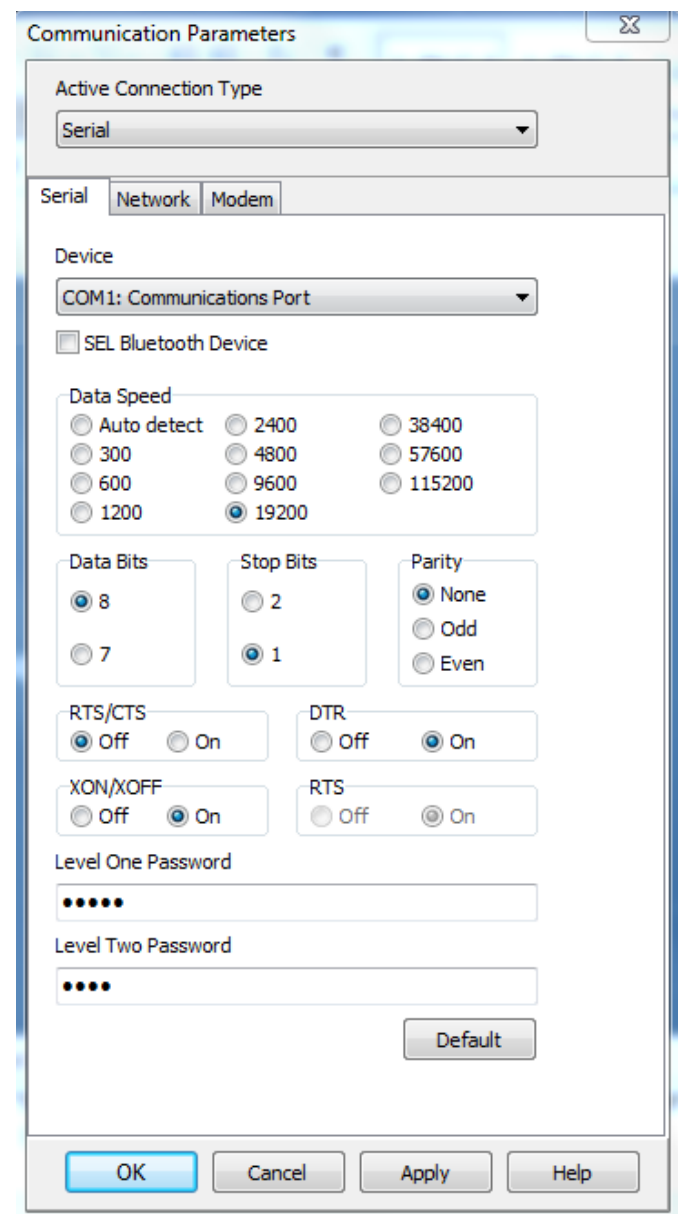

Figure 96: SEL-710 Communication Parameters Window

6. Click Apply at the bottom of the Communication Parameters window. Then click $\underline{\mathrm{Ok}}$. If the computer successfully connects to the relay, the connection status in the lower-left corner of the QuickSet main window should say "Connected."

7. Create a new settings file for the SEL-710 relay.

a. In the QuickSet main window, create a new settings file for the SEL-710 relay (File, New).

b. Choose the Device Family, Model, and Version for this specific relay unit from the available menus, then click Ok (Figure 97). Look up the relay's version number using the front-panel interface on the relay. Press the ENT button, and use the down-arrow button to navigate to the STATUS option. Press the enter button again. Select the Relay Status option. Navigate down to the FID option. Scroll across the relay's FID string until you come to the " $Z$-number." The first three digits following the ' $Z$ ' comprise the relay version number. Press the ESC button several times to restore the front-panel screen to its normal display. Note: if no devices are listed in the QuickSet drop-down menus, then the device drivers need to be installed using the SEL Compass software. Ask for assistance. 
c. Enter the relay Part Number (Figure 98) printed on the serial number label (P/N, Figure 99) attached somewhere on the relay chassis. Note that the 5 A Secondary Input Current reflects the convention for American current transformers.

Settings Editor Selection - Settings Database

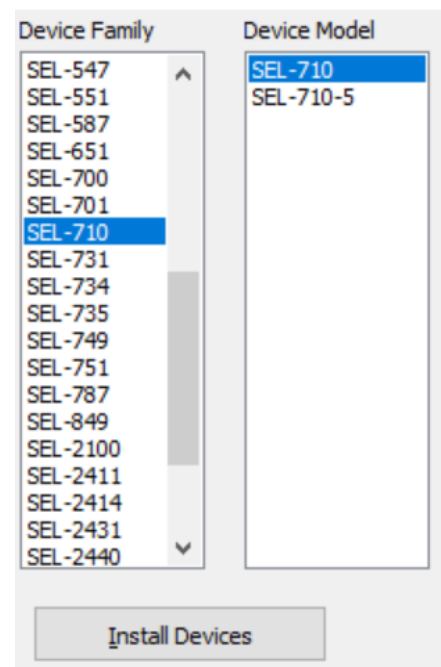

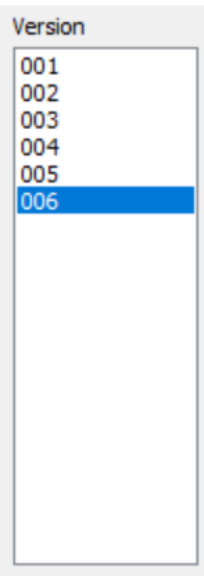

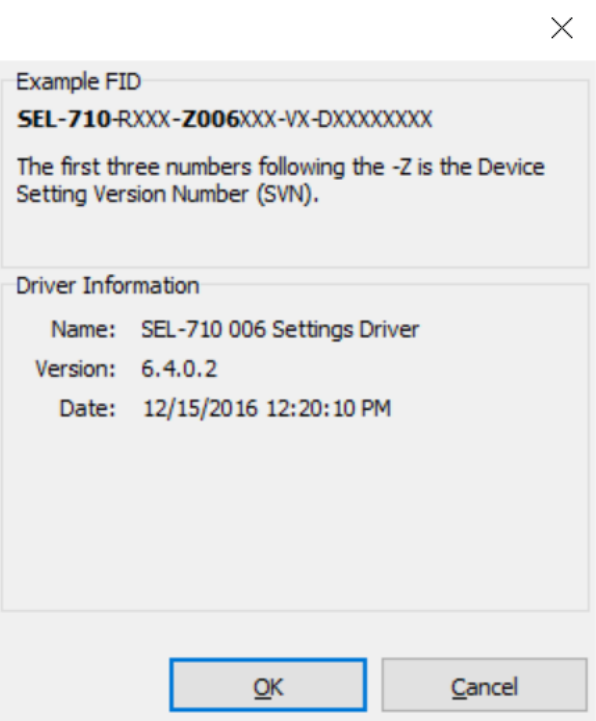

Figure 97: Identifying SEL-710 Relay Family, Model, and Version

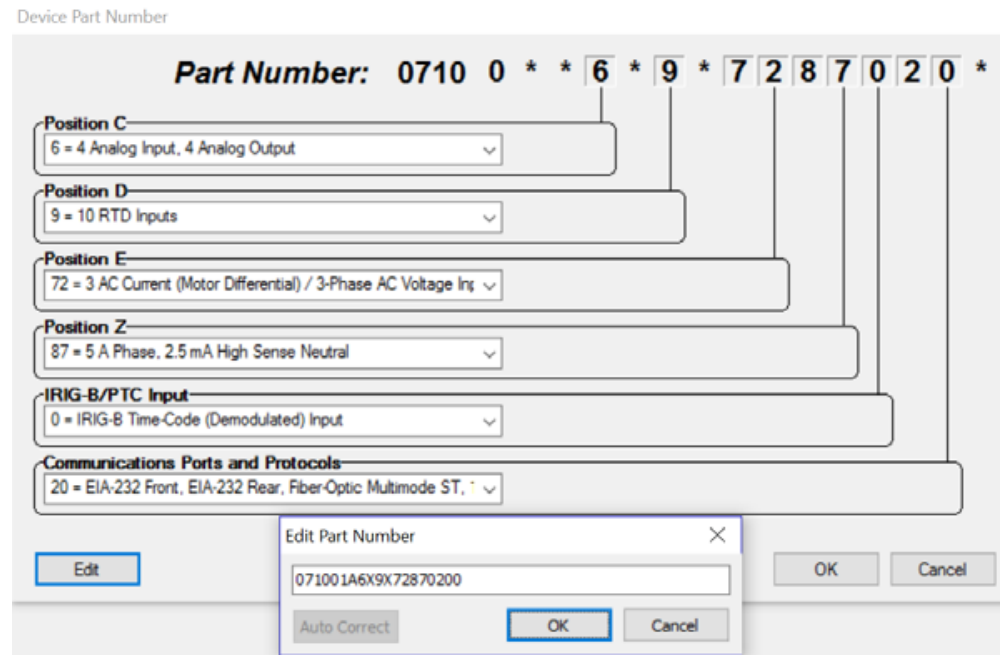

Figure 98: Identifying SEL-710 Relay Part Number

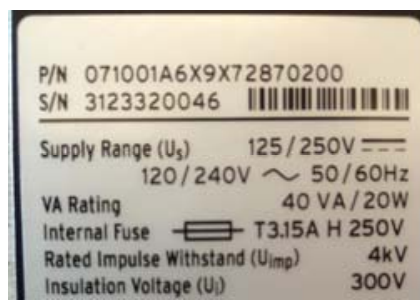

Figure 99: Example

SEL-710 Label with Relay Part Number

8. Save this relay settings database file ( $\underline{\text { File, }}$ Save As; New if you do not want to use an existing settings database) in a location where it may be reused in future experiments. See Figure 100 and Figure 101. Then create a Settings Name for this settings file. 


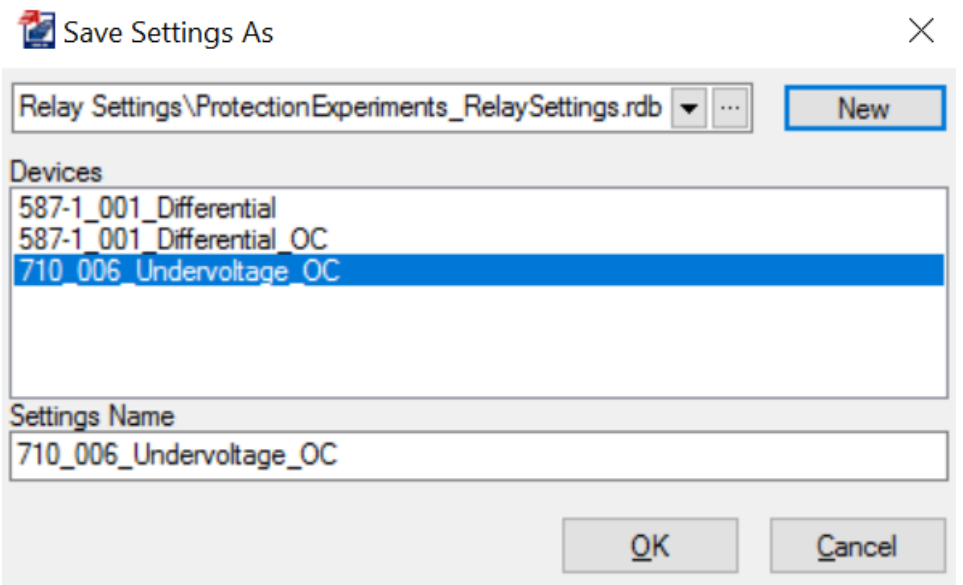

Figure 100: Saving SEL-710 Settings

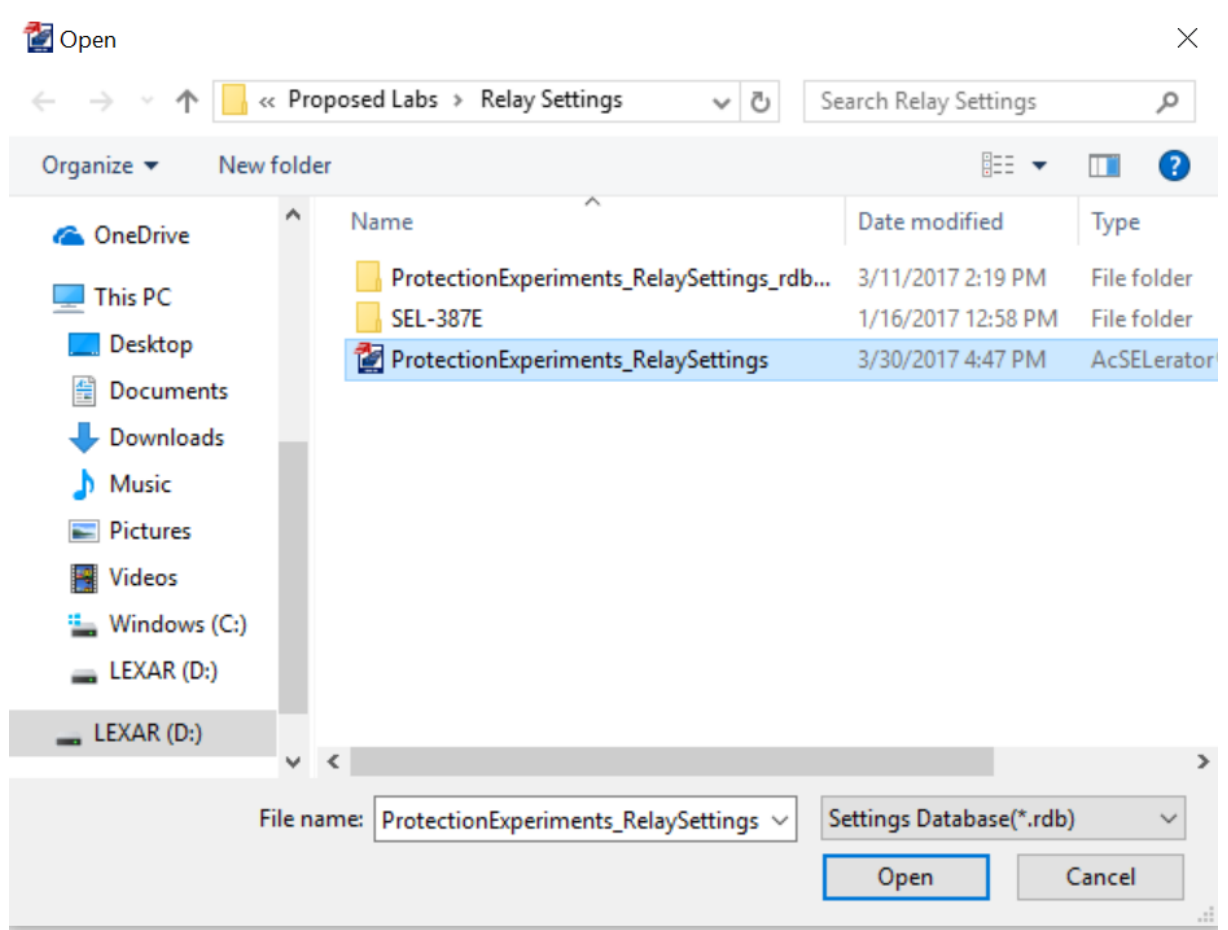

Figure 101: Choosing Location for New SEL-710 Relay Settings Database

9. Open Global settings in the drop-down menu on the left side of the Settings Editor main window (Figure 102).

a. Under General settings (Figure 103), choose a Phase Rotation sequence (PHROT) of ACB. The frequency and phase rotation settings correspond to electrical properties of the utility. Replace the default Fault Condition (FAULT) contents with TRIP.

b. Under Breaker Monitor settings (Figure 104), select $\underline{\mathrm{N}}$ for the Enable Breaker Monitor (EBMON) setting. 


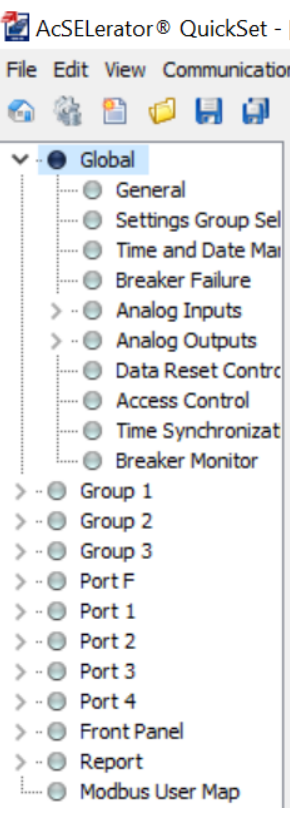

Figure 102: SEL-710 Settings Editor Main Window

\section{General}

APP Application WARNING: Nameplate sets mo:

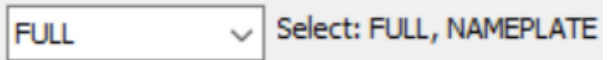

PHROT Phase Rotation

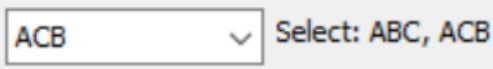

FNOM Rated Frequency $(\mathrm{Hz})$

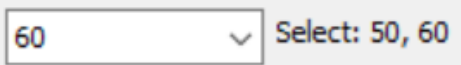

DATE_F Date Format

MDY $\quad \checkmark$ Select: MDY, YMD, DMY

FAULT Fault Condition (SELogic)

TRIP

Figure 103: SEL-710 General Settings

\section{Breaker Monitor}

EBMON Enable Breaker Monitor

$\mathrm{N}$

COSP1 Close/Open Operations Set Point 1-max

10000

Range $=0-65000$

Figure 104: SEL-710 Breaker Monitor Settings

10. Open the Group 1, Set 1 settings menu on the left side of the screen.

11. Enter the following information in the Main Settings (Figure 105 and Figure 106).

a. Enter a Phase Current Transformer Turns Ratio (CTR1) of $\underline{1}$, reflecting the fact that the currents measured by the relay are the actual system line currents (not stepped down). Current and potential transformers are not needed in this experiment because the system line currents and voltages (even during fault conditions) are relatively low.

b. Enter a Motor Full Load Amps (FLA1) value of 1.6 A. This setting acts like the pickup current setting in traditional electromechanical relays, in addition to its role in multiple motor performance calculations made by the SEL-710.

c. Enter a Neutral Current Transformer Turns Ratio (CTRN) of 1 .

d. Enter a Potential Transformer Turns Ratio (PTR) of $\underline{1}$, reflecting the fact that the voltages measured by the relay are the actual system voltages (not stepped down).

e. Enter a Nominal Line-to-Line Voltage (VNOM) value of $\underline{208} \mathrm{~V}$. 
f. Select WYE as the Transformer Connection (DELTA_Y) for the potential transformer.

\section{Main}

RID Relay Identifier (16 characters)

\begin{tabular}{|c|c|}
\hline SEL- & \\
\hline TID & fier (16 characters) \\
\hline MOT & \\
\hline CTR1 & ,IC) CT Ratio \\
\hline 1 & Range $=1-5000$ \\
\hline FLA1 & ull Load Amps] (amps) \\
\hline 1.6 & Range $=0.2-5000.0$ \\
\hline E2SP & d Protection \\
\hline $\mathrm{N}$ & Select: Y, N \\
\hline CTR2 & IC) CT Ratio, 2nd \\
\hline 100 & Range $=1-5000$ \\
\hline
\end{tabular}

Figure 105: SEL-710 Main
FLA2 Motor FLA (Full Load Amps), 2nd (amps) 250.0 Range $=0.2-5000.0$

FVR_PH Full Voltage Reversing Contactor Phasing NONE $\quad-$ Select: NONE, A, B, C

CTRN Neutral (IN) CT Ratio

1 Range $=1-2000$

\begin{tabular}{ll} 
PTR PT Ratio & \\
\hline 1.00 & Range $=1.00-250.00$
\end{tabular}

VNOM Line Voltage, Nominal Line-to-Line (volts)

208 Range $=100-30000$

DELTA_Y Transformer Connection

WYE $\quad$ Select: WYE, DELTA

SINGLEV Single Voltage Input

N $\quad$ Select: $Y, N$

Figure 106: SEL-710 Main Settings, cont.

12. Enter the following information in the Overcurrent Elements section (Figure 107, Figure 108, and Figure 109).

a. Under the Phase Overcurrent sub-heading, enter a Phase Overcurrent Pickup (50P1P) of 3.00 multiples of the full load amps setting. Leave the associated Trip Delay (50P1D) as its default value of $\underline{0.00} \mathrm{~s}$.

b. Under the Residual Overcurrent sub-heading, enter a Residual Overcurrent Pickup (50G1P) of 0.50 multiples of the full load amps setting. Set the associated Trip Delay (50G1D) to $\underline{0.10} \mathrm{~s}$.

c. Under the Negative-Sequence Overcurrent sub-heading, enter a NegativeSequence Overcurrent Pickup (50Q1P) of 0.50 multiples of the full load amps setting. Set the associated Trip Delay (50Q1D) to $\underline{0.15} \mathrm{~s}$. Turn $\underline{\mathrm{OFF}}$ the Negative-Sequence Overcurrent Alarm Pickup (50Q2P). 


\section{Phase Overcurrent}

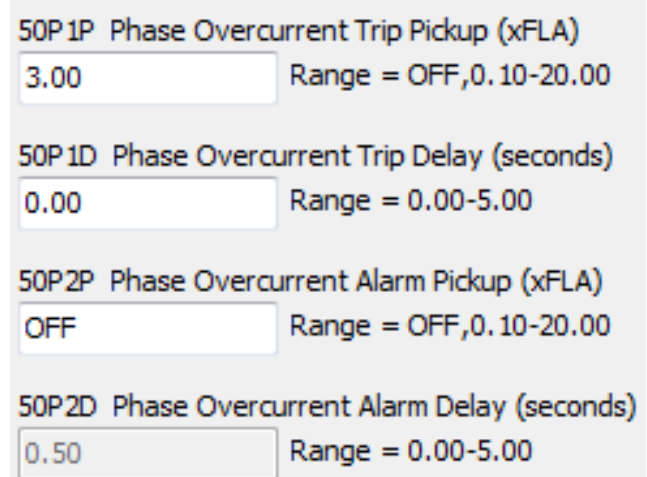

Figure 107: SEL-710 Phase

Overcurrent Settings

\section{Residual Overcurrent}

50G1P Residual Overcurrent Trip Pickup (xFLA) $0.50 \quad$ Range $=$ OFF, $0.10-20.00$

50G1D Residual Overcurrent Trip Delay (seconds) $0.10 \quad$ Range $=0.00-5.00$

50G2P Residual Overcurrent Alarm Pickup (xFLA) \begin{tabular}{l|l} 
OFF & Range $=$ OFF, $0.10-20.00$
\end{tabular}

50G2D Residual Overcurrent Alarm Delay (seconds) 10.0 Range $=0.0-120.0$

Figure 108: SEL-710 Residual Overcurrent Settings

\section{Negative Sequence Overcurrent}

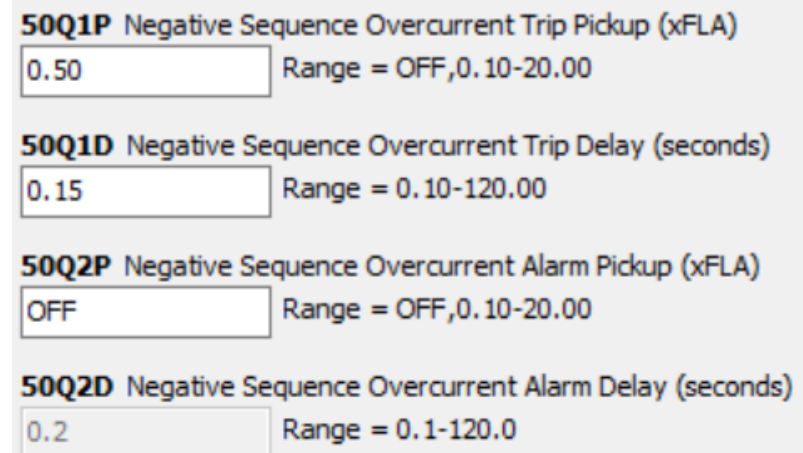

Figure 109: SEL-710 Negative-Sequence Overcurrent Settings

13. In the Undervoltage Elements, set the Undervoltage Trip Level (27P1P) to $\underline{0.80}$ multiples of the nominal motor voltage setting, VNOM (Figure 110). Increase the Undervoltage Trip Delay (27P1D) to $\underline{0.8} \mathrm{~s}$ to keep the relay from tripping due to effects of inrush current. 


\section{Undervoltage Elements}

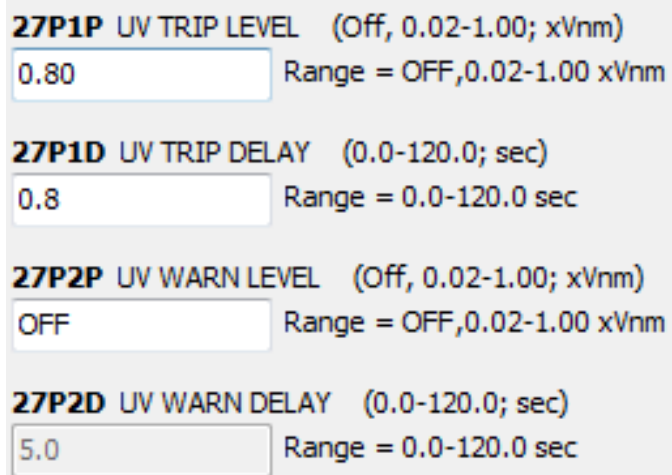

Figure 110: SEL-710 Undervoltage Elements

14. Under the Trip and Close Logic sub-heading, replace the default contents of the Trip (TR) equation with 50P1T OR 50G1T OR 50Q1T OR 27P1T OR STOP (Figure 111).

\section{Trip and Close Logic}

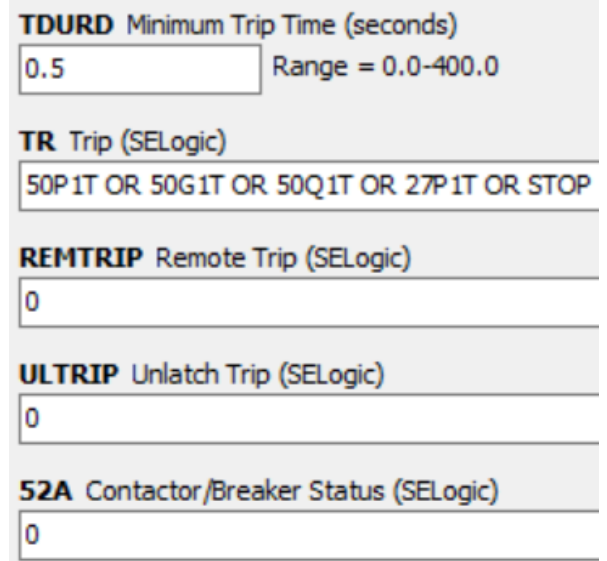

Figure 111: SEL-710 Trip and Close Logic

15. Enter the following information in the Logic 1, Slot A section (Figure 112).

a. Select $\underline{\mathrm{N}}$ for the OUT101 Fail-Safe (OUT101FS) option.

b. Select $\underline{Y}$ for the OUT102 Fail-Safe (OUT102FS) option.

c. Logically-invert the default OUT102 signal to be NOT START. Logical inversion is necessary for interfacing the normally-open switch (OUT102) on the SEL-710 with the normally-open circuit breaker trip coil. This choice allows the SEL-710 front-panel START button to operate the Breaker Control Close contact on the circuit breaker through the relay's rear-panel ports A05 and A06. 


\section{Slot A}

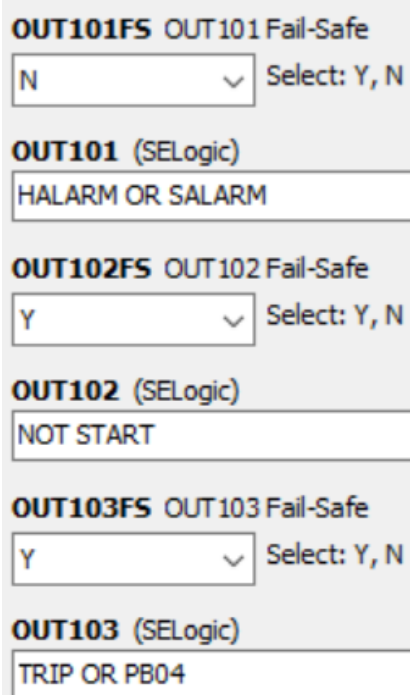

Figure 112: SEL-710 Logic 1, Slot A Output Logic

16. Repeat Steps 11 through 15 for the SEL-710 Group 2 - Set 2 and Group 2 - Logic 2 settings, with the following exceptions:

a. Enter a new Motor Full Load Amps (FLA1) value of 2.1 A.

b. Enter a Trip (TR) equation of 50P1T OR 50G1T OR 50Q1T OR STOP.

17. Open Port F settings in the menu on the left side of the Settings Editor main window. Set the Port F baud rate (SPEED) to 19,200. Change the AUTO setting to $\underline{Y}$. Leave all other Port F settings as their default values (Figure 113). 


\section{Port F}

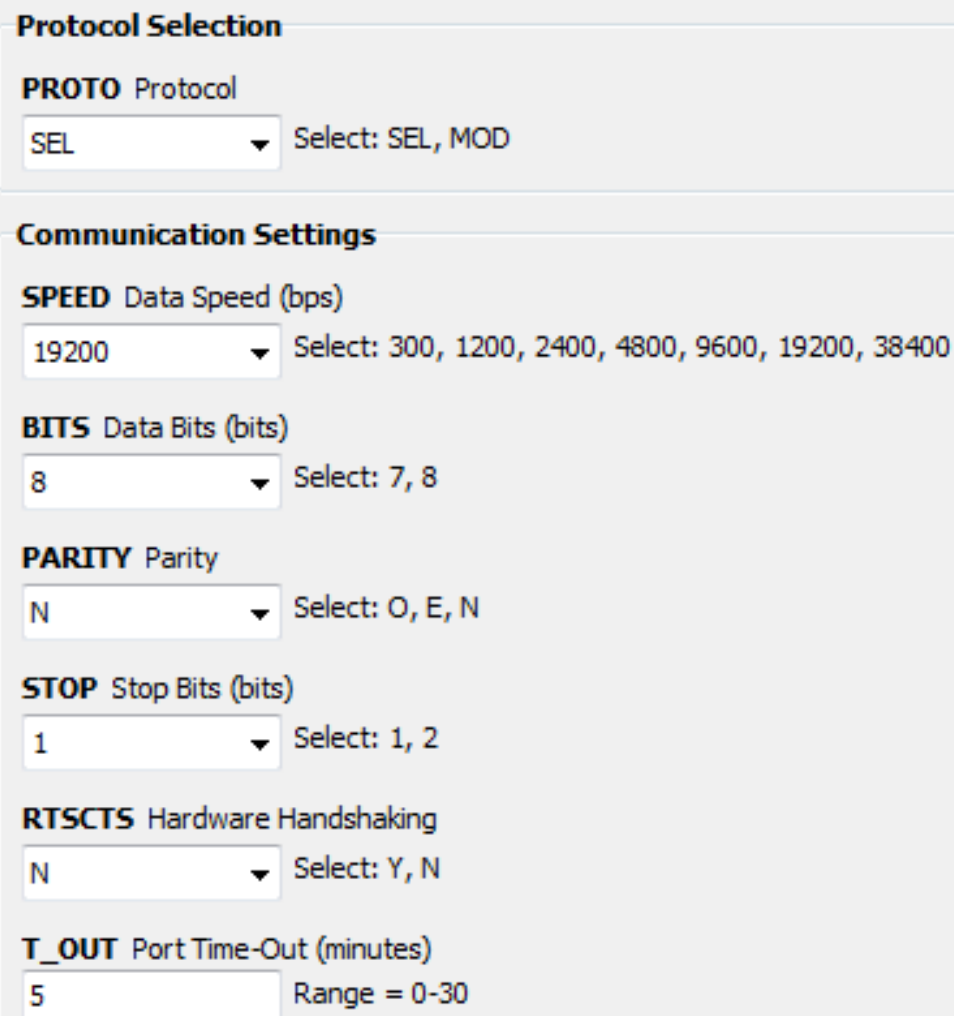

Figure 113: SEL-710 Port F Settings

18. Open the Port 3 settings on the left side of the Settings Editor main window. Set the Port 3 baud rate (SPEED) to $\underline{19,200}$. Change the AUTO setting to $\underline{Y}$. Leave all other Port 3 settings as their default values.

19. Enter the following information in the Report on the left side of the Settings Editor main window (Figure 114 and Figure 115).

a. Under the SER, SER Trigger Lists headings, add TRIP to the existing contents of the first Sequential Event Recorder (SER1). This addition causes the SEL-710 to generate an event report for any of the conditions specified by the TR equation.

b. Under the Event Report heading, change the Length of Event Report (LER) setting to $\underline{64}$ cycles.

c. Increase the Prefault Length (PRE) data collection time to 10 cycles. This setting defines the amount of data saved in an event report before the relay trips for a fault. 


\section{SER Trigger Lists}

SER1 (24 Relay Word bits)

IN101 IN102 PB01 PB02 PB03 PB04 ABSLO TBSLO NOSLO THERMLO TRIP

SER2 (24 Relay Word bits)

49T 49T_STR 49T_RTR LOSSTRIP JAMTRIP 46UBT 50P1T RTDT PTCTRIP 50G1T VART 37PT 27P1T 59P 1T 47T 55T SF

SER3 (24 Relay Word bits)

AMBTRIP PTCFLT RTDFLT COMMIDLE COMMLOSS REMTRIP RSTTRGT 49A LOSSALRM JAMALRM 46UBA RTDA 55A 50

SER4 (24 Relay Word bits)

SPDSAL 81D3T 81D4T OTHALRM AMBALRM SALARM WARNING LOADUP LOADLOW 50P2T STOPPED RUNNING STAR1

Figure 114: SEL-710 Trigger Lists Settings

\section{Event Report}

ER Event Report Trigger (SELogic)

R_TRIG LOSSALRM OR R_TRIG 46UBA OR R_TRIG 49A OR R_TRIG 37PA OR R_TRIG _..

LER Length of Event Report (cycles) PRE Prefault Length (cycles)

$\begin{array}{llll}64 & \text { Select: } 15,64 & \text { Range }=\text { OFF }, 1-59\end{array}$

Figure 115: SEL-710 Event Report Settings

20. Save your settings (ile, $\underline{\text { Save }})$.

21. Send your settings (File, Send...) to the SEL-710. In the window that appears, check the boxes for the Set 1, Set 2, Logic 1, Logic 2, Global, Port F, Port 3, and Report settings (Figure 116). Click $\underline{\mathrm{Ok}}$. Sending only the modified settings shortens the file transfer time. Ignore any error messages associated with changing the baud rate. Since it can take several minutes to transfer the relay settings, now is a good time to start constructing the circuit.

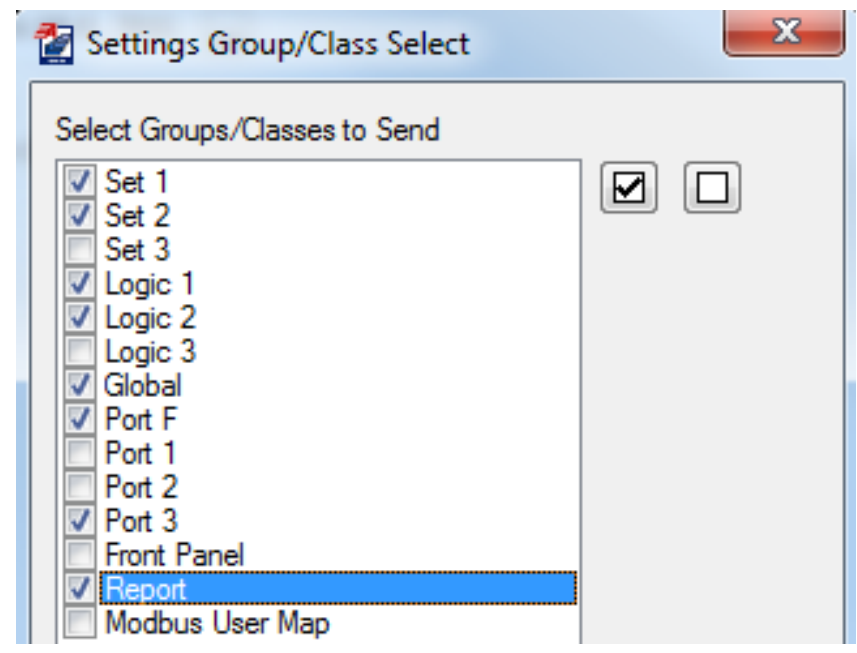

Figure 116: Send Modified Settings to the SEL-710 
22. Connect the three-phase circuit illustrated in Figure 94. Try to lay out the elements in the order illustrated in the schematic so that power flows across the bench from one end to the other. This linear arrangement limits the number of wires crossing each other and makes the path of the current flow easier to review (and troubleshoot). Start with the sequential connection points in Table 49, using the diagrams posted on the wattmeter at the lab bench for assistance. Then add the following connections:

a. Connect SEL-710 back-panel ports E01, E02, and E03 to the red Circuit Breaker phase A, B, and C terminals (respectively) on the circuit breaker.

b. Connect SEL-710 back-panel port E05 to the green circuit breaker chassis ground terminal.

c. Connect the green chassis ground terminals of the induction motor and circuit breaker together.

d. Connect SEL-710 back-panel port Z08 to the induction motor green chassis ground terminal.

e. Connect SEL-710 back-panel port Z07 to the green lab bench ground terminal.

f. Connect SEL-710 back-panel port A07 to the top Breaker Control Trip terminal on the circuit breaker. Connect the back-panel port $\mathbf{A 0 8}$ to the bottom Breaker Control Trip terminal on the circuit breaker. These terminals correspond to the signal OUT102 in the SEL-710.

g. Connect the positive (upper) Breaker Control $125 \mathrm{VDC}$ terminal to input terminal $\mathrm{G}$ on the lab bench. Connect the negative (lower) Breaker Control $125 \mathrm{~V}_{\mathrm{DC}}$ terminal on both circuit breakers to terminal $\mathrm{H}$. 
Table 49: Per-Phase Sequential Points of Connection

\begin{tabular}{|c|c|c|}
\hline Phase A & Phase B & Phase C \\
\hline Input Voltage & Input Voltage & Input Voltage \\
\hline $25 \Omega$ Resistor Input & $25 \Omega$ Resistor Input & $25 \Omega$ Resistor Input \\
\hline $25 \Omega$ Resistor Output & $25 \Omega$ Resistor Output & $25 \Omega$ Resistor Output \\
\hline $\begin{array}{c}\text { Bench Variac Phase A } \\
\text { Input }\end{array}$ & $\begin{array}{c}\text { Bench Variac Phase B } \\
\text { Input }\end{array}$ & $\begin{array}{c}\text { Bench Variac Phase C } \\
\text { Input }\end{array}$ \\
\hline $\begin{array}{c}\text { Bench Variac Phase A } \\
\text { Output }\end{array}$ & $\begin{array}{c}\text { Bench Variac Phase B } \\
\text { Output }\end{array}$ & $\begin{array}{c}\text { Bench Variac Phase C } \\
\text { Output }\end{array}$ \\
\hline Wattmeter & Wattmeter & Wattmeter \\
\hline $\begin{array}{l}\text { Relay Port Z01 } \\
\text { (Relay Input) }\end{array}$ & $\begin{array}{c}\text { Relay Port Z03 } \\
\text { (Relay Input) }\end{array}$ & $\begin{array}{l}\text { Relay Port Z05 } \\
\text { (Relay Input) }\end{array}$ \\
\hline $\begin{array}{l}\text { Relay Port Z02 } \\
\text { (Relay Output) }\end{array}$ & $\begin{array}{l}\text { Relay Port Z04 } \\
\text { (Relay Output) }\end{array}$ & $\begin{array}{l}\text { Relay Port Z06 } \\
\text { (Relay Output) }\end{array}$ \\
\hline $\begin{array}{c}\text { Circuit Breaker Red } \\
\text { Terminal } \\
\end{array}$ & $\begin{array}{c}\text { Circuit Breaker Red } \\
\text { Terminal } \\
\end{array}$ & $\begin{array}{c}\text { Circuit Breaker Red } \\
\text { Terminal } \\
\end{array}$ \\
\hline $\begin{array}{c}\text { Circuit Breaker Black } \\
\text { Terminal }\end{array}$ & $\begin{array}{c}\text { Circuit Breaker Black } \\
\text { Terminal }\end{array}$ & $\begin{array}{c}\text { Circuit Breaker Black } \\
\text { Terminal }\end{array}$ \\
\hline $\begin{array}{c}\text { Induction Motor Stator } \\
\text { Terminal, Phase A }\end{array}$ & $\begin{array}{c}\text { Induction Motor Stator } \\
\text { Terminal, Phase B }\end{array}$ & $\begin{array}{c}\text { Induction Motor Stator } \\
\text { Terminal, Phase C }\end{array}$ \\
\hline
\end{tabular}

23. Set the induction motor Magtrol Torque Adjust switch to the OFF position.

24. Verify the circuit connections and obtain instructor approval to apply power to the circuit.

25. Set the variac to provide the induction motor with its rated voltage.

a. Rotate the variac control dial to its fully-counter-clockwise position. This action sets the autotransformer tap to its lowest available output voltage.

b. Apply both $240 \mathrm{~V}_{\mathrm{AC}}$ and $125 \mathrm{VDC}$ (if needed for the circuit breaker) power from the bench.

c. Rotate the variac control dial clockwise until the wattmeter displays 208 V.

d. Press the TARGET RESET button on the front panel of the SEL-710 to clear any previous undervoltage conditions.

e. Close the circuit breaker (with the Manual Breaker Control Close button). Confirm that the three-phase power displayed on the wattmeter is approximately $1.5 \mathrm{~A}$. If the displayed current exceeds $2 \mathrm{~A}$, turn off the bench power and check the circuit wiring for errors. 
f. The induction motor should now be running; if so, proceed to the next step. If the SEL-710 immediately trips for an undervoltage condition, increase the value of the Undervoltage Trip Delay (27P1D) setting. This delay keeps the relay from tripping in response to the extra voltage drop across the current-limiting resistors due to the temporary motor inrush current. If this potential solution fails, decrease the Undervoltage Trip Level (27P1P) setting.

g. Rotate the variac control dial clockwise until the line-to-line voltage displayed on the wattmeter (for the induction motor terminals) again reads $208 \mathrm{~V}$. This action compensates for the voltage drop across the currentlimiting resistors due to the current drawn by the induction motor.

26. Create a line-to-line fault at the induction motor.

a. Turn off $\mathrm{AC}$ and DC power from the bench.

b. Jumper the black Circuit Breaker terminals to the red Fault Connections terminals (if present) on the circuit breaker. Jumper two of the black Fault Connections terminals together (line-to-line fault configuration).

c. Set the circuit breaker Fault Switch to the Normal position.

a. Turn on AC and DC bench power. Press the TARGET RESET button on the front panel of the SEL-710 to clear any previous undervoltage conditions.

d. Manually close the circuit breaker.

e. Flip the circuit breaker Fault Switch to the Fault position.

f. Watch the wattmeter to confirm that the SEL-710 trips the circuit breaker to clear the fault. If it does not, turn off AC bench power before sustained fault current damages circuit components.

g. Once the relay clears the fault, turn off AC and DC bench power and flip the Fault Switch to the Normal position. Press the TARGET RESET button on the SEL-710 to clear the relay's front-panel LED display.

h. Retrieve the event file from the SEL-710 (Step 21).

i. Add the 50P1P and 50P1T digital signals to the oscillogram plot.

27. Retrieve the SEL-710 event file for the fault trip.

a. In QuickSet, select Tools, Event Files, Get Event Files.

b. In the window that comes up, select Refresh Event History.

c. Choose an Event Type of 16 Samples / Cycle - Raw and an Event Length of 15 cycles.

d. Check the boxes of the event file(s) corresponding to the fault. Event files are indexed, with ' 1 ' being the most recent event file saved by the relay.

e. Click Get Selected Events. Save the events in a convenient location using either a default or custom naming convention.

f. Double-click on the event report file in its file path location. The AcSELerator Analytic Assistant software automatically opens an oscillogram plot of the event.

g. Click the Pref button in the lower-right corner of the oscillogram to add digital fault-trip signals to the plot. Left-click on the signal you wish to 
display (from the available list in the lower-left corner of the screen), then right-click-drag the signal to the Digital Axis list of signals to be displayed. Click $\underline{\mathrm{Ok}}$.

h. After saving the desired event files, enter the HIS C command in the QuickSet Terminal window (select Communications, Terminal) to clear previous event files from the relay's memory. If an error message appears about an invalid access level, type in $\mathbf{A C C}$, the Enter key, the level relay 1 password (default for SEL-710 is "OTTER"), and the Enter key. Proceed to clear the event files.

28. Create a three-phase fault (not grounded) at the induction motor.

a. Turn off AC and DC power from the bench.

b. Jumper the black Circuit Breaker terminals to the red Fault Connections terminals (if present) on the circuit breaker. Jumper together the black Fault Connections terminals (three-phase fault configuration).

c. Set the circuit breaker Fault Switch to the Normal position.

d. Turn on AC and DC bench power. Press the TARGET RESET button on the front panel of the SEL-710 to clear any previous undervoltage conditions.

e. Manually close the circuit breaker.

f. Flip the circuit breaker Fault Switch to the Fault position.

g. Watch the wattmeter to confirm that the SEL-710 trips the circuit breaker to clear the fault. If it does not, turn off $\mathrm{AC}$ bench power before sustained fault current damages circuit components.

h. Once the relay clears the fault, turn off AC and DC bench power and flip the Fault Switch to the Normal position. Press the TARGET RESET button on the SEL-710 to clear the relay's front-panel LED display.

i. Retrieve the event file from the SEL-710 (Step 21).

j. Add the 50P1P and 50P1T digital signals to the oscillogram plot.

29. Create an undervoltage condition at the terminals of the induction motor.

a. Turn on AC and DC bench power. Press the TARGET RESET button on the front panel of the SEL-710 to clear any previous undervoltage conditions.

b. Manually close the circuit breaker.

c. Rotate the variac control dial counter-clockwise to decrease the input voltage to the induction motor, while watching the motor's terminal voltage displayed on the voltmeter. Momentarily stop once the wattmeter reads $185 \mathrm{~V}$. Proceed to slowly rotate the variac dial until the SEL-710 trips the circuit breaker. Record the approximate voltage at which trip occurred.

d. Retrieve the event file from the SEL-710 (Step 21).

e. Add the 27P1 and 27P1T digital signals to the oscillogram plot. 


\section{Postlab Questions}

- Using your prelab calculations, justify the Phase and Negative-Sequence Overcurrent Trip Pickup settings used in this experiment.

- Explain why, for a three-phase fault, the SEL-710 trips on the phase overcurrent element before the undervoltage element. Hint: compare the chosen Phase Overcurrent Trip Delay (50P1D) and Undervoltage Trip Delay (27P1D) settings.

- Compare the line-to-line voltage measured at the terminals of the induction motor when the circuit breaker opened to the chosen Undervoltage Trip Level setting. Justify any difference between the two values. Hint: consider the Undervoltage Trip Delay (27P1D) setting.

\section{$\underline{\text { Deliverables }}$}

Answer the postlab questions. Turn in oscillograms for the fault events described in the procedure. The bottom of each oscillogram should show the digital signal associated with the type of protection triggered by the fault. Give each plot a caption specifying the relay name, fault type and location, and type of protection triggered.

Save the relay settings for use in future experiments. 


\title{
Appendix K: SEL-311L Overcurrent Protection Procedure
}

EE 518

\author{
ELECTRICAL ENGINEERING DEPARTMENT \\ California Polytechnic State University \\ San Luis Obispo
}

Transmission Line Overcurrent Protection Using the SEL-311L

\section{Learning Outcomes}

- Identify, record, and eliminate bolted faults at the end of a simulated transmission line using inverse-time overcurrent protection

- Analyze fault conditions from relay-generated event reports

\section{Background}

Relay coordination is a key component of power system protection because it ensures that vulnerable devices have more than one source of protection. That way, if the primary relay fails to operate during fault conditions, a backup relay can still protect the circuit. Backup relays are typically located further upstream in a circuit, away from the primary relay. This increase in distance away from the fault location means that larger sections of the circuit will be taken off-line when the backup relay trips. Backup relays are designed with delay mechanisms in their protection schemes, allowing the primary relay a chance to operate first. This coordination is desirable because operating a relay in its primary zone of protection minimizes the area affected by a fault.

Several options exist for delaying a relay from tripping. In definite-time overcurrent (ANSI prefix “50"), the relay waits a constant amount of time between when it detects a fault and trips a circuit breaker. The relay resets if the fault conditions disappear before the time delay elapses. For example, a definite-time overcurrent relay element of 50Q will trip after measuring continuous negative-sequence currents (symbolized by the letter 'Q') for a specified amount of time.

Inverse-time overcurrent (ANSI prefix "51") offers a more dynamic response to fault conditions. The amount of delay before the relay operates in response to a fault depends on the fault current magnitude. High currents receive a shorter delay, while lower fault currents are assigned a longer delay. This inverse relationship allows an overcurrent relay to respond faster to more dangerous fault conditions. As with definite-time overcurrent, the relay refrains from tripping if the fault disappears before the delay time elapses. As an example, an inverse-time overcurrent relay element of 51P will trip after the relay measures continuous phase currents (symbolized by the letter ' $P$ ') for an amount of time determined by the magnitude of the fault current. Inverse-time overcurrent curves illustrate the relationship between the relay response delay and fault current magnitude (in terms of multiples of a specified baseline amount called the "pickup current"). 


\section{Prelab}

Assume a fixed transmission line reactance for all symmetrical component sequences.

a) Calculate the negative-sequence currents (in Amps) produced by bolted line-toline and single-line-to-ground faults at the circuit breaker in Figure 117.

b) Assuming a negative-sequence pickup current of $0.5 \mathrm{~A}$ and a time-dial setting of 0.50 , use the following equation to calculate the expected relay operate time in response to these line-to-line and single-line-to-ground faults:

$$
t_{p}=T D \cdot\left[0.0226+\frac{0.0104}{M^{0.02}-1}\right]
$$

In this equation, $t_{p}$ represents the relay operate time, $T D$ represents the relay timedial setting, and $M$ represents the multiples of negative-sequence pickup current detected by the relay. This equation represents the family of curves in a U. S. moderately inverse coordination plot and appears in the SEL-311L instruction manual.

c) Estimate the per-phase current (in Amps) of a triple-line-to-ground fault at the same location. Neglect the relatively small reactance of the transformer. Hint: Apply Ohm's law.

d) Assuming a phase pickup current of $4.50 \mathrm{~A}$ and a time-dial setting of 0.50 , use the above equation to calculate the expected relay operate time in response to this triple-line-to-ground fault. Note that $M$ now represents the multiples of phase pickup current detected by the relay.

\section{Equipment}

- $25 \Omega$ Single-Phase Power Resistor (3x)

- $45 \mathrm{mH}$ Single-Phase Inductor (3x)

- Bag of Banana-Banana Short Leads (2x) *

- Banana-Banana or Banana-Spade Leads (36x)

- Circuit Breakers (2x)

- Computer with AcSELerator QuickSet Software

- Hampden Resistive Load (1x)

- SEL-311L Differential and Overcurrent Relay

- SEL-C234A Serial Cable

* Beware of extra flexible "small gauge" short leads, which can melt under fault current conditions.

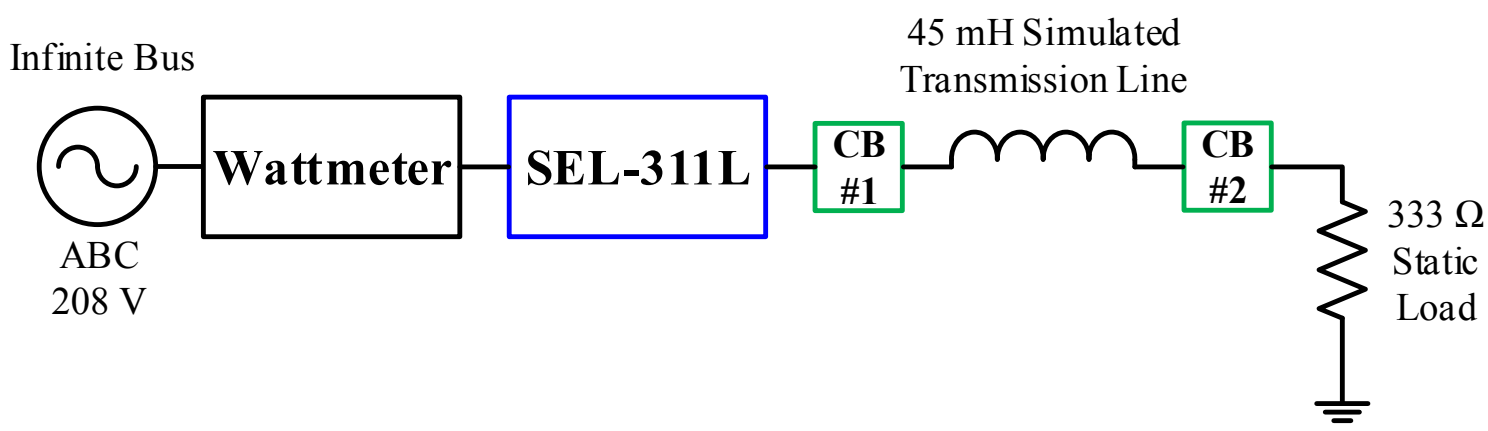

Figure 117: SEL-311L Overcurrent Procedure Single-Line Diagram 


\section{Procedure}

1. Plug in the power cord connected to the SEL-311L relay.

2. Connect an SEL-C234A serial cable between Port 2 on the back of the 311L and the main serial port on the back of the computer (surrounded by a light turquoise color).

3. On the computer, open the AcSELerator QuickSet software.

4. Determine the current baud rate for the rear-panel Serial Port on the 311L.

a. On the front panel of the relay, press the button labeled Set.

b. Use the right-arrow button to navigate to Port on the front panel display. Press the button for Select.

c. Navigate to Port 2 and press the button for Select.

d. Navigate to Show and press the button for Select.

e. Use the down-arrow button to navigate through the current Serial Port settings. The baud rate (SPEED) is near the top of the list. If the baud rate is already set to 19200 , press the Exit button twice to restore the screen to its normal display, and continue to the next step.

f. If the current relay baud rate is not set to 19200, use the following steps to change the baud rate.

g. Return to the relay's main front-panel screen by pressing Exit twice. Then press the Set button and select Port. Now select Set.

h. Use the up-arrow and right-arrow buttons to enter the relay's level 2 password (default is TAIL). Press Select.

i. Use the down-arrow button to navigate to the SPEED setting and press Select.

j. Press the up/down-arrow buttons until 19200 (not 19.2) appears. Press Select.

k. Press Exit and select Yes to save the new port setting.

5. On the QuickSet main window (Figure 118), open the Communication Parameters window (Communications, Parameters) (Figure 119) to define and create a communication link with the 311L. Enter the following information for a Serial Active Connection Type:

a. Device: COM1: Communications Port

b. SEL Bluetooth Device: Unchecked

c. Data Speed: $\underline{19200}$

d. Data Bits: 8

e. Stop Bits: 1

f. Parity: None

g. RTS/CTS: Off

h. DTR: On

i. XON/XOFF: On

j. RTS: N/A (On)

k. Level 1 Password (Default OTTER) 


\section{Level 2 Password (Default TAIL)}

AcSELerator ${ }^{\circledR}$ QuickSet - [Getting Started with QuickSet] File Edit View Communications Tools Windows Help Language

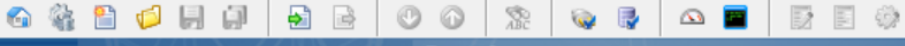

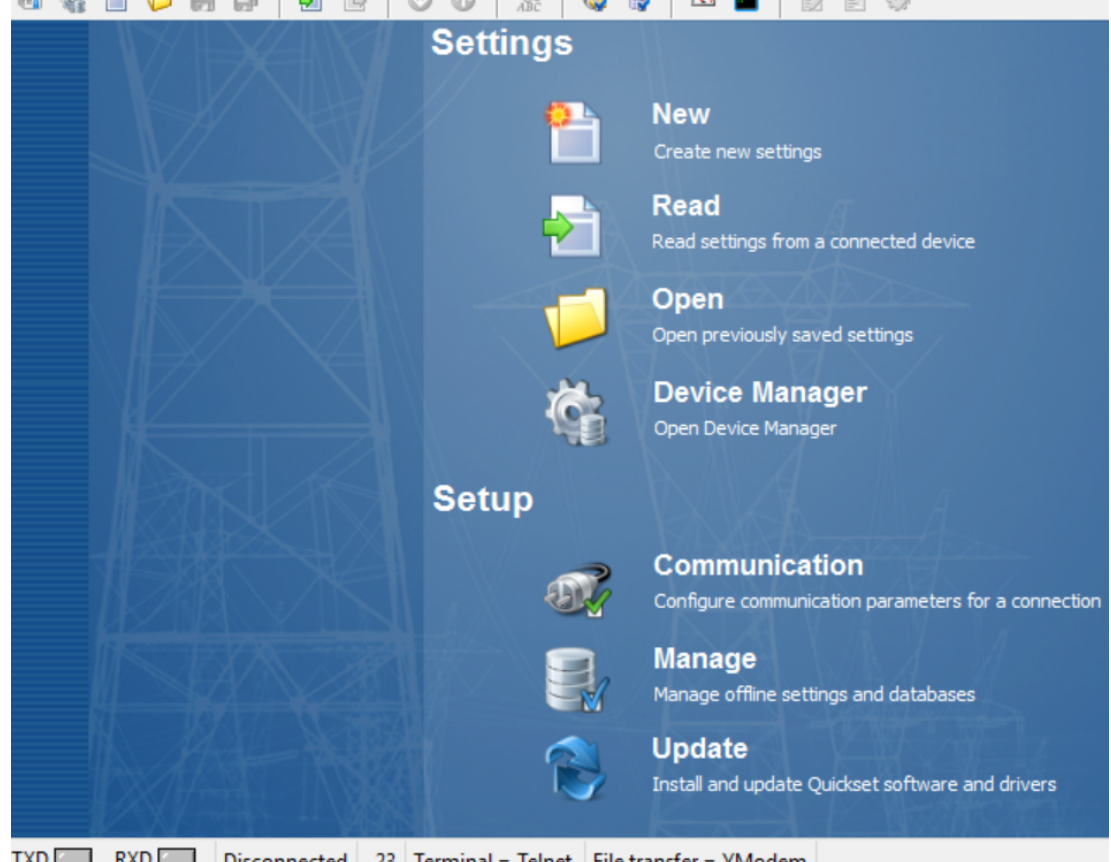

TXD $\square$ RXD $\square$ Disconnected 23 Terminal $=$ Telnet File transfer $=$ YModem

Figure 118: QuickSet Main Window 


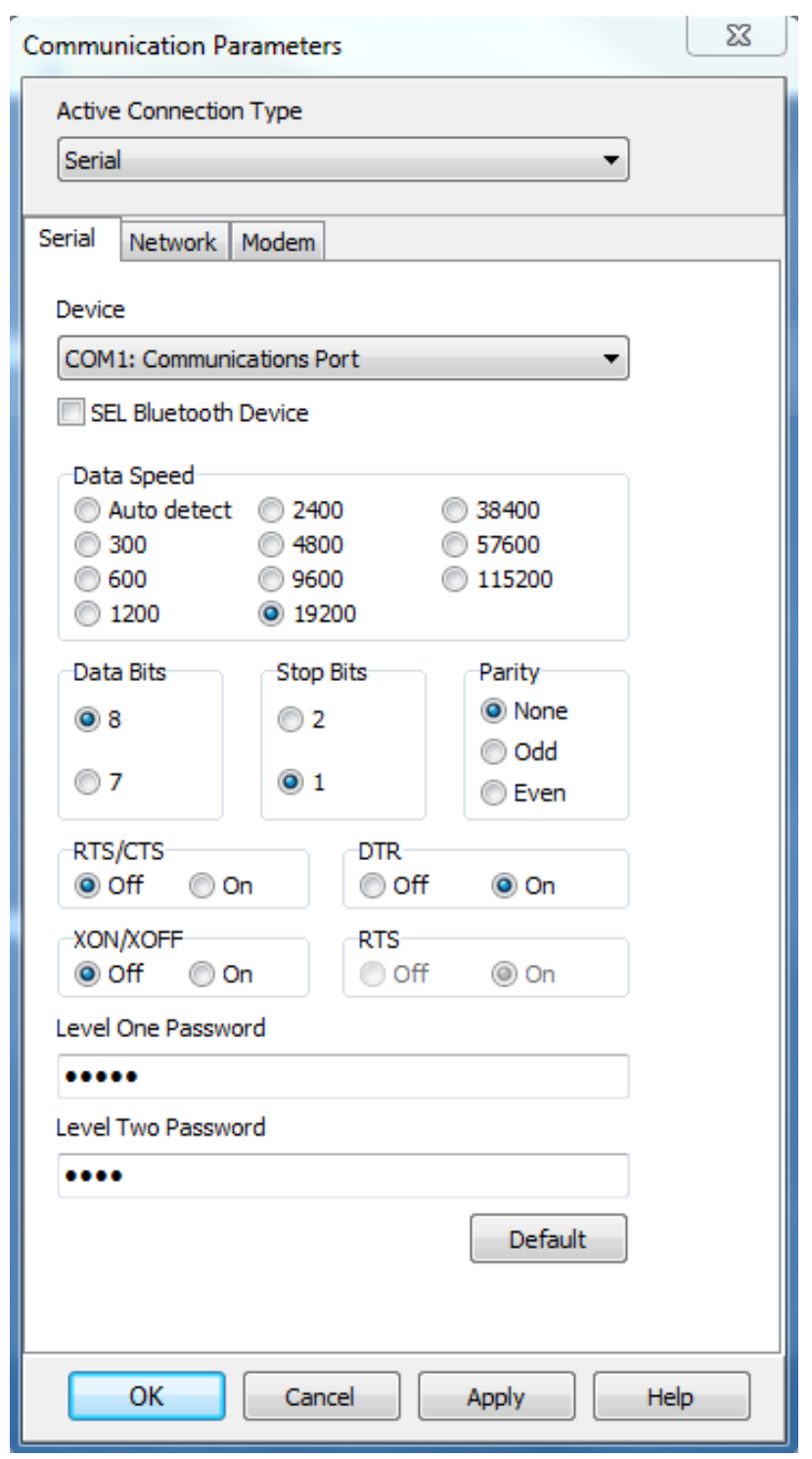

Figure 119: SEL-311L Communication Parameters Window

6. Click Apply at the bottom of the Communication Parameters window. Then click Ok. If the computer successfully connects to the relay, the connection status in the lower-left corner of the QuickSet main window should say "Connected."

7. Create a new settings file for the SEL-311L relay.

a. In the QuickSet main window, create a new settings file for the SEL-311L relay (File, New).

b. Choose the Device Family (SEL-311L), Model (SEL-311L-7), and Version for this specific relay unit from the available menus, then click Ok (Figure 120). Look up the relay's version number using the front-panel menu on the relay. Press the Status button and use the right-arrow button to navigate across the relay's FID string until you come to the " $\mathrm{Z}$ number." The first three digits following the ' $Z$ ' comprise the relay version number. Press the Exit button to restore the front-panel screen to 
its normal display. Do not change the current settings group on the relay. Note: if no devices are listed in the QuickSet drop-down menus, then the device drivers need to be installed using the SEL Compass software. Ask for assistance.

c. Enter the relay Part Number (Figure 121) printed on the serial number label (P/N, Figure 122) attached somewhere on the relay chassis. Note that the 5 A Secondary Input Current reflects the American convention for current transformers.

Settings Editor Selection - Settings Database
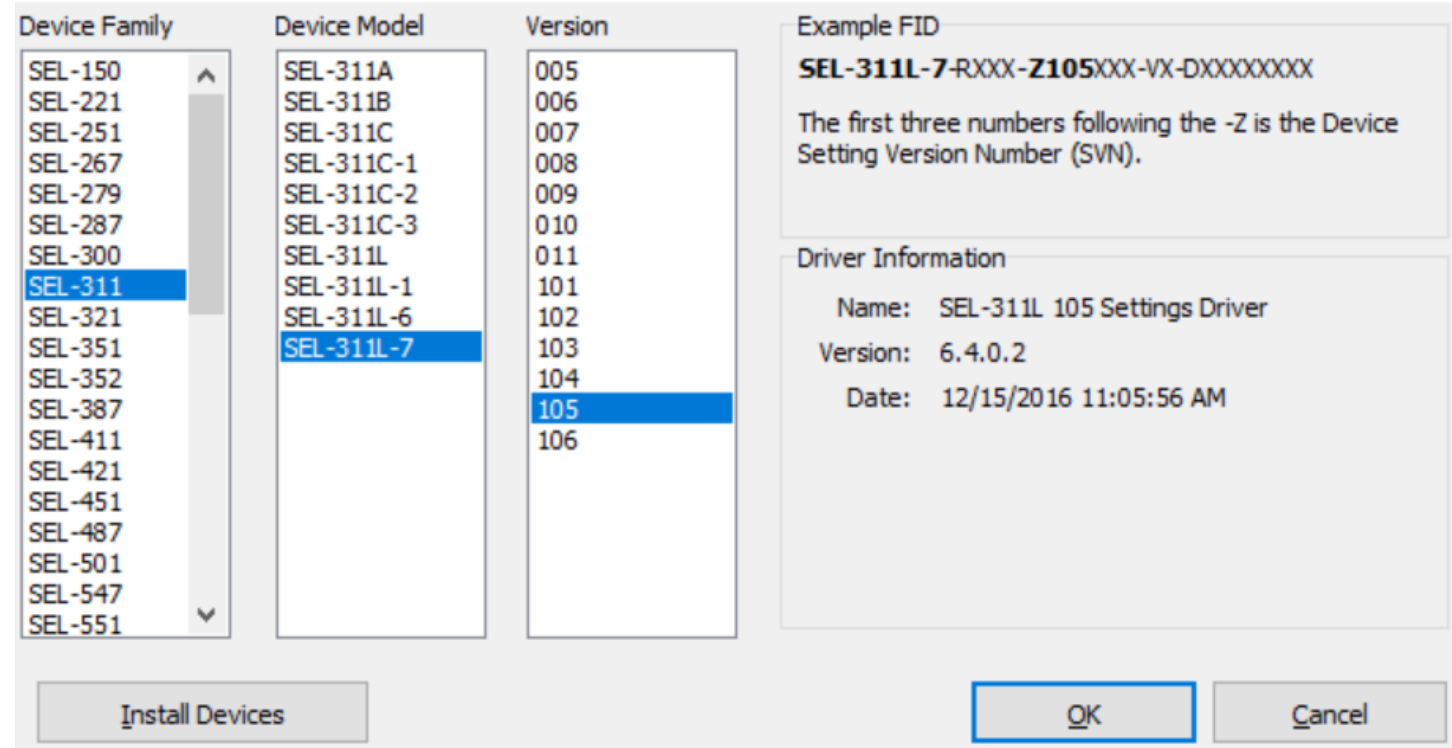

Figure 120: Identifying SEL-311L Relay Family, Model, and Version

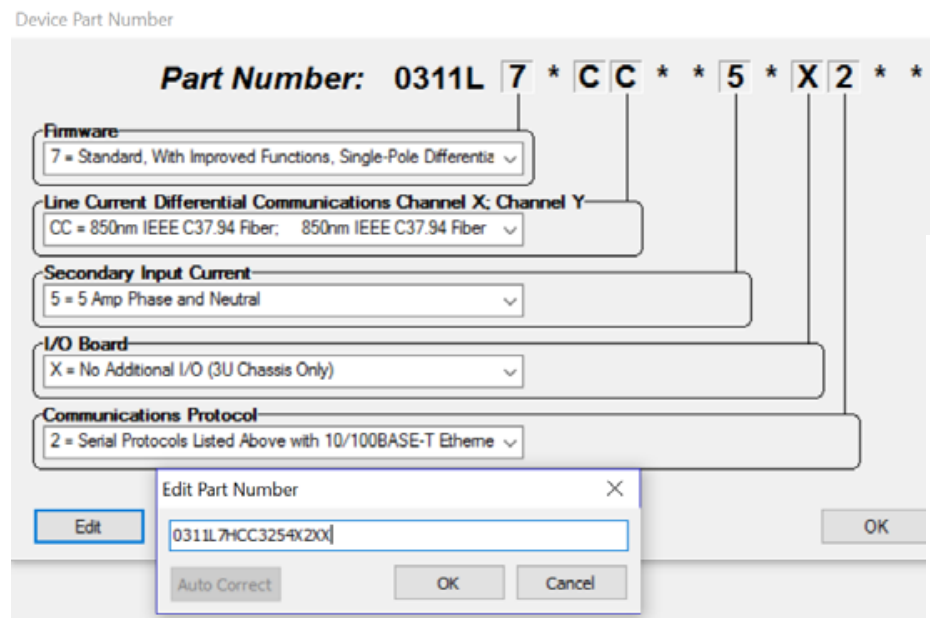

Figure 121: Identifying SEL-311L Relay Part Number

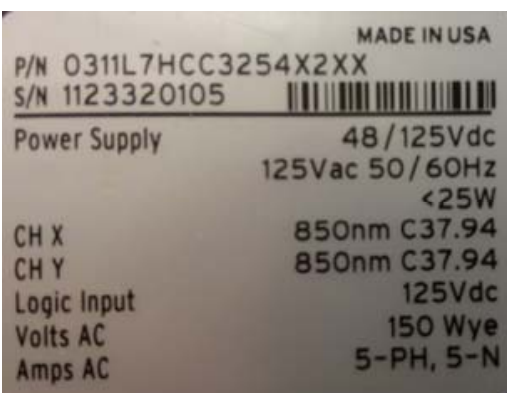

Figure 122: Example SEL311L Label with Relay Part Number 
8. Save this new relay settings database file (File, Save As and New) in a location where it may be reused in future experiments. Then create a Settings Name for this settings file. See Figure 123 and Figure 124.

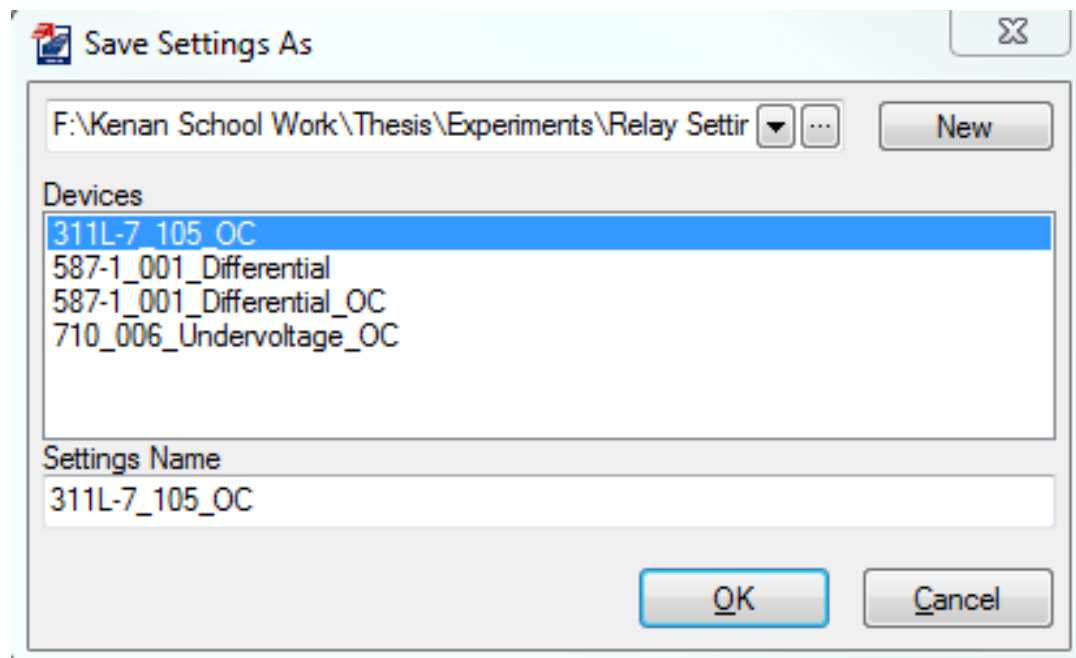

Figure 123: Saving SEL-311L Settings

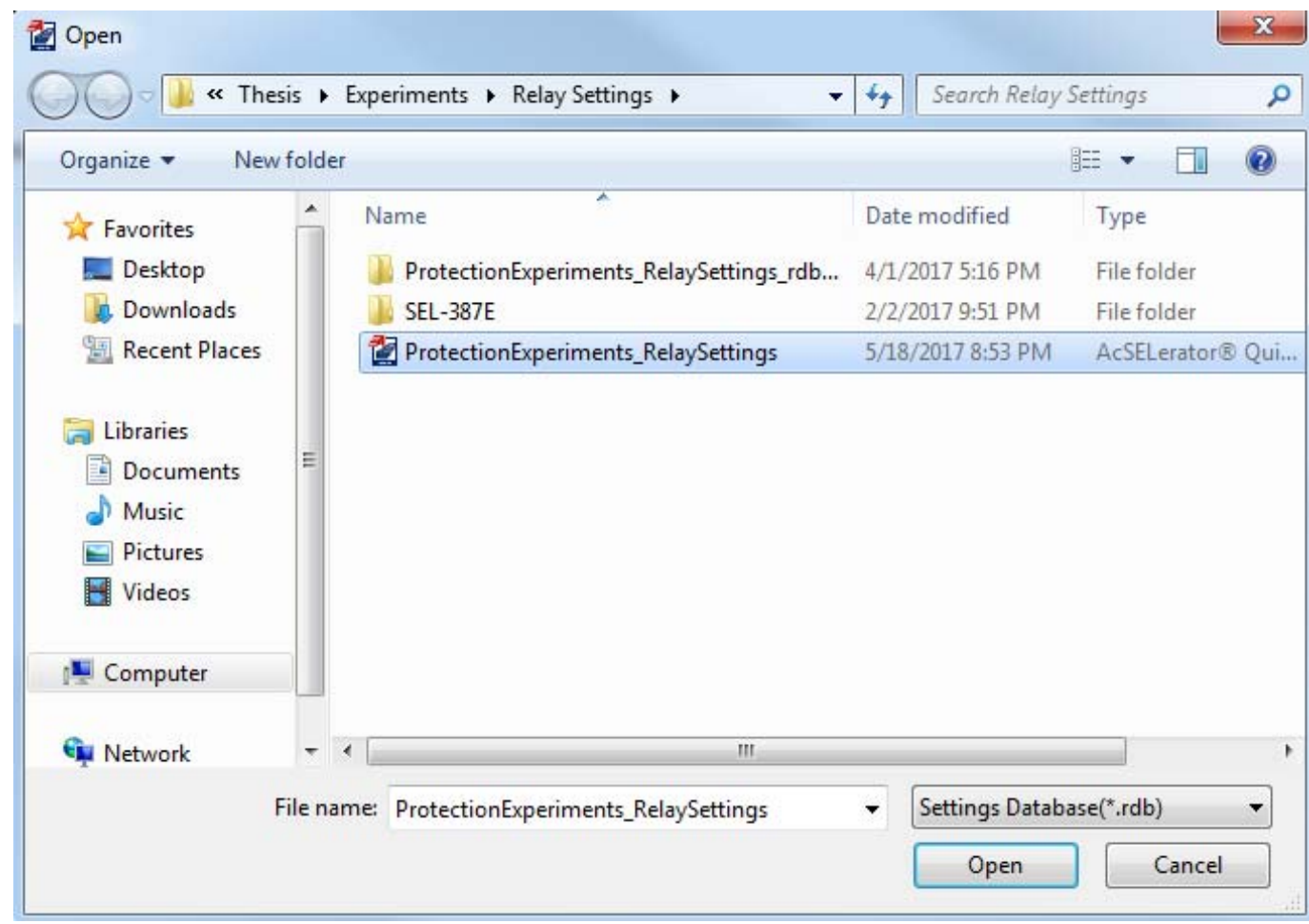

Figure 124: Choosing Location for New SEL-311L Relay Settings Database

9. Open the Group 1, Set 1, General Settings from the drop-down menu on the left side of the settings editor window (Figure 125).

a. Enter a Relay Identifier (RID) of SEL-311L to name the relay. 
b. Enter a Terminal Identifier (TID) of BENCH \# (RADIAL) (insert the number of your lab bench in place of '\#') to describe the relay's location.

c. Enter a Local Phase Current Transformer Turns Ratio (CTR) of 1 . Due to the relatively low currents associated with this experiment, actual current transformers are not necessary to step down the line currents in the system. They are therefore not used in the circuit and are modeled here in the settings with 1:1 CTs.

d. Select $\underline{Y}$ for the Advanced Settings Enable setting (EADVS). This selection allows you (rather than the relay) to set certain overcurrent elements.

\section{General Settings}

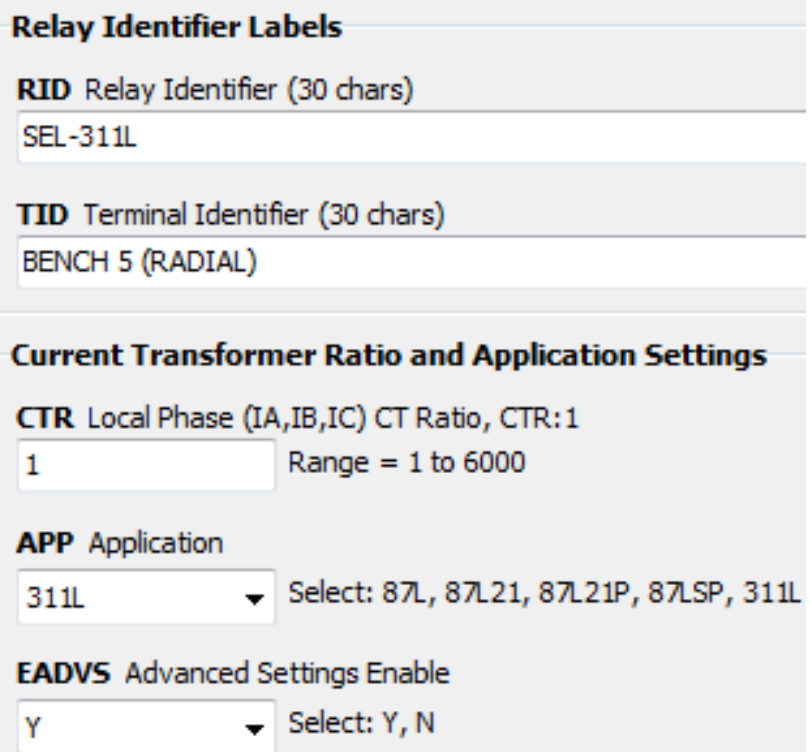

Figure 125: SEL-311L General Settings

10. Open the Group 1, Set 1, Backup Protection and Line Parameters settings (Figure 126).

a. Enter a Phase Potential Transformer Turns Ratio setting (PTR) of 1 . This procedure does not use potential (voltage) transformers because the system voltages are relatively low. The direct connections between the SEL-311L voltage-sense input ports and the system are therefore modeled as $1: 1$ voltage transformers.

b. Leave all other settings in this tab as their default values. 


\title{
Backup Protection and Line Parameters
}

\author{
Backup Protection Transformer Ratio Settings \\ CTRP Polarizing (IPOL) CT Ratio, CTRP: 1 \\ 200 Range $=1$ to 6000 \\ PTR Phase (VA,VB,VC) PT Ratio, PTR: 1 \\ 1.00 Range $=1.00$ to 10000.00
}

Figure 126: SEL-311L Backup Protection and Line Parameters Settings

11. Open the Group 1, Set 1, Phase Time-Overcurrent settings (Figure 127).

a. Select $\underline{Y}$ for the Enable Phase Time-Overcurrent Elements setting (E51P).

b. Enter a Phase Time-Overcurrent Pickup setting (51PP) of $4.50 \mathrm{~A}$.

c. Select $\underline{\mathrm{U} 1}$ as the Phase Time-Overcurrent Curve setting (51PC). Curve U1 corresponds to the American moderately-inverse coordination curve.

d. Enter a Phase Time-Overcurrent Time Dial setting (51PTD) of $\underline{0.50}$.

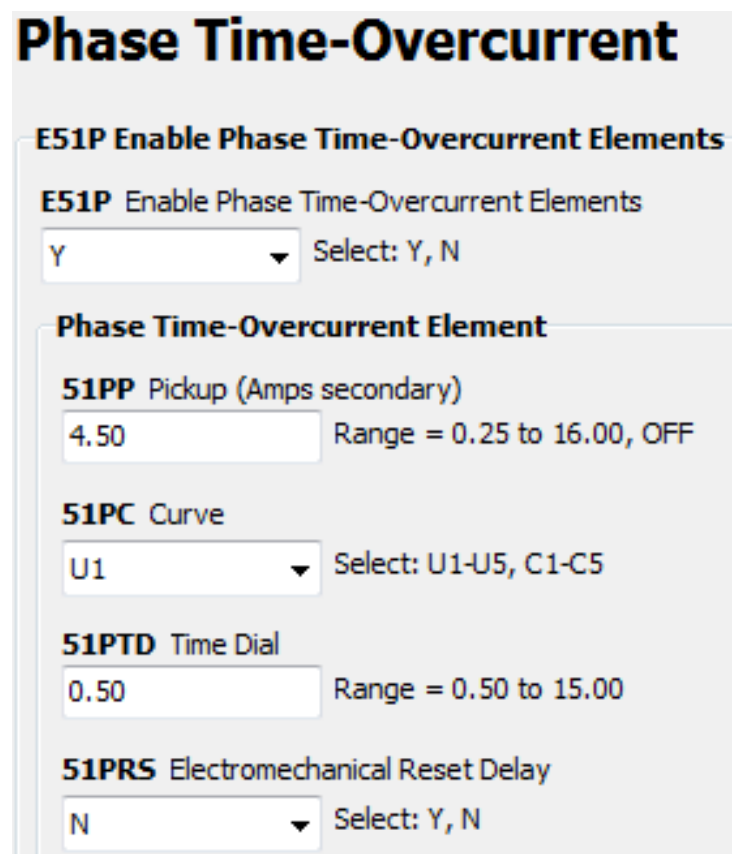

Figure 127: SEL-311L Inverse-Time Phase Overcurrent Settings

12. Open the Group 1, Set 1, Residual Ground Time-Overcurrent settings (Figure 128).

a. Enter a Residual Time-Overcurrent Pickup setting (51GP) of $\underline{0.25}$ A.

b. Select $\underline{\mathrm{U} 1}$ as the Residual Time-Overcurrent Curve setting (51GC).

c. Enter a Residual Time-Overcurrent Time Dial setting (51GTD) of $\underline{0.50}$.

d. Select $\underline{\mathrm{N}}$ to disable the Residual Ground Time-Overcurrent

Electromechanical Reset Delay setting (51GRS). The electromechanical reset delay setting causes the relay to slowly reset after tripping, mimicking the spinning disc on an electromechanical relay. 


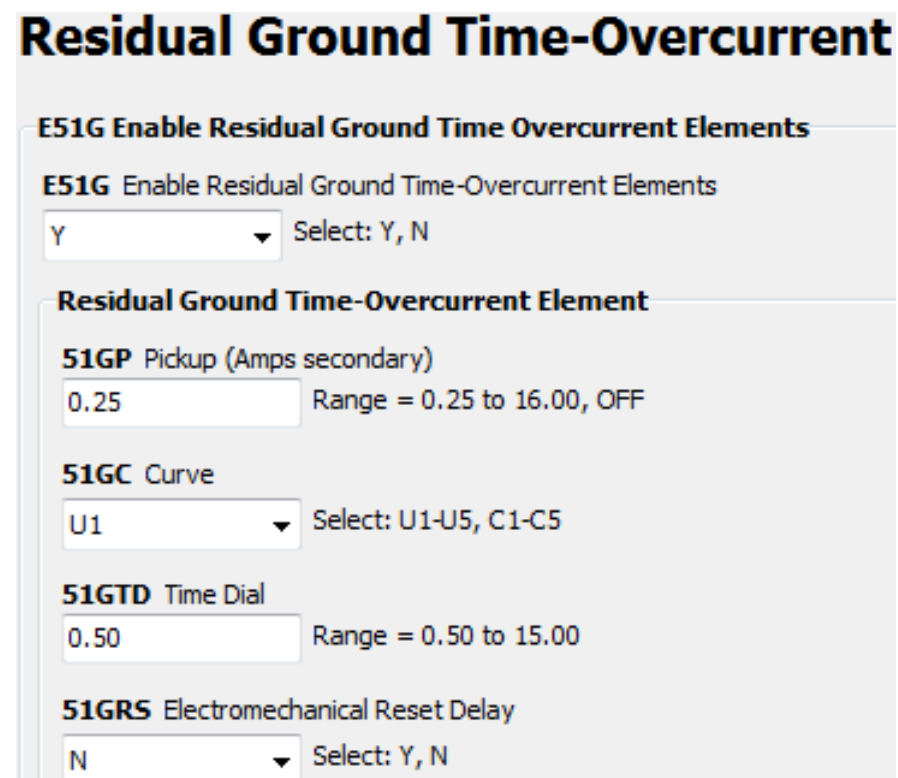

Figure 128: SEL-311L Inverse-Time Residual Overcurrent Settings

13. Open the Group 1, Set 1, Negative-Sequence Time-Overcurrent settings (Figure 129).

a. Enter a Negative-Sequence Time-Overcurrent Pickup setting (51QP) of $\underline{0.50} \mathrm{~A}$.

b. Select $\underline{\mathrm{U} 1}$ as the Negative-Sequence Time-Overcurrent Curve setting (51QC).

c. Enter a Negative-Sequence Time-Overcurrent Time Dial setting (51QTD) of $\underline{0.50}$.

\section{Negative-Sequence Time-Overcurrent}

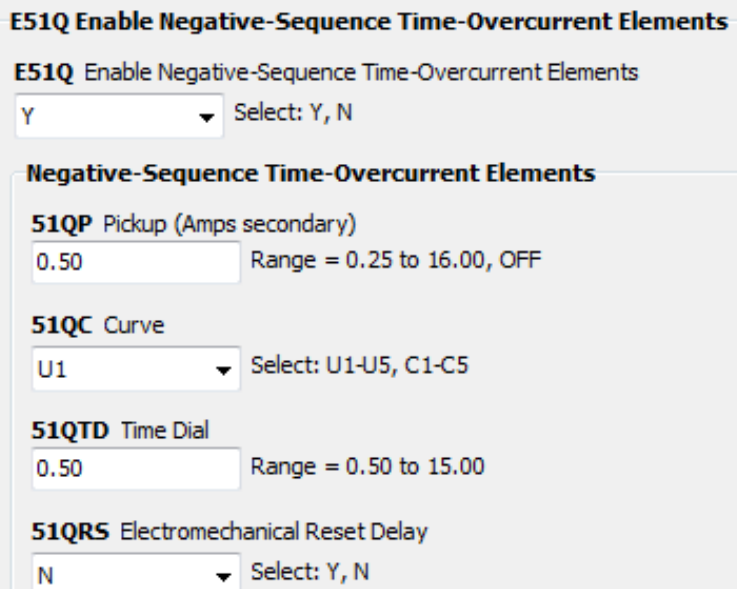

Figure 129: SEL-311L Inverse-Time Negative-Sequence Overcurrent Settings

14. Open the Group 1, Set 1, Logic 1, Trip/Comm.-Assisted Trip Logic settings (Figure 130). 
a. Replace the default contents of the Direct Trip Conditions equation (TR) with 51PT+51GT+51QT. This equation causes the SEL-311L to trip for the phase, residual, and negative-sequence inverse-time overcurrent elements.

b. Leave all other trip equations alone; they are unnecessary for this experiment.

\section{Trip/Comm.-Assisted Trip Logic

\begin{tabular}{l} 
Trip Logic Equations \\
TR Direct Trip Conditions \\
\hline $51 P T+51 G T+51 Q T$ \\
TRCOMM Communications-Assisted Trip Conditions \\
\hline M2P+Z2G \\
TRSOTF Switch-Onto-Fault Trip Conditions \\
\hline M2P +Z2G +50P1 \\
DTT Direct Transfer Trip Conditions \\
\hline 0 \\
\hline E3PT Three-Pole Trip Enable \\
\hline 0 \\
\hline ULTR Unlatch Trip Conditions \\
\hline !(50L+51G)
\end{tabular}

Figure 130: SEL-311L Trip Equations

15. Open the Group 1, Set 1, Logic 1, Output Contacts tab, and replace the default contents of the Output Contact 101 equation (OUT 101) to !TRIP (Figure 131). Logical inversion interfaces the normally-open switch on the SEL-311L with the circuit breaker trip coil.

\section{Output Contacts}

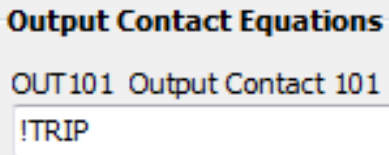

Figure 131: SEL-311L Output Contacts Equation

16. Open the Group 1, Set 1, Logic 1, Other Equations tab, and replace the default contents of the Event Report Trigger Conditions equation (ER) to $151 \mathrm{P}+/ 51 \mathrm{G}+/ 51 \mathrm{Q}$ (Figure 132). This equation creates an event report in response to the assertion (rising edge) of each overcurrent element, ensuring that an event report includes data for the beginning of a fault. 


\section{Other Equations}

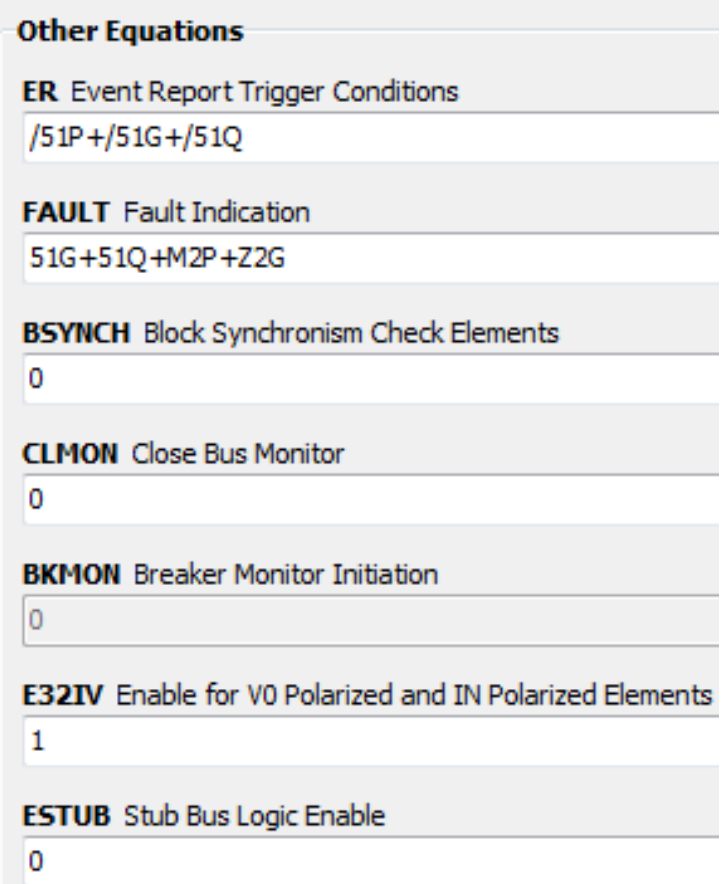

Figure 132: SEL-311L Event Report Trigger Conditions

17. Open the Global, General settings (Figure 133).

a. Change the Phase Rotation setting (PHROT) to ACB to reflect the negative-sequence phase rotation used by the local utility company.

b. Select $\underline{60}$ cycles as the Length of Event Report setting (LER) to ensure that the relay records and stores data through an entire fault. 


\section{General}

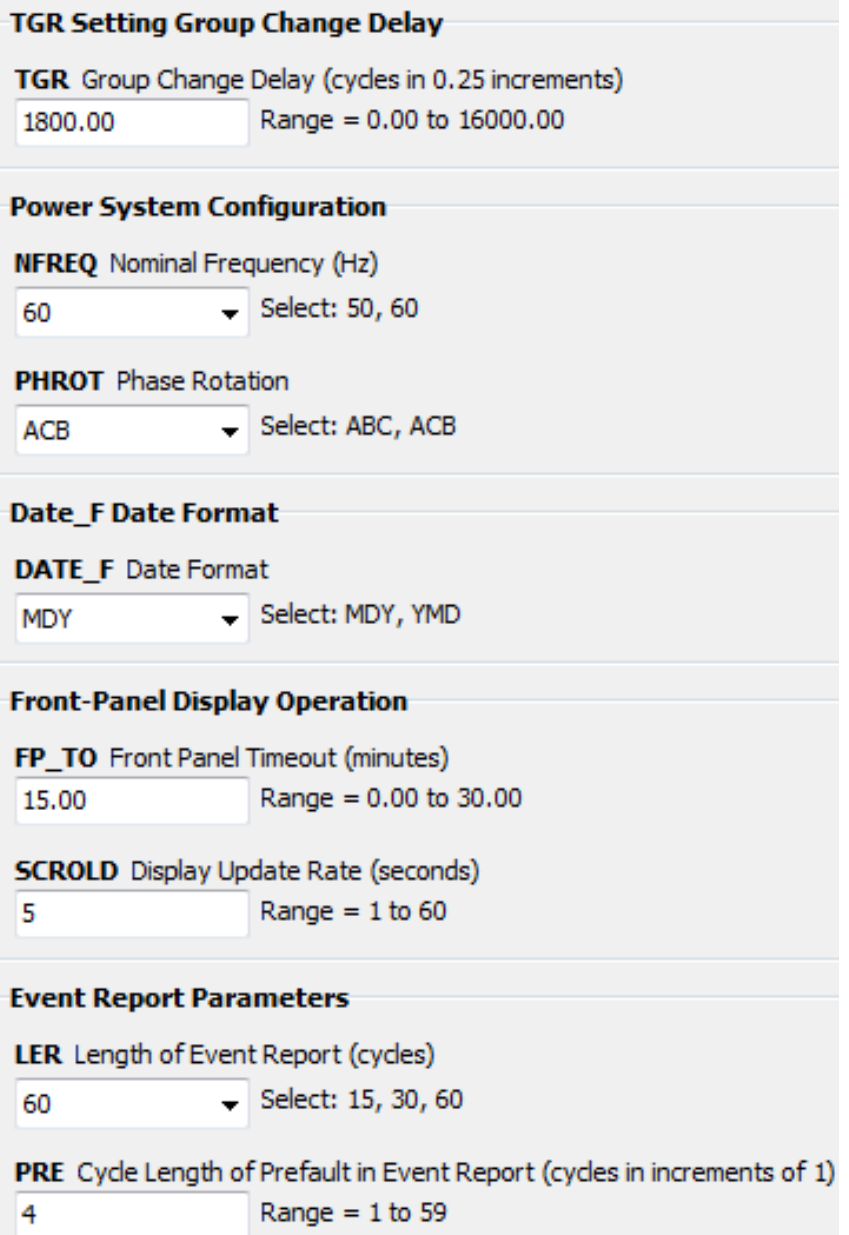

Figure 133: SEL-311L General Settings

18. Open the Sequential Events Recorder (SER) settings (Figure 134).

a. Replace the default contents of the first Sequential Events Recorder equation (SER1) with TRIP,51P,51PT,51G,51GT,51Q,51QT. This new equation generates event reports in response to the SEL-311L overcurrent elements.

b. Replace the default contents of SER2 and SER3 with NA. 


\section{SER}

SER1 Sequential Events Recorder 1, 24 elements max. (enter NA to null)

TRIP, 51P, 51PT, 51G, 51GT, 51Q, 51QT

SER2 Sequential Events Recorder 2, 24 elements max. (enter NA to null)

NA

SER3 Sequential Events Recorder 3, 24 elements max. (enter NA to null)

NA

Figure 134: SEL-311L Sequential Events Recorder Equations

19. Open the Port 2, Communications settings (Figure 135).

a. Change the Minutes to Port Time-Out setting (T_OUT) to $\underline{30}$ minutes.

b. Increase the Baud Rate setting (SPEED) to 19200 baud.

c. Select $\underline{Y}$ for the Send Auto Messages to Port setting (AUTO). This setting allows the relay to automatically send information to a device connected to its serial port 2 . 


\section{Communications}

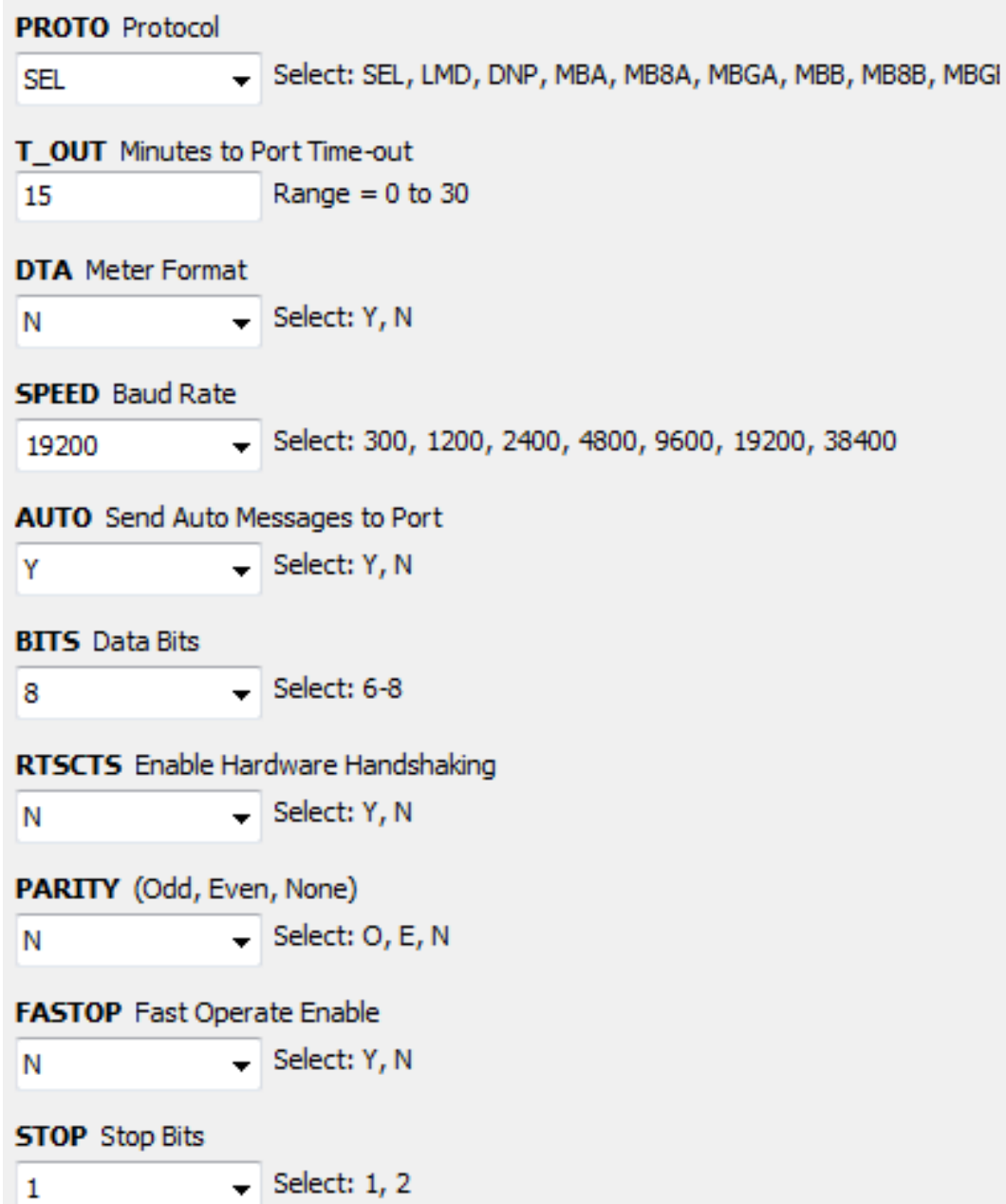

Figure 135: SEL-311L Port 2 Serial Communications Settings

20. Save your settings (File, Save).

21. Send your settings (File, Send...) to the SEL-311L. In the window that appears, check the boxes for the Device and Logic settings (Figure 136). Sending only the modified settings shortens the file transfer time. Since it can take several minutes to transfer the relay settings, now is a good time to start constructing the circuit. 


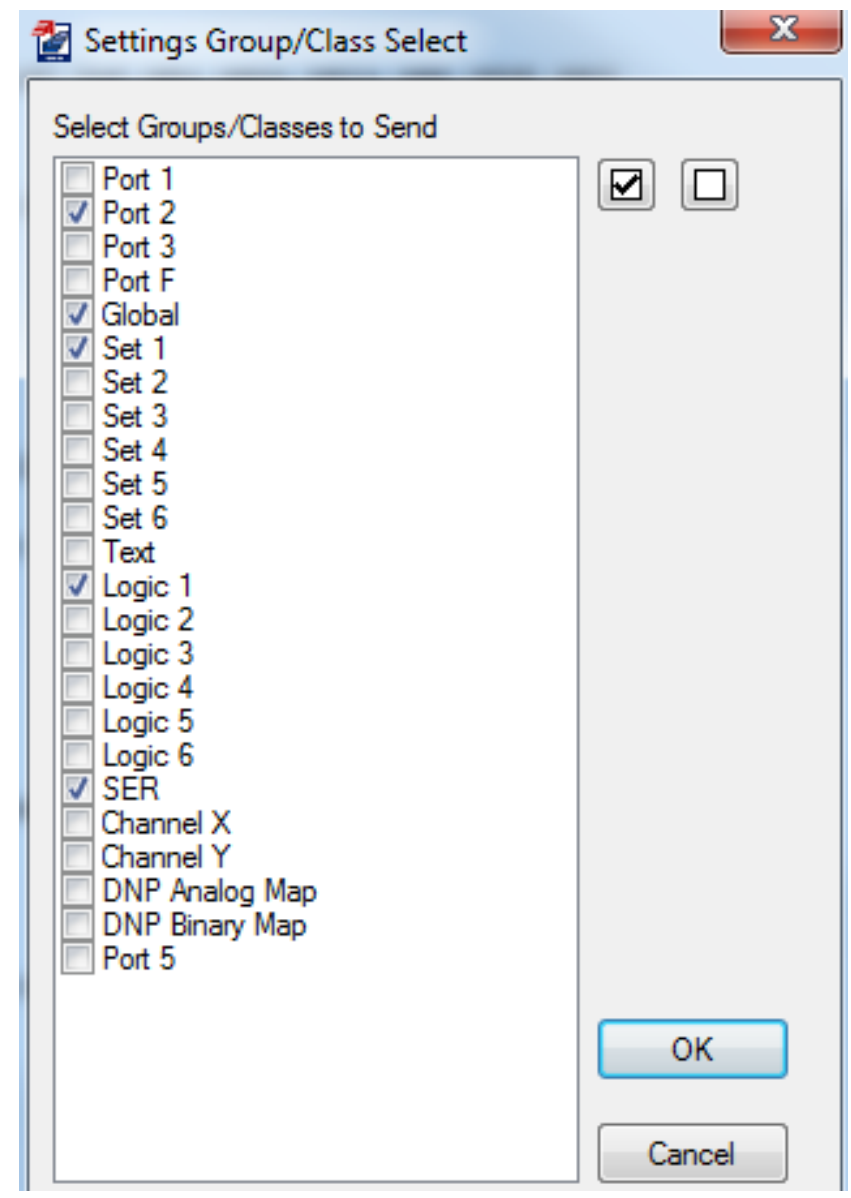

Figure 136: Send Modified Settings to SEL-311L

22. Connect the three-phase circuit illustrated in Figure 117. Try to lay out the elements in the order illustrated in the schematic so that power flows across the bench from one end to the other. This linear arrangement limits the number of wires crossing each other and makes the path of current flow easier to review (and troubleshoot). Start with the sequential connection points in Table 50, using the diagram posted on the wattmeter for assistance. Then add the following connections:

a. Connect ports A01 and A02 of the SEL-311L to the Breaker Control Trip terminals on circuit breaker \#1 (upstream of the inductors).

b. Connect port Z09 of the SEL-311L to the Circuit Breaker phase A terminal on circuit breaker \#1. Similarly, connect ports Z10 and Z11 to the phase $\mathrm{B}$ and $\mathrm{C}$ terminals, respectively.

c. Connect port $\mathbf{Z 1 2}$ to the green chassis ground terminal on circuit breaker \#1. Ports Z09, Z10, and Z11, and Z12 are the voltage inputs (phases A, B, $\mathrm{C}$, and neutral) to the SEL-311L.

d. Connect the positive (upper) Breaker Control 125 VDC terminal on both circuit breakers to input terminal $\mathrm{G}$ on the lab bench. Connect the negative (lower) Breaker Control $125 \mathrm{~V}_{\mathrm{DC}}$ terminal on both circuit breakers to terminal $\mathrm{H}$. 
e. Connect the green chassis ground terminals on the circuit breakers to the green bench ground terminal.

f. Jumper together the positive and negative Breaker Control Trip terminals on circuit breaker \#2. This connection replaces input from a relay and enables manual closing of the circuit breaker.

Table 50: Per-Phase Sequential Points of Connection

\begin{tabular}{|c|c|c|}
\hline Phase A & Phase B & Phase C \\
\hline Input Voltage & Input Voltage & Input Voltage \\
\hline Wattmeter & Wattmeter & Wattmeter \\
\hline $\begin{array}{l}\text { Relay Port Z01 } \\
\text { (Current Input) }\end{array}$ & $\begin{array}{l}\text { Relay Port Z03 } \\
\text { (Current Input) }\end{array}$ & $\begin{array}{l}\text { Relay Port Z05 } \\
\text { (Current Input) }\end{array}$ \\
\hline $\begin{array}{l}\text { Relay Port Z02 } \\
\text { (Current Output) }\end{array}$ & $\begin{array}{l}\text { Relay Port Z04 } \\
\text { (Current Output) }\end{array}$ & $\begin{array}{c}\text { Relay Port Z06 } \\
\text { (Current Output) }\end{array}$ \\
\hline $\begin{array}{c}\text { CB \#1, Circuit Breaker } \\
\text { Red Terminal }\end{array}$ & $\begin{array}{c}\text { CB \#1, Circuit Breaker } \\
\text { Red Terminal }\end{array}$ & $\begin{array}{c}\text { CB \#1, Circuit Breaker } \\
\text { Red Terminal }\end{array}$ \\
\hline $\begin{array}{c}\text { CB \#1, Circuit Breaker } \\
\text { Black Terminal } \\
\end{array}$ & $\begin{array}{c}\text { CB \#1, Circuit Breaker } \\
\text { Black Terminal } \\
\end{array}$ & $\begin{array}{c}\text { CB \#1, Circuit Breaker } \\
\text { Black Terminal } \\
\end{array}$ \\
\hline $45 \mathrm{mH}$ Inductor & $45 \mathrm{mH}$ Inductor & $45 \mathrm{mH}$ Inductor \\
\hline $\begin{array}{c}\text { CB \#2, Circuit Breaker } \\
\text { Red Terminal }\end{array}$ & $\begin{array}{c}\text { CB \#2, Circuit Breaker } \\
\text { Red Terminal }\end{array}$ & $\begin{array}{c}\text { CB \#2, Circuit Breaker } \\
\text { Red Terminal }\end{array}$ \\
\hline $\begin{array}{c}\text { CB \#2, Circuit Breaker } \\
\text { Black Terminal }\end{array}$ & $\begin{array}{c}\text { CB \#2, Circuit Breaker } \\
\text { Black Terminal }\end{array}$ & $\begin{array}{c}\text { CB \#2, Circuit Breaker } \\
\text { Black Terminal }\end{array}$ \\
\hline $\begin{array}{c}333 \Omega \text { Hampden Resistive } \\
\text { Load }\end{array}$ & $\begin{array}{c}333 \Omega \text { Hampden Resistive } \\
\text { Load }\end{array}$ & $\begin{array}{c}333 \Omega \text { Hampden Resistive } \\
\text { Load }\end{array}$ \\
\hline Bench Ground & Bench Ground & Bench Ground \\
\hline
\end{tabular}

23. Verify the circuit connections and obtain instructor approval to apply power to the circuit.

24. Apply both $208 \mathrm{~V}_{\mathrm{AC}}$ and $125 \mathrm{VDC}$ power from the bench and close all circuit breakers (with the Manual Breaker Control Close button). Confirm that the threephase current displayed on the wattmeter is less than $0.6 \mathrm{~A}$. If the displayed current exceeds $0.6 \mathrm{~A}$, turn off the bench power and check the circuit wiring for errors.

25. Create a line-to-line fault at the end of the transmission line.

a. Turn off $\mathrm{AC}$ and DC power from the bench.

b. Jumper the black Circuit Breaker terminals to the red Fault Connections terminals (if present) on circuit breaker \#2. Jumper two of the black Fault Connections terminals together. 
c. Set the circuit breaker \#2 Fault Switch to the Normal position.

d. Turn on AC and DC bench power. Manually close all circuit breakers.

e. Flip the circuit breaker \#2 Fault Switch to the Fault position.

f. Watch the wattmeter to confirm that the SEL-311L trips the circuit breaker to clear the fault. If it does not, turn off $\mathrm{AC}$ bench power immediately.

g. Once the relay clears the fault, turn off AC and DC bench power and flip the Fault Switch to the Normal position. Press the Target Reset button on the SEL-311L to clear the relay's front-panel LED display.

h. Retrieve the event file(s) from the SEL-311L.

i. Add the 51QT and 51Q digital signals to the oscillogram plot.

26. Retrieve the SEL-311L event file for the fault trip.

a. In QuickSet, select Tools, Event Files, Get Event Files.

b. In the window that comes up, select Refresh Event History.

c. Choose an Event Type of 16 Samples / Cycle - Raw.

d. Set the Event Length to $\underline{60}$ cycles.

e. Check the boxes of the event file(s) corresponding to the fault. Event files are indexed, with ' 1 ' being the most recent event file saved by the relay.

f. Click Get Selected Events. Save the events in a convenient location using either a default or custom naming convention.

g. Double-click on the event report file in its file path location. The AcSELerator Analytic Assistant software automatically opens an oscillogram plot of the event.

h. Click the Pref button in the lower-right corner of the oscillogram to open the Preferences menu and modify the information displayed on the oscillogram plot.

i. Under the Preferences menu, add digital fault-trip signals to the plot. Leftclick on the signal you wish to display (from the Digitals list in the lowerleft corner of the screen), then right-click-drag the signal to the Digital Axis list of signals to be displayed.

j. After saving the desired event files, enter the HIS C command in the QuickSet Terminal window (select Communications, Terminal) to clear previous event files from the relay's memory. If an error message appears about an invalid access level, type in ACC, the Enter key, the level relay 1 password (default for SEL-311L is OTTER), and the Enter key. Proceed to clear the event files.

27. Create a single-line-to-ground fault at the end of the transmission line.

a. Turn off $\mathrm{AC}$ and $\mathrm{DC}$ power from the bench.

b. Jumper the black Circuit Breaker terminals to the red Fault Connections terminals (if present) on circuit breaker \#2. Connect one of the black Fault Connections terminals directly to bench ground.

c. Set the circuit breaker \#2 Fault Switch to the Normal position.

d. Turn on AC and DC bench power. Manually close all circuit breakers.

e. Flip the circuit breaker \#2 Fault Switch to the Fault position. 
f. Watch the wattmeter to confirm that the SEL-311L trips the circuit breaker to clear the fault. If it does not, turn off $\mathrm{AC}$ bench power immediately.

g. Once the relay clears the fault, turn off AC and DC bench power and flip the Fault Switch to the Normal position. Press the Target Reset button on the SEL-311L to clear the relay's front-panel display.

h. Retrieve the event file(s) from the SEL-311L.

i. Add the $51 \mathrm{GT}$, and $51 \mathrm{G}$ digital signals to the oscillogram plot.

28. Create a three-phase fault at the end of the transmission line.

a. Turn off AC and DC power from the bench.

b. Jumper the black Circuit Breaker terminals to the red Fault Connections terminals (if present) on circuit breaker \#2. Jumper all three of the black Fault Connections terminals together.

c. Set the circuit breaker \#2 Fault Switch to the Normal position.

d. Turn on AC and DC bench power. Manually close all circuit breakers.

e. Flip the circuit breaker \#2 Fault Switch to the Fault position.

f. Watch the wattmeter to confirm that the SEL-311L trips the circuit breaker to clear the fault. If it does not, turn off $\mathrm{AC}$ bench power immediately. Note, however, that the relay waits much longer before tripping under this fault condition.

g. Once the relay clears the fault, turn off AC and DC bench power and flip the Fault Switch to the Normal position. Press the Target Reset button on the SEL-311L to clear the relay's front-panel display.

h. Retrieve the event file(s) from the SEL-311L.

i. Add the 51PT, and 51P digital signals to the oscillogram plot.

\section{Postlab Questions}

- Why did negative-sequence overcurrent protection trip the relay for a line-to-line fault?

- Why did residual overcurrent protection trip the relay for a single-line-to-ground fault?

- Why did phase overcurrent protection trip the relay for a three-phase fault?

- Compare the relay response time shown on the oscillograms with the expected values calculated in the prelab. Explain possible causes for these differences.

\section{Deliverables}

Answer the postlab questions. Turn in oscillograms for the fault events described in the procedure. The bottom of each oscillogram should show the digital signal associated with the type of protection triggered by the fault. Give each plot a caption specifying the relay, fault type and location, and type of protection triggered.

Keep the relay settings for use in future experiments. 


\section{Appendix L: SEL-387E Differential Protection Procedure}

\section{ELECTRICAL ENGINEERING DEPARTMENT \\ California Polytechnic State University \\ San Luis Obispo}

EE 518

Experiment \#5

Power Transformer Differential Protection Using the SEL-387E

\section{Learning Outcomes}

- Understand the effect of phasing currents in a differential relay

- Identify, record, and eliminate bolted faults in a two-winding power transformer using differential protection

- Analyze fault conditions from relay-generated event reports

\section{Background}

This experiment presents differential protection as a means of protecting power transformers against internal faults on their primary or secondary windings. A differential relay, such as the SEL-387E used in this experiment, compares the currents entering and leaving a "differential zone of protection." The zone of protection in this experiment is a power transformer, and the SEL-387E monitors the differential (net) current flowing through this zone. For reference, the ANSI code "87" in the name SEL-387E indicates that the device is a differential relay.

In a typical power transformer, current enters the primary winding and exits the secondary winding. These currents balance each other under normal operating conditions; all of the current entering the primary winding (except for the magnetizing current) exits the secondary winding. An imbalance in the currents entering and exiting the relay indicates that a fault exists somewhere in the transformer.

The SEL-387E used in this experiment operates in much the same way as the SEL-587 from the previous transformer differential protection experiment. Although not used in this procedure, the SEL-387E provides expanded protection capabilities that the SEL-587 does not support. These additional elements include: overexcitation (Volts-perHertz), overfrequency, underfrequency, and restricted earth fault protection.

\section{Equipment}

- $25-\Omega$ Single-Phase Power Resistor (3x)

- Bag of Banana-Banana Short Leads (3x)*

- Banana-Banana or Banana-Spade Leads (27x)

- Circuit Breakers (2x)

- Computer with AcSELerator QuickSet Software

- Hampden Resistive Load (1x)

- SEL-387E Differential and Overcurrent Relay

- SEL-C234A Serial Cable 
* Beware of extra flexible "small gauge" short leads, which can melt under fault conditions.

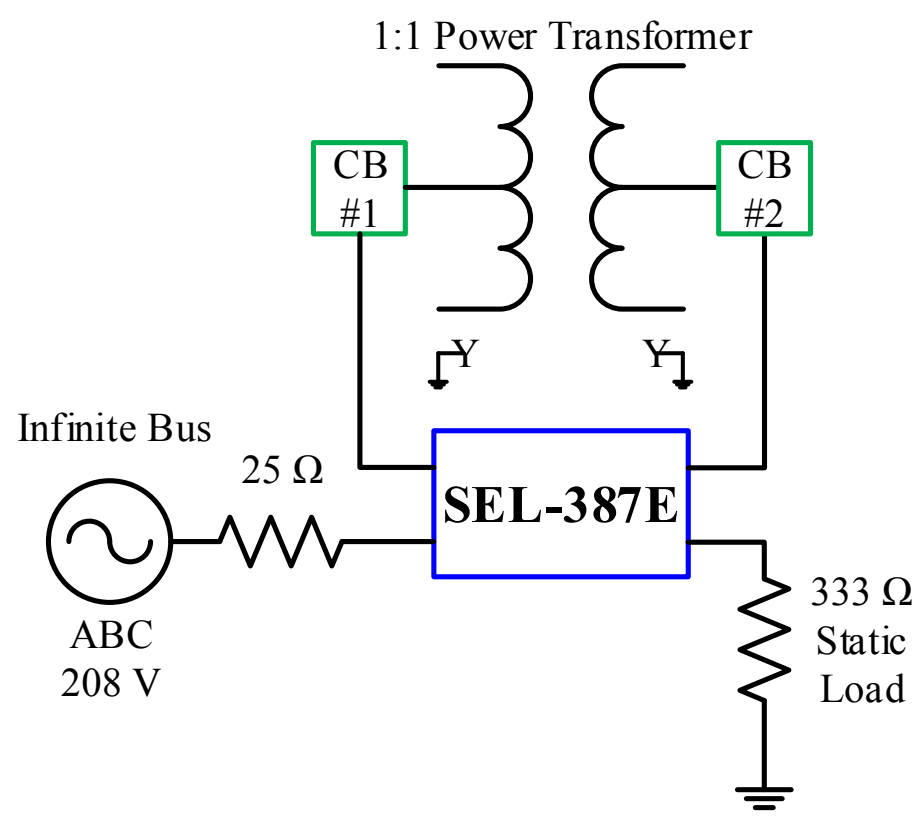

Figure 137: SEL-387E Differential Procedure Single-Line Diagram

\section{Procedure}

1. Plug in the power cord connected to the SEL-387E relay.

2. Connect an SEL-C234A serial cable between Port 2 on the back of the 387E and the main serial port on the back of the computer (surrounded by a light turquoise color).

3. On the computer, open the AcSELerator QuickSet software.

4. Determine the current baud rate for Port 2 on the 387E.

a. On the front panel of the relay, press the button labeled Set.

b. Use the down-arrow button to navigate to Port on the front panel display. Press the button for Select.

c. Navigate to Port $\mathbf{2}$ and press the button for Select.

d. Navigate to Show and press the button for Select.

e. Use the down-arrow button to navigate through the current Port 2 settings. The baud rate (SPEED) is near the top of the list. If the baud rate is already set to 19200 , press the Exit button to restore the screen to its normal display, and continue to the next step.

f. If the current relay baud rate is not set to 19200 , use the following steps to change the baud rate.

g. From the relay's main front-panel screen, press Set, and select Port, 2, and Set.

h. Use the up-arrow and right-arrow buttons to enter the relay's level 2 password (default is TAIL). Press Select. 
i. Use the down-arrow button to navigate to the SPEED setting and press Select.

j. Press the up/down-arrow buttons until 19200 (not 19.2) appears. Press Select.

k. Press Exit and select Yes to save the new port setting.

5. On the QuickSet main window (Figure 138), open the Communication Parameters window (Communications, Parameters) (Figure 139) to define and create a communication link with the 387E. Enter the following information for a Serial Active Connection Type:

a. Device: COM1: Communications Port

b. SEL Bluetooth Device: Unchecked

c. Data Speed: $\underline{19200}$

d. Data Bits: 8

e. Stop Bits: 1

f. Parity: None

g. RTS/CTS: Off

h. DTR: On

i. XON/XOFF: On

j. RTS: N/A (On)

k. Level 1 Password (Default OTTER)

1. Level 2 Password (Default $\underline{\text { TAIL) }}$

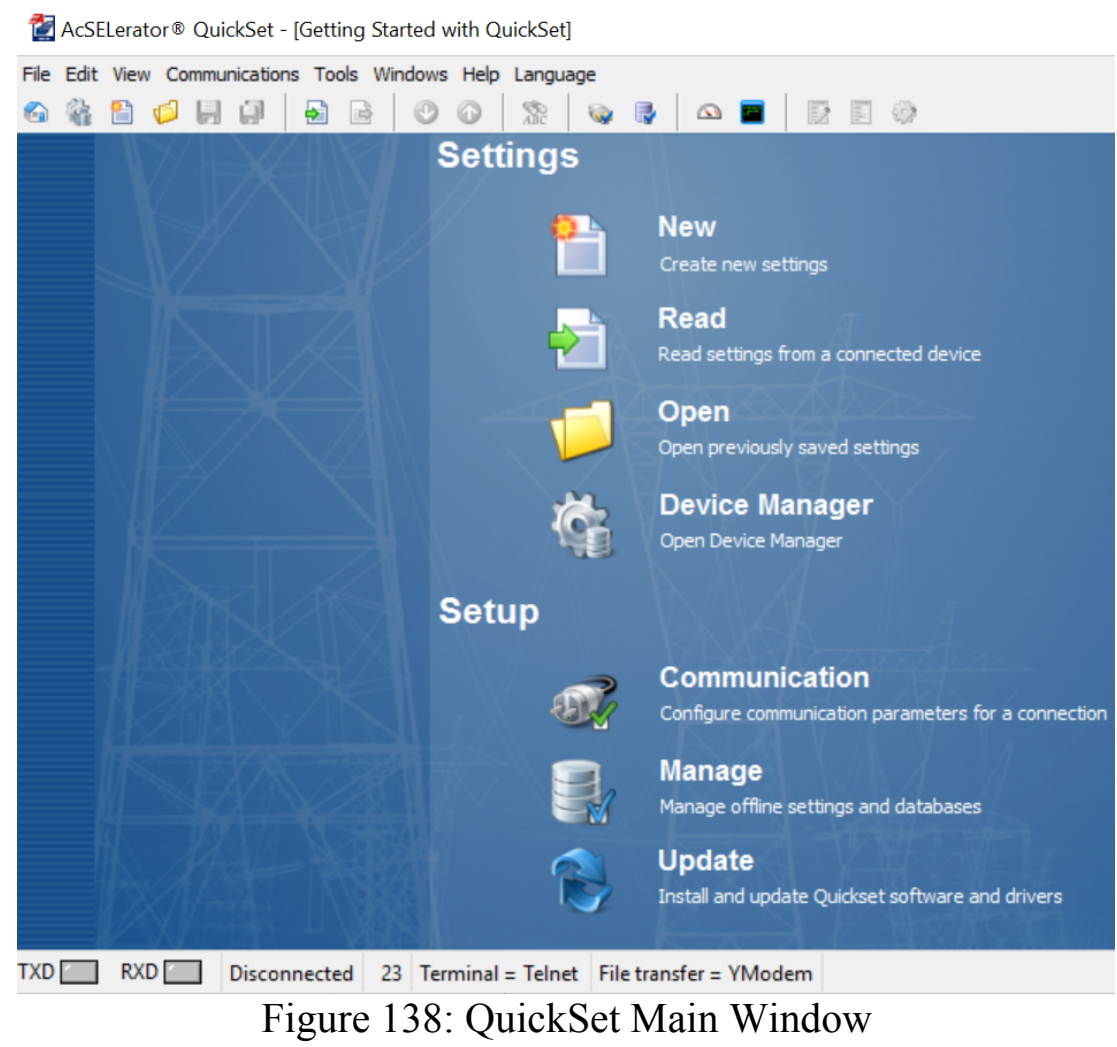




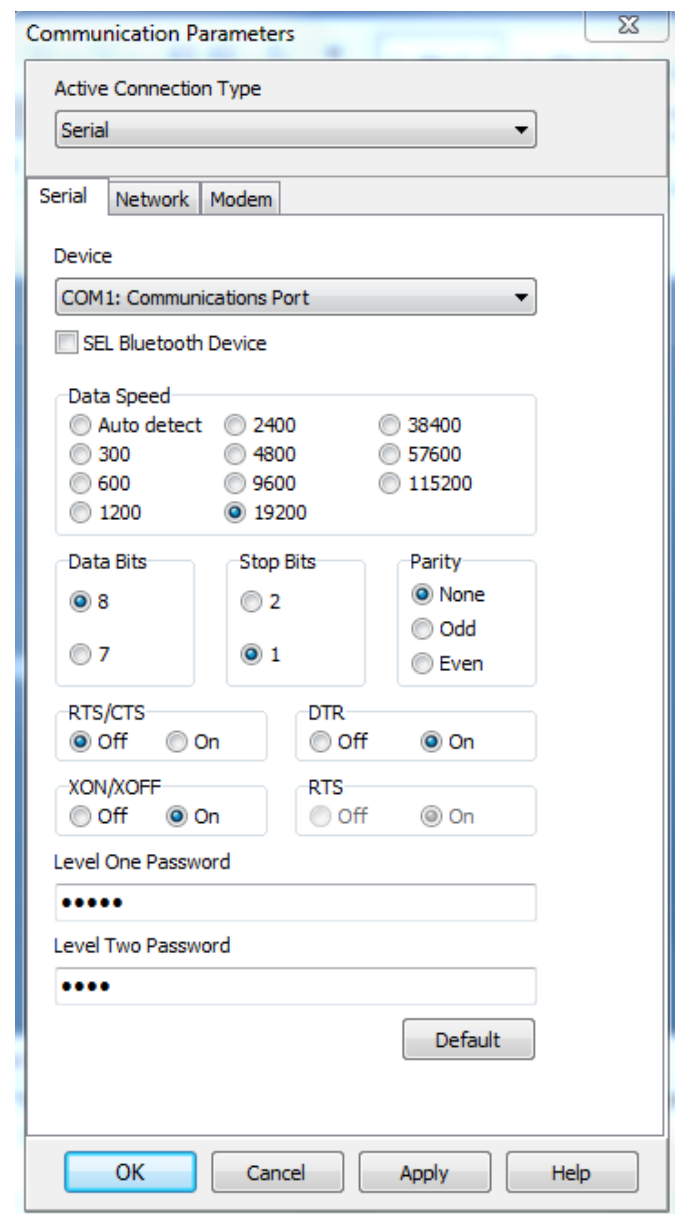

Figure 139: SEL-387E Communication Parameters Window

6. Click Apply at the bottom of the Communication Parameters window. Then click Ok. If the computer successfully connects to the relay, the connection status in the lower-left corner of the QuickSet main window should say "Connected."

7. Create a new settings file for the SEL-387E relay.

a. In the QuickSet main window, create a new settings file for the SEL-387E relay (File, New).

b. Choose the Device Family, Model, and Version for this specific relay unit from the available menus, then click Ok (Figure 140). Look up the relay's version number using the front-panel menu on the relay. Press the Status button and use the right-arrow button to navigate across the relay's FID string until you come to the "Z-number." The first three digits following the ' $Z$ ' comprise the relay version number. Press the Exit button to restore the front-panel screen to its normal display. Note: if no devices are listed in the QuickSet drop-down menus, then the device drivers need to be installed using the SEL Compass software. Ask for assistance.

c. Enter the relay Part Number (Figure 141) printed on the serial number label (P/N, Figure 142) attached somewhere on the relay chassis. Note that 
the 5 A Secondary Input Current reflects the American convention for current transformers.
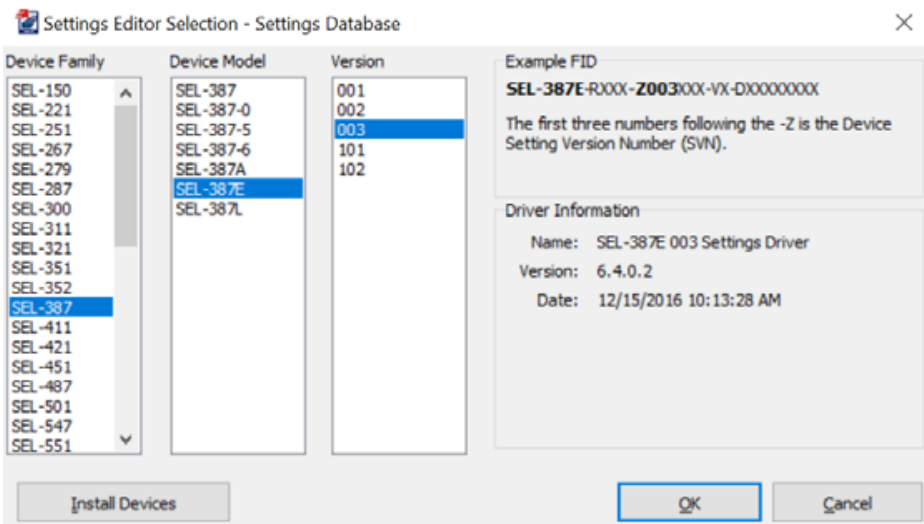

Figure 140: Identifying SEL-387E Relay Family, Model, and Version

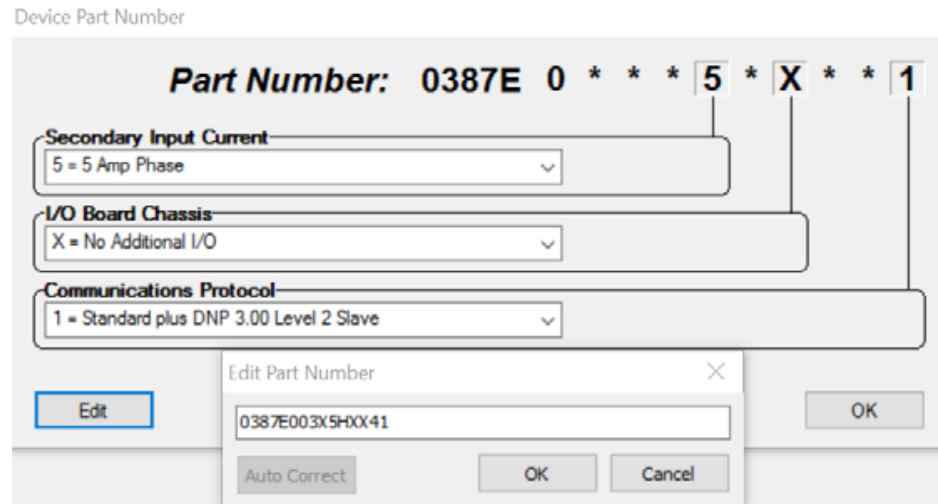

Figure 141: Identifying SEL-387E Relay Part Number

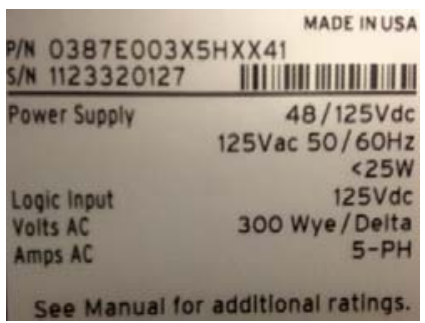

Figure 142: Example SEL-387E Label with Relay Part Number

8. Save this new relay settings database file (File, Save As and New) in a location where it may be reused in future experiments. See Figure 143 and Figure 144. Then create a Settings Name for this settings file.

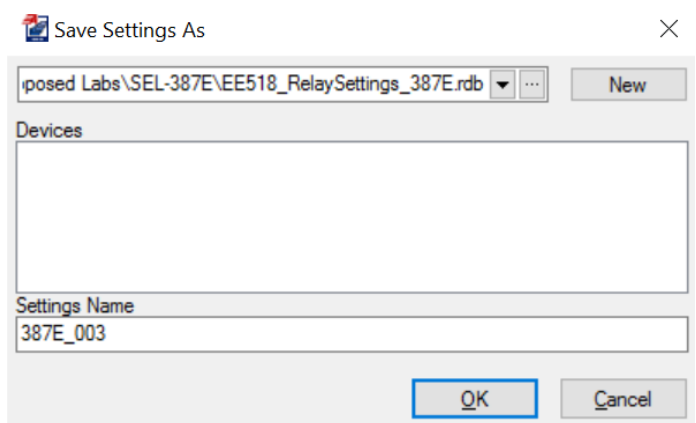

Figure 143: Saving SEL-387E Settings 


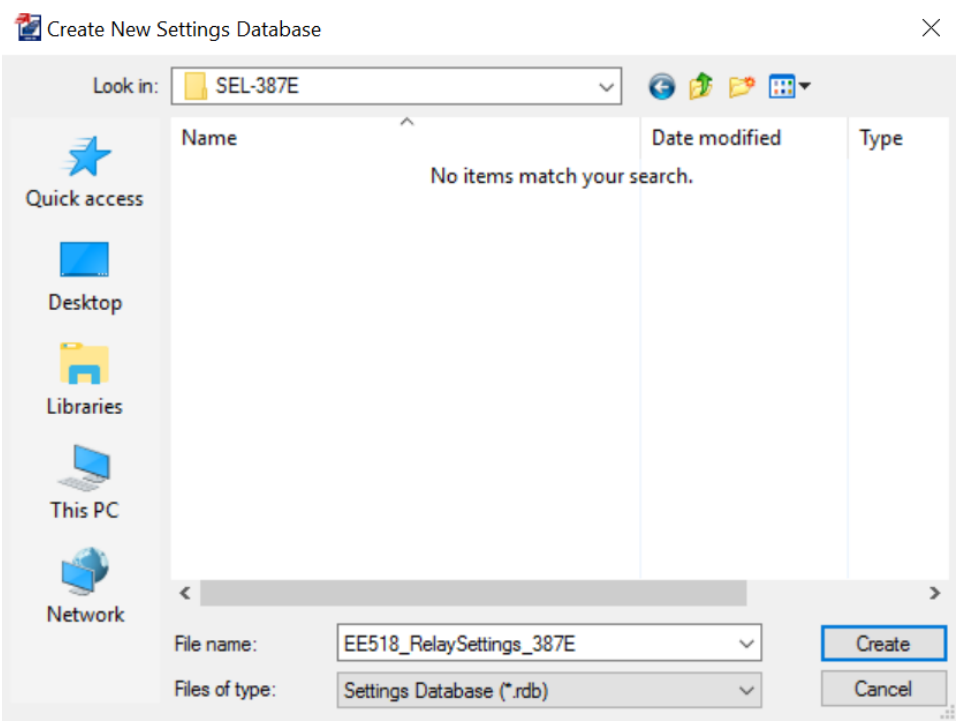

Figure 144: Choosing Location for New SEL-387E Relay Settings Database

9. Open Global settings in the drop-down menu on the left side of the Settings Editor main window (Figure 145).

a. Under Relay Settings (Figure 146), choose an event report length (LER) of $\underline{60}$ cycles.

b. Select a nominal frequency (NFREQ) of $\underline{60} \mathrm{~Hz}$.

c. Select a phase rotation (PHROT) of ACB. The frequency and phase rotation correspond to electrical properties of the utility.

d. Choose a Phase Potential Connection (DELTA_Y) of $\underline{Y}$ to reflect the Y-Y power transformer configuration in Figure 137.

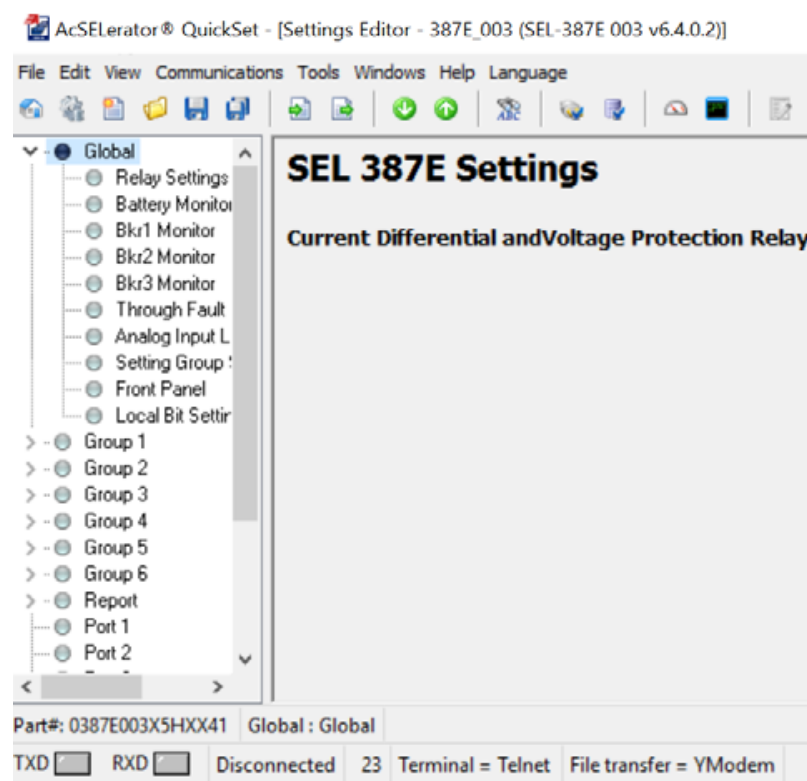

Figure 145: SEL-387E Settings Editor Window

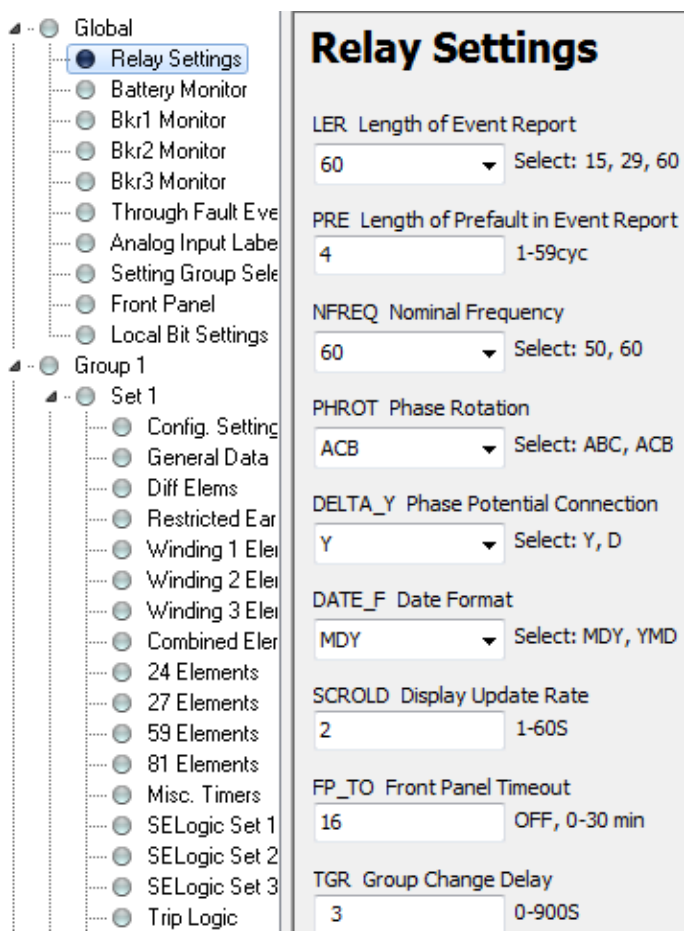

Figure 146: SEL-387E Global Settings 
10. Open the Group 1, Set 1 settings menu on the left side of the screen.

11. Enter the following information in the Configuration Settings (see Figure 147 and Figure 148).

a. Enable the Differential Elements (E87W1, E87W2) for power transformer windings 1 and 2. Choose the $\mathrm{Y1}$ option to enable features such as fourth harmonic, DC ratio blocking, and harmonic restraint.

b. Disable the Differential Element (E87W3) for power transformer winding 3 ; the power transformer in this topology has only two windings (one primary and one secondary).

c. Turn off all other protection elements; they are unnecessary for this experiment. Note, however, the expanded functionality these protection elements provide to the SEL-387E. The smaller SEL-587 differential relay does not support these protection elements.

\section{Config. Settings}

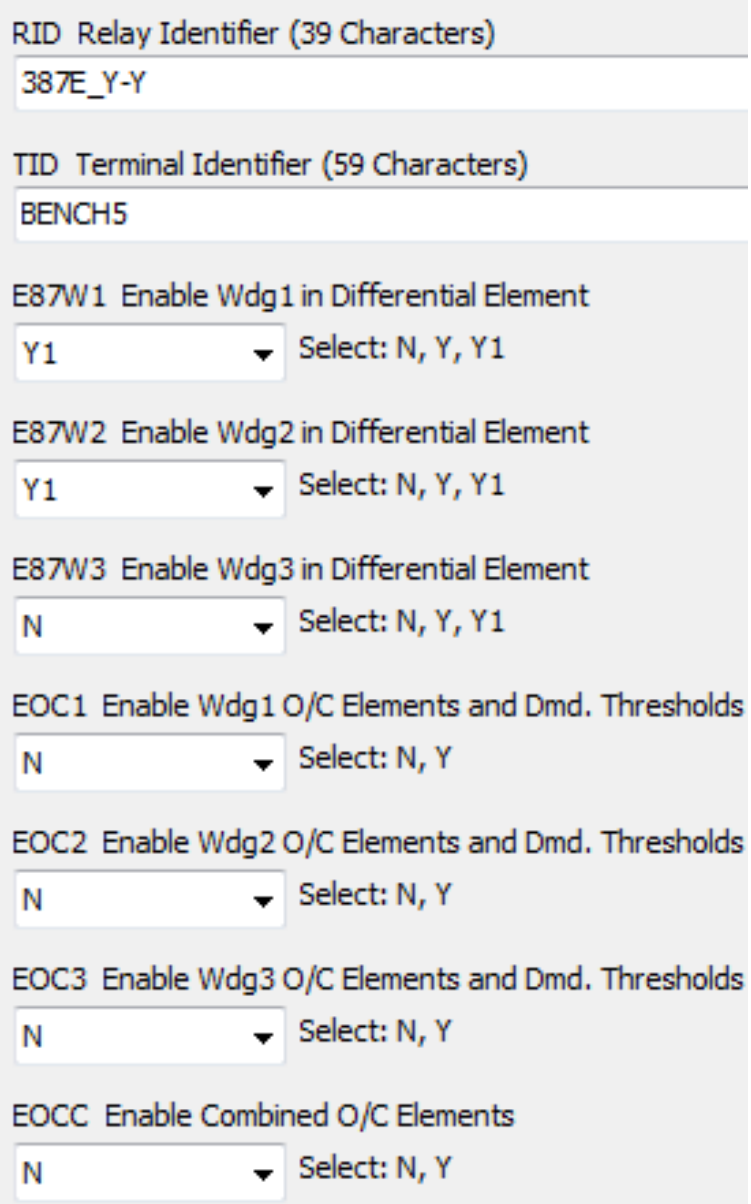

Figure 147: SEL-387E Group 1 Configuration Settings 


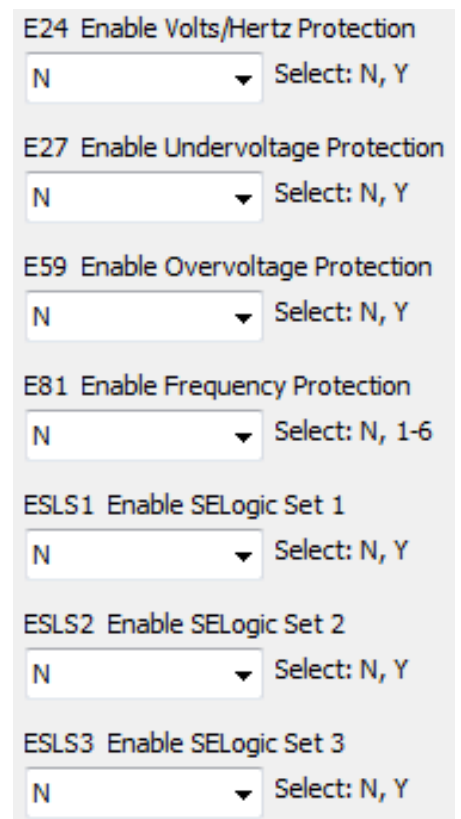

Figure 148: SEL-387E Group 1 Configuration Settings, cont.

12. Enter the following information in the General Data section (see Figure 149 and Figure 150).

a. Select $\underline{Y}$ for the current transformer winding settings (W1CT and W2CT). Note that the SEL-387E modifies the values associated with $\Delta$ connected current transformers. Due to the relatively low currents associated with this experiment, actual current transformers are not necessary to step down the line currents in the system. They are therefore not used in the circuit. However, to account for the phase shift that would normally occur due to the current transformers, the line currents must be rolled on either the primary or secondary (but not both) power transformer windings. The absence of current transformers forms the basis for switching the input and output connections on winding 2 of the power transformer when wiring up the circuit (see below). Failure to properly phase the currents causes the relay to evaluate normal load conditions as potential faults.

b. Identify the current transformer turns ratios (CTR1, CTR2, and CTR3) as 1:1 (line currents are not stepped down before entering the relay). Ignore for now any error messages that appear.

c. Turn OFF the Maximum Power Transformer Capacity (MVA). This choice allows current tap settings to be entered manually by the relay programmer for the differential elements, rather than relying on calculations made by the relay.

d. Disable Internal Current Transformer Connection Compensation (ICOM). Enabling this setting allows modifying phase shifts in and removing zerosequence components from current transformer secondary currents. 
e. Enter a Potential Transformer Ratio (PTR) of $\underline{1}$. The relay receives line voltages directly from the circuit without an intermediate potential transformer. A unity turns ratio models this configuration.

f. Enter a Compensation Angle (COMPANG) of $\underline{0}$ degrees. This setting rotates the phase angle of the voltage vector by a defined amount.

g. Enter a Voltage-Current Winding (VIWDG) reference of 1 . This choice causes the relay to report power values based on calculations for the current in winding 1 of the power transformer.

h. Enter $\underline{Y}$ for the Three-Phase Voltage Input setting (TPVI). This choice indicates to the relay that the equivalent of a three-phase (as opposed to only one single-phase) potential transformer is being used to obtain voltage measurements.

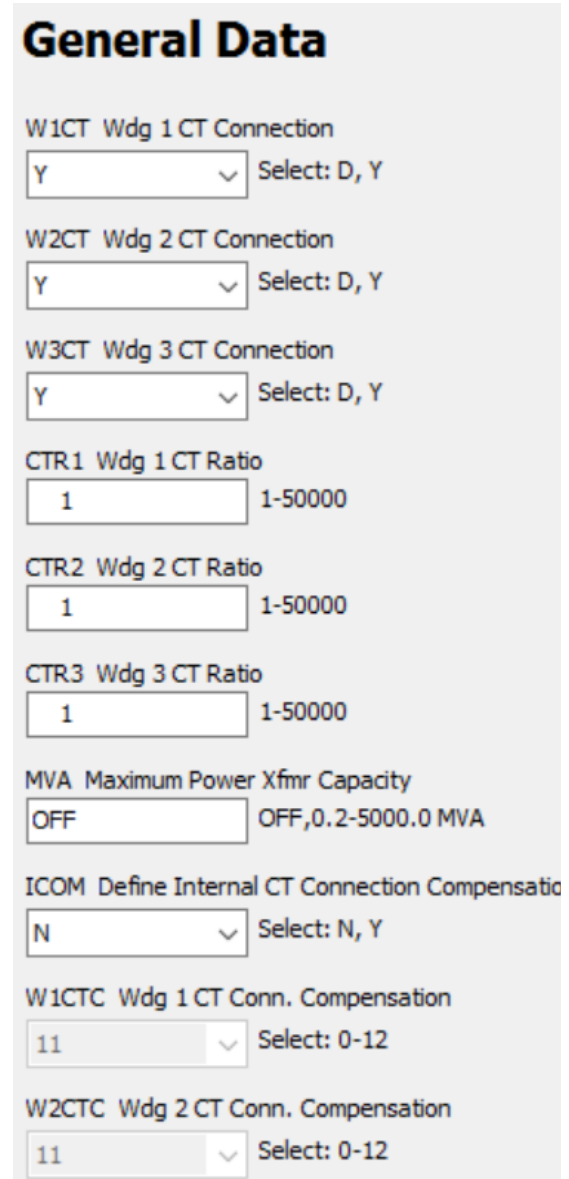

Figure 149: SEL-387E Group 1 General Data

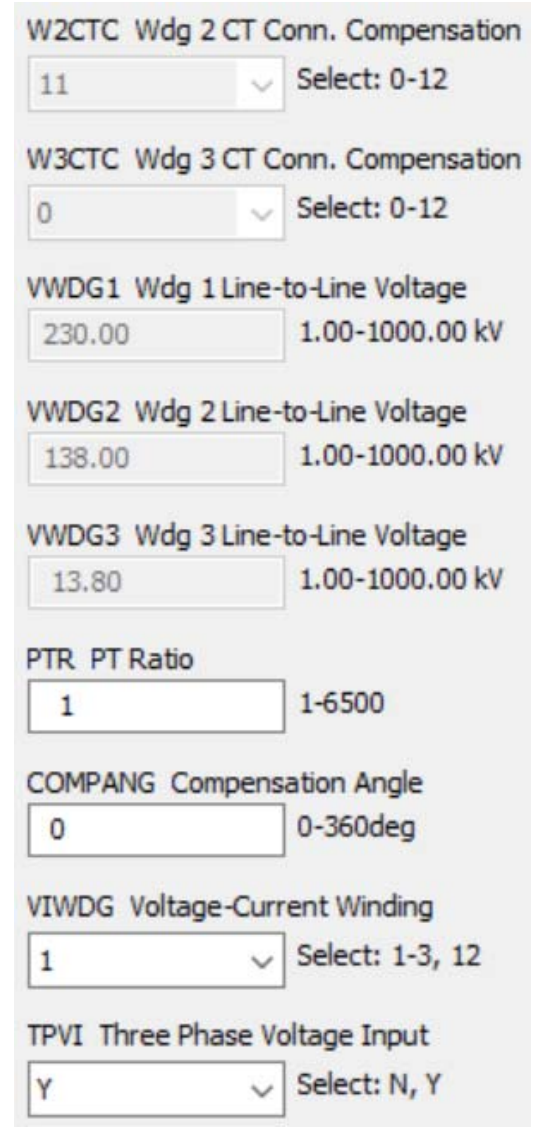

Figure 150: SEL-387E Group 1 General Data, cont.

13. Enter the following information in the General Data section (see Figure 151 and Figure 152)

a. Enter Current Tap values for winding 1 (TAP1) and winding 2 (TAP2) current transformers of $\underline{3.00}$. These values define the standard full-load 
current on the current transformers' secondary windings. The relay autocalculates these values unless the MVA setting is set to OFF.

b. Turn on DC Ratio Blocking (DCRB). This setting prevents the relay from tripping for inrush current, magnetization current, or faults outside of the differential protection zone.

c. Leave the remaining settings as their default values.

\section{Diff Elems}

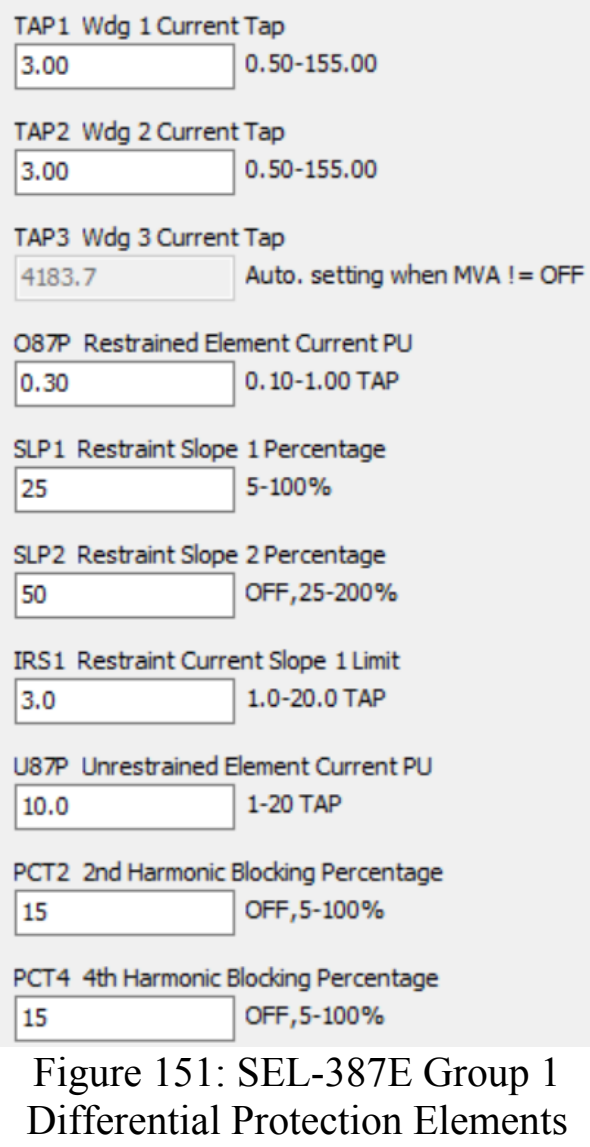

Figure 151: SEL-387E Group 1 Differential Protection Elements

PCT5 5th Harmonic Blocking Percentage \begin{tabular}{|l|l}
\hline 35 & OFF, $5-100 \%$ \\
\hline
\end{tabular}

TH5P 5th Harmonic Alarm Threshold OFF OFF, 0.02-3.2 TAP

TH5D 5th Harmonic Alarm TDPU

30.000 $0.000-8000.000$ cyc

DCRB DC Ratio Blocking

Y $\quad \checkmark$ Select: N, Y

HRSTR Harmonic Restraint

Y $\quad \checkmark$ Select: N, Y

IHBL Independent Harmonic Blocking

N

$$
\text { Select: N, Y }
$$

Figure 152: SEL-387E Group 1 Differential Protection Elements, cont.

14. Enter the following information in the Trip Logic section (see Figure 153).

a. Modify the first Assert Trip Logic (TR1) setting. Replace the default

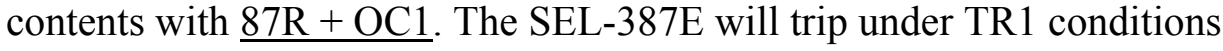
when either the restrained differential protection $(87 \mathrm{R})$ is tripped or a command $(\mathrm{OC} 1)$ is given to open breaker 1 on winding 1 of the power transformer.

b. Replace the default contents of the TR2 setting with OC2. The SEL-387E will trip under TR2 conditions when a command (OC2) is given to open breaker 2 on winding 2 of the power transformer. 
c. Replace the default contents of TR3 and TR4 with a $\underline{0}$ value.

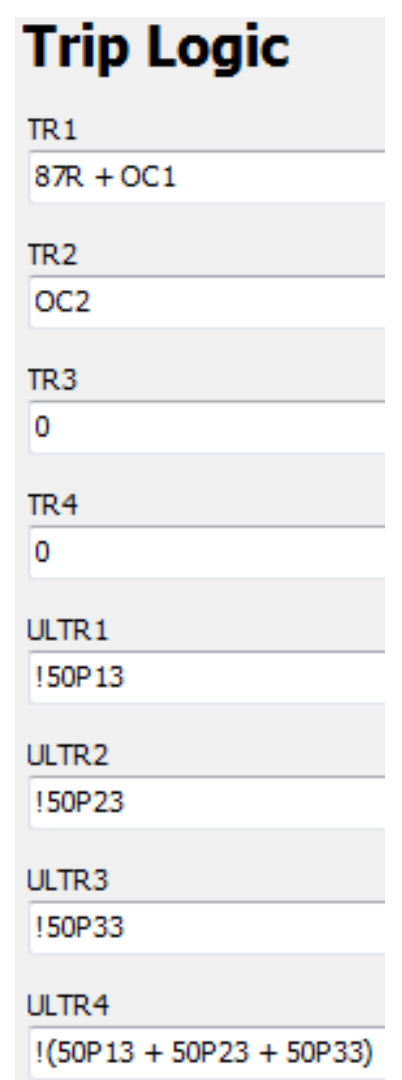

Figure 153: SEL-387E Group 1 Trip Logic

15. Enter the following information in the Output Contact Logic section (see Figure 154).

a. Logically-invert the default OUT101 signal to be !TRIP1. Logical inversion is necessary for interfacing the normally-open switch on the SEL-387E with the circuit breaker trip coil. This logic causes the circuit breaker (on the winding 1 side of the power transformer) connected to back-panel output port 101 on the SEL-387E to trip under TR1 fault conditions (see Step 12a).

b. Change the OUT102 signal to !TRIP1. This logic trips the winding 2 circuit breaker under TR1 fault conditions.

c. Set the OUT103 and OUT104 signals to $\underline{0}$. 


\section{Output Contact Logic}

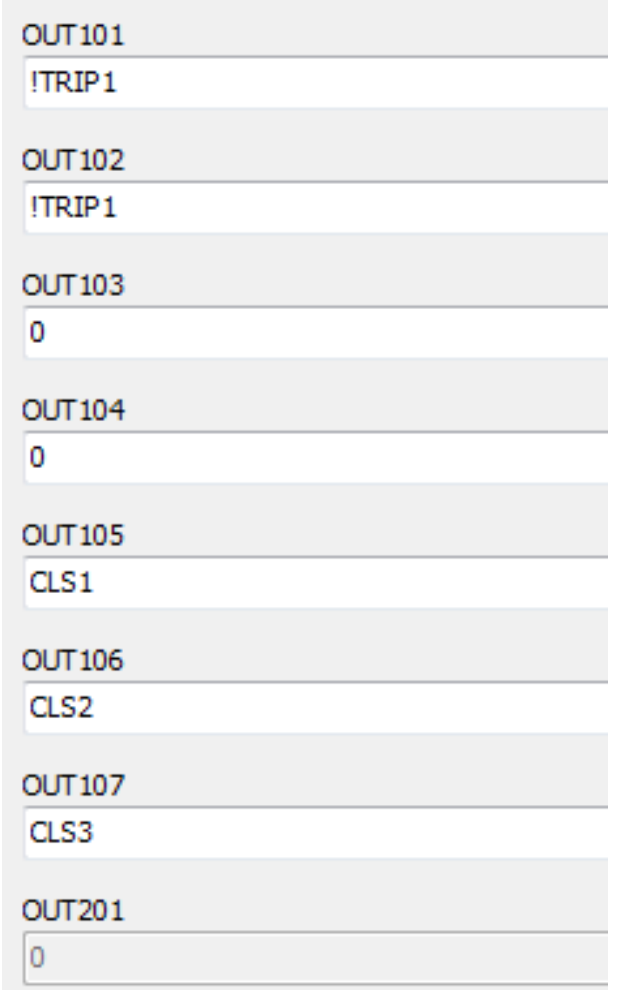

Figure 154: SEL-387E Group 1 Output Contact Logic

16. Open Port 2 settings in the drop-down menu on the left side of the Settings Editor main window (Figure 155).

a. Set the Port 2 baud rate (SPEED) to 19,200. This selection significantly speeds up communication between the SEL-387E and any communication processor connected to Port 2. Using the default baud rate can lead to timeout errors.

b. Increase the port Timeout setting (T_OUT) to $\underline{30}$ minutes to avoid loss of communication due to short periods of inactivity.

c. Select $\underline{Y}$ for the Send Automatic Messages to Port setting (AUTO). This choice causes the SEL-387E to automatically send data to an information processor connected to its serial port 2.

d. Leave all other Port 2 settings as their default values (Figure 156). 


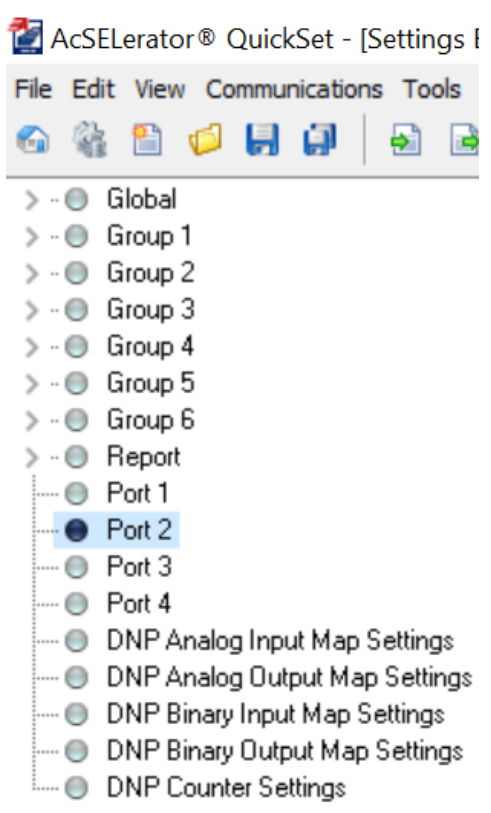

Figure 155: SEL-387E Port 2 Settings Location

\section{Port 2}

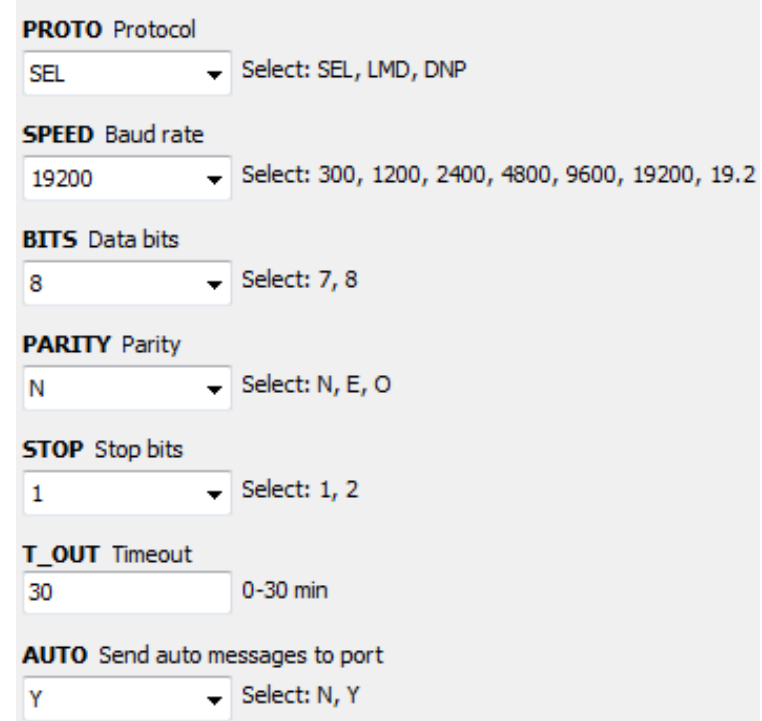

Figure 156: SEL-387E Serial Port 2 Settings

17. Save your settings (File, Save).

18. Send your settings (File, Send...) to the SEL-387E. In the window that appears, check the boxes for the Global, Group 1, and Port 2 settings (Figure 157).

Sending only the modified settings shortens the file transfer time. Ignore any error messages associated with changing the baud rate. Since it can take several minutes to transfer the relay settings, now is a good time to start constructing the circuit. 


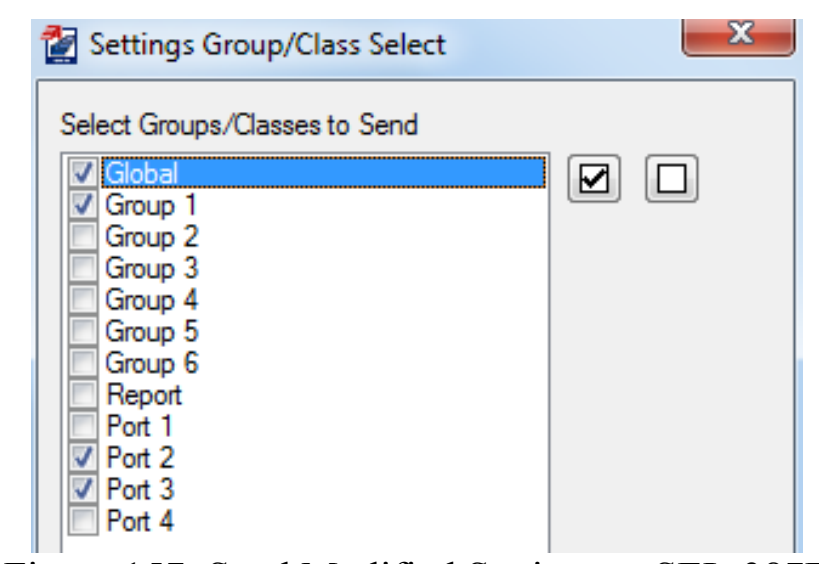

Figure 157: Send Modified Settings to SEL-387E

19. Connect the three-phase circuit illustrated in Figure 137. Try to lay out the elements in the order illustrated in the schematic so that power flows across the bench from one end to the other. This linear arrangement limits the number of wires crossing each other and makes the path of current flow easier to review (and troubleshoot). Start with the sequential connection points in Table 51, using the diagrams posted on the wattmeter and transformer at the lab bench for assistance. Then add the following connections:

a. Connect back-panel port Z19 of the SEL-387E to terminal 3 of the transformer phase A secondary winding.

b. Connect back-panel port $\mathbf{Z 2 0}$ of the SEL-387E to terminal 3 of the transformer phase B secondary winding.

c. Connect back-panel port Z21 of the SEL-387E to terminal 3 of the transformer phase $\mathrm{C}$ secondary winding.

d. Connect back-panel port $\mathbf{Z 2 2}$ of the SEL-387E to terminal 6 of the transformer secondary winding.

e. Jumper all transformer terminal 2 points together (Y-grounded primary).

f. Jumper transformer terminals 4 and 5 for each phase of the power transformer.

g. Jumper all transformer terminal 6 points together (Y-grounded secondary).

h. Connect back-panel port A01 of the SEL-387E to the top Breaker Control Trip terminal on circuit breaker \#1 (transformer primary winding). Connect back-panel port $\mathbf{A 0 2}$ to the bottom Breaker Control Trip terminal on circuit breaker \#1.

i. Connect back-panel port A03 of the SEL-387E to the top Breaker Control Trip terminal on circuit breaker \#2 (transformer secondary winding). Connect back-panel port A04 to the bottom Breaker Control Trip terminal on circuit breaker \#2.

j. Connect the positive (upper) Breaker Control $125 \mathrm{~V}_{\mathrm{DC}}$ terminal on both circuit breakers to input terminal $\mathrm{G}$ on the lab bench. Connect the negative (lower) Breaker Control $125 \mathrm{~V}_{\mathrm{DC}}$ terminal on both circuit breakers to terminal $\mathrm{H}$.

k. Connect the green chassis ground terminals on each circuit breaker to the green bench ground terminal. 
Table 51: Per-Phase Sequential Points of Connection

\begin{tabular}{|c|c|c|}
\hline Phase A & Phase B & Phase C \\
\hline Input Voltage & Input Voltage & Input Voltage \\
\hline Wattmeter & Wattmeter & Wattmeter \\
\hline $25 \Omega$ Resistor Input & $25 \Omega$ Resistor Input & $25 \Omega$ Resistor Input \\
\hline $25 \Omega$ Resistor Output & $25 \Omega$ Resistor Output & $25 \Omega$ Resistor Output \\
\hline $\begin{array}{l}\text { Relay Port Z01 } \\
\text { (Relay Input) }\end{array}$ & $\begin{array}{l}\text { Relay Port Z03 } \\
\text { (Relay Input) }\end{array}$ & $\begin{array}{l}\text { Relay Port Z05 } \\
\text { (Relay Input) }\end{array}$ \\
\hline $\begin{array}{l}\text { Relay Port Z02 } \\
\text { (Relay Output) }\end{array}$ & $\begin{array}{l}\text { Relay Port Z04 } \\
\text { (Relay Output) }\end{array}$ & $\begin{array}{l}\text { Relay Port Z06 } \\
\text { (Relay Output) }\end{array}$ \\
\hline CB \#1 (XFMR Primary & CB \#1 (XFMR Primary & CB \#1 (XFMR Primary \\
\hline $\begin{array}{c}\text { Side) Circuit Breaker Red } \\
\text { Terminal }\end{array}$ & $\begin{array}{c}\text { Side) Circuit Breaker Red } \\
\text { Terminal }\end{array}$ & $\begin{array}{c}\text { Side) Circuit Breaker Red } \\
\text { Terminal }\end{array}$ \\
\hline $\begin{array}{c}\text { CB \#1, Circuit Breaker } \\
\text { Black Terminal }\end{array}$ & $\begin{array}{c}\text { CB \#1, Circuit Breaker } \\
\text { Black Terminal }\end{array}$ & $\begin{array}{c}\text { CB \#1, Circuit Breaker } \\
\text { Black Terminal }\end{array}$ \\
\hline $\begin{array}{l}\text { Transformer Primary } \\
\text { Winding, Terminal } 1\end{array}$ & $\begin{array}{l}\text { Transformer Primary } \\
\text { Winding, Terminal } 1\end{array}$ & $\begin{array}{l}\text { Transformer Primary } \\
\text { Winding, Terminal } 1\end{array}$ \\
\hline $\begin{array}{l}\text { Transformer Secondary } \\
\text { Winding, Terminal } 3\end{array}$ & $\begin{array}{c}\text { Transformer Secondary } \\
\text { Winding, Terminal } 3\end{array}$ & $\begin{array}{c}\text { Transformer Secondary } \\
\text { Winding, Terminal } 3\end{array}$ \\
\hline $\begin{array}{c}\text { CB \#2, Circuit Breaker } \\
\text { Red Terminal }\end{array}$ & $\begin{array}{c}\text { CB \#2, Circuit Breaker } \\
\text { Red Terminal }\end{array}$ & $\begin{array}{c}\text { CB \#2, Circuit Breaker } \\
\text { Red Terminal }\end{array}$ \\
\hline $\begin{array}{l}\text { CB \#2, Circuit Breaker } \\
\text { Black Terminal }\end{array}$ & $\begin{array}{l}\text { CB \#2, Circuit Breaker } \\
\text { Black Terminal }\end{array}$ & $\begin{array}{l}\text { CB \#2, Circuit Breaker } \\
\text { Black Terminal }\end{array}$ \\
\hline $\begin{array}{l}\text { Relay Port Z08* } \\
\text { (Relay Input) }\end{array}$ & $\begin{array}{l}\text { Relay Port Z10 * } \\
\text { (Relay Input) }\end{array}$ & $\begin{array}{l}\text { Relay Port Z12 * } \\
\text { (Relay Input) }\end{array}$ \\
\hline $\begin{array}{l}\text { Relay Port Z07 * } \\
\text { (Relay Output) }\end{array}$ & $\begin{array}{l}\text { Relay Port Z09* } \\
\text { (Relay Output) }\end{array}$ & $\begin{array}{l}\text { Relay Port Z11* } \\
\text { (Relay Output) }\end{array}$ \\
\hline $\begin{array}{l}333 \Omega \text { Hampden Resistive } \\
\text { Load }\end{array}$ & $\begin{array}{c}333 \Omega \text { Hampden Resistive } \\
\text { Load }\end{array}$ & $\begin{array}{c}333 \Omega \text { Hampden Resistive } \\
\text { Load }\end{array}$ \\
\hline Bench Ground & Bench Ground & Bench Ground \\
\hline
\end{tabular}

* Rolling transformer secondary winding current phases.

20. Verify the circuit connections and obtain instructor approval to apply power to the circuit.

21. Apply both $208 \mathrm{~V}_{\mathrm{AC}}$ and $125 \mathrm{~V}_{\mathrm{DC}}$ power from the bench and close all circuit breakers (with the Manual Breaker Control Close button). Confirm that the threephase power displayed on the wattmeter is approximately $1 \mathrm{~A}$. If the displayed 
current exceeds $1.5 \mathrm{~A}$, turn off the bench power and check the circuit wiring for errors.

22. Create a line-to-line fault on the primary side of the power transformer.

a. Turn off $\mathrm{AC}$ and DC power from the bench.

b. Jumper the black Circuit Breaker terminals to the red Fault Connections terminals (if present) on circuit breaker \#1. Jumper two of the black Fault Connections terminals together (line-to-line fault configuration).

c. Set the circuit breaker Fault Switches to the Normal position.

d. Turn on AC and DC bench power. Manually close all circuit breakers.

e. Flip the circuit breaker \#1 Fault Switch to the Fault position.

f. Watch the wattmeter to confirm that the SEL-387E trips the circuit breaker to clear the fault. If it does not, turn off $\mathrm{AC}$ bench power before sustained fault current damages circuit components.

g. Once the relay clears the fault, turn off AC and DC bench power and flip the Fault Switch to the Normal position. Press the Target Reset button on the SEL-387E to clear the relay's front-panel LED display.

h. Retrieve the event file(s) from the SEL-387E (Step 21).

i. Add the TRIP1 and 87R digital signals to the oscillogram plot.

23. Retrieve the SEL-387E event file for the fault trip.

a. In QuickSet, select Tools, Event Files, Get Event Files.

b. In the window that comes up, select Refresh Event History.

c. Choose an Event Type of 64 Samples / Cycle - Raw and an Event Length of 15 cycles.

d. Check the boxes of the event file(s) corresponding to the fault. Event files are indexed, with ' 1 ' being the most recent event file saved by the relay.

e. Click Get Selected Events. Save the events in a convenient location using either a default or custom naming convention.

f. Double-click on the event report file in its file path location. The AcSELerator Analytic Assistant software automatically opens an oscillogram plot of the event.

g. Click the Pref button in the lower-right corner of the oscillogram to add digital fault-trip signals to the plot. Left-click on the signal you wish to display (from the available list in the lower-left corner of the screen), then right-click-drag the signal to the Digital Axis list of signals to be displayed.

h. After saving the desired event files, enter the HIS C command in the QuickSet Terminal window (select Communications, Terminal) to clear previous event files from the relay's memory. If an error message appears about an invalid access level, type in ACC, the Enter key, the level relay 1 password (default for SEL-387E is OTTER), and the Enter key. Proceed to clear the event files.

24. Create a double-line-to-ground fault on the secondary side of the power transformer. 
a. Turn off AC and DC power from the bench.

b. Jumper the black Circuit Breaker terminals to the red Fault Connections terminals (if present) on circuit breaker \#2. Jumper two of the black Fault Connections terminals together and connect these terminals directly to bench ground.

c. Set the circuit breaker Fault Switches to the Normal position.

d. Turn on AC and DC bench power. Manually close all circuit breakers.

e. Flip the circuit breaker \#2 Fault Switch to the Fault position.

f. Watch the wattmeter to confirm that the SEL-387E trips the circuit breaker to clear the fault. If it does not, turn off $\mathrm{AC}$ bench power before sustained fault current damages circuit components.

g. Once the relay clears the fault, turn off AC and DC bench power and flip the Fault Switch to the Normal position. Press the Target Reset button on the SEL-387E to clear the relay's front-panel display.

h. Retrieve the event file(s) from the SEL-387E (Step 21).

i. Add the TRIP1 and 87R digital signals to the oscillogram plot.

25. Create a three-phase fault (not grounded) on the secondary side of the power transformer.

a. Turn off $\mathrm{AC}$ and $\mathrm{DC}$ power from the bench.

b. Jumper the black Circuit Breaker terminals to the red Fault Connections terminals (if present) on circuit breaker \#2. Jumper all three of the black Fault Connections terminals together.

c. Set the circuit breaker Fault Switches to the Normal position.

d. Turn on AC and DC bench power. Manually close all circuit breakers.

e. Flip the circuit breaker \#2 Fault Switch to the Fault position.

f. Watch the wattmeter to confirm that the SEL-387E trips the circuit breaker to clear the fault. If it does not, turn off $\mathrm{AC}$ bench power before sustained fault current damages circuit components.

g. Once the relay clears the fault, turn off AC and DC bench power and flip the Fault Switch to the Normal position. Press the Target Reset button on the SEL-387E to clear the relay's front-panel display.

h. Retrieve the event file(s) from the SEL-387E (Step 21).

i. Add the TRIP1 and 87R digital signals to the oscillogram plot.

\section{Postlab Questions}

- Briefly describe how a differential relay operates (in principle).

- Explain why both circuit breakers \#1 and \#2 tripped for transformer faults (within the differential zone of protection). Base your explanation on the Trip Logic and Output Contact Logic relay settings. 


\section{Deliverables}

Answer the postlab questions. Turn in oscillograms for the fault events described in the procedure. The bottom of each oscillogram should show the digital signal associated with the type of protection triggered by the fault. Give each plot a caption specifying the relay, fault type and location, and type of protection triggered.

Save the relay settings for use in future experiments. 


\title{
Appendix M: SEL-387E Overcurrent Protection Procedure
}

EE 518

\author{
ELECTRICAL ENGINEERING DEPARTMENT \\ California Polytechnic State University \\ San Luis Obispo
}

Power Transformer Overcurrent Protection Using the SEL-387E

\section{Learning Outcomes}

- Identify, record, and eliminate bolted faults downstream of a two-winding power transformer using inverse-time overcurrent protection

- Analyze fault conditions from relay-generated event reports

\section{Background}

Relay coordination is a key component of power system protection because it ensures that vulnerable devices have more than one source of protection. That way, if the primary relay fails to operate during fault conditions, a backup relay can still protect the circuit. Backup relays are typically located further upstream in a circuit, away from the primary relay. This increase in distance away from the fault location means that larger sections of the circuit will be taken off-line when the backup relay trips. Backup relays are designed with delay mechanisms in their protection schemes, allowing the primary relay a chance to operate first. This delay is desirable because operating a relay in its primary zone of protection minimizes the area affected by a fault.

Several options exist for delaying a relay from tripping. In definite-time overcurrent (ANSI prefix "50"), the relay waits a constant amount of time between when it detects a fault and trips a circuit breaker. The relay resets if the fault conditions disappear before the time delay elapses. For example, a definite-time overcurrent relay element of 50Q will trip after measuring continuous negative-sequence currents (symbolized by the letter 'Q') for a specified amount of time.

Inverse-time overcurrent (ANSI prefix "51") offers a more dynamic response to fault conditions. The amount of delay before the relay operates in response to a fault depends on the fault current magnitude. High currents receive a shorter delay, while lower fault currents are assigned a longer delay. This inverse relationship allows an overcurrent relay to respond faster to more dangerous fault conditions. As with definite-time overcurrent, the relay refrains from tripping if the fault disappears before the delay time elapses. As an example, an inverse-time overcurrent relay element of 51P will trip after the relay measures continuous phase currents (symbolized by the letter ' $\mathrm{P}$,' corresponding to the amplitude of the current in the circuit) for an amount of time determined by the magnitude of the fault current. Inverse-time overcurrent curves illustrate the relationship between the relay response delay and fault current magnitude (in terms of multiples of a specified baseline amount called the "pickup current"). 


\section{Prelab}

For calculations, ignore connections to the relay (i.e. circuit breakers, current transformers, and potential transformers). Assume a transformer reactance of $1.8 \Omega$ for all symmetrical component sequences.

a) Calculate the negative-sequence currents (in Amps) produced by bolted line-toline and single-line-to-ground faults at circuit breaker CB \#3 in Figure 158.

b) Assuming a negative-sequence pickup current of $0.5 \mathrm{~A}$ and a time-dial setting of 0.55 , use the following equation to calculate the expected relay operate time in response to these line-to-line and single-line-to-ground faults:

$$
t_{p}=T D \cdot\left[0.0226+\frac{0.0104}{M^{0.02}-1}\right]
$$

In this equation, $t_{p}$ represents the relay operate time, $T D$ represents the relay timedial setting, and $M$ represents the multiples of negative-sequence pickup current detected by the relay. This equation represents the family of curves in a U. S. moderately inverse coordination plot and appears in the SEL-387E instruction manual.

c) Estimate the per-phase current (in Amps) of a triple-line-to-ground fault at the same location. Neglect the relatively small reactance of the transformer. Hint: Apply Ohm's law.

d) Assuming a phase pickup current of $4.50 \mathrm{~A}$ and a time-dial setting of 0.55 , use the above equation to calculate the expected relay operate time in response to this triple-line-to-ground fault. Note that $M$ now represents the multiples of phase pickup current detected by the relay.

\section{Equipment}

- $25-\Omega$ Single-Phase Power Resistor (3x)

- Bag of Banana-Banana Short Leads (3x) *

- Banana-Banana or Banana-Spade Leads (30x)

- Circuit Breakers (3x)

- Computer with AcSELerator QuickSet Software

- Hampden Resistive Load (1x)

- SEL-387E Differential and Overcurrent Relay

- SEL-C234A Serial Cable

* Beware of extra flexible "small gauge" short leads, which can melt under fault current conditions. 


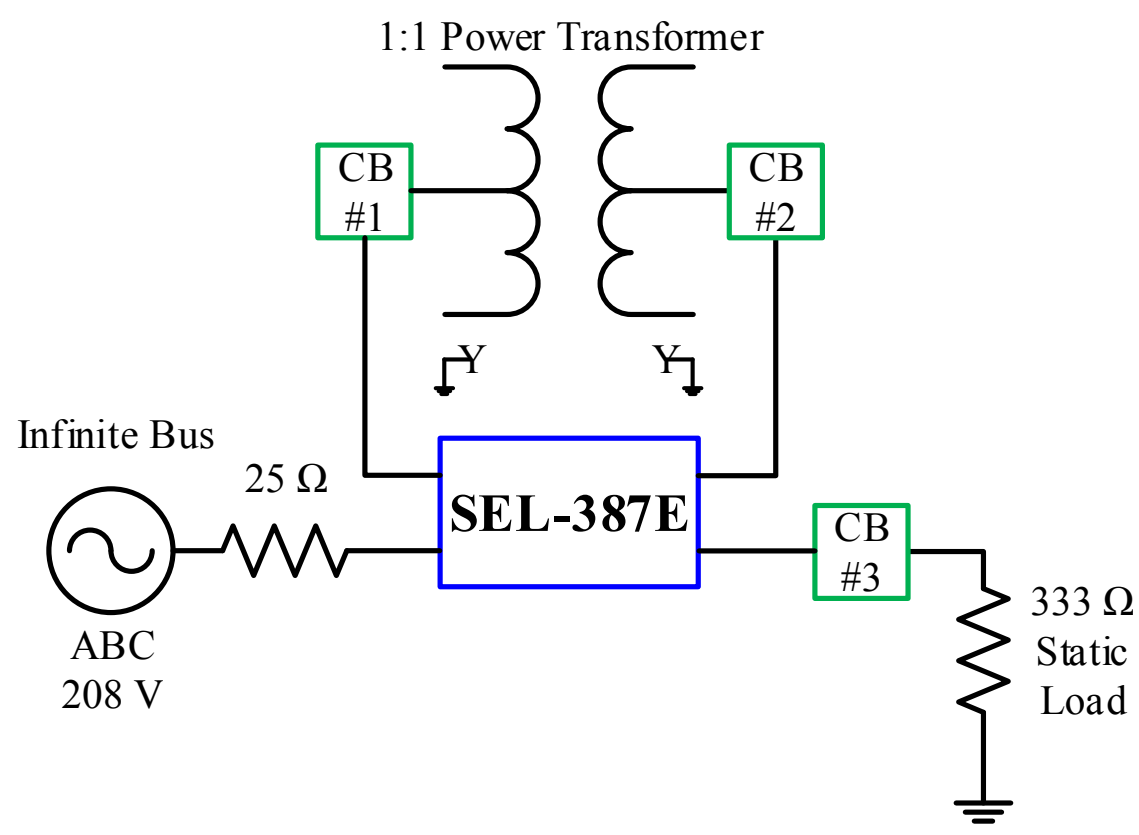

Figure 158: SEL-387E Overcurrent Procedure Single-Line Diagram

\section{Procedure}

1. Plug in the power cord connected to the SEL-387E relay.

2. Connect an SEL-C234A serial cable between Port 2 on the back of the 387E and the main serial port on the back of the computer (surrounded by a light turquoise color).

3. On the computer, open the AcSELerator QuickSet software.

4. Determine the current baud rate for Port 2 on the 387E.

a. On the front panel of the relay, press the button labeled Set.

b. Use the down-arrow button to navigate to Port on the front panel display. Press the button for Select.

c. Navigate to Port $\mathbf{2}$ and press the button for Select.

d. Navigate to Show and press the button for Select.

e. Use the down-arrow button to navigate through the current Port 2 settings. The baud rate (SPEED) is near the top of the list. If the baud rate is already set to 19200 , press the Exit button to restore the screen to its normal display, and continue to the next step.

f. If the current relay baud rate is not set to 19200 , use the following steps to change the baud rate.

g. From the relay's main front-panel screen, press Set, and select Port, 2, and Set.

h. Use the up-arrow and right-arrow buttons to enter the relay's level 2 password (default is TAIL). Press Select.

i. Use the down-arrow button to navigate to the SPEED setting and press Select. 
j. Press the up/down-arrow buttons until 19200 (not 19.2) appears. Press Select.

k. Press Exit and select Yes to save the new port setting.

5. On the QuickSet main window (Figure 159), open the Communication Parameters window (Communications, Parameters) (Figure 160) to define and create a communication link with the $387 \mathrm{E}$. Enter the following information for a Serial Active Connection Type:

a. Device: COM1: Communications Port

b. SEL Bluetooth Device: Unchecked

c. Data Speed: 19200 (baud)

d. Data Bits: 8

e. Stop Bits: 1

f. Parity: None

g. RTS/CTS: Off

h. DTR: On

i. XON/XOFF: On

j. RTS: N/A (On)

k. Level 1 Password (Default OTTER)

1. Level 2 Password (Default TAIL)

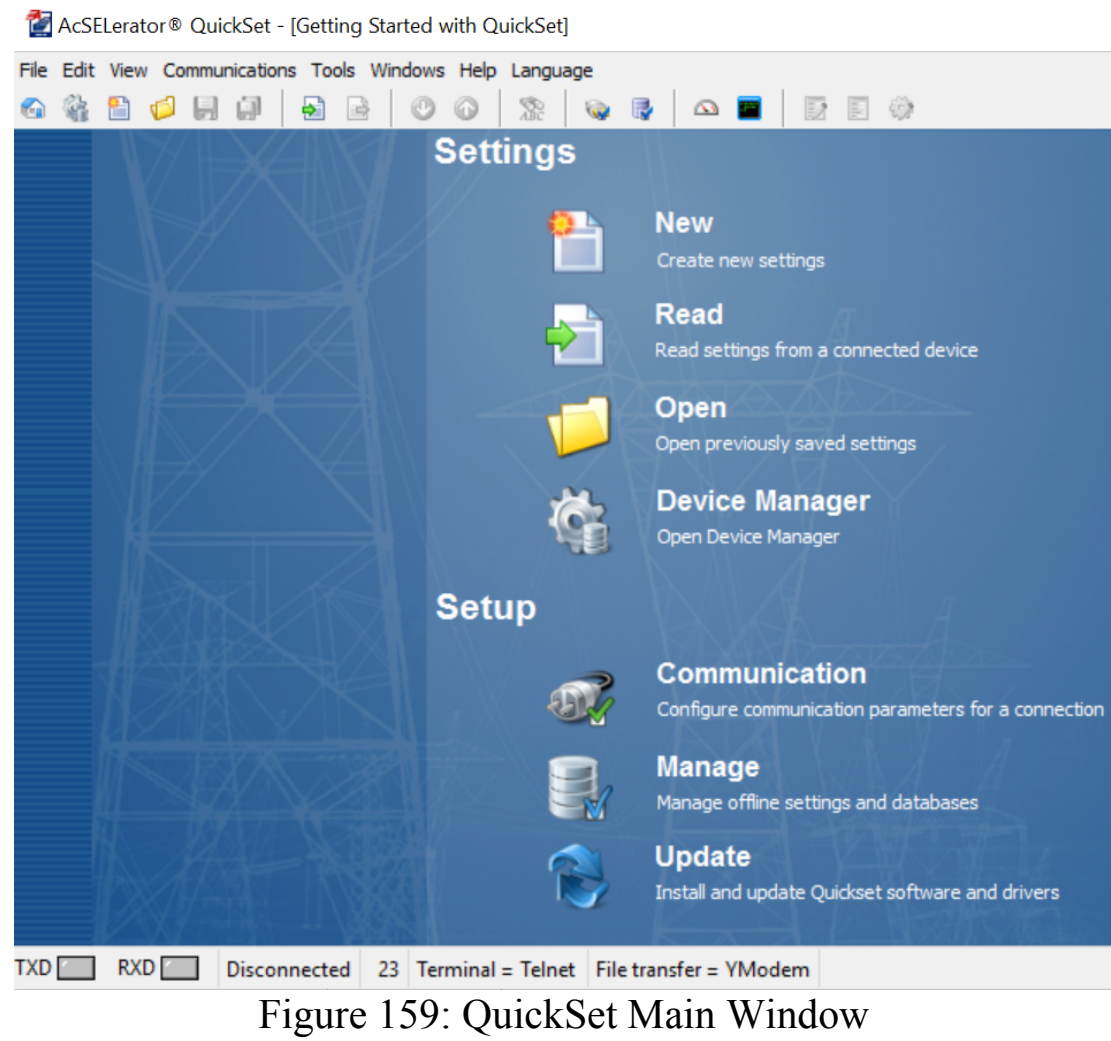




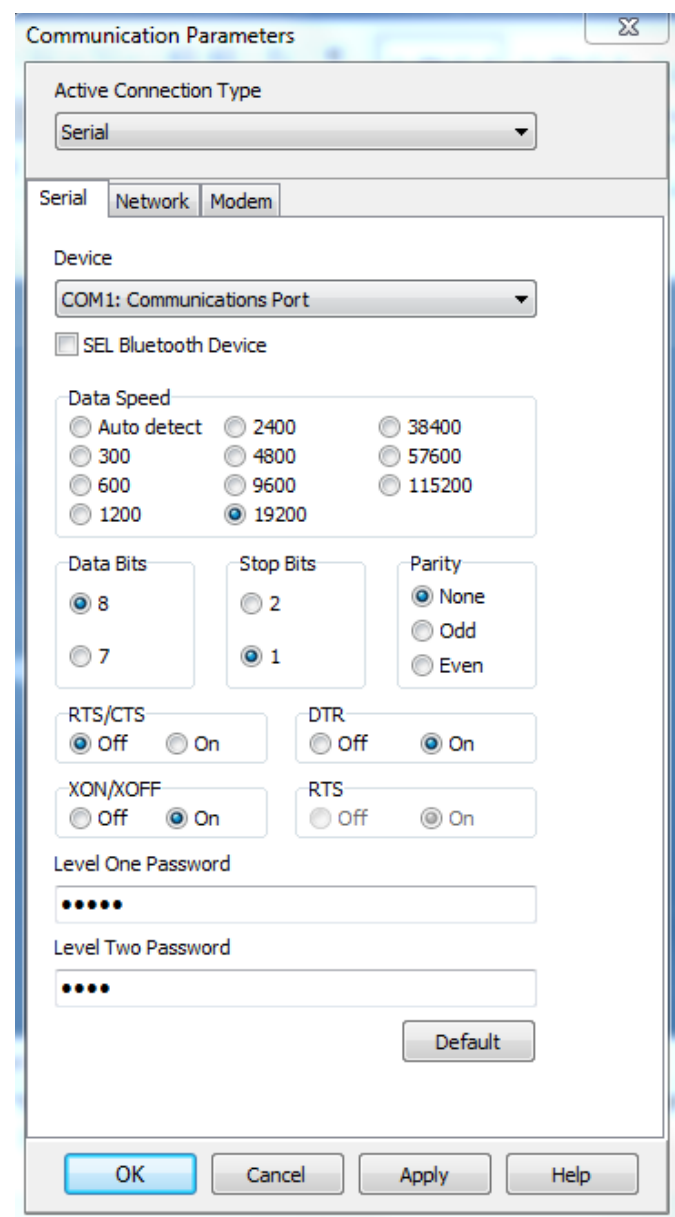

Figure 160: SEL-387E Communication Parameters Window

6. Click Apply at the bottom of the Communication Parameters window. Then click Ok. If the computer successfully connects to the relay, the connection status in the lower-left corner of the QuickSet main window should say "Connected."

7. Open your existing settings file for the SEL-387E relay (from the differential protection experiment).

a. Select File, Open in the QuickSet main window and navigate to the file path where you saved the relay database.

b. Open the database and select the SEL-387E settings file.

8. In the Configuration Settings under Group 1, Set 1, select $\underline{Y}$ for Enable Winding 2 Overcurrent Elements and Demand Thresholds (EOC2).

9. Enter the following information in the Winding 2 Overcurrent Elements section (see Figure 161 through Figure 164). These elements provide secondary (backup) protection for faults downstream of the power transformer.

a. Enter a Phase Inverse-Time Overcurrent Pickup (51P2P) value of $\underline{4.50} \mathrm{~A}$. This setting causes the relay to trip (after a delay) for high fault currents flowing through winding 2 of the power transformer. In this experiment, 
this setting only trips for three-phase faults, triple-line-to-ground faults, or overload conditions. Negative-sequence overcurrent protection will trip first for line-to-line, single-line-to-ground, and double-line-to-ground faults. As an aside, note that the different parts of this protection element describe its function: " $51 \mathrm{P}$ " denotes inverse-time phase overcurrent, ' 2 ' denotes winding two of the power transformer, and the second ' $\mathrm{P}$ ' denotes the pickup element.

b. Select a Phase Inverse-Time Overcurrent Curve (51P2C) of U1 to allow coordination with other downstream protective devices in future experiments. Curve U1 corresponds to the American moderately-inverse coordination curve.

c. Enter a Phase Inverse-Time Overcurrent Time-Dial (51P2TD) setting of 0.55. This delay allows time for downstream protective devices to trip first for faults within their primary zone of protection before the SEL-387E trips more of the system off-line.

d. Turn off the Phase Inverse-Time Overcurrent Electromechanical Reset (51P2RS). This choice causes the relay to reset after just one cycle of current below the pick-up value, as opposed to the slow reset of a traditional electromechanical relay.

e. Enter a Negative-Sequence Inverse-Time Overcurrent Pickup (51Q2P) value of $\underline{0.50} \mathrm{~A}$. This setting causes the relay to trip (after a delay) for line-to-line, single-line-to-ground, and double-line-to-ground faults downstream of the power transformer.

f. Select a Negative-Sequence Inverse-Time Overcurrent Curve (51Q2C) of U1 to allow coordination with other downstream protective devices.

g. Enter a Negative-Sequence Inverse-Time Overcurrent Time-Dial (51Q2TD) setting of $\underline{0.55}$. This delay allows time for downstream protective devices to trip first for faults within their primary zone of protection before the SEL-387E trips more of the system off-line.

h. Turn off the Negative-Sequence Inverse-Time Overcurrent Electromechanical Reset (51Q2RS). 


\section{Winding 2 Elems}

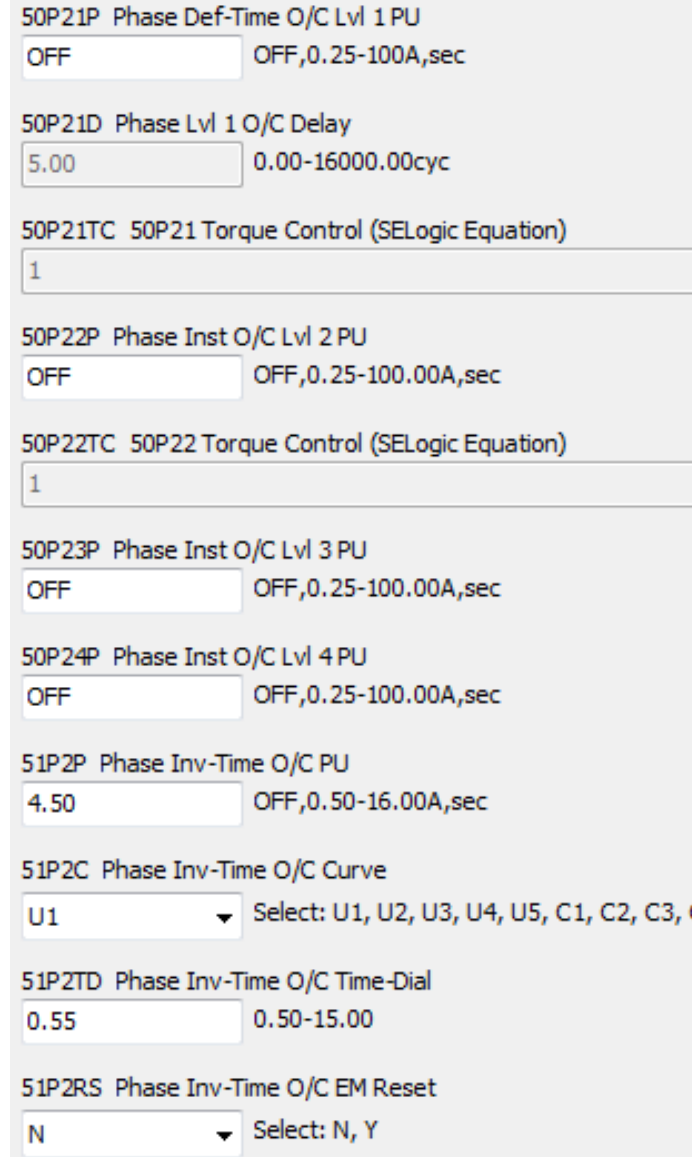

Figure 161: SEL-387E Group 1 Overcur Protection Elements
51P2TC 51P2 Torque Control (SELogic Equation)

1

50Q21P Neg-Seq Def-Time O/C Lvl 1 PU

OFF OFF, $0.25-100 \mathrm{~A}_{r} \mathrm{sec}$

50Q21D Neg-Seq Lvl 1 O/C Delay

$5.00 \quad 0.50-16000.00$ cyc

50Q21TC 50Q21 Torque Control (SELogic Equation)

1

50Q22P Neg-Seq Inst O/C Lvl 2 PU

OFF OFF, $0.25-100.00 \mathrm{~A}, \mathrm{sec}$

50Q22TC 50Q22 Torque Control (SELogic Equation)

1

51Q2P Neg-Seq Inv-Time O/C PU

$0.50 \quad$ OFF, $0.50-16.00 A_{r}$ sec

51Q2C Neg-Seq Inv-Time O/C Curve

U1 Select: U1, U2, U3, U4, U5, C1, C2, C3, C4, C5

51Q2TD Neg-Seq Inv-Time O/C Time-Dial

$0.55 \quad 0.50-15.00$

51Q2RS Neg-Seq Inv-Time O/C EM Reset

Y $\quad$ Select: N, Y

51Q2TC 51 Q2 Torque Control (SELogic Equation)

1

50N21P Res. Def-Time O/C Lvl 1 PU

OFF OFF, $0.25-100.00 \mathrm{~A}$, sec

Figure 162: SEL-387E Group 1 Overcurrent Protection Elements, cont. 


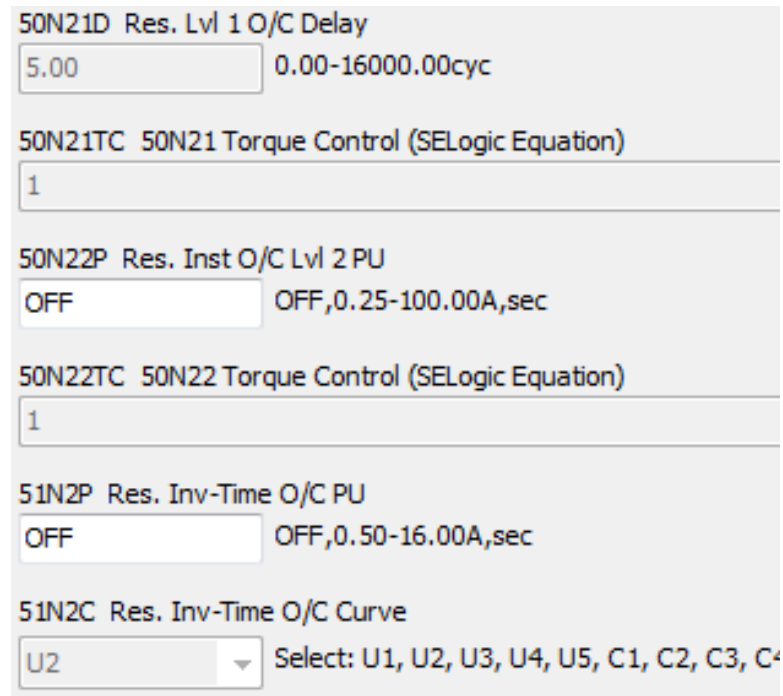

Figure 163: SEL-387E Group 1 Overcurren Protection Elements, cont.
51N2TD Res. Inv-Time O/C Time-Dial $0.50-15.00$

51N2RS Res. Inv-Time O/C EM Reset

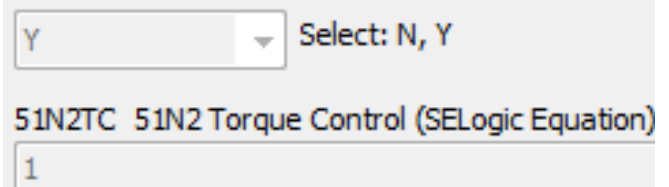

DATC2 Demand Ammeter Time Constant

15 OFF, $5-255 \mathrm{~min}$

PDEM2P Phase Demand Ammeter Thresh

$7.00 \quad 0.50-16.00 \mathrm{~A}, \mathrm{sec}$

QDEM2P Neg-Seq Demand Ammeter Thresh

$1.00 \quad 0.50-16.00 \mathrm{~A}, \mathrm{sec}$

NDEM2P Res. Demand Ammeter Thresh

$1.00 \quad 0.50-16.00 \mathrm{~A}, \mathrm{sec}$

Figure 164: SEL-387E Group 1

Overcurrent Protection Elements, cont.

10. Enter the following information in the Trip Logic section (see Figure 165).

a. Modify the first Assert Trip Logic (TR1) setting. Replace the default

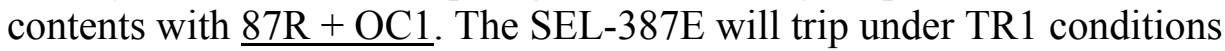
when either the restrained differential protection $(87 \mathrm{R})$ is tripped, or a command $(\mathrm{OC} 1)$ is given to open breaker 1 on winding 1 of the power transformer.

b. Leave the second Assert Trip Logic (TR2) setting with its default contents. The SLE-387E will trip under TR2 conditions when winding 2 phase inverse-time overcurrent (51P2T) protection trips, when winding 2 negative-sequence inverse-time overcurrent protection (51Q2T) trips, or when a command (OC2) is given to open breaker 2 on winding 2 of the power transformer. 


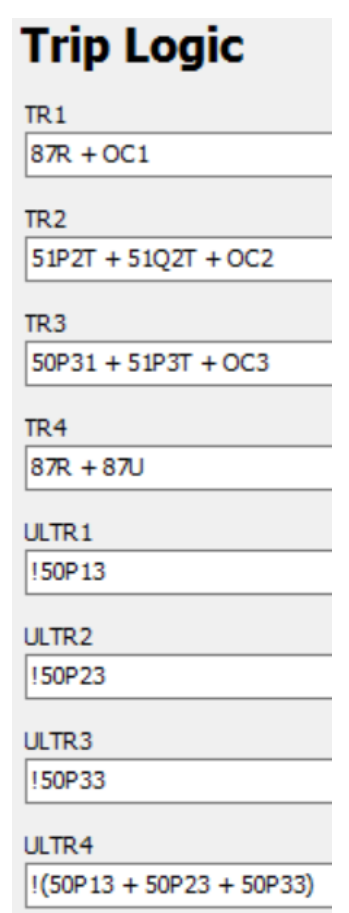

Figure 165: SEL-387E Group 1 Trip Logic

11. Enter the following information in the Output Contact Logic section (see Figure 166).

a. Logically-invert the default OUT101 signal to be !TRIP1. Logical inversion is necessary for interfacing the normally-open switch on the SEL-387E with the circuit breaker trip coil. This equation causes the circuit breaker (on the winding 1 side of the power transformer) connected to back-panel output port 101 on the SEL-387E to trip under TR1 fault conditions (see Step 12a).

b. Change the OUT102 signal to !(TRIP1 + TRIP2). This equation trips the winding 2 circuit breaker under either TR1 or TR2 fault conditions (see Step 12a).

c. Set the OUT103 and OUT104 signals to $\underline{0}$. 


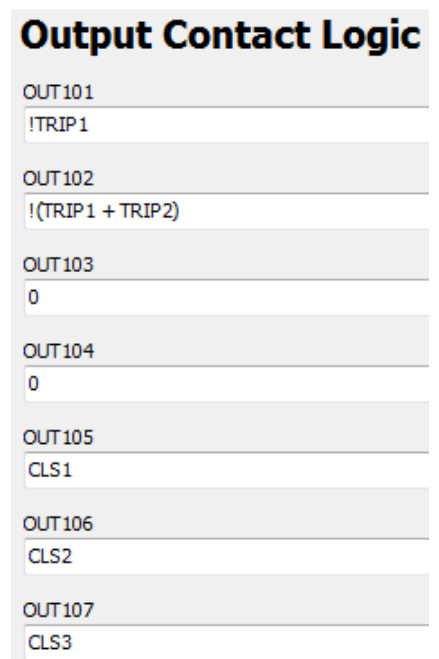

Figure 166: SEL-387E Group 1 Output Contact Logic

12. Save your settings (File, Save).

13. Send your settings (File, Send...) to the SEL-387E. In the window that appears, check the boxes for the Group 1 settings (Figure 157). Sending only the modified settings shortens the file transfer time. Since it can take several minutes to transfer the relay settings, now is a good time to start constructing the circuit.

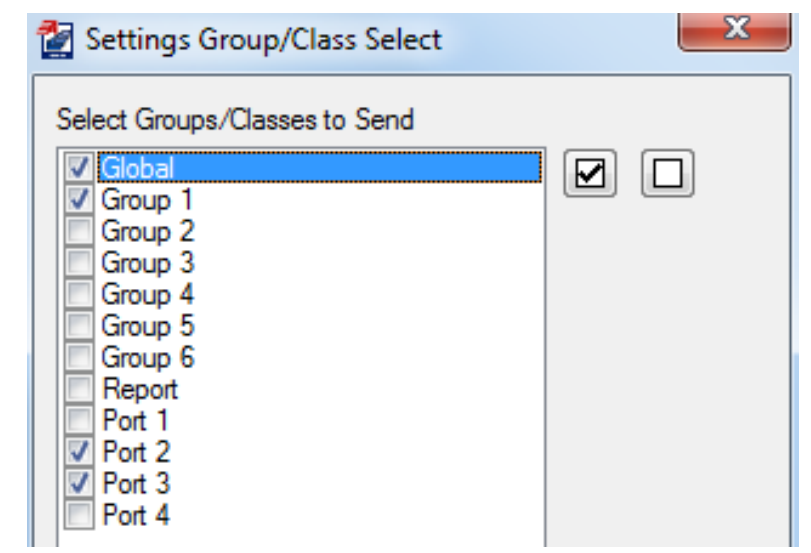

Figure 167: Send Modified Settings to SEL-387E

14. Connect the three-phase circuit illustrated in Figure 158. Try to lay out the elements in the order illustrated in the schematic so that power flows across the bench from one end to the other. This linear arrangement limits the number of wires crossing each other and makes the path of current flow easier to review (and troubleshoot). Start with the sequential connection points in Table 52, using the diagrams posted on the wattmeter and transformer at the lab bench for assistance. Then add the following connections:

a. Connect back-panel port Z19 of the SEL-387E to terminal 3 of the transformer phase A secondary winding. 
b. Connect back-panel port Z20 of the SEL-387E to terminal 3 of the transformer phase B secondary winding.

c. Connect back-panel port $\mathbf{Z 2 1}$ of the SEL-387E to terminal 3 of the transformer phase $\mathrm{C}$ secondary winding.

d. Connect back-panel port Z22 of the SEL-387E to terminal 6 of the transformer secondary winding.

e. Jumper all transformer terminal 2 points together (Y-grounded primary).

f. Jumper transformer terminals 4 and 5 for each phase of the power transformer.

g. Jumper all transformer terminal 6 points together (Y-grounded secondary).

h. Connect back-panel port A01 of the SEL-387E to the top Breaker Control Trip terminal on circuit breaker \#1 (transformer primary winding). Connect back-panel port A02 to the bottom Breaker Control Trip terminal on circuit breaker \#1.

i. Connect back-panel port A03 of the SEL-387E to the top Breaker Control Trip terminal on circuit breaker \#2 (transformer secondary winding). Connect back-panel port A04 to the bottom Breaker Control Trip terminal on circuit breaker \#2.

j. Connect the positive (upper) Breaker Control 125 VDC terminal on all circuit breakers to input terminal $\mathrm{G}$ on the lab bench. Connect the negative (lower) Breaker Control 125 VDC terminal on all circuit breakers to terminal $\mathrm{H}$.

k. Connect the green chassis ground terminals on each circuit breaker to the green bench ground terminal.

1. Jumper together the positive and negative Breaker Control Trip terminals on circuit breaker \#3. This connection replaces input from a relay and enables manual closing of the circuit breaker. 
Table 52: Per-Phase Sequential Points of Connection

\begin{tabular}{|c|c|c|}
\hline Phase A & Phase B & Phase C \\
\hline Input Voltage & Input Voltage & Input Voltage \\
\hline Wattmeter & Wattmeter & Wattmeter \\
\hline $25 \Omega$ Resistor Input & $25 \Omega$ Resistor Input & $25 \Omega$ Resistor Input \\
\hline $25 \Omega$ Resistor Output & $25 \Omega$ Resistor Output & $25 \Omega$ Resistor Output \\
\hline $\begin{array}{l}\text { Relay Port Z01 } \\
\text { (Relay Input) }\end{array}$ & $\begin{array}{l}\text { Relay Port Z03 } \\
\text { (Relay Input) }\end{array}$ & $\begin{array}{l}\text { Relay Port Z05 } \\
\text { (Relay Input) }\end{array}$ \\
\hline $\begin{array}{l}\text { Relay Port Z02 } \\
\text { (Relay Output) }\end{array}$ & $\begin{array}{l}\text { Relay Port Z04 } \\
\text { (Relay Output) }\end{array}$ & $\begin{array}{l}\text { Relay Port Z06 } \\
\text { (Relay Output) }\end{array}$ \\
\hline CB \#1 (XFMR Primary & CB \#1 (XFMR Primary & CB \#1 (XFMR Primary \\
\hline $\begin{array}{c}\text { Side) Circuit Breaker Red } \\
\text { Terminal }\end{array}$ & $\begin{array}{c}\text { Side) Circuit Breaker Red } \\
\text { Terminal }\end{array}$ & $\begin{array}{c}\text { Side) Circuit Breaker Red } \\
\text { Terminal }\end{array}$ \\
\hline $\begin{array}{c}\text { CB \#1, Circuit Breaker } \\
\text { Black Terminal }\end{array}$ & $\begin{array}{c}\text { CB \#1, Circuit Breaker } \\
\text { Black Terminal }\end{array}$ & $\begin{array}{c}\text { CB \#1, Circuit Breaker } \\
\text { Black Terminal }\end{array}$ \\
\hline $\begin{array}{l}\text { Transformer Primary } \\
\text { Winding, Terminal } 1\end{array}$ & $\begin{array}{l}\text { Transformer Primary } \\
\text { Winding, Terminal } 1\end{array}$ & $\begin{array}{l}\text { Transformer Primary } \\
\text { Winding, Terminal } 1\end{array}$ \\
\hline $\begin{array}{c}\text { Transformer Secondary } \\
\text { Winding, Terminal } 3\end{array}$ & $\begin{array}{c}\text { Transformer Secondary } \\
\text { Winding, Terminal } 3\end{array}$ & $\begin{array}{c}\text { Transformer Secondary } \\
\text { Winding, Terminal } 3\end{array}$ \\
\hline $\begin{array}{c}\text { CB \#2, Circuit Breaker } \\
\text { Red Terminal } \\
\end{array}$ & $\begin{array}{c}\text { CB \#2, Circuit Breaker } \\
\text { Red Terminal } \\
\end{array}$ & $\begin{array}{c}\text { CB \#2, Circuit Breaker } \\
\text { Red Terminal } \\
\end{array}$ \\
\hline $\begin{array}{l}\text { CB \#2, Circuit Breaker } \\
\text { Black Terminal }\end{array}$ & $\begin{array}{l}\text { CB \#2, Circuit Breaker } \\
\text { Black Terminal }\end{array}$ & $\begin{array}{l}\text { CB \#2, Circuit Breaker } \\
\text { Black Terminal }\end{array}$ \\
\hline $\begin{array}{c}\text { Relay Port Z08 * } \\
\text { (Relay Input) }\end{array}$ & $\begin{array}{c}\text { Relay Port Z10 * } \\
\text { (Relay Input) }\end{array}$ & $\begin{array}{c}\text { Relay Port Z12 * } \\
\text { (Relay Input) }\end{array}$ \\
\hline $\begin{array}{c}\text { Relay Port Z07 * } \\
\text { (Relay Output) }\end{array}$ & $\begin{array}{c}\text { Relay Port Z09* } \\
\text { (Relay Output) }\end{array}$ & $\begin{array}{c}\text { Relay Port Z11* } \\
\text { (Relay Output) }\end{array}$ \\
\hline $\begin{array}{c}\text { CB \#3, Circuit Breaker } \\
\text { Red Terminal }\end{array}$ & $\begin{array}{c}\text { CB \#3, Circuit Breaker } \\
\text { Red Terminal }\end{array}$ & $\begin{array}{c}\text { CB \#3, Circuit Breaker } \\
\text { Red Terminal }\end{array}$ \\
\hline $\begin{array}{c}\text { CB \#3, Circuit Breaker } \\
\text { Black Terminal }\end{array}$ & $\begin{array}{c}\text { CB \#3, Circuit Breaker } \\
\text { Black Terminal }\end{array}$ & $\begin{array}{c}\text { CB \#3, Circuit Breaker } \\
\text { Black Terminal }\end{array}$ \\
\hline $\begin{array}{c}333 \Omega \text { Hampden Resistive } \\
\text { Load }\end{array}$ & $\begin{array}{c}333 \Omega \text { Hampden Resistive } \\
\text { Load }\end{array}$ & $\begin{array}{l}333 \Omega \text { Hampden Resistive } \\
\text { Load }\end{array}$ \\
\hline Bench Ground & Bench Ground & Bench Ground \\
\hline
\end{tabular}

* Rolling transformer secondary winding current phases.

15. Verify the circuit connections and obtain instructor approval to apply power to the circuit. 
16. Apply both AC and DC power from the bench and close all circuit breakers (with the Manual Breaker Control Close button). Compare the three-phase current and voltage displayed on the wattmeter with prelab calculations to confirm expected operation under nominal loading conditions. If the values do not agree, turn off power and check the circuit wiring for errors.

17. Create a line-to-line fault downstream of the power transformer.

a. Turn off $\mathrm{AC}$ and DC power from the bench.

b. Jumper the black Circuit Breaker terminals to the red Fault Connections terminals (if present) on circuit breaker \#3. Jumper two of the black Fault Connections terminals together.

c. Set the circuit breaker Fault Switches to the Normal position.

d. Turn on AC and DC bench power. Manually close all circuit breakers.

e. Flip the circuit breaker \#3 Fault Switch to the Fault position.

f. Watch the wattmeter to confirm that the SEL-387E trips the circuit breaker to clear the fault. If it does not, turn off $\mathrm{AC}$ bench power before sustained fault current damages circuit components.

g. Once the relay clears the fault, turn off AC and DC bench power and flip the Fault Switch to the Normal position. Press the Target Reset button on the SEL-387E to clear the relay's front-panel LED display.

h. Retrieve the event file(s) from the SEL-387E.

i. Add the TRIP2, 51Q2T, and 51Q2 digital signals to the oscillogram plot.

18. Retrieve the SEL-387E event file for the fault trip.

a. In QuickSet, select Tools, Event Files, Get Event Files.

b. In the window that comes up, select Refresh Event History.

c. Choose an Event Type of 64 Samples / Cycle - Raw and an Event Length of 15 cycles.

d. Check the boxes of the event file(s) corresponding to the fault. Event files are indexed, with ' 1 ' being the most recent event file saved by the relay.

e. Click Get Selected Events. Save the events in a convenient location using either a default or custom naming convention.

f. Double-click on the event report file in its file path location. The AcSELerator Analytic Assistant software automatically opens an oscillogram plot of the event.

g. Click the Pref button in the lower-right corner of the oscillogram to add digital fault-trip signals to the plot. Left-click on the signal you wish to display (from the available list in the lower-left corner of the screen), then right-click-drag the signal to the Digital Axis list of signals to be displayed.

h. After saving the desired event files, enter the HIS C command in the QuickSet Terminal window (select Communications, Terminal) to clear previous event files from the relay's memory. If an error message appears about an invalid access level, type in ACC, the Enter key, the level relay 1 password (default for SEL-387E is OTTER), and the Enter key. Proceed to clear the event files. 
19. Create a single-line-to-ground fault downstream of the power transformer.

a. Turn off AC and DC power from the bench.

b. Jumper the black Circuit Breaker terminals to the red Fault Connections terminals (if present) on circuit breaker \#3. Connect one of the black Fault Connections terminals directly to bench ground.

c. Set the circuit breaker Fault Switches to the Normal position.

d. Turn on AC and DC bench power. Manually close all circuit breakers.

e. Flip the circuit breaker \#3 Fault Switch to the Fault position.

f. Watch the wattmeter to confirm that the SEL-387E trips the circuit breaker to clear the fault. If it does not, turn off $\mathrm{AC}$ bench power before sustained fault current damages circuit components.

g. Once the relay clears the fault, turn off AC and DC bench power and flip the Fault Switch to the Normal position. Press the Target Reset button on the SEL-387E to clear the relay's front-panel display.

h. Retrieve the event file(s) from the SEL-387E.

i. Add the TRIP2, 51Q2T, and 51Q2 digital signals to the oscillogram plot.

20. Create a triple-line-to-ground fault downstream of the power transformer.

a. Turn off AC and DC power from the bench.

b. Jumper the black Circuit Breaker terminals to the red Fault Connections terminals (if present) on circuit breaker \#3. Jumper all three of the black Fault Connections terminals together and connect these terminals directly to bench ground.

c. Set the circuit breaker Fault Switches to the Normal position.

d. Turn on AC and DC bench power. Manually close all circuit breakers.

e. Flip the circuit breaker \#3 Fault Switch to the Fault position.

f. Watch the wattmeter to confirm that the SEL-387E trips the circuit breaker to clear the fault. If it does not, turn off $\mathrm{AC}$ bench power before sustained fault current damages circuit components. Note, however, that the relay waits much longer before tripping under this fault condition.

g. Once the relay clears the fault, turn off AC and DC bench power and flip the Fault Switch to the Normal position. Press the Target Reset button on the SEL-387E to clear the relay's front-panel display.

h. Retrieve the event file(s) from the SEL-387E.

i. Add the TRIP2, 51P2T, and 51P2 digital signals to the oscillogram plot.

\section{Postlab Questions}

- Explain why both circuit breakers \#1 and \#2 tripped for transformer faults (within the differential zone of protection described in the previous SEL-387E experiment), whereas only circuit breaker \#2 tripped for faults downstream of the transformer (outside the differential zone of protection). Base your explanation on the Trip Logic and Output Contact Logic relay settings. 
- For faults downstream of the transformer, why did negative-sequence overcurrent protection only trip the relay for line-to-line, single-line-to-ground, and (if you tried it) double-line-to-ground faults? Why not three-phase or triple-line-toground faults?

- Compare the relay response time shown on the oscillograms with the expected values calculated in the prelab. Explain possible causes for these differences. Hint: the power transformers in the lab benches operate in saturation (recall the B$\mathrm{H}$ curve), which affects the expected impedance obtained from open-circuit and short-circuit tests.

\section{Deliverables}

Answer the postlab questions. Turn in oscillograms for the fault events described in the procedure. The bottom of each oscillogram should show the digital signal associated with the type of protection triggered by the fault. Give each plot a caption specifying the relay, fault type and location, and type of protection triggered.

Keep the relay settings for use in future experiments. 


\section{Appendix N: Radial System Coordination Procedure}

\section{ELECTRICAL ENGINEERING DEPARTMENT \\ California Polytechnic State University \\ San Luis Obispo}

EE 518

Experiment \#7

Radial Circuit Relay Coordination Using the SEL-311L, SEL-387E, and SEL-710

\section{Learning Outcomes}

- Identify, record, and eliminate bolted faults at the terminals of an induction motor using inverse-time overcurrent protection

- Coordinate multiple overcurrent relays to minimize the portions of a circuit affected by a fault

\section{Background}

Electric utility companies coordinate the relays in their power systems to minimize the number of devices and customers affected by a fault at any given location. In a properly coordinated radial distribution system (a circuit in which power flows straight from the source to the load), the nearest relay upstream of a fault trips first. To give enough time for the first relay to isolate the fault, all other relays upstream of the fault delay before tripping. If the nearest upstream relay fails to isolate the fault, the nextclosest upstream relay trips to provide backup protection for the system. This coordination continues all the way back to the relays at the power source, which delay the longest before tripping.

This experiment models a radial distribution system (Figure 168). Power enters the circuit from a connection to the infinite bus, which models a high-voltage transmission line entering a substation. A power transformer converts the voltages and currents from the transmission level (high voltages and relatively low currents) to the distribution level (lower voltages and higher currents). A transmission line, modeled in this experiment by discrete inductors, transmits power from the substation to the customer. An induction motor and static resistive load model customers located at the termination of the radial distribution system. Three relays protect this system against faults along the radial circuit. An SEL-387E protects the power transformer, an SEL$311 \mathrm{~L}$ protects the transmission line, and an SEL-710 protects the induction motor. 


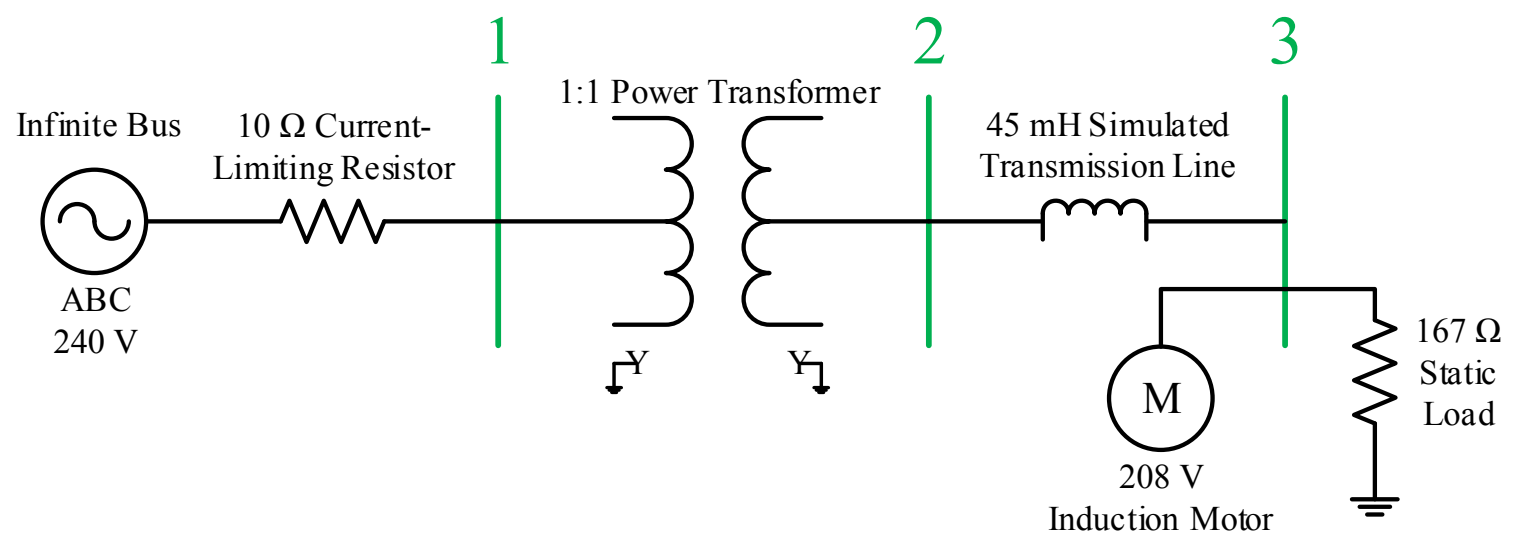

Figure 168: Radial Power Distribution System Model

Faulting the induction motor provides the best test of relay coordination in the radial system. If the relays are properly coordinated, the SEL-710 should trip for the fault before the SEL-311L and SEL-387E because it is the closest relay upstream of that fault location. If the SEL-710 fails to successfully isolate the fault, then the SEL-311L should trip to provide backup protection. By extension, the SEL-387E should trip if both the SEL-710 and SEL-311L fail to isolate the fault.

Post-fault event analysis in a multi-relay system depends heavily on all relays in a system sharing a common time reference. Without a common reference, fault events recorded by one relay could not be directly compared to those of another relay. Synchronizing all relay clocks to the same time enables engineers to piece together fault reports from multiple relays to determine the location and cause of the disturbance. This experiment uses an SEL-2407 Satellite-Synchronized Clock to provide a common time reference for all relays in the radial distribution system. 


\section{Procedure}

\section{Program SEL-2020/32 Settings}

1. Open the SEL-5020 Settings Assistant software (Figure 169).

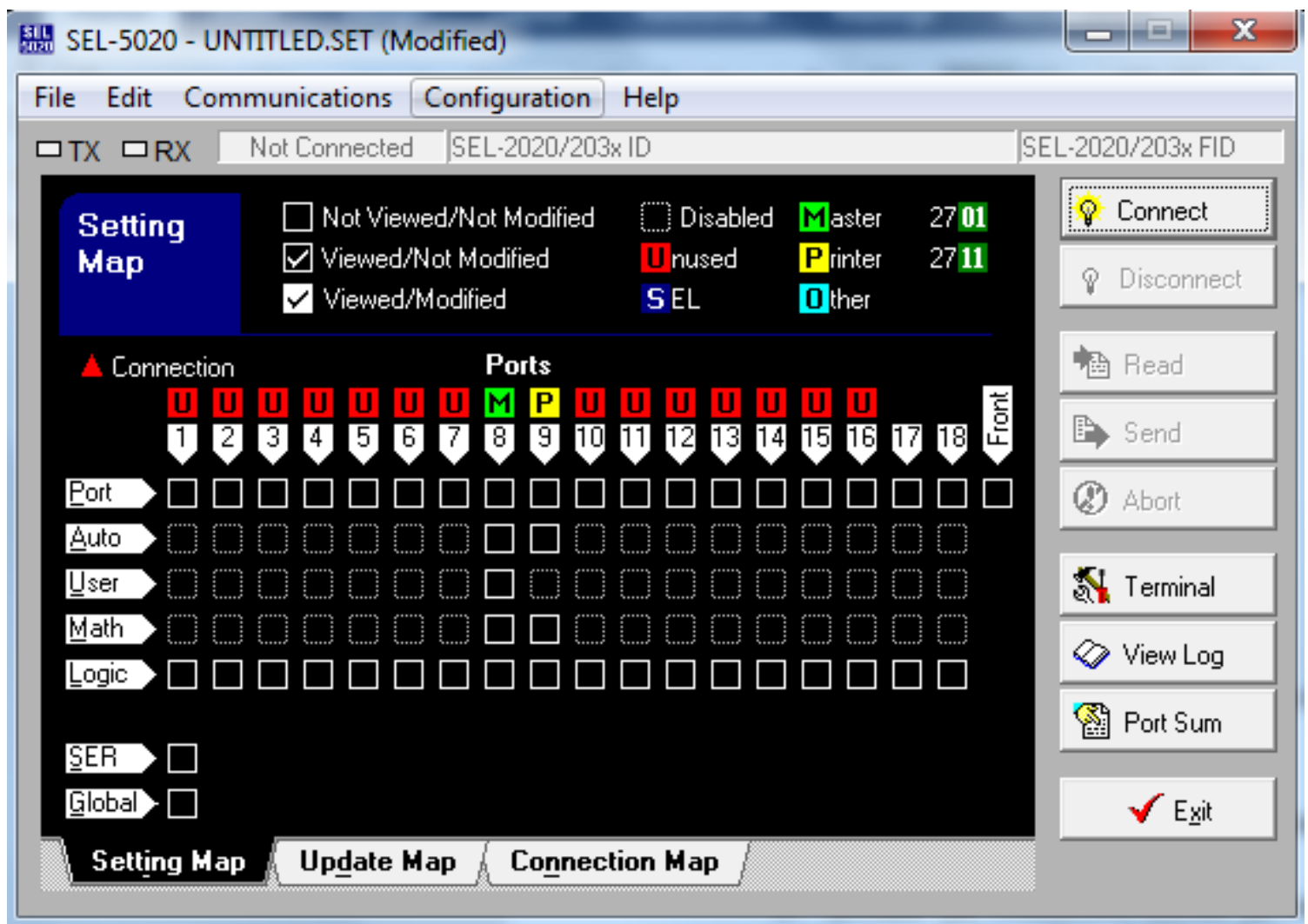

Figure 169: SEL-5020 Settings Assistant Software Main Screen

2. Configure the SEL-2020/32 rear-panel master serial port (first-time device setup only).

a. Connect SEL-2020/32 front-panel Port F to the main serial port on the back of the computer (surrounded by a light turquoise color) using an SEL-C234A serial cable.

b. Open AcSELerator QuickSet and the Communication Parameters window (Communications, Parameters) (Figure 181).

c. Connect to the SEL-2020/32 (guess the baud rate as either 2400 or 9600 and enter the default level 1 and 2 passwords: OTTER and TAIL). Click Apply. Ask for help if you get stuck on this step.

d. Open the AcSELerator QuickSet terminal window (Communications, Terminal) and press the ENTER key (on the keyboard). If you do not see an '*' displayed at the top of the window, you failed to successfully complete the previous step.

e. Type ACC followed by ENTER to gain level 1 access to the communications processor (Figure 170). 
f. Type the level one password (OTTER).

g. Type $2 \mathrm{AC}$ followed by ENTER to gain level 2 access to the communications processor.

h. Type the level two password (TAIL).

i. Type SET P 10 followed by ENTER to change the settings for serial port 10.

j. Type $\underline{\mathrm{M}}$ to use serial port 10 on the communications processor as the master port that communicates with the computer (Figure 171). Type the ENTER key five times until the first Communications Settings prompt appears.

k. Type 19200 to set the port 10 baud rate to a faster speed. Type the ENTER key.

1. Continue to type the ENTER key until asked whether you want to save the settings changes. Type $\underline{Y}$ followed by ENTER.

\begin{tabular}{|c|c|c|c|c|}
\hline \multirow{2}{*}{\multicolumn{5}{|c|}{$* a 00$}} \\
\hline & & & & \\
\hline \multicolumn{5}{|l|}{ Fassword: ? OTTER } \\
\hline & Date & $05 / 20 / 17$ & Time & $23: 53: 58$ \\
\hline \multicolumn{5}{|l|}{$\begin{array}{l}\text { Level } 1 \\
*>2 \mathrm{AC}\end{array}$} \\
\hline Fassword: ? TAIL & & & & \\
\hline
\end{tabular}

Figure 170: Obtaining Level 1 and Level 2 Access to a Communications Processor

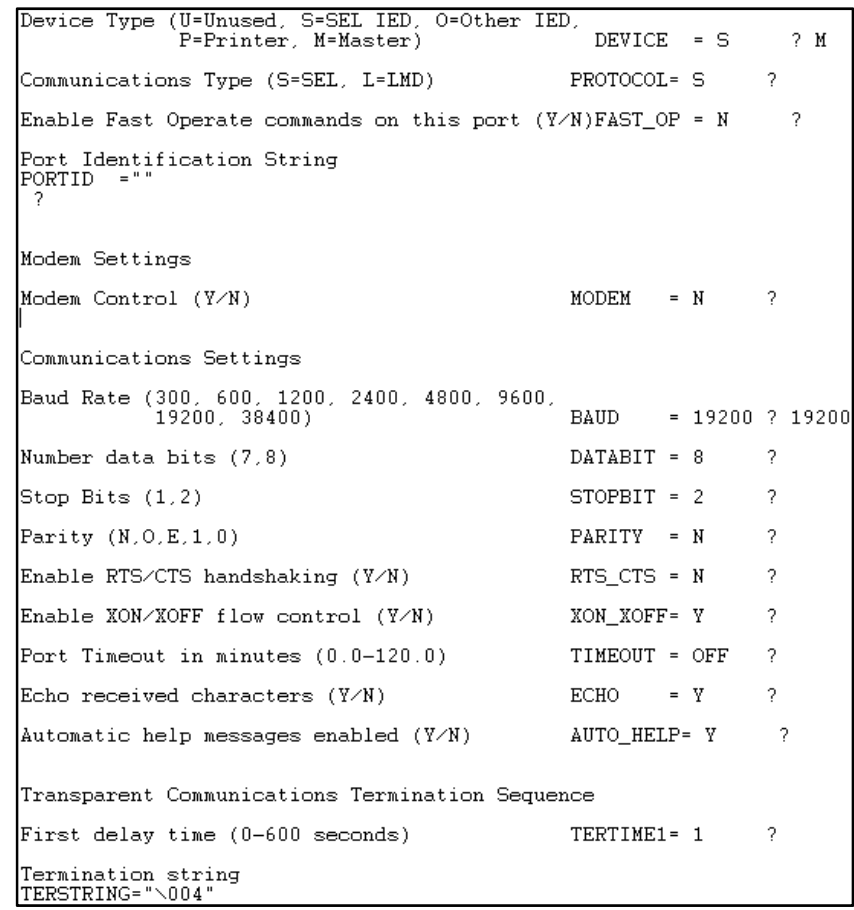

Figure 171: Establish SEL-2020/32 Master Port Using QuickSet Terminal 
2. Remove the serial cable from port F, and connect the SEL-2020/32 Port 10 to the main serial port on the back of the computer (surrounded by a light turquoise color) using an SEL-C234A serial cable.

3. Define communication parameters for the 2020/32:

a. Select Configuration, Connection Directory.

b. In the Connection Directory, select Add.

c. In the Communication Parameters (Figure 172), type in a name for the 2020/32 unit (like Bench5 2020). Choose a Serial connection and baud rate of 19200 (the default baud rate is 2400 , but has been previously changed to 19200 on this unit). If the standard SEL-C234A serial cable is being used, select Direct to COM1 as the Communication Port (standard desktop PC serial port, surrounded by a turquoise color). Click OK.

d. Back on the Communication Directory screen, select Set as Default to make this 2020/32 the default communication network. Click Close to return to the main screen.

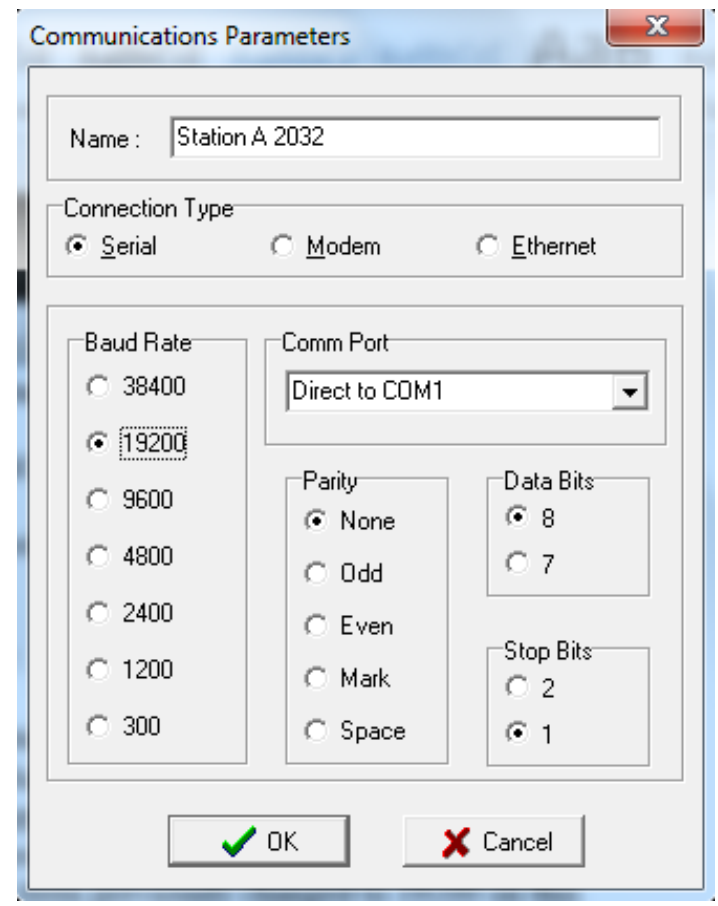

Figure 172: SEL-2020/32 Communication Parameters

4. Define the communications device:

e. Select File, New.

f. Select SEL-2020/32 as the hardware, with I/O Board checked (Figure 173). For the Connection Options, select the name of the 2020/32 network you created previously (e.g. Bench5_2020). Click OK.

g. Save the settings file being created by selecting File, Save As to create a record of the settings to be used. 


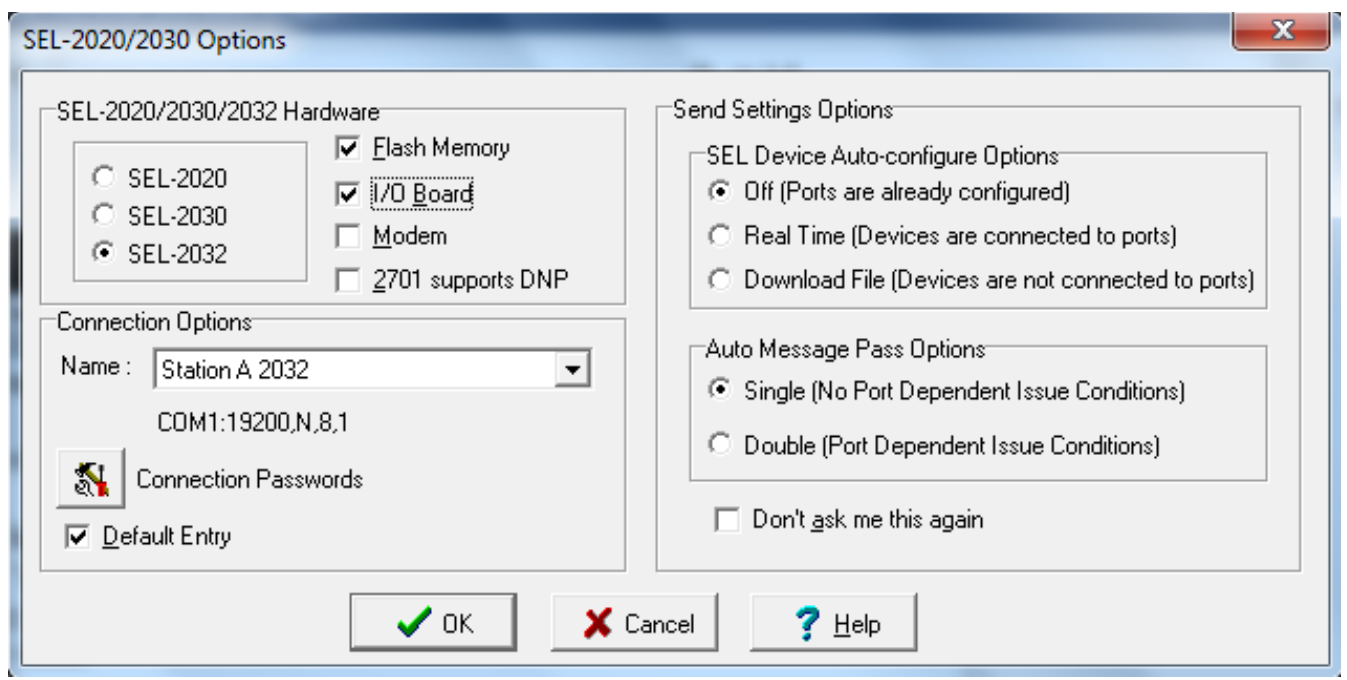

Figure 173: Defining SEL-2020/32 Device Options

5. Enter the settings for the master port (port 10) on the communications processor (Figure 174).

a. Select Edit, Port Settings to bring up the Port Settings window for the 2020/32 being programmed.

b. Select Port Number 10 .

c. Select Master as the Device.

d. Change the Baud setting to 19200 .

e. Click $\underline{\mathrm{OK}}$. 


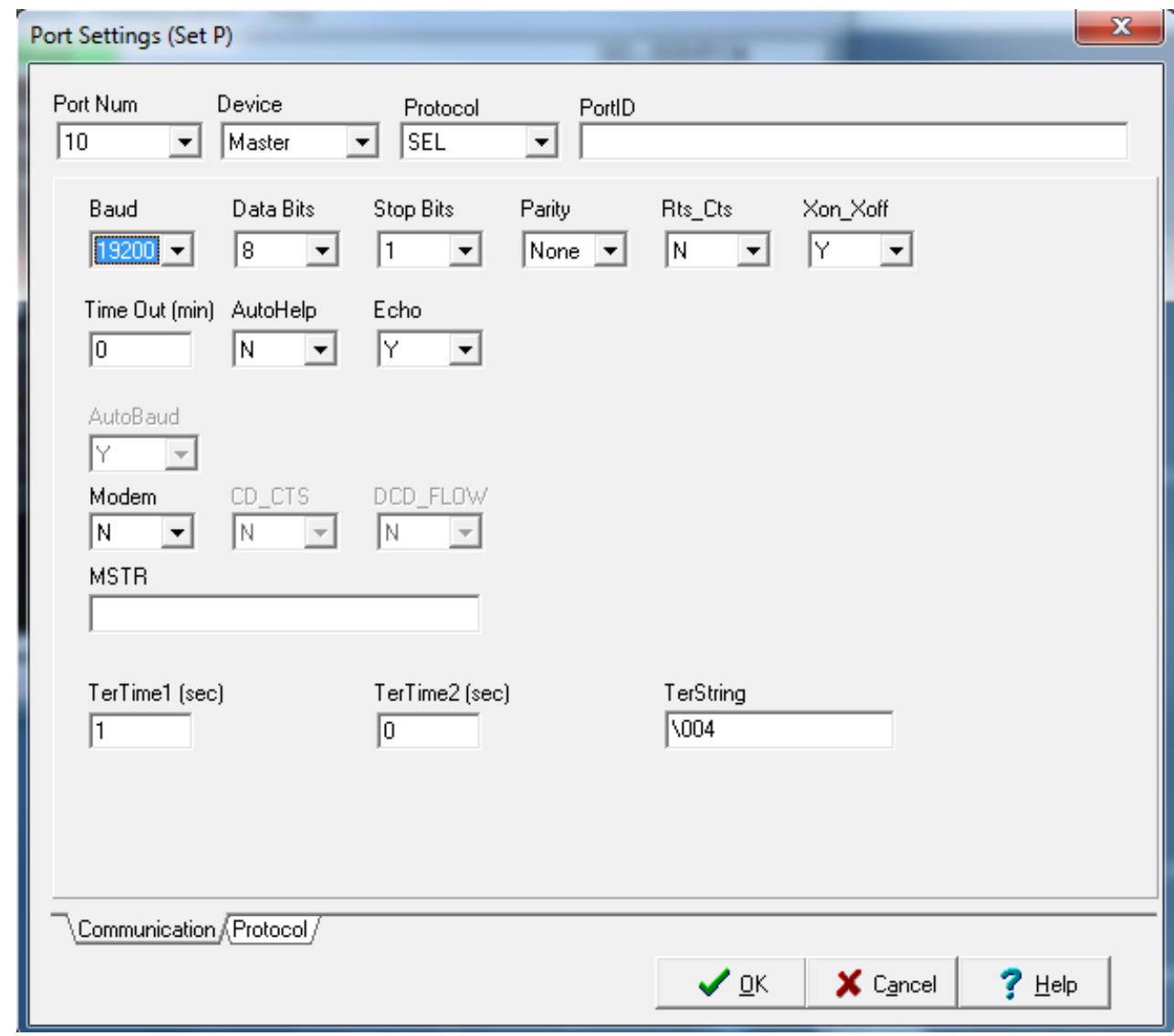

Figure 174: Master Port Settings

6. Establish a connection with the SEL-2020/32 communications processor:

a. Make sure that you have disconnected the active communication between QuickSet and the communications processor (Communications, Disconnect from the QuickSet main window).

b. On the main screen, click Connect (Figure 175) to bring up the terminal window.

c. A Password window may quickly come up prompting you for the level 1 password (the default is OTTER). Proceed to the next step if asked, instead, for the level 2 password. Check Save password as default so that you do not have to enter it again during this work session. Click Ok.

d. Another Password window should quickly come up prompting you for the Level 2 password (the default is TAIL). Check Save password as default so that you do not have to enter it again during this work session. Click Ok.

e. Returning to the main screen, you should see a status of "Connected" with a green background at the top of the screen (Figure 176).

f. Save your progress (File, $\underline{\text { Save }}$ ). 


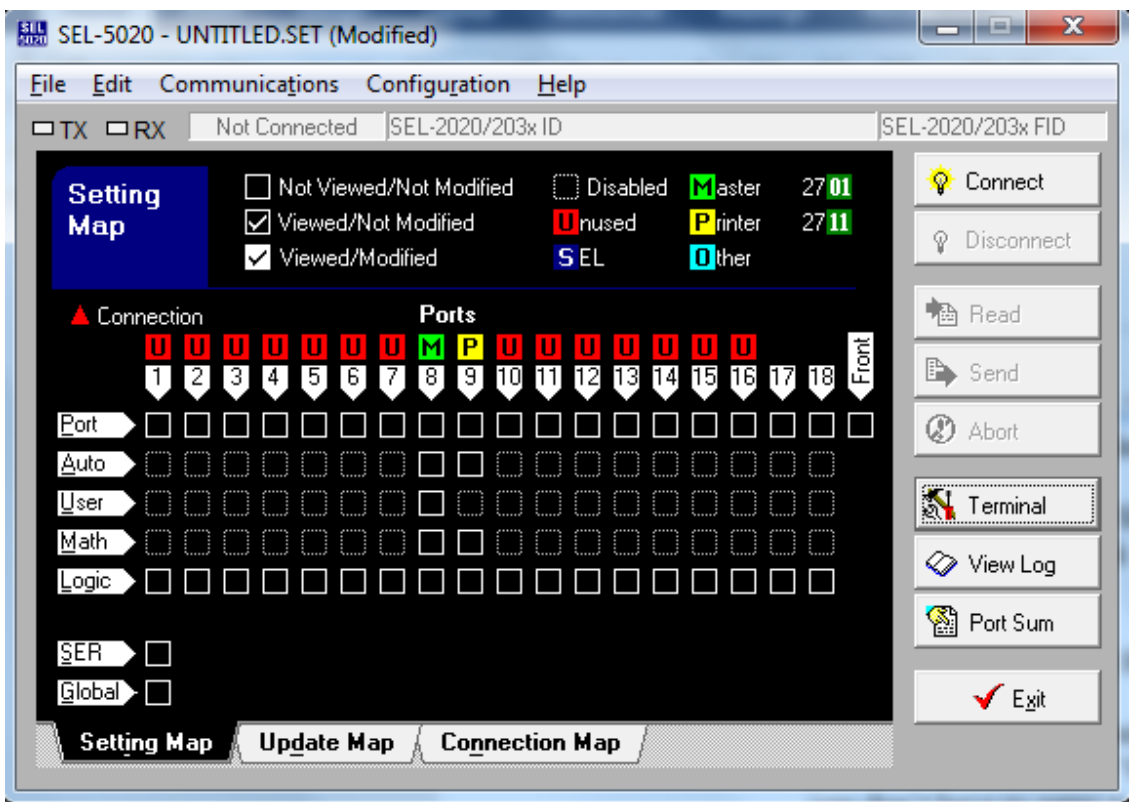

Figure 175: Main Screen before Establishing Connection

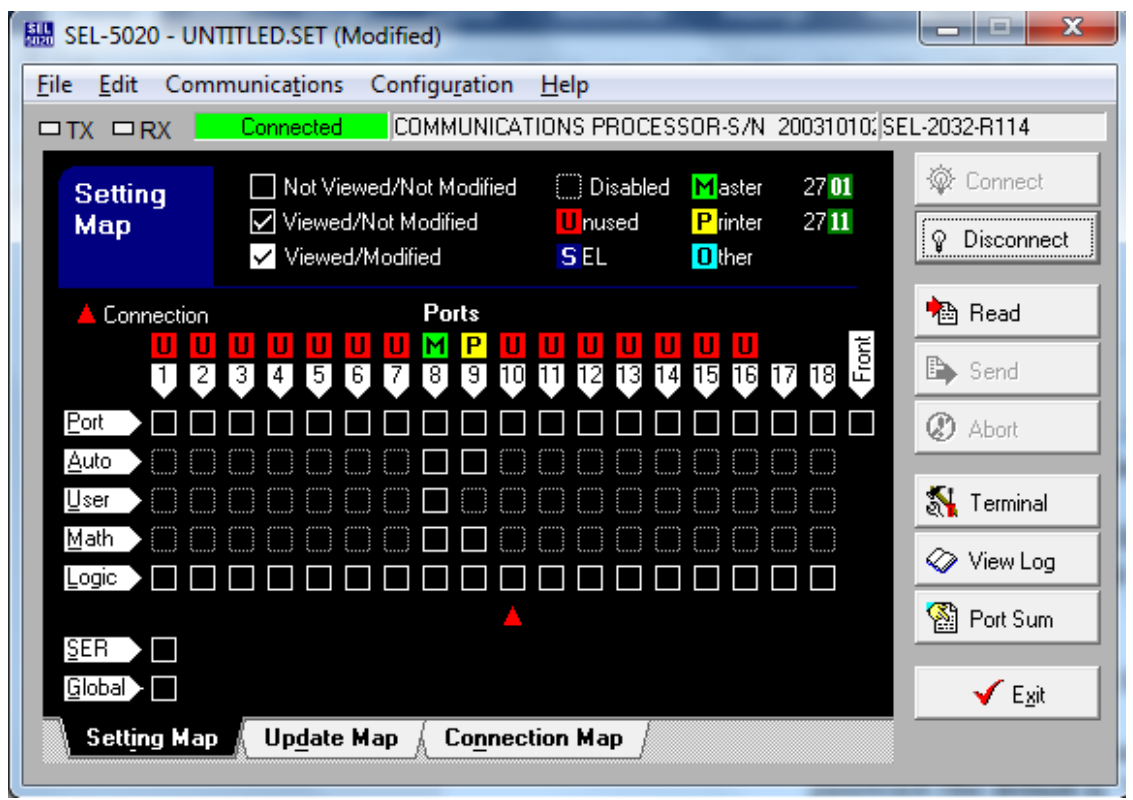

Figure 176: Main Screen after Establishing Connection

7. Connect and configure an SEL-387E differential relay:

a. Connect an SEL-C273A serial cable between Port 1 on the back of the 2020/32 and Port 2 on the back of the SEL-387E.

b. Select Edit, Port Settings to bring up the Port Settings window for the 2020/32 being programmed. Select the port ( $\underline{\text { Port } 1)}$ ) to which the serial cable is connected on the 2020/32. Identify the relay Device as an SEL (Figure 177). 
c. Configure the connection between the SEL-2020/32 and SEL-387E using the special SEL autoconfiguration feature by selecting AutoConfig. The $2020 / 32$ will talk to the $387 \mathrm{E}$ to determine its current relevant parameters.

d. Select Real Time AC in the Autoconfiguration Options window which pops up. Note that the 2020/32 front-panel RX and TX lights for Port 1 should soon begin blinking as the 2020/32 communicates with the 387E.

e. When the autoconfiguration procedure finishes, the Port Settings window fills in all necessary data fields for the connected 387E relay (Figure 178). Click $\underline{\mathrm{Ok}}$.

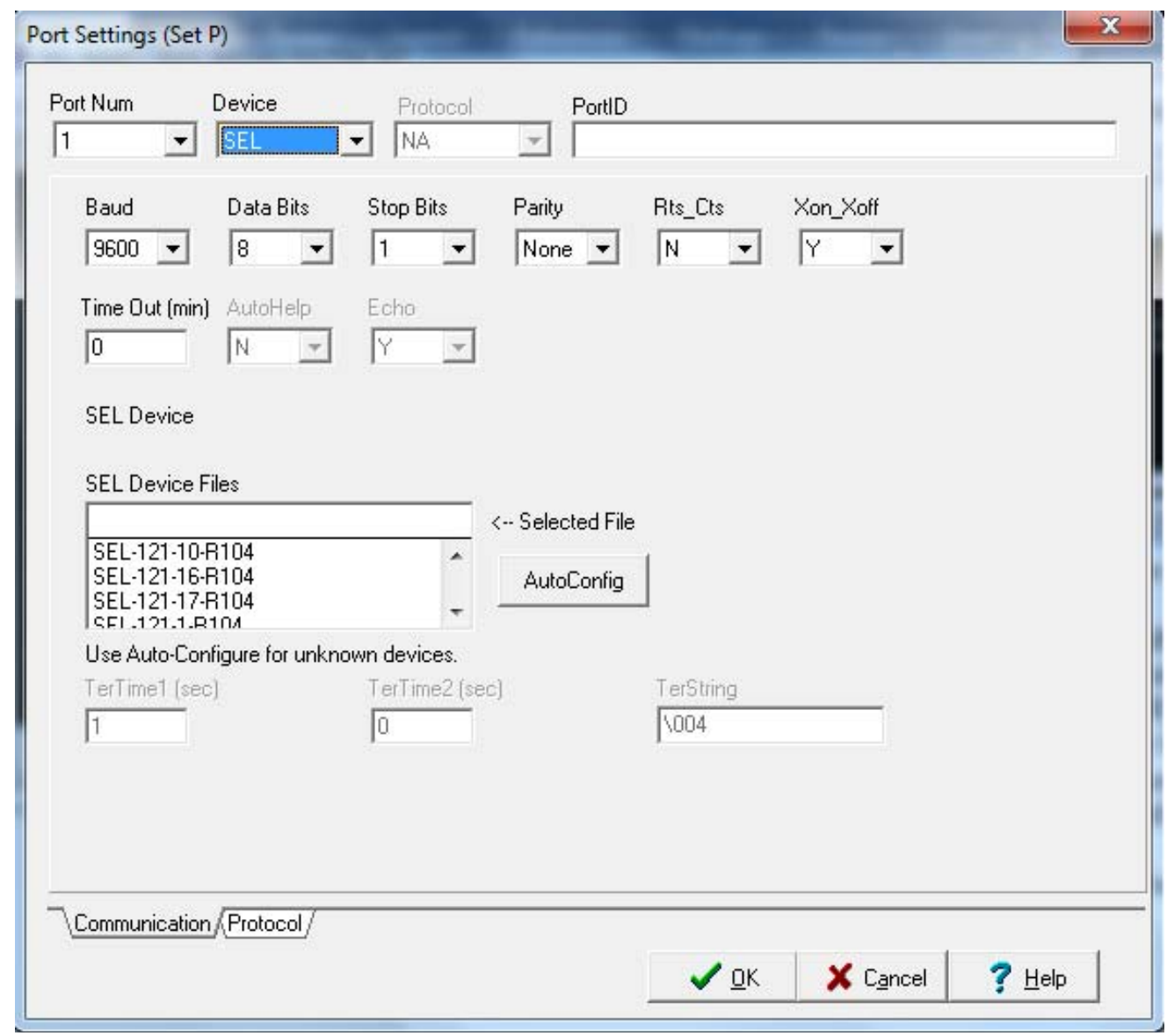

Figure 177: Port Settings Window 


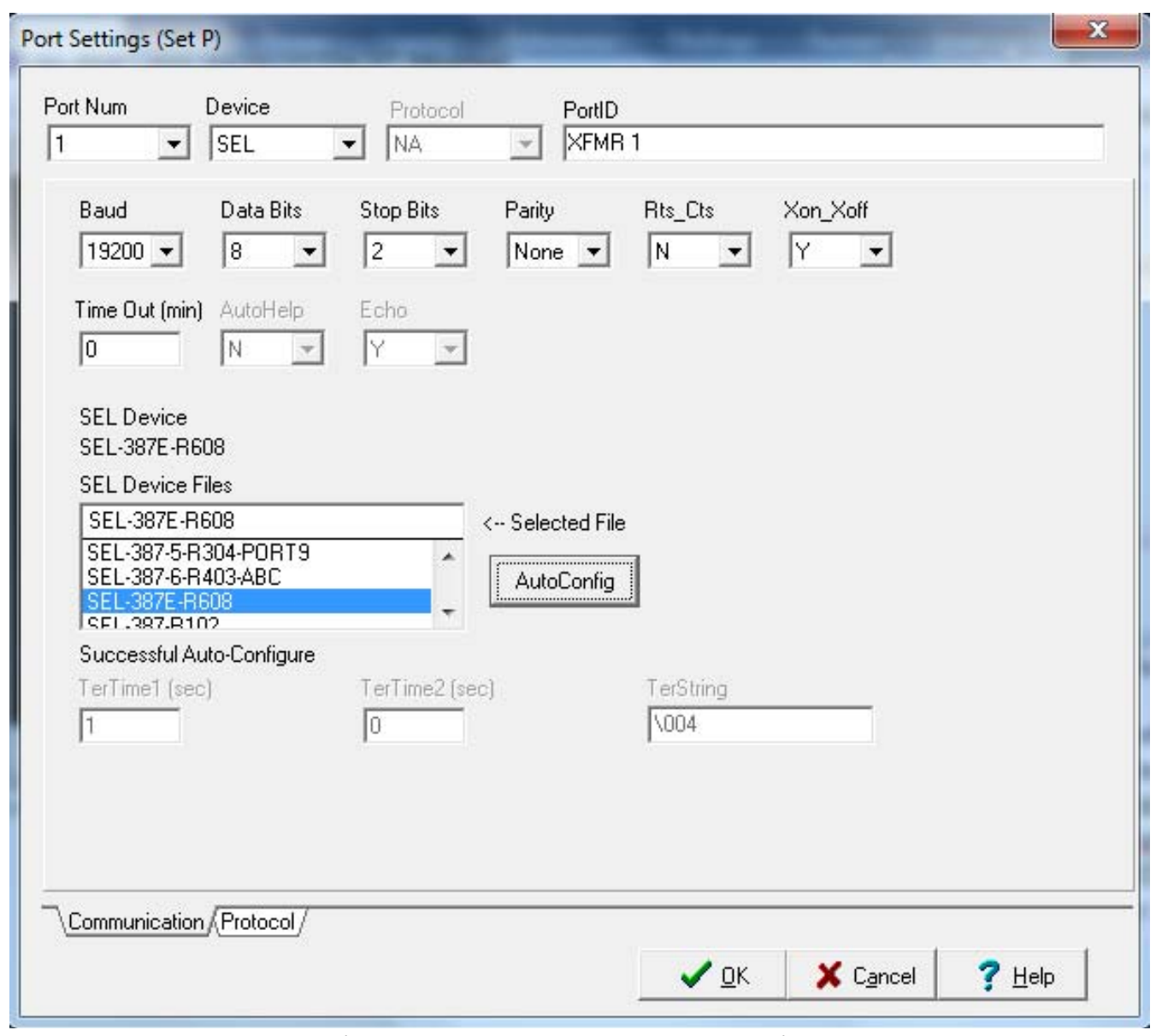

Figure 178: SEL-387E Port Settings

8. Connect and configure an SEL-311L line current relay:

a. Connect an SEL-C273A serial cable between Port 2 on the back of the 2020/32 and Port 2 on the back of the SEL-311L.

b. Select Edit, Port Settings to bring up the Port Settings window for the 2020/32 being programmed. Select the port (Port 2) to which the serial cable is connected on the 2020/32. Identify the relay Device as an SEL.

c. Configure the connection between the 2020/32 and 311L using the special SEL autoconfiguration feature by selecting AutoConfig. The 2020/32 will talk to the $311 \mathrm{~L}$ to determine its current relevant parameters.

d. Select Real Time AC in the Autoconfiguration Options window which pops up. Note that the 2020/32 front-panel RX and TX lights for Port 2 should soon begin blinking as the 2020/32 communicates with the 311L.

e. When the autoconfiguration procedure finishes, the Port Settings window fills in all necessary data fields for the connected 311L relay (Figure 179). Click $\underline{\text { Ok}}$. 


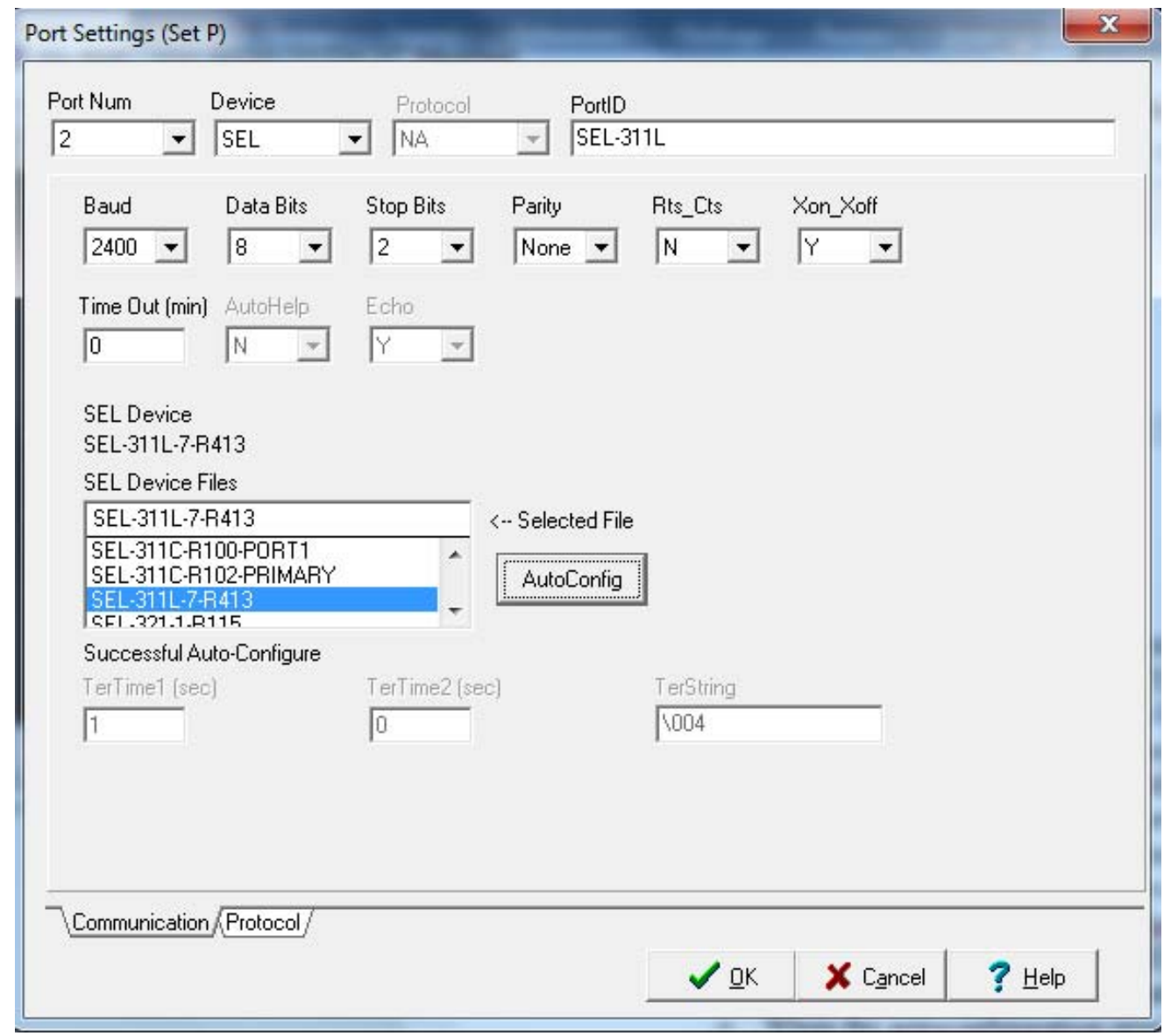

Figure 179: SEL-311L Port Settings

9. Connect and configure an SEL-710 motor relay:

a. Connect an SEL-C273A serial cable between Port 3 on the back of the 2020/32 and Port F on the front of the SEL-710.

b. Select Edit, Port Settings to bring up the Port Settings window for the 2020/32 being programmed. Select the port (Port 3) to which the serial cable is connected on the 2020/32. Identify the relay Device as an SEL.

c. Configure the connection between the 2020/32 and 710 using the special SEL autoconfiguration feature by selecting AutoConfig. The 2020/32 will talk to the 710 to determine its current relevant parameters.

d. Select Real Time AC in the Autoconfiguration Options window which pops up. Note that the 2020/32 front-panel RX and TX lights for Port 3 should soon begin blinking as the 2020/32 communicates with the 710 .

e. When the autoconfiguration procedure finishes, the Port Settings window fills in all necessary data fields for the connected 710 relay (Figure 180). Click Ok.

f. Save this SEL-5020 file. 


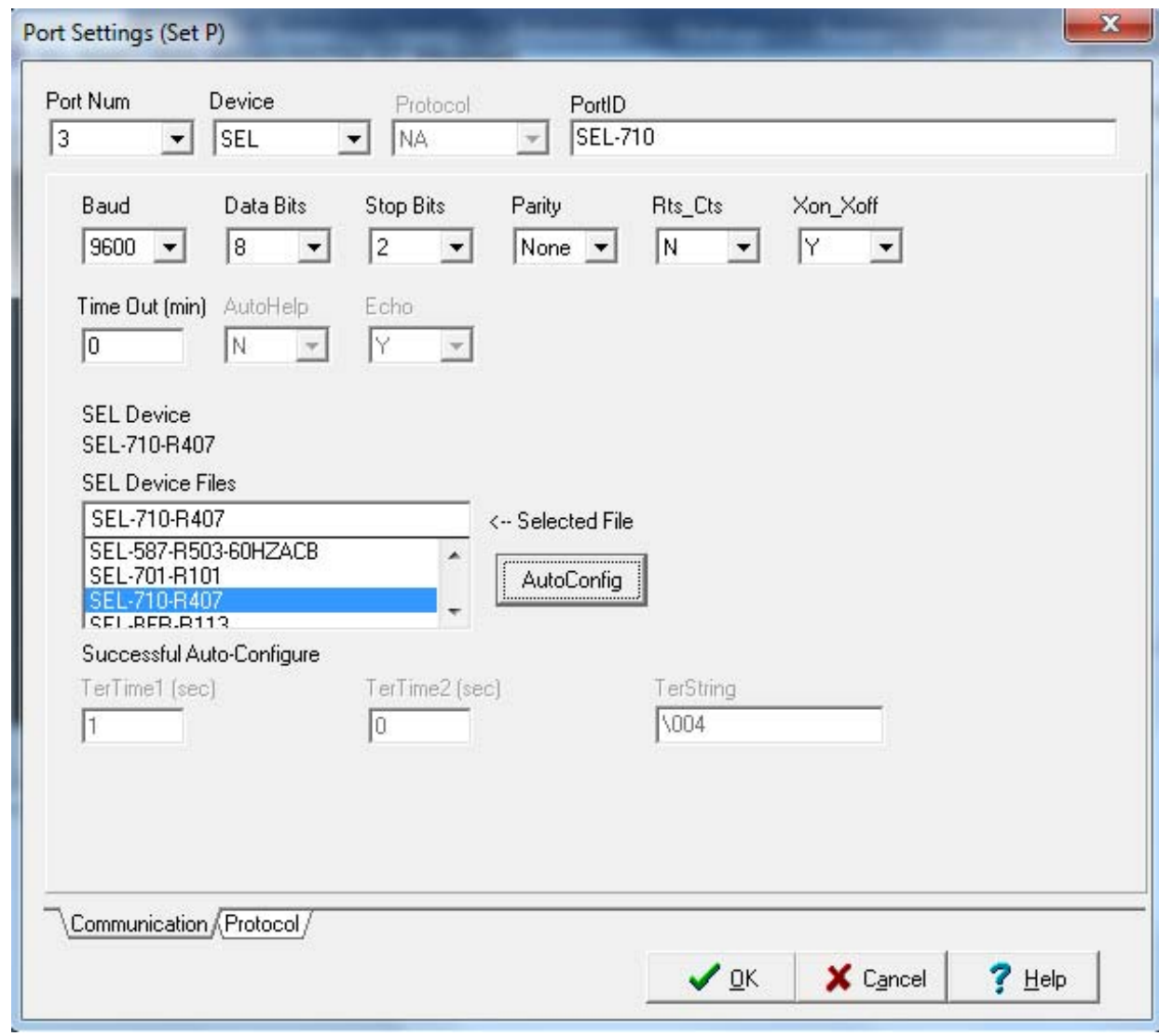

Figure 180: SEL-710 Port Settings

10. Select Disconnect on the right side of the main screen of the SEL-5020 software.

11. Connect the OUT1 back-panel terminal of an SEL-2407 Satellite-Synchronized Clock (if available) to the SEL-2020/32 back-panel IRIG-B input terminal with a BNC-to-BNC cable. Confirm from the front-panel display on the SEL-2407 that the clock locks onto a satellite (the green Satellite Lock LED lights up). After initially powering up, the SEL-2407 does not generate an IRIG-B output signal until the unit obtains a successful satellite lock. The unit continues to generate an IRIG-B signal after this initial lock, even after losing the connection to the satellite.

12. Open the AcSELerator QuickSet software. This program allows you to access the data stored on the relays but requires that the 2020/32 already be programmed (hence the need for the SEL-5020 Settings Assistant Software).

13. On the home screen of QuickSet, select Communication to define the communication parameters of the 2020/32 unit to which the relays are connected. In the Communication Parameters window which comes up (Figure 181), choose Serial Active Connection Type, COM1: Communications Port as the serial connection on the computer, and a Data Speed of 19200 (the default baud rate is 2400; Port 10 on the 2020/32 was specifically increased to 19200 to mitigate 
timeout errors during data transmission). Recall that the default Level One Password on the 2020/32 is OTTER and that the default Level Two Password on the 2020/32 is TAIL. Click Apply to initiate a communication link with the 2020/32. The RX and TX lights in the lower-left corner of the screen should blink. Click OK. Note: A link cannot be established if the 2020/32 is still connected through the 5020 software.

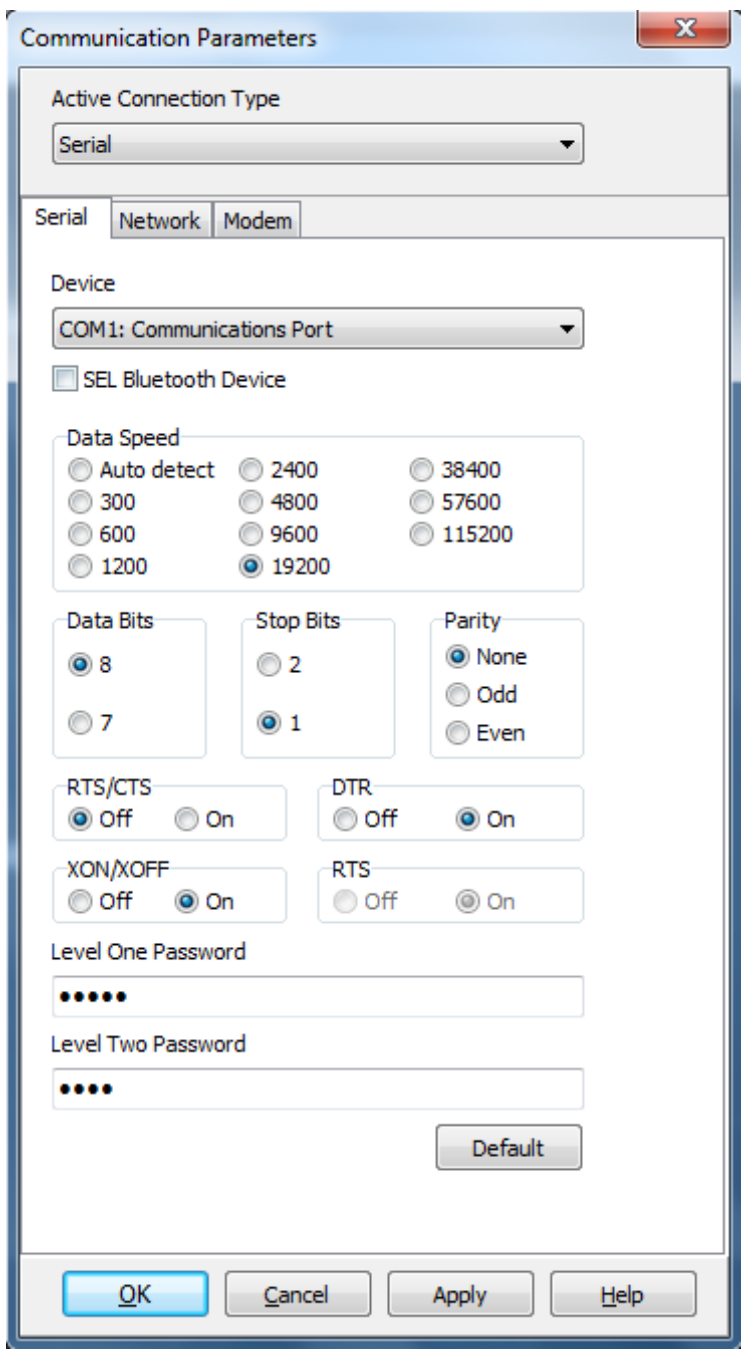

Figure 181: AcSELerator QuickSet Communication Parameters Window

14. Refresh the current settings stored on the SEL-387E.

a. Select Communications, Terminal to open the command prompt. In the terminal window which comes up, you should see the cursor blinking to the right of an asterisk.

b. Type ACC and hit the ENTER key (on the keyboard) to request Level 1 access to the 2020/32. Type in the 2020/32 Level 1 password (default OTTER) and ENTER when prompted. 
c. Type PORT $1 \mathrm{D}$ and ENTER to establish direct transparent communications between the SEL-2020/32 and the SEL-387E connected to Port 1 on the rear of the 2020/32 (Figure 182).

d. Type ACC and hit the ENTER key (on the keyboard) to request Level 1 access to the 387E. Type in the 387E Level 1 password (default OTTER) and ENTER when prompted.

e. Return to the main QuickSet window.

f. Open the settings created in the SEL-387E overcurrent experiment (containing both the differential and overcurrent protection elements).

g. Send the settings to the SEL-387E.

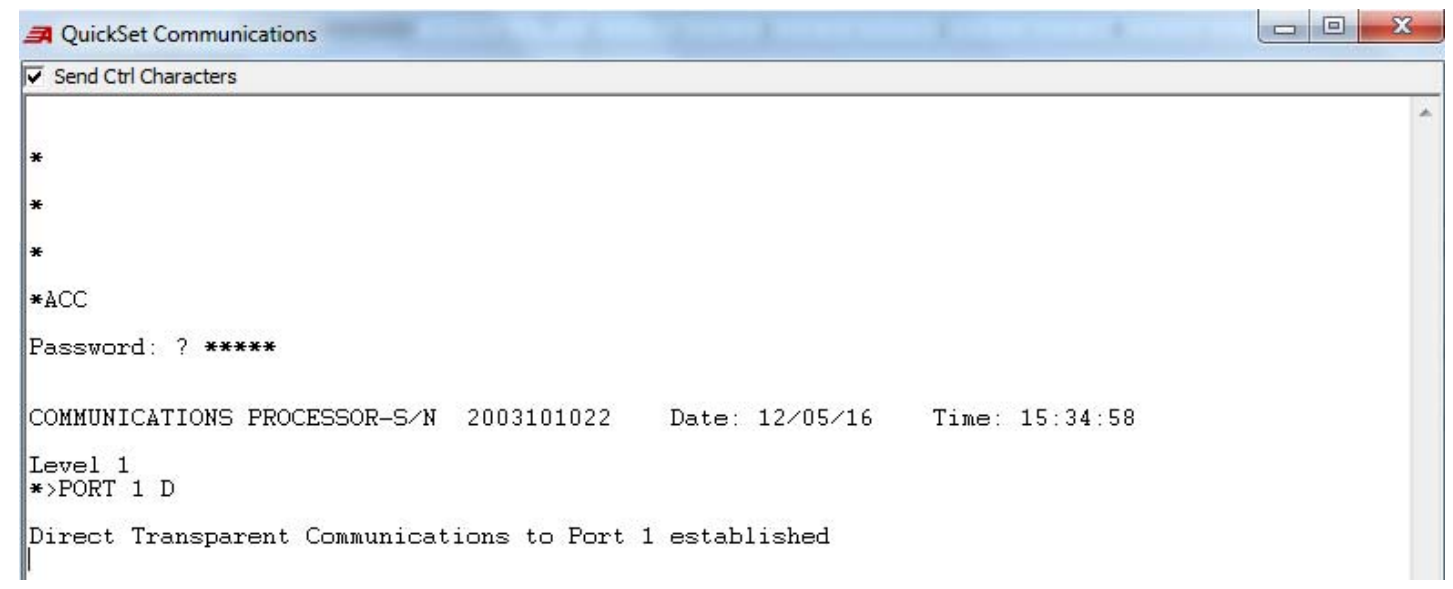

Figure 182: Establishing Transparent Communications Using the QuickSet Terminal

15. Refresh the current settings stored on the SEL-311L.

a. Return to the QuickSet terminal window.

b. Type $\mathrm{CTRL}+\mathrm{D}$ on the keyboard to terminate the direct transparent communications between the SEL-2020/32 and the SEL-387E.

c. Type PORT $2 \mathrm{D}$ and ENTER to establish direct transparent communications between the SEL-2020/32 and the SEL-311L connected to Port 2 on the rear of the 2020/32.

d. Type ACC and hit the ENTER key (on the keyboard) to request Level 1 access to the 311L. Type in the 311L Level 1 password (default OTTER) and ENTER when prompted.

e. Return to the main QuickSet window.

f. Open the settings created in the SEL-311L overcurrent experiment.

g. Send the settings to the SEL-311L.

16. Refresh the current settings stored on the SEL-710.

a. Return to the QuickSet terminal window.

b. Type $\mathrm{CTRL}+\mathrm{D}$ on the keyboard to terminate the direct transparent communications between the SEL-2020/32 and the SEL-311L.

c. Type PORT $3 \mathrm{D}$ and ENTER to establish direct transparent communications between the SEL-2020/32 and the SEL-710 connected to Port 3 on the rear of the 2020/32. 
d. Type ACC and hit the ENTER key (on the keyboard) to request Level 1 access to the 710. Type in the 710 Level 1 password (default OTTER) and ENTER when prompted.

e. Return to the main QuickSet window.

f. Open the settings created in the SEL-710 overcurrent and undervoltage experiment.

g. Remove the undervoltage element (27P1T) from the SEL-710 trip equation (TR). The keyboard shortcut $\mathrm{CTRL}+\mathrm{F}$ allows you to quickly search the settings file for the trip equation.

h. Send the settings to the SEL-311L.

17. Construct the circuit shown in the provided three-line diagram (Figure 183). Note that this circuit builds on the connections made in the previous experiments; reference the previous overcurrent procedures for assistance.

18. Verify the circuit connections and obtain instructor approval to apply power to the circuit.

19. Apply both $240 \mathrm{~V}_{\mathrm{AC}}$ and $125 \mathrm{~V}_{\mathrm{DC}}$ (if required for the circuit breakers) power from the bench and close all circuit breakers (with the Manual Breaker Control Close button). Confirm that the three-phase current displayed on the wattmeter is approximately $0.9 \mathrm{~A}$. If the displayed current exceeds $1.2 \mathrm{~A}$, turn off the bench power and check the circuit wiring for errors.

20. Create a line-to-line fault at the induction motor.

j. Turn off $\mathrm{AC}$ and $\mathrm{DC}$ power from the bench.

k. Jumper the black Circuit Breaker terminals to the red Fault Connections terminals (if present) on the circuit breaker \#4. Jumper two of the black Fault Connections terminals together (line-to-line fault configuration).

1. Set the circuit breaker Fault Switch to the Normal position.

j. Turn on AC and DC bench power. Press the TARGET RESET button on the front panel of each relay to clear any previous fault displays.

m. Manually close all circuit breakers.

n. Flip the circuit breaker \#4 Fault Switch to the Fault position.

o. Watch the wattmeter to confirm that the SEL-710 trips the circuit breaker to clear the fault. If no relay clears the fault, turn off $\mathrm{AC}$ bench power before sustained fault current damages circuit components.

p. Once the SEL-710 clears the fault, turn off AC and DC bench power and flip the Fault Switch to the Normal position. Press the TARGET RESET button on the tripped relays to clear their front-panel LED displays.

21. Jumper the circuit breaker \#4 Breaker Control Trip terminals and repeat the lineto-line fault at the induction motor. Verify that the SEL-311L successfully clears the fault. 


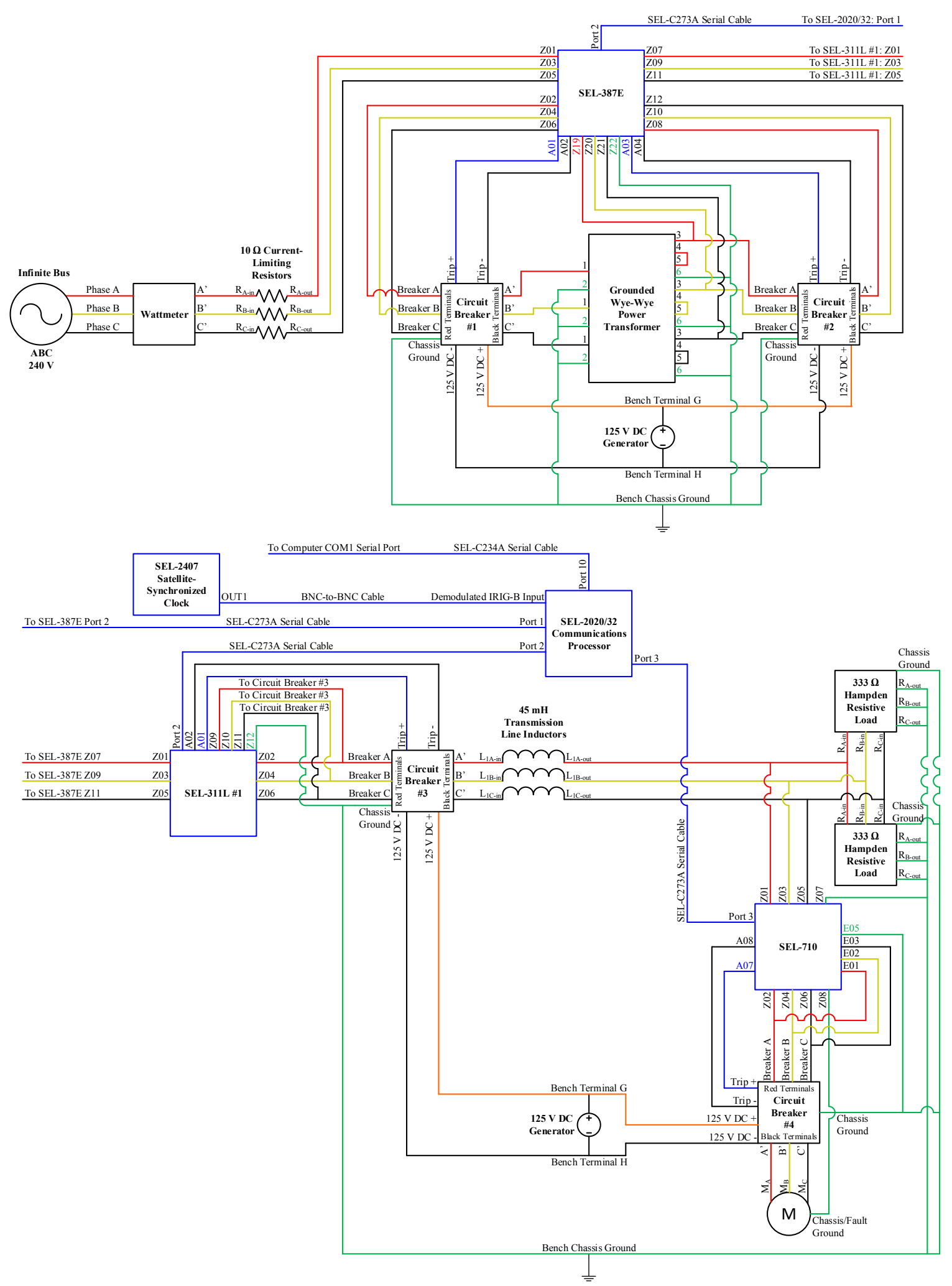

Figure 183: Radial Circuit Three-Line Diagram 
22. Jumper the circuit breaker \#3 Breaker Control Trip terminals and repeat the lineto-line fault at the induction motor. Verify that the SEL-387E successfully clears the fault.

\section{Postlab Questions}

- Describe the coordination scheme established in this radial system. Reference the overcurrent settings for each relay in the circuit. Consider the prelab calculations from the previous overcurrent experiments.

- Briefly describe the reason for coordinating relays in a power distribution system (in terms of the number of customers affected by a fault). 


\section{Appendix O: ABET Senior Project Analysis}

Project Title: Protective Relaying Student Laboratory

Student's Name: Kenan Pretzer Student's Signature:

Advisor's Name: Dr. Ali Shaban Advisor's Initials:

Date:

12017

\section{Summary of Functional Requirements}

Chapter 3 describes project functional requirements.

\section{Primary Constraints}

Table 4 and Table 5 in Chapter 3 detail primary project constraints. 


\section{Economic Support}

A breakdown of the estimated project duration appears in Table 14 through Table

18. Estimated costs appear in Table 19.

Generally, the primary economic burden for a microgrid rests with energy customers desiring to implement such a system. This burden includes direct costs associated with materials and labor required to construct the system. Direct benefits include a higher reliability of uninterrupted power (a safeguard against critical system failure leading to production loss or severed services) and the ability to utilize maximally cost-effective generation in real-time. Since energy customers on a microgrid possess the ability to island themselves from the larger electrical grid, they realize greater freedom over the method and timing of their power generation.

Industry support provides the economic basis for construction of this project. Donations of protective relays to Cal Poly by SEL offset the initial investment in capital required to implement protection of a microgrid system. Future Cal Poly power systems students will derive lasting benefit from this project if the proposed laboratory procedures become the basis for a new laboratory component to the existing EE 518 Power System Protection course. 


\section{If Manufactured on a Commercial Basis}

Generally, designs of microgrid systems directly address the specific needs and existing resources of energy customers who request them. Expected load conditions, points of interconnection to the larger electrical grid, and the placement of distributed energy generation and storage all require consideration. As such, exact protection schemes vary widely from one system to another. Customer real-time load magnitude and geographical density constrain energy generation and storage. The type and quantity of customer equipment needing protection determines necessary relaying equipment. If the customers desire automated system operation, the system then requires additional communication and control devices.

Given the educational nature and intent of this project, commercial manufacture of this microgrid system is pertinent to educational institutions. Supposing that SEL, or another similar company, looks favorably upon sponsoring the replication of this protection system at other universities through donations of required equipment, costs of replicating the project effectively reduce to labor and parts. Assuming the replication of this project requires 200 labor hours, the cost to replicate the protection system comes to $\$ 8,625$ (values from Table 19). A price-point of $\$ 9,000$ covers relatively small, unforeseen expenses. Each system therefore potentially returns a $\$ 375$ profit, fixed at a low value due to the educational nature of the project. If five universities annually adopt this protection system, potential annual profits amount to $\$ 1,875$.

Costs to operate this system depend on energy prices set by the electrical utility company and the cost to provide DC power to the circuit breakers. Assuming a fixed cost of 15 cents per kilowatt-hour for both $125 \mathrm{~V}_{\mathrm{DC}}$ and $240 \mathrm{~V}_{\mathrm{rms}}$ power, an average current across all $\mathrm{AC}$ devices of $50 \mathrm{~mA}_{\mathrm{rms}}$, and an average current across all $\mathrm{DC}$ devices of 50 
$\mathrm{mA}$, the average cost for system operation comes to approximately 0.4 cents per hour, as illustrated below:

$$
\begin{aligned}
& \text { Cost }=(\text { Price per kWh }) \cdot(\text { Avg. Power Draw }) \\
& \text { Cost }=(\text { Price per } k W h) \cdot\left(\frac{\sqrt{3} \cdot \mathrm{V}_{r m s} \cdot \mathrm{I}_{r m s}+\mathrm{V}_{D C} \cdot \mathrm{I}_{D C}}{1000}\right) \\
& \text { Cost }=\left(15^{\text {cents }} / \mathrm{kWh}\right) \cdot\left(\frac{\sqrt{3} \cdot(240 \mathrm{~V}) \cdot(0.05 \mathrm{~A})+(125 \mathrm{~V}) \cdot(0.05 \mathrm{~A})}{1000}\right) \\
& \text { Cost }=0.4^{\text {cents } / \text { hour }}
\end{aligned}
$$




\section{Environmental Considerations}

Protection serves a valuable function in maintaining the environment of a power system. Automated termination of fault conditions prevents the initiation of a conflagration [24]. This affects a wide array of ecosystems, from rural areas with hundreds of miles of high-voltage transmission lines to individual urban homes. Power system protection, therefore, stands as the first line of defense for people, property, flora, and fauna potentially endangered by electrical fires. This project teaches students how to apply the fundamentals of power system protection, concepts relevant to maintaining safe and reliable circuit operation throughout their careers in the power industry. 


\section{Manufacturability}

As described above in the section analyzing commercial manufacturability, microgrids require individual tailoring to meet the needs of each customer. Individually fitting a customer for a microgrid introduces unique design challenges in every project, ranging from physically placing distributed energy resources to sizing those resources to meet customer energy demands. Protection schemes for these power systems must prove adaptable to the varying real-time operating conditions of the system, particularly regarding the balance of generation and load. Relays and communications equipment selected to protect a microgrid must, therefore, possess the capability to actively meter complex system performance in real-time. Furthermore, because microgrid topologies and protection requirements vary from system to system, each relay requires unique trip settings. These unique settings necessitate programming the relays individually. 


\section{Sustainability}

As with the manufacturing of all electronic devices, producing relays requires industrial processing of earth's natural resources. However, once implemented into a power system, protective relays can potentially remain in the field for the duration of their functional lifespans. Even if a power system undergoes a thorough redesign, necessitating a new protection scheme, other systems may utilize the displaced relays. Reprogramming of electronic relays enables them to adapt to new system loading conditions, providing flexibility to meet future customer needs. When relays reach the end of their functional lives, recycling reduces the negative environmental effects of utilizing electronic components. 


\section{Ethicality}

Power system protection upholds key values outlined in the IEEE Code of Ethics [25]. Its use in microgrids, a relatively young technological frontier, improves "the understanding of technology, its appropriate application, and potential consequences" through innovative experimental designs that transform current energy generation, storage, and distribution practices. System protection also serves as a powerful barrier between hazardous unforeseen system operation and the general public. The timely relaying of downed power lines illustrates this principle in action. In contrast, the unintended or failed operation of protective devices due to faulty equipment compromises the lives and property of customers, a violation of the IEEE Code of Ethics. Manufacturers of microprocessor-based relaying equipment, such as SEL, recognize this liability and invest heavily in the quality of their products. SEL exemplifies a commitment to product reliability through the ten-year worldwide warranty with which it backs its relaying equipment [26]. Mitigation of potential equipment failures justifies using microprocessor-based relays in place of the traditional and reliable electromechanical relays.

In addition to obeying the IEEE Code of Ethics, power system protection exemplifies utilitarian principles. All electrical utility customers reap the benefits of the utility company implementing safeguards against the consequences of system failure. This equality holds true in both microgrids and the larger electrical grid network. Relays can isolate malfunctioning portions of a circuit, which protects customers at the location of the incident and enables the remaining portions of the circuit to continue operating normally. Most customers thus remain electrically on-line. Regarding the distribution of economic burden associated with funding protective relaying equipment, densely- 
populated urban areas have lower per-capita numbers of protective equipment, since fewer larger-gauge wires service more customers. Customers in these urban areas thus derive less per-capita benefit from each relaying device. This discrepancy challenges utilitarian principles. However, given that all customers benefit to some degree from protective relaying equipment, differences of degree in realized benefits among customers do not outweigh the overall benefits of power system protection provided by protective relaying equipment. 


\section{Health and Safety Considerations}

Power systems present inherent dangers for both operators and customers due to the high levels of voltage and current at which they function. Adding or modifying protective equipment in a power system therefore necessitates adherence to strict safety procedures. Safe practices include de-energizing live circuits whenever possible before servicing them and utilizing appropriate tools and personal protective equipment to mitigate hazards sufficiently. 


\section{Social and Political Considerations}

The customers requesting a microgrid system are the direct stakeholders of the microgrid. These individuals may pay equally for all protective devices at the onset of the project, since, as mentioned above in the section on ethics, all customers derive comparable benefits. The relay protecting the generation device of one individual within the microgrid during a fault condition simultaneously allows the rest of the microgrid system to continue operating. The direct stakeholders, therefore, can equally share both the benefits and costs of protective relaying equipment in a microgrid system.

In this specific project, university students stand as the direct stakeholders. The knowledge gained through utilizing this system prepares them for the rigors of protection engineering in the power systems industry. Secondary stakeholders of this system include any university implementing it as well as any protective relay manufacturing companies that sponsor the system implementation. The university initially pays for adoption of the project. However, students who benefit from this project pay tuition to attend their school, which eventually reimburses the cost. The relay manufacturing company that donates to a university also stands to benefit. Students familiar with that company's equipment after using it in this system may encourage protection companies they work for after graduation to invest in the manufacturer of the familiar equipment. 


\section{Development}

Relay settings require continued research. Examples of required research topics include information on harmonic blocking for differential protection as well as communications protocol requirements between the relays and central processor.

Instruction manuals for the individual devices contain much of the information necessary for surmounting these challenges. The references section lists sources for obtaining this information. 